$$
\begin{aligned}
& \text { UNIVERSIDADE DE SÃO PAULO } \\
& \text { INSTITUTO DE GEOCIÊNCIAS }
\end{aligned}
$$

\title{
IDADE, DURAÇÃO E CONDIÇÕES P-T DO METAMORFISMO DE TEMPERATURA ULTRA-ALTA, ANATEXIA E CRISTALIZAÇÃO DE FUNDIDO NA NAPPE SOCORRO-GUAXUPÉ
}

\author{
Brenda Chung da Rocha
}

Orientador: Prof. Dr. Renato Moraes

\section{TESE DE DOUTORAMENTO}

Programa de Pós-Graduação em Mineralogia e Petrologia

\author{
SÃO PAULO \\ 2016
}


Autorizo a reprodução e divulgação total ou parcial deste trabalho, por qualquer meio convencional ou eletrônico, para fins de estudo e pesquisa, desde que citada a fonte.

Ficha catalográfica preparada pelo Serviço de Biblioteca e Documentação do Instituto de Geociências da Universidade de São Paulo

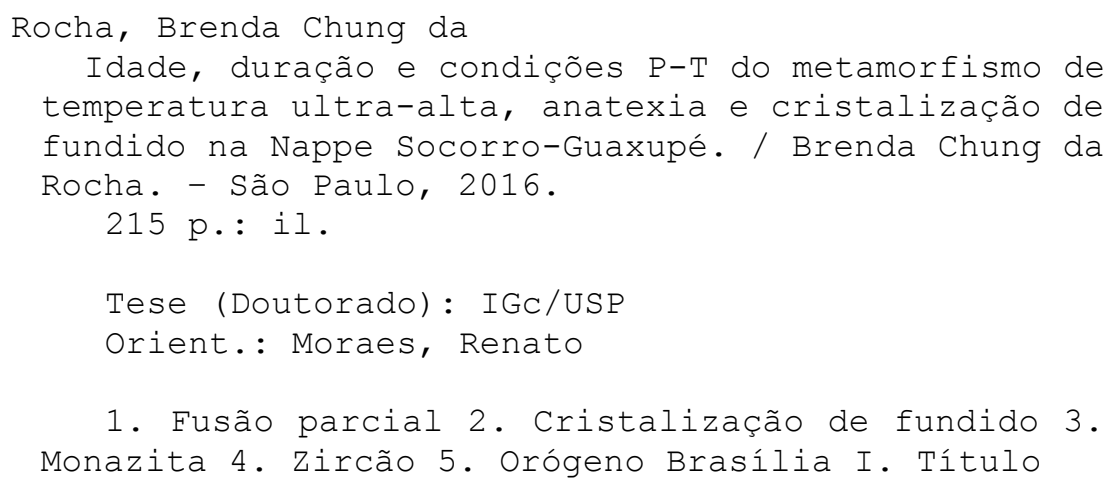


"A um quilômetro dali havia um morro com grande desbarrancado - a "barreira", como se dizia no sítio.

o Visconde levou-os para lá. Diante da barreira, parou e sorriu.

Os meninos entreolharam-se. Não compreendiam que o Visconde encontrasse matéria para sorriso num barranco feio como todos os mais.

- Que gosto é esse, Visconde? - perguntou Emília.

- Ah, o sorriso que tenho nos lábios é um sorriso geológico - o sorriso de quem sabe, olha, vê e compreende. Este barranco é para mim um livro aberto, uma página da história da terra na qual leio mil coisas interessantíssimas".

O Poço do Visconde (Monteiro Lobato) 


\section{AGRADECIMENTOS}

À FAPESP, que viabilizou o desenvolvimento deste trabalho através dos projetos de pesquisa FAPESP (13/04007-0 e 10/11152-8), bolsa de doutorado no país (12/22380-7) e no exterior (14/05563-6).

Ao CNPq, pelos oito primeiros meses de bolsa de doutorado no país (142028/2012-6).

Ao meu orientador Renato Moraes, por todo o apoio, participação, paciência, incentivo, confiança e por me dar todas as condições necessárias para o desenvolvimento da minha pesquisa. Me faltam palavras para expressar toda a gratidão que tenho por tudo o que você fez e ainda faz por mim, muito obrigada!

Ao Prof. Andreas Möller (The University of Kansas, USA), meu orientador do estágio de pesquisa no exterior, pelo enorme aprendizado e todo apoio dado durante o ano que passei no Kansas. E pelos comentários e sugestões essenciais no desenvolvimento do meu trabalho.

Ao Prof. Michael J. Jercinovic (University of Massachusetts, USA), quem me ensinou a enxergar a monazita com outros olhos.

Ao Prof. Mario da Costa Campos Neto, pela motivação, pelas inúmeras discussões a respeito do meu tema de trabalho e por todo o conhecimento que adquiri sobre o Orógeno Brasília. E prometo que um dia vou publicar um trabalho de Lima Duarte.

Ao Prof. Valdecir de Assis Janasi, pela contribuição no desenvolvimento deste trabalho com valiosas discussões e sugestões.

Aos funcionários da Pedreira Santa Terezinha, especialmente Edna e o técnico Luciano, por permitirem a coleta de amostras e por todo o apoio dados durante os trabalhos de campo.

A todos os professores do IGc-USP, por todos esses anos de convívio, em especial: Adriana Alves, Lucelene Martins, Gergely Szabó, Silvio Vlach, Renato Paes de Almeida.

A todos os funcionários do IGc-USP, em especial: Vasco Loios (CPGeo), sempre muito prestativo, por me ensinar todas as etapas de separação mineral; Samuel (Samuca), pela enorme boa vontade e prontidão em preparar dezenas de peneiras descartáveis, o que garantiu que minhas amostras não fossem contaminadas por zircões alheios; Sandra Andrade e Vinícius Martins, pelo apoio durante as análises de ICP-MS; Marcos Mansueto e Leandro Moraes, pelo suporte durante as análises de microssonda eletrônica; José Paulo Sertek, pelo apoio dado durante a preparação de amostras no LTA; Angélica (Óptica) pelo enorme carinho e apoio durante os vários meses que passei no microscópio; Paulinho e Luís (Laminação); Henrique e Claudionor (Gráfica); Brenda, Érica e Estela (Biblioteca) pelo convívio intenso na etapa final do meu trabalho.

A geóloga e amiga Sheila Schuindt (LCT, Poli-USP), pela enorme eficiência durante a aquisição de imagens BSE. 
A todos da Universidade do Kansas que contribuíram tanto com a aquisição e tratamento de dados, como em discussões a respeito do meu tema em seminários: Josh Feldman, Jeff Oalmann, Maggie Sochko, Heather Shinogle, Noah McLean, Douglas Walker.

Aos queridos amigos e colegas da pós que a Geologia me proporcionou e que fizeram parte desta etapa: Thaís Nogueira Hyppolito, Maurício Guerreiro dos Santos, Dante Bianchi, Vinícius Tieppo Meira, Leandro Coutinho, Bruna Borges Carvalho, Renato Henrique-Pinto, Filipe Isquierdo, Bernardo Tavares, Pedro Reis, Bruno Boito Turra, Rafael Bittencourt, Laísa Batista, Fabiana Santos, Ana Maciel, Victor Maurer, Luana Florisbal, Natasha Marteleto, Fabio Brentan, Juliana Livi, André Pires, Felipe Justino, Rafael Motta, Gabriela Frugis, Claudio Mora, Glaucia Barreto, Maurício Pavan.

Aos meus companheiros de sala: Laísa de Assis Batista, Vidyã Almeida, Alexander Gimenez, Fernanda Reverte, Andres Salazar, Johann Santiago Torres, obrigada por me aturar!

A toda a minha família, em especial à minha mãe Mel por todo o apoio dado durante esta jornada (até para o campo em Alfenas você foi!), pelo amor, carinho, motivação e incentivo em todas as etapas da minha vida.

Também não poderia deixar de agradecer o apoio constante da minha sogra Marisa e de toda a família Satt Rodrigues.

Não foi nada fácil conciliar a maternidade com o doutorado, mas felizmente pude contar com o apoio de inúmeras pessoas ao longo desta jornada, desde amigos, familiares, e a comunidade do IGc-USP (alunos, professores e funcionários), que seria impossível listar aqui todos os nomes. Então, um agradecimento geral para todos que me ajudaram, segurando a Manuela no colo enquanto eu terminava de preparar uma amostra, descrever uma lâmina, etc, muito obrigada gente!!

Ao Cauê Rodrigues Cioffi, pela enorme contribuição e participação intensiva em todas as etapas deste trabalho, pelas inúmeras discussões sobre o tema, pelo seu contagiante entusiasmo com a Geologia, pela motivação constante na minha vida, e por tudo o que vivemos juntos nesses últimos anos. De todas as nossas aventuras, a Manuela é sem dúvida a melhor de todas, amo vocês de todo o coração. 


\section{RESUMO}

A Nappe Socorro-Guaxupé (NSG) representa um arco magmático neoproterozóico intensamente erodido, desenvolvido na margem ativa da Placa Paranapanema. A NSG está localizada no Orógeno Brasília Sul, que registra a colisão Ediacarana entre a Placa Paranapanema e o paleocontinente São Francisco, relacionado com a aglutinação do Gondwana Ocidental. A NSG expõe uma seção espessa $(c a .10 \mathrm{~km}$ ) de crosta inferior, composta dominantemente por granulitos e migmatitos, e por intrusões de charnockito-granito de alto-K cálcio-alcalinos que registram um expressivo magmatismo sin-colisional. A evolução temporal dos eventos de fusão parcial, metamorfismo de temperatura ultra-alta e cristalização de fundido da NSG é acessada através de um estudo integrado envolvendo técnicas de datação in-situ de zircão e monazita, análise textural detalhada, geotermobarometria, geoquímica de elementos-traço em fases acessórias e fases metamórficas principais, geoquímica de rocha-total e isótopos de $\mathrm{Sr}-\mathrm{Nd}$ em dois afloramentos-chave na região de Alfenas (MG): Pedreira Alfenas (Unidade Metatexítica) e Pedreira Santa Terezinha (Unidade Granulítica). Cinco episódios distintos de geração de monazita foram reconhecidos em migmatitos com granada \pm ortopiroxênio na Unidade Metatexítica. A monazita registra idades progressivas de $c a .631 \pm 4 \mathrm{Ma}$ anteriores ao evento de fusão parcial, definindo assim um limite máximo de idade para o metamorfismo de fácies granulito na NSG. Monazita relacionada com apatita registra os estágios iniciais de descompressão a ca. $628 \pm 4 \mathrm{Ma}$. O crescimento abundante de zircão e monazita registra um evento de cristalização de fundido prolongado entre ca. 630-600 Ma, com crescimento episódico em ca. $625 \mathrm{Ma}$, ca. $615 \mathrm{Ma}$ e ca. $608 \mathrm{Ma}$ a 790-680 ${ }^{\circ} \mathrm{C}$, baseado em termometria de Ti-emzircão. O desenvolvimento de bordas de monazita ricas em Y e ETRP em ca. 600 Ma marcam os estágios finais de cristalização de fundido, concomitante com o consumo parcial de granada e crescimento extenso de biotita ao longo da trajetória retrometamórfica. Recristalização tardia promovida pela infiltração de fluidos é registrada em bordas de monazita ricas em Th em ca. $590 \mathrm{Ma}$. Idades de cristalização ígneas dos protólitos dos granulitos félsicos e granada granulitos se situam entre ca. 730$640 \mathrm{Ma}$, e são equivalentes ao intervalo de idades obtidos em xenocristais de zircão herdados dos leucossomas das Unidades Metatexítica e Granulítica, e são interpretadas como sendo o período de magmatismo de arco pré-colisional, com duração de pelo menos 90 m.y. As idades concordia de $c a$. 655-650 Ma obtidas nos granulitos félsicos e granada granulitos (Unidade Granulítica) refletem o principal período de magmatismo de arco pré-colisional. As condições de pico metamórfico foram determinadas a $\mathrm{ca} .1030{ }^{\circ} \mathrm{C}$ a $11,7 \mathrm{kbar}$ em megacristais de granada e ortopiroxênio dentro de leucossoma da Unidade Metatexítica e a $c a .900{ }^{\circ} \mathrm{C}$ at $12 \mathrm{kbar}$ em granada granulito da Unidade Granulítica, o que caracteriza o metamorfismo de temperatura ultra-alta sin-colisional na NSG, aqui estabelecido em ca. 630-625 Ma. Magma basáltico pode ter atuado como importante fonte de calor adicional durante o metamorfismo de temperatura ultra-alta, dada a ocorrência de rochas máficas intrusivas sin-metamórficas nas proximidades dos leucossomas charnockítico (com ortopiroxênio) e com hornblenda na Unidade Granulítica. Padrões de ETR contrastantes nestes leucossomas fornecem evidência para a presença de fundidos fracionados (maior abundância de ETR e anomalia negativa de Eu) e cumulatos (menor abundância de ETR e anomalia positiva de Eu). As rochas estudadas apresentam evidência isotópica de participação de fontes mantélicas enriquecidas em sua origem, pois retrabalhamento crustal envolvendo crostas arqueanas ou paleoproterozóicas mais antigas não foram reconhecidas até o presente momento. 


\begin{abstract}
The Socorro-Guaxupé Nappe (SGN) consists of a deeply eroded Neoproterozoic magmatic arc, developed at the active margin of Paranapanema Plate. The SGN is located within the southern Brasilia Orogen, that records the Ediacaran collision between the Paranapanema Plate and the São Francisco paleocontinent, related to the assembly of western Gondwana. The SGN exposes a thick section (ca. $10 \mathrm{~km}$ ) of the lower crust, mainly composed of granulites and migmatites, and by widespread high-K calc-alkaline charnockite-granite intrusions that record the syn-collisional magmatism. The timing of partial melting, ultra-high temperature (UHT) metamorphism and melt crystallization in the SGN is constrained by an integrated study involving zircon and monazite in-situ dating techniques, detailed textural analysis, geothermobarometry, trace element geochemistry in accessory phases and main metamorphic minerals, whole-rock geochemistry and Sr-Nd isotopes in two key outcrops in the Alfenas region (MG): Alfenas Quarry (Metatexite Unit) and Santa Terezinha Quarry (Granulite Unit). Five monazite growth episodes are recognized in (orthopyroxene)-garnet-bearing migmatites within the Metatexite Unit. Monazite preserves prograde growth ages of $c a .631 \pm 4$ Ma prior to the partial melting event, providing an upper age limit for the granulite-facies metamorphism in the SGN. Apatite-related monazite records the initial stages of decompression at ca. 628 $\pm 4 \mathrm{Ma}$. Abundant zircon and monazite growth records a protracted melt crystallization event between $c a .630-600 \mathrm{Ma}$, with episodic growth in ca. $625 \mathrm{Ma}$, ca. $615 \mathrm{Ma}$ e ca. $608 \mathrm{Ma}$ at $790-680{ }^{\circ} \mathrm{C}$, based on Ti-in-zircon thermometry. The development of $\mathrm{Y}+\mathrm{HREE}$-rich monazite rims documents the final stages of melt crystallization, concomitant to retrograde garnet breakdown and extensive biotite growth along the retrograde metamorphic path. Late recrystallization promoted by fluid infiltration is recorded by Th-rich monazite rims at ca. $590 \mathrm{Ma}$. Igneous crystallization ages from protoliths of the felsic and garnet granulites range from ca. 730-640 Ma, similarly to the age range of inherited xenocrystic zircon cores from leucosomes in both Metatexite and Granulite Units, and are interpreted to constrain the pre-collisional arc magmatism lasting for at least 90 m.y. The concordia ages of $c a .655-650 \mathrm{Ma}$ obtained from the felsic and garnet granulites (Granulite Unit) reflect the main period of pre-collisional arc magmatism. Peak metamorphic conditions were attained at a ca. $1030{ }^{\circ} \mathrm{C}$ a $11.7 \mathrm{kbar}$, recorded by (orthopyroxene)garnet-bearing leucosome within the Metatexite Unit, and at $c a .900{ }^{\circ} \mathrm{C}, 12 \mathrm{kbar}$ recorded by garnet granulites within the Granulite Unit, which characterizes the syn-collisional UHT metamorphism in the SGN, here established in ca. 630-625 Ma. Basaltic magma underplating could be a potential heat source for UHT metamorphism, given the occurrence of syn-metamorphic mafic rocks in close spatial relation to in-situ hornblende- and orthopyroxene-bearing leucosomes within the Granulite Unit. Contrasting REE patterns in these leucosomes provide evidence for the presence of both fractionated melt (higher REE abundance and negative Eu anomaly) and cumulates (lower REE abundance and positive Eu anomaly). Studied samples from the Granulite Unit show isotopic evidence for enriched-mantle sources in their origin, as crustal recycling involving either Archean or Paleoproterozoic older crust have not been recognized yet.
\end{abstract}




\section{Sumário}

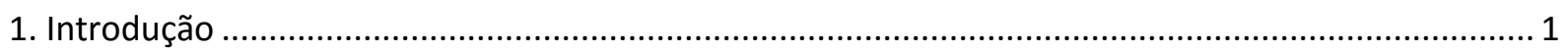

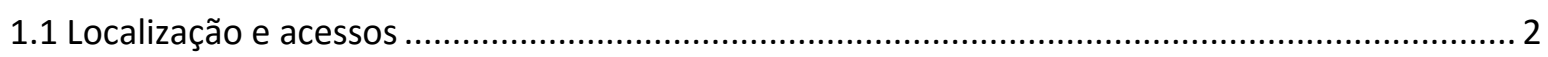

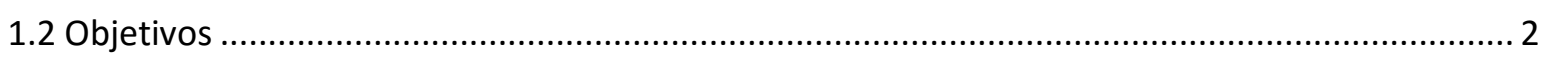

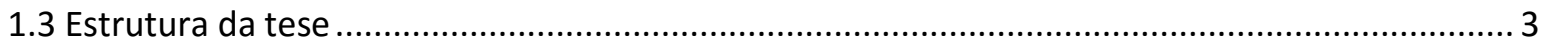

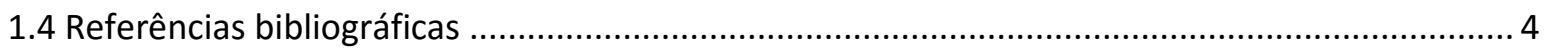

2. Revisão bibliográfica sobre a temática abordada ......................................................................... 7

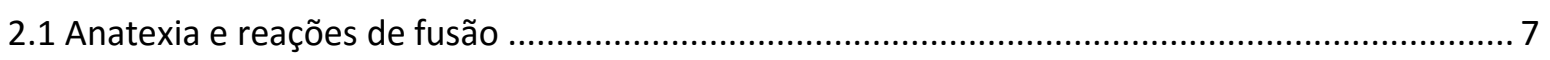

2.1.1 Reações de fusão envolvendo água em excesso (water-saturated melting reactions) ......... 9

2.1.2 Reações de fusão envolvendo muscovita em presença de água ........................................ 10

2.1.3 Reações de fusão sem água em excesso (water-undersaturated melting reactions) .......... 11

2.1.3.1 Reações de fusão envolvendo muscovita ................................................................. 11

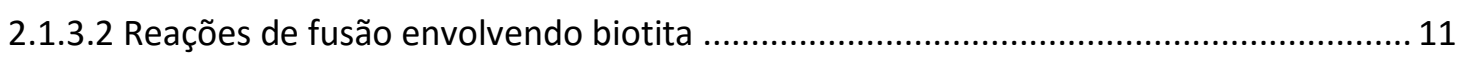

2.1.3.3 Reações de fusão envolvendo hornblenda ............................................................... 15

2.1.4 Reações de fusão anidra (dry melting reactions) ............................................................. 16

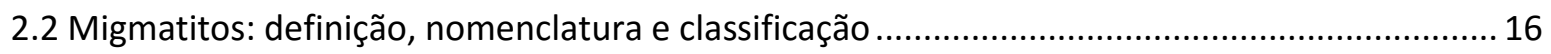

2.3 Investigação dos processos de fusão parcial através da assinatura geoquímica e geocronologia

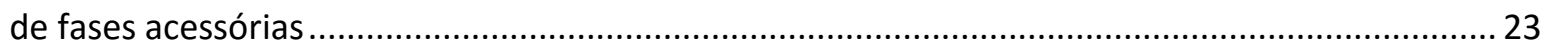

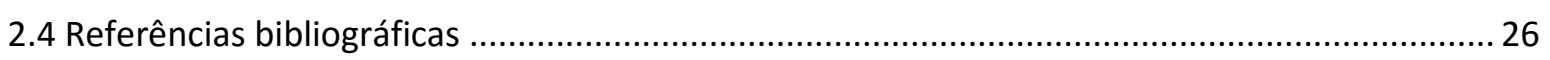

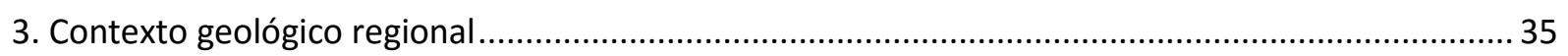

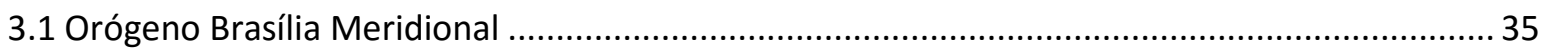

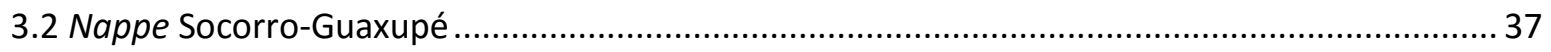

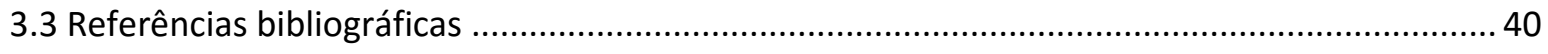

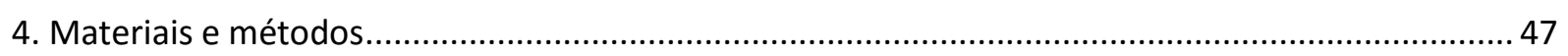

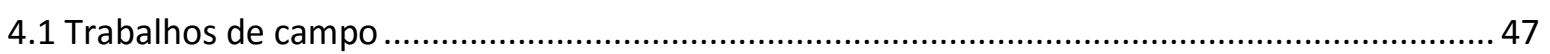

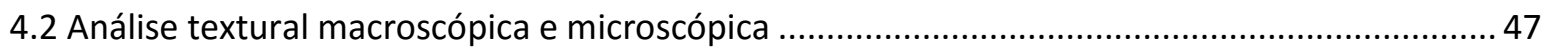

4.3 Química mineral através de microssonda eletrônica................................................................... 48

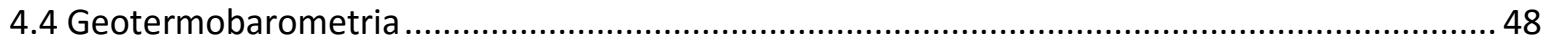

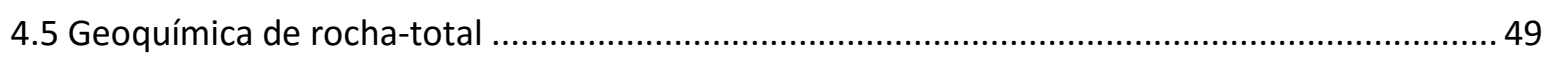

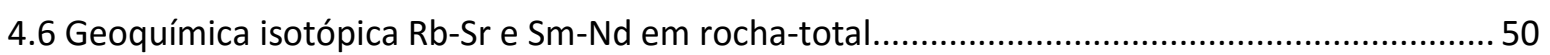

4.7 Geoquímica de elementos-traço em fases acessórias e fases metamórficas principais ............. 51

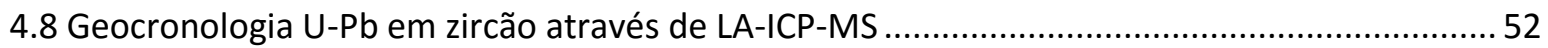

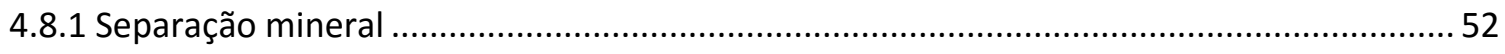

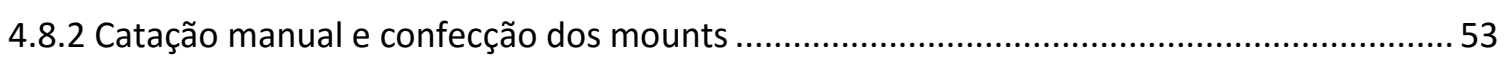

4.8.3 Imageamento dos mounts por CL (catodoluminescência) ................................................. 53

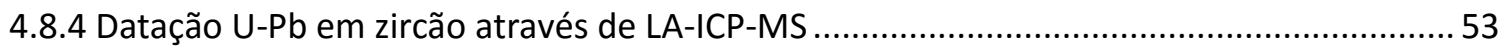

4.9 Geocronologia U-Th-Pb e geoquímica de elementos-traço em monazita através de

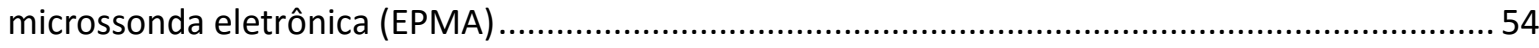




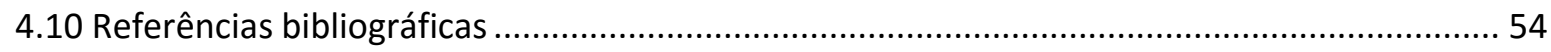

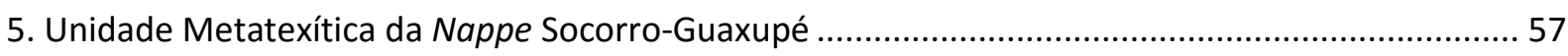

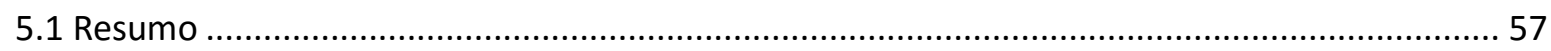

6. Unidade Granulítica da Nappe Socorro-Guaxupé ............................................................... 58

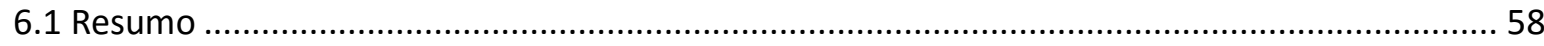

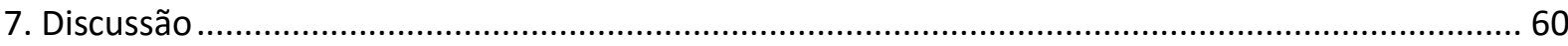

7.1 Evolução temporal dos eventos de fusão parcial e cristalização de fundido na Nappe Socorro-

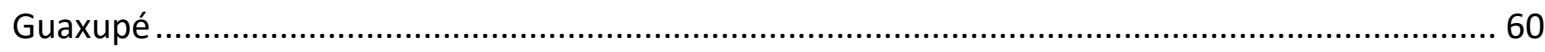

7.2 Origem dos charnockitos e hornblenda granitos da Unidade Granulítica .............................62 62

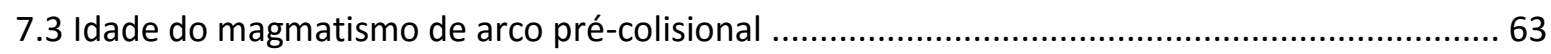

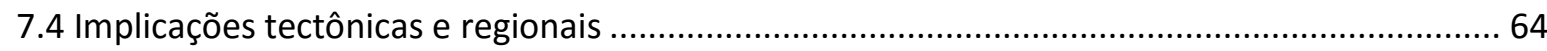

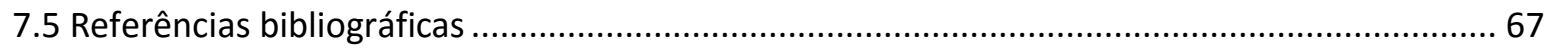

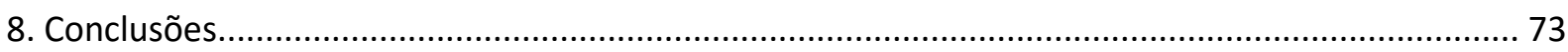

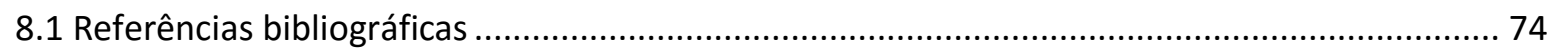

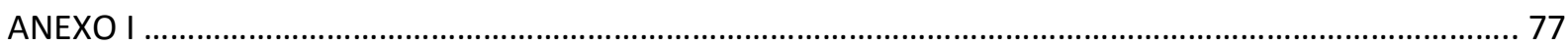

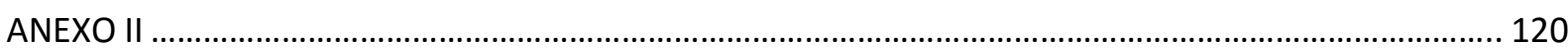

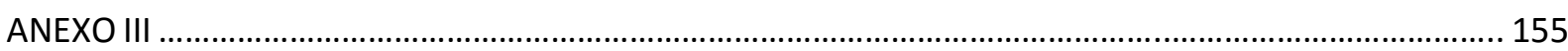

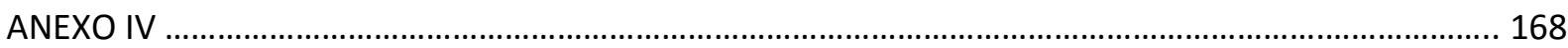

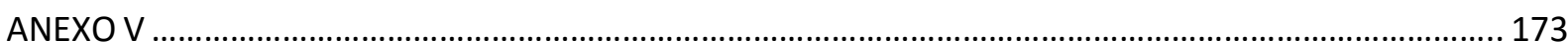

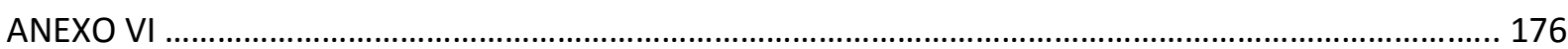

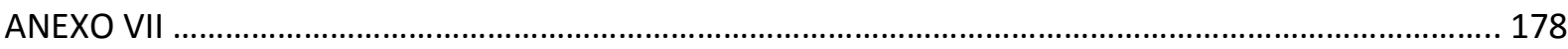

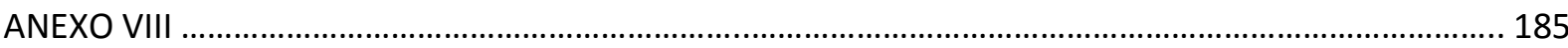

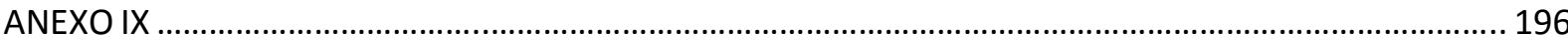

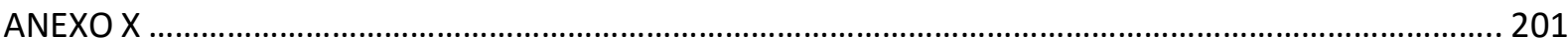

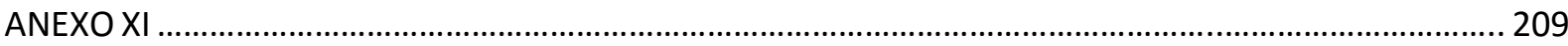





\section{Introdução}

Nesta tese é apresentado um estudo detalhado dos processos de fusão parcial e cristalização de fundido das rochas da Nappe Socorro-Guaxupé, através da integração de técnicas de datação insitu de zircão e monazita, análise textural, geotermobarometria, geoquímica de elementos-traço nas fases acessórias datadas e fases metamórficas principais, além de geoquímica de rocha-total e isótopos de $\mathrm{Sr}$ e Nd. A Nappe Socorro-Guaxupé (NSG) representa um domínio de arco magmático neoproterozóico intensamente erodido que expõe aproximadamente $10 \mathrm{~km}$ de crosta inferior (Campos Neto \& Caby, 1999, 2000), fornecendo condições excelentes para o estudo dos processos de fusão parcial em crosta continental profunda. Estudos petrológicos modernos se baseiam na correlação de episódios distintos de geração de zircão e monazita com reações metamórficas para reconstruir trajetórias $P$-T-t mais realistas (e.g. Rubatto et al., 2001; Taylor et al., 2014; Yakymchuk \& Brown, 2014; Kirkland et al., 2016).

Embora a idade do pico metamórfico na NSG tenha sido reconhecida previamente (ca.630620 Ma; Basei et al., 1995; Ebert et al., 1996; Töpfner, 1996; Janasi, 1999, 2002; Campos Neto et al., 2004; Martins et al., 2009; Reno et al., 2009; Mora et al., 2014), a duração do evento de alta temperatura era até então desconhecida ou pouco compreendida. Este fato é evidenciado pela ausência de uma distinção clara entre os eventos de magmatismo sin-colisional e pós-colisional na NSG. A idade de intrusão de sienitos potássicos pós-colisionais disponível na literatura (Sienito Pedra Branca, ca. $612 \pm 3$ Ma; Töpfner, 1996) é mais antiga do que as idades de cristalização de fundido de ca. 608 Ma recentemente obtidas por técnicas de datação in-situ (e.g. Martins et al., 2009; Mora et al., 2014), o que demonstra a necessidade de um maior refinamento dos dados geocronológicos da NSG. A maioria dos dados de U-Pb disponíveis se baseia em geocronologia ID-TIMS, o que pode implicar em misturas de idades de herança, mais antigas, com idades mais novas relacionadas ao evento metamórfico.

A geocronologia U-(Th)-Pb em zircão e monazita é amplamente utilizada para acessar a evolução temporal dos processos metamórficos na crosta profunda, devido à sua estabilidade química e altas temperaturas de fechamento (e.g. Cherniak \& Watson, 2001). Sabe-se que o crescimento de zircão relacionado com metamorfismo de alto grau é mais expressivo durante a cristalização de fundido, e não durante o pico metamórfico (e.g. Fraser et al., 1997; Schaltegger et al., 1999; Harley et al., 2007; Yakymchuk \& Brown, 2014). A monazita é um geocronômetro robusto, capaz de registrar eventos metamórficos de curta duração (e.g. Williams et al., 2007). Domínios composicionais distintos de monazita refletem diferentes estágios de crescimento durante o metamorfismo, que podem fornecer um registro detalhado da evolução metamórfica progressiva e retrometamórfica de áreas complexas (e.g. Möller et al., 2003; Mahan et al., 2006; Dumond et al., 2008; Kelly et al., 2012). 
No presente trabalho, cinco episódios distintos de geração de monazita foram identificados em migmatitos com granada \pm ortopiroxênio na Unidade Metatexítica, o que permitiu a determinação da evolução temporal completa do metamorfismo progressivo/fusão parcial e metamorfismo retrógrado/cristalização de fundido na Nappe Socorro-Guaxupé, com implicações diretas na evolução do Orógeno Brasília. Os eventos de fusão parcial e metamorfismo de temperatura ultra-alta na Nappe Socorro-Guaxupé é aqui estabelecido em ca. 630-625 Ma. A cristalização de fundido é um evento de longa duração entre $c a$. 630-600 Ma, com crescimento abundante e episódico de zircão e monazita em ca. $625 \mathrm{Ma}$, ca. $615 \mathrm{Ma}$ e ca. $608 \mathrm{Ma}$. Estágios finais de cristalização de fundido são registrados em ca. $600 \mathrm{Ma}$, sincrônico com o consumo parcial de granada e geração de biotita retrometamórfica. A integração de geocronologia U-Pb com padrões de elementos-traço em zircão foi utilizada para discriminar zircões herdados de zircões não-herdados com maior confiança, o que permitiu uma distinção clara dos eventos magmáticos pré-colisionais, sin-colisionais e pós-colisionais na Nappe Socorro-Guaxupé.

Dados isotópicos de Nd pré-existentes (e.g. Janasi, 1999, 2002; Hackspacher et al., 2003; Campos Neto et al., 2004; Janasi et al., 2009; Mora et al., 2014; Vinagre et al., 2014) indicam o

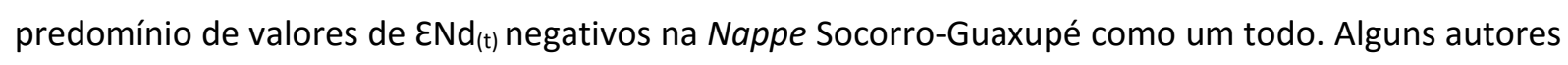
têm proposto a participação de fontes crustais paleoproterozóicas na gênese de magmas na NSG (e.g. Hackspacher et al., 2003), baseado em idades $T_{D M}$ com valores entre 2,0-1,9 Ga. No entanto, assinaturas isotópicas de $\mathrm{Sr}-\mathrm{Nd}$ combinadas com geocronologia $\mathrm{U}-\mathrm{Pb}$ e geoquímica de rocha-total forneceram evidências para o envolvimento de fontes mantélicas enriquecidas na geração dos protólitos ígneos na Unidade Granulítica, conforme sugerido anteriormente por Janasi, (1999), Janasi et al., (2009) e Carvalho et al., (2014).

\subsection{Localização e acessos}

A área de pesquisa situa-se no sudoeste de Minas Gerais, próxima à cidade de Alfenas, na porção sudoeste da folha Alfenas (SF-23-I-I-3), escala 1: 50000 - IBGE (1970). O principal acesso a partir da cidade de São Paulo é feito através da Rodovia Fernão Dias (BR-381) até o trevo de Pouso Alegre, BR-459 até a rodovia MG-179, seguindo pela rodovia MG-179 até Alfenas.

\subsection{Objetivos}

* Caracterização das texturas metamórficas dos litotipos das Unidades Metatexítica e Granulítica em escala macroscópica e microscópica; 
* Determinação das condições de pico do metamorfismo através de métodos termobarométricos clássicos, como Al-em-ortopiroxênio e do resfriamento de fundido através da termometria de Ti-em-zircão;

* Determinação da idade do metamorfismo, fusão parcial e resfriamento/cristalização de fundido através de datações U-Pb in-situ de zircão e monazita em contextos texturais distintos, para estabelecer trajetórias $P$-T-t nos litotipos das Unidades Metatexítica e Granulítica;

* Correlação da distribuição de ETR entre as fases acessórias (e.g. zircão e monazita), e os minerais metamórficos coexistentes (e.g. granada) através de análises de elementos-traço insitu em LA-ICP-MS, para inferir a participação das fases acessórias datáveis em reações metamórficas específicas;

* Determinação da idade de magmatismo de arco pré-colisional através da datação de herança dos grãos de zircão nos migmatitos da Unidade Metatexítica e nos leucossomas e granulitos da Unidade Granulítica;

* Caracterização das fontes dos protólitos ígneos e metassedimentares envolvidos no processo de fusão parcial na Nappe Socorro-Guaxupé, através de geoquímica e isótopos de Sr-Nd.

\subsection{Estrutura da tese}

* Capítulo 1 (Introdução): neste capítulo é apresentada uma introdução ao tema desta pesquisa, a localização da área de estudo, os principais objetivos e forma de apresentação desta tese.

* Capítulo 2 (Revisão bibliográfica sobre a temática abordada): neste capítulo é apresentada uma revisão bibliográfica sobre fusão parcial e as principais reações de fusão, definição e classificação de migmatitos e as ferramentas teóricas envolvidas no processo de fusão parcial e cristalização de fundido a partir da assinatura geoquímica de fases acessórias.

* Capítulo 3 (Contexto geológico regional): neste capítulo é apresentado o contexto geológico no qual se insere a área de pesquisa.

* Capítulo 4 (Materiais e métodos): neste capítulo estão descritos os métodos empregados na obtenção dos dados desta tese, bem como os procedimentos analíticos de cada uma das técnicas utilizadas.

* Capítulo 5 (Unidade Metatexítica da Nappe Socorro-Guaxupé): neste capítulo é apresentada uma integração de aspectos texturais com novos dados de termobarometria, geoquímica de elementos-traço em fases metamórficas principais e acessórias e geocronologia U-Pb em zircão e U-Th-Pb em monazita dos litotipos da Unidade Metatexítica da Nappe SocorroGuaxupé em forma de artigo (ANEXO I). O artigo intitulado "Timing of anatexis and melt crystallization in the Socorro-Guaxupé Nappe, SE Brazil: Insights from trace element 
composition of zircon, monazite and garnet coupled to U-Pb geochronology" encontra-se aceito para publicação (in press) no periódico Lithos e sua leitura é fundamental para o entendimento desta tese.

* Capítulo 6 (Unidade Granulítica da Nappe Socorro-Guaxupé): este capítulo abrange um estudo petrológico e geocronológico integrado dos litotipos da Unidade Granulítica da Nappe Socorro-Guaxupé, com novos dados de química mineral, termobarometria, geoquímica de rocha-total, geoquímica de elementos-traço e geocronologia U-Pb em zircão e isótopos de $\mathrm{Sr}$ e Nd. Este capítulo é apresentado sob a forma de artigo (ANEXO II), intitulado "Age and duration of pre-collisional arc magmatism and UHT metamorphism in the Socorro-Guaxupé Nappe (SE Brazil) constrained by in-situ charnockite melts and related rocks", que será submetido em breve para o periódico Precambrian Research e sua leitura é indispensável para a compreensão desta tese.

* Capítulo 7 (Discussão): neste capítulo é apresentada uma discussão integrada de todos os dados obtidos nesta tese e as implicações tectônicas e regionais dos resultados na evolução do Orógeno Brasília.

* Capítulo 8 (Conclusões): neste capítulo encontram-se sumarizadas as principais conclusões da presente tese.

\subsection{Referências bibliográficas}

Basei, M.A.S., Siga Jr., O., Sato, K., Sproesser, W.M., 1995. A metodologia urânio-chumbo na Universidade de São Paulo: princípios metodológicos, aplicações e resultados obtidos. Anais da Academia Brasileira de Ciências 67(2), 221-237.

Campos Neto, M.C., Basei, M.A., Vlach, S.R.F., Caby, R., Szabó, AJ., Vasconcelos, P., 2004. Migração de orógenos e superposição de orogêneses: um esboço da colagem brasiliana no sul do Cráton do São Francisco, SE-Brasil, 2004. Geologia USP, Série Científica 4 (1), 13-40.

Campos Neto, M.C., Caby, R., 1999. Neoproterozoic high-pressure metamorphism and tectonic constraint from the nappe system south of the São Francisco Craton, southeast Brazil. Precambrian Research 97, 3-26.

Campos Neto, M.C. \& Caby, R., 2000. Terrane accretion and upward extrusion of high-pressure granulites in the Neoproterozoic nappes of Southeast Brazil: Petrological and structural constraints. Tectonics 14, 669-687.

Carvalho, B.B., Janasi, V.A., Henrique-Pinto, R., 2014. Geochemical and Sr-Nd-Pb isotope constraints on the petrogenesis of the K-rich Pedra Branca Syenite: Implications for the Neoproterozoic postcollisional magmatism in SE Brazil. Lithos 205, 39-59.

Cherniak, D.J., Watson, E.B., 2001. Pb diffusion in zircon. Chemical Geology 172, 5-24. 
Del Lama, E.A., Zanardo, A., Oliveira, M.A.F., Morales, N., 2000. Exhumation of high-pressure granulites of the Guaxupé Complex, Southeastern Brazil. Geological Journal 35, 231-249.

Dumond, G., McLean, N., Williams, M.L., Jercinovic, M.J., Bowring, S.A., 2008. High-resolution dating of granite petrogenesis and deformation in a lower crustal shear zone: Athabasca granulite terrane, western Canadian Shield. Chemical Geology 254, 175-196.

Ebert, H.D., Chemale, F., Babinski, M., Artur, A.C., Van Schmus, W.R., 1996. Tectonic setting and U-Pb zircon dating of the plutonic Socorro Complex in the transpressive Rio Paraíba do Sul shear belt, SE Brazil. Tectonics 15, 668-699.

Fraser, G., Ellis, D., Eggins, S., 1997. Zirconium abundance in granulite-facies minerals, with implications for zircon geochronology in high-grade rocks. Geology 25, 607-610.

Hackspacher, P.C., Fetter, A.H., Ebert, H.D., Janasi, V.A., Oliveira, M.A.F., Braga, I.F., Negri, F.A., 2003. Magmatismo há ca. 660-640 Ma no Domínio Socorro: Registros de convergência pré-colisional na aglutinação do Gondwana Ocidental. Geologia USP, Série Científica 3, 85-96.

Hackspacher, P.C., Fetter, A.H., Teixeira, W., Dantas, E.L., Ebert, H.D., Trouw, R.A.J., Vasconcelos, P., 2004. Final stages of the Brasiliano Orogenesis in SE Brazil: U-Pb and ${ }^{40} \mathrm{Ar} /{ }^{39} \mathrm{Ar}$ evidence for overprinting of the Brasília Belt by the Ribeira Belt tectonics. In: Weinberg, R., Trouw, R.A.J., Fuck, R.A., Hackspacher, P.C. (eds.), The 750-550 Ma Brasiliano Event of South America, Journal of the Virtual Explorer, Electronic Edition, Vol. 17 (http://virtualexplorer.com.au/article/2004/108/final-stages-of-the-brasiliano-orogeny).

Harley, S.L., Kelly, N.M., Möller, A., 2007. Zircon behaviour and the thermal histories of mountain chains. Elements 3, 25-30.

Janasi, V.A. 1999. Petrogênese de granitos crustais da Nappe de Empurrão Socorro-Guaxupé (SP-MG): uma contribuição da geoquímica elemental e isotópica. Tese (Livre-Docência) - IGc-USP, 304 pp.

Janasi, V.A. 2002. Elemental and Sr-Nd isotope geochemistry of two Neoproterozoic mangerite suites in SE Brazil: implications for the origin of the mangerite-charnockite-granite series. Precambrian Research 119, 301-327.

Janasi, V.A., Vlach, S.R.F., Campos Neto, M.C., Ulbrich, H.H.G.J., 2009. Associated A-type subalkaline and high-K calc-alkaline granites in the Itú Granite Province, southeastern Brazil: petrological and tectonic significance. Canadian Mineralogist 47, 1505-1526.

Kelly, N.M., Harley, S.L., Möller, A., 2012. Complexity in the behavior and recrystallization of monazite during high-T metamorphism and fluid infiltration. Chemical Geology 322-323, 192-208.

Kirkland, C.L., Erickson, T.M., Johnson, T.E., Danišík, M., Evans, N.J., Bourdet, J., McDonald, B., 2016. Discriminating prolonged, episodic or disturbed monazite age spectra: an example from the Kalak Nappe Complex, Arctic Norway. Chemical Geology 424, 96-110. 
Mahan, K.H., Goncalves, P., Williams, M.L., Jercinovic, M.J., 2006. Dating metamorphic reactions and fluid flow: application to exhumation of high-P granulites in a crustal-scale shear zone, western Canadian Shield. Journal of Metamorphic Geology 24, 193-217.

Martins. L., Vlach, S.R.F., Janasi, V.A., 2009. Reaction microtextures of monazite: correlation between chemical and age domains in the Nazaré Paulista migmatite, SE Brazil. Chemical Geology 261, 271-285.

Möller, A., Hensen, B.J., Armstrong, R.A., Mezger, K., Ballèvre, M., 2003a. U-Pb zircon and monazite age constraints on granulite-facies metamorphism and deformation in the Strangways Metamorphic Complex (central Australia). Contributions to Mineralogy and Petrology 145, 406423.

Mora, C.A.S., Campos Neto, M.C., Basei, M.A.S., 2014. Syn-collisional lower continental crust anataxis in the Neoproterozoic Socorro-Guaxupé Nappe System, southern Brasília Orogen, Brazil: constraints from zircon $\mathrm{U}-\mathrm{Pb}$ dating, $\mathrm{Sr}-\mathrm{Nd}-\mathrm{Hf}$ signatures and whole-rock geochemistry. Precambrian Research 255, 847-864.

Rubatto, D., Williams, I.S., Buick, I.S., 2001. Zircon and monazite response to prograde metamorphism in the Reynolds Range, central Australia. Contributions to Mineralogy and Petrology 140, 458468.

Schaltegger, U., Fanning, C.M., Günther, D., Maurin, J.C., Schulmann, K., Gebauer, D., 1999. Growth, annealing and recrystallization of zircon and preservation of monazite in high-grade metamorphism: conventional and in-situ $\mathrm{U}-\mathrm{Pb}$ isotope, cathodoluminescence and microchemical evidence. Contributions to Mineralogy and Petrology 134, 186-201.

Taylor, R.J.M., Clark, C., Fitzsimons, I.C.W., Santosh, M., Hand, M., Evans, N., McDonald, B., 2014. Postpeak, fluid-mediated modification of granulite facies zircon and monazite in the Trivandrum Block, southern India. Contributions to Mineralogy and Petrology 168, 1-17.

Töpfner, C. 1996. Brasiliano-granitoide in den bundesstaaten São Paulo und Minas Gerais, Brasilieneine vergleichende studie. Münchner Geologische Hefte 4, 1-100.

Vinagre, R., Trouw, R.A.J., Mendes, J.C., Duffles, P., Peternel, R., Matos, G., 2014. New evidence of a magmatic arc in the Southern Brasília Belt, Brazil: The Serra da Água Limpa batholith (SocorroGuaxupé Nappe). Journal of South American Earth Sciences 54, 120-139.

Williams, M.L., Jercinovic, M.J., Hetherington, C.J., 2007. Microprobe monazite geochronology: understanding geologic processes by integrating composition and chronology. Annual Review of Earth and Planetary Sciences 35, 137-175.

Yakymchuk, C., Brown, M., 2014. Behaviour of zircon and monazite during crustal melting. Journal of the Geological Society $171,465-479$. 


\section{Revisão bibliográfica sobre a temática abordada}

\subsection{Anatexia e reações de fusão}

A anatexia é um termo geral para descrever a fusão parcial das rochas da crosta ou do manto, que quando é acompanhada de deformação, possibilita a ocorrência de outros processos relacionados, tais como: segregação e migração do fundido a partir da fração sólida, cristalização fracionada e fluxo magmático (Sawyer, 2008). Rochas silicáticas de composição apropriada começam a fundir em temperaturas em torno de $650{ }^{\circ} \mathrm{C}$ em presença de água livre (fácies anfibolito), em terrenos metamórficos de pressão média a alta (Vernon, \& Clarke, 2008). Com o aumento da temperatura durante o metamorfismo, os minerais que constituem a associação mineral reagente em reações de fusão se tornam instáveis, dando origem a produto caracterizado por fundido, em reações de fusão congruente, ou que pode ser acompanhado pela formação de novos minerais (peritéticos), em reações de fusão incongruente (Sawyer, 1999).

A fusão se inicia nas junções nos contatos entre os minerais reagentes (Mehnert et al., 1973), onde os ângulos diedrais são da ordem de $120^{\circ}$, quando contatos texturalmente estáveis ocorrem entre fases. A distribuição do fundido na rocha é controlada pela cinética da reação de fusão, pela microestrutura original da rocha, e.g. foliação, e pela taxa de fusão (Sawyer, 2001). Os estágios iniciais de reação de fusão só podem ser acessados por experimentos de laboratório ou em casos onde houve metamorfismo de contato em evento térmico relativamente curto. A progressão na fusão causa diminuição do ângulo diedral entre o sólido e o líquido (fundido) (Holness \& Sawyer, 2008). Quando este ângulo é maior que $60^{\circ}$ as gotas de fundido ficam aprisionadas entre os grãos reagentes, no sítio da fusão, mas com o aumento da taxa de fusão valores menores que $60^{\circ}$ ocorrem e há interconectividade de fundido ao longo dos contatos entre os minerais (Fig. 1). Isso resulta no desenvolvimento de filmes de fundido progressivamente mais espessos separando os grãos reagentes, com os contatos líquido-sólido agora caracterizados por formas em cúspide ou lobados. A formação de grãos euédricos de fases peritéticas junto desses sítios é comum (Vernon \& Collins, 1988; Grant \& Frost, 1990; Sawyer, 1999; Marchildon \& Brown, 2002, Vernon, 2004, Holness \& Sawyer, 2008).

Em estágios mais avançados de fusão, o fundido já está presente ao longo de quase todos os contatos entre os grãos, formando rede de interconexão, o que torna o sistema permeável, permitindo que ocorra segregação, migração e extração do fundido, ou fluxo da rocha, ambos os processos facilitados pela deformação (Sawyer, 1999, 2001). Após a extração do fundido, ocorre o equilíbrio textural entre as fases sólidas do resíduo por recristalização, dando origem a contatos diedrais de $120^{\circ}$, estado de menor energia, e os contatos entre os grãos adquirem a forma poligonizada. 
a)

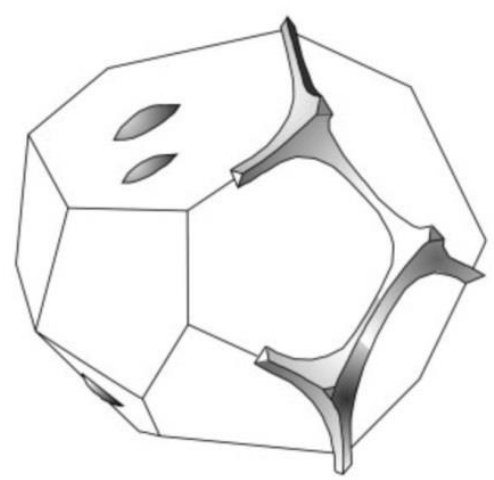

b)

$\Theta>60^{\circ}$

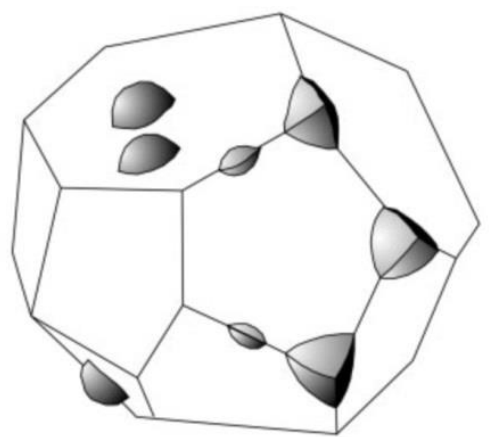

Figura 1: Ilustração esquemática mostrando as diferenças na topologia do fundido abaixo e acima do valor crítico de $60^{\circ}$. a) Ângulos diedrais menores que $60^{\circ}$ permitem a interconectividade de fundido, mesmo com pequenas frações de fundido. b) Ângulos maiores que $60^{\circ}$ impedem a migração e interconexão do fundido e as gotas de fundido ficam aprisionadas, a menos que maiores proporções de fração de fundido sejam alcançadas, e a migração seja facilitada pela deformação. Extraído de Holness \& Sawyer (2008).

O processo de fusão pode ser dividido em três categorias distintas: fusão com excesso de água, fusão envolvendo fases hidratadas e fusão anidra (Fyfe, 1973) (Fig. 2). Em condições de saturação em $\mathrm{H}_{2} \mathrm{O}$, as reações de fusão são caracterizadas por inclinação negativa e $\Delta V$ positivo. A pressão total do sistema é aproximadamente igual à pressão de água, e a fusão ocorre sob temperaturas mais baixas. Reações de fusão onde a água está presente nas fases hidratadas são dominantes na crosta e apresentam inclinação positiva e $\Delta \mathrm{V}$ negativo. Reações de fusão anidra apresentam inclinação positiva e $\Delta V$ negativo, onde a temperatura aumenta com a pressão. Os principais tipos de reações de fusão são descritos a seguir:
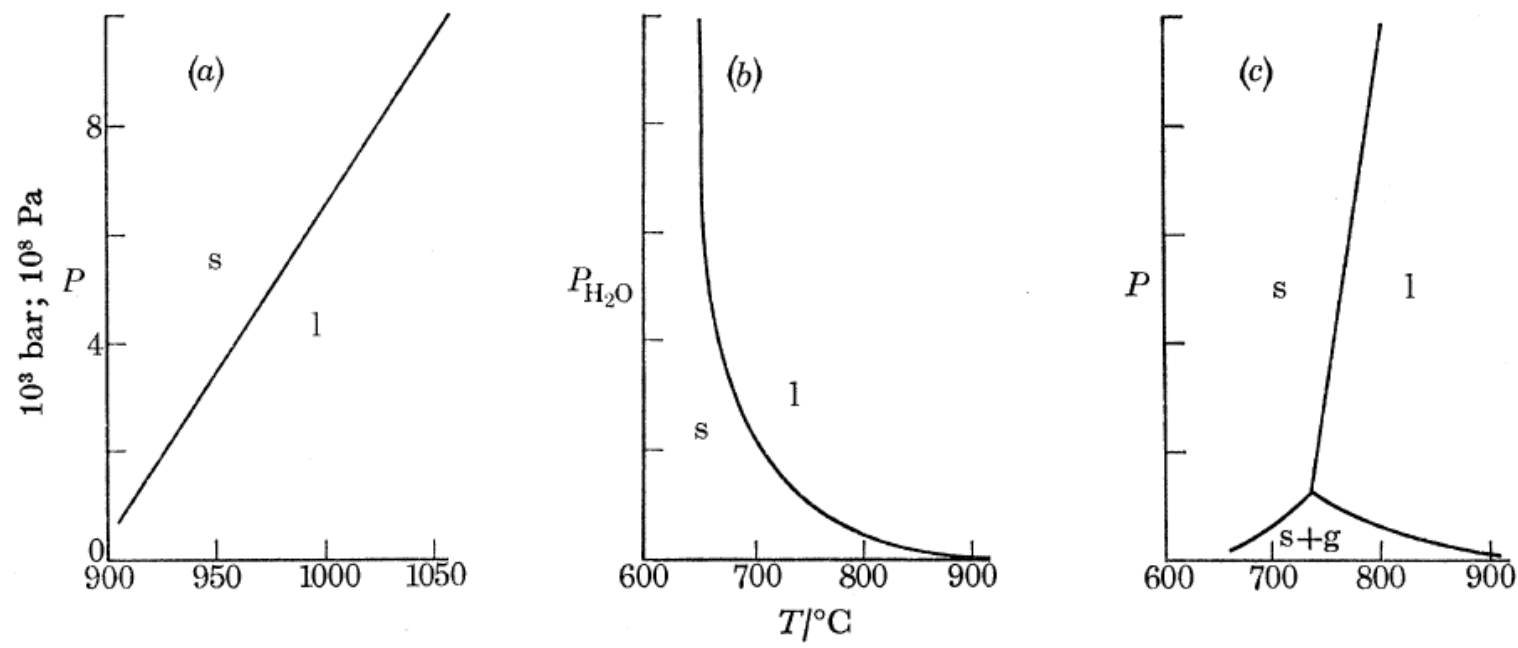

Figura 2: Topologia das reações de fusão no diagrama de fases para composições graníticas. a) fusão anidra; b) fusão com água em excesso; c) fusão envolvendo fases minerais hidratadas. s, sólido; I, líquido; g, gás. Extraído de Fyfe (1973). 


\subsubsection{Reações de fusão envolvendo água em excesso (water-saturated melting reactions)}

Sabe-se que os fluidos, particularmente $\mathrm{H}_{2} \mathrm{O}$, exercem papel fundamental na fusão, pois os fundidos silicáticos podem dissolver quantidades significativas de água, especialmente com o aumento de pressão (Wyllie, 1992). Desta forma, a disponibilidade de água livre pode ser um fator limitante para a produção de fundido na crosta (Thompson, 1982). A composição da fase fluida controla tanto as atividades dos componentes voláteis, como a natureza das reações (Clemens, 2006). Reações de fusão com excesso de água são caracterizadas por fusão congruente, onde todos os componentes reagentes da reação entram em fusão total, sem a formação de fases minerais sólidas e residuais. 0 líquido (fundido) gerado é saturado em $\mathrm{H}_{2} \mathrm{O}$ e possui exatamente a mesma composição da associação mineral reagente (Vernon \& Clarke, 2008). A reação de fusão com excesso de água em rochas quartzofeldspáticas mais conhecida é a seguinte (reação 1):

(1) $\mathrm{Kfs}+\mathrm{Pl}+\mathrm{Qtz}+\mathrm{H}_{2} \mathrm{O}=\mathrm{L}$ (fundido)

Reações de fusão com excesso de $\mathrm{H}_{2} \mathrm{O}$ são caracterizadas por curva de solidus com inclinação negativa e $\Delta V$ positivo, o que implica em produção de fundidos saturados em água e cristalização com a diminuição da pressão, que impede a ascensão de magmas graníticos saturados em água em crosta continental rasa (Fyfe, 1973; Wyllie, 1992). Reações de fusão com excesso de $\mathrm{H}_{2} \mathrm{O}$ produzem quantidades pequenas de fundido, pois geralmente não há quantidades significativas de água livre disponível para que ocorra a reação (Waters, 1988; Thompson \& Connolly,1995). No entanto, grandes volumes de fundido podem ser gerados a partir da fusão parcial de protólitos graníticos, granodioríticos e trondhjemíticos, facilitado por influxo de fluido aquoso (McLellan, 1988; Slagstad et al., 2005) e a temperaturas relativamente baixas (Piwinskii \& Wyllie, 1968; Büsch et al., 1974; Watkins et al., 2007). A quantidade de fundido produzida em migmatitos derivados de protólitos graníticos excede a quantidade de fundido esperada a partir de fusão por desidratação de minerais hidratados. Além disso, outras evidências, como ausência de fases minerais peritéticas e estabilidade da biotita, sugerem a atuação de processos de fusão por influxo de água (water-added melting ou water-fluxed melting) através de zonas de cisalhamento profundas (Sawyer, 2010).

Alguns autores também ressaltam que comportamento "híbrido" é esperado quando há variações locais na quantidade de fluidos disponíveis no início da fusão. Assim, situações intermediárias, onde o início da fusão parcial pode ocorrer sob condições de saturação em água (fluidpresent), passando para condições de insaturação em água (fluid-absent) são relativamente comuns na natureza (Vielzeuf \& Schmidt, 2001; White et al., 2005; Droop \& Brodie, 2012). 


\subsubsection{Reações de fusão envolvendo muscovita em presença de água}

A fusão de muscovita em protólitos pelíticos (reação 2) ocorre a temperaturas em torno de $700{ }^{\circ} \mathrm{C}$ e pressões maiores que $6 \mathrm{kbar}$, em presença de quartzo, assumindo conteúdo pequeno de $\mathrm{H}_{2} \mathrm{O}$ no subsolidus, alta solubilidade de $\mathrm{H}_{2} \mathrm{O}$ no fundido e que não haja adição externa de $\mathrm{H}_{2} \mathrm{O}$ no sistema (Spear et al., 1999). A reação pode envolver ou não plagioclásio e produz líquido granítico, feldspato potássico e aluminossilicato como fases peritéticas (reação 4) (Fig. 3). Desta forma, a geração de muscovita retrógrada durante o resfriamento só deve ocorrer em pressões acima de 6 kbar e se não houver extração significativa de fundido, uma vez que a $\mathrm{H}_{2} \mathrm{O}$ responsável pela formação de muscovita tardia estaria dissolvida no fundido (Spear et al., 1999).

(2) $\mathrm{Ms}+\mathrm{Pl} \pm \mathrm{Kfs}+\mathrm{Qtz}+\mathrm{H}_{2} \mathrm{O}=\mathrm{L}$ (fundido) (Spear et al., 1999)

(3) $\mathrm{Ms}+\mathrm{Bt}+\mathrm{Kfs}+\mathrm{PI}+\mathrm{Qtz}+\mathrm{H}_{2} \mathrm{O}=\mathrm{L}$ (fundido ou "melt") (Lambert et al., 1969)

Um metapelito constituído de $\mathrm{Ms}+\mathrm{Bt}+\mathrm{Pl}+\mathrm{Kfs}+\mathrm{Qtz}$, portanto, com a presença de duas fases hidratadas, em equilíbrio com fase fluida aquosa, inicia a fusão no wet solidus (solidus saturado em $\mathrm{H}_{2} \mathrm{O}$ ) através da reação (3) (Fig. 4a). A topologia do diagrama de fases é semelhante àquela da fusão com excesso de água, com inclinação negativa. A reação cessa quando a água disponível é totalmente consumida, e as fases minerais mais hidratadas permanecem em excesso. Se o conteúdo de $\mathrm{H}_{2} \mathrm{O}$ no sistema for baixo, toda a água presente estará dissolvida no fundido, e o sistema passa de condições saturadas em fluido (fluid-present) para condições insaturadas em fluido (fluid-absent), e a fusão prossegue com a reação (5).

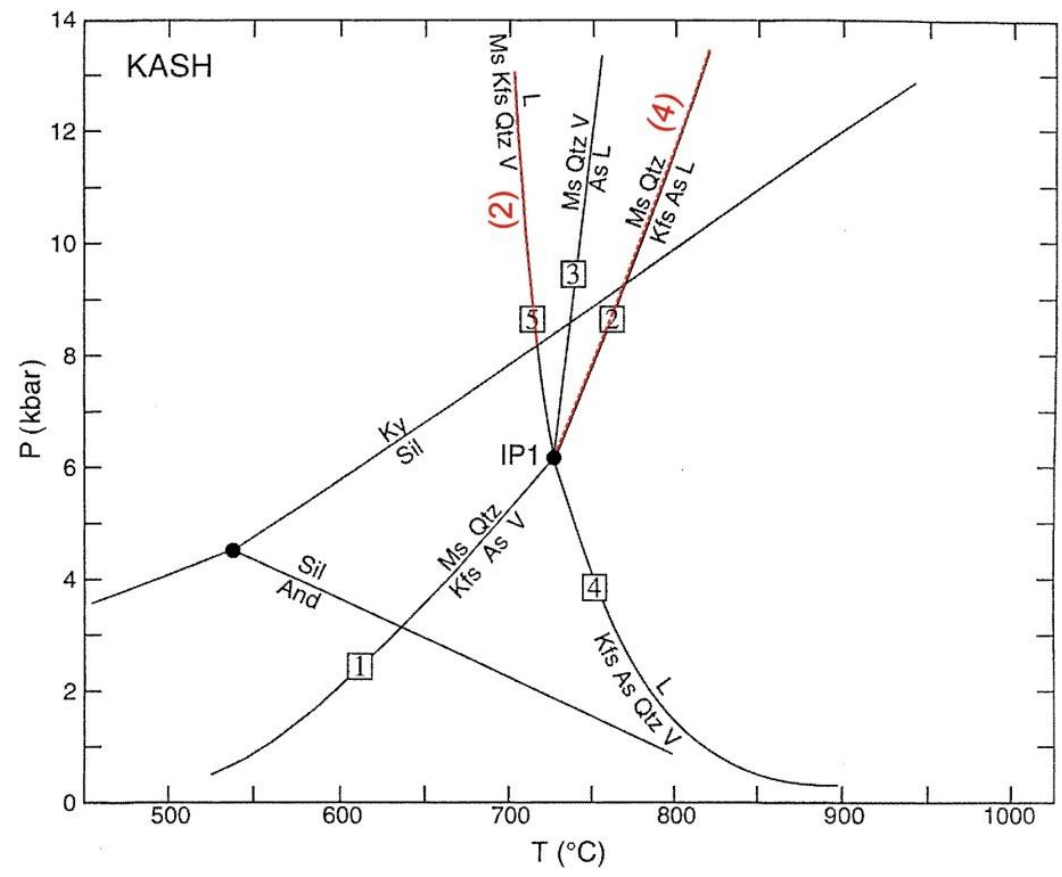

Figura 3: Diagrama de fases mostrando a localização das reações (2) e (4), destacadas em vermelho, no sistema simplificado KASH. Extraído de Spear et al., (1999). 


\subsubsection{Reações de fusão sem água em excesso (water-undersaturated melting reactions)}

As reações de fusão mais comuns em rochas crustais ocorrem a condições de temperatura e pressão do fácies granulito $\left(800-1000^{\circ} \mathrm{C}\right)$, na ausência de fase fluida livre e são responsáveis pela geração de grande volume de fundido na crosta continental (Wyllie et al., 1976; Wyllie, 1977; Thompson, 1982; Conrad et al., 1988; Clemens \& Watkins, 2001; Vigneresse, 2004; Clemens, 2005a). As reações de fusão sem excesso de água também são conhecidas como reações de fusão na ausência de fase fluida ou vapor (fluid-absent melting reactions ou vapour-absent melting reactions, respectivamente) (Grant, 1985a, b) ou reações de fusão por desidratação (dehydration-melting reactions) (Thompson, 1982). Recentemente alguns autores têm denominado estas reações de hydrate-breakdown melting reactions (e.g. Brown, 2008; Droop \& Brodie, 2012), onde fundido insaturado em $\mathrm{H}_{2} \mathrm{O}$ é formado a partir da fusão incongruente de minerais hidratados na ausência de fase fluida. Estas reações são caracterizadas por fusão incongruente, em que as fases minerais reagentes entram em fusão parcial, dando origem a um sistema híbrido constituído pelas fases líquida (fundido) e sólida residual (minerais peritéticos). A curva de solidus possui inclinação positiva e os produtos $\Delta V$ negativo. Ao considerar reações de fusão na ausência de fase fluida, a fertilidade do protólito vai depender do conteúdo de $\mathrm{H}_{2} \mathrm{O}$ disponível na rocha, expresso através do conteúdo de fases minerais hidratadas, da estabilidade termal da associação mineral hidratada, ou seja, a proporção de fases minerais que vão entrar em fusão, e da disponibilidade das outras fases requeridas para as reações de fusão, por exemplo, as proporções de quartzo e feldspatos (Clemens, 2006).

\subsubsection{Reações de fusão envolvendo muscovita}

As primeiras reações de fusão de muscovita na ausência de fase fluida (reações 4 e 6) são caracterizadas pela formação de fases peritéticas, aluminossilicatoe feldspato potássico, e no aumento significativo na proporção de fundido (Vielzeuf \& Schmidt, 2001) (Fig. 4a, 4d). As reações de quebra de muscovita (reação 4) produzem pequenas quantidades de fundido ( $<10 \%$ vol; Clemens \& Vielzeuf, 1987), porém em protólitos ricos em muscovita de composição pelítica este volume pode ultrapassar $20 \%$.

(4) $\mathrm{Ms}+\mathrm{Pl}+\mathrm{Qtz}=\mathrm{Al}_{2} \mathrm{SiO}_{5}+\mathrm{Kfs}+\mathrm{L}$ (Spear et al., 1999)

(5) $\mathrm{Ms}+\mathrm{Bt}+\mathrm{Pl}+\mathrm{Qtz}=\mathrm{L}[+\mathrm{Kfs}]($ Vielzeuf \& Schmidt, 2001)

(6) $\mathrm{Ms}+\mathrm{Pl}+\mathrm{Qtz}=\mathrm{Bt}+\mathrm{Kfs}+\mathrm{Al}_{2} \mathrm{SiO}_{5}+\mathrm{L}$ (Patiño-Douce \& Harris, 1998)

\subsubsection{Reações de fusão envolvendo biotita}

As reações de fusão envolvendo biotita na ausência de fase fluida são responsáveis pela geração de quantidades significativas de fundido, podendo produzir $20-35 \%$ de fundido em 
composições pelíticas, $10-40 \%$ em rochas quartzo-feldspáticas e 20-45\% em composições intermediárias (Clemens \& Vielzeuf, 1987). Diversos estudos experimentais realizados em metapelitos demonstram que o solidus a $10 \mathrm{kbar}$ está localizado a temperatura menor que $800{ }^{\circ} \mathrm{C}$ (Vielzeuf \& Holloway, 1988; Le Breton \& Thompson, 1988; Gardien et al., 1995, Stevens et al., 1997).

No entanto, segundo Vielzeuf \& Schmidt (2001), a primeira aparição de fundido proveniente de fusão incongruente em ausência de fase fluida ocorre a temperaturas mais baixas do que a quebra da biotita, com a quebra da muscovita (reações 5 e 6). Quando toda a muscovita excedente é consumida, a fusão prossegue com a reação (7), aumentando progressivamente o conteúdo de fundido até que as condições da reação (8) sejam alcançadas pela rocha. Esta reação marca o aparecimento da granada e o consumo total de biotita em composições pelíticas, a temperatura de $850^{\circ} \mathrm{C}$, com geração de aproximadamente $15 \%$ em volume de fundido (Vielzeuf \& Schmidt, 2001) (Fig. 4). A presença de granada em leucossoma ou neossoma constituído por feldspato potássico é indicativa de fusão por desidratação de biotita (Waters, 1988; Powell \& Downes, 1990; Fitzsimons, 1996; Sawyer, 2008).

Em composições metaluminosas (metagrauvacas) onde a biotita está em excesso, a fusão prossegue até o aparecimento de ortopiroxênio através da reação (10), com geração de aproximadamente $25 \%$ em volume de fundido (Fig. 4). Esta reação delimita o campo de estabilidade da biotita em metagrauvacas, com o desaparecimento de biotita e formação de ortopiroxênio (Vielzeuf \& Schmidt, 2001).

(7) $\mathrm{Bt}+\mathrm{Al}_{2} \mathrm{SiO}_{5}+\mathrm{Pl}+\mathrm{Qtz}=\mathrm{Kfs}+\mathrm{L}$ (Vielzeuf \& Schmidt, 2001)

(8) $\mathrm{Bt}+\mathrm{Pl}+\mathrm{Al}_{2} \mathrm{SiO}_{5}+\mathrm{Qtz}=\mathrm{Grt} / \mathrm{Crd}+\mathrm{Kfs}+\mathrm{L}$ (Vielzeuf \& Holloway, 1988; Le Breton \& Thompson, 1988; Gardien et al., 1995; Stevens et al., 1997)

(9) $\mathrm{Bt}+\mathrm{Pl}+\mathrm{Qtz}=\mathrm{Grt}+\mathrm{Kfs}+\mathrm{L}($ Vielzeuf \& Schmidt, 2001)

(10) $B t+P I+Q t z=O p x( \pm C p x \pm G r t)+K f s+L($ Vielzeuf \& Schmidt, 2001) 


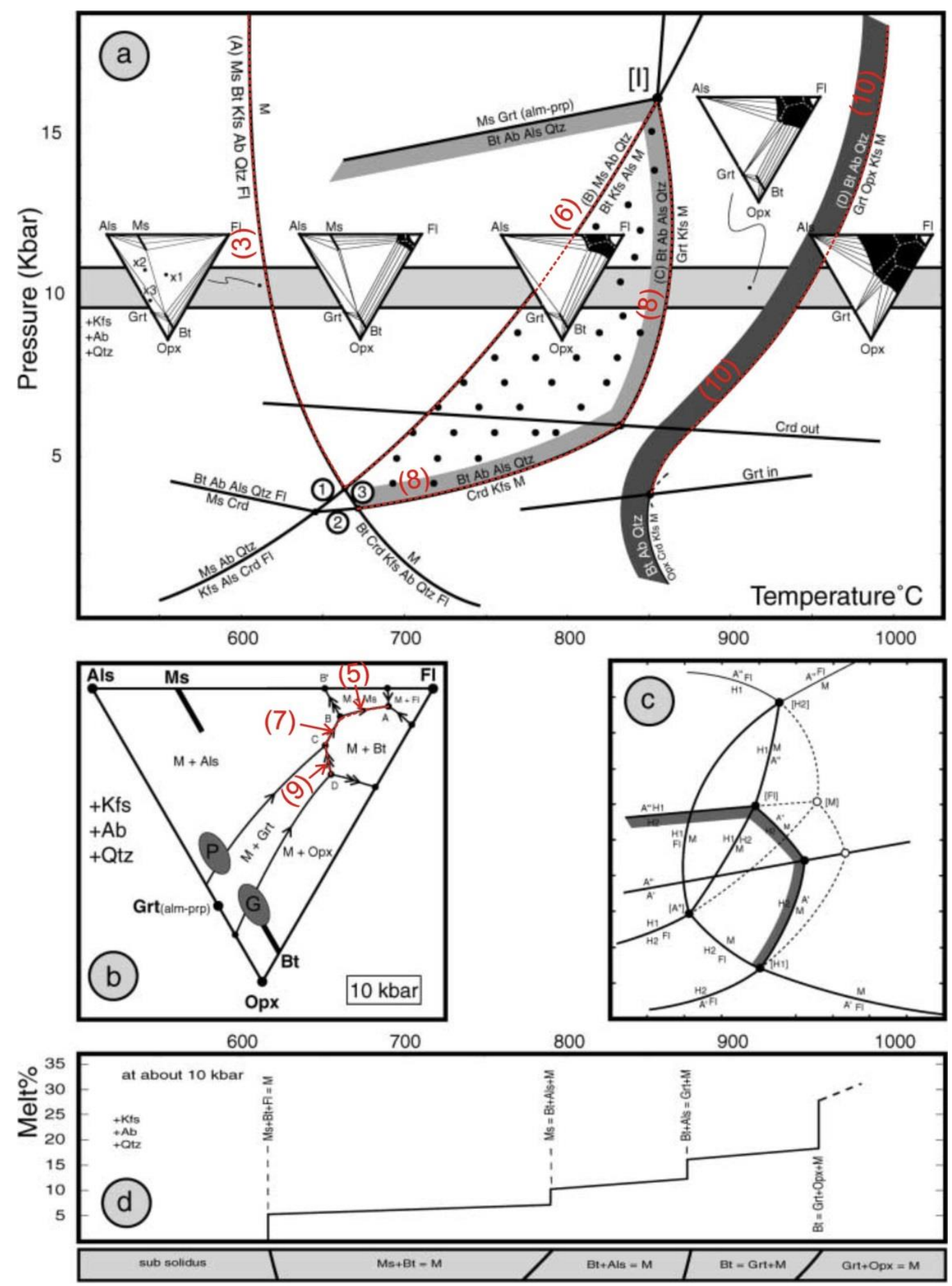

Figura 4: a) Projeção P-T simplificada no sistema NKFMASH com a localização das reações (3), (6), (8) e (10), destacadas em vermelho, para metapelitos e metagrauvacas. b) Diagrama liquidus no sistema NKFMASH a 10 kbar envolvendo as fases Als $\left(\mathrm{Al}_{2} \mathrm{SiO}_{5}\right)$, Ms, $\mathrm{Fl}\left(\mathrm{H}_{2} \mathrm{O}\right)$, Bt, Opx, Grt (com Kfs, Ab e Qtz em excesso). Projeção de Qz-Ab-Kfs no plano Als-Opx-Fl. $G$ e $P$ são campos composicionais de grauvacas e pelitos, respectivamente. c) Relações de fases teóricas no sistema $\mathrm{A}-\mathrm{H}_{2} \mathrm{O}$ com duas fases minerais hidratadas. Limite destacado em cor cinza em 4a e 4c (limite da estabilidade da associação Bt $+A b+$ Als + Qtz na Fig. 7a e H2 na Fig. 4c) ilustra a conexão entre o caso teórico e o sistema natural. d) Proporção de fundido gerado em função da temperatura a 10 kbar para uma composição conforme indicado em G (Fig. 4b). Extraído de Vielzeuf \& Schmidt (2001). 
Em composições levemente peraluminosas, o aluminossilicato é a primeira fase a desaparecer na quebra da biotita a $875^{\circ} \mathrm{C}$, de acordo com a reação contínua (8). Com o aumento da temperatura em altas pressões (acima de $20 \mathrm{kbar}$ ), a fusão vai prosseguir sem a geração de ortopiroxênio (reação 9) (Vielzeuf \& Schmidt, 2001). A produção de quantidades significativas de fundido é controlada pela quebra da biotita com a formação de ortopiroxênio através de múltiplos campos multivariantes até o consumo total de biotita a $850-900{ }^{\circ} \mathrm{C}$ (Johnson et al., 2008). Assim, o teor de anortita do plagioclásio é de extrema importância, pois controla o conteúdo de grossulária na granada na reação (8), de inclinação levemente positiva e com $\Delta V$ negativo, para vasta gama de composições. A identificação e a determinação da topologia das principais reações no sistema KCMASH foram descritas por Vielzeuf \& Montel (1994), sendo as mais importantes: $A n=G r s+A l s+Q t z, B t+A n=G r t+M s, B t+A n+Q t z=$ $G r t+K f s+L$ e $O p x+A n=G r t+Q t z$. Estas reações são responsáveis pela geração de uma curva de solidus com formato em S (Vielzeuf \& Schmidt, 2001). Os experimentos realizados por Vielzeuf \& Montel (1994) foram conduzidos em sistema KCMASH. Assim, apenas os membros-finais de magnésio foram considerados, onde biotita é representada por flogopita, granada pelos membros-finais piropo e grossulária, e ortopiroxênio é representado somente por enstatita.

Ao partir de associação mineral constituída de Bt-Grt-PI-Qtz a $775^{\circ} \mathrm{C}$ e 9 kbar, o componente anortita do plagioclásio reage para gerar o componente grossulária na granada, aluminossilicato e quartzo. Em pressões em torno de 15 kbar, ocorre a quebra da biotita com geração de granada e muscovita até que o aluminossilicato seja totalmente consumido, ao cruzar a reação Als-out. Os experimentos conduzidos por Vielzeuf \& Schmidt (2001) demonstram que em pressão elevada, a quebra da biotita ocorre em temperaturas mais baixas do que a quebra da muscovita. Isso se deve ao fato de que o fundido é capaz de dissolver maior quantidade de $\mathrm{H}_{2} \mathrm{O}$ em altas pressões (Wyllie, 1992), aumentando o campo de estabilidade da muscovita, que representa uma fase mais hidratada do que a biotita. Com a inversão das reações de fusão em alta pressão, a fase mais hidratada entra em fusão em temperaturas mais elevadas, a curva do solidus adquire um aspecto com forma em S. Estudos experimentais demonstram que as reações de fusão na ausência de fase fluida da muscovita (reação 6) e biotita (reação 8) devem ter a intersecção num ponto invariante em alta pressão (Thompson, 1982; Grant, 1985; Vielzeuf \& Holloway, 1988; Le Breton \& Thompson, 1988; Patiño-Douce \& Harris, 1998). Vielzeuf \& Schmidt (2001) sugeriram que este ponto invariante está localizado a aproximadamente $850^{\circ} \mathrm{C}$, a $15 \mathrm{kbar}$, em contraste com a proposta anterior de 9 kbar de Patiño-Douce \& Harris (1998).

Embora muitas reações de fusão sejam univariantes, sistemas mais complexos requerem variância maior devido à solução-sólida nas fases minerais reagentes e produtos (Clemens, 2006). Desta forma, entre duas reações univariantes existem campos multivariantes ( $F 2$ ), onde as reações são controladas pela heterogeneidade na composição inicial do protólito e podem gerar variações nas proporções modais das fases minerais e na composição do fundido. Como as reações (5), (7) e (9) são campos multivariantes, estão representados na Fig. 4b como linhas cotéticas (Vielzeuf \& Schmidt, 
2001). Portanto, estas reações não podem ser representadas no diagrama $P$ - $T$ e devem ser estudadas com o auxílio de pseudosseções (Johnson et al., 2008).

\subsubsection{Reações de fusão envolvendo hornblenda}

Reações de fusão envolvendo a hornblenda na ausência de fase fluida podem produzir 5-10\% de fundido em rochas quartzo-feldspáticas, 2-14\% em rochas de composição intermediária e 15-40\% em rochas máficas (Clemens \& Vielzeuf, 1987). A fusão por quebra da hornblenda se inicia a partir de $800^{\circ} \mathrm{C}$ a 8 kbar (Rushmer, 1991), onde o consumo total de hornblenda ocorre em torno de $950{ }^{\circ} \mathrm{C}$, a 10 kbar (Wolf \& Wyllie, 1994). Nos experimentos conduzidos por Patiño-Douce \& Beard (1995), o campo de estabilidade da hornblenda é estendido até $975^{\circ} \mathrm{C}$, com proporção de fundido de $20-30 \%$ em volume. No entanto, estes experimentos levavam em conta a presença de uma única fase mineral hidratada, a hornblenda. Ao partir de associação mineral com duas fases minerais hidratadas em metabasaltos, epídoto/zoisita e hornblenda, similarmente ao par muscovita-biotita em metapelitos/metagrauvacas, muitas analogias podem ser feitas nas reações de fusão na ausência de fase fluida envolvendo desde composições pelíticas/intermediárias até toleiíticas (Vielzeuf \& Schmidt, 2001).

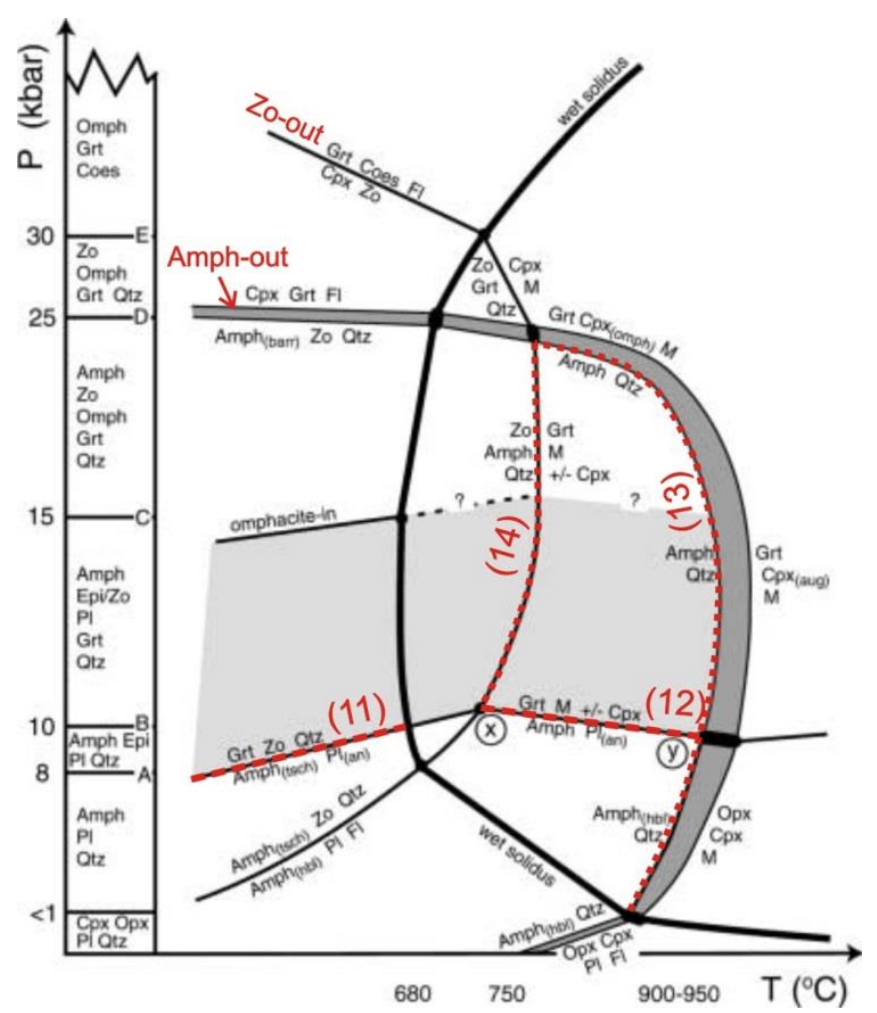

Figura 5: Diagrama de fases para rocha máfica (composição MORB) em sistema saturado em quartzo/coesita em condições subsolidus, com a representação das reações de fusão envolvendo hornblenda e zoisita (reações 11 a 14, destacadas em vermelho) discutidas no texto. Os campos delimitados em cinza escuro e cinza claro representam os campos multivariantes de quebra de $\mathrm{Hbl}+$ Qtz e Hbl + Pl, respectivamente. Extraído de Vielzeuf \& Schmidt (2001). 
O campo de estabilidade da zoisita aumenta em altas pressões em relação à da hornblenda, sendo que a zoisita é estável com fundido entre 685 e $775^{\circ} \mathrm{C}, 15-20$ kbar em composições gabróicas (Lambert \& Wyllie, 1972). O epídoto/zoisita é a fase mineral hidratada a entrar em fusão no intervalo de pressão 10-30 kbar (Vielzeuf \& Schmidt, 2001). A quantidade de epídoto/zoisita no subsolidus é pequena, e a proporção de fundido gerada a partir da fusão incongruente de zoisita também é pequena. No entanto, a proporção modal de zoisita, a principal fase hidratada na rocha, aumenta com a pressão, concomitante com o aparecimento de granada (reação 11). A expansão do campo de estabilidade da zoisita implica em que a fase mineral menos hidratada (hornblenda) entra em fusão em temperatura mais baixa. Em pressões mais baixas em temperaturas acima do campo de estabilidade da zoisita, a quebra de hornblenda em presença de plagioclásio envolve a formação de fundido insaturado em $\mathrm{H}_{2} \mathrm{O}$ (reação 12) (Fig. 5) (Vielzeuf \& Schmidt, 2001). Em baixas pressões, a quebra da hornblenda em presença de quartzo é descrita através da reação (13). A pressão acima de 10 kbar, a reação de fusão na ausência de fase fluida envolve hornblenda e zoisita (reação 14) e cessa quando o quartzo é totalmente consumido, e delimita o campo de estabilidade da hornblenda em torno de $950{ }^{\circ} \mathrm{C}$ (Fig. 8) (Vielzeuf \& Schmidt, 2001).

\author{
(11) $\mathrm{Hbl}+\mathrm{PI}=\mathrm{Ep} / \mathrm{Zo}+\mathrm{Grt}+\mathrm{Qtz}($ Poli, 1993) \\ $(12) \mathrm{Hbl}+\mathrm{Pl}=\mathrm{Grt}+\mathrm{L}( \pm \mathrm{Cpx})($ Wyllie \& Wolf, 1993) \\ $(13) \mathrm{Hbl}+\mathrm{Qtz}=\mathrm{Pl}+\mathrm{Opx}+\mathrm{Cpx}( \pm \mathrm{Grt})+\mathrm{L}$ (Patiño-Douce \& Beard, 1995) \\ $(14) \mathrm{Hbl}+$ Zo + Qtz $=$ Grt + L ( \pm Cpx $)($ Vielzeuf \& Schmidt, 2001)
}

\title{
2.1.4 Reações de fusão anidra (dry melting reactions)
}

Reações de fusão anidra envolvendo fases sólidas, tais como granada, clinopiroxênio, olivina, espinélio, são mais raras de ocorrer na crosta continental, pois a temperatura requerida é extremamente elevada, maior que $950{ }^{\circ} \mathrm{C}$, uma vez que não há $\mathrm{H}_{2} \mathrm{O}$ presente nem mesmo na forma de minerais hidratados, sendo necessária a adição de calor proveniente do manto (Clemens, 1990). Estas reações apresentam inclinação positiva, em que as temperaturas de fusão aumentam com o aumento de pressão (Fyfe, 1973). Reações de fusão envolvendo esses minerais são comuns no manto terrestre.

\subsection{Migmatitos: definição, nomenclatura e classificação}

O termo migmatito foi introduzido por Sederholm (1907), para descrever rocha de caráter híbrido em escala megascópica, atribuindo, entre outros processos, a participação de fusão parcial em 
sua gênese. Cunhou o termo anatexia como sinônimo de fusão parcial. O mesmo autor também propôs o termo "palingênese" para designar a formação de migmatitos através de injeção de magma em rochas brechadas e venuladas, além do processo de fusão parcial. Holmquist (1916) introduziu o conceito de ultrametamorfismo para correlacionar as condições de metamorfismo mais elevadas do que o normal no metamorfismo regional para que ocorra a fusão parcial. Mehnert (1968) propôs a seguinte definição: "migmatito é uma rocha megascopicamente constituída de duas ou mais partes petrograficamente distintas, em que uma é a rocha hospedeira em estágio metamórfico mais ou menos avançado, e a outra é de aparência pegmatítica, aplítica, granítica ou plutônica". Neste trabalho, Mehnert (1968) apresentou a primeira classificação de migmatitos, dividindo os mesmos em duas partes: paleossoma é a rocha hospedeira inalterada ou pouco modificada; neossoma é a parte neoformada da rocha, constituída por leucossoma (domínios félsicos) e por melanossoma (domínios máficos).

Mehnert (1968) fez classificação estrutural para os migmatitos apresentando doze estruturas típicas, de acordo com o grau de fusão (Fig. 6): i) agmática ou brechada (fragmentos de paleossoma são circundados por veios finos de neossoma); ii) dictionítica ou em rede (paleossoma é entrelaçado por veios em rede de neossoma, exibindo fábrica de cisalhamento); iii) schöllen ou raft (os fragmentos de paleossoma são geralmente menores do que nos tipos previamente descritos e encontram-se flutuando no neossoma. Frequentemente exibem estruturas de deformação devido ao cisalhamento e movimento rotacional); iv) flebítica ou em veios (o paleossoma é cortado por veios irregulares de neossoma); $v$ ) estromática ou acamadada (o neossoma forma camadas claras e escuras no paleossoma, geralmente paralelas ao plano da xistosidade); vi) surreica ou de dilatação (neossoma ou rochas incompetentes adjacentes preenchem fraturas e/ou outros espaços de pressão reduzida entre os fragmentos de paleossoma mais competentes); vii) dobrada (estrutura de compressão desenvolvida em rochas com contraste de competência, onde os veios de neossoma, mais incompetentes, ocorrem dobrados com plano axial perpendicular à direção de compressão, e geralmente com espessamento de charneira e adelgaçamento dos flancos); viii) ptigmática (veios de neossoma dobrados em padrão disarmônico, com adelgaçamento de charneira e espessamento de flanco, e comprimento de onda aproximadamente constante, em contraste com a estrutura dobrada previamente descrita); ix) oftalmítica ou augen (o neossoma encontra-se distribuído ou disperso no paleossoma, exibindo o formato de olhos, onde geralmente o neossoma é constituído de fenocristais de feldspato envolvidos por bandas mais máficas, aproximadamente paralelas ao plano da xistosidade); $x$ ) estictionlítica ou manchada (minerais máficos concentrados na forma de manchas, geralmente com um halo mais félsico ao redor, em meio ao paleossoma); xi) schilieren (constituem faixas claras e escuras, com formas alongadas, geralmente formadas por fluxo laminar); xii) nebulítica (paleossoma e neossoma não podem ser identificados separadamente). No entanto, as estruturas migmatíticas apresentadas por Mehnert (1968) não podem ser utilizadas como critério de classificação de migmatitos uma vez 
que a variação estrutural depende da escala e diversas estruturas podem ser encontradas em um único afloramento. Outro problema é que a nomenclatura proposta por Mehnert (1968), supostamente sem conotação genética e puramente descritiva não é condizente com a definição de paleossoma e neossoma, uma vez que a utilização destes termos implica em interpretação genética dos migmatitos.

Os termos metatexito e diatexito foram redefinidos por Brown (1973), da seguinte maneira: metatexito é o produto da segregação (geralmente de quartzo e feldspato) por diferenciação metamórfica e fusão parcial, em que o bandamento migmatítico é evidente; diatexito é uma rocha produzida por anatexia de alto grau em que a fusão deve ser completa e onde não há bandamento migmatítico contínuo. Segundo Brown (1973), o metatexito é constituído de três partes: paleossoma, leucossoma e melanossoma, onde o leucossoma e melanossoma constituem o neossoma e representam as porções segregadas. O mesmo autor restringiu a utilização do termo "migmatito" para os tipos estromáticos, excluindo diatexito e agmatito da classificação de migmatitos, em contraste com a proposta inicial de Mehnert (1968).
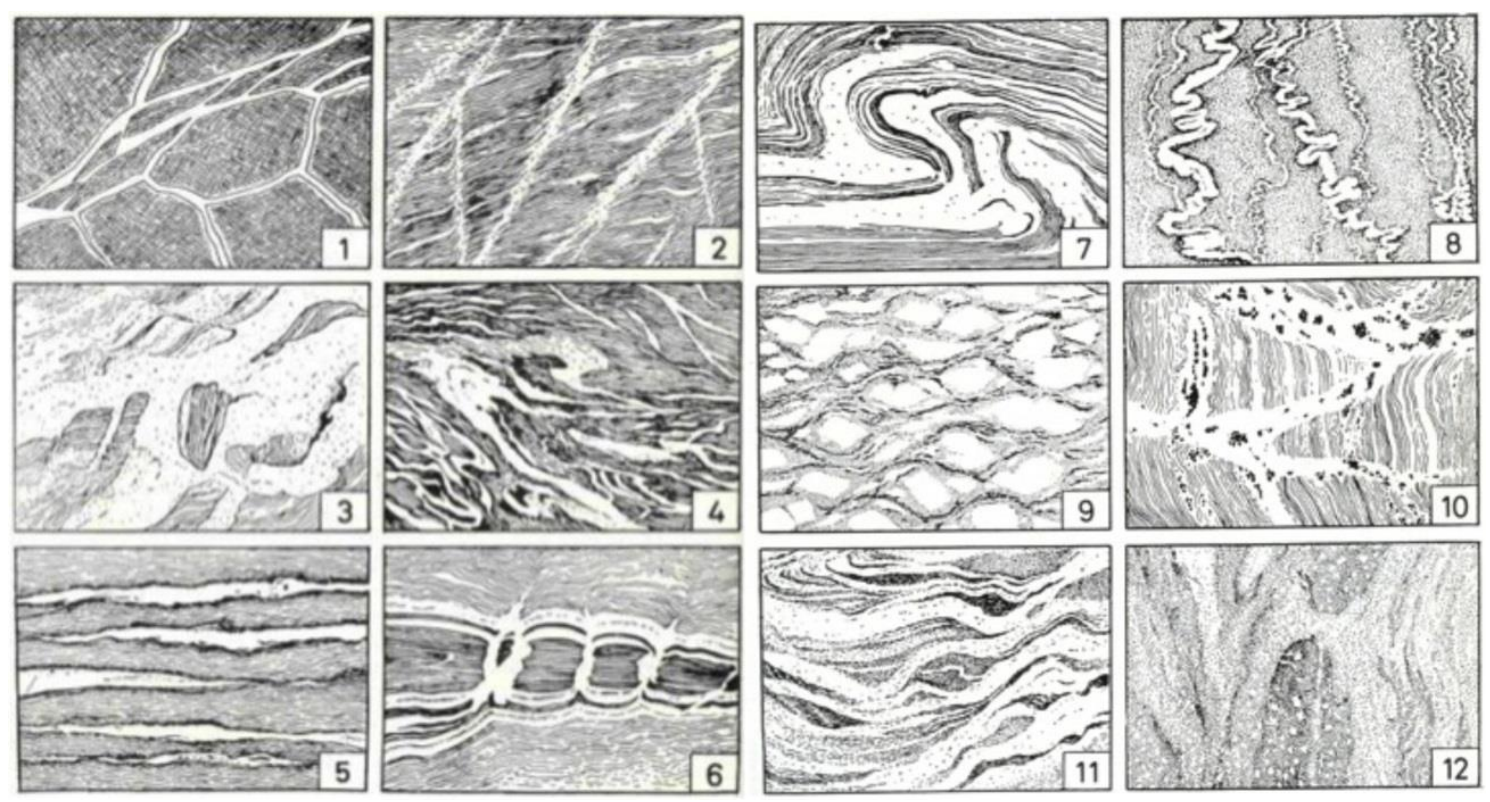

Figura 6: Estruturas típicas de migmatitos: 1- agmática ou brechada; 2- dictionítica ou em rede; 3schöllen ou raft; 4- flebítica ou em veios; 5- estromática ou acamadada; 6- surreica ou de dilatação; 7dobrada; 8- ptigmática; 9- oftalmítica ou augen; 10- stictiolítica ou manchada; 11- schilieren; 12nebulítica (Mehnert, 1968).

A utilização do termo "paleossoma" causou bastante confusão, pois não necessariamente representa a rocha parental inalterada ou pouco modificada, de composição equivalente ao leucossoma e melanossoma, conforme postulado por Mehnert (1968), uma vez que o protólito deve ser inexistente na região que foi submetida à fusão parcial. Desta forma, o termo mesossoma foi introduzido por Henkes \& Johannes (1981), para uso descritivo da rocha de coloração intermediária 
entre o leucossoma e o melanossoma. Deste modo, se uma rocha bandada for submetida à fusão, o mesossoma vai representar cada uma das camadas em estágios diferentes de fusão parcial, dependendo da fertilidade de cada uma. As mais férteis durante a fusão parcial dão origem a quantidades significativas de neossoma, leucossoma e melanossoma (Johannes \& Gupta, 1982; Johannes, 1983, 1985, 1988). Posteriormente, o mesossoma passou a ter caráter restítico, ao considerar que o fundido foi segregado do mesossoma ou do seu protólito original e concentrado no neossoma (Stüwe \& Powell, 1989; Powell \& Downes, 1990; Fitzsimons, 1996; Greenfield et al., 1998; Kriegsman \& Hensen, 1998).

Yardley (1978) postulou que os migmatitos podem ser gerados em sistema aberto, por injeção (rochas brechadas - estrutura agmática de Mehnert, 1968) ou metassomatismo, ou em sistema fechado, por anatexia ou segregação metamórfica. Ashworth (1985) redefiniu migmatito como "rocha encontrada em regiões metamórficas de médio a alto grau, que é pervasivamente heterogênea em escala macroscópica, uma parte sendo de coloração clara e de composição quartzo-feldspática". No entanto, não foi atribuída uma origem (anatética, segregação metamórfica, metassomatismo) aos migmatitos.

A evolução no conceito de migmatitos resultou em redefinição do termo por Sawyer (2008), sendo a mais moderna, tem caráter genético e foi empregada no presente trabalho: "migmatito é uma rocha encontrada em áreas metamórficas de médio a alto grau que pode ser heterogênea na escala microscópica a macroscópica, e que é constituída de duas ou mais partes petrograficamente distintas. Uma destas partes tem que ter sido formada por fusão parcial e contém rochas que são petrogeneticamente relacionadas entre si (chamadas de neossoma) e com seu protólito através de fusão parcial ou segregação do fundido e da fração sólida. A parte parcialmente fundida tipicamente contém rochas de coloração clara que são de composição quartzo-feldspática ou feldspática, e rochas de coloração escura que são enriquecidas em minerais ferro-magnesianos. No entanto, a parte parcialmente fundida pode simplesmente ter sido modificada na mineralogia, microestrutura e granulação, sem que houvesse segregação (desenvolvimento de partes claras e escuras separadas). A terminologia descritiva adotada no presente trabalho é de Sawyer (2008) para partes constituintes do migmatito, onde:

Anatexia é o termo geral para fusão parcial da crosta continental, sem referência específica ao grau de fusão parcial. Protólito ou rocha parental são rochas presentes nas porções de mais baixo grau metamórfico de uma área metamórfica que são equivalentes àquelas que geraram o neossoma. Assim sendo, o protólito é praticamente inexistente em migmatitos, uma vez que se tornou neossoma após ter sido submetido à anatexia. Paleossoma é a parte do migmatito que não foi afetada por fusão parcial, devido à sua composição mais refratária e foi chamada de resister por Read (1957). Neossoma é a parte neoformada do migmatito resultante da fusão parcial, geralmente apresenta granulação mais grossa do que o protólito e o paleossoma e é dividido em duas partes: uma é derivada do fundido e a 
outra é derivada dos minerais que estavam em excesso na reação de fusão e/ou representam os produtos sólidos da fusão incongruente (fases peritéticas). No neossoma não segregado não houve separação entre a fração sólida e o fundido. O neossoma segregado pode ser dividido em duas partes: leucossoma e melanossoma. O leucossoma é a parte do migmatito derivada da fusão parcial, apresenta coloração clara e é constituído predominantemente por feldspato e quartzo. O leucossoma não necessariamente apresenta a composição de um fundido anatético, pois outros processos como cristalização fracionada ou contaminação podem ter afetado sua composição original. O melanossoma é a parte do neossoma rica em minerais máficos como biotita, granada, cordierita, ortopiroxênio, hornblenda ou clinopiroxênio, que representa a fração sólida remanescente após a fusão parcial e extração de parte do fundido e é constituído pelas fases peritéticas das reações de fusão. 0 melanossoma tem caráter residual, mas o termo resíduo é de uso mais genérico, uma vez que não há referência específica quanto à mineralogia, coloração ou granulação, e um resíduo pode ser constituído por minerais félsicos e que estavam em excesso na rocha em relação à proporção estequiométrica da reação de fusão que a rocha alcançou.

Selvedges são camadas de rocha com coloração, composição, associação mineral e microestruturas diferentes e que separam duas partes distintas de um migmatito, sendo o tipo mais comum rico em biotita. Não deve ser confundido com melanossoma, pois não representam as fases peritéticas da fusão parcial e podem ser leucocráticos, mesocráticos ou melanocráticos (Sawyer, 2008). Os selvedges provavelmente representam bordas de reação entre o fundido e o resíduo controladas por difusão (White \& Powell, 2010). No modelo de reação reversa (back reaction) de Kriegsman (2001), a geração de leucossoma quase anidro está relacionada com a reação retrógrada entre o fundido segregado e o resíduo, onde a $\mathrm{H}_{2} \mathrm{O}$ e eventuais fases ferro-magnesianas presentes no leucossoma migram para o melanossoma retrógrado (Kriegsman, 2001), que é equivalente ao selvedge. A preservação de minerais ferro-magnesianos peritéticos no leucossoma é atribuída à formação de selvedges por diferença de potencial químico, resultando em leucossoma de caráter anidro que fica sem a fase principal, a $\mathrm{H}_{2} \mathrm{O}$, para atacar os minerais peritéticos (Powell \& Downes, 1990; Kriegsman \& Hensen, 1998; Brown, 2002; White \& Powell, 2002).

Desta forma, no presente trabalho o uso do termo melanossoma só é aplicado para casos em que este é formado por reações progressivas e de caráter residual (fases incongruentes peritéticas: e.g. granada, cordierita, ortopiroxênio), conforme sugerido por Sawyer (2008) e o melanossoma retrógrado de Kriegsman (2001) é denominado selvedge (Brown, 2002; White \& Powell, 2002; Sawyer, 2008; White \& Powell, 2010). 
MIGMATITO

Morfologias de primeira ordem

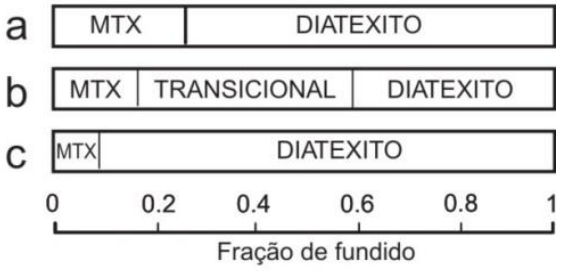

Morfologias de segunda ordem

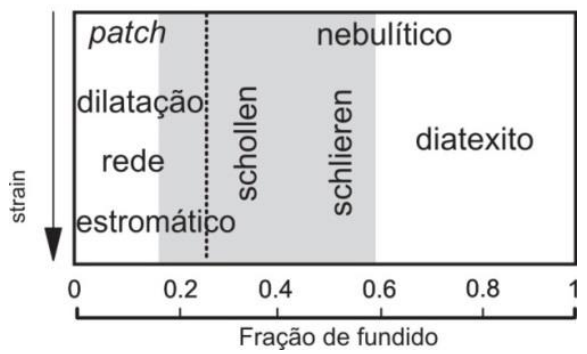

Figura 7: Classificação de migmatitos proposta por Sawyer (2008), com divisões de morfologias de primeira e segunda ordem. Três posições para a transição de metatexito (MTX) para diatexito são mostradas. Duas (a \& b) são para rochas parcialmente fundidas que são cristais em suspensão no fundido, e uma (c) é para a rocha parcialmente fundida em que o fundido anatético ocorre na forma de filmes na maioria dos contatos entre os grãos. As morfologias de segunda ordem para migmatitos metatexíticos e diatexíticos são mostradas com base na fração de fundido (aumenta da esquerda para a direita) com a transição definida pelo modelo (a) indicada como uma linha tracejada, e o domínio transicional do modelo (b) indicado como um campo cinza.

A nomenclatura de migmatitos adotada no presente trabalho segue a classificação de migmatitos proposta por Sawyer (2008), considerando a divisão em morfologias de primeira e segunda ordem (Fig. 7). No entanto, há algumas restrições quanto ao uso de algumas definições, como paleossoma e mesossoma. A denominação de qualquer parte do migmatito que não foi afetada por fusão parcial de paleossoma não é adequada, pois não há uma relação com a composição original do protólito e sua fertilidade. Assim é preferível que uma rocha de composição mais refratária (e.g. camadas de quartzitos, rochas cálcio-silicáticas ou anfibolitos) seja chamada de resistato (resister), e não exclusivamente de paleossoma, porque esta rocha não entrou em fusão por apresentar composição menos fértil em relação a um protólito pelítico ou psamítico. $\mathrm{O}$ uso do termo paleossoma é infeliz, pois a definição, mesmo que ruim, mas consagrada na literatura, é mudada para algo completamente diferente. 


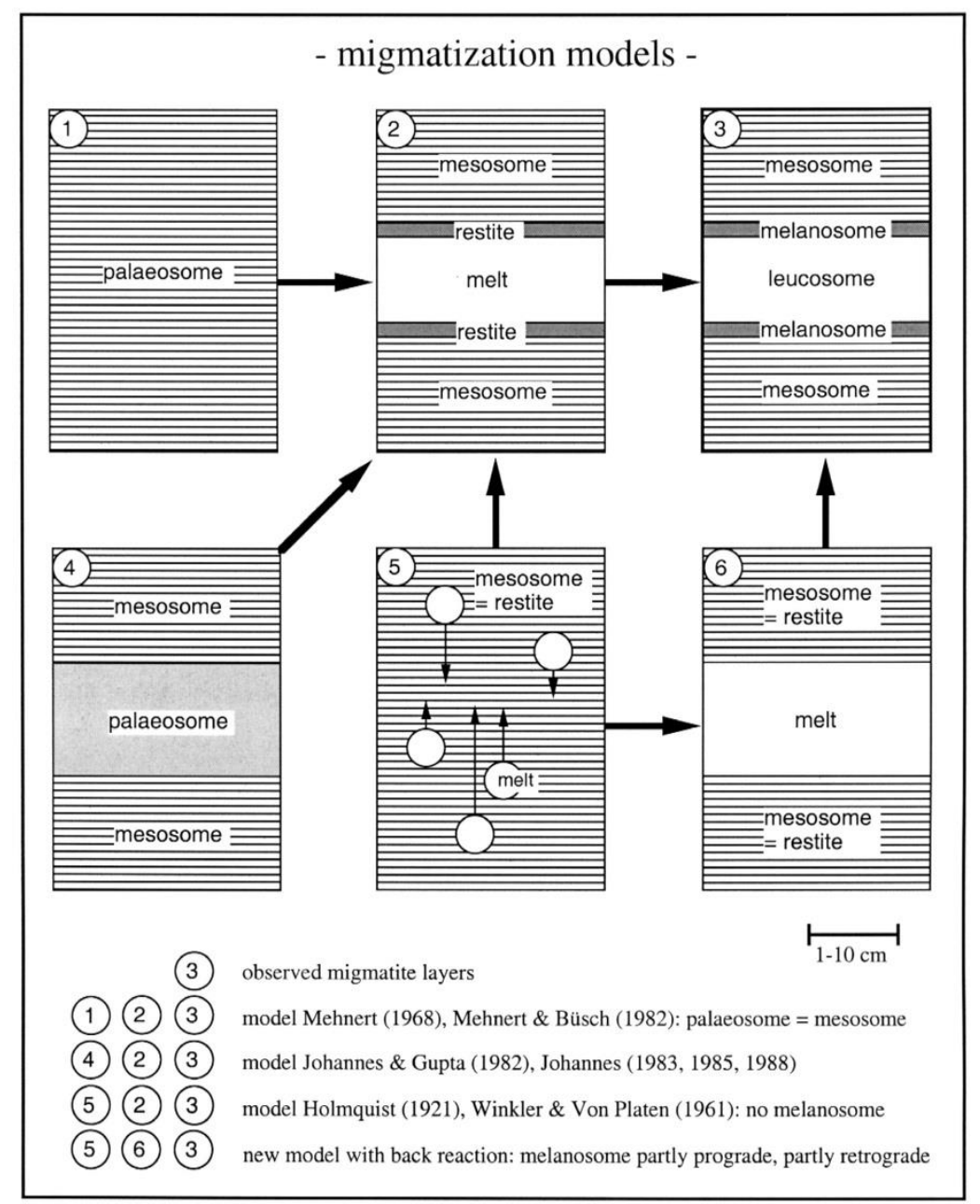

Figura 8: Representação esquemática dos modelos de migmatitos disponíveis na literatura (extraído de Kriegsman, 2001).

Houve ainda a sugestão da eliminação do termo mesossoma por Sawyer (2008), alegando a inconsistência no uso deste termo por alguns autores no passado (Henkes \& Johannes, 1981; Ashworth, 1985), pois rochas mesocráticas podem ser encontradas tanto no neossoma, no paleossoma ou até mesmo em selvedges. O autor sugere que termos como resíduo mesocrático, leucossoma mesocrático e/ou paleossoma mesocrático devem ser utilizados no lugar de mesossoma. No modelo de geração de migmatitos de Kriegsman (2001) (Fig. 8) o mesossoma representa o protólito original que foi afetado por fusão parcial, onde houve segregação do fundido e que foi parcialmente extraído, dando origem a um mesossoma relativamente restítico. Posteriormente, as reações reversas (back reaction) entre leucossoma e o resíduo (mesossoma) resultam na formação de melanossoma retrógrado. O presente trabalho utiliza a classificação de migmatitos proposta por Sawyer (2008), com algumas exceções. A sugestão de Sawyer (2008) de denominar a rocha mesocrática cinza de resíduo, paleossoma ou neossoma não segregado não foi adotada, pois possui implicações genéticas, sendo necessário um estudo mais acurado das relações texturais em escala microscópica para determinar a origem da rocha mesocrática cinza (mesossoma de Kriegsman, 2001), dificultando a utilização destes 
termos em campo. Além disso, a proposta de Sawyer (2008) de denominar certas porções mesocráticas de resíduo mesocrático não se aplica, pois geraria confusão com outros tipos de resíduos presentes no migmatito, no caso resisters (rochas que não fundiram) ou fração sólida residual gerada durante a progressão de reações de fusão (fases peritéticas incongruentes).

\subsection{Investigação dos processos de fusão parcial através da assinatura geoquímica e geocronologia de fases acessórias}

Um dos grandes desafios da petrologia metamórfica é vincular o crescimento de fases acessórias, tais como zircão e monazita, que fornecem as informações de idade, com a associação metamórfica principal a partir da qual as informações $P$-T são extraídas (Möller et al., 2003). Assim, é possível avaliar a taxa e duração dos processos metamórficos e de fusão, que são fundamentais para a compreensão do ambiente tectônico relacionado com a formação da crosta inferior (Spear \& Pyle, 2002). Apesar do zircão e da monazita serem comumente usados para a geocronologia U-Th-Pb, devido à sua estabilidade química singular durante os processos ígneos e metamórficos e suas altas temperaturas de fechamento, eles podem ser consumidos se temperaturas acima do seu ponto de fusão forem alcançadas pela rocha ao longo da trajetória $P-T$ do metamorfismo (Pyle \& Spear, 1999, 2003; Hoskin \& Black, 2000; Harley et al., 2007; Kelly et al., 2012).

Os avanços nos métodos analíticos permitem a determinação de idades U-Pb precisas. No entanto, a interpretação das idades de zircão é comumente ambígua, particularmente em rochas metamórficas, onde o objetivo é relacionar com precisão as condições P-T obtidas com a geocronologia (Vavra et al., 1996; Schaltegger et al., 1999; Rubatto et al., 2001; Foster \& Parrish, 2003; Whitehouse \& Platt, 2003; Harley \& Kelly, 2007; Baldwin \& Brown, 2008). Em terrenos de alta temperatura, a interpretação correta de idades U-Pb obtidas a partir de zircão é uma tarefa difícil, pois o zircão previamente formado pode passar por uma série de modificações nos eventos de fusão parcial e metamorfismo subsequentes (Harley et al., 2007).

Vários mecanismos são responsáveis pela formação e/ou modificação de zircão metamórfico (Fig. 9). Os principais processos compreendem reações metamórficas em estado sub-sólido entre silicatos e fases acessórias (Fraser et al., 1997; Möller et al., 2003), fusão parcial e cristalização de fundido (Roberts \& Finger, 1997; Schaltegger et al., 1999; Vavra et al., 1999; Rubatto, 2002) e recristalização de zircão pré-existente (Pidgeon, 1992; Schaltegger et al., 1999; Hoskin \& Black, 2000), ou dissolução e reprecipitação devido às interações com fluidos ou fundido (Vavra et al., 1999; Geisler et al., 2007). Desta forma, é necessário realizar a análise textural detalhada integrada com microanálises in situ para identificar assinaturas químicas distintas e determinar os processos que afetaram ou controlaram o comportamento do zircão durante o metamorfismo e a fusão parcial (Vavra et al., 1996, 1999; Schaltegger et al., 1999; Hoskin \& Black, 2000; Rubatto, 2002; Whitehouse \& Platt, 2003; Harley \& Kelly, 2007). Assim, o significado dos valores das datações U-Pb em zircão ou monazita 
para estabelecimento de idades que possam ser associadas a momentos específicos da trajetória $P$ - $T$ $\mathrm{t}$, consiste em distinguir a origem do mecanismo específico que originou o crescimento do mineral e relacioná-lo a alguma reação metamórfica ou de fusão, ou ainda se houve participação de fluidos atuando na alteração e dissolução-reprecipitação nas fases finais de formação dos minerais (Harley et al., 2007).

A morfologia e as estruturas internas do zircão e monazita são reveladas através de imageamento por catodoluminescência ( $\mathrm{CL}$ ) ou elétrons retroespalhados (BSE), método discutido com detalhe por Hanchar \& Rudnick (1995) e atualmente amplamente utilizados para identificar o caráter ígneo ou metamórfico do zircão. O estudo da composição de elementos-traço em zircão também pode auxiliar na distinção de sua origem ígnea ou metamórfica (e.g. Rubatto, 2002). O comportamento das fases acessórias (zircão e monazita) durante a fusão e cristalização, e a redistribuição dos elementostraço entre essas fases acessórias, os minerais metamórficos essenciais e o fundido proporciona evidência para os diferentes episódios de crescimento de zircão e monazita, e são combinados com os dados geocronológicos para estabelecer trajetórias $P$ - $T$-t (Bea \& Montero, 1999; Hermann \& Rubatto, 2003; Möller et al., 2003; Villaseca et al., 2003; Whitehouse \& Platt, 2003; Mahan et al., 2006; Harley et al., 2007; Dumond et al., 2008, 2015).

O comportamento das fases acessórias durante o metamorfismo de alto grau e a fusão parcial depende de três fatores: 1 ) solubilidade e cinética de dissolução no fundido; 2) estabilidade em condições subsolidus e participação em reações metamórficas e 3) posição textural das fases acessórias, como inclusões em minerais de alto ou baixo ponto de fusão, ou ainda na matriz, que determina a disponibilidade tanto para a participação de reações de fusão, em estado sólido ou reações reversas entre fundido e as fases sólidas, essenciais ou acessórias (Bea \& Montero, 1999; Kriegsman, 2001). Os ETRL são geralmente mais incompatíveis do que os ETRP, devido ao seu maior raio iônico, e tendem a ser particionados e permanecer no líquido por mais tempo. No entanto, ETR são altamente compatíveis com muitos minerais acessórios que se formam nos estágios finais de cristalização de magmas félsicos, e são constituintes principais da monazita (ETRL-PO ${ }_{4}$ ) e xenotima (ETRP-PO ${ }_{4}$ ). Desta forma, a cristalização de fases acessórias controla a distribuição de ETR em rochas félsicas (Watt \& Harley, 1993; Bea, 1996; Hanchar \& van Westrenen, 2007). Além disso, os ETR apresentam concentrações significativas em granada, apatita e zircão (Bea, 1996). 


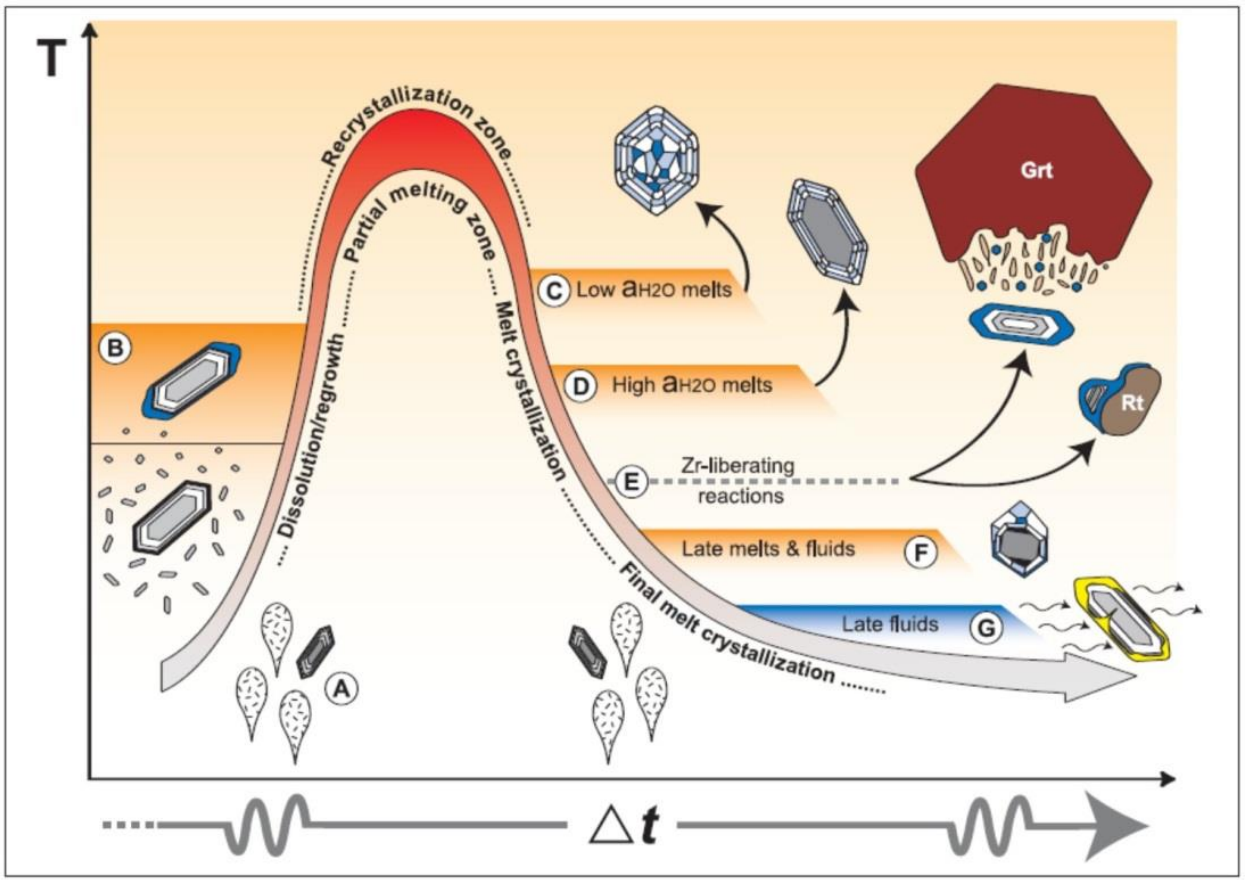

Figura 9: Representação esquemática da utilização do zircão na datação de eventos distintos em terrenos de alto grau, através de trajetória $T$-t hipotética. Com o aumento da temperatura, as rochas podem ser submetidas a fusão parcial, causando dissolução de zircão pré-existente, seguido de precipitação em grãos de zircão herdados. $O$ crescimento de zircão com cristalização de fundidos de alta temperatura geralmente ocorre na trajetória de resfriamento, em diferentes intervalos, dependendo da $\mathrm{a}_{\text {н2о }}$ ou pode estar associado a reações metamórficas que liberam $\mathrm{Zr}$, como a quebra da Grt ou dissolução do Rt. O sobrecresimento de zircão também pode ser proveniente de fundidos "residuais", onde os fluidos liberados podem ser responsáveis ainda pela recristalização do zircão previamente formado (extraído de Harley et al., 2007).

A formação de selvedges, comumente ricos em biotita, é atribuída à reação reversa entre o fundido e o resíduo, onde a diferença de potencial químico entre ambos resulta na migração de $\mathrm{H}_{2} \mathrm{O}$ e, por vezes, de componentes dissolvidos no líquido, tais como ferro, magnésio e alguns álcalis do fundido para a formação do selvedge (Kriegsman, 2001; White \& Powell, 2010). A geração de fundidos insaturados em $\mathrm{H}_{2} \mathrm{O}$ em rochas granulíticas inibe a solubilidade de zircão e monazita no fundido, o que resulta na concentração destas fases acessórias no resíduo e formação de fundido empobrecido em ETRL e ETRP (Watt \& Harley, 1993). Desta forma, há tendência de a biotita apresentar inclusões de fases acessórias ricas em ETR, Y, Th e $U$, provavelmente devido aos efeitos de saturação local, fazendo com que a mesma exerça importante controle na geoquímica de ETR, $Y$, Th e $U$ em migmatitos com selvedges de biotita (Bea, 1996).

O zircão é uma fase acessória portadora de quantidades significativas de $\mathrm{Y}, \mathrm{Zr}, \mathrm{Hf}, \mathrm{P}, \mathrm{U}$, Th e ETRM a ETRP, enquanto que a monazita incorpora preferencialmente ETRL, mas também pode acomodar Th, $\mathrm{Y}, \mathrm{U}$ e $\mathrm{Pb}$ (e.g. Rubatto \& Hermann, 2003). Os minerais peritéticos ou o fundido 
geralmente incorporam os elementos liberados pela dissolução de fases acessórias. Desta forma, a dissolução de fosfatos (e.g. xenotima) no fundido leva a partição de elementos altamente compatíveis, como Y e ETRP (elementos terras-raras pesados), para a granada peritética (Pyle \& Spear, 1999, 2003) enquanto que a partição de ETRL (elementos terras-raras leves) e Eu é controlada pelos feldspatos (Bea, 1996; Villaseca et al., 2007). O crescimento de zircão pode ser resultado de reações metamórficas responsáveis pela liberação de $\mathrm{Zr}$ através da quebra de granada e/ou dissolução parcial de rutilo (Fig. 9) (e.g. Fraser et al., 1997; Möller et al., 2003; Harley et al., 2007).

Diversos estudos investigaram a coexistência de granada com zircão e/ou monazita através da comparação de padrões de elementos-traço para inferir a idade de crescimento da granada e/ou as condições P-T do crescimento de zircão e/ou monazita (Rubatto et al., 2001, 2006; Rubatto, 2002; Möller et al., 2003; Whitehouse \& Platt, 2003; Harley \& Kelly, 2007; Rubatto \& Hermann, 2007; Harley et al., 2007). Recentemente foi desenvolvido modelo de atividade a-x para zircão e fases metamórficas portadoras de $\operatorname{Zr}$ (e.g. granada), o que possibilita o cálculo de pseudosseções em sistemas mais complexos, NCKFMASHTZr (Kelsey \& Powell, 2010). Assim, é possível investigar o crescimento e a dissolução de Zr em condições sub e suprasolidus durante a evolução de uma associação metamórfica ao longo da trajetória $P$-T. Diagramas de fase com modelo de atividade a- $x$ para monazita foram apresentados por Spear \& Pyle (2010). Desta forma, com a inclusão de alguns elementos-traço no banco de dados termodinâmicos, o cálculo de pseudosseções envolvendo zircão (ou monazita) pode ser utilizado para correlacionar com maior segurança o crescimento das fases acessórias com a geocronologia U-Pb e a termometria de fases acessórias (Kelsey \& Powell, 2010).

A investigação de zircão, monazita, rutilo e outras fases acessórias e sua relação com a associação metamórfica principal, bem como suas zonas de sobrecrescimento devem ser examinadas por técnicas in situ, uma vez que as texturas e os sobrecrescimentos podem ser destruídos através de técnicas padrão de separação mineral (Möller et al., 2003). Atualmente, o LA-ICP-MS consiste na técnica de datação que apresenta o melhor custo-benefício, pois é possível realizar análises mais rápidas e com baixo custo em comparação com outros métodos analíticos como SHRIMP (sensitive high resolution ion microprobe) ou ID-TIMS (isotope dilution-thermal ionization mass spectrometry) (Simonetti et al., 2006; McFarlane \& Luo, 2012). A capacidade de realizar datações in situ em seções delgadas através de LA-ICP-MS fornece informações de idade relativamente precisas (cerca de 95\% de nível de confiança) e que podem ser relacionadas com dados $P$ - $T$. No entanto, a resolução espacial do laser ainda não se compara ao do feixe de prótons usados no SHRIMP.

\subsection{Referências bibliográficas}

Ashworth, J.R. 1985. Introduction. In: Ashworth, J.R. (Ed.), Migmatites. Blackie and Son, Glasgow, UK, pp. 1-35. 
Baldwin, J.A. \& Brown, M. 2008. Age and duration of ultrahigh-temperature metamorphism in the Anápolis-Itauçu Complex, Southern Brasília Belt, central Brazil - constraints from U-Pb geochronology, mineral rare earth element chemistry and trace-element thermometry. Journal of Metamorphic Geology 26, 213-233.

Bea, F. 1996. Residence of REE, Y, Th and $U$ in granites and crustal protoliths, implications for the chemistry of crustal melts. Journal of Petrology 37(2), 521-552.

Bea, F. \& Montero, P. 1999. Behavior of accessory phasesand redistribution of Zr, REE, Y, Th and U during metamorphism and partial melting of metapelites in the lower crust: Na exxample from the Kinzigite Formation of Ivrea-Verbano, NW Italy. Geochimica et Cosmochimica Acta 63, 1133 1153.

Brown, M. 1973. The definition of metatexis, diatexis and migmatite. Proceedings of the Geologists' Association 84, 371-382.

Brown, M. 2002. Retrograde processes in migmatites and granulites revisited. Journal of metamorphic Geology 20, 25-40.

Brown, M. 2008. Granites, migmatites and residual granulites: relationships and processes. In: Sawyer, E.W., Brown, M. (Eds.), Working with migmatites. Mineralogical Association of Canada, vol. 38, Quebec City, Quebec, pp. 97-144.

Büsch, W., Schneider, G., Mehnert, K.R., 1974. Initial melting at grain boundaries. Part II: melting in rocks of granodioritic, quartz-dioritic and tonalitic composition. Neues Fahrbuch für Mineralogie, Abhandlungen 1974, 345-370.

Clemens, J.D. 1990. The granulite-granite conexion. In: Vielzeuf, D. \& Vidal, Ph. (Eds.), Granulites and Crustal Differentiation, Kluwer Academic Publishing, Dordrecht, pp. 25-36.

Clemens, J.D. 2005. Granites and granitic magmas: strange phenomena and new perspectives on some old problems. Proc. Geol. Assoc., 116: 9-16.

Clemens, J.D. 2006. Melting of the continental crust: fluid regimes, melting reactions, and source-rock fertility. In: Brown, M. \& Rushmer, T. (Eds.). Evolution and Differentiation of the Continental Crust, Cambridge University Press, pp. 296-330.

Clemens, J.D. \& Vielzeuf, D. 1987. Constraints on melting and magma production in the crust. Earth and Planetary Science Letters 86, 287-306.

Clemens, J.D. \& Watkins, J.M. 2001. The fluid regime of high-temperature metamorphism during granitoid magma genesis. Contributions to Mineralogy and Petrology 140, 600-606.

Conrad, W.K., Nicholls, I.A. \& Wall, V.J. 1988. Metaluminous and peraluminous crustal compositions at 10kb: evidence for the origin of silicic magmas in the Taupo Volcanic Zone, New Zealand, and other occurences. Journal of Petrology 29, 765-803.

Droop, G.T.R. \& Brodie, K.H. 2012. Anatectic melt volumes in the thermal aureole of the etive Complex, Scotland: the roles of fluid-present and fluid-absent melting. Journal of metamorphic Geology 
$30,843-864$.

Dumond, G., Goncalves, P., Williams, M.L., Jercinovic, M.J., 2015. Monazite as a monitor of melting, garnet growth and feldspar recrystallization in continental lower crust. Journal of Metamorphic Geology 33, 735-762.

Dumond, G., McLean, N., Williams, M.L., Jercinovic, M.J., Bowring, S.A., 2008. High-resolution dating of granite petrogenesis and deformation in a lower crustal shear zone: Athabasca granulite terrane, western Canadian Shield. Chemical Geology 254, 175-196.

Fitzsimons, I.C.W. 1996. Metapelitic migmatites from Brattstrand Bluffs, East Antarctica metamorphism, melting and exhumation of the mid crust. Journal of Petrology 37, 395-414.

Foster, G. \& Parrish, R.R. 2003. Metamorphic monazite and the generation of P-T-t paths. In: D. Vance, W. Müller, I.M, Villa (Eds). Geochronology: Linking the Isotopic Record with Petrology and Textures - Geological Society, London, Special Publications 220, 25-47.

Fraser, G., Ellis, D. \& Eggins, S. 1997. Zirconium abundance in granulite-facies minerals, with implications for zircon geochronology in high-grade rocks. Geology 25, 607-610.

Fyfe, W.S. 1973. The granulite facies, partial melting and the Archaean crust. Philosophical Transactions of the Royal Society of London 273A, 457-461.

Gardien, V., Thompson, A.B., Grujic, D. \& Ulmer, P. 1995. Experimental melting of biotite + plagioclase + quartz \pm muscovite assemblages and implications for crustal melting. Journal of Geophysical Research 100, 15581-15591.

Geisler, T., Schaltegger, U. \& Tomaschek, F. 2007. Re-equilibration of zircon in aqueous fluids and melts. Element 3, 43-50.

Grant, J.A. 1985a. Phase equilibria in low-pressure partial melting of pelitic rocks. American Journal of Science 285, 409-435.

Grant, J.A. 1985b. Phase equilibria in partial melting of politic rocks. In: Ashworth, J.R. (Ed.), Migmatites. Blackie and Son, Glasgow, UK, pp. 86-144.

Grant, J.A. \& Frost, B.R. 1990. Contact metamorphism and partial melting of pelitic rocks in the aureole of the Laramie anorthosite complex, Morton Pass, Wyoming. American Journal of Science 290, 425-472.

Greenfield, J.E., Clarke, G.L. \& White, R.W. 1998. A sequence of partial melting reactions at Mt Stafford, central Australia. Journal of metamorphic Geology 16, 363-378.

Hanchar, J.M. \& Rudnick, R.L. 1995. Revealing hidden structures: the application of cathodoluminescence and back-scattered eléctron imaging to dating zircons from lower crustal xenoliths. Lithos 36, 289-303.

Hanchar, J.M. \& van Westrenen, W. 2007. Rare Earth Element Behavior in Zircon-Melt Systems. Elements, 3, 37-42.

Harley, S.L. \& Kelly, N.M. 2007. The impact of zircon-garnet REE distribution data on the interpretation 
of zircon U-Pb ages in complex high-grade terrains: An example from the Rauer Islands, East Antarctica. Chemical Geology 241, 62-87.

Harley, S.L., Kelly, N.M. \& Möller, A. 2007. Zircon behaviour and the termal histories of mountain chains. Elements 3, 25-30.

Hermann, J. \& Rubatto, D. 2003. Relating zircon and monazite domains to garnet growth zones: age and duration of granulite facies metamorphism in the Val Malenco lower crust. Journal of Metamorphic Geology 21, 833-852.

Henkes, L. \& Johannes, W. 1981. The petrology of a migmatite (Arkiva, Värmland, western Sweden). Neues Jb. Miner. Abh 141, 113-133.

Holmquist, P.J. 1916. Swedish Archean structures and their meaning. Bull. Geol. Inst. Uppsala 15, 125148.

Holness, M.B. \& Sawyer, E.W. 2008. On the pseudomorphing of melt-filled pores in migmatites. Journal of Petrology 49 (7), 1343-1363.

Hoskin, P.W.O. \& Black, L.P. 2000. Metamorphic zircon formation by solid-state recrystallization of protolith igneous zircon. Journal of Metamorphic Geology 18, 423-439.

Johannes, W. 1983. On the origin of layered migmatites. In: Atherton, M.P., Gribble, C.D. (Eds.), Migmatites, Melting and Metamorphism. Shiva Geol. Ser. Shiva, Nantwich, UK, pp. 234-248.

Johannes, W. 1985. The significance of experimental studies for the formation of migmatites. In: Ashworth, J.R. (Ed.), Migmatites. Blackie and Son, Glasgow. UK, pp. 36-85.

Johannes, W. 1988. What controls partial melting in migmatites? Journal of metamorphic Geology 6, 451-466.

Johannes, W. \& Gupta, L.N. 1982. Origin and evolution of a migmatite. Contributions to Mineralogy and Petrology 79, 114-123.

Johnson, T.E., White, R.W. \& Powell, R. 2008. Partial melting of metagreywacke: a calculated mineral equilibria study. Journal of metamorphic Geology 26, 837-853.

Kelly, N.M., Harley, S.L. \& Möller, A. 2012. Complexity in the behaviour and recrystallization of monazite during high-T metamorphism and fluid infiltration. Chemical Geology 322-323, $192-$ 208.

Kelsey, D.E. \& Powell, R. 2010. Progress in linking accessory mineral growth and breakdown to major mineral evolution in metamorphic rocks: a thermodynamic approach in the $\mathrm{Na}_{2} \mathrm{O}-\mathrm{CaO}-\mathrm{K}_{2} \mathrm{O}-\mathrm{FeO}-$ $\mathrm{MgO}-\mathrm{Al}_{2} \mathrm{O}_{3}-\mathrm{SiO}_{2}-\mathrm{H}_{2} \mathrm{O}-\mathrm{TiO}_{2}-\mathrm{ZrO}_{2}$ system. Journal of metamorphic Geology 29(1), 151-166.

Kriegsman, L. M. 2001. Partial melting, partial melt extraction and partial back reaction in anatectic migmatites. Lithos 56, 75-96.

Kriegsman, L.M. \& Hensen, B.J. 1998. Back reaction between restite and melt: implications for geothermobarometry and pressure-temperature paths. Geology 26, 1111-1114.

Lambert, I.B., Robertson, J.K. \& Wyllie, P.J. 1969. Melting reactions in the system $\mathrm{KAISi}_{3} \mathrm{O}_{8}-\mathrm{SiO}_{2}-\mathrm{H}_{2} \mathrm{O}$ to 
18-5 kilobars. American Journal of Science 267, 609-626.

Lambert, I.B. \& Wyllie, P.J. 1972. Melting of gabbro (quartz eclogite) with excess water to 35 kilobars, with geological applications. Journal of Geology 80, 693-708.

Le Breton, N. \& Thompson, A.B. 1988. Fluid-absent (dehydration) melting of biotite in metapelites in early stages of crustal anatexis. Contributions to Mineralogy and Petrology 99, 226-237.

Mahan, K.H., Goncalves, P., Williams, M.L. \& Jercinovic, M.J. 2006. Dating metamorphic reactions and fluid flow: application to exhumation of high-P granulites in a crustal-scale shear zone, western Canadian Shield. Journal of metamorphic Geology 24, 193-217.

Marchildon, N. \& Brown, M. 2002. Grain-scale melt distribution in two contact aureole rocks: implications for controls on melt localization and deformation. Journal of metamorphic Geology 20, 381-396.

McFarlane, C.R.M. \& Luo, Y. 2012. U-Pb geochronology using 193nm Excimer LA-ICP-MS optimized for in-situ accessory mineral dating in thin sections. Geoscience Canada 39, 158-172.

McLellan, E.L. 1988. Migmatite structures in the Central Gneiss Complex, Boca de Quadra, Alaska. Journal of metamorphic Geology 6, 517-542.

Mehnert, K.R. 1968. Migmatites and the origin of granitic rocks. Developments in Petrology 1. Elsevier, Amsterdam. 393 pp.

Möller, A., Hensen, B.J., Armstrong, R.A., Mezger, K. \& Ballèvre, M. 2003a. U-Pb zircon and monazite age contraints on granulite-facies metamorphism and deformation in the Strangways Metamorphic Complex (central Australia). Contributions to Mineralogy and Petrology 145, 406423.

Möller, A., O’Brien, P.J., Kennedy, A. \& Kröner, A. 2003b. Linking growth episodes of zircon and metamorphic textures to zircon chemistry: an example from the ultrahigh-temperature granulites of Rogaland (SW Norway). In: D. Vance, W. Müller, I.M, Villa (eds). Geochronology: Linking the Isotopic Record with Petrology and Textures - Geological Society, London, Special Publications 220, 65-81.

Patiño-Douce, A.E. \& Beard, J.S. 1995. Dehydration-melting of Biotite Gneiss and Quartz Amphibolite from 3 to 15 Kbar. Journal of Petrology 36, 707-738.

Patiño-Douce, A.E. \& Harris, N. 1998. Experimental constraints on Himalayan anatexis. Journal of Petrology 39, 689-710.

Pidgeon, R.T. 1992. Recrystallisation of oscillatory zoned zircon: some geochronological implications. Contributions to Mineralogy and Petrology 110, 463-472.

Piwinskii, A. J. \& Wyllie, P. J. 1968. Experimental studies of igneous rock series: a zoned pluton in the Wallowa Batholith, Oregon. Journal of Geology 76, 205-234.

Poli, S. 1993. Amphibole behaviour through amphibolite-eclogite transition: an experimental study on phase relationships in basalts. American Journal of Science 293, 1061-1107. 
Powell, R. \& Downes, R. 1990. Garnet porphyroblast-bearing leucosomes in metapelites: mechanisms, phase diagrams, and an example from Broken Hill, Australia. In: Ashworth, J.R., Brown, M. (Ed.), High-temperature Metamorphism and Crustal Anatexis. Mineral. Soc. Ser., vol. 2. Unwin Hyman, London, pp. 105-123.

Pyle, J.M. \& Spear, F.S. 1999. Yttrium zoning in garnet: coupling of major and accessory phases during metamorphic reactions. Geological Materials Research 1(6), 1-49.

Pyle, J.M. \& Spear, F.S. 2003. Four generations of accessory-phase growth in low-pressure migmatites from SW New Hampshire. American Mineralogist 88, 338-351.

Read, H.H. 1957. The Granite Controversy. London, Thomas Murby \& Co. 430 pp.

Roberts, M.P. \& Finger, F. 1997. Do U-Pb zircon ages from granulites reflect peak metamorphic conditions? Geology 25(4), 319-322.

Rubatto, D. 2002. Zircon trace element geochemistry: partitioning with garnet and the link between U-Pb ages and metamorphism. Chemical Geology 184, 123-138.

Rubatto, D. \& Hermann, J. 2003. Zircon formation during fluid circulation in eclogites (Monviso, Western Alps): implications for $\mathrm{Zr}$ and $\mathrm{Hf}$ budget in subduction zones. Geochimica et Cosmochimica Acta 67(12), 2173-2187.

Rubatto, D. \& Hermann, J. 2007. Experimental zircon/melt and zircon/garnet trace element partitioning and implications for the geochronology of crustal rocks. Chemical Geology 241(1), 38-61.

Rubatto, D., Hermann, J. \& Buick, I.S. 2006. Temperature and bulk composition control on the growth of monazite and zircon during low-pressure anatexis (Mount Stafford, Australia). Journal of Petrology 47(10), 1973-1996.

Rubatto, D., Williams, I.S. \& Buick, I.S. 2001. Zircon and monazite response to prograde metamorphism in the Reynolds Range, central Australia. Contributions to Mineralogy and Petrology, 140, 458468.

Rushmer, T. 1991. Partial melting of two amphibolites: contrasting experimental results under fluidabsent conditions. Contributions to Mineralogy and Petrology 107, 41-59.

Sawyer, E.W. 1999. Criteria for the recognition of partial melting. Physics and Chemistry of the Earth 24, 269-279.

Sawyer, E.W. 2001. Melt segregation in the continental crust: distribution and movement of melt in anatectic rocks. Journal of metamorphic Geology 19, 291-309.

Sawyer, E.W. 2008a. The Atlas of Migmatites. The Canadian Mineralogist, Special Publication 9. NRC Research Press, Ottawa, ON. 371pp.

Sawyer, E.W. 2008b. Working with migmatites: nomenclature for the constituent parts. In: Sawyer, E.W., Brown, M. (Eds.), Working with migmatites. Mineralogical Association of Canada, vol. 38, Quebec City, Quebec, pp. 1-28. 
Sawyer, E.W. 2010. Migmatites formed by water-fluxed partial melting of a leucogranodiorite protolith: Microstructures in the residual rocks and source of fluid. Lithos 116, 273-286.

Schaltegger, U., Fanning, C.M., Günther, D., Maurin, J.C., Schulmann, K. \& Gebauer, D. 1999. Growth, annealing and recrystallization of zircon and preservation of monazite in high-grade metamorphism: conventional and in-situ U-Pb isotope, cathodoluminescence and microchemical evidence. Contributions to Mineralogy and Petrology 134, 186-201.

Simonetti, A., Heaman, L.M., Chacko, T. \& Banerjee, N.R. 2006. In situ petrographic thin section U-Pb dating of zircon, monazite, and titanite using laser ablation-MC-ICP-MS. International Journal of Mass Spectrometry 253, 87-97.

Slagstad, T., Jamieson, R.A. \& Culshaw, N.G. 2005. Formation, crystallisation and migration of melt in the mid-orogenic crust: Muskoka domain migmatites, Grenville Province, Ontario. Journal of Petrology 46, 893-919.

Sederholm, J.J. 1907. Om granit och gneiss, deras uppkomst, uppträdande och utbredning inom urberget I Fennoskandia. Bull. Commission géologique de Finlande 23, 110p.

Spear, F.S., Kohn, M.J., \& Cheney, J.T. 1999. P-T paths from anatectic pelites. Contributions to Mineralogy and Petrology 134, 17-32.

Spear, F.S., \& Pyle, J.M. 2002. Apatite, monazite, and xenotime in metamorphic rocks. In: M.J. Kohn, J. Rakovan, and J.M. Hughes, (Eds.) Phosphates: Geochemical, Geobiological, and Materials Importance, 48, p. 293-335. Reviews in Mineralogy and Geochemistry, Mineralogical Society of America, Washington, D. C.

Spear, F. S. \& J. M. Pyle 2010. Theoretical modeling of monazite growth in a low-Ca metapelite. Chemical Geology 273, 111-119

Stevens, G., Clemens, J.D. \& Droop, G. 1997. Melt production during granulite-facies anatexis: experimental data from "primitive" metasedimentary protoliths. Contributions to Mineralogy and Petrology 128, 352-370.

Stüwe, K. \& Powell, R. 1989. Metamorphic segregations associated with garnet and orthopyroxene porphyroblast growth: two examples from the Larsemann Hills, East Antarctica. Contributions to Mineralogy and Petrology 103, 523-530.

Thompson, A.B. 1982. Dehydration melting of pelitic rock and the generation of $\mathrm{H}_{2} \mathrm{O}$-undersaturated granitic liquids. America Journal of Science 282, 1567-1595.

Thompson, A.B. \& Connolly, J.A.D. 1995. Melting of the continental crust: some thermal and petrological constraints on anatexis in continental collision zones and other tectonic settings. Journal of Geophysical Research 100, 15565-15579.

Vavra, G., Gebauer, D., Schmid, R. \& Compston, W. 1996. Multiple zircon growth and recrystallization during polyphase Late Carboniferous to Triassic metamorphism in granulites of the Ivrea Zone (Southern Alps): an ion microprobe (SHRIMP) study. Contributions to Mineralogy and Petrology 
$122,337-358$.

Vavra, G., Schmidt, R. \& Gebauer, D. 1999. Internal morphology, habit and U-Th-Pb microanalysis of amphibolite-to-granulite facies zircons: geochronology of the Ivrea Zone (Southern Alps). Contributions to Mineralogy and Petrology 134, 380-404.

Vernon, R.H. 2004. A Practical Guide to Rock Microstructure. Cambridge: Cambridge University Press. Vernon, R.H. \& Clarke, G.L. 2008. Partial melting during high-grade metamorphism. In: Vernon \& Clarke (Eds.), Principles of Metamorphic Petrology. Cambridge University Press, New York, pp. 140-205. Vernon, R.H. \& Collins, W.J. 1988. Igneous microstructures in migmatites. Geology 16, 1126-1129.

Vielzeuf, D. \& Holloway, J.R. 1988. Experimental determination of the fluid-absent melting relations in the pelitic system. Contributions to Mineralogy and Petrology 98, 257-276.

Vielzeuf, D. \& Montel, J.M. 1994. Partial melting of metagreywackes. Fluid-absent experiments and phase relationships. Contributions to Mineralogy and Petrology 117, 375-393.

Vielzeuf, D. \& Schmidt, M.W. 2001. Melting relations in hydrous systems revisited: application to metapelites, metagreywackes and metabasalts. Contributions to Mineralogy and Petrology 141, 251-267.

Vigneresse, J.-L. 2004. A new paradigm for granite generation. Transactions of the Royal Society of Edinburgh: Earth Sciences 95, 11-22.

Villaseca, C., Romera, C.M., De la Rosa, J. \& Barbero, L. 2003. Residence and redistribution of REE, Y, $\mathrm{Zr}$, Th and $\mathrm{U}$ during granulite facies metamorphism: behaviour of accessory and major phases in peraluminous granulites of central Spain. Chemical Geology 200, 293-323.

Villaseca, C., Orejana, D. \& Paterson, B.A. 2007. Zr-LREE rich minerals in residual peraluminous granulites, another factor in the origin of low Zr-LREE granitic melts? Lithos 96, 375-386.

Waters, D.J. 1988. Partial melting and the formation of granulite facies assemblages in Namaqualand, South Africa. Journal of metamorphic Geology 6, 387-404.

Watkins, J.M., Clemens, J.D. \& Treloar, P.J. 2007. Archaean TTGs as sources of younger granitic magmas: melting of sodic metatonalites at 0.6-1.2 GPa. Contributions to Mineralogy and Petrology 154, 91-110.

Watt, G.R. \& Harley, S.L. 1993. Accessory phase controls on the geochemistry of crustal melts and restites produced during water-undersaturated partial melting. Contributions to Mineralogy and Petrology 114, 550-566.

White, R.W., Pomroy, N.E. \& Powell, R. 2005. An in situ metatexite-diatexite transition in upper amphibolite facies rocks from Broken Hill, Australia. Journal of metamorphic Geology 23, 579602.

White, R. W. \& Powell, R. 2002. Melt loss and the preservation of granulite facies mineral assemblages. Journal of metamorphic Geology 20, 621-632.

White, R.W. \& Powell, R. 2010. Retrograde melt-residue interaction and the formation of near- 
anhydrous leucosomes in migmatites. Journal of Metamorphic Geology 28, 579-597.

Whitehouse, M.J. \& Platt, J.P. 2003. Dating high-grade metamorphism - constraints from rare-earth elements in zircon and garnet. Contributions to Mineralogy and Petrology 145, 61-74.

Wolf, M.B. \& Wyllie, P.J. 1994. Dehydration-melting of amphibolite at $10 \mathrm{kbar}$ : effect of temperature and time. Contributions to Mineralogy and Petrology 115, 369-383.

Wyllie, P. J., 1992. Experimental petrology: Earth materials science. In: Brown, G. C., Hawkesworth, C.J. and Wilson, C.L. (Eds.) Understanding the Earth. Cambridge University Press, pp. 65-87.

Wyllie, P. J., 1977. Crustal anatexis: an experimental review. Tectonophysics 13, 41-71.

Wyllie, P. J., Huang, W. L., Stern, C. R., \& Maaloe, S. 1976. Granitic magmas: possible and impossible sources, water contents, and crystallization sequences. Canadian Journal of Earth Sciences 13, 1007-1019.

Wyllie, P.J. \& Wolf, M.B. 1993. Amphibolite dehydration-melting: sorting out the solidus. In: Prichard, H.M., Alabaster, T., Harris, NBW \& Neary, C.R. (Eds.), Magmatic processes and plate tectonics. Geol. Soc. Spec. Publ, 76: 405-416.

Yardley, B.W.D. 1978. Genesis of the Skagit Gneiss migmatites, Washington, and the distinction between possible mechanisms of migmatization. Geol. Soc. Am. Bull. 89, 941-951. 


\section{Contexto geológico regional}

\subsection{Orógeno Brasília Meridional}

A Faixa Brasília está inserida na Província Tocantins (Almeida et al., 1977), e é dividida em dois domínios: Faixa Brasília Setentrional a norte, e Faixa Brasília Meridional a sul (Valeriano et al., 2004). O Orógeno Brasília meridional (Fuck et al., 1994; Dardenne, 2000) registra a colisão neoproterozóica entre a margem ativa da Placa Paranapanema e a margem passiva do paleocontinente São Francisco (Brito Neves et al., 1999; Campos Neto, 2000; Trouw et al., 2000). O Orógeno Brasília meridional é caracterizado por uma pilha de nappes sub-horizontais do tipo thick-skinned, com mergulho da cunha orogênica para sul-sudoeste e vergência para leste-nordeste infletindo para norte-nordeste próximo ao domínio cratônico (Campos Neto et al., 2004), onde três ambientes tectônicos são reconhecidos de WSW para ENE: i-Nappe Socorro-Guaxupé, domínio de arco magmático desenvolvido na margem continental ativa da Placa Paranapanema (e.g. Campos Neto \& Caby, 2000; Janasi, 2002); ii- Sistema de Nappes Andrelândia, domínio continental subductado, constituído por unidades metassedimentares relacionadas ao prisma acrescionário e bacias de ante-arco (e.g. Campos Neto et al., 2010, 2011); iii-domínio de margem continental passiva relacionado ao paleocontinente São Francisco, representado por rochas ortoderivadas do embasamento (e.g. Fetter et al., 2001; Cioffi et al., 2016), e por rochas metassedimentares do Complexo São Vicente (e.g. Westin et al., 2016), do Sistema de Nappes Carrancas (e.g. Trouw et al., 2008; Westin \& Campos Neto, 2013) e da Nappe Lima Duarte (Campos Neto et al., 2004; Rocha, 2011) (Figura 10).

Segundo Campos Neto et al., $(2010,2011)$ as idades mais antigas estão registradas nas partes externas do sistema de nappes (ca. 630-620 Ma na Nappe Socorro-Guaxupé; Janasi 1999, 2002; Campos Neto et al., 2004; Rocha et al., 2016), gradando progressivamente para idades mais novas em direção ao domínio cratônico (ca. 620-605 Ma no Sistema de Nappes Andrelândia; ca. 590 Ma nos sistemas de nappes Carrancas e Lima Duarte; Machado et al., 1996; Valeriano et al., 2004; Campos Neto et al., 2010, 2011), e interpretou este padrão como migração da frente de deformação e metamorfismo.

A Nappe Socorro-Guaxupé é constituída por unidades granulito-granito-migmatíticas neoproterozóicas que expõe pelo menos $10 \mathrm{~km}$ de espessura de crosta continental profunda (e.g. Campos Neto \& Caby, 1999, 2000; Janasi, 2002). Estas unidades registram condições metamórficas de alto grau e são interpretadas como a raiz de um arco magmático desenvolvida ao longo de paleomargem continental ativa da placa Paranapanema a oeste (Campos Neto \& Caby, 2000; Janasi, 2002). O Grupo Andrelândia (Trouw et al., 1983) representa um sistema de nappes com rochas de alta pressão, estiradas e transportadas para ENE e NE, e que estão colocadas sob a Nappe Socorro-Guaxupé (Campos Neto \& Caby, 1999). 


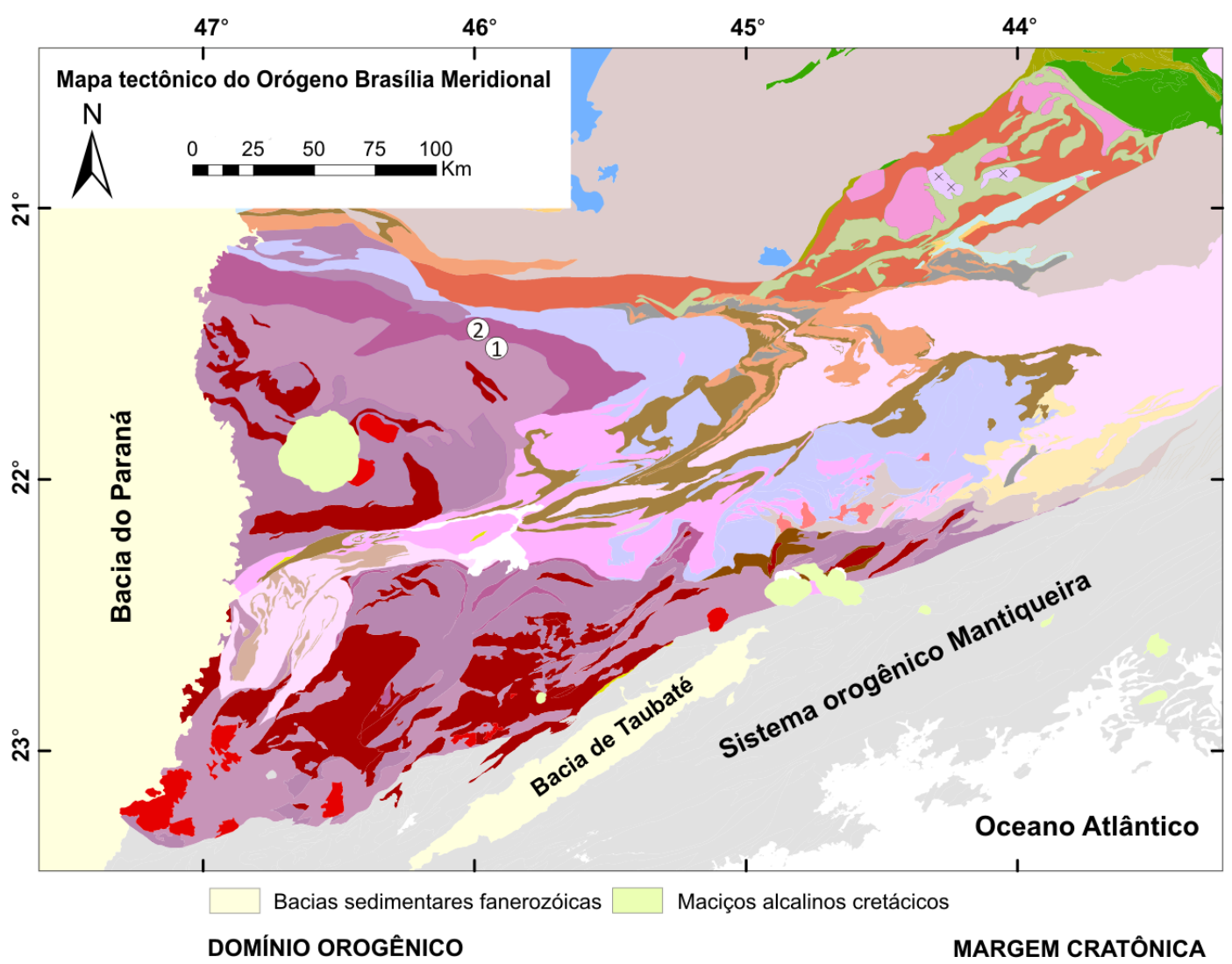

Domínio de margem ativa

Prisma acrescionário neoproterozóico e bacias de ante-país

Leucogranitos

Sistema de Nappes Andrelândia

Migmatitos Alagoa e Rio Preto

Domínio de arco neoproterozóico

Nappe Socorro-Guaxupé

Granitóides pós-tectônicos

Granitóides orogênicos

Unidade Metatexítica (ortognaisses)

Unidade Metatexítica (paragnaisses)

Unidade Diatexítica (ortognaisses)

Unidade Granulítica
Domínio de margem passiva

Idade desconhecida - Grupo Itapira Sequência flysch neoproterozóica

Nappes psamo-pelíticas neoproterozóicas

Carrancas $\square$ Lima Duarte

\section{Mesoproterozóico}

- Sequências São João del Rei e Carandaí

Paleoproterozóico

Sequência metassedimentar imatura Complexo São Vicente

Complexo Pouco Alegre (ortognaisses)

\section{Arqueano}

Ortognaisses e migmatitos
MARGEM CRATÔNICA

Plataforma carbonática neoproterozóica Paleoproterozóico (Riaciano-Sideriano)

\section{Cinturão Mineiro}

Suítes ígneas de 2,13-2,17 Ga

Suítes supracrustais de 2,2-2,35 Ga

$x \times$ Suítes ígneas de $2,35 \mathrm{Ga}$

Granitóides indivisos

Paleoproterozóico

Supergrupo Minas

Arqueano

Supergrupo Rio das Velhas

Complexos granito-gnáissicos (cráton São Francisco)

(1) Pedreira Alfenas (Unidade Metatexítica)

(2) Pedreira Santa Terezinha (Unidade Granulítica)

Figura 10: Mapa Tectônico do Orógeno Brasília Meridional (Cioffi et al., 2016), com a localização das pedreiras Alfenas e Santa Terezinha (inseridas nas Unidades Metatexítica e Granulítica, respectivamente) indicadas no domínio da Nappe Socorro-Guaxupé.

Os alóctonos maiores que configuram o setor oriental do Sistema de Nappes Andrelândia são: a Nappe Três Pontas-Varginha e Nappe Pouso Alto, superiores (e klippen Aiuruoca, Carvalhos e Serra da Natureza), a Nappe Liberdade e a Nappe Andrelândia, inferior (e.g. Ribeiro et al., 1995; Campos Neto \& Caby, 1999, 2000; Trouw et al., 2000; Garcia \& Campos Neto, 2003; Campos Neto et al., 2007, 2010, 2011; Cioffi, 2009; Motta, 2009). As rochas contidas nas nappes registram metamorfismo de alta pressão, tanto em fácies anfibolito, com retro-eclogitos associados, quanto em fácies granulito (e.g. Garcia \& Campos Neto, 2003; Campos Neto et al., 2010; Cioffi, 2009; Motta, 2009). São reconhecidas 
duas trajetórias metamórficas distintas na pilha metassedimentar (Campos Neto \& Caby, 1999, 2000). O Complexo São Vicente é constituído por rochas metassedimentares imaturas (Westin et al., 2016) derivadas de uma fonte paleoproterozóica juvenil representada por ortognaisses do Complexo Pouso Alegre (Cioffi et al., 2016). A Nappe Lima Duarte é constituída por unidades metassedimentares que registram o metamorfismo de fácies anfibolito superior a granulito e por lascas do Complexo Mantiqueira retrabalhadas e incorporadas na estrutura (Campos Neto et al., 2004; Rocha, 2011). No Sistema de Nappes Carrancas (Trouw et al., 1982, 1986, 2000, 2002; Ribeiro et al., 1995, 2002; Paciullo et al., 2002; Quéméneur et al., 2002; Westin \& Campos Neto, 2013) prevalece padrão metamórfico inverso, em que a sucessão de minerais-índice é indicativa de metamorfismo barroviano (Ribeiro \& Heilbron, 1982; Heilbron, 1985), mas em regime de pressões mais elevadas (Pavan, 2010). O metamorfismo aumenta de norte para sul, de fácies xisto verde a fácies anfibolito em presença de (Sil)St-Grt-Ky (Ribeiro \& Heilbron, 1982; Heilbron, 1985) e metapelitos da frente alóctone apresentam condições metamórficas de aproximadamente $500^{\circ} \mathrm{C}-7,5 \pm 0,5 \mathrm{kbar}$ (Campos Neto \& Caby, 1999).

Alguns autores consideram que a evolução do segmento meridional do Orógeno Brasília é resultante da superposição de dois eventos termotectônicos distintos, sendo interpretada como uma zona de interferência entre as Faixas Brasília e Ribeira (Ebert, 1984; Trouw et al., 1994; Peternel et al., 2005), pois as sequências teriam sido afetadas por mais de um episódio de deformação e metamorfismo neoproterozóicos (Ribeiro et al., 1995). No entanto, tal hipótese não á assumida no presente trabalho e a evolução do sistema de nappes é interpretada como sendo resultante de um único evento colisional, do tipo himalaiano, com a migração orogênica em direção ao domínio cratônico (Campos Neto \& Caby, 1999).

\subsection{Nappe Socorro-Guaxupé}

A Nappe Socorro-Guaxupé (Figura 10) está segmentada em dois lobos, Guaxupé a norte e Socorro sul, separados por rampas laterais de alto ângulo onde afloram ortognaisses arqueanos e paleoproterozóicos do embasamento do Orógeno Brasília (Fetter et al., 2001; Cioffi et al., 2016) em uma grande janela estrutural (15-75 km de largura). A Nappe Socorro-Guaxupé está organizada em pilha alóctone de três unidades distintas: Unidade Granulítica Basal, Unidade Diatexítica Intermediária e Unidade Migmatítica Superior (Campos Neto \& Caby, 2000).

A Unidade Granulítica Basal consiste de (granada) -biotita-ortopiroxênio granulito bandados, de coloração esverdeada, os litotipos dominantes, com intercalações locais de rochas máficas intrusivas sin-metamórficas (Campos Neto \& Caby, 2000). São comuns veios de leucossoma hololeucocrático com ortopiroxênio \pm granada e pequenos bolsões de charnockito, interpretados como produto de fusão anidra in situ (e.g. Campos Neto \& Caby, 2000; Campos Neto et al., 2004; Mora et al., 2014). O topo da unidade é marcado pela transição gradual para condições de fácies anfibolito. 
Os granulitos de composição intermediária são cálcio-alcalinos, enquanto que os granulitos máficos exibem assinatura toleiítica (Campos Neto et al., 1996; Choudhuri et al., 1995; Janasi, 1999). Os granulitos basais não apresentam distinção clara de assinatura geoquímica em comparação com as rochas presentes nos batólitos cálcio-alcalinos potássicos mais jovens, tendo sido considerados produtos da tectônica convergente pré-colisional. Idades de cristalização ígneas (ID-TIMS; intercepto superior) de ca. 640-660 Ma (e.g. Basei et al., 1995; Ebert et al., 1996; Hackspacher et al., 2003; Mora et al., 2014; Gengo, 2014) sugerem que o magmatismo ocorreu pouco antes do auge metamórfico, em processo contínuo.

A Unidade Diatexítica Intermediária é constituída por corpos descontínuos de migmatitos estromáticos e granitóides porfiríticos de coloração rosada, que resultam da fusão por quebra de biotita, de fontes metaluminosas a peraluminosas (Haddad, et al., 1997; Janasi, 1997a; Campos Neto \& Caby, 2000). Os migmatitos apresentam mesossoma cinza escuro composto de hornblenda-biotitaclinopiroxênio gnaisses, de composição tonalítica a diorítica, recortados por veios de leucossoma tonalítico cinza claro, alternado com melanossoma constituído por biotita e hornblenda. As rochas hospedeiras regionais são nebulitos rosa, com estruturas migmatíticas variadas e composição modal granítica, com biotita e mais raramente hornblenda. Encraves metassedimentares ocorrem como faixas de migmatitos kinzigíticos com espinélio, sillimanita, cordierita e granada (Campos Neto \& Caby, 2000).

A Unidade Metatexítica Superior (Complexo Piracaia, Campos Neto \& Basei, 1983) consiste de sequência metassedimentar com menor taxa de anatexia em direção ao topo estrutural da nappe, onde o grau de fusão diminui para SW. É constituída de granada-(sillimanita)-biotita gnaisses migmatíticos bandados de coloração cinza clara e leucossoma com granada e biotita, que gradam para mica xistos peraluminosos em direção ao topo, com intercalações locais de leucossomas com muscovita. Também ocorrem intercalações subordinadas de sillimanita-muscovita quartzito feldspático, gnaisses calciossilicáticos, raros corpos de mármore, hornblenda gnaisse e rochas intrusivas máficas (Campos Neto \& Caby, 2000). As unidades apresentam foliação metamórfica de baixo ângulo, com lineação mineral associada a indicadores cinemáticos, de transporte de topo para ENE. Também ocorrem zonas de cisalhamento sin-metamórficas normal-oblíquas (Campos Neto et al., 2004). Idades U-Pb em zircão de 1.9-2.1 Ga (ID-TIMS; Ebert et al., 1996) obtidas em metapelito de alto grau do Domínio Socorro foram interpretadas como idade média dos grãos de zircão herdados. Heranças de zircão com intervalo de idades entre $c a$. 640-800 Ma foram recentemente reconhecidas em migmatitos da Unidade Metatexítica (Domínio Guaxupé) através de técnicas de datação in-situ (Mora et al., 2014; Rocha et al., 2016). Heranças em torno de ca. 800 Ma também foram identificadas no Domínio Socorro (Negri, 2002; Martins et al., 2009).

Expressivo magmatismo cálcio-alcalino sin-orogênico é manifestado na forma de inúmeros batólitos dominados por hornblenda-biotita-quartzo monzonito e monzodiorito porfirítico, 
representados pelo Batólito Pinhal-Ipuiúna ( 625-620 Ma, Haddad, 1995), e Batólito Socorro (629 \pm 8 Ma, Töpfner, 1996), além de intrusões menores. Os batólitos são constituídos por granitóides híbridos derivados da crosta inferior, que formam série cálcio-alcalina expandida (Janasi, 1997c). A suíte mangerítica-granítica São José do Rio Pardo é constituída de corpos tabulares de mangerito e charnockito deformados, de coloração esverdeada e granulação média a grossa, intercalados com hornblenda granito grosso de coloração rosada e granito hololeucocrático (Campos Neto et al., 1988; Campos Neto \& Caby, 2000; Janasi, 1999; 2002; Mora et al., 2014). A suíte foi subdividida em duas subsuítes charnockíticas distintas: suíte São Pedro de Caldas (623 $\pm 3 \mathrm{Ma}$, Janasi, 1999), mais félsica (mangerito, hornblenda granito e leucogranito) e proveniente da fusão de granulitos mais férteis e com idades-modelo Sm-Nd da ordem de 1.5 Ga; e suíte Divinolândia (625 \pm 7 Ma, Basei et al., 1995), mais máfica e com maior proporção de diorito em relação à granito, deriva da fusão de granulitos mais refratários e com maior residência crustal, com idades-modelo Sm-Nd mais antigas do que $1.8 \mathrm{Ga}$ (Janasi, 2002).

Além das suítes, plútons graníticos resultantes da anatexia regional também estão presentes na Nappe Socorro-Guaxupé. Corpos de biotita granito equigranular do tipo Pinhal (Wernick \& Penalva, 1980) são produtos da fusão parcial de gnaisses na porção SW do lobo Guaxupé, com idade U-Pb em zircão de $625 \mathrm{Ma}$, que é tida como a de sua cristalização (Janasi, 1999). Corpos de granada leucogranito e granada-biotita granito do tipo Nazaré Paulista (Wernick et al., 1987; Janasi, 1999; Martins, 2005; Martins et al., 2009) foram gerados em níveis mais rasos a partir da fusão de rochas metassedimentares no extremo sul do lobo Socorro, em $626 \pm 4$ Ma, idade U-Pb em zircão (Janasi, 1999), idêntica à idade U-Pb em monazita (Martins, 2005). A fase tardi-orogênica é associada ao desenvolvimento de zonas transcorrentes NE-SW e representada pelos granitos do Cinturão Itú (590$580 \mathrm{Ma}$, Vlach et al., 1990; Janasi et al., 2009), e por suíte ultrapotássica colocada a 10 km de profundidade (Janasi et al., 1993), constituída pelos corpos de sienito potássico dos Maciços Pedra Branca e Capituva (612 \pm 3 Ma, Töpfner, 1996) e pelos corpos de diorito potássico do Maciço Piracaia (581 \pm 13 Ma, Janasi, 1986).

A idade do metamorfismo de fácies granulito na Nappe Socorro-Guaxupé é registrada em ca. 630-620 Ma (e.g. Basei et al., 1995; Janasi, 1999; 2002; Campos Neto et al., 2004; Valeriano et al., 2004; Martins et al., 2009; Reno et al., 2009, 2012; Mora et al., 2014; Rocha et al., 2016), coeval com uma série de suítes charnockíticas de cálcio-alcalinas de alto-K intrusivas na NSG, que marcam o magmatismo sin-colisional (Janasi, 2002; Mora et al., 2014). Recentemente Rocha et al., (2016) estabeleceram a idade do evento de fusão parcial e metamorfismo de temperatura ultra-alta em ca. 630-625 Ma baseado em idades de monazita por microssonda eletrônica. A cristalização de fundido foi reconhecida como um evento de longa duração entre ca. 630-600 Ma, com crescimento abundante, porém episódico de zircão e monazita em ca. $625 \mathrm{Ma}$, ca. $615 \mathrm{Ma}$ e ca. $608 \mathrm{Ma}$. Os picos de idade de 
ca. 615 e 608 Ma são compatíveis com estudos geocronológicos prévios na Nappe Socorro-Guaxupé (e.g. Basei et al., 1995; Janasi, 1999, 2002; Hackspacher et al., 2004; Martins et al., 2009; Mora et al., 2014, Gengo, 2014).

As temperaturas foram atingidas regionalmente a pressões de $12 \mathrm{kbar}$, e coincidem com a colocação de magmas charnockíticos/mangeríticos extraídos dos granulitos da unidade basal (Campos Neto \& Caby, 1999). Condições de alta temperatura e pressão são calculadas regionalmente, com valores em torno de $850-900^{\circ} \mathrm{C}$ e $12-14$ kbar para a Unidade Granulítica Basal (Del Lama et al., 2000; Campos Neto \& Caby, 2000; Freitas, 2000; Garcia \& Campos Neto, 2003; Alexandre, 2013; Benetti, 2013), condições atingidas em ambiente tectônico relacionado a profunda raiz de arco magmático (Campos Neto \& Caby, 2000; Campos Neto et al., 2004). Temperaturas mais elevadas da ordem de ca. $1030{ }^{\circ} \mathrm{C}$ a $11,7 \mathrm{kbar}$ foram obtidas em migmatitos com granada e ortopiroxênio da Unidade Metatexítca, o que caracteriza o metamorfismo de temperatura ultra-alta na NSG (Rocha et al., 2016). As rochas da Unidade Diatexítica apresentam composição semi-pelítica e registram pico metamórfico entre 750 a $950{ }^{\circ} \mathrm{C}$, compatível com a fusão da biotita e hornblenda, e pressão inferior a $10 \mathrm{kbar}$, delimitado pelo campo de estabilidade da sillimanita (e.g. Martins et al., 2009). Iyer et al. (1996) obtiveram condições mínimas de pico metamórfico a $850{ }^{\circ} \mathrm{C}$ e $8,5 \mathrm{kbar}$.

Dados isotópicos de Nd pré-existentes (e.g. Janasi, 1999, 2002; Hackspacher et al., 2003; Campos Neto et al., 2004; Janasi et al., 2009; Mora et al., 2014; Vinagre et al., 2014) indicam o predomínio de valores de $\varepsilon \mathrm{Nd}_{(\mathrm{t})}$ negativos na Nappe Socorro-Guaxupé como um todo. $\mathrm{O}$ padrão de idades-modelo Sm-Nd registra, no domínio oriental da nappe, valores entre 1,4 e 1,7 Ga, ao contrário do domínio ocidental, em que prevalecem valores superiores a 2,0 Ga (Janasi, 1999; 2002). Para alguns autores (e.g. Campos Neto et al., 2011) a Nappe Socorro-Guaxupé poderia representar a extensão sul do Arco Magmático de Goiás (Pimentel \& Fuck, 1992; Pimentel et al., 2000; Laux et al., 2004), embora rochas juvenis não tenham sido reconhecidas na NSG até o momento. Alguns autores têm proposto a participação de fontes crustais paleoproterozóicas na gênese de magmas na NSG (e.g. Hackspacher et al., 2003), baseado em idades TDM com valores entre 2,0-1,9 Ga. No entanto, Carvalho et al., (2014) propuseram recentemente que o avanço e colocação final da Nappe Socorro-Guaxupé é posterior à geração de suítes magmáticas, dado que não há evidências de participação de embasamento mais antigo na sua gênese.

\subsection{Referências bibliográficas}

Alexandre, E.L. 2013. Caracterização dos granulitos e migmatitos da região de Alfenas, MG. Dissertação de Mestrado, IGc-USP: 151pp.

Almeida, F.F.M., Hasui, Y., Brito Neves, B.B., Fuck, R.A., 1977. As províncias estruturais brasileiras. In: SGB Simpósio Geologia do Nordeste, 8, Campina Grande. Atas... p. 363-391. 
Basei, M.A.S., Siga Jr., O., Sato, K., Sproesser, W.M. 1995. A metodologia urânio-chumbo na Universidade de São Paulo: princípios metodológicos, aplicações e resultados obtidos. Anais da Academia Brasileira de Ciências 67(2), 221-237.

Benetti, B.Y. 2013. Termobarometria das rochas da Nappe Socorro-Guaxupé, na região de Varginha, MG. Monografia de Trabalho de Formatura, IGc-USP, 35 pp.

Brito Neves, B.B.; Campos Neto, M.C., Fuck, R.A. 1999. From Rodinia to Western Gondwana: An approach to the Brasiliano-Pan African Cycle and orogenic collage. Episodes 22, 155-166.

Campos Neto, M.C., 2000. Orogenic systems from south-western Gondwana: an approach to Brasiliano-Pan African cycle and collage in southeastern Brazil. In: Cordani, U.G., Milani, E.J., Thomaz Filho, A., Campos, D.A. (Eds). Tectonic Evolution of South America, Rio de Janeiro, pp. 335-365.

Campos Neto, M.C., Caby, R., 1999. Neoproterozoic high-pressure metamorphism and tectonic constraints from the nappe system south of the São Francisco Craton, southeast Brazil. Precambrian Research 97, 3-26.

Campos Neto, M.C., Caby, R., 2000. Terrane accretion and upward extrusion of high-pressure granulites in the Neoproterozoic nappes of Southeast Brazil: Petrologial and structural constraints. Tectonics 14 (4), 669-687.

Campos Neto, M.C., Basei, M.A., Vlach, S.R.F., Caby, R., Szabó, AJ., Vasconcelos, P., 2004. Migração de orógenos e superposição de orogêneses: um esboço da colagem brasiliana no sul do Cráton do São Francisco, SE-Brasil, 2004. Geologia USP, Série Científica 4 (1), 13-40.

Campos Neto, M.C., Basei, M.A.S., Janasi, V.A., Moraes, R. 2011. Orogen migration and tectonic setting of the Andrelândia Nappe System: An Ediacaran Western Gondwana Collage, South of São Francisco craton. Journal of South American Earth Sciences 32, 393-406.

Campos Neto, M.C., Cioffi, C.R., Moraes, R., Motta, R.G., Siga Jr, O., Basei, M.A.S., 2010. Structural and metamorphic control on the exhumation of high-P granulites: The Carvalhos Klippe example, from the oriental Andrelândia Nappe System, southern portion of the Brasília Orogen, Brazil. Precambrian Research 180, 125-142.

Campos Neto, M.C.; Figueiredo, M.C.H., Janasi, V.A., Basei, M.A.S., Fryer, B.J. 1988. The São José do Rio Pardo Mangeritic-Suite, southeastern Brazil. Geochimica Brasiliensis 2, 185-199.

Campos Neto, M.C., Janasi, V.A., Caby, R. 1996. Ocorrências de granulitos empobrecidos nas porções basais da Nappe de Empurrão Socorro-Guaxupé. Boletim do IG-USP 18, 11-14.

Campos Neto, M.C., Janasi, V.A., Basei, M.A.S., Siga Junior, O. 2007. Sistema de Nappes Andrelândia, setor oriental: litoestratigrafia e posição estratigráfica. Revista Brasileira de Geociências 37 (suplemento $\mathrm{n} \div 4$ ), 47-60. 
Carvalho, B.B., Janasi, V.A., Henrique-Pinto, R., 2014. Geochemical and Sr-Nd-Pb isotope constraints on the petrogenesis of the K-rich Pedra Branca Syenite: Implications for the Neoproterozoic postcollisional magmatism in SE Brazil. Lithos 205, 39-59.

Choudhuri, A., Schrank, A., Roig, H.L., Szabó, G,A.J. 1995 . Negative Ce anomaly in mafic rocks of a possible Late Proterozoic ophiolite from SW Minas Gerais, Brazil. In: Srivastava, R.K., Chandra, R. (Eds.) Magmatism in relation to diverse tectonic settings. Oxford: IBH Publishing Co, p. 293-315.

Cioffi, C.R., 2009. Geologia dos granulitos de alta pressão da Klippe Carvalhos, extensaõ sul da Faixa Brasília. Dissertação de Mestrado, IGc-USP: 104 pp.

Cioffi, C.R., Campos Neto, M.C., Möller, A., Rocha, B.C., 2016. Paleoproterozoic continental crust generation events at 2.15 and $2.08 \mathrm{Ga}$ in the basement of the Southern Brasília Orogen, SE Brazil. Precambrian Research 275, 176-196.

Dardenne, M.A. 2000. The Brasília Fold Belt. In: Cordani, U.G.; Milani, E.J., Thomaz Filho, A., Campos, D.A. (Eds.), Tectonic Evolution of South America. Rio de Janeiro, pp. 231-263.

Del Lama, E.A., Zanardo, A., Oliveira, M.A.F., Morales, N. 2000. Exhumation of high-pressure granulites of the Guaxupé Complex, Southeastern Brazil. Geological Journal 35, 231-249.

Ebert, H. 1984. Aspectos da geologia da região de São João Del Rei. Os Paraibides entre São João del Rei e Itapira e a bifurcação entre Paraibides e Araxaides. Publicação Especial SBG-NSP, 12, 114pp.

Ebert, H., Chemale Jr., F., Babinski, M., Artur, A.C., Van Schmus, W.R. 1996. Tectonic setting and U-Pb zircon dating of the plutonic Socorro Complex in the transpressive Rio Paraíba do Sul shear belt, SE Brazil. Tectonics 15, 688-699.

Fetter, A.H., Hackspacher, P.C., Ebert, H.D., Dantas, E.L., Costa, A.C.D., 2001. New Sm-Nd and U-Pb geochronological constraints on the Archean to Paleoproterozoic evolution of the Amparo basement complex of the central Ribeira belt, southeastern Brazil. $3^{\text {rd }}$ South American Symposium on Isotope Geology (Extended Abstracts, CD-ROM).

Freitas, F.C. 2000. Geotermobarometria e evolução metamórfica das rochas granulíticas da região de Socorro-SP. Dissertação de Mestrado, IGc-USP, 175 pp.

Fuck, R.A., Pimentel, M.M., Silva, L.J.H.D. 1994. Compartimentação tectônica da porção oriental da Província Tocantins, $38^{\text {th }}$ Congresso Brasileiro de Geologia, Camboriú, Abstract vol 1, 215-216.

Garcia, M.G.M., Campos Neto, M.C. 2003. Contrasting metamorphic conditions in the Neoproterozoic collision-related nappes, South of the São Francisco Craton, SE Brazil. Journal of South American Earth Sciences 15(8), 853-870.

Gengo, R.M., 2014. Petrologia de ortognaisses e granitoides do Domínio Socorro, Nappe SocorroGuaxupé, Seção Extrema-Camanducaia. Dissertação de Mestrado, IGc-USP: 121 p.

Hackspacher, P.C., Fetter, A.H., Ebert, H.D., Janasi, V.A., Oliveira, M.A.F., Braga, I.F., Negri, F.A. 2003. Magmatismo há ca. 660-640 Ma no Domínio Socorro: Registros de convergência pré-colisional na aglutinação do Gondwana Ocidental. Geologia USP, série científica 3, 85-96. 
Hackspacher, P.C., Fetter, A.H., Teixeira, W., Dantas, E.L., Ebert, H.D., Trouw, R.A.J., Vasconcelos, P., 2004. Final stages of the Brasiliano Orogenesis in SE Brazil: U-Pb and ${ }^{40} \mathrm{Ar} /{ }^{39} \mathrm{Ar}$ evidence for overprinting of the Brasília Belt by the Ribeira Belt tectonics. In: Weinberg, R., Trouw, R.A.J., Fuck, R.A., Hackspacher, P.C. (eds.), The 750-550 Ma Brasiliano Event of South America, Journal of the Virtual Explorer, Electronic Edition, Vol. 17 (http://virtualexplorer.com.au/article/2004/108/final-stages-of-the-brasiliano-orogeny).

Haddad, R.C. 1995. O batólito Pinhal-Ipuíuna (SP-MG): um exemplo de magmatismo cálcio-alcalino potássico neoproterozóico no sudeste brasileiro. Tese de Doutoramento, IGc-USP, 270 pp.

Haddad, R.C., Janasi, V.A., Ulbrich, H.H.G.J. 1997. Caracterização geoquímica preliminary dos granitóides aflorantes nas vizinhanças do batólito Pinhal-Ipuiúna (SP-MG). Revista Brasileira de Geociências 27, 129-138.

Heilbron, M., 1985. O metamorfismo da área de Itutinga- Madre de Deus de Minas - MG. In: SBG, $3^{\circ}$ Simpósio de Geologia de Minas Gerais, Anais, 219-233.

Iyer, S.S., Choudhuri, A., Pattison, D.R.M., De Paoli, G.R. 1996. Petrology and geochemistry of the Neoproterozoic Guaxupé granulite facies terrain, southeastern Brazil. Precambrian Research 77, 23-40.

Janasi, V.A. 1986. Geologia e petrologia do maciço monzodiorítico-monzonítico de Piracaia (SP). Dissertação de Mestrado, Instituto de Geociências, USP, 281 pp.

Janasi, V.A. 1997c. Neoproterozoic mangerite-granite magmatism in the southeastern Brazil: the São Pedro de Caldas massif. Anais da Academia Brasileira de Ciências 69, 267-294.

Janasi, V.A. 1999. Petrogênese de granitos crustais da Nappe de Empurrão Socorro-Guaxupé (SP-MG): uma contribuição da geoquímica elemental e isotópica. Tese (Livre-Docência) - IGc-USP, 304 pp. Janasi, V.A. 2002. Elemental and Sr-Nd isotope geochemistry of two Neoproterozoic mangerite suites in SE Brazil: implications for the origin of the mangerite-charnockite-granite series. Precambrian Research 119, 301-327.

Janasi, V.A., Vlach, S.R.F. 1997a. Sr and Nd isotope systematic of the Capituva and Pedra Branca syenitic massifs (SW Minas Gerais, Brazil): petrogenesis and inference on Neoproterozoic lithospheric mantle reservoirs. In: South-American Symposium on Isotope Geology. Campos do Jordão. Extend Abstracts. FAPESP/CNPq/CPRM, p. 143-146.

Janasi, V.A., Vlach, S.R.F., Campos Neto, M.C., Ulbrich, H.H.G.J., 2009. Associated A-type subalkaline and high-K calc-alkaline granites in the Itú Granite Province, southeastern Brazil: petrological and tectonic significance. Canadian Mineralogist 47, 1505-1526.

Machado, N., Valladares, C., Heilbron, M., Valeriano, C., 1996. U-Pb geochronology of central Ribeira belt (Brazil) and implications for the evolution of the Brazilian Orogeny. Precambrian Research 79, 347-361.

Martins, L. 2005. Geração e migração de magmas graníticos na crosta continental: estudos de detalhe 
em granitos e migmatitos da região de Nazaré Paulista (SP). Tese de doutoramento, IGc-USP, 159 pp.

Martins. L., Vlach, S.R.F., Janasi, V.A., 2009. Reaction microtextures of monazite: correlation between chemical and age domains in the Nazaré Paulista migmatite, SE Brazil. Chemical Geology 261, 271-285.

Mora, C.A.S., Campos Neto, M.C., Basei, M.A.S., 2014. Syn-collisional lower continental crust anataxis in the Neoproterozoic Socorro-Guaxupé Nappe System, southern Brasília Orogen, Brazil: constraints from zircon U-Pb dating, Sr-Nd-Hf signatures and whole-rock geochemistry. Precambrian Research 255, 847-864.

Motta, R.G. 2009. Evolução tectono-metamórfica do Domínio Serra da Natureza, Terreno Andrelândia, MG. Dissertação de Mestrado, IGc-USP, 157 pp.

Negri, F.A., 2002. Petrologia das rochas charnockito-graníticas e encaixantes de alto grau associadas na região de São Francisco Xavier, SP. Unpublished PhD Thesis, Universidade Estadual Paulista, Brazil, 404 pp.

Paciullo, F.V.P., Trouw, R.A.J., Ribeiro, A., 2002. Geologia da Folha Andrelândia. In: Pedrosa-Soares, A.C., Noce, C.M., Trouw, R.A.J., Heilbron, M. (orgs.) Geologia e Recursos Minerais do Sudeste Mineiro, Projeto Sul de Minas 1, 84-120.

Pavan, M.S. 2010. Modelamento metamórfico de rochas das fácies xisto-verde e anfibolito com o uso de pseudosseções: exemplo das rochas da Klippe Carrancas, sul de Minas Gerais. Dissertação de Mestrado, IGc-USP, 142 pp.

Peternel, R.M.N., Trouw, R.A.J., Schmitt, R. 2005. Interferência entre duas faixas móveis neoproterozóicas: o caso das faixas Brasília e Ribeira no sudeste do Brasil. Revista Brasileira de Geociências 35, 297-310.

Pimentel, M.M., Fuck, R.A., 1992. Neoproterozoic crustal accretion in central Brazil. Geology 20, 375379.

Pimentel, M.M., Fuck, R.A., Gioia, S.M.C.L., 2000. The Neoproterozoic Goiás Magmatic Arc, Central Brazil: a review and new Sm-Nd isotopic data. Brazilian Journal of Geology 30(1): 35-39.

Quéméneur, J. J.G., Ribeiro, A., Paciullo, F.V.P., Heilbron, M., Trouw, R.A.J., Valença, J.G., Noce, C.M., 2002. Mapa Geológico-Folha Lavras, escala 1:100.000. COMIG,UFRJ,UFMG, Projeto Sul de Minas-Etapa I.

Reno, B.L., Brown, M., Kobayashi, K., Nakamura, E., Piccoli, P.M., Trouw, R.A.J., 2009. Eclogite-highpressure granulite metamorphism records early collision in West Gondwana: new data from the Southern Brasília Belt, Brazil. Journal of the Geological Society, London 166, 1013-1032.

Reno, B.L., Piccoli, P.M., Brown, M., Trouw, R.A.J., 2012. In situ monazite (U-Th)-Pb ages from the Southern Brasília Belt, Brazil: constraints on the high-temperature retrograde evolution of HP granulites. Journal of Metamorphic Geology 30, 81-112. 
Ribeiro, A., Heilbron, M. 1982. Estratigrafia e metamorfismo dos Grupos Carrancas e Andrelândia, sul de Minas Gerais. In : SBG, Congresso Brasileiro de Geologia, 32, Salvador, Anais, 1, 177-186.

Ribeiro, A., Paciullo, F.V.P., Noce, C.M., Valeriano, C.M., Valença, J.G., Ávila, C. A., Trouw, R.A.J., Silva, M.A., 2002. Mapa Geológico-Folha São João Del Rei, escala 1:100.000. COMIG, UFRJ, UFMG, Projeto Sul de Minas-Etapa I.

Ribeiro, A., Trouw, R.A.J., Andreis, R.R., Paciullo, F.V.P., Valença, J. 1995. Evolução das bacias Proterozóicas e o termo-tectonismo Brasiliano na margem sul do cráton do São Francisco. Revista Brasileira de Geociências 25, 235-248.

Rocha, B.C., 2011. Evolução metamórfica dos metassedimentos da Nappe Lima Duarte e rochas associadas do Complexo Mantiqueira. Dissertação de Mestrado, IGc-USP: 201pp.

Rocha, B.C., Moraes, R., Möller, A., Cioffi, C.R., Jercinovic, M.J., 2016. Timing of anatexis and melt crystallization in the Socorro-Guaxupé Nappe, SE Brazil: insights from trace element composition of zircon, monazite and garnet coupled to U-Pb geochronology. Lithos, http://dx.doi.org/10.1016/i.lithos.2016.05.020, in press.

Töpfner, C. 1996. Brasiliano-granitoide in den bundesstaaten São Paulo und Minas Gerais, Brasilieneine vergleichende studie. Münchner Geologische Hefte 4, 1-100.

Trouw, R.A.J., Heilbron, M., Ribeiro, A., Paciullo, F., Valeriano, C.M., Almeida, J.C.H., Tupinambá, M., Andreis, R.R., 2000. The central segment of Ribeira Belt. Tectonic Evolution of South America, Rio de Janeiro, 2000, 287-310.

Trouw, R.A.J., Nunes, R.P.M., Castro, E.M.O., Trouw, C.C., Matos, G.C., 2008. Nota explicativa das Folhas Varginha (SF-23-V-D-VI) e Itajubá (SF-23-Y-B-III). Programa Geologia do Brasil. Contrato CPRM-UFRJ Nº67/PR/05 (99pp).

Trouw, R.A.J., Paciullo, F.V.P., Chrispim, S.J., Dayan, H., 1982. Análise da deformação numa area a SE de Lavras, Minas Gerais. In: Congresso Brasileiro de Geologia, Anais, 32, Salvador, 1, 187-198.

Trouw, R.A.J., Paciullo, F.V.P., Ribeiro, A., Bittar, S., Almeida, J.C.H., 2002. Mapa Geológico Folha Caxambu, escala 1:100.000. COMIG,UFRJ,UFMG, Projeto Sul de Minas-Etapa I.

Trouw, R.A.J., Paciullo, F.V.P., Ribeiro, A. 1994. A Faixa Alto Rio Grande reinterpretada como zona de interferência entre a Faixa Brasília e a Faixa Ribeira. In: 38th Congresso Brasileiro de Geologia, resumo expandido, v. 3, 234-235.

Trouw, R.A.J., Ribeiro, A., Paciullo, F.V.P. 1983. Geologia estrutural dos Grupos São João del Rei, Carrancas e Andrelândia, Sul de Minas Gerais. Anais da Academia Brasileira de Ciências 55 (1), 71-85.

Trouw, R.A.J., Ribeiro, A., Paciullo, F.V.P., 1986. Contribuição à geologia da Folha Barbacena 1:250.000. In: Congresso Brasileiro de Geologia, anais, 34, Goiânia, 974-986. 
Valeriano, C., Machado, N., Simonetti, A., Valladares, C.S., Seer, H.J., Simões, L.S.A., 2004. U-Pb geochronology of the Southern Brasília belt (SE-Brazil): sedimentar provenance, Neoproterozoic orogeny and assembly of West Gondwana. Precambrian Research 130, 27-55.

Vinagre, R., Trouw, R.A.J., Mendes, J.C., Duffles, P., Peternel, R., Matos, G., 2014. New evidence of a magmatic arc in the Southern Brasília Belt, Brazil: The Serra da Água Limpa batholith (SocorroGuaxupé Nappe). Journal of South American Earth Sciences 54, 120-139.

Vlach, S.R.F., Janasi, V.A., Vasconcellos, A.C.B. 1990. The Itú belt: associated calc-alkalic and aluminous A-type Brasiliano granitoids in the States of São Paulo and Paraná, southern Brazil. In: $36^{\text {th }}$ Congresso Brasileiro de Geologia, Natal, vol. 4, p. 1700-1711.

Wernick, E., Penalva, F. 1980. Contribuição à geologia do Grupo Pinhal (SP e MG). Revista Brasileira de Geociências 10, 43-62.

Wernick, E., Weber-Diefenbach, K., Correia, P.R. 1987. O granitoide Nazaré Paulista: dados petrográficos, químicos e de tipologia do zircão. In: Simpósio Regional de Geologia, 6, Rio Claro, SP. Atas, SGB-NSP, 1, 123-134.

Westin, A., Campos Neto, M.C., 2013. Provenance and tectonic setting of the external nappe of the Southern Brasília Orogen. Journal of South American Earth Sciences 48, 220-239.

Westin, A., Campos Neto, M.C., Hawkesworth, C., Cawwod, P., Dhuime, B., Delavault, H., 2016. A Paleoproterozoic intra-arc basin associated with a juvenile source in the southern Brasília Orogen: using U-Pb ages and Hf-Nd isotopic analyses in provenance studies of complexes areas. Precambrian Research 276, 178-193. 


\section{Materiais e métodos}

\subsection{Trabalhos de campo}

A primeira etapa de campo (junho de 2012) foi realizada na região de Alfenas, Paraguaçu e Varginha (MG), para reconhecimento regional, obtenção de dados estruturais e coleta de amostras, utilizando as folhas topográficas Alfenas (SF-23-I-I-3), Elói Mendes (SF-23-I-III-2) e Varginha (SF-23-I-IV1), escala 1: 50000 - IBGE (1970). Os demais trabalhos de campo foram concentrados na região de Alfenas, com a realização de duas etapas de campo (setembro de 2012 e outubro de 2013) para levantamentos de detalhe nas duas áreas-alvo principais: pedreira Alfenas e pedreira Santa Terezinha, identificadas em trabalhos de mapeamento prévios por Alexandre (2013) e Souza (2014). Foi realizado o mapeamento detalhado dos taludes das pedreiras para o estabelecimento de relações precisas entre os litotipos, de acordo com a seguinte sistemática: primeiro são fotografadas as paredes em que as relações estruturais e de contato entre os diferentes litotipos estão claras; é feito o tratamento das imagens e em alguns casos montado o panorama com várias imagens sobrepostas de uma porção selecionada do talude; as fotos e os panoramas são impressas em papel A4 ou A3, sobre as quais são destacadas cada uma das porções reconhecidas, que são descritas em detalhe, assim como as relações de contato. Foi realizada uma descrição detalhada de treze localidades da Pedreira Alfenas (Unidade Metatexítica) (ANEXO X) e seis localidades da Pedreira Santa Terezinha (Unidade Granulítica), destacando as principais relações de campo. Foi realizada uma amostragem sistemática dos litotipos, com a indicação das amostras na foto sempre que possível. A última etapa de campo realizada em novembro de 2013 teve a participação do Prof. Dr. Andreas Möller (The University of Kansas, USA), com o intuito de apresentar a área de estudo para o orientador do estágio de pesquisa no exterior (BEPE-FAPESP), bem como aspectos regionais em afloramentos-chave na região de Alfenas, Varginha, Três-Pontas e Campos Gerais.

\subsection{Análise textural macroscópica e microscópica}

As amostras coletadas foram fatiadas em diversas posições e cuidadosamente descritas, a fim de abranger a maior variação textural possível. A partir da análise textural macroscópica destas fatias de rocha, noventa e três seções delgadas foram confeccionadas para a realização da petrografia microscópica, visando à determinação das relações texturais principais, como texturas de fusão e de cristalização, relações entre minerais-índices e acessórios, e reações metamórficas. Para as descrições das seções delgadas, foram utilizados os microscópios ZEISS (Axioplan) e OLYMPUS (BXP-50) do Laboratório de Microscopia Petrográfica (LMP) do NAP Geoanalítica-USP. Vinte e sete seções polidas com 40-70 $\mu \mathrm{m}$ de espessura foram confeccionadas a partir de duplicatas de seções delgadas selecionadas para análises químicas in-situ. A partir destas, onze seções polidas foram investigadas 
através de imagens de elétrons retroespalhados (back-scattered electron imaging) (BSE), com o intuito de identificar todas as fases acessórias presentes (e.g. zircão, monazita, apatita, xenotima, allanita, molibdenita, pirita, calcopirita, magnetita, ilmenita) e verificar a existência de zoneamento composicional nos cristais. As imagens BSE foram obtidas através de microscópio eletrônico de varredura (MEV) - FEI Quanta 600F, com detector de EDS tipo SDD (Silicon Drift Detector), Bruker XFlash 4030 e software de microanálise Esprit Bruker, no Laboratório de Caracterização Tecnológica (LCT), Departamento de Engenharia de Minas e de Petróleo, Escola Politécnica, Universidade de São Paulo (USP). Pranchas com fotomicrografias dos litotipos da pedreira Alfenas encontram-se no ANEXO $\mathrm{XI}$.

\subsection{Química mineral através de microssonda eletrônica}

As análises de química mineral quantitativa e mapas composicionais dos cristais de granada da Unidade Metatexítica foram realizadas através da microssonda eletrônica CAMECA SX-50 na Universidade de Massachusetts, EUA (University of Massachusetts-Amherst Electron Microprobe Facility), utilizando voltagem de $15 \mathrm{kV}$ e diâmetro de feixe de $20 \mathrm{nA}$ e $300 \mathrm{nA}$ para análises quantitativas e mapas composicionais, respectivamente. $O$ restante das análises em granada, feldspatos, piroxênios, anfibólios e biotita foram realizadas com a utilização da Microssonda Eletrônica JEOL JXA-8530F Hyperprobe, Field Emission Electron Probe Microanalyzer (FE-EPMA) no laboratório NAP Geoanalítica da USP. As condições analíticas incluem voltagem de $15 \mathrm{kV}$, corrente de $20 \mathrm{nA}$ e com spots de $5 \mu \mathrm{m}$ de diâmetro, exceto para as análises de feldspato $(10 \mu \mathrm{m})$. Os mapas composicionais foram obtidos com $15 \mathrm{kV}, 250 \mathrm{nA}$ e dwell time de $20 \mathrm{~ms}$. Análises representativas de granada, piroxênio, feldspatos, anfibólios e biotita foram recalculados utilizando 0 software $A-X$ (http://www.esc.cam.ac.uk/research/research-groups/holland/ax), baseado no balanço de carga com dupla-normalização para obtenção da distribuição catiônica dos minerais analisados. Os resultados analíticos de química mineral obtidos através de microssonda eletrônica estão apresentados no ANEXO III.

\subsection{Geotermobarometria}

Apesar de granulitos serem gerados em condições $P$ - $T$ condizentes com a calibração de muitos geotermobarômetros, o cálculo $P$-T para essas rochas nem sempre é fácil e direto. Isso ocorre, pois comumente os granulitos resfriam durante longo tempo na base da crosta continental o que permite reequilíbrio químico dos minerais (Pattison et al., 2003) ou a destruição dos minerais do pico metamórfico por reação com fundido (White \& Powell, 2002, Moraes et al., 2002). A aplicação de termômetros Fe-Mg muitas vezes falha nas determinações do pico metamórfico e a aplicação de métodos de banco de dados internamente consistentes, como o THERMOCALC, podem falhar por não 
ser possível estabelecer um número mínimo de reações linearmente independentes, que são o ponto de partida para obtenção de dados confiáveis. Neste trabalho, as condições de pico metamórfico foram obtidas utilizando o geotermobarômetro Al-em-ortopiroxênio com correção para Fe-Mg de Pattison et al., (2003) e o barômetro granada-ortopiroxênio-plagioclásio-quartzo (Newton \& Perkins, 1982; Perkins \& Chipera, 1985; Eckert et al., 1991). A temperatura de cristalização do fundido foi obtida através de termometria Ti-em-zircão (Watson et al., 2006). Os resultados obtidos através de termobarometria estão apresentados no ANEXO IV.

Tabela 1: Relação das amostras analisadas e os métodos analíticos utilizados.

\begin{tabular}{|c|c|c|c|c|c|c|c|}
\hline \multirow[t]{2}{*}{ AMOSTRA } & \multirow[t]{2}{*}{ LITOTIPO } & \multicolumn{6}{|c|}{ MÉTODO } \\
\hline & & $\mathrm{FRX}$ & ICP-MS & $\mathrm{U}-\mathrm{Pb}(\mathrm{LA}-\mathrm{ICP}-\mathrm{MS})$ & U-Th-Pb (EPMA) & $\mathrm{Rb}-\mathrm{Sr}$ & $\mathrm{Sm}-\mathrm{Nd}$ \\
\hline \multicolumn{8}{|c|}{ PEDREIRA ALFENAS (UNIDADE METATEXÍTICA) } \\
\hline $6 \mathrm{D}$ & Grt-Bt meta texito es tromá tico & & & $x$ & $x$ & & \\
\hline $1 \mathrm{~A}$ & leucossoma com Grt \pm Opx & & & $x$ & $x$ & & \\
\hline $7 \mathrm{~A}$ & leucossoma sem Grt & & & $x$ & & & \\
\hline $9 B$ & (Grt)-Bt gnaisse & & & $x$ & $x$ & & \\
\hline 7C & granulito máfico & & & $\mathrm{x}$ & & & \\
\hline \multicolumn{8}{|c|}{ PEDREIRA SANTA TEREZINHA (UNIDADE GRANULÍTICA) } \\
\hline A2 & leucossoma com Hbl & $x$ & $\mathrm{x}$ & $\mathrm{x}$ & & $\mathrm{x}$ & $x$ \\
\hline A2-2 & granulito félsico & $x$ & $x$ & & & & \\
\hline 1B1 & granulito félsico & $x$ & $x$ & & & & \\
\hline $1 C$ & granulito máfico & $x$ & $x$ & & & & \\
\hline $4 \mathrm{~A}$ & leucossoma com Opx & $x$ & $x$ & & & & \\
\hline 2B1 & granulito félsico & $x$ & $x$ & & & & \\
\hline $2 \mathrm{~B} 2$ & granito fino & $x$ & $x$ & & & & \\
\hline $2 \mathrm{C} 1$ & granulito máfico & $x$ & $x$ & & & $x$ & $x$ \\
\hline $2 \mathrm{C} 2$ & granulito máfico & $x$ & $x$ & & & & \\
\hline SGB2-3 & granada granulito & $x$ & $x$ & & & & \\
\hline 3B1 & granulito félsico & $x$ & $x$ & & & & \\
\hline $3 C$ & granulito máfico & $x$ & $x$ & & & & \\
\hline SGB2-5 & leucossoma com $\mathrm{Hbl}$ & $x$ & $x$ & & & & \\
\hline 4B1 & granulito félsico & $x$ & $x$ & & & & \\
\hline $4 \mathrm{~B} 2$ & granito fino & $x$ & $x$ & & & & \\
\hline $4 C 1$ & granulito máfico & $x$ & $x$ & & & & \\
\hline $4 C 2$ & granulito máfico & $x$ & $x$ & & & & \\
\hline $\mathrm{A} 1$ & granulito félsico & $x$ & $x$ & $x$ & & $x$ & $x$ \\
\hline $5 B 1$ & granulito félsico & $x$ & $x$ & $x$ & & $x$ & $x$ \\
\hline B2 & granito fino & $x$ & $x$ & $x$ & & $x$ & $x$ \\
\hline SGB2-6 & leucossoma com Opx & $x$ & $x$ & & & & \\
\hline SGB2-7 & leucossoma com Opx & $x$ & $x$ & & & & \\
\hline $6 \mathrm{~A} 2$ & leucossoma com $\mathrm{Hbl}$ & $x$ & $x$ & & & & \\
\hline $6 \mathrm{~B} 1$ & granada granulito & $x$ & $x$ & $\mathrm{x}$ & & $x$ & $x$ \\
\hline
\end{tabular}

\subsection{Geoquímica de rocha-total}

A preparação das amostras para análise de elementos maiores e menores, foi realizada no Laboratório de Tratamento de Amostras (LTA) do NAP Geoanalítica-USP, seguindo as seguintes etapas: 1) lavagem das amostras e retirada de porções alteradas da rocha; 2) fragmentação das amostras com marreta; 3) segunda etapa de lavagem e secagem, a fim de reduzir eventuais riscos de contaminação a partir da marreta; 4) fragmentação das amostras utilizando o britador com mandíbulas de aço; 5) quarteamento das amostras utilizando o quarteador Jones para a retirada de aproximadamente $100 \mathrm{~g}$ 
de amostra representativa; 6) fragmentação das amostras utilizando prensa hidráulica, na fração grânulo; 7) pulverização das amostras utilizando moinho com anéis de ágata até atingir fração inferior a 200 mesh; 8) pesagem de 7,5g de amostra; 9) micronização utilizando micronizadores de ágata; 10) secagem em estufa por $48 \mathrm{hs} ; 11$ ) pesagem de $7 \mathrm{~g}$ de amostra; 12 ) homogeneização manual da amostra com $20 \%$ de parafina em saco plástico; 13) confecção das pastilhas de pó prensado para análise dos elementos menores utilizando prensa hidráulica. As etapas de preparação das pastilhas vítreas para análise dos elementos maiores, realizadas no Laboratório de Química e ICP-MS do (IGc-USP), foram as seguintes: 1) secagem em estufa por $24 \mathrm{hs} ; 2$ ) pesagem de $1 \mathrm{~g}$ de amostra; 3) pesagem de $9 \mathrm{~g}$ de fundente; 4) homogeneização da amostra com o fundente em frasco de vidro; 5) fusão do material a $1200^{\circ} \mathrm{C}$ por $15 \mathrm{~min}$ para confecção das pastilhas vítreas.

Análises químicas para determinação dos elementos maiores e menores através de espectrometria de fluorescência de raios- $X$, foram realizadas em vinte e quatro no ACME Analytical Laboratory (Vancouver, Canadá) após fusão das amostras com meta/tetraborato de lítio. As análises químicas para a determinação dos elementos traço, incluindo os elementos terras-raras, foram realizados em vinte e quatro amostras no Laboratório de Química e ICP-AES/MS do NAP GeoanalíticaUSP, através de espectrometria de massa com plasma induzido acoplado (Inductively Coupled PlasmaMass Spectrometry) (ICP-MS), dotado de espectrômetro do tipo quadrupolo, modelo ELAN 6100DRC da PerkinElmer/Sciex. As amostras foram dissolvidas por ataque ácido $\left(\mathrm{HF}+\mathrm{HNO}_{3}\right)$ durante cinco dias em bombas do tipo Parr, aquecidas a $200^{\circ} \mathrm{C}$ anteriormente às análises, de acordo com a metodologia descrita por Navarro et al. $(2002,2008)$. A relação das amostras selecionadas para análises químicas encontra-se na Tabela 1. Os resultados analíticos de geoquímica de rocha-total de elementos maiores, menores e traço estão apresentados no ANEXO V.

\subsection{Geoquímica isotópica $\mathrm{Rb}-\mathrm{Sr}$ e Sm-Nd em rocha-total}

As composições isotópicas de $\mathrm{Sr}$ e $\mathrm{Nd}$ em rocha-total foram obtidas em cinco amostras no Centro de Pesquisas Geocronológicas (CPGeo), Instituto de Geociências, Universidade de São Paulo, via TIMS (Thermal Ionization Mass Spectrometry), utilizando um espectrômetro FINNIGAN MAT 262 para análises de Sr e um ICP-MS multicoletor ThermoScientific Neptune Plus para análises de Nd, de acordo com os procedimentos analíticos descritos em Sato et al. (1995) e Souza (2009). Uma alíquota do mesmo pó de rocha utilizado para geoquímica de elementos maiores e menores em rocha-total foi dissolvido em ácido, e o Nd foi separado em colunas iônicas seguindo os procedimentos analíticos descritos em Sato (1995). Os brancos analíticos foram de 122 pg para Sr e 59 pg para Nd. O padrão NBS987 forneceu valores médios de $0,710237 \pm 0,0000021(2 \sigma)$ para a razão ${ }^{87} \mathrm{Sr} /{ }^{86} \mathrm{Sr}$ durante o período de um ano. O padrão JNdi (Serviço Geológico do Japão; Tanaka et al., 2000; valor recomendado de ${ }^{143} \mathrm{Nd} /{ }^{144} \mathrm{Nd}=0,512115 \pm 0,000007$ ) forneceu uma razão ${ }^{143} \mathrm{Nd} /{ }^{144} \mathrm{Nd}$ média de 0,512090 $\pm 0,000006$ 
( $n=14 ; 2 \sigma)$, exceto durante as análises da amostra 5B2 $(0,512068 \pm 0,000006 ; n=6 ; 2 \sigma)$. As razões ${ }^{87} \mathrm{Rb} /{ }^{86} \mathrm{Sr}$ e ${ }^{147} \mathrm{Sm} /{ }^{144} \mathrm{Nd}$ foram calculadas a partir das concentrações determinadas por ICP-MS. As idades $T_{D M}$ foram calculadas a partir de De Paolo (1981). A relação das amostras selecionadas para análises isotópicas encontra-se na Tabela 1. Os resultados analíticos de isótopos de Sr e Nd estão apresentados no ANEXO VI.

\subsection{Geoquímica de elementos-traço em fases acessórias e fases metamórficas principais}

A distribuição dos ETR no zircão e na monazita foram utilizados para correlacionar sua assinatura geoquímica com o crescimento de um domínio específico de minerais metamórficos (e.g. granada), para examinar a participação das fases acessórias em reações metamórficas e estabelecer trajetórias P-T-t, conforme descrito na literatura (e.g. Rubatto, 2002; Mahan et al., 2006; Harley \& Kelly 2007, Harley et al., 2007). As análises de elementos-traço in-situ em zircão (10 amostras) e em cristais de granada de migmatitos da Unidade Metatexítica (3 amostras) foram realizadas no Isotope Geochemistry Laboratory (IGL), na Universidade do Kansas (EUA), utilizando um espectrômetro ICPMS de alta resolução ThermoScientific Element2 acoplado a um sistema de ablação a laser ArF Excimer,

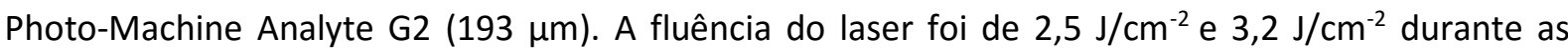
análises de zircão e granada, respectivamente, e com taxa de repetição de $10 \mathrm{~Hz}$. Spots com diâmetro de $15 \mu \mathrm{m}$ (zircão) e $40 \mu \mathrm{m}$ (granada) foram utilizados. Calibração externa foi realizada relativamente ao material de referência NIST 612 durante as análises de zircão, utilizando as concentrações do banco de dados GeoRem atualizadas em dezembro de 2009. Os spots das análises de elementos-traço em zircão foram posicionados próximos aos spots de U-Pb sempre que possível. O procedimento analítico de elementos-traço em zircão envolveu análises simultâneas de elementos-traço e U-Pb. No entanto, as análises de U-Pb obtidas em conjunto com elementos-traço só tiveram o intuito de distinguir com mais confiança os diferentes domínios composicionais do zircão e foram descartadas. Análises sistemáticas do material de referência primário GJ1 (Jackson et al., 2004) foram utilizadas para correções de fracionamento elemental, fracionamento downhole e calibração para o zircão. Os materiais de referência USGS GSD-1G e GSE-1G foram analisados como padrões interno e secundário durante as análises de granada, respectivamente. Concentrações estequiométricas de $\mathrm{Si}$, e concentrações de Si obtidas através de microssonda eletrônica foram utilizadas como padrões internos para zircão e granada, respectivamente. A redução dos dados foi realizada através do VizualAge (Petrus and Kamber, 2012) utilizando o software IOLITE (Paton et al., 2011).

As análises de elementos-traço de granada em duas amostras da Unidade Granulítica foram conduzidas no laboratório NAP Geoanalítica-USP, utilizando um ICP-MS Thermo Scientific iCAP Q acoplado a um sistema de ablação a laser New Wave UP $213 \mathrm{~nm}$. A granada foi analisada com spot de $55 \mu \mathrm{m}$ de diâmetro, fluência do laser de $10,98 \mathrm{~J} / \mathrm{cm}^{2}$, e taxa de repetição de $15 \mathrm{~Hz}$. As análises de ICP- 
MS seguem os procedimentos analíticos descritos em Andrade et al., (2014). A calibração externa foi realizada relativa ao material de referência NIST 610 utilizando as concentrações de Pearce et al., (1997). O material de referência BCR-2G foi analisado como padrão secundário durante as análises. As concentrações de Si e Ca determinados através de microssonda eletrônica foram utilizados como padrões internos para cada spot de granada analisado. A redução dos dados de granada obtidos na USP foi realizada através do software Glitter. Os resultados analíticos de elementos-traço em zircão e granada estão apresentados no ANEXO VII.

\subsection{Geocronologia U-Pb em zircão através de LA-ICP-MS}

A preparação inicial das onze amostras selecionadas foi realizada no Laboratório de Tratamento de Amostras (LTA) do NAP Geoanalítica-USP, envolvendo as etapas de fragmentação de amostras em britador com mandíbulas de aço, seguida de moagem em moinho de discos de tungstênio. A partir desta etapa, a preparação das amostras foi realizada no Laboratório de Separação Mineral do CPGeo, seguindo as seguintes etapas:

\subsubsection{Separação mineral}

- Peneiramento: separação das frações com granulação entre 60 e 100 \# (mesh), 100 e 250 \# e inferior a 250 \#. A separação da fração mais grossa (60-100\#) foi necessária devido à presença de cristais de zircão e monazita de até 1-3 mm, visíveis a olho nu em seção delgada.

- Mesa de Wiffley: separação de minerais por diferença de densidade através da inserção da amostra em um funil, que a despeja lentamente sobre uma mesa vibratória inclinada e com fluxo de água constante, onde a amostra será coletada no final da mesa em duas canecas, uma destinada a minerais pesados e outra a minerais leves.

- Separação magnética: na primeira etapa, a magnetita é extraída através do auxílio de um ímã de mão. Então, o zircão e a monazita são separados dos demais minerais magnéticos utilizando um separador magnético Frantz. A amostra é inserida em um funil e submetida a uma corrente inicial muito baixa, em torno de $0 \mathrm{~A}$. Os minerais são divididos em magnéticos e não magnéticos e recolhidos. Cada amostra é submetida a corrente de 1,0; 0,8 e 0,7 A. Segue-se a etapa de espalhamento do mineral, onde a fração acima é submetida a corrente de 0,4; 0,5; 0,6 e 0,7 A. O zircão e a monazita são concentrados na fração não magnética.

- Líquidos densos: os minerais pesados coletados na caneca de minerais não magnéticos são separados primeiramente através do bromofórmio. São separados os minerais mais densos do que o bromofórmio $\left(2,89 \mathrm{~g} / \mathrm{cm}^{3}\right)$ e levados ao separador magnético Frantz, e submetidos a corrente de 0,5 A. Posteriormente é realizada a separação da fração não magnética em iodeto de metileno $\left(3,32 \mathrm{~g} / \mathrm{cm}^{3}\right)$ e obtida uma concentração de minerais densos, dentre os quais o zircão $\left(4,7 \mathrm{~g} / \mathrm{cm}^{3}\right)$. A separação 
mineral por líquidos densos em duas amostras foi realizada no Isotope Geochemistry Laboratory (IGL), Universidade do Kansas (EUA).

\subsubsection{Catação manual e confecção dos mounts}

A partir do concentrado de minerais pesados foi realizada a catação manual dos cristais de zircão em lupa binocular no Isotope Geochemistry Laboratory (IGL), Universidade do Kansas (EUA), utilizando uma agulha fina ou uma pinça. Para a confecção das pastilhas de resina (mounts), os cristais selecionados foram dispostos em uma fita adesiva e impregnados com resina Epoxy, e posteriormente polidos manualmente até expor o núcleo dos grãos. Os mounts foram confeccionados no Departamento de Geologia da Universidade do Kansas (EUA).

\subsubsection{Imageamento dos mounts por CL (catodoluminescência)}

As estruturas internas dos grãos de zircão foram identificadas através de imagens de catodoluminescência (CL), realizadas no Microscope and Analytical Imaging Laboratory (MAI), na Universidade do Kansas (EUA). As imagens SEM (scanning electron microscope) foram obtidas através de um microscópio eletrônico de varredura FEI Versa 3D Dual Beam, utilizando o modo com baixo vácuo.

\subsubsection{Datação U-Pb em zircão através de LA-ICP-MS}

As datações U-Pb in-situ em zircão foram realizadas em onze amostras no Isotope Geochemistry Laboratory (IGL), na Universidade do Kansas (EUA), utilizando um ICP-MS ThermoScientific Element2 acoplado a um sistema de ablação a laser ArF Excimer, Photo-Machine

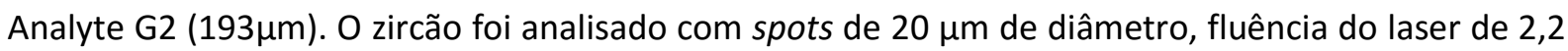
$\mathrm{J} / \mathrm{cm}^{-2}$ com taxa de repetição de $10 \mathrm{~Hz}$. Análises sistemáticas do material de referência primário GJ1 (Jackson et al., 2004) foram utilizadas para correções de fracionamento elemental, fracionamento downhole e calibração. A redução dos dados foi realizada através do VizualAge (Petrus and Kamber, 2012) utilizando o software IOLITE (Paton et al., 2011). O padrão secundário Plešovice (Sláma et al.,

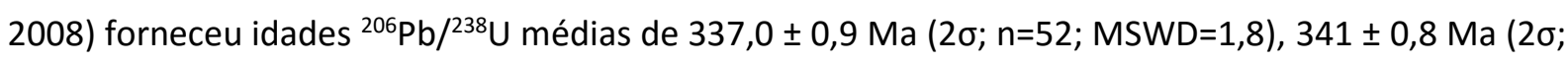
$n=26 ; M S W D=1,3)$ e 338,8 $\pm 0,9 M a(2 \sigma ; n=26 ; M S W D=1,1)$ durante as análises, dentro da margem de erro de $1 \%$ quando comparadas com o dado obtido por ID-TIMS (337,13 $\pm 0,37 \mathrm{Ma}$; Sláma et al., 2008). O programa Isoplot (Ludwig, 2003) foi utilizado para o cálculo das idades concordia e diagramas concordia. A relação das amostras selecionadas para análises U-Pb em zircão encontra-se na Tabela 1. Os resultados analíticos de U-Pb estão apresentados no ANEXO VIII. 


\subsection{Geocronologia U-Th-Pb e geoquímica de elementos-traço em monazita através de microssonda eletrônica (EPMA)}

As datações $\mathrm{U}-\mathrm{Th}-\mathrm{Pb}$ e análises de elementos-traço em monazita foram realizadas em cinco amostras na Universidade de Massachusetts, EUA (University of Massachusetts-Amherst Electron Microprobe Facility), seguindo os procedimentos analíticos de Williams et al., (2006), Jercinovic et al., (2008) e Dumond et al., (2008), com uma correção adicional de interferência de $N d L \alpha_{3}$ e $\operatorname{Pr} L \beta_{2.15}$ em EuL $\alpha$ que não está descrita nestes trabalhos prévios. Os mapas composicionais de monazita e granada foram obtidos na microssonda eletrônica CAMECA SX-50, utilizando voltagem de 15kV e corrente de 300nA. Análises quantitativas e background scans de monazita foram obtidos na microssonda eletrônica CAMECA SX-100 "UltraChron", utilizando voltagem de 15kV e corrente de 200nA. Este equipamento foi desenvolvido especificamente para geocronologia de monazita, otimizado para análises de elementos-traço com alta precisão (principalmente $\mathrm{U}$, Th e $\mathrm{Pb}$ ) e possui o melhor protocolo analítico atualmente disponível para calibração de monazita.

Mapas composicionais completos de Ce $L \alpha, Y L \alpha, Z r L \alpha, C a K \alpha$ e $M g K \alpha$ das cinco seções delgadas (full thin-section WDS maps) foram obtidos anteriormente às análises para avaliar a distribuição textural de monazita. O zoneamento composicional de monazita foi investigado através de mapas composicionais de $\mathrm{Ca} K \alpha, \mathrm{Nd} L \alpha, U M \beta, Y L \alpha$ e ThM $\alpha$ de alta-resolução, obtidos em vinte e dois grãos de monazita distintos. $\mathrm{O}$ tratamento dos dados analíticos de microssonda eletrônica foi realizado através do software Probe for EPMA v. 10.8.6 (John J. Donovan, 2013). O cálculo das idades e incertezas, bem como a geração de histogramas foi realizado utilizando o software Datconlll (unpublished) do Prof. Michael Williams (Universidade de Massachusetts, EUA). As idades são plotadas como curvas de distribuição Gaussianas, calculadas a partir de um conjunto de cinco a sete análises pontuais que representam a idade e o erro $2 \sigma$ para cada domínio composicional, conforme descrito em Williams et al., (2006) e Dumond et al., (2008). A idade para cada domínio composicional foi calculada a partir das composições médias ponderadas e da equação de idade proposta por Montel et al., (1996). O padrão secundário Moacyr (TIMS ${ }^{208} \mathrm{~Pb} /{ }^{232} \mathrm{Th}=506 \pm 1 \mathrm{Ma} ;{ }^{207} \mathrm{~Pb} /{ }^{235} \mathrm{U}=506 \pm 1 \mathrm{Ma} ;{ }^{206} \mathrm{~Pb} /{ }^{238} \mathrm{U}=515 \pm 1 \mathrm{Ma}$; W.J. Davis, Serviço Geológico do Canadá; comunicação pessoal) foi analisado antes e depois de cada sessão analítica, e forneceu uma idade média ponderada de $505 \pm 5 \mathrm{Ma}(2 \sigma, n=11$ conjuntos de 5-6 análises pontuais). Os resultados analíticos de geocronologia U-Th- $\mathrm{Pb}$, elementos-traço e idades calculadas de monazita estão apresentados no ANEXO IX.

\subsection{Referências bibliográficas}

Alexandre, E.L. 2013. Caracterização dos granulitos e migmatitos da região de Alfenas, MG. Dissertação de Mestrado, IGc-USP: 151pp.

De Paolo, D.J., 1981. Neodymium isotopes in the Colorado Front Range and crust-mantle evolution in the Proterozoic. Nature 291, 193-196. 
Dumond, G., McLean, N., Williams, M.L., Jercinovic, M.J., Bowring, S.A., 2008. High-resolution dating of granite petrogenesis and deformation in a lower crustal shear zone: Athabasca granulite terrane, western Canadian Shield. Chemical Geology 254, 175-196.

Eckert, J.O.Jr., Newton, R.C., Kleppa, O. J., 1991. The $\Delta \mathrm{H}$ of reaction and recalibration of garnetpyroxene-plagioclase-quartz geobarometers in the CMAS system by solution calorimetry. American Mineralogist 76, 148-160.

Harley, S.L., Kelly, N.M., 2007. The impact of zircon-garnet REE distribution data on the interpretation of zircon $\mathrm{U}-\mathrm{Pb}$ ages in complex high-grade terrains: an example from the Rauer Islands, East Antarctica. Chemical Geology 241, 62-87.

Harley, S.L., Kelly, N.M., Möller, A., 2007. Zircon behaviour and the thermal histories of mountain chains. Elements 3, 25-30.

Jackson, S.E., Pearson, N.J., Griffin, W.L., Belousova, E.A., 2004. The application of laser ablationinductively coupled plasma-mass spectrometry to in-situ U-Pb zircon geochronology. Chemical Geology 211, 47-69.

Jercinovic, M.J., Williams, M.L., Lane, E.D., 2008. In situ trace element analysis in complex, multi-phase materials by EMPA. Chemical Geology 254, 197-215.

Ludwig, K.R., 2003. User's Manual for Isoplot 3.00, A Geochronological Toolkit for Microsoft Excel. Berkeley Geochronology Center Special Publication 4.

Mahan, K.H., Goncalves, P., Williams, M.L., Jercinovic, M.J., 2006. Dating metamorphic reactions and fluid flow: application to exhumation of high-P granulites in a crustal-scale shear zone, western Canadian Shield. Journal of Metamorphic Geology 24, 193-217.

Montel, J.-M., Foret, S., Veschambre, M., Nicollet, C., Provost, A., 1996. Electron microprobe dating of monazite. Chemical Geology 131 (1-4), 37-53.

Moraes, R., Brown, M., Fuck, R.A., Camargo, M.A. \& Lima, T.M. 2002. Characterization and P-T evolution of melt-bearing ultrahigh-temperature granulites: an example from the AnápolisItauçu Complex of the Brasília fold belt, Brazil. Journal of Petrology 43, 1673-1705.

Navarro, M.S., Andrade, S., Ulbrich, H., Gomes, C.B., Girardi, V.A.A., 2008. The Direct Determination of Rare Earth Elements in Basaltic and Related Rocks using ICP-MS: Testing the Efficiency of Microwave Oven Sample Decomposition Procedures. Geostandards and Geoanalytical Research $32(2), 167-180$

Navarro, M.S., Ulbrich, H.H.G.J., Andrade, S., Janasi, V.A., 2002. An adaptation of ICP-OES routine determination techniques for the analysis of rare-earth elements by chromatographic separation in geologic materials: test with reference material and granitic rock. Journal of Alloys and Compounds 344, 40-45.

Newton, R.C., Perkins III, D., 1982. Thermodynamic calibration of geobarometers based on the assemblages garnet-plagioclase-orthopyroxene(clinopyroxene)-quartz. American Mineralogist 
67, 203-222.

Pattison, D.R.M., Chacko, T., Farquhar, J., McFarlane, C.R.M., 2003. Temperatures of granulite-facies metamorphism: constraints from experimental phase equilibria and thermobarometry for retrograde exchange. Journal of Petrology 44(5), 867-900.

Paton, C., Hellstrom, J., Paul, B., Woodhead, J., Hergt, J., 2011. Iolite: Freeware for the visualization and processing of mass spectrometry data. Journal of Analytical Atomic Spectrometry 26, 25082518. Geostandards and Geoanalytical Research 21 (1), 115-144.

Perkins III, D., Chipera, S.J., 1985. Garnet-orthopyroxene-plagioclase-quartz barometry: refinement and application to the English River subprovince and the Minnesota River valley. Contributions to Mineralogy and Petrology 89(1), 69-80.

Petrus, J.A., Kamber, B.S., 2012. VizualAge: A Novel Approach to Laser Ablation ICP-MS U-Pb Geochronology Data Reduction. Geostandards and Geoanalytical Research 36, 247-270.

Rubatto, D., 2002. Zircon trace element geochemistry: partitioning with garnet and the link between U-Pb ages and metamorphism. Chemical Geology 184, 123-138.

Sato, K., Tassinari, C.C.G., Kawashita, K., Petronilho, L., 1995. O método geocronológico Sm-Nd no IG/USP e suas aplicações. Anais da Academia Brasileira de Ciências 67, 315-336.

Sláma, J., Košler, J., Condon, D.J., Crowley, J.L., Gerdes, A., Hanchar, J.M., Horstwood, S.A., Morris, G.A., Nasdala, L., Norberg, N., Schaltegger, U., Schoene, B., Tubrett, M.N., Whitehouse, M.J., 2008. Plešovice zircon - A new natural reference material for $\mathrm{U}-\mathrm{Pb}$ and $\mathrm{Hf}$ isotopic microanalysis. Chemical Geology 249, 1-35.

Souza, A.M., 2014. Fusão, geração e preservação de rochas da fácies granulito. Dissertação de Mestrado, IGc-USP: 134 pp.

Souza, S.L., 2009. Métodos radiométricos Rb-Sr e Sm-Nd no CPGeo IGc-USP. In: Simpósio 45 anos de Geocronologia no Brasil, 2009, São Paulo. Boletim de Resumos Expandidos, 347-349.

Tanaka, T., Togashi, S., Kamioka, H., Amakura, H., Kagami, H., Hamamoto, T., Yuhara, M., Orihashi, Y., Yoneda, S., Shimizu, H., Kunimaru, T., Takahashi, K., Yanagi, T., Nakano, T., Fujimaki, H., Shinjo, R., Asahara, Y., Tanimizu, M., Dragasanu, C., 2000. JNdi-1: a neodymium isotopic reference in consistency with La Jolla Neodymium. Chemical Geology 168(3-4), 279-281.

Watson, E.B., Wark, D.A., Thomas, J.B., 2006. Crystallization thermometers for zircon and rutile. Contributions to Mineralogy and Petrology 151, 413-433.

White, R. W. \& Powell, R. 2002. Melt loss and the preservation of granulite facies mineral assemblages. Journal of metamorphic Geology 20, 621-632.

Williams, M.L., Jercinovic, M.J., Goncalves, P., Mahan, K., 2006. Format and philosophy for collecting, compiling, and reporting microprobe monazite ages. Chemical Geology 225, 1-15. 


\section{Unidade Metatexítica da Nappe Socorro-Guaxupé}

Neste capítulo é apresentada uma integração dos aspectos texturais dos litotipos da Unidade Metatexítica com novos dados de termobarometria, geoquímica de elementos-traço em fases metamórficas principais e acessórias e geocronologia U-Pb em zircão e U-Th-Pb em monazita em forma de artigo (ANEXO I). O artigo intitulado "Timing of anatexis and melt crystallization in the SocorroGuaxupé Nappe, SE Brazil: Insights from trace element composition of zircon, monazite and garnet coupled to U-Pb geochronology" encontra-se aceito para publicação (in press) no periódico Lithos e sua leitura é fundamental para o entendimento desta tese.

\subsection{Resumo}

A evolução temporal dos eventos de fusão parcial e cristalização de fundido nas rochas de fácies granulito da Nappe Socorro-Guaxupé (NSG), Brasil, é acessada através de uma combinação de técnicas de imageamento, datação por LA-ICP-MS e microssonda eletrônica (EPMA), geoquímica de elementos-traço e geotermobarometria. Migmatitos com granada e ortopiroxênio registram extensa fusão parcial envolvendo quebra de biotita, ao longo de uma trajetória $P$ - $T$-t horária. As condições de pico do metamorfismo de temperatura ultra-alta são registradas a $1030 \pm 110^{\circ} \mathrm{C}, 11.7 \pm 1.4 \mathrm{kbar}$, com re-equilíbrio a $865 \pm 38{ }^{\circ} \mathrm{C}, 8,9 \pm 0,8$ kbar durante o resfriamento. Herança ígnea Criogeniana de ca. 720-640 Ma é identificada em núcleos de zircão ( $n=167)$ ricos em ETRP e com zoneamento oscilatório. Núcleos de monazita ricos em Y parcialmente dissolvidos preservam um estágio de crescimento progressivo a $631 \pm 4 \mathrm{Ma}$, anterior ao evento de fusão parcial, o que define um limite de idade para o início do metamorfismo de fácies granulito na Nappe Socorro-Guaxupé. Monazita rica em ETR e pobre em Th, relacionada com a apatita registra as fases iniciais de descompressão a ca. $628 \pm 4$ Ma. Múltiplos episódios de crescimento de monazita registram eventos de cristalização de fundido em $624 \pm 3 \mathrm{Ma}$, $612 \pm 5$ Ma e $608 \pm 6$ Ma. Cristais de zircão isométricos do tipo soccer ball fornecem evidência de cristalização de fundido em $613 \pm 2 \mathrm{Ma}$ e $607 \pm 4 \mathrm{Ma}$. O espalhamento dos dados de idades de zircão e monazita entre $629 \pm 4$ e $601 \pm 3 \mathrm{Ma}$ é interpretado como crescimento descontínuo e episódico dentro deste intervalo, caracterizando um evento metamórfico prolongado na Nappe Socorro-Guaxupé com duração de ca. 30 m.y. O desenvolvimento de bordas de monazita ricas em Y e ETRP em ca. $600 \mathrm{Ma}$ marca o consumo parcial de granada, crescimento extenso de biotita e os estágios finais de cristalização de fundido ao longo da trajetória retrometamórfica. Bordas de monazita ricas em Th e pobres em Y e ETRP em ca. 590 Ma registram recristalização tardia promovida pela infiltração de fluidos. 


\section{Unidade Granulítica da Nappe Socorro-Guaxupé}

Este capítulo consiste de um estudo petrológico e geocronológico integrado dos litotipos da Unidade Granulítica da Nappe Socorro-Guaxupé, onde são apresentados novos dados de química mineral, termobarometria, geoquímica de rocha-total, isótopos de $\mathrm{Sr}-\mathrm{Nd}$, geoquímica de elementostraço e geocronologia U-Pb em zircão. Este capítulo é apresentado sob a forma de artigo (ANEXO II), intitulado "Age and duration of pre-collisional arc magmatism and UHT metamorphism in the SocorroGuaxupé Nappe (SE Brazil) constrained by in-situ charnockite melts and related rocks", que será submetido em breve para o periódico Precambrian Research e sua leitura é indispensável para a compreensão desta tese.

\subsection{Resumo}

A Nappe Socorro-Guaxupé (NSG) representa um arco magmático intensamente erodido que registra a colisão Ediacarana entre a Placa Paranapanema e o paleocontinente São Francisco, relacionada com a aglutinação do Gondwana Ocidental. A NSG expõe uma seção espessa (ca. $10 \mathrm{~km}$ ) de crosta inferior, composta dominantemente por granulitos e migmatitos. O magmatismo sincolisional é registrado por intrusões de charnockitos e granitos cálcio-alcalinos de alto-K por toda a nappe. Um estudo petrológico e geocronológico integrado dos leucossomas com ortopiroxênio e com hornblenda e dos granulitos hospedeiros da Unidade Granulítica é apresentado, a fim de determinar a idade e duração do magmatismo de arco pré-colisional e do metamorfismo de temperatura ultraalta na NSG. Novas idades U-Pb de zircão obtidas por LA-ICP-MS são combinadas com geoquímica de elementos-traço em zircão para discriminar com maior confiança zircões herdados de zircões nãoherdados. Idades de cristalização ígneas dos granulitos félsicos e granada granulitos se situam entre ca. 730-640 Ma, e são equivalentes àquelas obtidas em xenocristais de zircão herdados no leucossoma com ortopiroxênio e com hornblenda. Este intervalo de idade é interpretado como sendo o período de magmatismo de arco pré-colisional, com duração de pelo menos 90 m.y. As idades concordia de $c a$. 655-650 Ma obtidas nos granulitos félsicos e granada granulitos refletem o principal período de magmatismo de arco pré-colisional. A NSG evoluiu a partir de um ambiente de subducção para um ambiente colisional, envolvendo a formação de fundidos charnockíticos e leucossomas com hornblenda in-situ a ca. 630-625 Ma durante o metamorfismo sin-colisional de temperatura ultra-alta. As condições de pico metamórfico de temperatura ultra-alta foram atingidas a ca. $900{ }^{\circ} \mathrm{C}, 12 \mathrm{kbar}$, através da fusão parcial de granulitos félsicos. Magmas básicos (mafic underplating) poderiam ter atuado como importante fonte de calor adicional durante o metamorfismo de temperatura ultra-alta, dada a ocorrência de rochas máficas intrusivas sin-metamórficas nas proximidades dos leucossomas charnockítico (com ortopiroxênio) e com hornblenda. Padrões de ETR contrastantes nos leucossomas fornecem evidência para a presença de fundidos fracionados (maior abundância de ETR e anomalia negativa de Eu) e cumulatos (menor abundância de ETR e anomalia positiva de Eu). As rochas 
estudadas apresentam evidência isotópica de participação de fontes mantélicas enriquecidas em sua origem, pois retrabalhamento crustal envolvendo crostas arqueanas ou paleoproterozóicas mais antigas não foram reconhecidas até o presente momento. 


\section{Discussão}

\subsection{Evolução temporal dos eventos de fusão parcial e cristalização de fundido na Nappe Socorro- Guaxupé}

A Nappe Socorro-Guaxupé representa um domínio de arco magmático Neoproterozóico intensamente erodido que expõe aproximadamente $10 \mathrm{~km}$ de crosta inferior (Campos Neto \& Caby, 1999, 2000), fornecendo condições excelentes para o estudo dos processos de fusão parcial em crosta continental profunda. Os dados apresentados nesta tese permitiram uma compreensão mais detalhada dos processos de fusão parcial e cristalização de fundido na Nappe Socorro-Guaxupé, baseado na integração de técnicas de datação in-situ de zircão e monazita, análise textural detalhada, geotermobarometria e geoquímica de elementos-traço nas fases acessórias datadas e fases metamórficas principais. A conexão de episódios distintos de crescimento e/ou alteração de zircão e monazita com reações metamórficas específicas permite a reconstrução de trajetórias P-T-t, e se tornou o grande foco em estudos petrológicos modernos (e.g. Rubatto et al., 2001; Taylor et al., 2014; Yakymchuk \& Brown, 2014; Kirkland et al., 2016).

O crescimento de zircão ocorre preferencialmente durante o resfriamento de fundido ao longo da trajetória retrometamórfica e registra dois episódios principais de cristalização de fundido em ca. 615 Ma e ca. 608 Ma, tanto nos litotipos da Unidade Metatexítica, como da Unidade Granulítica Basal. Migmatitos com protólito sedimentar (Unidade Metatexítica) apresentam monazita em abundância e em diversos contextos texturais. A monazita ocorre preservada como inclusões na granada, ao redor de grãos de apatita, com inclusões de zircão, sobrecrescendo cristais de zircão ou na forma de cristais euédricos grossos na matriz com feldspato e biotita. Cinco episódios distintos de geração de monazita foram identificados e correlacionados com reações metamórficas específicas, baseado na partição de Y e ETRP entre monazita, granada e xenotima (e.g. Foster \& Parrish, 2003; Hermann \& Rubatto, 2003; Spear \& Pyle, 2003; Williams et al., 2007), o que permitiu determinar a evolução temporal completa do metamorfismo progressivo/fusão parcial e metamorfismo retrógrado/cristalização de fundido. 0 pico do metamorfismo de temperatura ultra-alta é registrado por megacristais de granada e ortopiroxênio dentro de leucossoma da Unidade Metatexítica a $1027 \pm 108^{\circ} \mathrm{C}, 11,7 \pm 1,4 \mathrm{kbar}$, com reequilíbrio a $865 \pm 38^{\circ} \mathrm{C}, 8,9 \pm 0,8 \mathrm{kbar}$ durante o resfriamento. A associação granada + ortopiroxênio aluminoso permitiu a determinação das condições de pico utilizando o método de recuperação de composição de Pattison et al., (2003).

A monazita do domínio 1 é caracterizada por núcleos ricos em Y e ETRP preservados como inclusões na granada. A dissolução parcial destes núcleos marca o aparecimento de granada peritética e fundido a ca. $631 \pm 4 \mathrm{Ma}$ através da incorporação de $\mathrm{Y}$ na granada e crescimento de monazita rica em Th e pobre em $\mathrm{Y}$, conforme descrito na seguinte reação: (3) $\mathrm{Bt}_{1}+\mathrm{Pl}_{1}+\mathrm{Qtz}+\mathrm{Mnz}_{\text {Dominio } 1}$ (rica em $\mathrm{Y}$, $\mathrm{ETRP}) \rightarrow \mathrm{Grt} \pm \mathrm{Opx}+\mathrm{Kfs}+$ fundido $+\mathrm{Mnz}_{\text {Domínio } 3}$ (rica em Th, pobre em Y e ETRP). A monazita do domínio 
2 ocorre na forma de grãos pequenos ao redor de apatita, e registra os estágios iniciais de descompressão a ca. $628 \pm 4 \mathrm{Ma}$.

A diminuição nos conteúdos de Y e ETRP acompanhada de incorporação de Th na monazita, reflete o crescimento de granada na presença de fundido (e.g. Bea \& Montero, 1999; Mahan et al. 2006; McFarlane \& Frost, 2009; Dumond et al., 2015). A presença de anomalias negativas de európio (e.g. Bea \& Montero, 1999; Rubatto, 2002) e de zoneamento oscilatório de Th na monazita (e.g. Schaltegger et al., 1999; Townsend et al., 2000; Rubatto et al., 2001; Dumond et al., 2015) reforçam a hipótese de crescimento de monazita a partir de fundido. Três episódios de cristalização de fundido foram reconhecidos a partir de monazita rica em Th e pobre em Y e ETRP do domínio 3: (1) monazita com zoneamento oscilatório e setorial registra os estágios iniciais de cristalização de fundido a ca. 625 Ma; (2) o principal episódio de geração de monazita a ca. 615 Ma coincide com a cristalização de zircão no mesmo período; (3) o crescimento de monazita euédrica grossa ( $3 \mathrm{~mm})$ rica em Th no leucossoma com granada e ortopiroxênio é sincrônico com a geração de zircão tipo soccer ball em granulitos máficos, e marca os estágios finais de cristalização de fundido a ca. $608 \mathrm{Ma}$. Os picos de idade de ca. 615 e 608 Ma são compatíveis com estudos geocronológicos prévios na Nappe Socorro-Guaxupé (e.g. Basei et al., 1995; Janasi, 1999, 2002; Hackspacher et al., 2004; Martins et al., 2009; Mora et al., 2014, Gengo, 2014) e são interpretados como sendo os principais episódios de crescimento de zircão durante a cristalização de fundido com temperaturas na ordem de $680-790{ }^{\circ} \mathrm{C}$, o que é aqui reforçado pelos dados de termometria de Ti-em-zircão.

A monazita do domínio 4 é caracterizada por bordas ricas em Y e ETRP, que indicam o crescimento localizado de monazita concomitante com o consumo parcial de granada e crescimento abundante de biotita durante o retrometamorfismo em ca. 600-590 Ma. A monazita incorpora Y e ETRP liberados da granada, através da reação: (4) Grt $\pm \mathrm{Opx}+\mathrm{Kfs}+$ fundido $+\mathrm{Mnz}_{\text {Domínio } 3}$ (rica em Th, pobre em Y e ETRP) $\rightarrow \mathrm{Bt}_{2}+\mathrm{Pl}_{2}+\mathrm{Qtz}+\mathrm{Mnz}_{\text {Domínio } 4}$ (rica em Y e ETRP). A monazita do domínio 5 é representada por bordas ricas em Th, que difere da monazita do domínio 3 em seu destacado empobrecimento em ETRP e marca a recristalização de monazita por processos de dissoluçãoreprecipitação (e.g. Williams et al., 2011) na presença de fluidos em ca. $590 \mathrm{Ma}$.

Os dados apresentados nesta tese corroboram com as idades de ca. 630-620 Ma estimadas anteriormente para o metamorfismo de temperatura alta na Nappe Socorro-Guaxupé (Basei et al., 1995; Janasi, 1999, 2002; Campos Neto et al., 2004; Martins et al., 2009; Reno et al., 2009; Mora et al., 2014). O crescimento abundante de zircão e monazita no leucossoma registra um evento prolongado

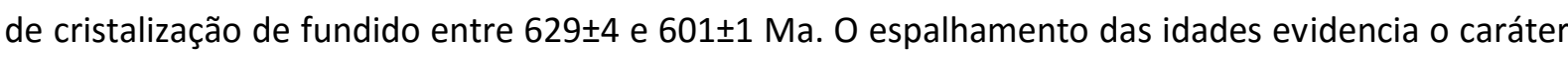
episódico de geração de zircão e monazita, conforme proposto por Rubatto et al., (2013), porém durante um intervalo de tempo indistinguível com a precisão analítica dos métodos utilizados. 


\subsection{Origem dos charnockitos e hornblenda granitos da Unidade Granulítica}

Charnockitos e granitos constituem os principais tipos de rochas ígneas em terrenos granulíticos pré-cambrianos e o estudo de sua formação pode contribuir no entendimento da evolução da crosta continental inferior (e.g. Percival \& Mortensen, 2002; Rajesh, 2004; Frost \& Frost, 2008; Zhao et al., 2014; Klaver et al., 2015). Os veios de leucossoma com ortopiroxênio e hornblenda da Unidade Granulítica Basal da Nappe Socorro-Guaxupé representam o produto da fusão in-situ de granulitos félsicos de composição intermediária. Concentrações de leucossoma ocorrem no contato dos granulitos félsicos com rochas máficas intrusivas sin-metamórficas, sugerindo a atuação de magmas básicos como fonte de calor adicional na geração de leucossoma charnockítico (com ortopiroxênio) durante o metamorfismo de temperatura ultra-alta, conforme proposto na literatura (e.g. Wells, 1980; Harley, 1989, 1992). No entanto, não se pode descartar a possibilidade de participação de outras fontes de calor adicionais, tendo em vista que a ocorrência de rochas máficas sin-intrusivas não é bastante expressiva na área de estudo.

Os veios de leucossoma com ortopiroxênio e hornblenda estudados são magnesianos, metaluminosos, alcalinos a cálcio-alcalinos e se situam no limite entre os campos de granito de arco vulcânico e granitos sin-colisionais de Pearce et al., (1984). Duas assinaturas contrastantes de elementos-traço foram reconhecidas nos veios de leucossoma com ortopiroxênio e hornblenda: (1) conteúdos elevados de ETR, fracionamento moderado em ETR $\left((\mathrm{La} / \mathrm{Yb})_{\mathrm{N}}=16\right)$, e anomalias negativas de Eu pouco pronunciadas $\left(E u / E u^{*}=0,2\right)$; (2) conteúdos baixos de ETR, padrões mais fracionados $\left((\mathrm{La} / \mathrm{Yb})_{N}=75\right)$ e forte anomalias positivas de Eu $\left(E u / E u^{*}=8\right)$. Segundo Sawyer $(1987)$, essas assinaturas são indicativas de magmas mais fracionados e de cumulatos, respectivamente. Os veios de leucossoma com ortopiroxênio e hornblenda com padrões de ETR semelhantes às de cumulatos, envolvem completamente blocos de granada granulito e de granulito félsico. Desta forma, não pode ser descartada a hipótese de interação local entre leucossomas e granulitos através de processos de dissolução, mistura e/ou assimilação (e.g. Klaver et al., 2015). Os veios de leucossoma com ortopiroxênio e hornblenda apresentam um padrão geoquímico análogo à média crustal (Rudnick \& Fountain, 1995; Wedepohl, 1995) e exibem assinaturas típicas de arco continental, caracterizadas por enriquecimento em ETRL e presença de anomalias negativas de $\mathrm{Nb}$ e Ti, em semelhança à outras áreas (e.g. Percival \& Mortensen, 2002). Essa assinatura geoquímica enriquecida em potássio e elementos incompatíveis é comparável à de outros charnockitos magnesianos cálcio-alcalinos (e.g. Zhao et al., 1997) e reflete fontes relativamente férteis, porém anidras (e.g. Klaver et al., 2015). Os granulitos félsicos apresentam conteúdos mais elevados de $\mathrm{K}_{2} \mathrm{O}, \mathrm{TiO}_{2}, \mathrm{P}_{2} \mathrm{O}_{5}, \mathrm{Ba}$, $\mathrm{Zr}$ e ETR do que a média crustal e são ligeiramente mais empobrecidos em elementos móveis (e.g. Th, $U, R b$ ), e possivelmente representam a fonte. Os granulitos máficos apresentam fracionamento moderado de ETR, ausência de anomalia de Eu, e anomalia de $\mathrm{Nb}$ bem pronunciada, com assinaturas geoquímicas semelhantes às de arcos de ilhas modernos (e.g. Korsch et al., 2011). 
O contato entre os veios de leucossoma com ortopiroxênio e hornblenda é geralmente transicional e localmente foi observada a ocorrência de relíquias de ortopiroxênio preservadas em megacristais de hornblenda, o que sugere a atuação de processos de fracionamento de água para o magma residual, com a destruição de ortopiroxênio seguida de cristalização de hornblenda em composições mais evoluídas (e.g. Percival \& Mortensen, 2002). Ambos apresentam assinaturas geoquímicas semelhantes e idades de cristalização idênticas ( $c a .615 \mathrm{Ma}$ ). A combinação de evidências texturais, geoquímicas e geocronológicas sugere uma relação genética entre os veios de leucossoma com ortopiroxênio e hornblenda, onde a cristalização fracionada constitui um importante processo na formação de leucossomas de composições variadas na Unidade Granulítica, mesmo em pequena escala (veios e pequenos bolsões de leucossoma). Desta forma, durante a sequência de cristalização, o leucossoma com ortopiroxênio cristaliza precocemente. Com o processo de cristalização fracionada, o magma residual é enriquecido em água, favorecendo a cristalização de hornblenda posterior. Os granitos hololeucocráticos finos representam as fases mais residuais e ricas em água, o que é compatível com a cristalização de fases mais hidratadas (e.g. actinolita, biotita e clorita). As assinaturas geoquímicas e idades obtidas nos leucossomas com ortopiroxênio e hornblenda se assemelham àquelas dos charnockitos e hornblenda granitos das suítes São Pedro de Caldas e Divinolândia (Janasi, 2002), os equivalentes plutônicos regionais que caracterizam o magmatismo sin-colisional da Nappe Socorro-Guaxupé (Janasi, 1999, 2002; Mora et al., 2014).

\subsection{Idade do magmatismo de arco pré-colisional}

A idade do magmatismo de arco foi determinada através da datação de uma população grande ( $n=363$ ) de núcleos de xenocristais de zircão herdados nos litotipos de protólito sedimentar (Unidade Metatexítica), nos leucossomas com ortopiroxênio e hornblenda, bem como dos zircões provenientes dos protólitos ígneos granulíticos (Unidade Granulítica). A integração de geocronologia U-Pb com padrões de elementos-traço em zircão foi utilizada para discriminar zircões herdados de zircões nãoherdados com maior confiança, o que permitiu uma distinção clara dos eventos magmáticos précolisionais e sin-colisionais na Nappe Socorro-Guaxupé.

Zircões com zoneamento oscilatório nos granulitos félsicos (amostras A1,5B1) e granada granulito (amostra 6B1) da Unidade Granulítica Basal forneceram idades entre ca. 730-640 Ma, interpretadas como idades de cristalização dos protólitos ígneos. Idades concordia de ca. 655-650 Ma obtidas nestes litotipos caracterizam o principal período de magmatismo de arco pré-colisional em ca. 655-650 Ma. Núcleos de xenocristais de zircão herdados nos veios de leucossoma com ortopiroxênio e hornblenda (amostras A2 e C1, respectivamente) registram idades de ca. 705-640 Ma, dentro do mesmo intervalo de idades dos granulitos, embora xenocristais de zircão sejam mais abundantes no leucossoma com hornblenda. Xenocristais herdados de zircão são bastante comuns em rochas 
graníticas, visto que magmas de baixa temperatura saturados em $\mathrm{Zr}$ são incapazes de dissolver completamente os grãos de zircão herdados (e.g. Miller et al., 2003). A comparação de idades obtidas a partir dos leucossomas e rochas hospedeiras também permite a identificação de herança uma vez que que as rochas hospedeiras sejam a fonte provável dos zircões herdados (e.g. Crowley et al., 2008). Os migmatitos da Unidade Metatexítica preservam padrões de herança de ca. 800-640 Ma idênticos. Este intervalo de idades também foi reconhecido em outras partes da Nappe Socorro-Guaxupé (e.g. Janasi, 1999, 2002; Negri, 2002; Hackspacher et al., 2003; Martins et al., 2009; Mora et al., 2014; Gengo, 2014). Portanto, as evidências de campo combinadas com os novos dados de elementos-traço e U-Pb em zircão desta tese indicam que o magmatismo de arco pré-colisional ocorreu entre ca. 730640 Ma com duração de pelo menos 90 m.y., e que este magmatismo foi mais expressivo em ca. 655$650 \mathrm{Ma}$.

\subsection{Implicações tectônicas e regionais}

A idade do pico metamórfico e resfriamento no sul do Orógeno Brasília tem sido amplamente debatida ao longo dos últimos 20 anos (e.g. Janasi, 2002; Hackspacher et al., 2004; Martins et al., 2009; Reno et al., 2009; Campos Neto et al., 2010, 2011; Mora et al., 2014). Segundo Campos Neto et al., $(2010,2011)$ as idades mais antigas estão registradas nas partes externas do sistema de nappes (ca. 630-620 Ma na Nappe Socorro-Guaxupé), gradando progressivamente para idades mais novas em direção ao domínio cratônico (ca. 620-605 Ma no Sistema de Nappes Andrelândia; ca. 590 Ma nos sistemas de nappes Carrancas e Lima Duarte), e interpretou este padrão como migração da frente de deformação e metamorfismo. No entanto, os dados obtidos nesta tese indicam que os estágios finais de cristalização de fundido ocorrem em ca. $600 \mathrm{Ma}$, o que demonstra que o metamorfismo de temperatura ultra-alta na Nappe Socorro-Guaxupé foi um evento de longa duração, e que deve se estender por todo o Orógeno Brasília. A intrusão dos sienitos potássicos pós-colisionais Pedra Branca (Carvalho \& Janasi, 2012) e Capituva marca o último evento magmático conhecido na Nappe SocorroGuaxupé (e.g. Janasi, 1999, 2002; Campos Neto et al., 2004), com idade de ca. 612 Ma (Töpfner, 1996). Porém os dados obtidos neste trabalho demonstram que a idade de $612 \pm 3$ Ma obtida por Töpfner (1996) para o sienito Pedra Branca necessita ser revista, uma vez que este representa um período expressivo de cristalização de fundido na Nappe Socorro-Guaxupé, e que o magmatismo pós-colisional é registrado em ca. 590-580 Ma e representado por rochas da Província Granítica Itú (Janasi et al., 2009).

Uma evolução metamórfica distinta para o Orógeno Brasília foi proposta recentemente por Reno et al. (2009). Estes autores afirmam que o pico do metamorfismo poderia ter começado em torno de ca. $680 \mathrm{Ma}$, baseado em idade U-Pb SIMS de um retro-eclogito da Nappe Andrelândia. Uma idade U-Pb SIMS de ca. 622 Ma foi obtida para um granulito da base da Nappe Socorro-Guaxupé, e 
interpretada como sendo a idade de resfriamento de um fundido enriquecido em ETRP pós-pico metamórfico. No entanto esta interpretação é baseada em um conjunto de dados relativamente pequeno, pois a idade concordia de ca. $622 \mathrm{Ma}$ é resultante de sete dados com espalhamento entre ca. 666-590 Ma, o que não caracteriza uma população estatisticamente consistente. Zircões da amostra 04-7-1 (Reno et al., 2009) possui núcleos com zoneamento oscilatório e padrões de ETR bastante fracionados $\left(\mathrm{Yb}_{N} / G d_{N}=14-34\right)$, sobrecrescidos por bordas finas e com alta resposta de catodoluminescência, o que dificulta a obtenção de idades confiáveis relacionadas ao evento metamórfica. Desta forma, as idades obtidas por Reno et al. (2009) provavelmente representam misturas de idades de núcleos de zircões herdados com zoneamento oscilatório de idades em torno de $c a$. 670-640 Ma e bordas metamórficas mais novas do que ca. $630 \mathrm{Ma}$. Idades ainda mais antigas de 800 Ma obtidas por Reno et al. (2009) deve estar associadas ao estágio de subduç̧ão e aparentemente são equivalentes às idades de herança determinadas por Negri (2002) e Martins et al. (2009).

Os dados geocronológicos obtidos nesta tese confirmam a presença de heranças de zircão com idades entre ca. 730-640 Ma através da datação de uma população grande $(n=363)$ de núcleos de zircões herdados com zoneamento oscilatório com padrão de ETR fracionado, típico de zircões magmáticos, além de zircões do protólito ígneo granulítico, o que caracteriza este período como magmatismo de arco pré-colisional. A monazita registra idades progressivas de ca. $631 \pm 4 \mathrm{Ma}$ anteriores ao evento de fusão parcial, definindo assim um limite máximo de idade para o metamorfismo de fácies granulito na Nappe Socorro-Guaxupé. Monazita relacionada com a apatita registra as fases iniciais de descompressão a ca. $628 \pm 4 \mathrm{Ma}$, seguido por fusão envolvendo quebra de biotita, com a geração de granada e ortopiroxênio peritéticos em $1027 \pm 108^{\circ} \mathrm{C}, 11,7 \pm 1,4 \mathrm{kbar}$. Desta forma, a idade do pico metamórfico de temperatura ultra-alta é estabelecida em ca. 630-625 Ma. Estes dados corroboram com as estimativas anteriores para a idade de metamorfismo de alta temperatura em ca. 630-620 Ma (Basei et al, 1995; Janasi, 1999, 2002; Martins et al, 2009; Reno et al, 2009; Mora et al, 2014). O crescimento abundante de zircão e monazita registra um evento de cristalização de fundido prolongado entre $629 \pm 4$ e $601 \pm 1 \mathrm{Ma}$. O espalhamento dos dados sugere o crescimento de zircão e monazita em qualquer momento dentro deste intervalo, porém principalmente entre ca.625$605 \mathrm{Ma}$. Os estágios finais de cristalização de fundido são consistentes com o desenvolvimento de bordas de monazita ricas em Y e ETRP em ca. $600 \mathrm{Ma}$, concomitante com o consumo parcial de granada e crescimento extenso de biotita ao longo da trajetória retrometamórfica. Recristalização tardia promovida pela infiltração de fluidos é registrada em bordas de monazita ricas em Th em ca. 590 Ma.

A sobreposição de idades obtidas para episódios distintos de crescimento de monazita na Nappe Socorro-Guaxupé pode ser atribuída às incertezas inerentes ao método de datação por microssonda eletrônica. Neste método, assume-se que praticamente todo o $\mathrm{Pb}$ analisado é thorogênico $\left({ }^{208} \mathrm{~Pb}\right)$, que quantidades de $\mathrm{Pb}$ comum $\left({ }^{204} \mathrm{~Pb}\right)$ são desprezíveis, e que os isótopos de $\mathrm{U}$ 
$\left({ }^{206} \mathrm{~Pb},{ }^{207} \mathrm{~Pb}\right)$ estão presentes em abundâncias crustais (Montel et al., 1996; Williams et al., 2006, 2007). No entanto, o método de datação por microssonda eletrônica não fornece informações relativas à discordância de idades, presença de $\mathrm{Pb}$ comum ou excesso de ${ }^{206} \mathrm{~Pb}$, o que poderia afetar a interpretação correta das idades. Embora a espectrometria de massa de diluição isotópica e ionização termal (ID-TIMS) seja reconhecida como um importante método analítico com alta precisão e acurácia (incertezas <0,2\%; e.g. Schoene et al., 2013), a complexidade nos padrões de zoneamento químico identificados na monazita impõe limitações claras a este método, e a obtenção de idades de mistura é um problema comum em datação de monazita por ID-TIMS. Uma distinção mais precisa de múltiplos episódios de crescimento de monazita na Nappe Socorro-Guaxupé e em outros orógenos précambrianos exige alta precisão e alta resolução espacial. No entanto, não é possível solucionar algumas questões em monazita com padrão de zoneamento complexo se a variação de idade é menor do que a precisão do método analítico utilizado. Desta forma, novos avanços analíticos são necessários para desvendar por completo histórias prolongadas em orógenos pré-cambrianos.

Para alguns autores (e.g. Campos Neto et al., 2011) a Nappe Socorro-Guaxupé poderia representar a extensão sul do Arco Magmático de Goiás (Pimentel \& Fuck, 1992; Pimentel et al., 2000; Laux et al., 2004). No entanto, rochas juvenis não foram reconhecidas na Nappe Socorro-Guaxupé até o momento (Campos Neto et al., 2011), e valores de $\varepsilon N d_{(t)}$ negativos são frequentes em vários litotipos da Nappe Socorro-Guaxupé (e.g. Janasi, 1999, 2002; Campos Neto et al., 2004; Janasi et al., 2009; Mora et al., 2014; Vinagre et al., 2014). Idades-modelo ( $\left.\mathrm{Nd}_{\mathrm{TDM}}\right)$ apresentam valores entre 1,6 a 1,8 $\mathrm{Ga}$, compatíveis com as idades-modelo mais novas do subdomínio Alfenas quando comparadas ao subdomínio Machado ( $\mathrm{Nd}_{\mathrm{TDM}}>2,0 \mathrm{Ga}$ ) (Janasi, 2002), e sugerem a fusão de uma crosta granulítica fértil. Uma maneira de explicar as assinaturas pouco radiogênicas de $\mathrm{Nd}$ na Nappe Socorro-Guaxupé seria através de contaminação e/ou assimilação de um componente crustal mais antigo, como constatado em rochas do Cráton Kaapvaal (e.g. Schoene et al., 2009). Ortognaisses arqueanos e paleoproterozóicos do embasamento do Orógeno Brasília (Fetter et al., 2001; Cioffi et al., 2016) afloram em uma grande janela tectônica (15-75 km de largura), dividindo os dois domínios da Nappe Socorro-Guaxupé. A existência de uma crosta antiga sotoposta pela Nappe Socorro-Guaxupé poderia representar a fonte provável de contaminação. No entanto, nenhuma herança arqueana ou paleoproterozóica foi reconhecida nos zircões herdados tanto neste trabalho, como em todos os estudos geocronológicos in-situ disponíveis na literatura (e.g. (Mora et al., 2014; Gengo, 2014). A presença abundante de xenocristais de zircão herdados com idades entre ca. 730-640 Ma nos leucossomas demonstra que não houve dissolução completa de zircão no magma, mesmo em magmas charnockíticos de temperatura ultra-alta. Portanto, é bastante improvável que processos de contaminação-assimilação sejam responsáveis pelas assinaturas isotópicas de Nd menos radiogênicas identificadas neste trabalho. Uma alternativa mais viável seria que estas assinaturas resultem de misturas entre componentes crustais e manto litosférico enriquecido (e.g. Hagen-Peter et al., 2015). 
Conforme proposto recentemente por Carvalho et al., (2014), o avanço e colocação final da Nappe Socorro-Guaxupé é posterior à geração de suítes magmáticas, dado que não há evidências de participação de embasamento mais antigo na sua gênese. Portanto, os resultados obtidos nesta tese, em conjunto com os dados disponíveis na literatura (Janasi, 1999, 2002; Campos Neto et al., 2004; Carvalho et al., 2014; Mora et al., 2014; Vinagre et al., 2014), sugerem que as assinaturas de Nd da Nappe Socorro-Guaxupé possivelmente resultam da geração de magmas a partir de fontes mantélicas enriquecidas, pois retrabalhamento crustal envolvendo crostas arqueanas ou paleoproterozóicas mais antigas não foram reconhecidas até o presente momento.

\subsection{Referências bibliográficas}

Basei, M.A.S., Siga Jr., O., Sato, K., Sproesser, W.M., 1995. A metodologia urânio-chumbo na Universidade de São Paulo: princípios metodológicos, aplicações e resultados obtidos. Anais da Academia Brasileira de Ciências 67(2), 221-237.

Bea, F., Montero, P., 1999. Behavior of accessory phases and redistribution of Zr, REE, Y, Th and $U$ during metamorphism and partial melting of metapelites in the lower crust: an example from the Kinzigite Formation of Ivrea-Verbano, NW Italy. Geochimica et Cosmochimica Acta 63, 11331153.

Campos Neto, M.C. \& Caby, R., 1999. Neoproterozoic high-pressure metamorphism and tectonic constraints from the nappe system south of the São Francisco Craton, southeast Brazil. Precambrian Research 97, 3-26.

Campos Neto, M.C., Caby, R., 2000. Terrane accretion and upward extrusion of high-pressure granulites in the Neoproterozoic nappes of Southeast Brazil: Petrological and structural constraints. Tectonics 14 (4), 669-687.

Campos Neto, M.C., Basei, M.A., Vlach, S.R.F., Caby, R., Szabó, AJ. \& Vasconcelos, P., 2004. Migração de orógenos e superposição de orogêneses: um esboço da colagem brasiliana no sul do Cráton do São Francisco, SE-Brasil, 2004. Geologia USP, Série Científica 4 (1), 13-40.

Campos Neto, M.C., Basei, M.A.S., Janasi, V.A. \& Moraes, R. 2011. Orogen migration and tectonic setting of the Andrelândia Nappe System: An Ediacaran Western Gondwana Collage, South of São Francisco craton. Journal of South American Earth Sciences 32, 393-406.

Carvalho, B.B., Janasi, V.A., 2012. Crystallization conditions and controls on trace elemento residence in the main minerals from the Pedra Branca Syenite, Brazil: an electron microprobe and LAICPMS study. Lithos 153, 208-223.

Carvalho, B.B., Janasi, V.A., Henrique-Pinto, R., 2014. Geochemical and Sr-Nd-Pb isotope constraints on the petrogenesis of the K-rich Pedra Branca Syenite: Implications for the Neoproterozoic postcollisional magmatism in SE Brazil. Lithos 205, 39-59. 
Cioffi, C.R., Campos Neto, M.C., Möller, A., Rocha, B.C., 2016. Paleoproterozoic continental crust generation events at 2.08 and $2.15 \mathrm{Ga}$ in the basement of the southern Brasília Orogen, SE Brazil. Precambrian Research 275, 176-196.

Crowley, J.L., Brown, R.L., Gervais, F., Gibson, H.D., 2008. Assessing inheritance of zircon and monazite in granitic rocks from the Monashee Complex, Canadian Cordillera. Journal of Petrology 49 (11), 1915-1929.

Dumond, G., Goncalves, P., Williams, M.L., Jercinovic, M.J., 2015. Monazite as a monitor of melting, garnet growth and feldspar recrystallization in continental lower crust. Journal of Metamorphic Geology 33, 735-762.

Fetter, A.H., Hackspacher, P.C., Ebert, H.D., Dantas, E.L., Costa, A.C.D., 2001. New Sm-Nd and U-Pb geochronological constraints on the Archean to Paleoproterozoic evolution of the Amparo basement complex of the central Ribeira belt, southeastern Brazil. $3^{\text {rd }}$ South American Symposium on Isotope Geology (Extended Abstracts, CD-ROM).

Foster, G., Parrish, R.R., 2003. Metamorphic monazite and the generation of P-T-t paths. In: D. Vance, W. Müller, I.M, Villa (Eds). Geochronology: Linking the Isotopic Record with Petrology and Textures - Geological Society, London, Special Publications 220, 25-47.

Frost, B.R., Frost, C.D., 2008. On charnockites. Gondwana Research 13, 30-44.

Gengo, R.M., 2014. Petrologia de ortognaisses e granitoides do Domínio Socorro, Nappe SocorroGuaxupé, Seção Extrema-Camanducaia. Dissertação de Mestrado, IGc-USP: 121 p.

Hackspacher, P.C., Fetter, A.H., Ebert, H.D., Janasi, V.A., Oliveira, M.A.F., Braga, I.F., Negri, F.A., 2003. Magmatismo há ca. 660-640 Ma no Domínio Socorro: Registros de convergência pré-colisional na aglutinação do Gondwana Ocidental. Geologia USP, Série Científica 3, 85-96.

Hackspacher, P.C., Fetter, A.H., Teixeira, W., Dantas, E.L., Ebert, H.D., Trouw, R.A.J., Vasconcelos, P., 2004. Final stages of the Brasiliano Orogenesis in SE Brazil: U-Pb and ${ }^{40} \mathrm{Ar} /{ }^{39} \mathrm{Ar}$ evidence for overprinting of the Brasília Belt by the Ribeira Belt tectonics. In: Weinberg, R., Trouw, R.A.J., Fuck, R.A., Hackspacher, P.C. (eds.), The 750-550 Ma Brasiliano Event of South America, Journal of the Virtual Explorer, Electronic Edition, Vol. 17 (http://virtualexplorer.com.au/article/2004/108/final-stages-of-the-brasiliano-orogeny).

Hagen-Peter, G., Cottle, J.M., Tulloch, A.j., Cox, S.C., 2015. Mixing between enriched lithospheric mantle and crustal components in a short-lived subduction-related magma system, Dry Valley area, Antarctica: Insights from U-Pb geochronology, $\mathrm{Hf}$ isotopes, and whole-rock geochemistry. Lithosphere, doi: 10.1130/L384.1

Harley, S.L., 1989. The origins of granulites: a metamorphic perspective. Geological Magazine 126 (3): 215-247.

Harley, S.L., 1992. Proterozoic granulite terranes. In: Condie, K.C. Proterozoic crustal evolution, Elsevier, New York, pp. 301-359. 
Hermann, J., Rubatto, D., 2003. Relating zircon and monazite domains to garnet growth zones: age and duration of granulite facies metamorphism in the Val Malenco lower crust. Journal of Metamorphic Geology 21, 833-852.

Janasi, V.A., 1999. Petrogênese de granitos crustais da Nappe de Empurrão Socorro-Guaxupé (SP-MG): uma contribuição da geoquímica elemental e isotópica. Tese (Livre-Docência) - IGc-USP, 304 pp. Janasi, V.A., 2002. Elemental and Sr-Nd isotope geochemistry of two Neoproterozoic mangerite suites in SE Brazil: implications for the origin of the mangerite-charnockite-granite series. Precambrian Research 119, 301-327.

Janasi, V.A., Vlach, S.R.F., Campos Neto, M.C., Ulbrich, H.H.G.J., 2009. Associated A-type subalkaline and high-K calc-alkaline granites in the Itú Granite Province, southeastern Brazil: petrological and tectonic significance. Canadian Mineralogist 47, 1505-1526.

Kelsey, D.E., Hand, M., 2015. On ultrahigh temperature crustal metamorphism: phase equilibria, trace element thermometry, bulk composition, heat sources, timescales and tectonic settings. Geoscience Frontiers 6, 311-356.

Kirkland, C.L., Erickson, T.M., Johnson, T.E., Danišík, M., Evans, N.J., Bourdet, J., McDonald, B., 2016. Discriminating prolonged, episodic or disturbed monazite age spectra: an example from the Kalak Nappe Complex, Arctic Norway. Chemical Geology 424, 96-110.

Klaver, M., de Roever, E.W.F., Nanne, J.A.M., Mason, P.R.D., Davies, G.R., 2015. Charnockites and UHT metamorphism in the Bakhuis Granulite Belt, western Suriname: Evidence for two separate UHT events. Precambrian Research 262, 1-19.

Laux, J.H., Pimentel, M.M., Dantas, E.L., Armstrong, R., Armele, A., Nilson, A.A., 2004. Mafic magmatism associated with the Goiás Magmatic arc in the Anicuns region, Goiás, central Brazil: Sm-Nd isotopes and new ID-TIMS U-Pb data. Journal of South American Earth Sciences 16, 599-614.

Mahan, K.H., Goncalves, P., Williams, M.L., Jercinovic, M.J., 2006. Dating metamorphic reactions and fluid flow: application to exhumation of high-P granulites in a crustal-scale shear zone, western Canadian Shield. Journal of Metamorphic Geology 24, 193-217.

Martins. L., Vlach, S.R.F., Janasi, V.A., 2009. Reaction microtextures of monazite: correlation between chemical and age domains in the Nazaré Paulista migmatite, SE Brazil. Chemical Geology 261, 271-285.

McFarlane, C.R.M., Frost, B.R., 2009. Constraints on the early metamorphic evolution of Broken Hill, Australia, from in situ U-Pb dating and REE geochemistry of monazite. Journal of Metamorphic Geology 27, 3-17.

Miller, C.F., McDowell, S.M., Mapes, R.W., 2003. Hot and cold granites? Implications of zircon saturation temperatures and preservation of inheritance. Geology 31 (6), 529-532.

Montel, J.-M., Foret, S., Veschambre, M., Nicollet, C., Provost, A., 1996. Electron microprobe dating of monazite. Chemical Geology 131 (1-4), 37-53. 
Mora, C.A.S., Campos Neto, M.C., Basei, M.A.S., 2014. Syn-collisional lower continental crust anataxis in the Neoproterozoic Socorro-Guaxupé Nappe System, southern Brasília Orogen, Brazil: constraints from zircon $\mathrm{U}-\mathrm{Pb}$ dating, $\mathrm{Sr}-\mathrm{Nd}-\mathrm{Hf}$ signatures and whole-rock geochemistry. Precambrian Research 255, 847-864.

Negri, F.A., 2002. Petrologia das rochas charnockito-graníticas e encaixantes de alto grau associadas na região de São Francisco Xavier, SP. Unpublished PhD Thesis, Universidade Estadual Paulista, Brazil, 404 pp.

Pattison, D.R.M., Chacko, T., Farquhar, J., McFarlane, C.R.M., 2003. Temperatures of granulite-facies metamorphism: constraints from experimental phase equilibria and thermobarometry for retrograde exchange. Journal of Petrology 44(5), 867-900.

Pearce, J.A., Harris, N.B.W., Tindle, A.G., 1984. Trace element discrimination diagrams for tectonic interpretation of granitic rocks. Journal of Petrology 25, 956-983.

Percival, J.A., Mortensen, J.K., 2002. Water-deficient calc-alkaline plutonic rocks of northeastern Superior Province, Canada: Significance of charnockitic magmatism. Journal of Petrology 43(6), 1617-1650.

Pimentel, M.M., Fuck, R.A., 1992. Neoproterozoic crustal accretion in central Brazil. Geology 20, 375379.

Pimentel, M.M., Fuck, R.A., Gioia, S.M.C.L., 2000. The Neoproterozoic Goiás Magmatic Arc, Central Brazil: a review and new Sm-Nd isotopic data. Brazilian Journal of Geology 30(1): 35-39.

Pyle, J.M., Spear, F.S., 2003. Four generations of accessory-phase growth in low-pressure migmatites from SW New Hampshire. American Mineralogist 88, 338-351.

Rajesh, H.M., 2004. The igneous charnockite-high-K alkali-calcic I-type granite-incipient charnockite association in Trivandrum Block, southern India. Contributions to Mineralogy and Petrology 147, 346-362.

Reno, B.L., Brown, M., Kobayashi, K., Nakamura, E., Piccoli, P.M., Trouw, R.A.J., 2009. Eclogite-highpressure granulite metamorphism records early collision in West Gondwana: new data from the Southern Brasília Belt, Brazil. Journal of the Geological Society, London 166, 1013-1032.

Rubatto, D., 2002. Zircon trace element geochemistry: partitioning with garnet and the link between U-Pb ages and metamorphism. Chemical Geology 184, 123-138.

Rubatto, D., Chakraborty, S., Dasgupta, S., 2013. Timescales of crustal melting in the Higher Himalayan Crystalines (Sikkim, Eastern Himalaya) inferred from trace element-constrained monazite and zircon chronology. Contributions to Mineralogy and Petrology 165, 349-372.

Rubatto, D., Williams, I.S., Buick, I.S., 2001. Zircon and monazite response to prograde metamorphism in the Reynolds Range, central Australia. Contributions to Mineralogy and Petrology 140, 458468.

Schaltegger, U., Fanning, C.M., Günther, D., Maurin, J.C., Schulmann, K., Gebauer, D., 1999. Growth, 
annealing and recrystallization of zircon and preservation of monazite in high-grade metamorphism: conventional and in-situ $\mathrm{U}-\mathrm{Pb}$ isotope, cathodoluminescence and microchemical evidence. Contributions to Mineralogy and Petrology 134, 186-201.

Schoene, B., Condon, D.J., Morgan, L., McLean, N., 2013. Precision and accuracy in geochronology. Elements 9, 19-24.

Schoene, B., Dudas, F.O.L., Bowring, S.A., de Wit, M., 2009. Sm-Nd isotopic mapping of lithospheric growth and stabilization in the eastern Kaapvaal craton. Terra Nova 21, 219-228.

Taylor, R.J.M., Clark, C., Fitzsimons, I.C.W., Santosh, M., Hand, M., Evans, N., McDonald, B., 2014. Postpeak, fluid-mediated modification of granulite facies zircon and monazite in the Trivandrum Block, southern India. Contributions to Mineralogy and Petrology 168, 1-17.

Töpfner, C. 1996. Brasiliano-granitoide in den bundesstaaten São Paulo und Minas Gerais, Brasilieneine vergleichende studie. Münchner Geologische Hefte 4, 1-100.

Townsend, K.J., Miller, C.F., D’Andrea, J.L., Ayers, J.C., Harrison, T.M., Coath, C.D., 2000. Low temperature replacement of monazite in the Ireteba granite, Southern Nevada: geochronological implications. Chemical Geology 172, 95-112.

Vielzeuf, D., Schmidt, M.W., 2001. Melting relations in hydrous systems revisited: application to metapelites, metagreywackes and metabasalts. Contributions to Mineralogy and Petrology 141, 251-267.

Vinagre, R., Trouw, R.A.J., Mendes, J.C., Duffles, P., Peternel, R., Matos, G., 2014. New evidence of a magmatic arc in the Southern Brasília Belt, Brazil: The Serra da Água Limpa batholith (SocorroGuaxupé Nappe). Journal of South American Earth Sciences 54, 120-139.

Wells, P.R.A., 1980. Thermal models for the magmatic accretion and subsequent metamorphism of continental crust. Earth and Planetary Science Letters 46 (2), 253-265.

Williams, M.L., Jercinovic, M.J., Goncalves, P., Mahan, K., 2006. Format and philosophy for collecting, compiling, and reporting microprobe monazite ages. Chemical Geology 225, 1-15.

Williams, M.L., Jercinovic, M.J., Harlov, D.E., Budzýn, B., Hetherington, C.J., 2011. Resetting monazite ages during fluid-related alteration. Chemical Geology 283, 218-225.

Williams, M.L., Jercinovic, M.J., Hetherington, C.J., 2007. Microprobe monazite geochronology: understanding geologic processes by integrating composition and chronology. Annual Review of Earth and Planetary Sciences 35, 137-175.

Yakymchuk, C., Brown, M., 2014. Behaviour of zircon and monazite during crustal melting. Journal of the Geological Society $171,465-479$.

Zhao, J.X., Ellis, D.J., Kilpatrick, J.A., McCulloch, M.T., 1997. Geochemical and Sr-Nd study of charnockites and related rocks in the northern Prince Charles Mountains, East Antarctica: implications for charnockite petrogenesis and Proterozoic crustal evolution. Precambrian Research 81, 37-66. 
Zhao, L., Zhou, X., Zhai, M., Santosh, M., Ma, X., Shan, H., Cui, X., 2014. Paleoproterozoic tectonic transition from collision to extension in the eastern Cathaysia Block, South China: Evidence from geochemistry, zircon $\mathrm{U}-\mathrm{Pb}$ geochronology and $\mathrm{Nd}-\mathrm{Hf}$ isotopes of a granite-charnockite suite in southwestern Zhejiang. Lithos 184-187, 259-280. 


\section{Conclusões}

Os dados levantados nesta tese permitiram determinar a evolução temporal completa do metamorfismo progressivo/fusão parcial e metamorfismo retrógrado/cristalização de fundido na Nappe Socorro-Guaxupé, com implicações diretas na evolução do Orógeno Brasília. Cinco episódios distintos de geração de monazita foram identificados em migmatitos com granada \pm ortopiroxênio na Unidade Metatexítica, e correlacionados com reações metamórficas específicas para descrever a evolução $P$ - $T$-t registrada pelas rochas. Um estágio de crescimento progressivo de monazita (domínio 1) anterior ao evento de fusão parcial a ca. $631 \pm 4 \mathrm{Ma}$ é registrado em núcleos de monazita ricos em $Y$ e ETRP inclusos em granada, o que define um limite de idade para o início do metamorfismo de fácies granulito na Nappe Socorro-Guaxupé. Monazita relacionada com a apatita (domínio 2) registra as fases iniciais de descompressão a ca. $628 \pm 4 \mathrm{Ma}$, seguidas por fusão parcial envolvendo quebra de biotita, com a geração de granada e ortopiroxênio peritéticos. As condições de pico metamórfico foram determinadas a $c a .1030{ }^{\circ} \mathrm{C}$ a 11,7 kbar em megacristais de granada e ortopiroxênio dentro de leucossoma da Unidade Metatexítica e a $c a .900{ }^{\circ} \mathrm{C}$ at $12 \mathrm{kbar}$ em granada granulito da Unidade Granulítica, o que caracteriza o metamorfismo de temperatura ultra-alta na Nappe Socorro-Guaxupé, aqui estabelecido em ca. 630-625 Ma. Estes dados corroboram com as estimativas anteriores para a idade de metamorfismo de alta temperatura em ca. 630-620 Ma (Basei et al, 1995; Janasi, 1999, 2002; Campos Neto et al., 2004; Martins et al, 2009; Reno et al, 2009; Mora et al, 2014).

O crescimento abundante de zircão e monazita registra um evento de cristalização de fundido prolongado entre $629 \pm 4$ e $601 \pm 1 \mathrm{Ma}$, com temperaturas na ordem de $790-680{ }^{\circ} \mathrm{C}$ baseado em termometria de Ti-em-zircão. Três episódios de cristalização de fundido foram reconhecidos a partir de monazita rica em Th e pobre em Y e ETRP do domínio 3: (1) um estágio inicial a ca. $625 \mathrm{Ma}$; (2) um episódio principal a ca. $615 \mathrm{Ma}$, que coincide com a cristalização de zircão no mesmo período; (3) e um estágio final a ca. $608 \mathrm{Ma}$ sincrônico com a geração de zircão tipo soccer ball em granulitos máficos. O espalhamento dos dados sugere o crescimento de zircão e monazita em qualquer momento dentro deste intervalo, porém os dados desta tese evidenciam o caráter episódico de crescimento de zircão e/ou monazita em ca. $625 \mathrm{Ma}$, ca. $615 \mathrm{Ma}$ e ca. $608 \mathrm{Ma}$. Os picos de idade de $c a .615$ e $608 \mathrm{Ma}$ são compatíveis com estudos geocronológicos prévios na Nappe Socorro-Guaxupé (e.g. Basei et al., 1995; Janasi, 1999, 2002; Hackspacher et al., 2004; Martins et al., 2009; Mora et al., 2014, Gengo, 2014). Os estágios finais de cristalização de fundido são consistentes com o desenvolvimento de bordas de monazita ricas em Y e ETRP (domínio 4) em ca. $600 \mathrm{Ma}$, concomitante com o consumo parcial de granada e crescimento extenso de biotita ao longo da trajetória retrometamórfica. Recristalização tardia promovida pela infiltração de fluidos é registrada em bordas de monazita ricas em Th (domínio 5) em ca. $590 \mathrm{Ma}$. 
A idade do magmatismo de arco pré-colisional foi determinada a partir da datação de uma população grande $(n=363$ ) de núcleos de zircões herdados nos litotipos de protólito sedimentar (Unidade Metatexítica), nos leucossomas com ortopiroxênio e hornblenda, bem como dos zircões provenientes dos protólitos ígneos granulíticos (Unidade Granulítica). As evidências de campo combinadas com os novos dados de elementos-traço e U-Pb em zircão desta tese indicam que o magmatismo de arco pré-colisional ocorreu entre ca. 730-640 Ma com duração de pelo menos 90 m.y., e que este magmatismo foi mais expressivo em ca. 655-650 Ma.

Embora a Nappe Socorro-Guaxupé tenha sido interpretada (e.g. Campos Neto et al., 2011) como a extensão sul do Arco Magmático de Goiás (Pimentel \& Fuck, 1992; Pimentel et al., 2000; Laux et al., 2004), não foram reconhecidas até o momento a presença de rochas juvenis na Nappe SocorroGuaxupé. Os dados apresentados nesta tese em conjunto com dados disponíveis na literatura (e.g. Janasi, 1999, 2002; Campos Neto et al., 2004; Janasi et al., 2009; Mora et al., 2014; Vinagre et al., 2014), mostram que valores de $\varepsilon \mathrm{Nd}_{(\mathrm{t})}$ negativos prevalecem na Nappe Socorro-Guaxupé como um todo. As assinaturas pouco radiogênicas de Nd na Nappe Socorro-Guaxupé poderiam resultar da contaminação e/ou assimilação de um componente crustal mais antigo, como constatado em rochas do Cráton Kaapvaal (e.g. Schoene et al., 2009). Uma provável fonte de contaminação seriam os ortognaisses arqueanos e paleoproterozóicos do embasamento do Orógeno Brasília (Fetter et al., 2001; Cioffi et al., 2016) que afloram em uma grande janela tectônica (15-75 km de largura) entre os dois domínios da Nappe Socorro-Guaxupé. A presença abundante de xenocristais de zircão herdados com idades entre ca. 730-640 Ma nos leucossomas indica que não houve dissolução completa de zircão no magma. No entanto, heranças arqueanas ou paleoproterozóicas não foram reconhecidas nos xenocristais de zircões herdados tanto neste trabalho, como em todos os estudos geocronológicos in-situ disponíveis na literatura (e.g. Mora et al., 2014; Gengo, 2014), o que invalida a hipótese de contaminaçãoassimilação na geração de assinaturas isotópicas de $\mathrm{Nd}$ menos radiogênicas. Desta forma, conclui-se que as assinaturas de $\mathrm{Nd}$ da Nappe Socorro-Guaxupé possivelmente resultam da geração de magmas a partir de fontes mantélicas enriquecidas, pois retrabalhamento crustal envolvendo crostas arqueanas ou paleoproterozóicas mais antigas não foram reconhecidas até o presente momento.

\subsection{Referências bibliográficas}

Basei, M.A.S., Siga Jr., O., Sato, K., Sproesser, W.M., 1995. A metodologia urânio-chumbo na Universidade de São Paulo: princípios metodológicos, aplicações e resultados obtidos. Anais da Academia Brasileira de Ciências 67(2), 221-237.

Campos Neto, M.C., Basei, M.A., Vlach, S.R.F., Caby, R., Szabó, AJ. \& Vasconcelos, P., 2004. Migração de orógenos e superposição de orogêneses: um esboço da colagem brasiliana no sul do Cráton do São Francisco, SE-Brasil, 2004. Geologia USP, Série Científica 4 (1), 13-40. 
Campos Neto, M.C., Basei, M.A.S., Janasi, V.A. \& Moraes, R. 2011. Orogen migration and tectonic setting of the Andrelândia Nappe System: An Ediacaran Western Gondwana Collage, South of São Francisco craton. Journal of South American Earth Sciences 32, 393-406.

Cioffi, C.R., Campos Neto, M.C., Möller, A., Rocha, B.C., 2016. Paleoproterozoic continental crust generation events at 2.08 and $2.15 \mathrm{Ga}$ in the basement of the southern Brasília Orogen, SE Brazil. Precambrian Research 275, 176-196.

Fetter, A.H., Hackspacher, P.C., Ebert, H.D., Dantas, E.L., Costa, A.C.D., 2001. New Sm-Nd and U-Pb geochronological constraints on the Archean to Paleoproterozoic evolution of the Amparo basement complex of the central Ribeira belt, southeastern Brazil. $3^{\text {rd }}$ South American Symposium on Isotope Geology (Extended Abstracts, CD-ROM).

Gengo, R.M., 2014. Petrologia de ortognaisses e granitoides do Domínio Socorro, Nappe SocorroGuaxupé, Seção Extrema-Camanducaia. Dissertação de Mestrado, IGc-USP: 121 p.

Hackspacher, P.C., Fetter, A.H., Teixeira, W., Dantas, E.L., Ebert, H.D., Trouw, R.A.J., Vasconcelos, P., 2004. Final stages of the Brasiliano Orogenesis in SE Brazil: U-Pb and ${ }^{40} \mathrm{Ar} /{ }^{39} \mathrm{Ar}$ evidence for overprinting of the Brasília Belt by the Ribeira Belt tectonics. In: Weinberg, R., Trouw, R.A.J., Fuck, R.A., Hackspacher, P.C. (eds.), The 750-550 Ma Brasiliano Event of South America, Journal of the Virtual Explorer, Electronic Edition, Vol. 17 (http://virtualexplorer.com.au/article/2004/108/final-stages-of-the-brasiliano-orogeny).

Janasi, V.A., 1999. Petrogênese de granitos crustais da Nappe de Empurrão Socorro-Guaxupé (SP-MG): uma contribuição da geoquímica elemental e isotópica. Tese (Livre-Docência) - IGc-USP, 304 pp. Janasi, V.A., 2002. Elemental and Sr-Nd isotope geochemistry of two Neoproterozoic mangerite suites in SE Brazil: implications for the origin of the mangerite-charnockite-granite series. Precambrian Research 119, 301-327.

Janasi, V.A., Vlach, S.R.F., Campos Neto, M.C., Ulbrich, H.H.G.J., 2009. Associated A-type subalkaline and high-K calc-alkaline granites in the Itú Granite Province, southeastern Brazil: petrological and tectonic significance. Canadian Mineralogist 47, 1505-1526.

Laux, J.H., Pimentel, M.M., Dantas, E.L., Armstrong, R., Armele, A., Nilson, A.A., 2004. Mafic magmatism associated with the Goiás Magmatic arc in the Anicuns region, Goiás, central Brazil: Sm-Nd isotopes and new ID-TIMS U-Pb data. Journal of South American Earth Sciences 16, 599-614.

Martins. L., Vlach, S.R.F., Janasi, V.A., 2009. Reaction microtextures of monazite: correlation between chemical and age domains in the Nazaré Paulista migmatite, SE Brazil. Chemical Geology 261, 271-285.

Mora, C.A.S., Campos Neto, M.C., Basei, M.A.S., 2014. Syn-collisional lower continental crust anataxis in the Neoproterozoic Socorro-Guaxupé Nappe System, southern Brasília Orogen, Brazil: constraints from zircon $\mathrm{U}-\mathrm{Pb}$ dating, $\mathrm{Sr}-\mathrm{Nd}-\mathrm{Hf}$ signatures and whole-rock geochemistry. Precambrian Research 255, 847-864. 
Pimentel, M.M., Fuck, R.A., 1992. Neoproterozoic crustal accretion in central Brazil. Geology 20, 375379.

Pimentel, M.M., Fuck, R.A., Gioia, S.M.C.L., 2000. The Neoproterozoic Goiás Magmatic Arc, Central Brazil: a review and new Sm-Nd isotopic data. Brazilian Journal of Geology 30(1): 35-39.

Reno, B.L., Brown, M., Kobayashi, K., Nakamura, E., Piccoli, P.M., Trouw, R.A.J., 2009. Eclogite-highpressure granulite metamorphism records early collision in West Gondwana: new data from the Southern Brasília Belt, Brazil. Journal of the Geological Society, London 166, 1013-1032.

Schoene, B., Dudas, F.O.L., Bowring, S.A., de Wit, M., 2009. Sm-Nd isotopic mapping of lithospheric growth and stabilization in the eastern Kaapvaal craton. Terra Nova 21, 219-228.

Vinagre, R., Trouw, R.A.J., Mendes, J.C., Duffles, P., Peternel, R., Matos, G., 2014. New evidence of a magmatic arc in the Southern Brasília Belt, Brazil: The Serra da Água Limpa batholith (SocorroGuaxupé Nappe). Journal of South American Earth Sciences 54, 120-139. 


\section{ANEXO I}

Timing of anatexis and melt crystallization in the Socorro-Guaxupé Nappe, SE Brazil: Insights from trace element composition of zircon, monazite and garnet coupled to U-Pb geochronology

Artigo aceito para publicação no periódico Lithos 


\title{
ANEXO I
}

\section{Artigo aceito para publicação no periódico Lithos}

Timing of anatexis and melt crystallization in the Socorro-Guaxupé Nappe, SE Brazil: insights from trace element composition of zircon, monazite and garnet coupled to $\mathrm{U}-\mathrm{Pb}$ geochronology

\author{
B.C. Rocha ${ }^{a, b^{*}}$, R. Moraes ${ }^{a}$, A. Möller ${ }^{b}$, C.R. Cioffi ${ }^{a, b}$, M.J. Jercinovic ${ }^{c}$
}

${ }^{a}$ Departamento de Mineralogia e Petrologia, Instituto de Geociências, Universidade de São Paulo, Rua do Lago, 562, CEP 05508-080, São Paulo, SP, Brazil

${ }^{b}$ Department of Geology, The University of Kansas, 2335 Irving Hill Road, Nichols Hall, Lawrence, KS, 66045-7559, USA

'Department of Geosciences, University of Massachusetts, 611 North Pleasant Street, Amherst, MA, 01003-9297, USA

* Corresponding author: brendaroch@yahoo.com.br

\section{ABSTRACT}

The timing of partial melting and melt crystallization in granulite facies rocks of the Socorro-Guaxupé Nappe (SGN), Brazil is constrained using a combination of imaging techniques, LA-ICP-MS and EPMA dating, trace element geochemistry and thermobarometry. (Orthopyroxene)-garnet-bearing migmatite that records extensive biotite dehydration melting shows evidence for a clockwise P-T-t path. UHT peak conditions were attained at $1030 \pm 110^{\circ} \mathrm{C}, 11.7 \pm 1.4 \mathrm{kbar}$, with post-peak cooling to $865 \pm 38^{\circ} \mathrm{C}, 8.9 \pm 0.8 \mathrm{kbar}$. Cryogenian igneous inheritance of $c a .720-640 \mathrm{Ma}$ is identified in oscillatory zoned zircon cores ( $n=167)$ with steep HREE patterns. Resorbed, Y-rich monazite cores preserve a prograde growth stage at $631 \pm 4$ Ma prior to the partial melting event, providing an upper age limit for the granulite facies metamorphism in the SGN. REE-rich, Th-depleted monazite related to apatite records the initial stages of decompression at $628 \pm 4 \mathrm{Ma}$. Multiple monazite growth episodes record melt crystallization events at $624 \pm 3 \mathrm{Ma}, 612 \pm 5 \mathrm{Ma}$ and $608 \pm 6 \mathrm{Ma}$. Stubby, equant "soccer ball" zircon provide evidence for melt crystallization at $613 \pm 2 \mathrm{Ma}$ and $607 \pm 4 \mathrm{Ma}$. The excess scatter in zircon and monazite age populations between $629 \pm 4$ and $601 \pm 3 \mathrm{Ma}$ is interpreted as discontinuous and episodic growth within this age range, characterizing a prolonged metamorphic event in the SGN lasting $c a .30$ m.y. The development of $\mathrm{Y}+\mathrm{HREE}-$ rich monazite rims at $c a .600 \mathrm{Ma}$ documents retrograde garnet breakdown, extensive biotite growth and the final stages of melt crystallization. Th-rich, Y+HREE-poor monazite rims at $c a .590 \mathrm{Ma}$ record monazite recrystallization.

Keywords: partial melting; melt crystallization; monazite; zircon; trace elements; Southern Brasília Orogen 


\section{Introduction}

The timescales involved in orogenic processes in the deep crust rely mainly on zircon and monazite U-(Th)-Pb geochronology, due to their chemical stability and high closure temperatures (e.g. Cherniak \& Watson, 2001). Linking the growth of zircon and monazite that provide age information to the key metamorphic mineral assemblage from which $P-T$ is extracted can ideally provide a direct appraisal of the rate and timing of tectono-metamorphic events (e.g. Rubatto et al., 2001; Möller et al., 2003). Even though precise U-Pb dating is highly accessible now, the variable response of zircon and monazite to metamorphic processes, in addition to the complexity of its growth zones (e.g. Vavra et al., 1999; Williams, 2001), can make interpretations of the U-Pb dates in high-T rocks challenging (e.g. Schaltegger et al., 1999; Rubatto et al., 2001; Foster \& Parrish, 2003; Whitehouse \& Platt, 2003; Kelly \& Harley, 2005; Harley et al., 2007). Zircon growth in high-grade rocks is likely to record the cooling history from high temperature rather than the peak metamorphic conditions (Roberts \& Finger, 1997; Harley et al., 2007). Rapid and abundant zircon growth occurs at the onset of nucleation with cooling, and diminishes as temperature decreases (Kelsey et al., 2008).

New zircon formation is also attributed to subsolidus metamorphic reactions between $\mathrm{Zr}$ bearing silicates and accessory phases (Fraser et al., 1997; Degeling et al. 2001; Möller et al., 2003b). Modification and/or recrystallization of pre-existing zircon are controlled by dissolution-precipitation, due to interactions with fluids or melt (Pidgeon, 1992; Schaltegger et al., 1999; Hoskin \& Black, 2000; Geisler et al., 2007) and precipitation from fluids (Williams et al., 1996). Trace element compositions of zircon and/or monazite can be used to relate their growth to an association of major metamorphic minerals, providing evidence for different growth episodes of zircon/monazite, and are combined with geochronological data to establish P-T-t evolution paths (e.g. Bea \& Montero, 1999; Rubatto, 2002; Hermann \& Rubatto, 2003; Möller et al., 2002, 2003a, b; Kelly \& Harley, 2005; Harley et al., 2007).

The growth of monazite under high-grade conditions tends to define a narrower age distribution than zircon within the same rock, because pre-metamorphic inheritance is less common (e.g. Williams, 2001; Möller et al. 2003a; Yakymchuk \& Brown, 2014). Compositional domains in monazite reflect different growth stages that can be tied to distinct geological events (e.g. Williams et al., 2006, 2007; Pyle \& Spear, 2003; Mahan et al., 2006; Dumond et al., 2008, 2015; Kelly et al., 2012), as monazite has the ability to record events from prograde to retrograde evolution and helps bracket the timing of high-grade metamorphism (Möller et al., 2003a; McFarlane \& Frost, 2009).

This approach is used here to investigate high-grade metasedimentary rocks, as stromatic garnet-biotite metatexite, schollen diatexite, and a mafic granulite within a segregated leucosome from the Socorro-Guaxupé Nappe, MG, Brazil, to place constraints on the timing of the partial melting and melt crystallization. The southern Brasília Orogen in southeast Brazil corresponds to a Himalayantype collisional orogen related to the assembly of western Gondwana during the Neoproterozoic 
(Campos Neto \& Caby, 1999, 2000). The correlation of zircon and monazite growth stages to distinct crystallization events allows a better comprehension of the metamorphism, partial melting and melt crystallization episodes of rocks formed the base of the continental crust and their exhumation.

\section{Geological setting}

The southern Brasília Orogen has been interpreted as a result of the Neoproterozoic collision between the active margin of Paranapanema Plate and the passive margin of the São Francisco Craton (Brito Neves et al., 1999; Campos Neto \& Caby, 2000; Trouw et al., 2000). It comprises a stack of flatlying to gently SW dipping thick-skinned nappes, in which three different tectonic settings are recognized, from WSW to ENE: (i) a magmatic arc domain represented by the Socorro-Guaxupé Nappe (SGN), (ii) the subducted metasedimentary sequence of the Andrelândia Nappe System, (iii) a passive continental margin domain related to the São Francisco Plate represented by the Carrancas and Lima Duarte Nappe Systems (Fig. 1) (Campos Neto \& Caby, 1999, 2000; Trouw et al., 2000, 2013; Campos Neto et al., 2010, 2011; Reno et al., 2009, 2012).

The SGN represents a $\sim 10 \mathrm{~km}$ thick section of the lower continental crust, interpreted as the root of a magmatic arc developed at the active margin of the Paranapanema Plate (Campos Neto \& Caby, 1999, 2000). The SGN (Fig. 1) is composed of three distinct units: (i) a basal granulite unit with banded (Grt)-Opx granulites with orthopyroxene-bearing leucosome ( $3 \mathrm{~km}$ thick), (ii) a middle diatexite unit that comprises grey to pink metaluminous migmatites ( $6 \mathrm{~km}$ thick), and (iii) an upper metatexite unit composed mainly of metasedimentary migmatites (Campos Neto \& Caby, 1999, 2000).

Hackspacher et al. (2003) report igneous crystallization ages between ca. 640 and $655 \mathrm{Ma}$ for orthogneisses and granulites of calc-alkaline affinities from the basal granulite and middle diatexite unit and interpret them as products of pre-collisional magmatism. Recently, Mora et al. (2014) reported an igneous protolith crystallization age of $646 \pm 6 \mathrm{Ma}$ (TIMS upper intercept) for a granulite from the basal unit, and zircon inheritance between ca. 640 and $670 \mathrm{Ma}$ in metatexites from the upper metatexite unit.

High-T metamorphism in the SGN is recorded at ca. 630-620 Ma, coeval to a series of charnockite and high-K calc alkaline suites intrusive into the SGN (Basei et al., 1995; Janasi, 1999, 2002; Martins et al., 2009; Reno et al., 2009; Mora et al., 2014). A SIMS zircon U-Pb age of ca. 622 Ma in granulites from the Guaxupé Domain records the initial stages of retrograde cooling after high-T metamorphism (Reno et al., 2009). EMPA monazite dating of granite leucosome (Martins et al., 2009) and laser ablation MC-ICP-MS U-Pb dating of soccer ball zircons from orthopyroxene-bearing leucosome (Mora et al., 2014) yielded youngest ages of ca. $610 \mathrm{Ma}$, interpreted as the result of a later retrograde cooling stage. 


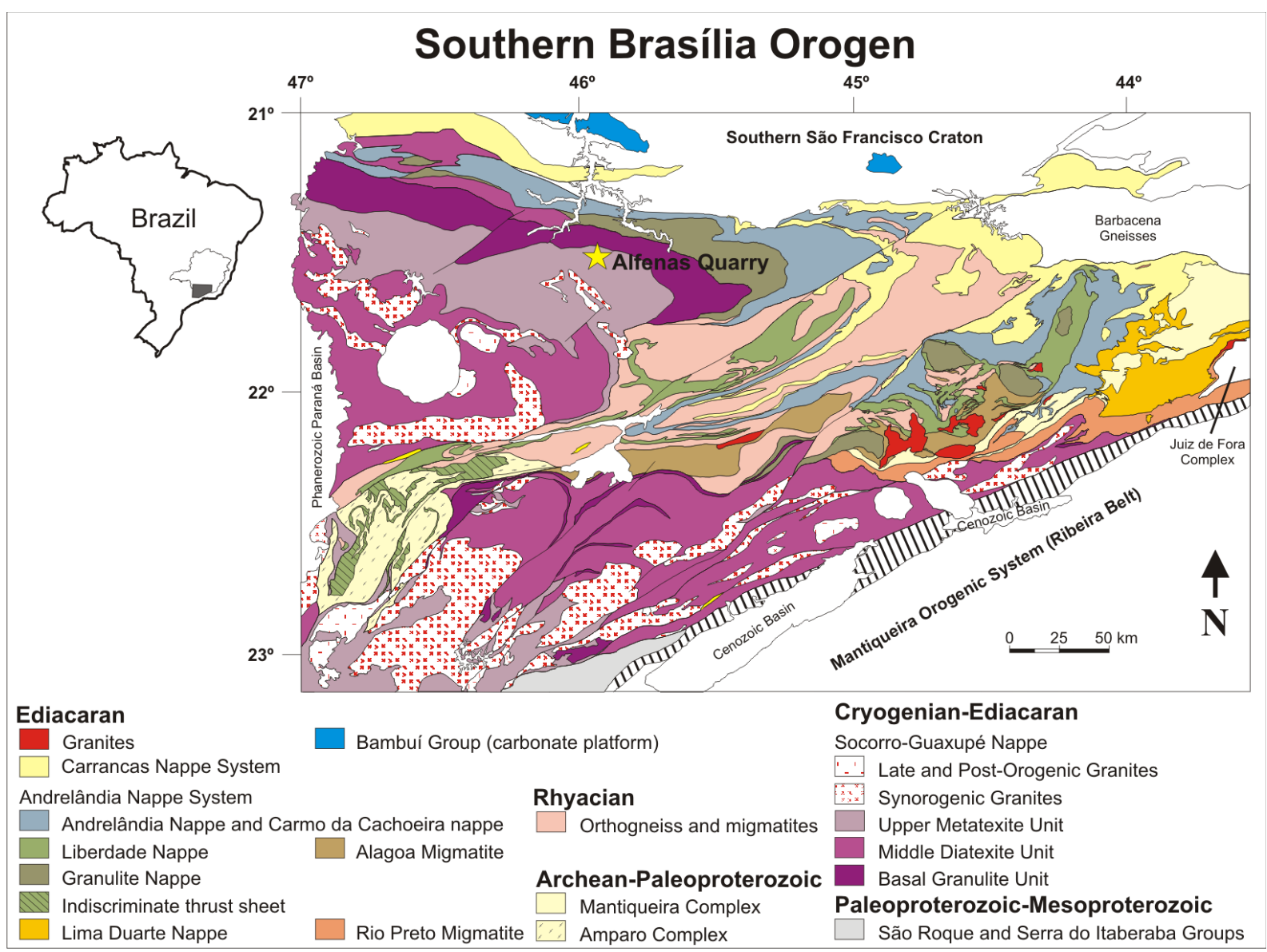

Figure 1: Geological map of the Southern Brasília Orogen, with the location of the studied area (Alfenas Quarry) marked with a yellow star (Campos Neto et al., 2010).

\section{Geological relationships}

Migmatite terminology in this paper follows Sawyer (2008), in which neosome is the newly formed part of the migmatite, as a result of partial melting. Thus, it contains one part derived from the melt, and another derived from minerals that were either present in excess in melting reactions and/or are the solid products of incongruent melting. If segregation occurs, leucosome and melanosome (solid residuum left from partial melting) are recognized within the neosome. Unsegregated neosome consists of melt and solid fractions not separated by segregation.

Seven selected samples within the Metatexite Unit were collected from a single outcrop at Alfenas Quarry, located at the MG-179 state highway (Fig. 1). The study area is dominated by migmatites with variable degree of partial melting, schollen diatexite and stromatic metatexite, with subordinate mafic granulite layers and voluminous leucosome. Schollen diatexite consists of a residual (garnet)-biotite gneiss with large volume of pinkish granite leucosome (Fig. 2a), with schollen of either (garnet)-biotite gneiss or mafic granulite. Wide biotite selvedges (1-4 cm) typically occur at the contact between garnet-bearing leucosome and its (garnet)-biotite gneiss schollen (Fig. 2b).

Coarse-grained segregated leucosome locally displays abundant, euhedral garnet up to $3 \mathrm{~cm}$ in diameter (Figs. 2c, d) and rare orthopyroxene grains $(1-2 \mathrm{~cm})$. Peritectic garnet within leucosome 
might represent original sites of melt generation (e.g. White \& Powell, 2010). The preservation of large garnet and orthopyroxene crystals within the leucosome is attributed to the formation of biotite selvedges by the retrograde interaction between segregated melt and the residue (Kriegsman, 2001). Differences in chemical potential of $\mathrm{H}_{2} \mathrm{O}$ may lead to diffusion of $\mathrm{H}_{2} \mathrm{O}$ from the leucosome to the residue until $\mu_{\mathrm{H}_{2} \mathrm{O}}$ values are equalized, leaving behind a near-anhydrous leucosome (White \& Powell, 2010).

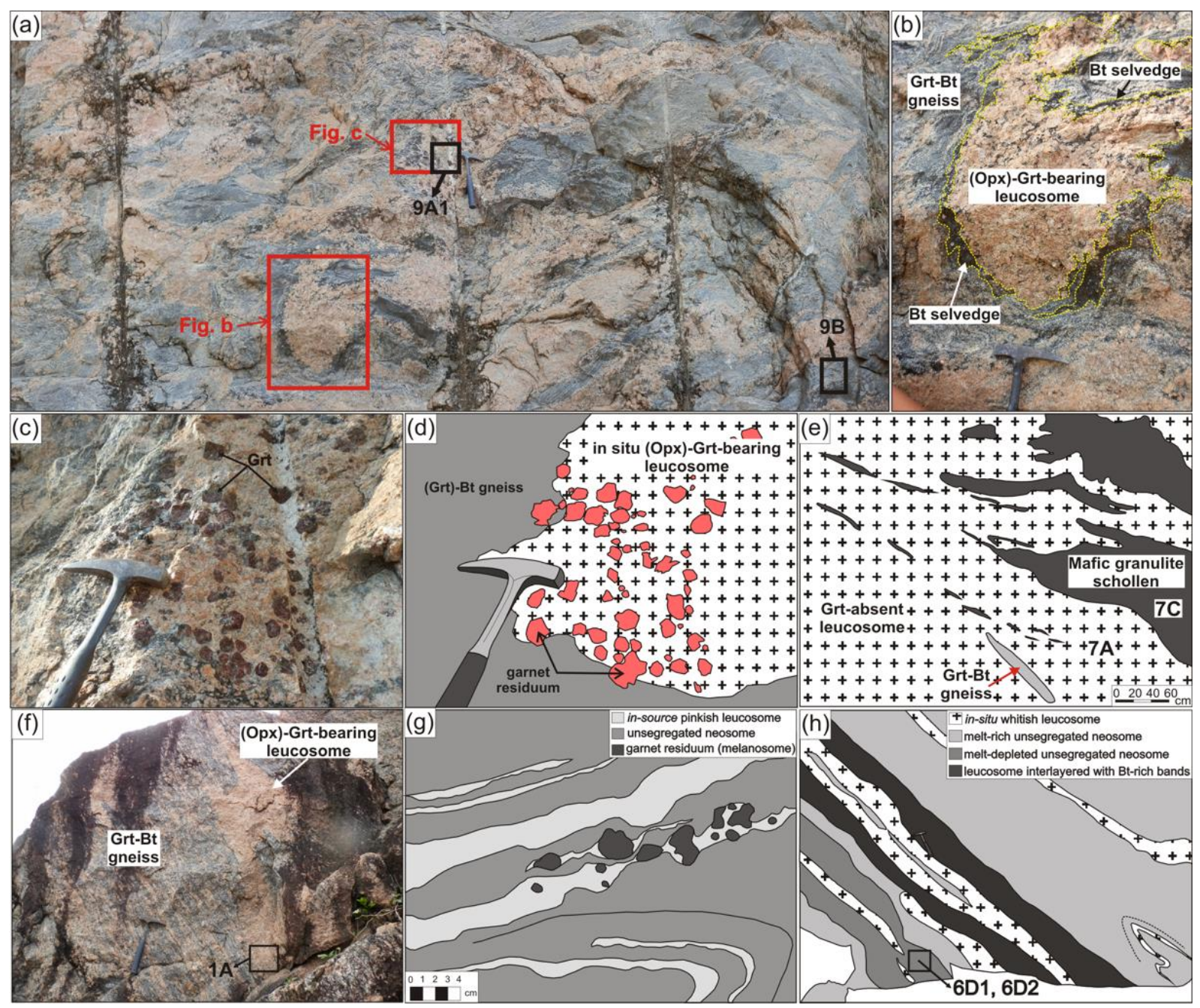

Figure 2: Studied rocks collected at the Alfenas Quarry. (a) Schollen migmatite with a large volume of pinkish garnet-bearing leucosome. (b) Biotite-rich selvedge commonly developed between (orthopyroxene)-garnet-bearing leucosome and its host (garnet)-biotite gneiss. (c) Detail of centimeter-scale euhedral garnet within alkali-feldspar-rich leucosome and (d) corresponding sketch. (e) Sketch of segregated (garnet)-absent leucosome with rafts of mafic granulite. (f) Schollen migmatite with syn-kinematic pinkish garnet-bearing leucosome and grey (garnet)-biotite gneiss. (g) Sketch of (garnet)-biotite gneiss with leucosome parallel to the axial planes of centimeter-scale isoclinal folds and residual peritectic garnet. (h) Field sketch showing the relationship between the different parts of the stromatic garnet-biotite metatexite. Light bands consist of melt-rich unsegregated neosome, with 
milimeter-scale leucosome parallel to the compositional banding. Dark bands are biotite-rich layers with abundant garnet and accessory phases that developed nearby segregated neosome layers.

The presence of an interconnected melt network suggests that garnet-absent leucosome could represent accumulation of segregated melt into dilatant sites (Sawyer, 2001). A common feature in the garnet-absent leucosome is the presence of numerous schollen and lenses of mafic granulite; some are up to $2 \mathrm{~m}$ long (Fig. 2e). Syn-kinematic $\mathrm{S}_{2}$-oriented leucosome has sparse coarse-grained garnet (Fig. 2f). (Garnet)-biotite gneiss has narrow leucosome bands parallel to the axial planes of centimeter-scale isoclinal folds, and garnet residuum left after partial melting and melt extraction (Fig. $2 \mathrm{~g}$ ). It is also cut by discordant leucosome veins.

Stromatic garnet-biotite metatexite is characterized by a millimeter to centimeter-scale compositional banding. Segregated neosome consists of light in-situ plagioclase-quartz leucosome derived from anatectic melt with abundant fine to medium-grained residuum garnet (melanosome) (Fig. 3a). Light-grey bands comprise melt-rich unsegregated neosome composed of quartz + plagioclase + garnet \pm biotite. Dark-colored bands are biotite-rich layers with abundant garnet and accessory phases that developed nearby segregated neosome layers (Fig. $2 \mathrm{~h}$ ).

\section{Petrography, textural relationships and mineral compositions}

Representative major element composition of garnet, orthopyroxene, plagioclase and biotite are given in ANEXO III. Petrography and mineral chemistry of five samples (6D1, 6D2, 1A, 9A1, 9B) studied in most detail are presented. Sample description of the remaining samples (7A, 7C) are shown. Mineral abbreviations follow Whitney \& Evans (2010). Analyzed garnet grains are referred from now on by their grain number. Garnets 1, 2 and 3 correspond to analyzed grains in the stromatic garnetbiotite metatexite (samples 6D1, 6D2) and garnet 4 is a large euhedral garnet in the (orthopyroxene)garnet-bearing leucosome (sample 1A).

\subsection{Stromatic garnet-biotite metatexite (samples 6D1, 6D2)}

The stromatic garnet-biotite metatexite contains abundant fine to medium-grained garnet (20$25 \%)$ in a foliated matrix mainly composed of plagioclase $\left(A_{30-35}\right)$, quartz, biotite, and minor K-feldspar (Fig. 3a). The main foliation $\mathrm{S}_{2}$ is defined by aligned biotite. Garnet porphyroblasts (2-6 $\mathrm{mm}$ in diameter) contain abundant quartz, plagioclase, biotite, zircon and monazite inclusions (Fig. 3b), whereas finegrained garnet crystals $(<1 \mathrm{~mm})$ are mostly inclusion-free or may have only zircon inclusions (Fig. $4 \mathrm{~d}$; inset in the lower right). Zircon and monazite are the main accessory phases in the matrix and all occur as inclusions in garnet. Monazite is generally present as large, euhedral grains related to matrix feldspar, quartz and/or biotite or as inclusions within garnet (Table 2). Matrix coarse-grained monazite may have zircon inclusions (Fig. A1). Zircon inclusions in garnet typically have elongate shape and few 
grains exhibit late replacement by xenotime (Fig. A2). Sparse chlorite and muscovite locally replaces biotite. Other accessory minerals include ilmenite, apatite, pyrite, chalcopyrite and calcite.

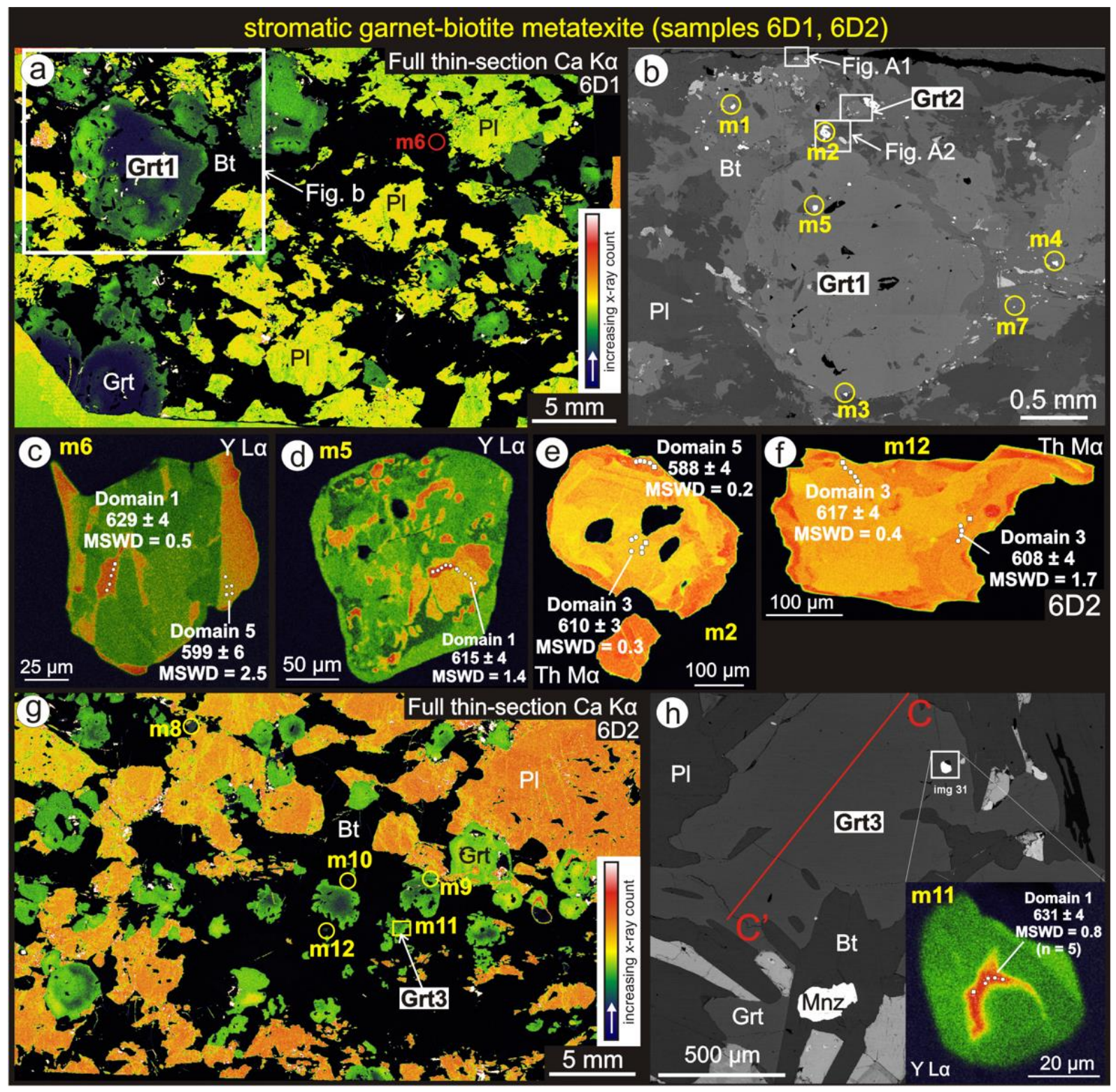

Figure 3: Stromatic garnet-biotite metatexite (sample 6D1). (a) Ca Ka full thin-section map illustrating the textural setting of EPMA analyzed garnet and monazite. (b) BSE image displaying the location of monazite high resolution X-ray maps and analyzed garnet grains. High resolution $Y L \alpha(c-d)$ and Th $M \alpha$ (e-f) X-ray maps of representative monazite grains. (c) grain m6 (matrix monazite). (d) grain m5 (inclusion in garnet 1). (e) grain $\mathrm{m} 2$ (matrix monazite with zircon inclusions). (f) grain $\mathrm{m} 12$ (matrix monazite). Stromatic garnet-biotite metatexite (sample 6D2). (g) Ca Ka full thin-section map illustrating the textural setting of EPMA analyzed garnet and monazite. (h) BSE image illustrating garnet 3 with inclusion of monazite grain $\mathrm{m} 11$. Inset is $\mathrm{Y} L \alpha \mathrm{X}$-ray map of monazite grain $\mathrm{m} 11$. 

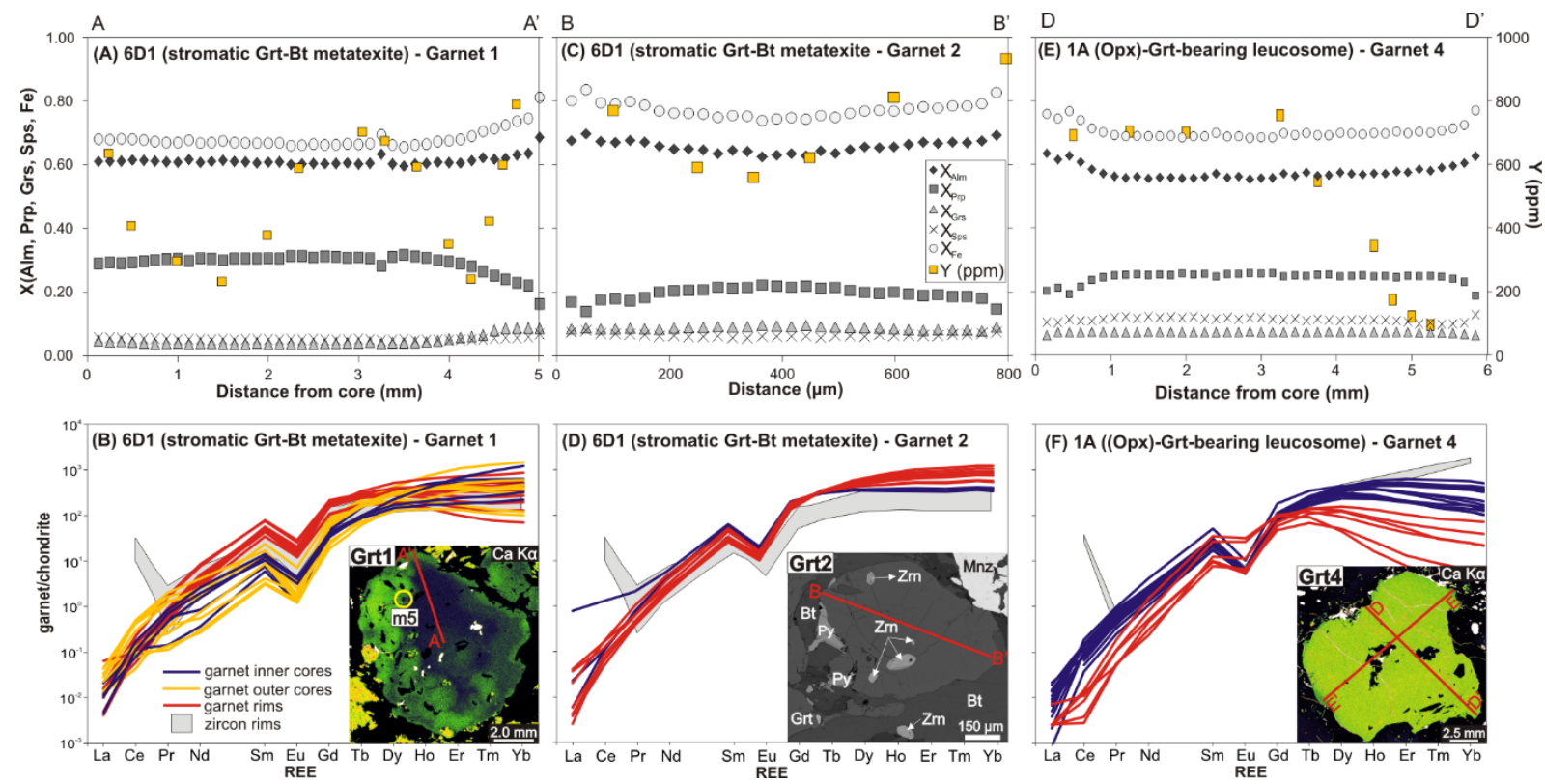

Figure 4: Compositional profiles across garnet and REE patterns normalized to the chondrite values of McDonough \& Sun (1995). (a-d) stromatic garnet-biotite metatexite (sample 6D1). (a-b) garnet 1, (c-d) garnet 2. (e-f) (orthopyroxene)-garnet-bearing leucosome (sample 1A) garnet 4.

Compositional transects and X-ray concentration maps garnet $1(\sim 2 \mathrm{~mm}$ wide) show Alm ${ }_{60} \mathrm{Prp}_{30} \mathrm{Grs}_{4} \mathrm{Sps}_{5}$ as core composition, with a progressive outward decrease in pyrope and increase in almandine to the inner rims $\left(X_{\text {Prp }}=0.22-0.26 ; X_{A l m}=0.62\right)$ and outermost rims $\left(X_{\text {Prp }}=0.16 ; X_{A l m}=0.68\right)$ (Figs. 4a, b). The inner rim domain has abundant biotite, plagioclase, ilmenite and monazite inclusions, and a marked grossular enrichment $\left(\mathrm{X}_{\mathrm{Grs}}=0.09\right)$ compared to the garnet core. Chondrite-normalized REE patterns display a wide variation in REE concentrations between core and rims. Garnet cores have a marked depletion in MREE (DyN/GdN $/ d_{N}=2-9$ av. 5) compared to rims ( $D y_{N} / G d_{N}=2-3$, av. 2). Cores have steep chondrite-normalized HREE patterns $\left(\mathrm{Yb}_{N} / \mathrm{Gd}_{N}=3-36\right.$, av.14) and strongly negative Eu anomalies $\left(\mathrm{Eu} / \mathrm{Eu}^{*}=0.09\right)$ in contrast to flat HREE patterns in rims $\left(\mathrm{Yb}_{N} / \mathrm{Gd}_{N}=1-5\right.$, av.2) (Fig. $\left.4 b\right) . \mathrm{Y}$ concentration is variable from core to rim, and might be controlled by growth of competing phases such as monazite. Mineral inclusions are rare in garnet inner cores, where $Y$ is relatively high (763 ppm), which decreases to lower contents ( 234 ppm) in the outer cores. Inner rims are Y-enriched (700-1051 ppm) near Y-rich monazite m5 (up to $26000 \mathrm{ppm}$ ). Yttrium contents drop to $240 \mathrm{ppm}$ in the grossular-rich domains and increase to $976 \mathrm{ppm}$ at the outermost rims (Fig. 4a).

Major element zoning in fine-grained garnet (garnets 2 and 3 ) is characterized by an increase in almandine and decrease in pyrope from core $\left(\mathrm{Alm}_{64} \operatorname{Prp}_{21} \mathrm{Grs}_{9} \mathrm{Sps}_{6}\right)$ to $\mathrm{rim}\left(\mathrm{Alm}_{70} \mathrm{Prp}_{14} \mathrm{Grs}_{9} \mathrm{Sps}_{7}\right)$ with a change of $\mathrm{X}_{\mathrm{Fe}}<0.09$. Grossular is essentially unzoned, with the same content as medium-grained garnet rims $\left(\mathrm{X}_{\mathrm{Grs}}=0.09\right.$ ) (Fig. 4c). Minor increases in $\mathrm{X}_{\mathrm{Sps}}$ at the outermost rims (0.07) are related to the retrograde kick-up effect (Kohn \& Spear, 2000), and seen in both coarse- and fine-grained varieties. The increase in $\mathrm{X}_{\mathrm{Fe}}$ from core to rim is most likely related to retrograde exchange reactions between 
garnet and matrix biotite. Garnets 2 and 3 exhibit contrasting REE compositional patterns compared to garnet 1 with rimward HREE-enrichment. Garnet 2 ( 500 $\mu \mathrm{m}$ across) in sample 6D1 has zircon inclusions and is adjacent to a large euhedral matrix-monazite. The garnet core has flat chondritenormalized HREE patterns $\left(\mathrm{Yb}_{N} / \mathrm{Gd}_{N}=2\right)$ with lower $\mathrm{Y}(560 \mathrm{ppm})$ contents. Rims have flat to slightly positive HREE patterns $\left(\mathrm{Yb}_{N} / \mathrm{Gd}_{\mathrm{N}}=3-9\right.$, av. 5), with a gentle depletion in LREE and MREE and higher $Y$ concentrations (932 ppm) (Fig. 4d). Negative Eu anomaly (Eu/Eu*=0.13-0.16, av. 0.14) is slightly less pronounced compared to zircon rims. Garnet 3 ( 750 $\mu \mathrm{m}$ diameter) in sample 6D2 has monazite and zircon inclusions and is partially replaced by biotite. This garnet is zoned, with slightly positive HREEdepleted patterns $\left(\mathrm{Yb}_{N} / G_{N}=0.1\right)$ in the core, to flat HREE-enriched patterns $\left(\mathrm{Yb}_{N} / G_{N}=1\right)$ towards the rims, with an increase in $Y$ contents (from 90 to 691 ppm) (Fig. 12c). The low $Y$ content in the garnet core $(90 \mathrm{ppm})$ is correlated with high $\mathrm{Y}$ in the monazite $\mathrm{m} 11$ inclusion (Fig. $3 \mathrm{~h}$ ).

\section{2 (orthopyroxene)-garnet-bearing leucosome (samples $9 A 1$ and $1 A$ )}

The (orthopyroxene)-garnet-bearing leucosome is composed of coarse-grained K-feldspar, plagioclase, quartz, garnet (5-10\%), minor biotite and scarce orthopyroxene (1-5\%) (Figs. 5a, e, k). Zircon, monazite, apatite, ilmenite, tourmaline, calcite, chlorite and muscovite are the main accessory minerals. Plagioclase $\left(\mathrm{An}_{20-27}\right)$ typically occurs as subhedral inclusions within euhedral K-feldspar and/or as myrmekite surrounding K-feldspar megacrysts $(5-10 \mathrm{~cm})$. Large euhedral garnet $(1-4 \mathrm{~cm}$ in diameter) contains abundant rounded and lobate quartz, and fewer plagioclase, apatite, ilmenite, and zircon inclusions. Plagioclase inclusions occur as subhedral grains or as films, mimicking trapped melt within garnet. Subhedral orthopyroxene megacrysts (Fig. 5k) have Al-rich cores (0.134-0.216 Al p.f.u.) and slightly lower Al contents at the rims ((0.106-0.132 Al p.f.u.). Few grains are partially replaced by late biotite and/or biotite + quartz intergrowths. $A$ distinctive feature in sample $1 \mathrm{~A}$ is the occurrence of small monazite related to abundant apatite (Fig. $5 f-j$ ). Sample 9A1 is characterized by large, euhedral monazite grains up to $3 \mathrm{~mm}$, hosted in interstitial quartz.

Major element profiles from core to rim in a euhedral coarse-grained garnet (garnet 4; 1.5 $\mathrm{cm}$ wide) in sample $1 \mathrm{~A}$ show a $6 \mathrm{~mm}$ wide plateau of homogeneous composition ( $\mathrm{Alm}_{57} \operatorname{Prp}_{25} \mathrm{Grs}_{7} \mathrm{Sps}_{11}$ ) (Fig. 4e). The composition of outermost rims $\left(\mathrm{Alm}_{64} \mathrm{Prp}_{18} \mathrm{Grs}_{7} \mathrm{Sps}_{13}\right)$ is related to retrograde reactions. Grossular contents are unzoned. The chondrite-normalized REE pattern is characterized by a progressive LREE- and HREE depletion from core to rim, which is correlated to a decrease in $Y$ from 1000 to $26 \mathrm{ppm}$ towards the rims. The core displays a flat to slightly positive HREE chondritenormalized pattern $\left(\mathrm{Yb}_{N} / \mathrm{Gd}_{N}=1-6\right.$, av. 3), with a decrease in MREE ( $D \mathrm{y}_{N} / \mathrm{Gd}_{N}=2-4$, av. 4) and a strong negative Eu anomaly $\left(E u / E u^{*}=0.09-0.12\right.$, av. 0.10). Rims are depleted in $\mathrm{HREE}\left(\mathrm{Yb}_{N} / \mathrm{Gd}_{N}=0.2-1.1\right.$, av. 0.4 ) and MREE (DyN $/ G d_{N}=0.5-2$, av. 1.4), and have a less pronounced negative Eu anomaly (Eu/Eu* $=0.15-0.47$, av. 0.27) (Fig. 4f). 


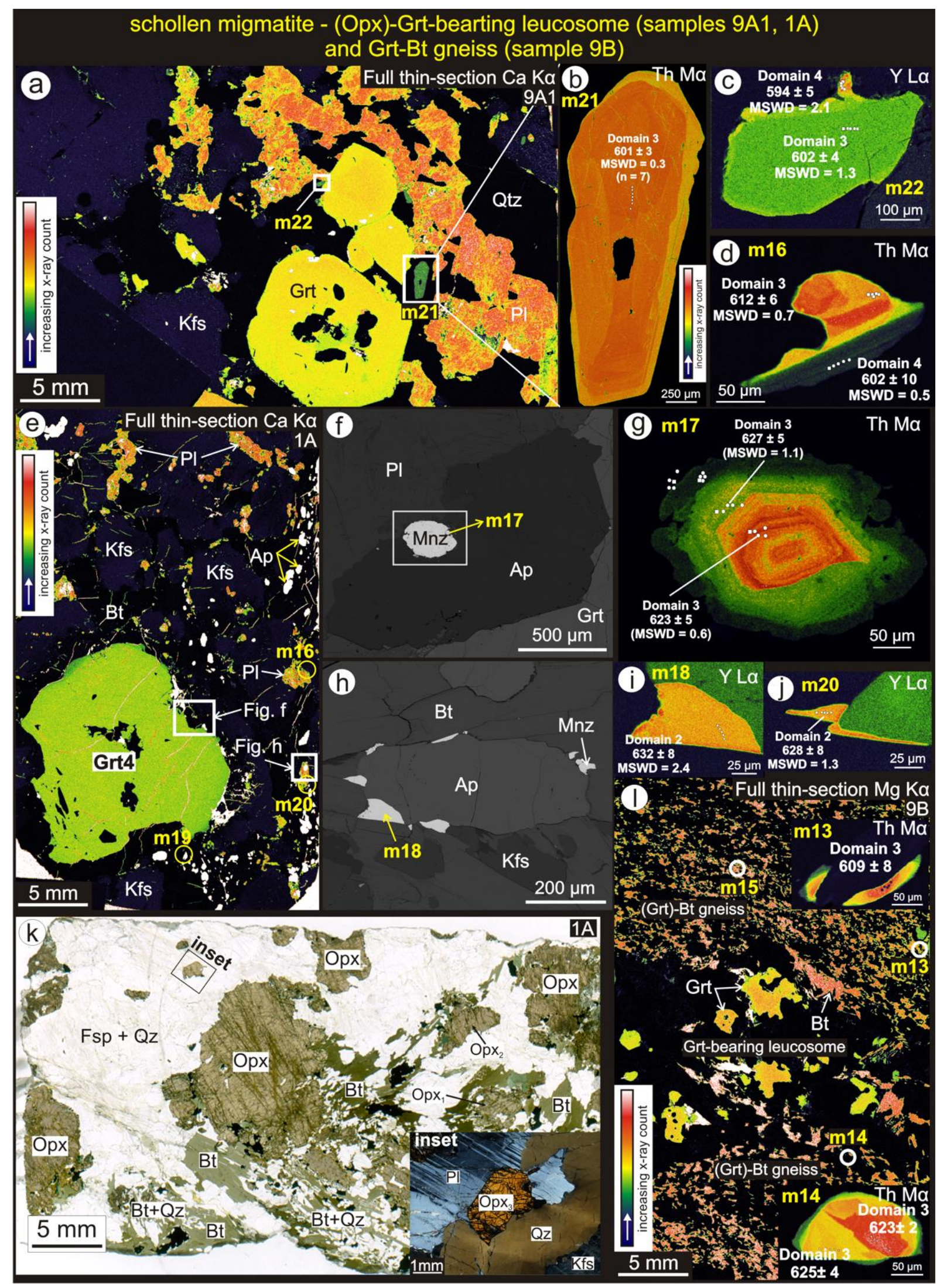

Figure 5: (a) Ca Ka full thin-section map of (orthopyroxene)-garnet-bearing leucosome (sample 9A1) illustrating the textural setting of EPMA analyzed monazite. High-resolution X-ray maps of $(b, d, g)$ Th $M \alpha$ and $(c, i, j) Y L \alpha$ for grains $m 21, m 16, m 17, m 22, m 18$ and $m 20$. Note Th oscillatory zoning in grain m17 and weak oscillatory and sector zoning in large, euhedral monazite grain m21. (e) Ca Ka full thin- 
section map of (orthopyroxene)-garnet-bearing leucosome (sample $1 \mathrm{~A}$ ) illustrating the textural setting of EPMA analyzed garnet and monazite. (f, h) BSE images of apatite-related monazite (grains $\mathrm{m} 17$ and m18, respectively). (k) Photograph of standard thin-section of (orthopyroxene)-garnet bearing leucosome (sample $1 \mathrm{~A}$ ), illustrating subhedral orthopyroxene megacrysts partially replaced by biotite + quartz intergrowths. Inset in the lower right is a photomicrograph with crossed polarized light of $\mathrm{Opx}_{3}$. (I) Mg Ka full thin-section map of (garnet)-biotite gneiss illustrating the textural setting of EPMA analyzed monazite. Insets in the lower right and upper right are high-resolution Th M $\alpha$ X-ray maps of grains $\mathrm{m} 14$ (Th sector zoning) and $\mathrm{m} 13$ (Th-rich rims overgrowing zircon), respectively.

\subsection{Garnet-absent leucosome (sample 7A)}

Garnet-absent leucosome is composed of coarse-grained perthite, plagioclase, interstitial quartz, scarce biotite $(<5 \%)$ and zircon, monazite, apatite, opaques, chlorite and calcite as accessory phases. Many perthite megacrysts have rounded quartz and subhedral plagioclase, biotite and monazite inclusions, and are surrounded by myrmekite. Skeletal biotite intergrown with quartz may occur adjacent to myrmekite.

\subsection{Schollen of (garnet)-biotite gneiss (sample 9B)}

The schollen of (garnet)-biotite gneiss is fine to medium-grained and composed of plagioclase, quartz, biotite, and minor garnet, with opaque minerals, apatite, zircon, monazite, muscovite and chlorite as accessory phases. Monazite occurs as matrix-related grains or overgrowths on zircon (grains m14 and m13; Fig. 5l). The compositional banding is defined by millimeter-scale granoblastic bands composed mainly of plagioclase, quartz and minor biotite interleaved with biotite-rich lepidoblastic bands. Remnants of in-situ leucosome are locally recognized in granoblastic bands with K-feldspar. A 10-15 $\mathrm{mm}$ wide garnet-bearing leucosome vein, parallel to the compositional layering of the gneiss, can be seen in the center of the thin-section from sample 9B (Fig. 5I). The leucosome is composed of garnet, quartz, K-feldspar, plagioclase, and biotite. Garnet is partially replaced by skeletal intergrowths of biotite + quartz.

\subsection{Retrogressed mafic granulite (sample 7C)}

The mafic granulite is fine-grained and composed of orthopyroxene, hornblende, plagioclase, quartz, biotite, with minor opaques and with apatite, zircon, chlorite and calcite as accessory phases. Subhedral orthopyroxene with inclusions of opaques is related to the metamorphic peak conditions, with extensive retrograde overprint of amphibole and/or biotite+quartz intergrowths. Plagioclase $\left(A n_{20}\right)$ occurs as anhedral grains associated with hornblende and orthopyroxene. Scarce zircon is present as rounded, equidimensional grains within the nematogranoblastic matrix. The mafic granulite is cross-cut by a $\sim 1 \mathrm{~cm}$ wide tonalitic leucosome. 


\section{$5 P-T$ conditions of granulite-facies metamorphism}

Compositions of coexisting garnet and orthopyroxene are used to estimate the pressuretemperature conditions using garnet-orthopyroxene Al-solubility-based thermobarometry, corrected for late Fe-Mg exchange (Pattison et al., 2003). P-T results are reported in ANEXO IV. Peak metamorphic conditions of the M1 stage are calculated using garnet (garnet 4) and Al-rich orthopyroxene core compositions and vary from $918-1139{ }^{\circ} \mathrm{C}$ and $10.3-13 \mathrm{kbar}$, with average P-T conditions of $1027 \pm 108^{\circ} \mathrm{C}, 11.7 \pm 1.4 \mathrm{kbar}$. Orthopyroxene rims have slightly lower Al contents than cores. Based on the assumption that Al content in orthopyroxene is controlled by a Tschermaks exchange vector and that Al diffusion is negligible (Kelsey \& Hand, 2015 and references therein), orthopyroxene and garnet rim compositions were used to calculate the M2 metamorphic stage conditions, which gave averages of $865 \pm 38^{\circ} \mathrm{C}, 8.9 \pm 0.8 \mathrm{kbar}$.

The temperature of melt crystallization is constrained by Ti-in-zircon thermometry (Watson et al., 2006). Ilmenite is present and $\mathrm{a}_{\mathrm{T} \mathrm{TO}_{2}}=0.5$ is assumed. The $\mathrm{Ti}$ contents in sector-zoned zircon overgrowths and bright-CL rims vary from 4 to $9 \mathrm{ppm}$ and yield Ti-in-zircon minimum temperatures of ca. $690-734{ }^{\circ} \mathrm{C}$ in the stromatic garnet-biotite metatexite (6D) and (orthopyroxene)-garnet-bearing leucosome (1A). The recrystallized domains in the (garnet)-biotite gneiss (9B) and mafic granulite (7C) yield dates of $c a$. 615-603 Ma and similar minimum Ti-in-zircon temperatures, although with slightly lower values of $c a .657-707^{\circ} \mathrm{C}$ for the mafic granulite. Soccer ball zircon (e.g. grain 14; Fig. 6e) yielded $607 \pm 4 \mathrm{Ma}$ and $700{ }^{\circ} \mathrm{C}$, recording melt crystallization in the mafic granulite.

\section{Zircon composition and age}

Analytical procedures for LA-ICP-MS are described in Appendix A. Zircon grains are shown in Fig. 6. Five distinct domains are identified by $\mathrm{CL}$ imaging of zircon. Lowly luminescent xenocrystic cores with preserved oscillatory zoning (domain 1$)$ are generally surrounded by narrow $(<5 \mu \mathrm{m})$, dark outer rims (domain 2). The zircon overgrowths (20-100 $\mu \mathrm{m}$ wide) prevail in melt-rich samples (6D, 1A, 7A) and are characterized by an internal moderately luminescent zone typically exhibiting sector, fir-tree and/or oscillatory zoning (domain 3 ) followed by a high luminescent domain with sector and fir-tree zoning, locally grading into planar oscillatory zoning at the outer rims (domain 4). Zircon in melt-poor samples (9B, 7C) commonly displays xenocrystic cores partially surrounded or truncated by reaction fronts, followed by lowly luminescent recrystallized domains (domain 5) (Fig. 7a). Sector zoned overgrowths, bright-CL rims and recrystallized domains are mostly depleted in REE, $\mathrm{Y}$ and $\mathrm{U}$ compared to xenocrystic cores. The relative depletion in HREE relative to MREE is indicated by higher $\mathrm{Yb}_{\mathrm{N}} / \mathrm{Gd}_{\mathrm{N}}$ ratios, thus leading to flatter chondrite-normalized REE patterns (Fig. 7), except for the (orthopyroxene)-garnet-bearing leucosome (sample 1A). Yttrium concentration is distinctly 4-6 times higher in xenocrystic cores. Zircon overgrowths also have less pronounced positive Ce and marked 
negative Eu anomalies and slightly higher $\mathrm{Hf}$ contents (av. $1.2 \mathrm{wt} \% \mathrm{HfO}_{2}$ vs. 0.9 wt\% $\mathrm{HfO}_{2}$ ). The key trace element data from different zircon domains in each rock type are presented in Table 1. Corresponding $\mathrm{U}-\mathrm{Pb}$ and trace element analyses are summarized in Tables $\mathrm{A} 1$ and $\mathrm{A} 2$ and shown in Figs. 7 and 8, respectively. Grey-filled ellipses correspond to rejected data (data $>1 \%$ discordant were excluded from concordia age calculations).

Sample 6D contains pink to medium brown elongate zircons ranging from 200-350 $\mu \mathrm{m}$ (3:1 length to width aspect ratio) (Fig. 6a; grains 10,91) and few colorless to pinkish equidimensional grains $(\sim 100 \mu \mathrm{m})$ with rounded xenocrystic cores and wide "metamorphic" overgrowths (Fig. 6a; grains 9, 49). A total of sixty analyses were obtained from the stromatic garnet-biotite metatexite (sample 6D, Fig. 8a, b). Two analyses yielded older ${ }^{207} \mathrm{~Pb} /{ }^{206} \mathrm{~Pb}$ dates of $1470 \pm 210$ and $3100 \pm 260 \mathrm{Ma}$, but both are highly discordant ( $21 \%$ and $55 \%$, respectively) with high errors and are not shown in Fig. 8a. Oscillatory zoned xenocrystic cores $(n=21)$ have a large scatter of concordant ${ }^{206} \mathrm{~Pb} /{ }^{238} \mathrm{U}$ dates from $641 \pm 11$ to $798 \pm 8 \mathrm{Ma}$ (black ellipses in Fig. 8a). Sector, fir-tree and/or oscillatory zoned overgrowths and bright$\mathrm{CL}$ outer rims (blue and red ellipses in Fig. 8b, respectively) give a combined concordia age of $613 \pm 1$ Ma ( $n=34 ; M S W D=1.3)$. Three discordant analyses were excluded from concordia age calculations.

The (orthopyroxene)-garnet-bearing leucosome (sample 1A) contains four distinct zircon populations. The predominant types are pink to medium brown elongate grains ranging from 100-200 $\mu \mathrm{m}(2: 1$ aspect ratios) (Fig. 6b; grains 7, 86) and pink to colorless euhedral "soccer ball" zircons with sector and planar zoning (Fig. 6b; grains 40, 61, 63). Few elongate dark brown grains of $400 \mu \mathrm{m}(5: 1$ aspect ratio) exhibit lowly luminescent xenocrystic cores surrounded by discontinuous, thin, bright-CL rims (Fig. 6b; grain 9). ${ }^{206} \mathrm{~Pb} /{ }^{238} \mathrm{U}$ dates from xenocrystic cores $(n=30)$ scatter from $644 \pm 8$ to $759 \pm 14$ Ma. One highly discordant analysis $(17 \%)$, with the oldest ${ }^{207} \mathrm{~Pb} /{ }^{206} \mathrm{~Pb}$ date of $2082 \pm 22 \mathrm{Ma}$ is considered inconclusive and therefore not shown in Fig. 8c (see Table A1). "Soccer ball" zircons and bright-CL rims yielded a combined concordia age of $613.6 \pm 1.4 \mathrm{Ma}(n=36 ; M S W D=1.5)$. Soccer ball zircons give a concordia age of $613 \pm 1.7 \mathrm{Ma}\left(\mathrm{n}=13 ; \mathrm{MSWD}=1.3\right.$ ) (Fig. $8 \mathrm{~d}$ ). The youngest ${ }^{206} \mathrm{~Pb} /{ }^{238} \mathrm{U}$ dates on highly luminescent rims ranging from 572 to $586 \mathrm{Ma}$ are $>3 \%$ discordant (Fig. 8c) and were rejected from the concordia age calculation.

Zircon populations in the garnet-absent leucosome (sample 7A) comprise pink to medium brown elongate grains (200-400 $\mu \mathrm{m} ; 3: 1$ to $4: 1$ aspect ratios) with rounded terminations and colorless to pink ovoid grains ( $100 \mu \mathrm{m} ; 2: 1$ aspect ratios) (Fig. 6c; grains 44,61$)$. Xenocrystic cores $(n=24)$ yielded ${ }^{206} \mathrm{~Pb} /{ }^{238} \mathrm{U}$ dates ranging from $749 \pm 22$ to $641 \pm 8 \mathrm{Ma}$ (Fig. 8e). Thirty analyses of sector-zoned, fir-tree or oscillatory zoned overgrowths and bright-CL rims range between $628 \pm 10$ to $605 \pm 9$, and give a combined concordia age of $617.7 \pm 1.6 \mathrm{Ma}$ (only ${ }^{206} \mathrm{~Pb} /{ }^{238} \mathrm{U}$ dates with $<1 \%$ discordance; 20 ; MSWD=0.92) (Fig. 8f). 

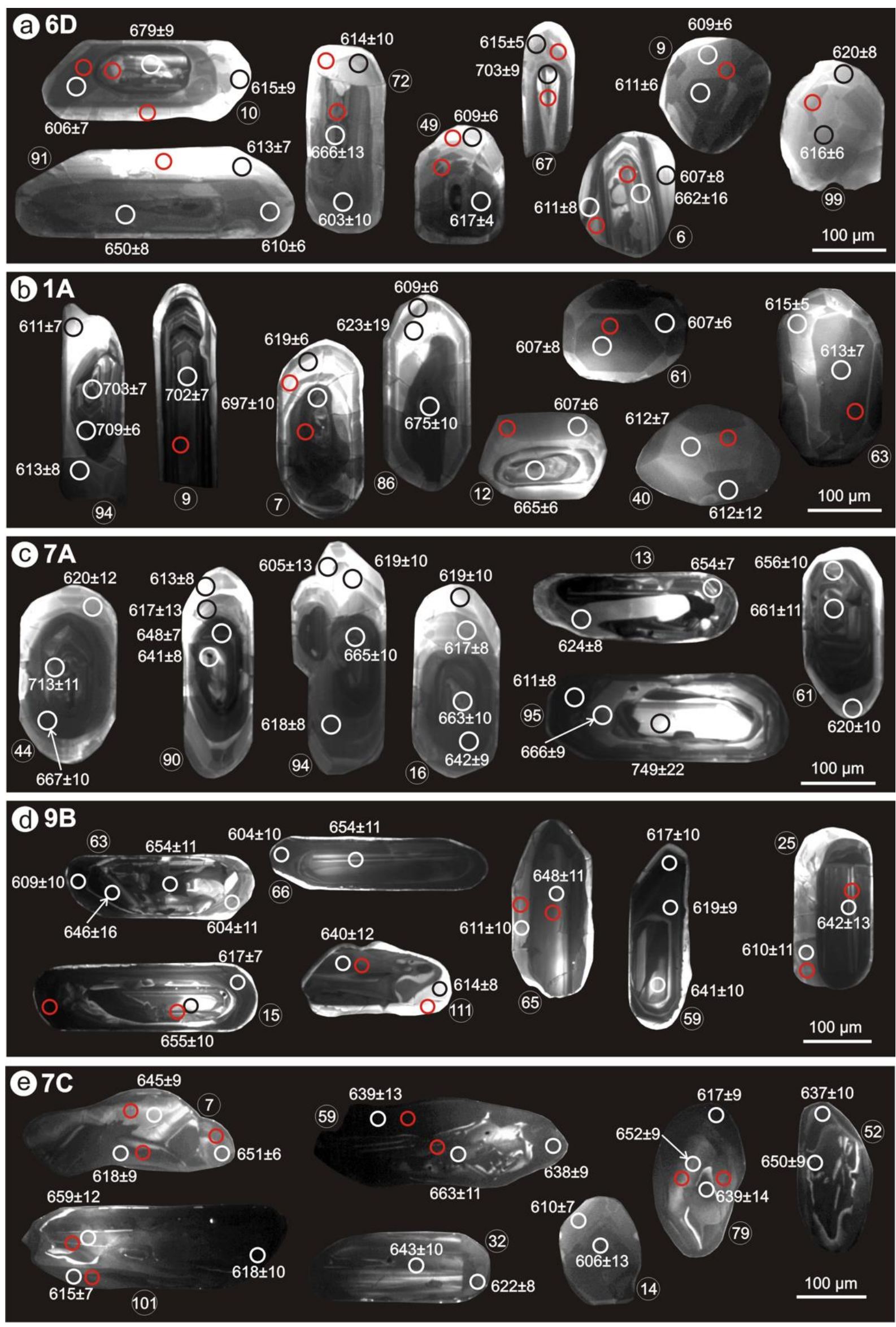

Figure 6: Cathodoluminescence $(C L)$ images of representative zircon grains, with the location of LAICP-MS spot analyses (20 $\mu \mathrm{m}$ diameter) and corresponding ${ }^{206} \mathrm{~Pb} /{ }^{238} \mathrm{U}$ ages in Ma. Red circles indicate 
the location of trace element analyses (15 $\mu \mathrm{m}$ diameter). (a) zircon from stromatic garnet-biotite metatexite, characterized by xenocrystic cores with thick overgrowths typically displaying sector zoning. (b) zircon from (orthopyroxene)-garnet-bearing leucosome with xenocrystic cores surrounded by thick overgrowths with sector, fir-tree and/or oscillatory zoning, and "soccer ball" zircon. (c) zircon from garnet-absent leucosome with xenocrystic cores overgrown by sector zoned rims. (d) zircon from (garnet)-biotite gneiss, with xenocrystic cores partially surrounded by reaction fronts and recrystallization domains, locally with bright-CL rims. (e) zircon from mafic granulite that occurs as rafts within the garnet-absent leucosome, characterized by blurred and convoluted xenocrystic cores, followed by discontinuous reaction fronts and an external featureless recrystallized domain.

The dominant zircon type in the garnet-biotite gneiss (sample 9B) is pink to colorless, and elongate with rounded terminations (200-400 $\mu \mathrm{m}$; 4:1 to 5:1 aspect ratios) (Fig. 6d; Zrn15, 66). Xenocrystic cores yielded dates ranging from $637 \pm 14$ to $663 \pm 11$ by twenty analyses (Fig. $8 \mathrm{~g}$ ). ${ }^{206} \mathrm{~Pb} /{ }^{238} \mathrm{U}$ dates obtained for recrystallized domains and bright-CL rims $(n=21 ; 4$ analyses with $>1 \%$ discordance were rejected) range from $620 \pm 8$ to $604 \pm 11 \mathrm{Ma}$, and yielded a concordia age of $613 \pm 2 \mathrm{Ma}(\mathrm{n}=17$; MSWD=1.08) (Fig. 8h).

Zircon is dark brown to pinkish in the mafic granulite (sample 7C), with stubby (100-200 $\mu \mathrm{m})$ (Fig. 6e; Zrn14) and elongate prismatic shapes (Fig. 6e; Zrn32) (200-300 $\mu \mathrm{m} ; 2: 1$ to 3:1 aspect ratios). Xenocrystic cores typically display blurred and convoluted oscillatory zoning and produce a cluster of concordant ${ }^{206} \mathrm{~Pb} /{ }^{238} \mathrm{U}$ dates from $657 \pm 16$ to $635 \pm 8 \mathrm{Ma}$, eight analyses are $2-4 \%$ discordant (Fig. $8 \mathrm{i}$ ). Four analyses in two "soccer ball" zircons yielded a combined concordia age of $607 \pm 4 \mathrm{Ma}$ $(M S W D=0.37)$. These soccer ball zircons, together with recrystallized domains and few high luminescent rims spread in age from $623 \pm 7$ to $606 \pm 7 \mathrm{Ma}\left({ }^{206} \mathrm{~Pb} /{ }^{238} \mathrm{U}\right.$ ages, $\left.2 \sigma\right)$ and give a concordia age of $614 \pm 1.8 \mathrm{Ma}(\mathrm{n}=23 ; \mathrm{MSWD}=1.5$ ) (Fig. 8j).

\begin{tabular}{|c|c|c|c|c|c|c|c|c|}
\hline Zircon domains & Zoning & Hf (ppm) & $\mathrm{Y}(\mathrm{ppm})$ & Th (ppm) & $\mathrm{U}(\mathrm{ppm})$ & $\mathrm{Th} / \mathrm{U}$ & $\mathrm{Eu} / \mathrm{Eu}^{*}$ & $\mathrm{Yb}_{\mathrm{N}} / \mathbf{G d}_{\mathrm{N}}$ \\
\hline \multicolumn{9}{|c|}{ stromatic garnet-biotite metatexite (sample 6D) } \\
\hline xenocrystic cores & $\mathrm{oz}$ & $8993(7130-10150)$ & $1380(469-2820)$ & $186(36-345)$ & $420(130-1245)$ & $0.45(0.04-1.44)$ & $0.18(0.11-0.22)$ & $14.4(9.7-18.8)$ \\
\hline low -moderate $\mathrm{CL}$ overgrow ths & $\mathrm{sz}, \mathrm{ftz}$ & $12008(11030-12760)$ & $354(237-575)$ & $163(76-231)$ & $387(128-921)$ & $0.43(0.2-1.18)$ & $0.16(0.11-0.22)$ & $2.9(1.5-6.7)$ \\
\hline bright-CL rims & $\mathrm{sz}, \mathrm{oz}$ & $11992(11420-12650)$ & $309(253-354)$ & $67(42-89)$ & $174(102-385)$ & $0.42(0.23-0.5)$ & $0.17(0.09-0.25)$ & $4.1(1.5-6.1)$ \\
\hline \multicolumn{9}{|c|}{ (orthopyroxene)-garnet-bearing leucosome (sample 1A) } \\
\hline xenocrystic cores & $\mathrm{oz}$ & $10780(9820-12190)$ & $1461(702-2160)$ & $104(44-222)$ & $700(165-3160)$ & $0.26(0.02-0.76)$ & $0.12(0.09-0.14)$ & $20.5(9.7-18.8)$ \\
\hline low -moderate $\mathrm{CL}$ overgrow ths & $\mathrm{sz}, \mathrm{ftz}$ & $12361(11480-13500)$ & $1170(744-1394)$ & $106(50-185)$ & $357(130-976)$ & $0.35(0.07-0.63)$ & $0.09(0.07-0.10)$ & $15.6(12.3-19.8)$ \\
\hline bright-CL rims & $s z, o z$ & $11844(10330-12570)$ & $924(677-1089)$ & $68(17-131)$ & $320(111-1193)$ & $0.35(0.03-0.57)$ & $0.12(0.08-0.13)$ & $16.1(14.3-18.2)$ \\
\hline \multicolumn{9}{|l|}{ garnet-biotite gneiss (sample 9B) } \\
\hline xenocrystic cores & $\mathrm{oz}$ & $9082(7820-10080)$ & $1534(900-2470)$ & $140(26-361)$ & $351(164-653)$ & $0.42(0.06-0.74)$ & $0.14(0.11-0.17)$ & $17.1(12.1-21.9)$ \\
\hline recrystallization domain & - & $11173(10840-11790)$ & $371(245-487)$ & $33(15-51)$ & $386(54-610)$ & $0.15(0.05-0.46)$ & $0.12(0.12-0.13)$ & $5.8(4.3-8.6)$ \\
\hline bright- $\mathrm{CL}$ rims & $\mathrm{oz}$ & $10255(9810-10700)$ & $439(199-679)$ & $54(18-195)$ & $499(300-841)$ & $\mathbf{0 . 1 1}(0.05-0.32)$ & $0.10(0.08-0.13)$ & $13.9(2.4-25.5)$ \\
\hline \multicolumn{9}{|l|}{ mafic granulite (sample $7 C$ ) } \\
\hline xenocrystic cores & $\mathrm{oz}$ & $8410(6130-9670)$ & $2473(1590-3380)$ & $427(176-700)$ & $1562(339-7450)$ & $0.55(0.05-1.2)$ & $0.18(0.15-0.21)$ & $23(20-26)$ \\
\hline altered xenocrystic cores & $\mathrm{oz}$ & 9670 & 1590 & $129(28-375)$ & $1124(601-2890)$ & $0.13(0.02-0.60)$ & 0.23 & 31 \\
\hline recrystallization domain & - & $10980(10360-11700)$ & $385(240-492)$ & $111(34-369)$ & $942(273-1090)$ & $0.12(0.05-0.44)$ & $0.32(0.09-0.51)$ & $22(4.7-55)$ \\
\hline
\end{tabular}

Table 1: Summary of trace element data from different zircon domains in each rock type. 

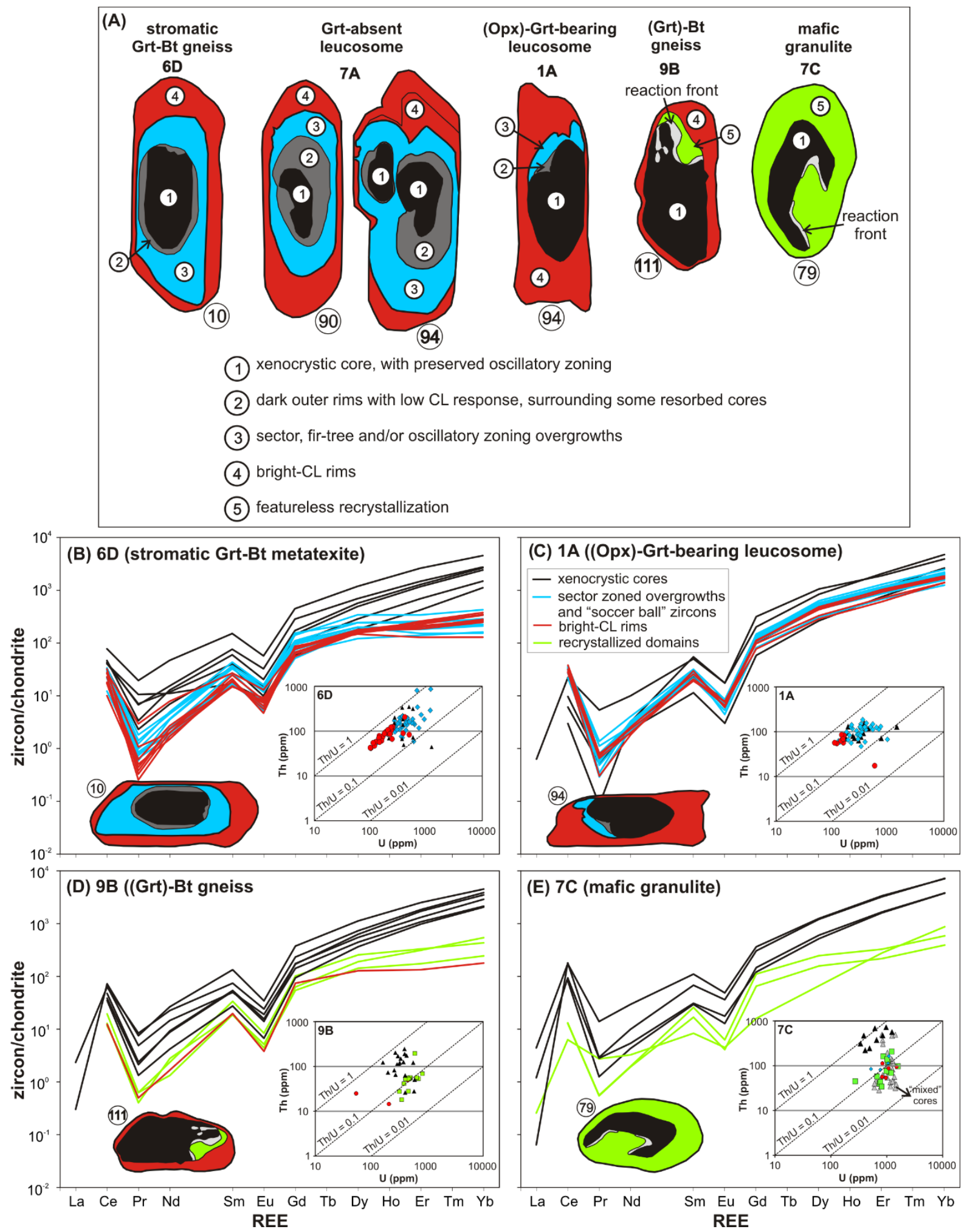

Figure 7: Zircon REE patterns normalized to the chondrite values of McDonough \& Sun (1995), colorcoded by distinct zircon internal structures. 

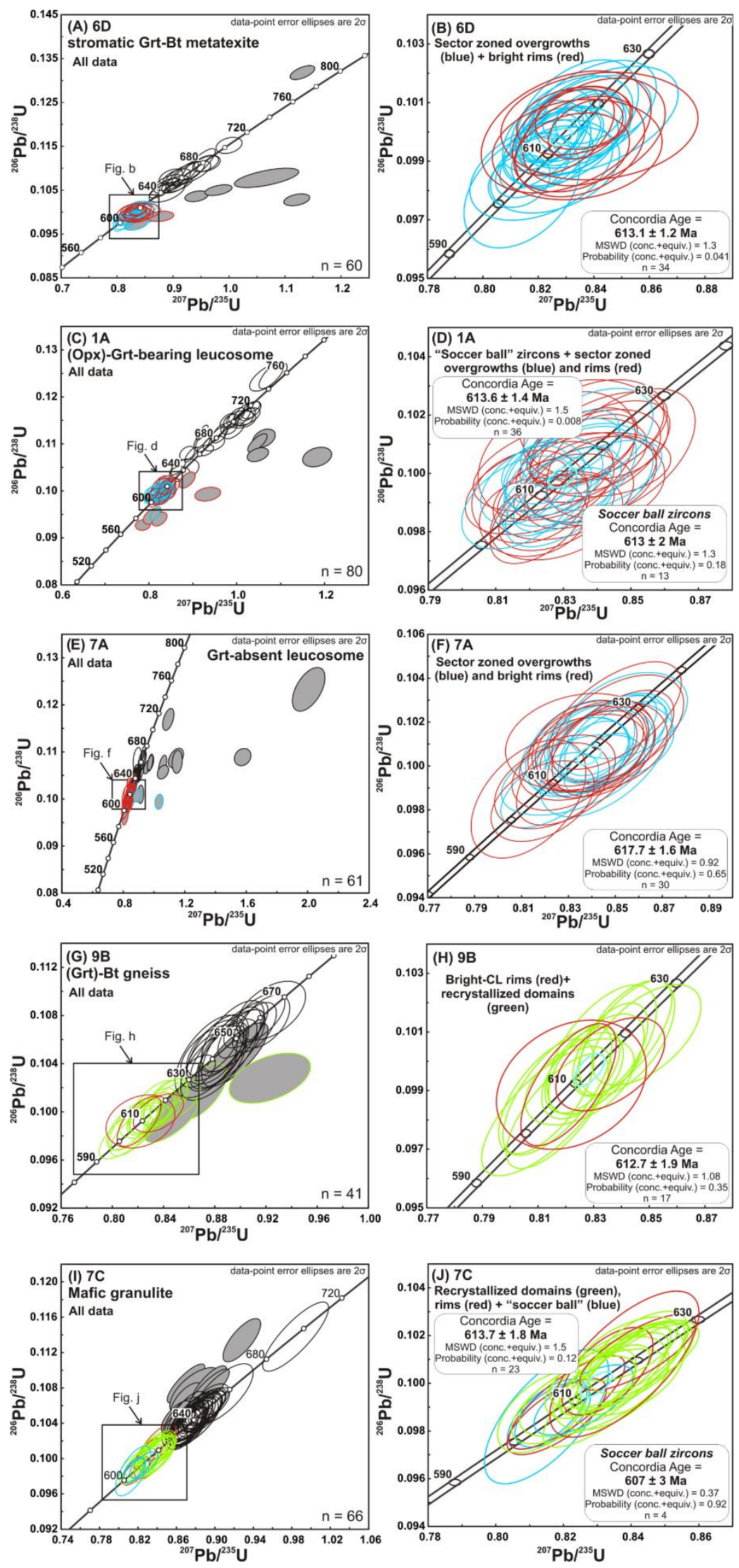

Figure 8: Concordia diagrams showing the results for zircon LA-ICP-MS U-Pb analyses ( $2 \sigma$ error ellipses) from stromatic garnet-biotite metatexite, (orthopyroxene)-garnet-bearing leucosome, garnet-absent leucosome, (garnet)-biotite gneiss and mafic granulite samples (a, c, e, g, i) of the Socorro-Guaxupé 
Nappe and corresponding concordia ages related to the metamorphic event (b, $d, f, h, j)$. Color-coding follows Figure 5. Dark-grey filled ellipses correspond to rejected data.

\section{Monazite composition and age}

Twenty-two monazite grains (numbered from $\mathrm{m} 1$ to $\mathrm{m} 22$ - see Table 2 for details) were analyzed and their locations within the thin-section are indicated in Figs. 3 and 5. Analytical procedures for EPMA are described in Appendix A. Chondrite-normalized REE patterns and compositional variation in monazite are illustrated in Figs. 9 and 10, respectively. U-Th-Pb geochronology, trace element data and calculated dates are summarized in ANEXO IX and Fig. 11. Monazite grains are present in a wide variety of textural settings. Matrix-type monazite (100 $\mu \mathrm{m}$ up to $3 \mathrm{~mm}$ in diameter) is generally euhedral, and typically occurs enclosed in matrix feldspar, quartz and/or biotite. Grain m21 (Fig.5b) in the (orthopyroxene)-garnet bearing leucosome (sample 9A1) has well-developed crystal morphology, secondary twinning, sharp contact with matrix quartz and inclusions of feldspar, quartz and biotite. Rare anhedral monazite with lobate morphology (grain m16; Fig. 5d) also occur within matrix feldspar. Zircon can be found completely enclosed (Figs. A1 and 3e) or partially rimmed by matrix monazite (grains $\mathrm{m} 2$ and $\mathrm{m} 13$, respectively) (Fig. $5 \mathrm{l}$ ). Matrix monazite is also present as tiny, irregular-shaped grains grown around the apatite surface (grains m18, m20; Figs. 5h-j) in the (orthopyroxene)-garnet bearing leucosome (sample $1 \mathrm{~A}$ ). Monazite inclusions in garnet are common in the stromatic garnetbiotite metatexite and occur as roundish fine-grained crystals with 50 to $150 \mu \mathrm{m}$ diameter (Figs. 3b, d, h).

Monazite compositional variation in the stromatic garnet-biotite metatexite is mainly controlled by the cheralite substitution $\left(\mathrm{Th}^{4+}+\mathrm{Ca}^{2+}=2 \mathrm{REE}^{3+}\right)$, whereas some of the matrix-type grains with late recrystallization follow the huttonite substitution trend $\left(\mathrm{Th}^{4+}+\mathrm{Si}^{4+}=\mathrm{REE}^{3+}+\mathrm{P}^{5+}\right)$ (Fig. 10a). A compositional trend between monazite inclusions in garnet (Type $I I$ ) and matrix-type grains (Type $I$ ) is defined by higher $\mathrm{Y}$ and lower LREE concentrations in monazite inclusions compared to matrix-type monazite (Fig. 10b, c). High resolution $\mathrm{CaK} \alpha, \mathrm{Nd} L \alpha, \mathrm{U} M \beta, \mathrm{Y} L \alpha$ and ThM $\alpha \mathrm{X}$-ray maps (Figs. A2, A3 and A4) were crucial to identify distinct monazite compositional domains within the same sample and among different lithotypes. Contrasting $Y$ and Th concentrations were particularly helpful, and five compositional domains were recognized in samples $6 D 1,6 D 2,9 B, 1 A$ and $9 A 1$ according to these zoning patterns: (1) Y-rich cores, (2) Y-rich rims related to apatite, (3) Th-rich, Y-poor monazite, (4) Yrich rims related to matrix feldspar and/or biotite and (5) Th-rich rims (see Table 2 for details).

Monazite inclusions in garnet preserve complex patchy zoning with remnants of Y-rich cores (7000-26000 ppm) (e.g. grain m5; Fig. 3d). Domain 1 consists of $Y$-rich resorbed cores exhibiting the highest MREE-HREE concentration compared to other compositional domains (grain m11; Figs. 3h and 9a). Dates range from $631 \pm 4 \mathrm{Ma}(\mathrm{MSWD}=0.8$ ) to $612 \pm 4 \mathrm{Ma}(\mathrm{MSWD}=1)$, with a weighted mean of 
$623 \pm 17 \mathrm{Ma}$ ( $\mathrm{n}=2$ sets of 5 points, MSWD=11.1) in sample 6D2. Domain 2 corresponds to small monazite grains surrounding apatite, with distinct low Th concentrations (0.1-0.5 wt $\left.\% \mathrm{ThO}_{2}\right)$, high LREE (0.834$0.85 \mathrm{pfu}$ ) and total REE (0.912-0.948 pfu) (Fig. 10c, d). It has the highest Si+Y+REE (Fig. 10e) and a nearuniform ( $\mathrm{La} / \mathrm{Sm})_{\mathrm{N}}$ ratio (Fig. 10f). Dates for Domain 2 monazite range from $632 \pm 8$ to $626 \pm 7 \mathrm{Ma}$, with a weighted mean of $628 \pm 4 \mathrm{Ma}$ ( $n=3$ sets of 5 points, MSWD=0.67).

\begin{tabular}{ccccccc}
\hline \multirow{2}{*}{ Monazite } & \multirow{2}{*}{ Textural } & \multicolumn{5}{c}{ Compositional domain } \\
\cline { 3 - 7 } grain label & setting $^{\mathrm{a}}$ & $\mathbf{1}$ & 2 & 3 & 4 & 5 \\
& & Y-rich cores & Y-rich rims & Th-rich, y-poor & Y-rich rims & Th-rich rims \\
\hline
\end{tabular}

stromatic garnet-biotite metatexite (sample 6D1)

$\begin{array}{lcl}\mathrm{m} 1 & \text { II } & \mathrm{x} \\ \mathrm{m} 2 & \text { III } & \\ \mathrm{m} 3 & \mathrm{I} & \\ \mathrm{m} 4 & \text { I, II } & \mathrm{x} \\ \mathrm{m} 5 & \text { II } & \mathrm{x} \\ \mathrm{m} 6 & \mathrm{I} & \\ \mathrm{m} 7 & \mathrm{I} & \end{array}$

stromatic garnet-biotite metatexite (sample 6D2)

$\begin{array}{llll}\mathrm{m} 8 & \text { I } & & \mathrm{x} \\ \mathrm{m} 9 & \text { II } & \mathrm{x} & \mathrm{x} \\ \mathrm{m} 10 & \mathrm{I} & & \mathrm{x} \\ \mathrm{m} 11 & \text { II } & \mathrm{x} & \mathrm{x} \\ \mathrm{m} 12 & \mathrm{I} & & \mathrm{x}\end{array}$

garnet-biotite gneiss (schollen migmatite) (sample 9B)

$\begin{array}{lll}\text { m13 } & \text { VI } & x \\ \text { m14 } & \text { I } & x \\ \text { m15 } & \text { I } & x\end{array}$

(orthopyroxene)-garnet-bearing leucosome (schollen migmatite) (sample 1A)

$\begin{array}{lllll}\mathrm{m} 16 & \text { IV } & & \mathrm{x} & \mathrm{x} \\ \mathrm{m} 17 & \mathrm{~V} & & \mathrm{x} & \\ \mathrm{m} 18 & \mathrm{~V} & \mathrm{x} & & \mathrm{x} \\ \mathrm{m} 19 & \mathrm{~V} & \mathrm{x} & & \\ \mathrm{m} 20 & \mathrm{~V} & \mathrm{x} & & \end{array}$

(orthopyroxene)-garnet-bearing leucosome (schollen migmatite) (sample 9A1)

$\begin{array}{llll}\mathrm{m} 21 & \mathrm{I} & \mathrm{x} & \\ \mathrm{m} 22 & \mathrm{I} & \mathrm{x} & \mathrm{x}\end{array}$

\footnotetext{
a Textural setting: I = matrix monazite enclosed in feldspar or biotite; $I$ = inclusion in garnet; III = matrix monazite with zircon inclusions; IV = matrix monazite with lobate shape enclosed in K-feldspar; $\mathrm{V}=$ monazite related to apatite; $\mathrm{VI}=$ monazite overgrowing zircon

${ }^{\mathrm{b}}$ Monazite grain $\mathrm{m} 4$ is partially included in garnet. Note that Th-rich rims developed in part of the grain enclosed by matrix biotite

See text for details
}

Table 2: Monazite textural varieties within the studied rocks, listing the monazite grain label. 


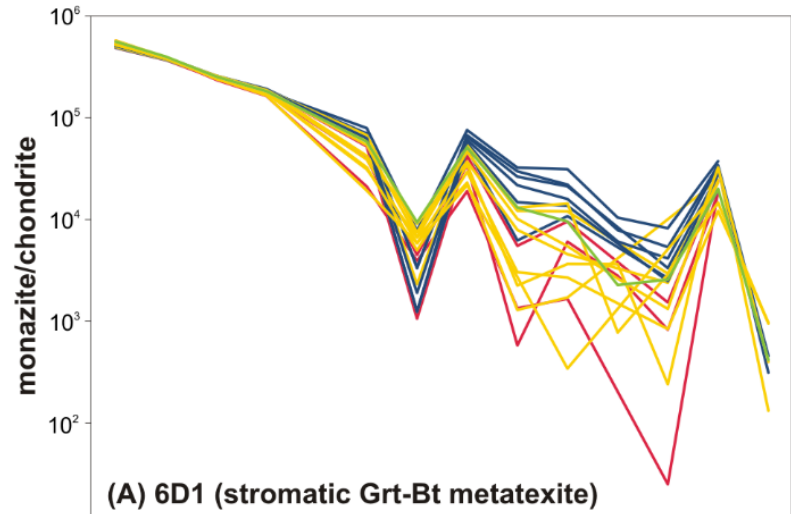

\section{Monazite compositional domains}

Domain 1 (Y-rich cores): pre to syn-garnet growth Domain 2 (Y-rich): pre-garnet growth, related to apatite

Domain 3 (Th-rich, Y-poor): melt crystallization

Domain 4 (Y-rich rims): retrograde garnet breakdown

Domain 5 (Th-rich rims): late recrystallization
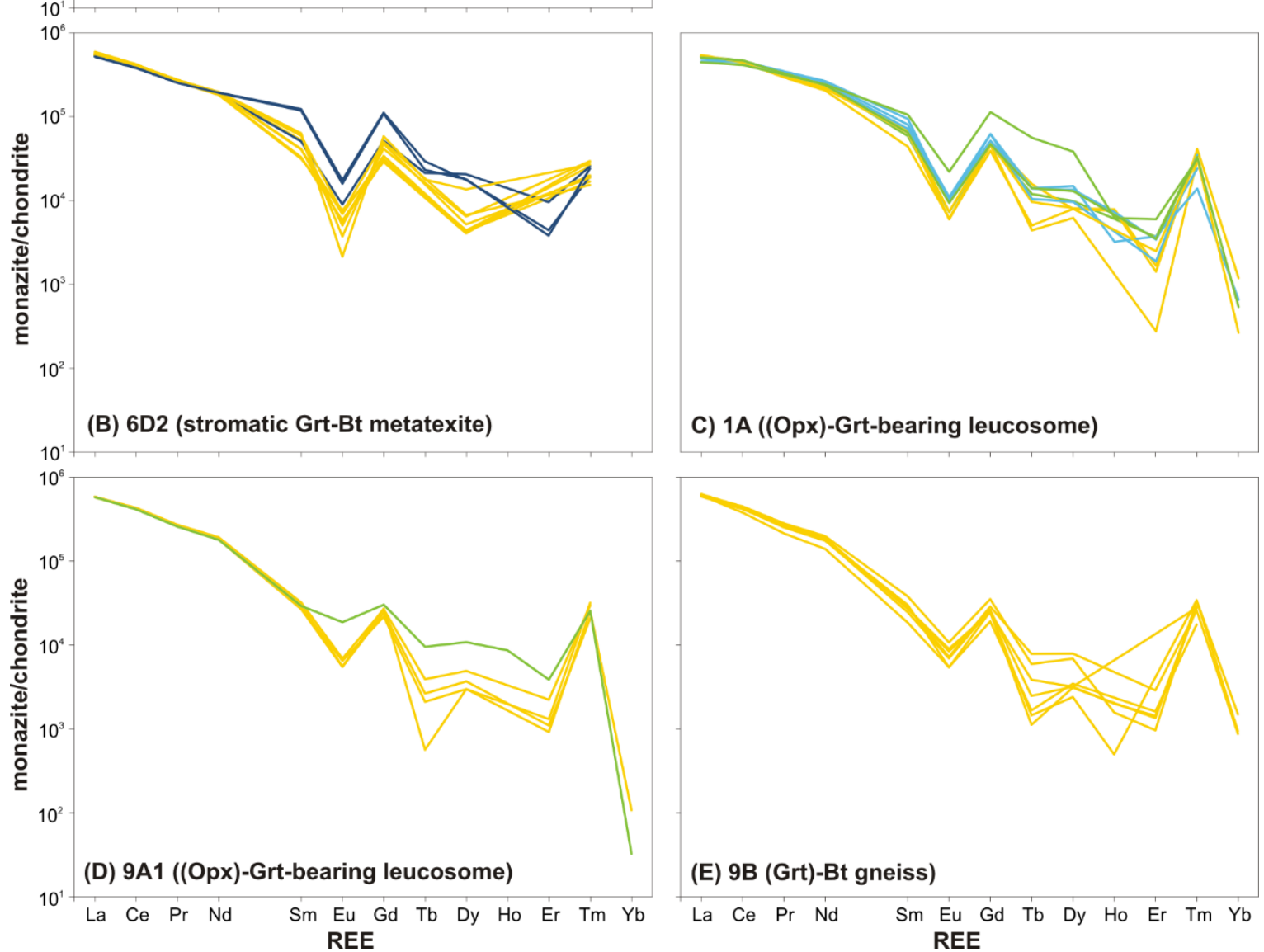

La Ce Pr Nd Sm Eu Gd Tb Dy Ho Er Tm Yb REE

Figure 9: Monazite REE patterns normalized to the chondrite values of McDonough \& Sun (1995), color-coded by distinct compositional domains. 

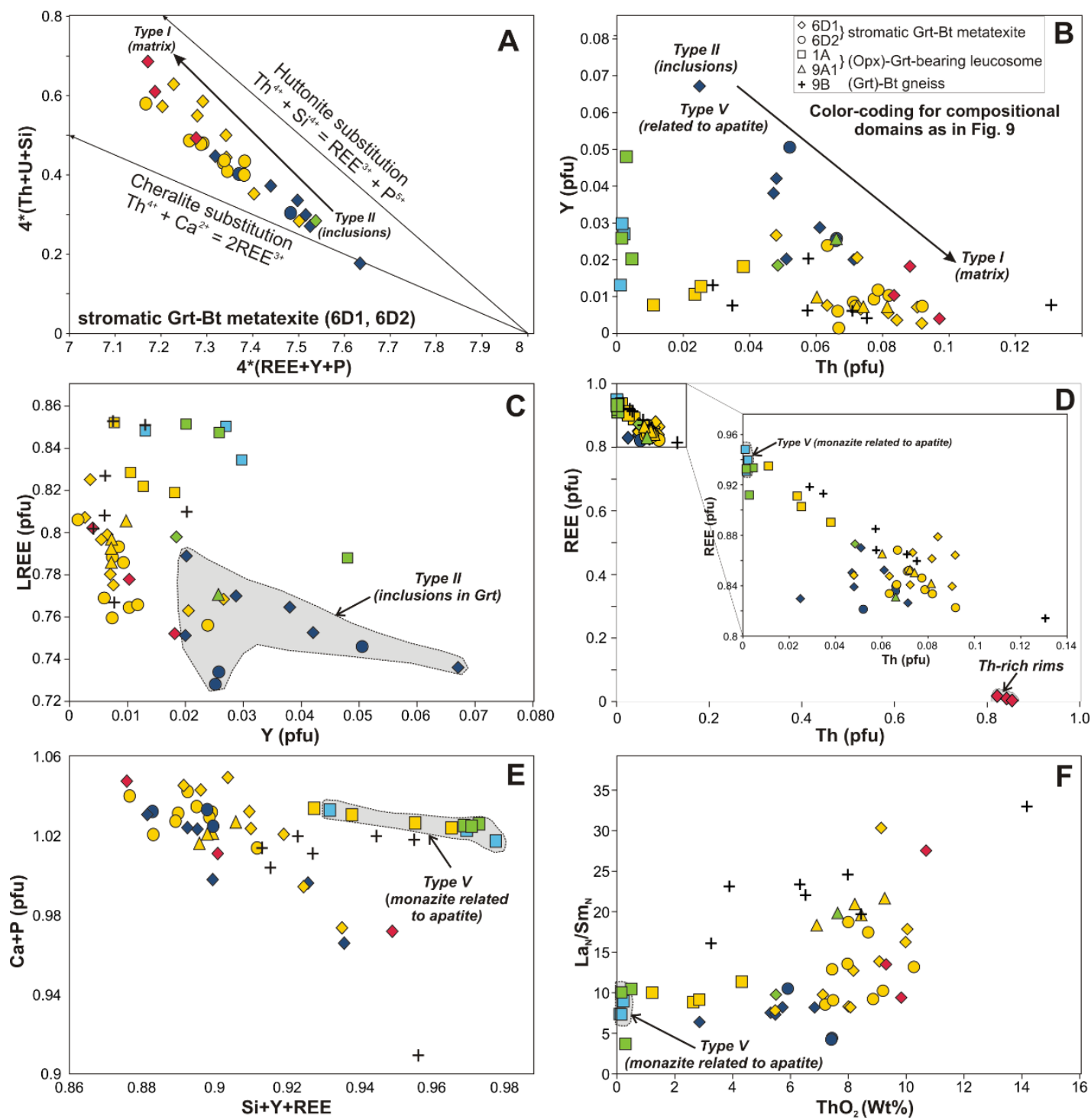

Figure 10: Compositional variation (expressed in cations per formula unit) among monazite textural varieties and between samples. (a) Monazite cation plot normalized to 16 oxygens, with cheralite and huttonite exchange vectors plotted (from Pyle et al., 2001), illustrating the compositional variation between Type II (inclusions in garnet) and Type I (matrix) monazite in the stromatic Grt-Bt metatexite. (b) $Y$ vs. Th and (c) LREE ( $=\sum$ La-Nd) vs. Y, plots, illustrating the negative correlation between LREE and Th related to $Y$ concentration. (d) REE vs. Th plots distinguish Type $V$ (related to apatite) from other monazite. (e) Ca+P vs. Si+Y+REE. (f) $\mathrm{La}_{\mathrm{N}} / \mathrm{Sm}_{\mathrm{N}}$ vs. $\mathrm{ThO}_{2}$ (wt\%). Color-coding follows Figure 9.

Domain 3 monazite is Th-rich (>60000 ppm) and Y-poor and typically occurs as matrix-type grains enclosed in feldspar, quartz and/or biotite (e.g. grains m6, m21 and m22; Figs. 3c, 5b-c) or overgrowing Domain 1 monazite included in garnet (e.g. grains m5 and m11; Figs. 3d, h). They are characterized by MREE, HREE-depletion and pronounced negative Eu anomalies (Fig. 9). REE and $\mathrm{Si}+\mathrm{Y}+\mathrm{REE}$ are variable in this group, without any systematic pattern (Fig. 10c-f). Domain 3 monazite yields a wide spectrum of dates between $629 \pm 4$ to $601 \pm 3 \mathrm{Ma}$, with weighted mean dates of $612 \pm 5 \mathrm{Ma}$ ( $n=7$ sets of $5-6$ points, MSWD=13) and $611 \pm 3 \mathrm{Ma}(\mathrm{n}=7$ sets of 5 points, MSWD=5.3) in monazite cores 
with patchy zoning (grains $\mathrm{m} 5, \mathrm{m6}, \mathrm{m} 12$ ) in the stromatic garnet-biotite metatexite (samples 6D1 and $6 D 2$, respectively). The distribution of dates in sample 9B ((garnet)-biotite gneiss) defines two clusters, and yields the following weighted mean dates: 624 \pm 3 Ma (MSWD=2) in Th-rich sector-zoned cores (up to $124000 \mathrm{ppm}$ ) and 608 $\pm 6 \mathrm{Ma}$ (MSWD=0.091) in Th-rich overgrowth on zircon (e.g. grains m14 and m13, respectively; Figs. $5 \mathrm{I}$ and 11).The distribution of dates in sample 1A ((orthopyroxene)-garnet bearing leucosome) also defines two similar clusters with weighted mean dates of $625 \pm 25 \mathrm{Ma}$ (MSWD=1.3) in Th oscillatory zoned cores and 610 \pm Ma $(M S W D=0.89)$ in a mantle overgrowth on partially resorbed Th oscillatory zoned cores (e.g. grain m17; Fig 5g). Large euhedral grains with weak oscillatory and sector zoning (grains m21, m22; Fig. 5b, c) in sample 9A1 have weighted mean date of $603 \pm 4 \mathrm{Ma}$ ( $\mathrm{n}=4$ sets of 7 points, MSWD=2.1). Domain 4 is represented by Y-rich rims (7000-18000 ppm) in some monazite grains from garnet-bearing lithotypes (Figs. 3c and 5c), with MREE-HREE enrichment compared to Domain 3 monazite (Fig. 9c, d). In sample 1A,

Domain 4 is characterized by very low Th contents $\left(0.15-0.49\right.$ wt\% $\left.\mathrm{ThO}_{2}\right)$ similar to Domain 2 (Fig. 10b), which may be correlated with bulk rock composition. Dates for Domain 4 range between 602-590 Ma and yield a weighted mean date of $601 \pm 6$ Ma ( $n=3$ sets of 5 points, MSWD=0.89) for sample $1 \mathrm{~A}$ (Fig. 11). Domain 5 is characterized by Th-rich rims (9.3-10.7 wt\% $\mathrm{ThO}_{2}$ ) (e.g. grain $\mathrm{m} 2$; Fig. 3e) with a marked MREE-HREE depletion compared to Domain 3 monazite (Fig. 9a). Domain 5 dates range from 597-588 Ma, with a weighted mean date of 593 $\pm 11 \mathrm{Ma}$ ( $\mathrm{n}=3$ sets of 5 points, MSWD=6.2) in the stromatic garnet-biotite metatexite (sample 6D1).

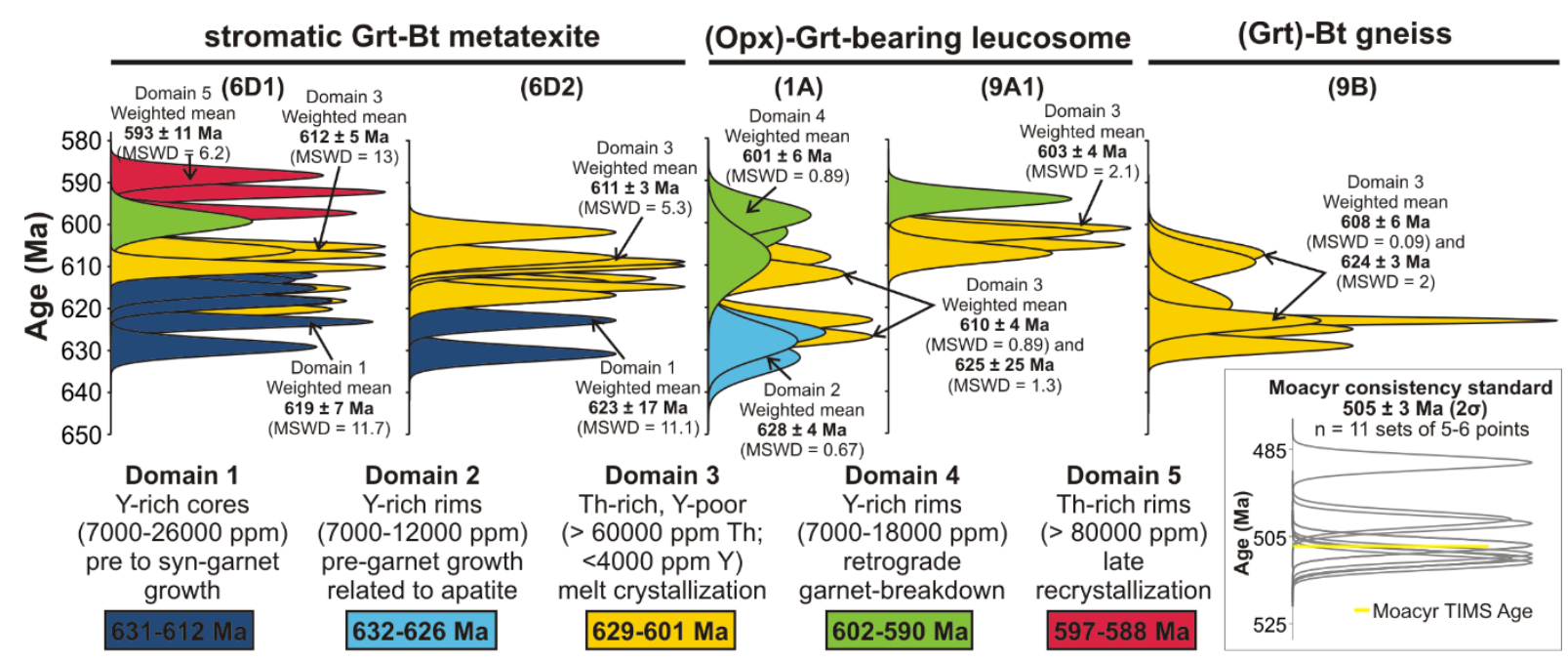

Figure 11: Summary of EMPA monazite geochronology data from SGN plotted as Gaussian probability curves calculated from a set of five analyses, which represents the date and $2 \sigma$ error for a single compositional domain. Color-coding follows Figure 9. 


\section{DISCUSSION}

\subsection{Timing of partial melting and melt crystallization events in the SGN}

The integration of petrographic, textural, geochemical and thermobarometric information with Th, $Y$ and REE systematics in monazite are used in this study to infer the participation of monazite in metamorphic reactions. The results are then combined with geochronological data to unravel the PT-t evolution of (orthopyroxene)-garnet-bearing migmatites and constrain the timing of partial melting and melt crystallization in the SGN. Most zircon growth is related to retrograde cooling of the crystallizing melt. A more complex history from the prograde to retrograde evolution is recorded by five generations of monazite and growth episodes can be linked with specific metamorphic reactions. The complete crystallization sequence of accessory phases and the link with geochronological data is summarized in Fig. 12. A P-T-t evolution path inferred for the (orthopyroxene)-garnet-bearing migmatite is illustrated in Fig. 13.

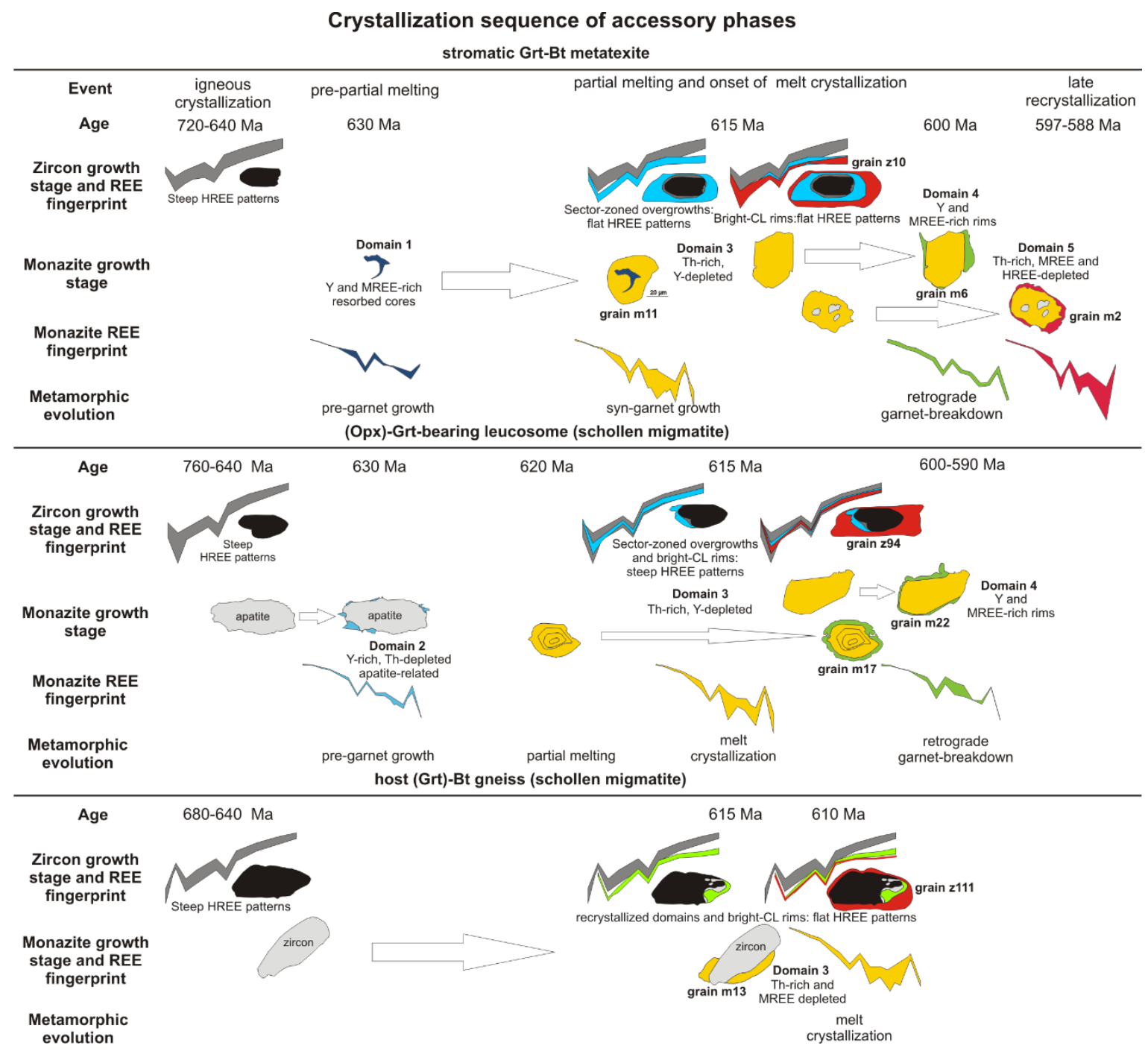


Figure 12: Schematic diagram illustrating the crystallization sequence of zircon and monazite and its correlation with the metamorphic events recorded by the migmatites from the Socorro-Guaxupe Nappe (color-coding follows Figs. 7 and 9, for zircon and monazite, respectively).

\subsubsection{Interpretation and significance of zircon data}

LA-ICP-MS U-Pb zircon ages from five samples indicate the presence of two well-defined age groups: oscillatory zoned xenocrystic cores (ca. 800-640 Ma) and sector, fir-tree and/or oscillatory zoned overgrowths, bright-CL rims and recrystallized domains (ca. 630-600 Ma, with a combined concordia age of ca. $613 \mathrm{Ma}$ for all samples). Oscillatory zoned xenocrystic cores ( $\mathrm{n}=167)$ are texturally and chemically distinct from the metamorphic zircon overgrowths. They yielded the oldest dates of $c a$. 800-640 Ma, interpreted as inheritance from the pre-collisional magmatism in the SGN. Xenocrystic cores display convoluted oscillatory zoning truncated by reaction fronts in the (garnet)-biotite gneiss and mafic granulite (samples 9B and $7 \mathrm{C}$ ). Irregular domains adjacent to reaction fronts have some features of recrystallized domains such as low Th/U ratio of 0.06 , high $\mathrm{Hf}\left(1.0 \mathrm{wt} \% \mathrm{HfO}_{2}\right)$ and low $\mathrm{Y}$ contents $(240 \mathrm{ppm})$, contrasting to HREE-enriched patterns $\left(\mathrm{Yb}_{N} / \mathrm{Gd}_{\mathrm{N}}=54\right)$ common in xenocrystic cores. This distinct behavior may reflect a "ghost texture" of a relict oscillatory zoned core that was not fully recrystallized (e.g. Pidgeon, 1992; Hoskin \& Black, 2000; Corfu et al., 2003). Thus their ca. 632$642 \mathrm{Ma}$ range might represent mixed ages between inherited cores and younger recrystallized domains.

New zircon growth is controlled by bulk rock composition and availability of melt (e.g. Rubatto et al., 2001). Not surprisingly, sector, fir-tree and/or oscillatory zoned zircon overgrowths, which are consistent with granulite-facies zircon growth in the presence of anatectic melt (Vavra et al., 1999; Hoskin \& Schaltegger, 2003; Kelly \& Harley, 2005), are most abundant in the (orthopyroxene)-garnetbearing leucosome and stromatic garnet-biotite metatexite (samples $1 A$ and 6D). The (orthopyroxene)-garnet-bearing leucosome (sample 1A) exhibits REE concentrations and Th/U ratios similar to inherited xenocrystic cores, which is expected for zircon growth in the presence of large amounts of melt due to an advanced stage of dehydration melting (Schaltegger et al., 1999). The timing of melt crystallization is constrained by "soccer ball" zircons, typical of growth from a melt (e.g. Harley et al., 2007). Results indicate a main growth stage at ca. $613 \mathrm{Ma}$ recorded by the (orthopyroxene)garnet-bearing leucosome (sample $1 \mathrm{~A}$ ) and final stages of melt crystallization are recorded at ca. 607 Ma in the mafic granulite (sample 7C). The replacement of zircon by xenotime can occur by a coupled dissolution-reprecipitation process, where most of the unstable and $\mathrm{Y}, \mathrm{HREE}, \mathrm{Th}, \mathrm{P}$-enriched zircon is dissolved and reprecipitated along the reaction interface (e.g. Tomaschek et al., 2003; Geisler et al., 2007). This is in agreement with petrographic observation, where oscillatory zoned, Y-rich zircon (av. $1380 \mathrm{ppm}$ ) is partially replaced by late xenotime along a fracture in sample 6D (Fig. A1). 


\subsubsection{Linking the five monazite generations with the P-T-t evolution of the SGN}

Several studies have established a link between monazite compositional zoning and nettransfer metamorphic reactions involving garnet, based on the partitioning of $Y$ and HREE between garnet, monazite and xenotime. In garnet-bearing rocks, high $\mathrm{Y}$ monazite is typically related to a prograde stage prior to significant garnet growth (e.g. Spear \& Pyle, 2002; Pyle \& Spear, 2003; Foster \& Parrish, 2003; Herman \& Rubatto, 2003; Williams et al., 2007; Cottle et al, 2009). The subsequent decrease in $\mathrm{Y}, \mathrm{MREE}$ and HREE in monazite, if accompanied by incorporation of Th, reflects the timing of garnet growth in the presence of melt (e.g. Bea \& Montero, 1999; Mahan et al., 2006; McFarlane \& Frost, 2009; Dumond et al., 2015). The growth of peritectic garnet and orthopyroxene along a prograde clockwise P-T path is controlled by the following generalized biotite dehydration melting reactions: (1) $\mathrm{Bt}+\mathrm{Pl}+\mathrm{Qtz} \rightarrow \mathrm{Grt}+\mathrm{Kfs}+$ melt and (2) Bt $+\mathrm{Pl}+\mathrm{Qtz} \rightarrow \mathrm{Grt}+\mathrm{Opx}+\mathrm{Kfs}+$ melt (Vielzeuf \& Schmidt, 2001). Peak metamorphic conditions were attained at $1027 \pm 108{ }^{\circ} \mathrm{C}, 11.7 \pm 1.4$ kbar (Fig. 13), compatible with the development of garnet + aluminous orthopyroxene assemblages under UHT conditions (Kelsey \& Hand, 2015). Progressive decrease in alumina towards orthopyroxene rims provides evidence for re-equilibration upon cooling at $865 \pm 38^{\circ} \mathrm{C}, 8.9 \pm 0.8 \mathrm{kbar}$. Our data are in good agreement with previous estimates of $850-950^{\circ} \mathrm{C}, 5-8 \mathrm{kbar}$ for the migmatite units of the SGN (Campos Neto \& Caby, 2000; Campos Neto et al., 2011).

Domain 1 monazite is characterized by resorbed $\mathrm{Y}+\mathrm{HREE}-$ rich cores preserved as inclusions in

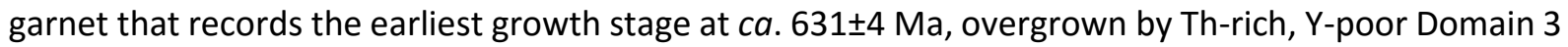
monazite at ca. $615 \pm 3 \mathrm{Ma}$, (grain m11; Fig. 12). The partial dissolution of $Y+H R E E-r i c h$ cores is ascribed to the first appearance of peritectic garnet and melt, consistent with $\mathrm{Y}$ incorporation into garnet and concomitant growth of Th-rich, Y-depleted monazite, according to the following reaction: (3) $\mathrm{Bt}_{1}+\mathrm{Pl}_{1}$ + Qtz + Y+HREE-rich Mnz Domain $1 \rightarrow$ Grt \pm Opx + Kfs + melt + Th-rich, Y+HREE-poor Mnz Domain 3. Monazite consumption along the prograde P-T path has been reported by Kelsey et al. (2008) and Yakymchuk \& Brown (2014). The exact position of Domain 1 monazite within the P-T space remains uncertain, but it clearly precedes garnet growth $\left(\mathrm{T}<850^{\circ} \mathrm{C}, \mathrm{P}<12 \mathrm{kbar}\right.$; Fig. 13$)$. 


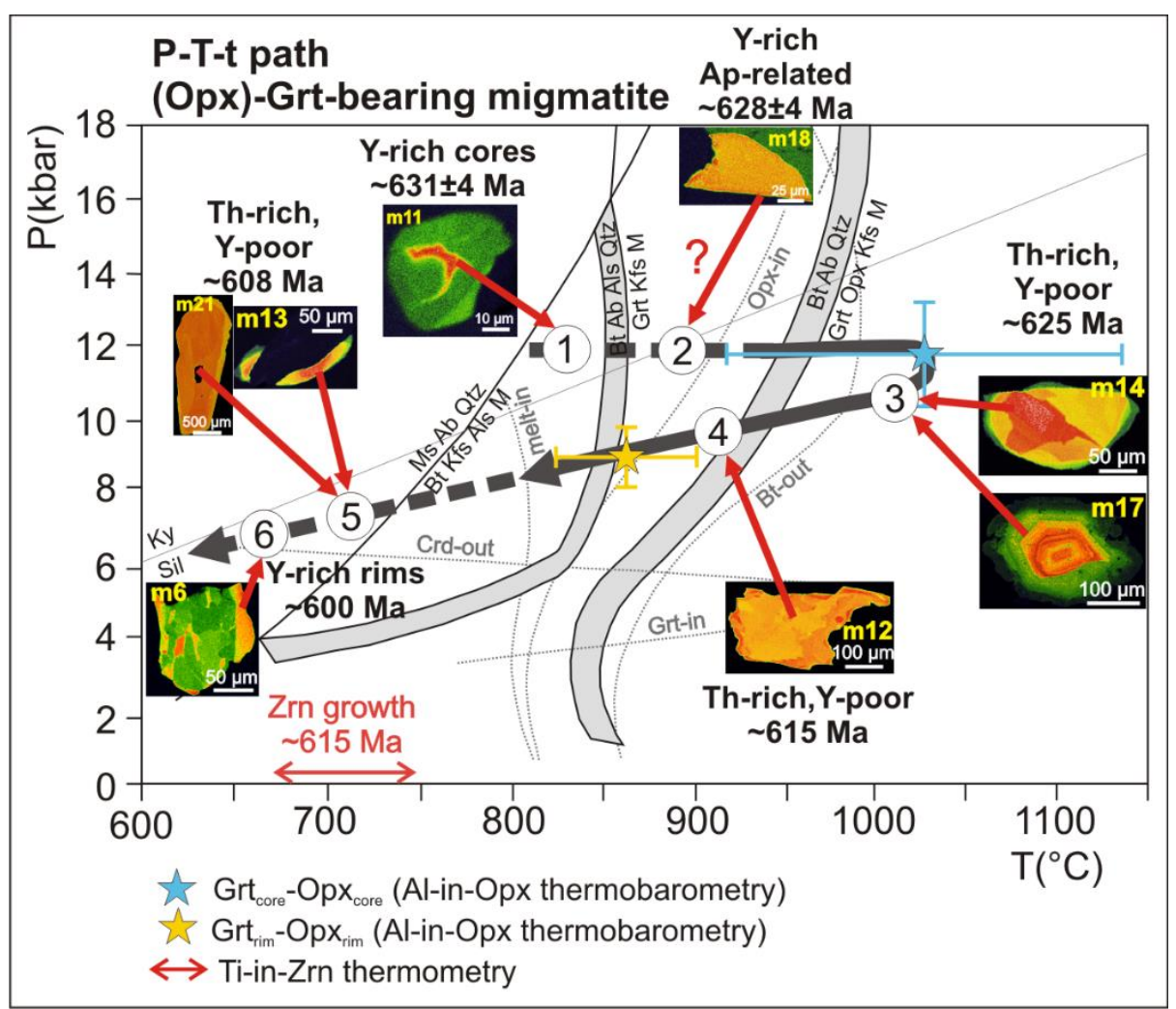

Figure 13: Pressure-temperature-time (P-T-t) path for the migmatites of the Socorro-Guaxupé Nappe based on textural relationships, Al-in-orthopyroxene thermobarometry, Ti-in-zircon thermometry and EPMA geochronology data of five distinct monazite generations. High-resolution X-ray maps of the main monazite types are shown. Biotite-dehydration melting reactions are extracted from Vielzeuf \& Schmidt (2001).

Apatite-related Domain 2 monazite yielded a weighted mean age of $628 \pm 4 \mathrm{Ma}$ (MSWD=0.67). Apatite incorporates significant amounts of REE with increasing metamorphic grade (Bingen et al., 1996), especially under high pressure conditions, and REE-rich apatite could therefore be an important source for monazite growth along the decompression path (Spear \& Pyle, 2002; Finger \& Krenn, 2007; Krenn et al., 2009). A highly probable explanation for the origin of apatite-related monazite from Domain 2 is related to decompression prior to the metamorphic peak and the formation of significant amounts of melt and garnet along a clockwise path, common in many collisional orogens, rather than by retrograde dissolution-precipitation processes (e.g. Harlov \& Förster, 2002; Harlov et al., 2005). This interpretation is supported by a combination of textural, chemical and geochronological evidence: (1) the extremely low Th contents (0.1-0.5 wt\% $\mathrm{ThO}_{2}$ ) preclude monazite crystallization from a melt, as Th is strongly partitioned into monazite in the presence of melt; (2) higher REE contents are exclusive to Domain 2 monazite, and most likely affected the REE budget in the whole-rock; (3) the relatively high $\mathrm{Y}$ concentration (up to $11000 \mathrm{ppm}$ ) in apatite-related monazite is indicative of pre-garnet growth, thus earlier than ca. $615 \mathrm{Ma}$; (4) Domain 2 monazite yielded the oldest dates, which is not consistent with a retrograde origin by dissolution-precipitation processes; (5) Relatively flat $Y$ and Th zoning in Domain 
2 monazites, in addition to the high spatial resolution of the EPMA, also excludes any possibility that the $628 \pm 4 \mathrm{Ma}$ age could represent a mixture age between older inherited grains and monazite precipitated from the melt (Domain 3). Therefore, Y-rich rims related to apatite (Domain 2) express a new episode of monazite growth at ca. $628 \mathrm{Ma}$, preceding abundant garnet growth, even though the position along the P-T-t path remains somewhat speculative.

We suggest that Th-rich, Y+HREE-poor monazite from Domain 3 crystallized along with the products of reaction (3). The relative Th-enrichment in monazite during biotite dehydration melting has been demonstrated by Watt \& Harley (1993). Dumond et al. (2015) assigned a similar reaction (3) to the formation of high-Th and low-Y monazite in the presence of melt and garnet. Concomitant growth of feldspar from a crystallizing melt contributes to a decrease in Eu contents in monazite (e.g. Bea \& Montero, 1999; Rubatto, 2002). Consequently, the pronounced negative Eu anomaly in Domain 3 (Fig. 9) implies crystallization in the presence of melt. Thorium oscillatory zoning in monazite provides further evidence for melt crystallization (e.g. Schaltegger et al., 1999; Townsend et al., 2000; Rubatto et al., 2001; Dumond et al., 2015). Even though there is a large scatter in dates from $629 \pm 4$ to $601 \pm 3$ Ma in Domain 3 monazites, the distribution of dates among different samples define consistent age clusters (Fig. 11). Rubatto et al. (2013) proposed that scatter of dates may be attributed to episodic accessory phase growth in the Eastern Himalayas, but within a short period of time that is below the analytical precision of the method used. We interpret that monazite growth was episodic during melt crystallization and three main episodes are recognized: (1) 625 Ma, (2) 615 Ma and (3) 608 Ma. Thrich sector and oscillatory zoned monazites record the early stages of melt crystallization at ca. $625 \mathrm{Ma}$ (grains $\mathrm{m} 14$ and $\mathrm{m} 17$ ). Extensive monazite growth at ca. $615 \mathrm{Ma}$ (e.g. grain $\mathrm{m} 12$ ) coincides with most metamorphic zircon growth. The growth of large euhedral monazite with weak oscillatory and sector zoning (grain $\mathrm{m} 21$ ) and Th-rich overgrowths on zircon at $c a .608 \mathrm{Ma}$ is synchronous to the growth of "soccer ball" zircon in the mafic granulite and mark the final stages of melt crystallization (Fig. 13).

\begin{tabular}{|c|c|c|c|c|c|c|c|}
\hline Sample & Rock type & Zircon domain & $\begin{array}{l}\text { Zircon Age } \\
\text { (Ma) }\end{array}$ & Zircon REE & $\begin{array}{c}\text { Monazite } \\
\text { compositional domain }\end{array}$ & $\begin{array}{l}\text { Monazite Age } \\
\text { (Ma) }\end{array}$ & Monazite REE \\
\hline $6 \mathrm{D} 1$ & $\begin{array}{l}\text { stromatic Grt-Bt } \\
\text { metatexite }\end{array}$ & $\begin{array}{c}\text { xenocrystic cores } \\
\text { sector zoned overgrowths + bright-CL rims }\end{array}$ & $\begin{array}{l}800-640 \mathrm{Ma} \\
613 \pm 1 \mathrm{Ma}\end{array}$ & $\begin{array}{c}\text { steep REE } \\
\text { pattern } \\
\text { flat REE pattern }\end{array}$ & $\begin{array}{l}\text { Domain } 1 \\
\text { Domain } 3 \\
\text { Domain } 4 \\
\text { Domain } 5 \\
\end{array}$ & $\begin{array}{l}629 \pm 4 \mathrm{Ma} \\
612 \pm 5 \mathrm{Ma} \\
599 \pm 6 \mathrm{Ma} \\
593 \pm 11 \mathrm{Ma} \\
\end{array}$ & $\begin{array}{c}\text { Y+HREE-rich cores } \\
\text { Th-rich, Y+HREE depleted cores } \\
\text { Y+HREE-rich rims } \\
\text { Th-rich, Y+HREE depleted rims }\end{array}$ \\
\hline 6D2 & $\begin{array}{l}\text { stromatic Grt-Bt } \\
\text { metatexite }\end{array}$ & & & & $\begin{array}{l}\text { Domain } 1 \\
\text { Domain } 3\end{array}$ & $\begin{array}{l}631 \pm 4 \mathrm{Ma} \\
611 \pm 3 \mathrm{Ma}\end{array}$ & $\begin{array}{c}\text { Y+HREE-rich cores } \\
\text { Th-rich, Y+HREE depleted cores }\end{array}$ \\
\hline $1 \mathrm{~A}$ & $\begin{array}{l}\text { (Opx)-Grt-bearing } \\
\text { leucosome }\end{array}$ & $\begin{array}{l}\text { xenocrystic cores } \\
\text { sector zoned overgrowths + soccer ball + rims } \\
\text { soccer ball zircons }\end{array}$ & $\begin{array}{c}760-644 \mathrm{Ma} \\
614 \pm 1 \mathrm{Ma} \\
613 \pm 2\end{array}$ & $\begin{array}{l}\text { steep REE pattern } \\
\text { flat REE pattern }\end{array}$ & $\begin{array}{l}\text { Domain } 2 \\
\text { Domain } 3 \\
\text { Domain } 4 \\
\end{array}$ & $\begin{array}{c}628 \pm 4 \mathrm{Ma} \\
625 \pm 25 \mathrm{Ma} \\
610 \pm 4 \mathrm{Ma} \\
601 \pm 6 \mathrm{Ma} \\
\end{array}$ & $\begin{array}{c}\text { Y+REE-rich cores } \\
\text { Th-rich, Y+HREE depleted cores } \\
\text { Y+HREE-rich rims }\end{array}$ \\
\hline $9 \mathrm{~A} 1$ & $\begin{array}{c}\text { (Opx)-Grt-bearing } \\
\text { leucosome }\end{array}$ & & n.a. & & $\begin{array}{l}\text { Domain } 3 \\
\text { Domain } 4 \\
\end{array}$ & $\begin{array}{l}603 \pm 4 \mathrm{Ma} \\
594 \pm 5 \mathrm{Ma}\end{array}$ & $\begin{array}{c}\text { Th-rich, Y+HREE depleted cores } \\
\text { Y+HREE-rich rims }\end{array}$ \\
\hline $7 \mathrm{~A}$ & $\begin{array}{l}\text { Grt-absent } \\
\text { leucosome }\end{array}$ & $\begin{array}{c}\text { xenocrystic cores } \\
\text { sector zoned overgrowths + bright-CL rims }\end{array}$ & $\begin{array}{l}750-640 \mathrm{Ma} \\
618 \pm 2 \mathrm{Ma}\end{array}$ & & & n.a. & \\
\hline $9 B$ & Grt-Bt gneiss & $\begin{array}{c}\text { xenocrystic cores } \\
\text { recrystallized domains + bright-CL rims }\end{array}$ & $\begin{array}{l}660-640 \mathrm{Ma} \\
613 \pm 2 \mathrm{Ma}\end{array}$ & $\begin{array}{l}\text { steep REE pattern } \\
\text { flat REE pattern }\end{array}$ & Domain 3 & $\begin{array}{l}624 \pm 3 \mathrm{Ma} \\
608 \pm 6 \mathrm{Ma}\end{array}$ & Th-rich, Y+HREE depleted cores \\
\hline $7 \mathrm{C}$ & mafic granulite & $\begin{array}{l}\text { xenocrystic cores } \\
\text { recrystallized domains + soccer ball + rims } \\
\text { soccer ball zircons }\end{array}$ & $\begin{array}{l}660-640 \mathrm{Ma} \\
614 \pm 2 \mathrm{Ma} \\
607 \pm 4 \mathrm{Ma}\end{array}$ & $\begin{array}{l}\text { steep REE pattern } \\
\text { flat REE pattern }\end{array}$ & & n.a. & \\
\hline
\end{tabular}

Table 3: Summary of zircon and monazite geochronology and trace element data from analyzed samples in this study. 
Domain 4 is characterized by $\mathrm{Y}$, HREE-rich monazite rims ranging from $c a .600-590 \mathrm{Ma}$, and their occurrence is restricted to matrix monazite enclosed by biotite-rich layers. The HREE enrichment indicates minor monazite growth related to garnet breakdown, with incorporation of both $\mathrm{Y}$ and MREE released from garnet during retrogression (e.g. Pyle \& Spear, 2003; Mahan et al., 2006; Williams et al., 2007; Dumond et al., 2008, 2015; Langille et al., 2012). A weighted mean date of $601 \pm 6 \mathrm{Ma}$ $(M S W D=0.89)$ places a lower limit age for garnet growth in the (orthopyroxene)-garnet-bearing leucosome. The formation of $\mathrm{Y}, \mathrm{HREE}-$ rich rims can be expressed by the following retrograde reaction: (4) Grt $\pm \mathrm{Opx}+\mathrm{Kfs}+$ melt + Th-rich, $\mathrm{Y}+\mathrm{HREE}$-poor $\mathrm{Mnz}_{\text {Domain } 3} \rightarrow \mathrm{Bt}_{2}+\mathrm{Pl}_{2}+\mathrm{Qtz}+\mathrm{Y}+\mathrm{HREE}$-rich Mnz Domain 4 .

Domain 5 consists of Th-rich, $Y+$ HREE-poor monazite rims that differ from Domain 3 in their strong HREE depletion. Th-rich rims are restricted to sample 6D1 (stromatic Grt-Bt metatexite), where scarce xenotime is present (Fig. A1). The formation of Th-rich, HREE-poor rims is interpreted by Kelly et al. (2012) to be the result of a dissolution-precipitation mechanism in the presence of fluids during decompression. These authors have correlated formation of these rims to continuous $\mathrm{Y}+\mathrm{HREE}$ enrichment in garnet rims during retrogression, as opposed to Y-enrichment on monazite rims due to garnet breakdown (e.g. Pyle \& Spear, 2003; Mahan et al., 2006). An increase in Y+HREE on garnet rims (Grt2, Grt3) is compatible with the findings of Kelly et al. (2012). The Th-enrichment and Y+HREEdepletion of monazite rims is therefore related to late recrystallization at $c a .590 \mathrm{Ma}$, and xenotime could have accommodated part of the Y+HREE released, given the occurrence of late xenotime replacing zircon in this sample (6D1).

\subsection{Tectonic implications for the southern Brasília Orogen}

The age of metamorphic peak and retrograde cooling in the southern Brasilia Orogen has been widely debated over the past 20 years (e.g. Janasi, 2002; Campos Neto et al., 2010, 2011; Martins et al., 2009; Reno et al., 2009; Mora et al., 2014). Campos Neto et al. (2010 and 2011) proposed that older metamorphic ages are recorded in the external parts of the nappe system (ca. 630-620 Ma in the SGN) grading to progressive younger ages towards the cratonic domain (ca. 620-605 Ma in the Andrelândia Nappe System; ca. $590 \mathrm{Ma}$ in the Carrancas and Lima Duarte Nappe Systems), and interpreted this pattern as the migration front of deformation and metamorphism.

Reno et al. (2009) proposed a different metamorphic evolution for the southern Brasília Orogen, and thus for the amalgamation of the West Gondwana. These authors have claimed that peak metamorphism could have begun as early as ca. $680 \mathrm{Ma}$ based on SIMS U-Pb dating of a retrograded eclogite from the underlying Andrelândia Nappe System. They reported a SIMS U-Pb age of ca. $622 \mathrm{Ma}$ for a granulite at the base of the SGN, interpreted to date the immediate post-peak temperature cooling of an HREE-enriched anatectic melt. However, such interpretations rely on a very small dataset. 
The concordia age of ca. $622 \mathrm{Ma}$ resulted from seven zircon dates that scatter from ca. 666-590 Ma and do not form a consistent statistical population. Zircon from sample 04-7-1 (Reno et al., 2009) has oscillatory zoned cores with steep REE patterns $\left(\mathrm{Yb}_{N} / \mathrm{Gd}_{N}=14-34\right)$, overgrown by narrow high luminescent rims ( $<5 \mu \mathrm{m}$ wide), making it difficult to get a reliable age related to metamorphism. These dates most likely represent mixture ages of inherited oscillatory zoned cores of $c a$. 670-640 Ma and metamorphic rims younger than $630 \mathrm{Ma}$. Sample 05-06-3 (Reno et al., 2009) yielded even older dates of $c a .800 \mathrm{Ma}$, which are equivalent to inheritance ages determined by Martins et al. (2009).

The present study attests the presence of $c a$. 720-640 Ma zircon inheritance by dating a large population ( $n=167$ ) of oscillatory zoned cores with the typical magmatic fingerprint of steep REE patterns. Monazite preserves prograde growth ages of $631 \pm 4$ Ma prior to the partial melting event, providing an upper age limit for the granulite facies metamorphism in the SGN. Apatite-related monazite records the initial stages of decompression at ca. $628 \pm 4$ Ma followed by biotite dehydration melting, with production of peritectic garnet and orthopyroxene at $1027 \pm 108^{\circ} \mathrm{C}, 11.7 \pm 1.4 \mathrm{kbar}$. Our data are in good agreement with previous estimates for the age of high-T metamorphism at ca. 630620 Ma (Basei et al., 1995; Janasi, 1999, 2002; Martins et al., 2009; Reno et al., 2009; Mora et al., 2014). Extensive zircon and monazite growth records a prolonged melt crystallization event between $629 \pm 4$ and $601 \pm 1 \mathrm{Ma}$. The excess scatter in dates provides evidence of episodic zircon and monazite growth at any time within the 629-601 Ma range, but mainly between ca.625-605 Ma (Table 3). Therefore, further high-precision studies involving ID-TIMS dating are needed, as these ages are indistinguishable with the precision of the LA-ICP-MS technique. The late stage of melt crystallization and stability of garnet and biotite is supported by the development of $\mathrm{Y}+\mathrm{HREE}-$ rich monazite rims at $c a .600 \mathrm{Ma}$. Late monazite recrystallization was responsible for the formation of Th-rich rims at ca. $590 \mathrm{Ma}$.

\section{CONCLUSIONS}

The present study demonstrates that the SGN preserves five generations of monazite with complex zoning pattern. The high-spatial resolution of the EPMA allowed determination of a prograde monazite stage at $631 \pm 4 \mathrm{Ma}$ in a very small ( $\sim 20 \mu \mathrm{m}$ wide) Y-rich compositional domain, interpreted as pre-garnet growth. The subsequent monazite growth episode is recorded by Y-rich, apatite-related monazite at $628 \pm 4$ Ma during initial stages of decompression prior to the metamorphic peak at 1027 $\pm 108^{\circ} \mathrm{C}, 11.7 \pm 1.4 \mathrm{kbar}$ and development of UHT assemblages of Al-rich Opx $+\mathrm{Grt}+\mathrm{Kfs}$. Early stages of melt crystallization at ca. $625 \mathrm{Ma}$ are recorded by sector and oscillatory zoned monazite. Episodic monazite and "soccer ball" zircon growth records the main melt crystallization stage at ca. $615 \mathrm{Ma}$ and final stages at ca. $608 \mathrm{Ma}$. The formation of $\mathrm{Y}+\mathrm{HREE}$-rich monazite rims marks garnet breakdown and extensive biotite growth at $c a .600 \mathrm{Ma}$. Monazite recrystallization at $c a .590 \mathrm{Ma}$ was responsible for the development of Th-rich, HREE-poor rims. The overlap in dates obtained for distinct monazite growth episodes in the SGN can be attributed to the uncertainties inherent to the EPMA method. 
Additionally, chemical dating is based on the assumption that most measured $\mathrm{Pb}$ in monazite is thorogenic, with negligible amounts of common $\mathrm{Pb}$, and that $\mathrm{U}$ isotopes are present in their crustal abundances (Montel et al., 1996; Williams et al., 2006, 2007). Thus it does not provide any isotopic information on discordance of dates, presence of common $\mathrm{Pb}$ or excess ${ }^{206} \mathrm{~Pb}$, which would affect the correct interpretation of dates. Isotope dilution-thermal ionization mass spectrometry (ID-TIMS) is a very powerful technique with a high degree of precision and accuracy $(<0.2 \%$ uncertainties) (e.g. Schoene et al., 2013). However, the complexity of zoning patterns commonly found in monazite imposes clear limitations to this method, even when it involves micro sampling ID-TIMS (e.g. Hawkins \& Bowring, 1997) and apparent mixed ages are a prevailing issue concerning the ID-TIMS monazite dating technique. The recently developed laser-ablation split stream (LASS-ICP-MS) technique provides simultaneous measurements of U-Th-Pb isotopic ratios and elemental concentrations using a multicollector ICPMS and a single-collector ICP-MS at high spatial resolution (10-30 $\mu \mathrm{m}$ spot diameter) (e.g. Kylander-Clark et al., 2013). Nevertheless, the LASS-ICP-MS technique is suitable for deciphering the geological history of relatively young orogenic belts (e.g. Cottle et al., 2009; Langille et al., 2012). A more precise distinction of multiple episodes of monazite growth in the SGN and in other Precambrian orogens requires both high-precision and high spatial resolution. However, some issues in complex zoned monazites remain unsolved if the age variation is smaller than the analytical precision of the method. The techniques currently available are not fully capable of unraveling protracted histories in Precambrian orogens, and further analytical advances are needed.

\section{ACKNOWLEDGEMENTS}

This research was supported by FAPESP grant 13/04007-0. Financial support for field work was given by FAPESP grant 10/11152-8. B.C. Rocha acknowledges her CNPq (142028/2012-6) and FAPESP scholarships (14/05563-6, 12/22380-7). We thank for the assistance of Vasco Loios (CPGeo-USP) and Josh Feldman (IGL-KU) with mineral separation, Sean Regan (UMass) with microprobe major element analysis, Sheila Schuindt (LCT-USP) with BSE imaging, Heather Shinogle (MAI-KU) with CL imaging, Jeff Oalmann (IGL-KU) with trace element data reduction, and Maggie Sochko (IGL-KU) for LA-ICP-MS technical support. Insightful reviews by Fernando Corfu and an anonymous reviewer helped to improve the manuscript and are greatly appreciated.

\section{REFERENCES}

Basei, M.A.S., Siga Jr., O., Sato, K., Sproesser, W.M., 1995. A metodologia urânio-chumbo na Universidade de São Paulo: princípios metodológicos, aplicações e resultados obtidos. Anais da Academia Brasileira de Ciências 67(2), 221-237.

Bea, F., Montero, P., 1999. Behavior of accessory phases and redistribution of Zr, REE, Y, Th and U 
during metamorphism and partial melting of metapelites in the lower crust: an example from the Kinzigite Formation of Ivrea-Verbano, NW Italy. Geochimica et Cosmochimica Acta 63, 11331153.

Bingen, B., Demaiffe, D., Hertogen, J., 1996. Redistribution of rare earth elements, thorium and uranium over accessory minerals in the course of amphibolite to granulite facies metamorphism: The role of apatite and monazite in orthogneisses from southwestern Norway. Geochimica et Cosmochimica Acta 60 (80), 1341-1354.

Brito Neves, B.B.; Campos Neto, M.C., Fuck, R.A., 1999. From Rodinia to Western Gondwana: An approach to the Brasiliano-Pan African Cycle and orogenic collage. Episodes 22, 155-166.

Campos Neto, M.C., Basei, M.A.S., Janasi, V.A., Moraes, R., 2011. Orogen migration and tectonic setting of the Andrelândia Nappe System: An Ediacaran Western Gondwana collage, south of São Francisco craton. Journal of South American Earth Sciences 32, 393-406.

Campos Neto, M.C., Caby, R., 1999. Neoproterozoic high-pressure metamorphism and tectonic constraint from the nappe system south of the São Francisco Craton, southeast Brazil. Precambrian Research 97, 3-26.

Campos Neto, M.C., Caby, R., 2000. Terrane accretion and upward extrusion of high-pressure granulites in the Neoproterozoic nappes of Southeast Brazil: Petrological and structural constraints. Tectonics 14, 669-687.

Campos Neto, M.C., Cioffi, C.R., Moraes, R., Motta, R.G., Siga Jr, O., Basei, M.A.S., 2010. Structural and metamorphic control on the exhumation of high-P granulites: The Carvalhos Klippe example, from the oriental Andrelândia Nappe System, southern portion of the Brasília Orogen, Brazil. Precambrian Research 180, 125-142.

Cherniak, D.J., Watson, E.B., 2001. Pb diffusion in zircon. Chemical Geology 172, 5-24.

Corfu, F., Hanchar, J.M., Hoskin, P.W.O., Kinny, P., 2003. Atlas of zircon textures. In: Hanchar, J.M., Hoskin, P.W.O. (Eds). Zircon. Mineralogical Society of America. Reviews in Mineralogy and Geochemistry 53, Washington, pp. 469-495.

Cottle, J.M., Searle, M.P., Horstwood, M.S.A., Waters, D.J., 2009. Timing of mid-crustal metamorphism, melting and deformation in the Mt. Everest region of southern Tibet revealed by $\mathrm{U}(-\mathrm{Th})-\mathrm{Pb}$ geochronology. Journal of Geology 117, 643-664.

Degeling, H., Eggins, S., Ellis, D.J., 2001. Zr budgets for metamorphic reactions, and the formation of zircon from garnet breakdown. Mineralogical Magazine 65(6), 749-758.

Dumond, G., Goncalves, P., Williams, M.L., Jercinovic, M.J., 2015. Monazite as a monitor of melting, garnet growth and feldspar recrystallization in continental lower crust. Journal of Metamorphic Geology 33, 735-762.

Dumond, G., McLean, N., Williams, M.L., Jercinovic, M.J., Bowring, S.A., 2008. High-resolution dating of granite petrogenesis and deformation in a lower crustal shear zone: Athabasca granulite 
terrane, western Canadian Shield. Chemical Geology 254, 175-196.

Finger, F., Krenn, E., 2007. Three metamorphic monazite generations in a high-pressure rock from the Bohemian Massif and the potentially important role of apatite in stimulating polyphaser monazite growth along a PT loop. Lithos 95, 103-115.

Foster, G., Parrish, R.R., 2003. Metamorphic monazite and the generation of P-T-t paths. In: D. Vance, W. Müller, I.M, Villa (Eds). Geochronology: Linking the Isotopic Record with Petrology and Textures - Geological Society, London, Special Publications 220, 25-47.

Fraser, G., Ellis, D., Eggins, S., 1997. Zirconium abundance in granulite-facies minerals, with implications for zircon geochronology in high-grade rocks. Geology 25, 607-610.

Geisler, T., Schaltegger, U., Tomaschek, F., 2007. Re-equilibration of zircon in aqueous fluids and melts. Elements 3, 43-50.

Hackspacher, P.C., Fetter, A.H., Ebert, H.D., Janasi, V.A., Oliveira, M.A.F., Braga, I.F., Negri, F.A., 2003. Magmatismo há ca. 660-640 Ma no Domínio Socorro: Registros de convergência pré-colisional na aglutinação do Gondwana Ocidental. Geologia USP, Série Científica 3, 85-96.

Harlov, D.E., Förster, H-J., 2002. High-grade fluid metasomatism on both a local and a regional scale: the Seward Peninsula, Alaska, and the Val Strona di Omegna, Ivrea-Verbano Zone, northern Italy. Part II: Phosphate mineral chemistry. Journal of Petrology 43(5), 801-824.

Harlov, D.E., Wirth, R., Förster, H-J., 2005. An experimental study of dissolution-reprecipitation in fluorapatite: fluid infiltration and the formation of monazite. Contributions to Mineralogy and Petrology 150, 268-286.

Harley, S.L., Kelly, N.M., Möller, A., 2007. Zircon behaviour and the thermal histories of mountain chains. Elements 3, 25-30.

Hawkins, D.P., Bowring, S.A., 1997. U-Pb systematics of monazite and xenotime; case studies from the Paleoproterozoic of the Grand Canyon, Arizona. Contributions to Mineralogy and Petrology 127, 87-103.

Hermann, J., Rubatto, D., 2003. Relating zircon and monazite domains to garnet growth zones: age and duration of granulite facies metamorphism in the Val Malenco lower crust. Journal of Metamorphic Geology 21, 833-852.

Hoskin, P.W.O., Black, L.P., 2000. Metamorphic zircon formation by solid-state recrystallization of protolith igneous zircon. Journal of Metamorphic Geology 18, 423-439.

Hoskin, P.W.O., Schaltegger, U., 2003. The composition of zircon and igneous and metamorphic petrogenesis. In: Hanchar, J.M. and Hoskin, P.W.O. (Eds.). Zircon. Mineralogical Society of America. Reviews in Mineralogy and Geochemistry 53, Washington, pp.27-62.

Jackson, S.E., Pearson, N.J., Griffin, W.L., Belousova, E.A., 2004. The application of laser ablationinductively coupled plasma-mass spectrometry to in-situ U-Pb zircon geochronology. Chemical Geology 211, 47-69. 
Janasi, V.A., 1999. Petrogênese de granitos crustais da Nappe de Empurrão Socorro-Guaxupé (SP-MG): uma contribuição da geoquímica elemental e isotópica. Tese (Livre-Docência) - IGc-USP, 304 pp.

Janasi, V.A., 2002. Elemental and Sr-Nd isotope geochemistry of two Neoproterozoic mangerite suites in SE Brazil: implications for the origin of the mangerite-charnockite-granite series. Precambrian Research 119, 301-327.

Jercinovic, M.J., Williams, M.L., Lane, E.D., 2008. In situ trace element analysis in complex, multi-phase materials by EMPA. Chemical Geology 254, 197-215.

Kelly, N.M., Harley, S.L., 2005. An integrated microtextural and chemical approach to zircon geochronology: refining the Archaean history of the Napier Complex, east Antarctica. Contributions to Mineralogy and Petrology 149, 57-84.

Kelly, N.M., Harley, S.L., Möller, A., 2012. Complexity in the behavior and recrystallization of monazite during high-T metamorphism and fluid infiltration. Chemical Geology 322-323, 192-208.

Kelsey, D.E., Clark, C., Hand, M., 2008. Thermobarometric modelling of zircon and monazite growth in melt-bearing systems: examples using model metapelitic and metapsammitic granulites. Journal of Metamorphic Geology 26, 199-212.

Kelsey, D.E., Hand, M., 2015. On ultrahigh temperature crustal metamorphism: phase equilibria, trace element thermometry, bulk composition, heat sources, timescales and tectonic settings. Geoscience Frontiers 6, 311-356.

Kohn, M.J., Spear, F., 2000. Retrograde net-transfer reaction (ReNTR) insurance for pressuretemperature estimates. Geology 28, 1127-1130.

Krenn, E., Janák, M., Finger, F., Broska, I., Konečný, P., 2009. Two types of metamorphic monazite with contrasting $\mathrm{La} / \mathrm{Nd}$, Th and $\mathrm{Y}$ signatures in an ultra-high-pressure metapelite from the Pohorje Mountains, Slovenia: indications for pressure-dependent REE exchange between apatite and monazite. American Mineralogist 94, 801-815.

Kriegsman, L.M., 2001. Partial melting, partial melt extraction and partial back reaction in anatectic migmatites. Lithos 56, 75-96.

Kylander-Clark, A.R.C., Hacker, B.R., Cottle, J.M., 2013. Laser-ablation split-stream ICP Petrochronology. Chemical Geology 345, 99-112.

Langille, J.M., Jessup, M.J., Cottle, J.M., Lederer, G., Ahmad, T., 2012. Timing of metamorphism, melting and exhumation of the Leo Pargil Dome, northwest India. Journal of Metamorphic Geology 30, 769-791.

Mahan, K.H., Goncalves, P., Williams, M.L., Jercinovic, M.J., 2006. Dating metamorphic reactions and fluid flow: application to exhumation of high-P granulites in a crustal-scale shear zone, western Canadian Shield. Journal of Metamorphic Geology 24, 193-217. 
Martins. L., Vlach, S.R.F., Janasi, V.A., 2009. Reaction microtextures of monazite: correlation between chemical and age domains in the Nazaré Paulista migmatite, SE Brazil. Chemical Geology 261, 271-285.

McDonough, W.F., Sun, S.-S., 1995. The composition of the Earth. Chemical Geology 120, 223-253.

McFarlane, C.R.M., Frost, B.R., 2009. Constraints on the early metamorphic evolution of Broken Hill, Australia, from in situ U-Pb dating and REE geochemistry of monazite. Journal of Metamorphic Geology 27, 3-17.

Möller, A., O’Brien, P.J., Kennedy, A., Kröner, A., 2002. Polyphase zircon in ultrahigh-temperature granulites (Rogaland, SW Norway): constraints for Pb diffusion in zircon. Journal of Metamorphic Geology 20, 727-740.

Möller, A., Hensen, B.J., Armstrong, R.A., Mezger, K., Ballèvre, M., 2003a. U-Pb zircon and monazite age contraints on granulite-facies metamorphism and deformation in the Strangways Metamorphic Complex (central Australia). Contributions to Mineralogy and Petrology 145, 406423.

Möller, A., O’Brien, P.J., Kennedy, A., Kröner, A., 2003b. Linking growth episodes of zircon and metamorphic textures to zircon chemistry: an example from the ultrahigh-temperature granulites of Rogaland (SW Norway). In: D. Vance, W. Müller, I.M, Villa (Eds). Geochronology: Linking the Isotopic Record with Petrology and Textures - Geological Society, London, Special Publications 220, 65-81.

Montel, J.-M., Foret, S., Veschambre, M., Nicollet, C., Provost, A., 1996. Electron microprobe dating of monazite. Chemical Geology 131 (1-4), 37-53.

Mora, C.A.S., Campos Neto, M.C., Basei, M.A.S., 2014. Syn-collisional lower continental crust anataxis in the Neoproterozoic Socorro-Guaxupé Nappe System, southern Brasília Orogen, Brazil: constraints from zircon $\mathrm{U}-\mathrm{Pb}$ dating, $\mathrm{Sr}-\mathrm{Nd}-\mathrm{Hf}$ signatures and whole-rock geochemistry. Precambrian Research 255, 847-864.

Pattison, D.R.M., Chacko, T., Farquhar, J., McFarlane, C.R.M., 2003. Temperatures of granulite-facies metamorphism: constraints from experimental phase equilibria and thermobarometry for retrograde exchange. Journal of Petrology 44(5), 867-900.

Paton, C., Hellstrom, J., Paul, B., Woodhead, J., Hergt, J., 2011. Iolite: Freeware for the visualisation and processing of mass spectrometry data. Journal of Analytical Atomic Spectrometry 26, 25082518.

Petrus, J.A., Kamber, B.S., 2012. VizualAge: A Novel Approach to Laser Ablation ICP-MS U-Pb Geochronology Data Reduction. Geostandards and Geoanalytical Research 36, 247-270.

Pidgeon, R.T., 1992. Recrystallisation of oscillatory zoned zircon: some geochronological implications. Contributions to Mineralogy and Petrology 110, 463-472. 
Pyle, J.M., Spear, F.S., 2003. Four generations of accessory-phase growth in low-pressure migmatites from SW New Hampshire. American Mineralogist 88, 338-351.

Reno, B.L., Brown, M., Kobayashi, K., Nakamura, E., Piccoli, P.M., Trouw, R.A.J., 2009. Eclogite-highpressure granulite metamorphism records early collision in West Gondwana: new data from the Southern Brasília Belt, Brazil. Journal of the Geological Society, London 166, 1013-1032.

Reno, B.L., Piccoli, P.M., Brown, M., Trouw, R.A.J., 2012. In situ monazite (U-Th)-Pb ages from the Southern Brasília Belt, Brazil: constraints on the high-temperature retrograde evolution of HP granulites. Journal of Metamorphic Geology 30, 81-112.

Roberts, M.P., Finger, F., 1997. Do U-Pb zircon ages from granulites reflect peak metamorphic conditions? Geology 25, 319-322.

Rubatto, D., 2002. Zircon trace element geochemistry: partitioning with garnet and the link between U-Pb ages and metamorphism. Chemical Geology 184, 123-138.

Rubatto, D., Chakraborty, S., Dasgupta, S., 2013. Timescales of crustal melting in the Higher Himalayan Crystalines (Sikkim, Eastern Himalaya) inferred from trace element-constrained monazite and zircon chronology. Contributions to Mineralogy and Petrology 165, 349-372.

Rubatto, D., Williams, I.S., Buick, I.S., 2001. Zircon and monazite response to prograde metamorphism in the Reynolds Range, central Australia. Contributions to Mineralogy and Petrology 140, 458468.

Sawyer, E.W., 2001. Melt segregation in the continental crust: distribution and movement of melt in anatectic rocks. Journal of Metamorphic Geology 19, 291-309.

Sawyer, E.W., 2008. The Atlas of Migmatites. The Canadian Mineralogist, Special Publication 9. NRC Research Press, Ottawa, ON. 371pp.

Schaltegger, U., Fanning, C.M., Günther, D., Maurin, J.C., Schulmann, K., Gebauer, D., 1999. Growth, annealing and recrystallization of zircon and preservation of monazite in high-grade metamorphism: conventional and in-situ U-Pb isotope, cathodoluminescence and microchemical evidence. Contributions to Mineralogy and Petrology 134, 186-201.

Schoene, B., Condon, D.J., Morgan, L., McLean, N., 2013. Precision and accuracy in geochronology. Elements 9, 19-24.

Sláma, J., Košler, J., Condon, D.J., Crowley, J.L., Gerdes, A., Hanchar, J.M., Horstwood, S.A., Morris, G.A., Nasdala, L., Norberg, N., Schaltegger, U., Schoene, B., Tubrett, M.N., Whitehouse, M.J., 2008. Plešovice zircon - A new natural reference material for $\mathrm{U}-\mathrm{Pb}$ and $\mathrm{Hf}$ isotopic microanalysis. Chemical Geology 249, 1-35.

Spear, F.S., Pyle, J.M., 2002. Apatite, monazite, and xenotime in metamorphic rocks. In: M.J. Kohn, J. Rakovan, and J.M. Hughes, (Eds.) Phosphates: Geochemical, Geobiological, and Materials Importance, 48, pp. 293-335. Reviews in Mineralogy and Geochemistry, Mineralogical Society of America, Washington, D. C. 
Tomaschek, F., Kennedy, A.K., Villa, I.M., Lagos, M., Ballhaus, C., 2003. Zircons from Syros, Cyclades, Greece - recrystallization and mobilization of zircon during high-pressure metamorphism. Journal of Petrology 44 (11), 1977-2002.

Townsend, K.J., Miller, C.F., D’Andrea, J.L., Ayers, J.C., Harrison, T.M., Coath, C.D., 2000. Low temperature replacement of monazite in the Ireteba granite, Southern Nevada: geochronological implications. Chemical Geology 172, 95-112.

Trouw, R.A.J., Heilbron, M., Ribeiro, A., Paciullo, F., Valeriano, C.M., Almeida, J.C.H., Tupinambá, M., Andreis, R.R., 2000. The central segment of Ribeira Belt. In: Cordani, U.G., Milani, E.J., ThomazFilho, A., Campos, D.A. (Eds.) Tectonic Evolution of South America. pp. 287-310. 31 ${ }^{\text {th }}$ International Geological Congress. Rio de Janeiro, Brasil.

Trouw, R.A.J., Peternel, R., Ribeiro, A., Heilbron, M., Vinagre, R., Duffles, P., Trouw, C.C., Fontainha, M., Kussama, H.H., 2013. A new interpretation for the interference zone between Southern Brasília belt and the central Ribeira belt, SE Brazil. Journal of South American Earth Sciences 48, 43-57.

Vavra, G., Schmidt, R., Gebauer, D., 1999. Internal morphology, habit and U-Th-Pb microanalysis of amphibolite-to-granulite facies zircons: geochronology of the Ivrea Zone (Southern Alps). Contributions to Mineralogy and Petrology 134, 380-404.

Vielzeuf, D., Schmidt, M.W., 2001. Melting relations in hydrous systems revisited: application to metapelites, metagreywackes and metabasalts. Contributions to Mineralogy and Petrology 141, 251-267.

Watson, E.B., Wark, D.A., Thomas, J.B., 2006. Crystallization thermometers for zircon and rutile. Contributions to Mineralogy and Petrology 151, 413-433.

White, R.W., Powell, R., 2010. Retrograde melt-residue interaction and the formation of nearanhydrous leucosomes in migmatites. Journal of Metamorphic Geology 28, 579-597.

Whitehouse, M.J., Platt, J.P., 2003. Dating high-grade metamorphism - constraints from rare-earth elements in zircon and garnet. Contributions to Mineralogy and Petrology 145, 61-74.

Whitney, D.L., Evans, B.W., 2010. Abbreviations for names of rock-forming minerals. American Mineralogist 95, 185-187.

Williams, I.S., Buick, I.S., Cartwright, I., 1996. An extended episode of early Mesoproterozoic metamorphic fluid flow in the Reynolds Range, central Australia. Journal of Metamorphic Geology 14, 29-47.

Williams, I.S., 2001. Response of detrital zircon and monazite, and their U-Pb isotopic systems, to regional metamorphism and host-rock partial melting, Cooma Complex, southeastern Australia. Australian Journal of Earth Sciences 48, 557-580

Williams, M.L., Jercinovic, M.J., Goncalves, P., Mahan, K., 2006. Format and philosophy for collecting, compiling, and reporting microprobe monazite ages. Chemical Geology 225, 1-15.

Williams, M.L., Jercinovic, M.J., Hetherington, C.J., 2007. Microprobe monazite geochronology: 
understanding geologic processes by integrating composition and chronology. Annual Review of Earth and Planetary Sciences 35, 137-175.

Yakymchuk, C., Brown, M., 2014. Behaviour of zircon and monazite during crustal melting. Journal of the Geological Society $171,465-479$.

\section{APPENDIX A}

\section{Analytical methods}

Wavelength-dispersive spectrometry (WDS) analyses and X-ray compositional maps for garnet imaging were performed with a CAMECA SX-50 electron microprobe at the University of Massachusetts-Amherst Electron Microprobe Facility. Operating conditions were $15 \mathrm{kV}$, using a beam current of $20 \mathrm{nA}$ and $300 \mathrm{nA}$ for quantitative analyses and X-ray maps, respectively. Orthopyroxene, plagioclase and biotite (WDS) analyses were carried out using a JEOL JXA-8530F Hyperprobe, Field Emission Electron Probe Microanalyzer (FE-EPMA) at the NAP Geoanalítica Laboratory, Universidade de São Paulo (USP), using a focused beam at $15 \mathrm{kV}$ and 20nA with $5 \mu \mathrm{m}$ spot size, except for feldspar analyses (10 $\mu \mathrm{m}$ diameter). Representative analyses of garnet, orthopyroxene, plagioclase and biotite were recalculated with the A-X software (http://www.esc.cam.ac.uk/research/researchgroups/holland/ax), based on charge balance with double-normalization and are given in ANEXO III. Thermobarometric results are given in ANEXO IV.

Zircon was separated using a disk grinder, a Wilfley table, a Frantz ${ }^{\mathrm{TM}}$ isodynamic magnetic separator and standard heavy-liquid techniques at CPGeo (Geochronology Research Center), USP. Subsequently, zircon grains were handpicked under a binocular microscope and selected grains were mounted in one-inch epoxy discs and polished to approximately half their thickness to expose the grain cores. Detailed backscattered electron (BSE) images of mineral textures were performed in a FEI Quanta 600F Scanning Electron Microscope (SEM), at the Technological Characterization Laboratory, USP. Cathodoluminescence $(\mathrm{CL})$ images were acquired using a FEI Versa 3D Dual Beam field emission scanning microscope using low vacuum mode at the Microscopy and Analytical Imaging (MAI) Lab, at The University of Kansas (KU), in order to identify internal compositional zoning.

Laser ablation-inductively coupled plasma mass spectrometry (LA-ICP-MS) analyses were performed on five different samples (6D, 1A, 7A, 9B, 7C) at the IGL (Isotope Geochemistry Laboratory) at KU, using a Thermo Scientific Element 2 ICP-MS attached to a Photon Machines Analyte.G2 $193 \mathrm{~nm}$ ArF excimer laser. Analytical conditions include a laser fluency of $2.2 \mathrm{~J} / \mathrm{cm}^{-2}$ at a repetition rate of $10 \mathrm{~Hz}$, and spot size of $20 \mu \mathrm{m}$. Elemental fractionation, downhole fractionation and calibration drift were corrected using the GJ1 zircon reference material (Jackson et al., 2004), and data reduction using the VizualAge data reduction scheme (Petrus and Kamber, 2012) for the IOLITE software package (Paton et al., 2011). The secondary zircon standard Plešovice (Sláma et al., 2008) yielded a weighted mean 
${ }^{206} \mathrm{~Pb} /{ }^{238} \mathrm{U}$ date of $337.0 \pm 0.9(2 \sigma)(n=52 ; M S W D=1.8)$ during the analytical sessions, within analytical uncertainty of the age determined by high precision thermal ionization mass spectrometry (Sláma et al., 2008). Zircon U-Pb data is summarized in ANEXO VIII.

Zircon and garnet trace element analyses were also performed with the LA-ICP-MS at the IGL, $\mathrm{KU}$. Laser fluency was $2.5 \mathrm{~J} / \mathrm{cm}^{-2}$ for zircon and $3.2 \mathrm{~J} / \mathrm{cm}^{-2}$ for garnet, at a repetition rate of $10 \mathrm{~Hz}$. Spot sizes of $15 \mu \mathrm{m}$ (zircon) and $40 \mu \mathrm{m}$ (garnet) were used. External calibration was performed relative to NIST 612 glass using the values from the GeoRem database as of Dec09 during zircon analysis. The trace element analyses spots were placed near the $\mathrm{U}-\mathrm{Pb}$ dating spots and their location is indicated by red circles in Fig. 6. The USGS GSD-1G and GSE-1G basaltic glass reference materials were analyzed as internal and secondary standard during garnet analysis, respectively. Internal standards were stoichiometric Si for zircon and Si determined from electron microprobe for garnet. Zircon and garnet trace element data are shown in ANEXO VII.

Monazite $\mathrm{U}-\mathrm{Th}-\mathrm{Pb}$ geochronology and trace element analyses were conducted at the University of Massachusetts-Amherst Electron Microprobe Facility in five selected thin-sections (6D1, 6D2, 1A2, 9A1, 9B). X-ray maps were acquired on a CAMECA SX-50 electron microprobe. Quantitative analyses and background scans were acquired at 15kV and 200nA focused beam on a CAMECA SX-100 "UltraChron" optimized for high precision trace element analyses, especially $\mathrm{U}$, Th and Pb. Prior to quantitative analyses, the textural distribution of monazite was evaluated using full thin section WDS maps of $\mathrm{Ce} L \alpha, \mathrm{Y} L \alpha, \mathrm{ZrL} \alpha, \mathrm{CaK} \alpha$ and $\mathrm{MgK \alpha}$. Compositional zoning in monazite was investigated by highresolution X-ray maps of $\mathrm{Ca} K \alpha, \mathrm{Nd} L \alpha, \mathrm{UM} \beta, \mathrm{Y} L \alpha$ and $\mathrm{ThM} \alpha$ generated in each grain. This study follows the analytical strategies of Willliams et al. (2006), Jercinovic et al. (2008) and Dumond et al. (2008), with an additional interference correction of both $N d L \alpha_{3}$ and $\operatorname{Pr} L \beta_{2.15}$ on EuL $\alpha$ that was not included in these previous papers. All dates are plotted as Gaussian probability curves calculated from a set of five analyses, which represents the date and $2 \sigma$ error for a single compositional domain, as described in Williams et al. (2006) and Dumond et al. (2008). A single date for each compositional domain was calculated from the weighted mean compositions and the age equation of Montel et al. (1996). The Moacyr monazite (TIMS ${ }^{208} \mathrm{~Pb} /{ }^{232} \mathrm{Th} 506 \pm 1 \mathrm{Ma},{ }^{207} \mathrm{~Pb} /{ }^{235} \mathrm{U} 506 \pm 1 \mathrm{Ma}$ and ${ }^{206} \mathrm{~Pb} /{ }^{238} \mathrm{U} 515 \pm 1 \mathrm{Ma}$; W.J. Davis, personal communication) was used as a consistency standard before and after each analytical session and yielded a weighted mean date of $505 \pm 5 \mathrm{Ma}$ ( $2 \sigma$ error, $n=11$ sets of 5-6 analytical points). $\mathrm{U}-\mathrm{Th}-\mathrm{Pb}$ geochronology, trace element data and calculated dates are shown in ANEXO IX. 


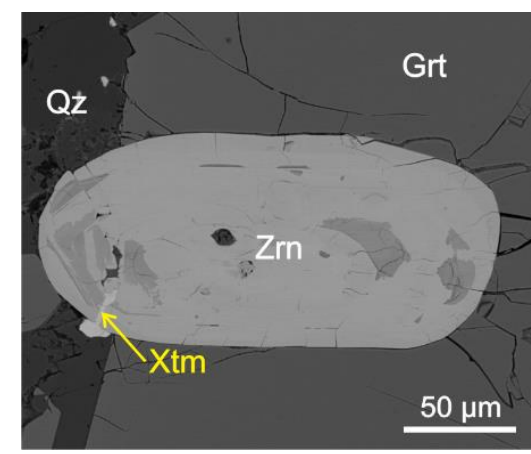

Figure A1: Zircon partially replaced by late xenotime along a fracture. 


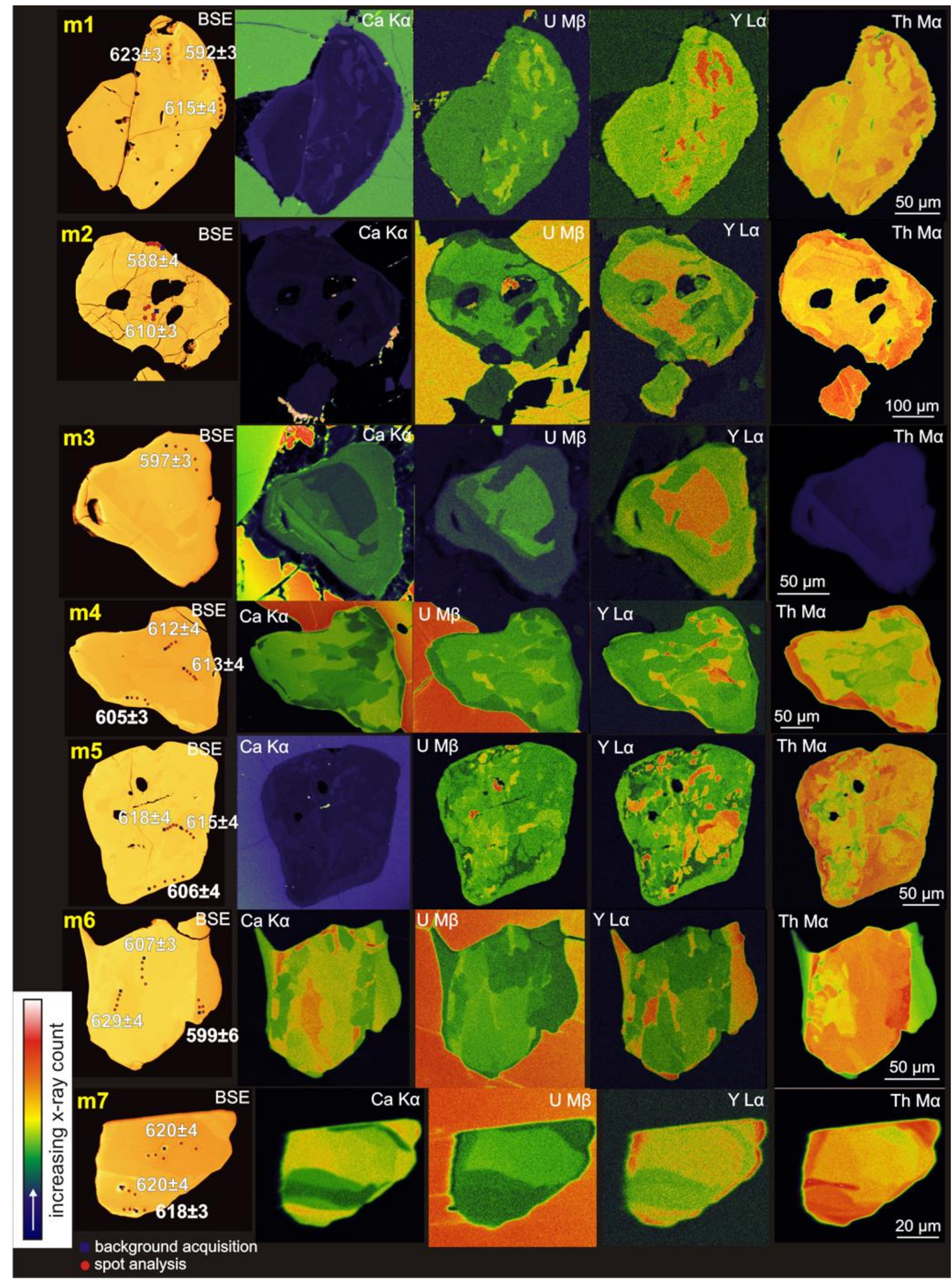

Figure A2: BSE image showing the location of spots and calculated age for each compositional domain (see ANEXO IX) and high-resolution X-ray maps of CaK $\alpha, U M \beta, Y L \alpha$ and ThM $\alpha$ for grains m1-m7 (sample 6D1). 


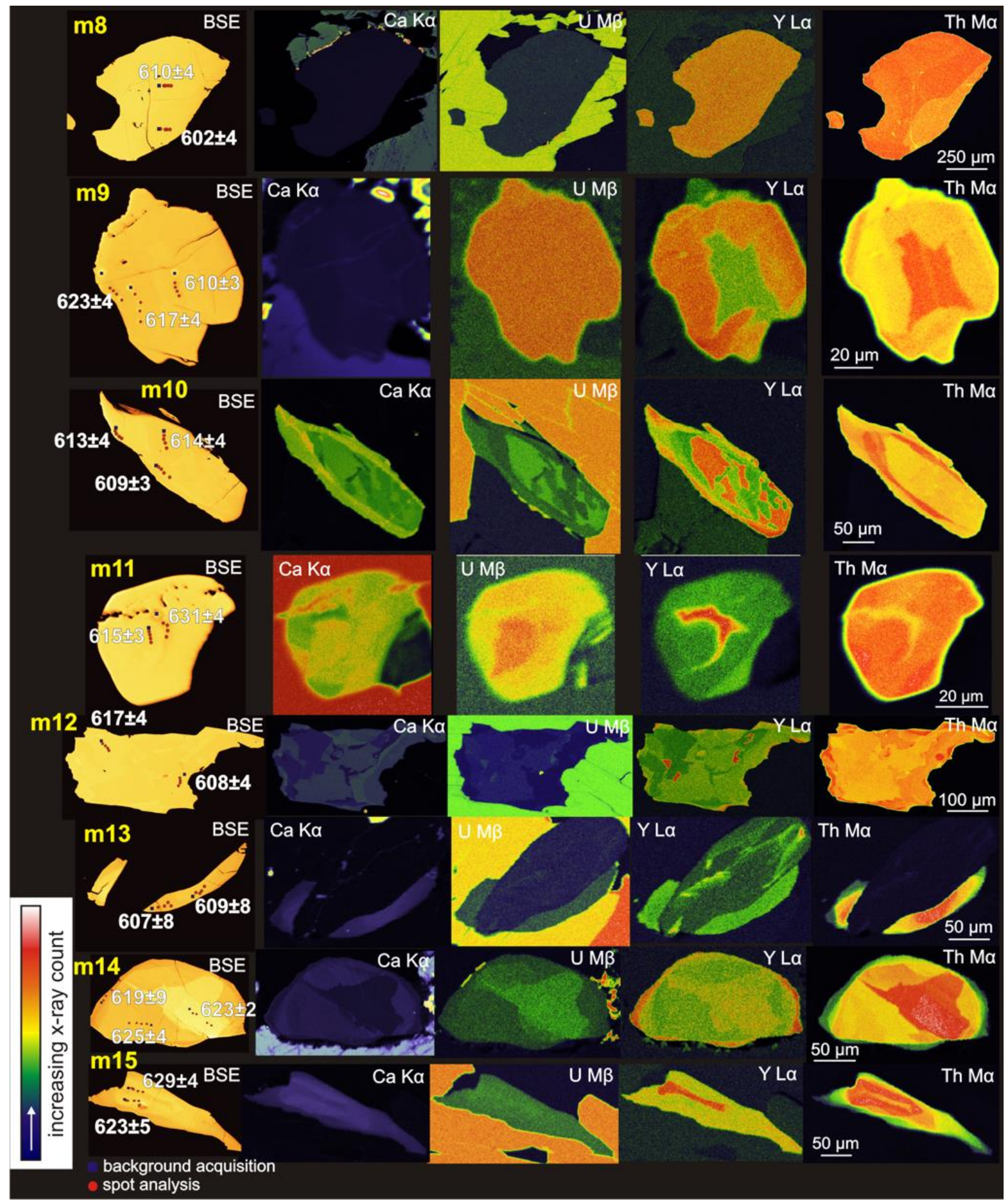

Figure A3: BSE image showing the location of spots and calculated age for each compositional domain

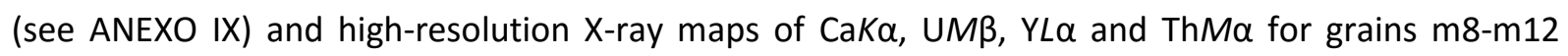
(sample 6D2) and grains m13-m15 (sample 9B). 


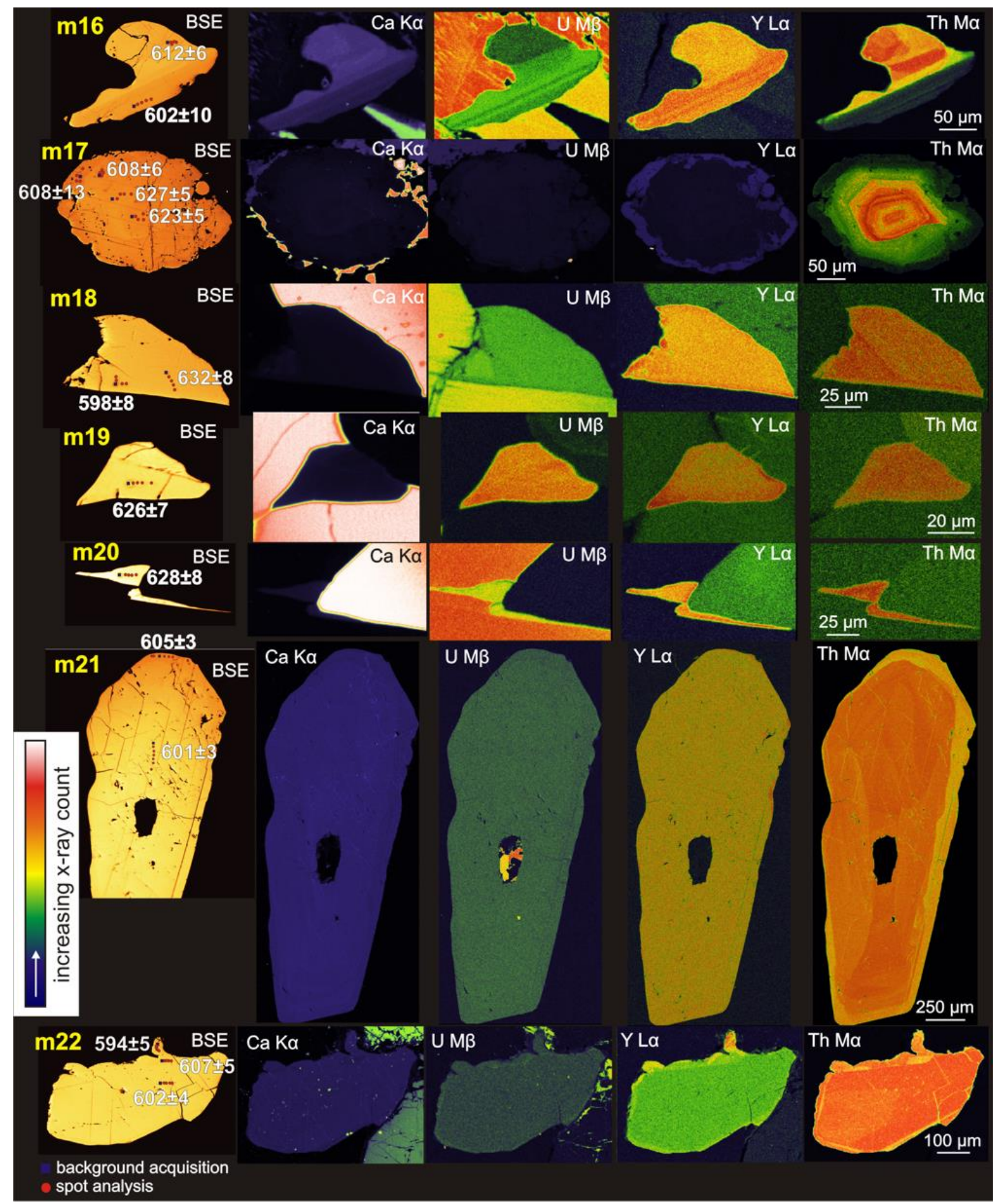

Figure A4: BSE image showing the location of spots and calculated age for each compositional domain (see ANEXO IX) and high-resolution X-ray maps of CaK $\alpha, U M \beta, Y L \alpha$ and ThM $\alpha$ for grains m16-m20 (sample 1A) and grains m21, m22 (sample 9A1). 


\section{ANEXO II}

Age and duration of pre-collisional arc magmatism and UHT metamorphism in the Socorro-Guaxupé Nappe (SE Brazil), constrained by in-situ charnockite melts and related rocks

Artigo a ser submetido ao periódico Precambrian Research 


\title{
ANEXO II
}

\section{Artigo a ser submetido no periódico Precambrian Research}

\section{Age and duration of pre-collisional arc magmatism and UHT metamorphism in the Socorro-Guaxupé Nappe (SE Brazil), constrained by in-situ charnockite melts and related rocks}

\author{
Brenda Chung Rocha ${ }^{a, b^{*}}$, Renato Moraes ${ }^{a}$, Andreas Möller ${ }^{b}$, Caue Rodrigues Cioffi ${ }^{a, b}$ \\ ${ }^{a}$ Departamento de Mineralogia e Petrologia, Instituto de Geociências, Universidade de São Paulo, Rua \\ do Lago, 562, CEP 05508-080, São Paulo, SP, Brazil \\ ${ }^{b}$ Department of Geology, The University of Kansas, 2335 Irving Hill Road, Nichols Hall, Lawrence, KS, \\ 66045-7559, USA \\ *Corresponding author: brendaroch@yahoo.com.br
}

\section{ABSTRACT}

The Socorro-Guaxupé Nappe (SGN) consists of a deeply eroded magmatic arc that records the Ediacaran collision between the Paranapanema Plate and the São Francisco paleocontinent, related to the assembly of western Gondwana. The SGN exposes a thick section $(c a .10 \mathrm{~km})$ of the lower crust, composed mainly of granulites and migmatites. Syn-collisional magmatism is recorded by widespread charnockite and high-K calc-alkaline intrusions. Here we present an integrated petrological and geochronological study of orthopyroxene- and hornblende-bearing leucosomes and their granulite hosts from the Granulite Unit, in order to determine the age and duration of pre-collisional arc magmatism and ultra-high temperature (UHT) metamorphism in the SGN. New LA-ICP-MS zircon U-Pb ages are combined to zircon trace element geochemistry to discriminate inherited and non-inherited zircon with more confidence. Igneous crystallization ages from the felsic and garnet granulites range from ca. 730-640 Ma, similarly to inherited xenocrystic zircon cores from hornblende- and orthopyroxene-bearing leucosomes, and are interpreted to constrain the pre-collisional arc magmatism lasting for at least 90 m.y. The concordia ages of $c a .655-650 \mathrm{Ma}$ obtained from the felsic and garnet granulites reflect the main period of pre-collisional arc magmatism. The SGN evolved from a subduction-related to a collisional setting, involving the formation of in-situ charnockite melts and hornblende-bearing leucosome at ca. 630-625 Ma during syn-collisional UHT metamorphism. Peak UHT metamorphic conditions were attained at $c a .900{ }^{\circ} \mathrm{C}, 12 \mathrm{kbar}$, by partial melting of felsic granulites. We propose that mafic underplating could be a potential heat source for UHT metamorphism, given the occurrence of syn-metamorphic mafic intrusions in close spatial relation to in-situ hornblende- and orthopyroxene-bearing leucosomes. Contrasting REE patterns in leucosomes provide evidence for the presence of both fractionated melt (higher REE abundance and negative Eu anomaly) and cumulates (lower REE abundance and positive Eu anomaly). Studied samples show 
isotopic evidence for enriched-mantle sources in their origin, and crustal recycling involving either Archean or Paleoproterozoic older crust have not been recognized yet.

Key-words: arc magmatism, UHT metamorphism, granulite, charnockite, lower crust, southern Brasília Orogen

\section{Introduction}

Charnockites and granites constitute major rock types in Precambrian granulite terranes and the understanding of their formation can provide important insights to the evolution of the lower crust (e.g. Percival \& Mortensen, 2002; Rajesh, 2004; Frost \& Frost, 2008; Zhao et al., 2014; Klaver et al., 2015). Charnockites can form by deep crustal melting (e.g. Zhao et al., 1997; Bhattacharya \& Sen, 2000; Kar et al., 2003; Rajesh \& Santosh, 2004), which requires an external heat source that also produces ultrahigh temperature (UHT) metamorphism (Harley, 2008, Kelsey, 2008; Clark et al., 2011). UHT metamorphism is characterized by temperatures higher than $900{ }^{\circ} \mathrm{C}$ and pressures within the $7-13$ kbar range (Harley, 1998). Such extreme conditions are prevalent in deep crustal processes and many UHT localities have been recently identified worldwide (Kelsey \& Hand, 2015). Charnockites in deeply eroded arcs (e.g. Percival \& Mortensen, 2002) have a typical magnesian, calc to calc-alkalic and metaluminous geochemical signature (Frost \& Frost, 2008). Many charnockite-granulite associations of Neoarchean to Paleoproterozoic age (e.g. Rajesh, 2004; Kornohen et al., 2013) are characterized by accreted juvenile crust to the cratons margins (e.g. Bhattacharya et al., 2001; Zhao et al., 2014; Klaver et al., 2015) and may represent episodic crustal growth driven by higher geothermal gradients in the early evolution of Earth's history (Condie, 1998). However, charnockites may also result from crustal reworking, which may involve the partial melting of older crustal components (e.g. Bai et al., 2015).

The Socorro-Guaxupé Nappe (SGN) represents a deeply eroded Neoproterozoic magmatic arc, which was developed at the active margin of Paranapanema plate in a subduction-related setting and evolved to a collisional orogeny (Campos Neto \& Caby, 1999, 2000; Campos Neto, 2000; Trouw et al., 2000). The SGN corresponds to a large-scale exposure of the lower crust ( $c a .10 \mathrm{~km}$ thick; Campos Neto \& Caby, 1999, 2000), what makes the SGN a natural laboratory for the study of petrogenetic and geodynamic processes in deep crust. Several workers (e.g. Campos Neto et al., 2011) have suggested that the SGN might represent the southern extension of the Goiás Magmatic Arc (Pimentel \& Fuck, 1992; Pimentel et al., 2000; Laux et al., 2004), even though there is a lack of juvenile rocks in the geological record of the $\mathrm{SGN}$ until now. Negative $\mathrm{ENd}_{(\mathrm{t})}$ values are frequent in many rock types within the SGN (e.g. Janasi, 1999, 2002; Janasi et al., 2009; Mora et al., 2014). In this contribution, the results of an integrated petrological and geochronological study of the main rock types from the Basal Granulite Unit of the SGN are presented, including new zircon U-Pb ages and trace element 
geochemistry, thermobarometry, whole-rock geochemistry and $\mathrm{Sr}-\mathrm{Nd}$ isotopic compositions. A combination of techniques is used to refine the timescales of pre-collisional arc magmatism, and syncollisional UHT metamorphism, and determine the origin and possible sources for in-situ charnockite and hornblende-bearing granite melts. This has important implications for the origin of charnockites in a broader context, and for the currently available tectonic models of the southern Brasília Orogen, and thus for the amalgamation of western Gondwana.

\section{Geological setting}

The southern Brasilia Orogen results from the neoproterozoic collision between the active margin of Paranapanema Plate and the passive margin of the São Francisco paleocontinent (Brito Neves et al., 1999; Campos Neto \& Caby, 2000; Trouw et al., 2000). It comprises a stack of flat-lying to gently SW dipping thick-skinned nappes, in which three different tectonic settings are recognized, from WSW to ENE: (i) a magmatic arc domain represented by the Socorro-Guaxupé Nappe (SGN), (ii) the subducted metasedimentary sequence of the Andrelândia Nappe System, (iii) a passive continental margin domain related to the São Francisco Plate represented by the Carrancas and Lima Duarte Nappe Systems (Fig. 1; e.g. Campos Neto \& Caby, 1999, 2000; Trouw et al., 2000, 2013; Campos Neto et al., 2010, 2011; Reno et al., 2009, 2012). The SGN represents a 10km thick section of the lower continental crust, interpreted as the root of a magmatic arc developed at the active margin of the Paranapanema Plate (Campos Neto \& Caby, 1999, 2000). The SGN is composed of three distinct units (Fig. 1): (i) a basal granulite unit with banded garnet granulites with orthopyroxene-bearing leucosome ( $3 \mathrm{~km}$ thick), (ii) a middle diatexite unit that comprises grey to pink metaluminous migmatites ( $6 \mathrm{~km}$ thick), and (iii) an upper metatexite unit composed mainly of metasedimentary migmatites (Campos Neto \& Caby, 1999, 2000).

The Basal Granulite Unit, focus of this study, comprises banded felsic and mafic granulites with concordant coarse-grained charnockite and pink hornblende granite veins, and minor garnet granulites and biotite gneisses. Igneous protolith crystallization ages (ID-TIMS; upper intercept) of $c a$. 640-660 Ma (e.g. Hackspacher et al., 2003; Mora et al., 2014) have been reported for granulites from the Basal Granulite Unit. Zircon inheritance between ca. 640-800 Ma have been recognized in migmatites with sedimentary protolith from the adjacent Metatexite Unit (Mora et al., 2014; Rocha et al., 2016). The age of granulite facies metamorphism in the SGN is recorded at ca. 630-620 Ma (e.g. Basei et al., 1995; Janasi, 1999; 2002; Valeriano et al., 2004; Martins et al., 2009; Reno et al., 2009; Mora et al., 2014; Rocha et al., 2016), synchronous to syn-collisional charnockite and high-K calc-alkaline magmatism (Janasi, 2002; Mora et al., 2014). Recently, Rocha et al., (2016) defined the partial melting event and UHT metamorphism in the SGN at ca. 630-625 Ma based on EPMA monazite dating, and a prolonged 
melt crystallization event between $c a .630-600 \mathrm{Ma}$, with main episodes of zircon and monazite growth at ca. $625 \mathrm{Ma}, c a .615 \mathrm{Ma}$ and ca. $608 \mathrm{Ma}$.

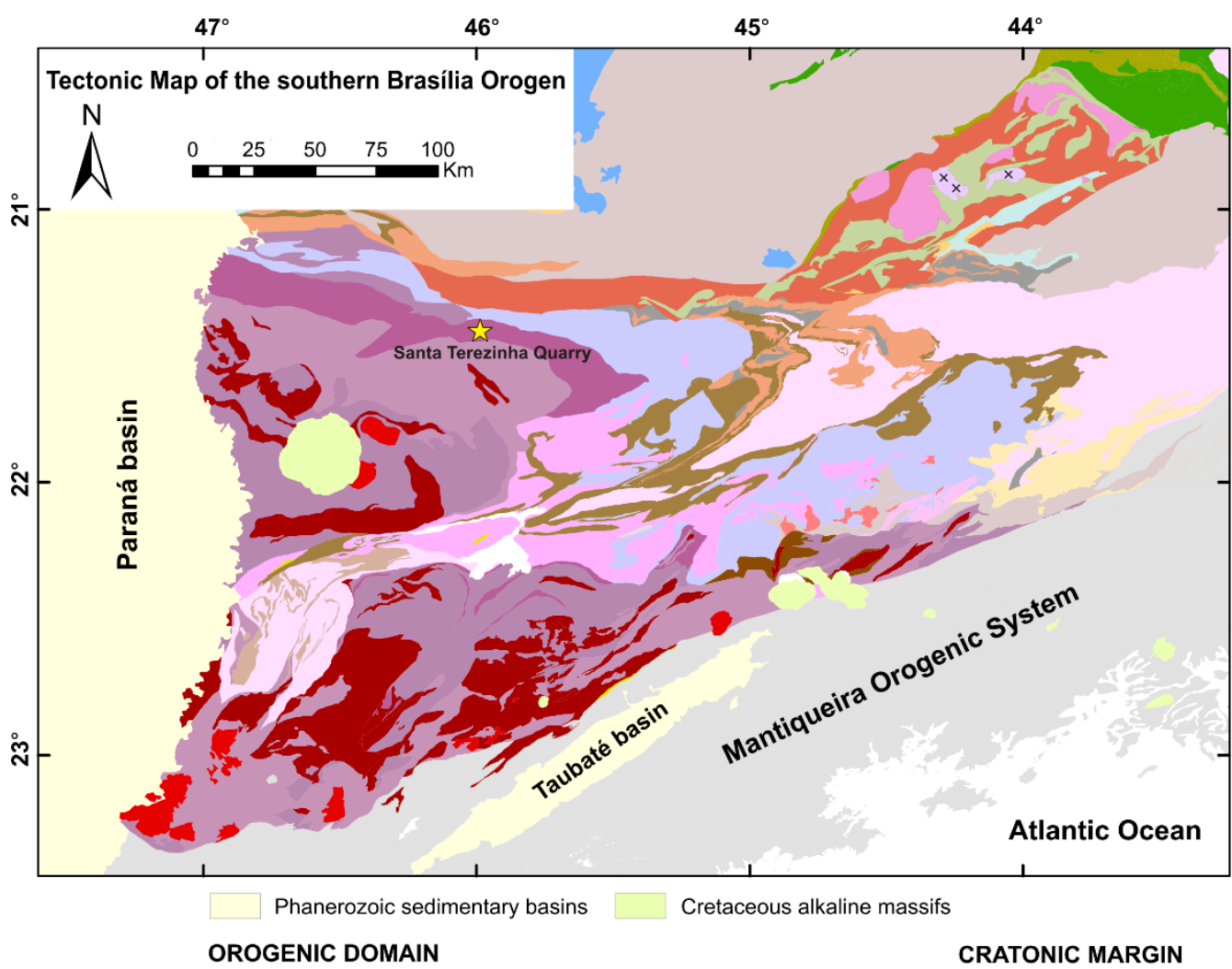

\begin{tabular}{|c|c|c|c|c|}
\hline & \multicolumn{2}{|c|}{ Passive Margin Domain } & \multicolumn{2}{|c|}{ Neoproterozoic carbonate platform } \\
\hline & \multicolumn{2}{|c|}{ Unknown age - Itapira Group } & \multirow{2}{*}{\multicolumn{2}{|c|}{$\begin{array}{l}\text { Paleoproterozoic (Rhyacian-Siderian) } \\
\text { Mineiro Belt }\end{array}$}} \\
\hline & \multicolumn{2}{|c|}{ Neoproterozoic flysch sequence } & & \\
\hline $\begin{array}{l}\text { Active Margin Domain } \\
\text { Neoproterozoic accretionary prism } \\
\text { and fore-arc basin } \\
\text { Leucogranites }\end{array}$ & \multicolumn{2}{|c|}{ Neoproterozoic psamo-pelite nappe systems } & & 2.13-2.17 Ga igneous suites \\
\hline Alagoa and Rio Preto Migmatites & Carrancas & Lima Duarte & & 2.2-2.35 Ga supracrustal sequences \\
\hline \multirow{2}{*}{$\begin{array}{l}\text { Neoproterozoic arc domain } \\
\text { Socorro - Guaxupé Nappe }\end{array}$} & & \multirow{2}{*}{$\begin{array}{l}\text { Mesoproterozoic } \\
\quad \text { São João del Rei and Carandai sequences }\end{array}$} & $2.35 \mathrm{Ga}$ igneous suites \\
\hline & \multicolumn{2}{|c|}{ São João del Rei and Carandaí sequences } & & Undivided granitoids \\
\hline \multirow{2}{*}{$\begin{array}{l}\text { Post tectonic and anorogenic granitoids } \\
\text { Orogenic and late orogenic granitoids } \\
\text { Orthogneiss metatexite Unit }\end{array}$} & \multicolumn{2}{|c|}{$\begin{array}{l}\text { Paleoproterozoic } \\
\text { Immature metasedimentary sequence } \\
\text { São Vicente Complex }\end{array}$} & \multicolumn{2}{|c|}{ Paleoproterozoic } \\
\hline & \multicolumn{2}{|c|}{ Orhogneisses - Pouso Alegre Complex } & \multicolumn{2}{|c|}{ Archean } \\
\hline Paragneiss metatexite Unit & \multirow{2}{*}{\multicolumn{2}{|c|}{$\begin{array}{r}\text { Archean } \\
\text { Ortho }\end{array}$}} & & Rio das Velhas Supergroup \\
\hline Orthogneiss diatexite Unit & & & & Granite-gneiss complexes \\
\hline
\end{tabular}

Figure 1: Geological map of the southern Brasilia Orogen (Cioffi et al., 2016), with the location of the studied area in the Basal Granulite Unit (Santa Terezinha Quarry) marked with a yellow star.

\section{Field relationships}

Twenty-four representative samples from the Basal Granulite Unit of the SGN were collected in the Santa Terezinha Quarry, located in the south of town of Alfenas (Fig. 1). The location of selected samples for zircon U-Pb geochronological studies is shown in (Fig. 2). The charnockite terminology adopted in this paper follows Frost \& Frost (2008), defined as an orthopyroxene-bearing granitic rock that is clearly of igneous origin or that is present as an orthopyroxene-bearing orthogneiss within a 
granulite terrane. The studied area comprises banded felsic and mafic granulites, interlayered with banded garnet granulites, fine-grained granite, and concordant coarse-grained pink hornblende granite and greenish charnockite veins (Fig. 2a, b). The later are suggestive to be the in-situ products of partial melting and are referred from now on as hornblende-bearing and orthopyroxene-bearing leucosomes, respectively (Fig. 2a-d).

In-source coarse-grained hornblende-bearing leucosome displays near-euhedral hornblende grains up to $5 \mathrm{~cm}$ in diameter, locally with relic cores of orthopyroxene (Fig. 2e) and transitional contact towards the orthopyroxene-bearing leucosome (Fig. 2g), denoting a genetic link between pink hornblende-bearing and dark orthopyroxene-bearing leucosomes. Orthopyroxene-bearing leucosome forms veins and larger patches commonly with euhedral orthopyroxene crystals up to $4 \mathrm{~cm}$, which might represent accumulation of segregated melt into dilatant sites as discussed by Sawyer (2001). Leucosomes are present either parallel to the axial planes of centimeter-scale isoclinal folds and discordant to the main foliation. Segregation and migration of orthopyroxene-bearing leucosome may cause the rupture of mafic granulite layers (Fig. $2 \mathrm{~d}$ ). Garnet granulite occurs as $\sim 1 \mathrm{~m}$ wide lenses either interlayered with felsic granulite (Fig. 2c) and as rafts engulfed in hornblende-bearing and orthopyroxene-bearing leucosomes (Fig. 2e, f). Syn-metamorphic basaltic intrusions are also present, and commonly exhibit concentrations of either hornblende- and orthopyroxene-bearing leucosomes in their surroundings (Fig. 2h).

\section{Petrography and mineral chemistry}

Petrography and mineral chemistry of samples studied in most detail are presented. Mineral abbreviations after Whitney \& Evans (2010). Representative major element composition of garnet, orthopyroxene, plagioclase, amphibole and biotite are given in ANEXO III. Analyzed garnet and orthopyroxene grains are referred from now on by their grain number.

\subsection{Hornblende-bearing leucosome (samples A2, 5B)}

The hornblende-bearing leucosome consists mainly of euhedral, coarse-grained K-feldspar (55$65 \%)$ up to $10 \mathrm{~cm}$, both perthitic orthoclase and microcline are observed, hornblende (10-15\%) up to $5 \mathrm{~cm}$ length, anhedral quartz (10-15\%), and plagioclase (5-10\%) defining an inequigranular texture, with minor biotite $(<5 \%)$. Fine-grained plagioclase $\left(\mathrm{An}_{20-30}\right)$ typically occurs as myrmekite surrounding K-feldspar megacrysts (Fig. 3a). Hornblende contains inclusions of zircon, apatite and exsolution of opaque minerals. Late biotite + quartz intergrowths are the products of partial replacement of hornblende (Fig. 3b). Apatite, zircon, titanite, opaque minerals, allanite, epidote, calcite, chlorite and tourmaline are the accessory phases. Apatite clusters occur within fine-grained quartz-feldspathic aggregates commonly associated with epidote and calcite. 

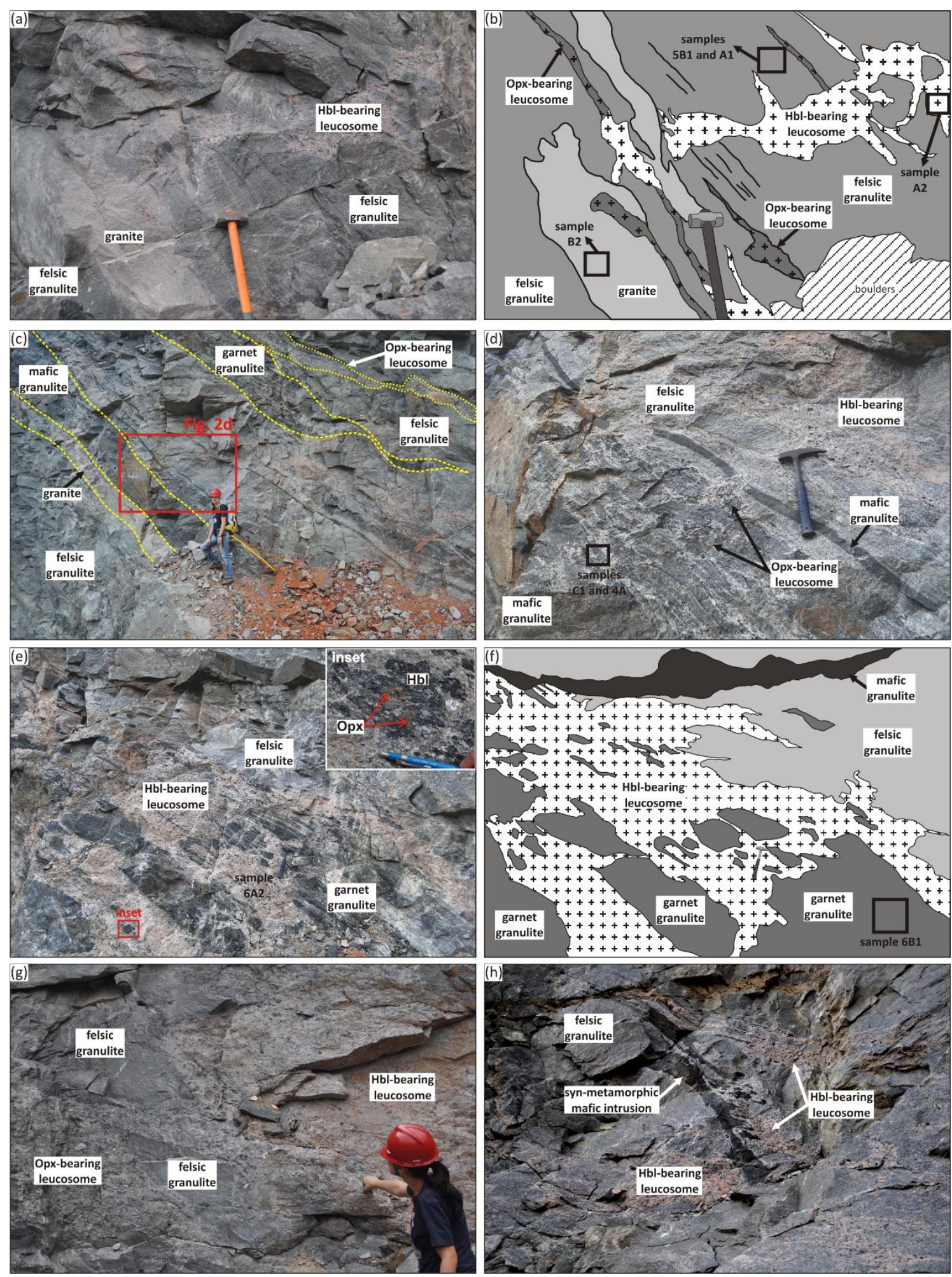

Figure 2: Studied rocks within the Basal Granulite Unit of the SGN collected at the Santa Terezinha Quarry. (a) Felsic granulite crosscut by hornblende- and orthopyroxene-bearing leucosomes, indicative of in-situ products of partial melting and (b) corresponding sketch. (c) Banded felsic and mafic granulite with concordant orthopyroxene-bearing leucosome up to $1 \mathrm{~m}$ wide interlayered with garnet granulite and fine-grained granite. (d) Detail of orthopyroxene-bearing leucosome causing rupture of a mafic granulite layer, consistent with in-situ partial melting. (e) In-source coarse-grained hornblende-bearing leucosome with numerous rafts of garnet granulite. Inset in the upper right shows relics of 
orthopyroxene preserved in centimeter-scale hornblende grains within hornblende-bearing leucosome. (f) Field sketch illustrating the relationship between hornblende-bearing leucosome and garnet granulite. (g) Transitional contact between light-grey orthopyroxene-bearing leucosome and pinkish hornblende-bearing leucosome. (h) Concentration of hornblende-bearing leucosome at the surroundings of syn-metamorphic mafic intrusions.

\subsection{Fine-grained granite (sample B2)}

Sample B2 is mainly composed of subhedral to anhedral K-feldspar (55-60\%), interstitial quartz (20-25\%), plagioclase (10-15\%) and minor biotite (5-10\%). Opaques, apatite, zircon, tourmaline, zoisite, calcite and chlorite occur as accessory phases. Perthite crystals generally has inclusions of zircon, apatite and subhedral plagioclase, and are surrounded by fine-grained myrmekite. Partial replacement by late muscovite is also present.

\subsection{Orthopyroxene-bearing leucosome and host mafic granulite (samples C1, 4A)}

Orthopyroxene-bearing leucosome comprises orthopyroxene (10-15\%), plagioclase (50-55\%), and hornblende (5-10\%) megacrysts, K-feldspar (1-5\%) and interstitial quartz (15-20\%) defining a fine to coarse-grained inequigranular texture. Apatite, opaque minerals, zircon, allanite, biotite and calcite are the main accessory minerals. Orthopyroxene locally displays quartz and plagioclase films along grain boundaries, mimicking trapped melt (Fig. 3e). Euhedral to subhedral orthopyroxene megacrysts are slightly magnesian $\left(X_{\mathrm{Mg}}=0.53-0.59\right)$, with alumina contents varying from core to rim between 0.08 and $0.06 \mathrm{Al}$ p.f.u. Subhedral plagioclase $\left(\mathrm{An}_{27-29}\right)$ has abundant zircon and needle-like biotite inclusions. Coarse-grained hornblende frequently exhibits bleb-like quartz or zircon inclusions, and orthopyroxene relics partially replaced by uralite. Orthopyroxene-bearing leucosome has a diffusive contact towards the host mafic granulite in sample 4A. Fine to medium-grained mafic granulite with a nematogranoblastic texture is composed by hornblende (55-60\%), plagioclase (20-25\%), biotite (5$10 \%)$, quartz (5-10\%) with minor orthopyroxene (<4\%) relics preserved within hornblende (Fig. 3f). Opaque minerals, apatite and zircon are the main accessory phases. Hornblende in both orthopyroxene-bearing leucosome and mafic granulite belongs to the calcic group ( $\mathrm{ANa}+\mathrm{AK}>0.5 ; \mathrm{Ti}$ $<0.5$; ${ }^{\mathrm{V}} \mathrm{Al}<\mathrm{Fe}^{3+}$; Hawthorne \& Oberti, 2007) and is classified as magnesiohastingsite (see Supplementary Fig. A1). Orthopyroxene relics are commonly present as inclusions within hornblende, and rare grains are preserved within matrix plagioclase $\left(\mathrm{An}_{28-29}\right)$ (Fig. 3g). The orthopyroxene composition is slightly more magnesian $\left(X_{\mathrm{Mg}}=0.58-0.60\right)$ compared to orthopyroxene-bearing leucosome grains, with similar Al contents (0.08-0.06 Al p.f.u). 

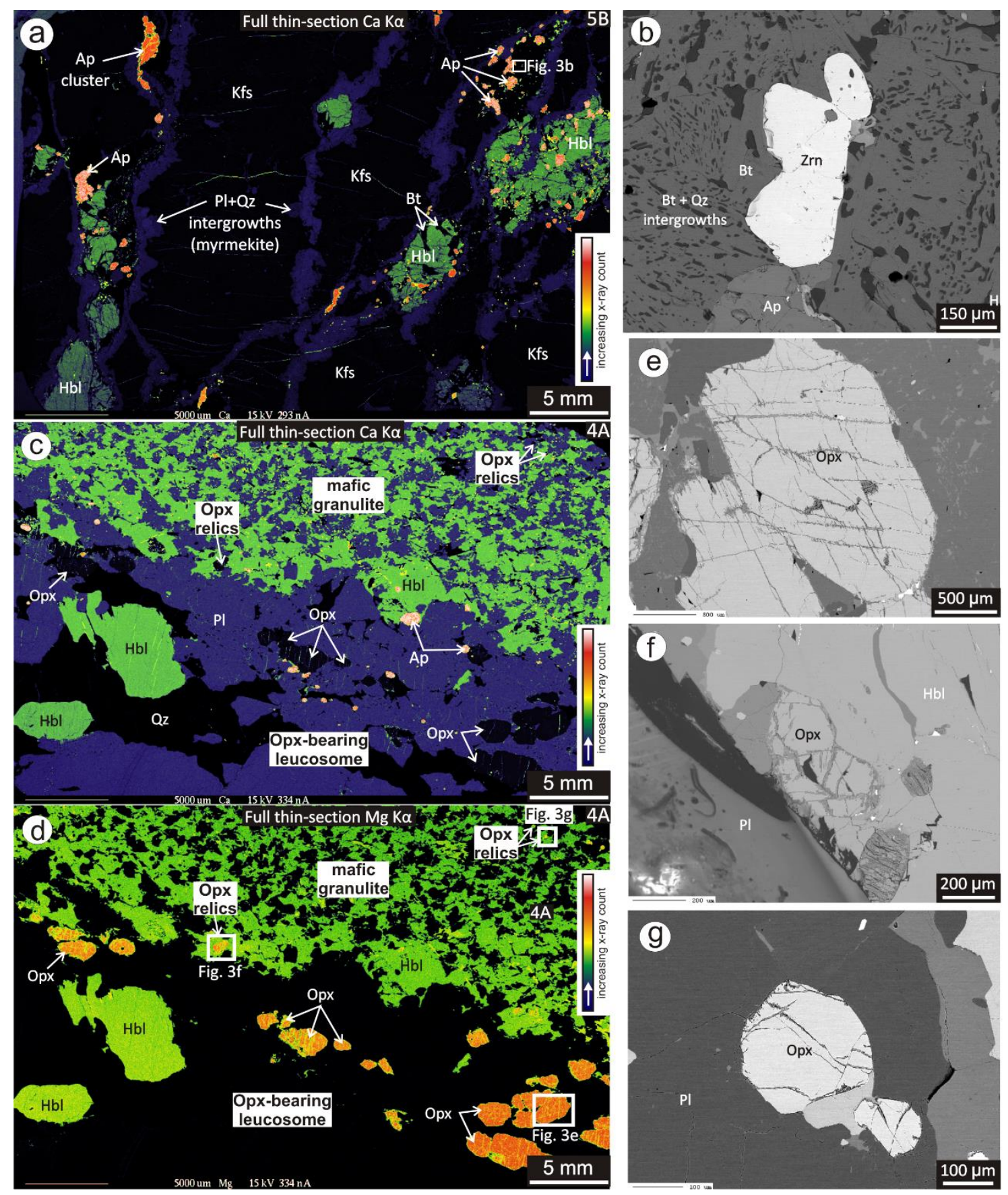

Figure 3: (a) Ca Ka full thin-section map of hornblende-bearing leucosome (sample 5B). Note myrmekite surrounding K-feldspar megacrysts and apatite clusters associated to late biotite after hornblende (b) Detail of zircon grains within biotite + quartz intergrowths. c) Ca K $\alpha$ and d) Mg Ka full thin-section map of orthopyroxene-bearing leucosome with diffusive contact with mafic granulite (sample 4A). Note coarse-grained euhedral orthopyroxene and hornblende grains in the orthopyroxene-bearing leucosome. e) Euhedral orthopyroxene in the orthopyroxene-bearing leucosome. $\mathrm{f}-\mathrm{g}$ ) Detail of orthopyroxene relics within mafic granulite. 


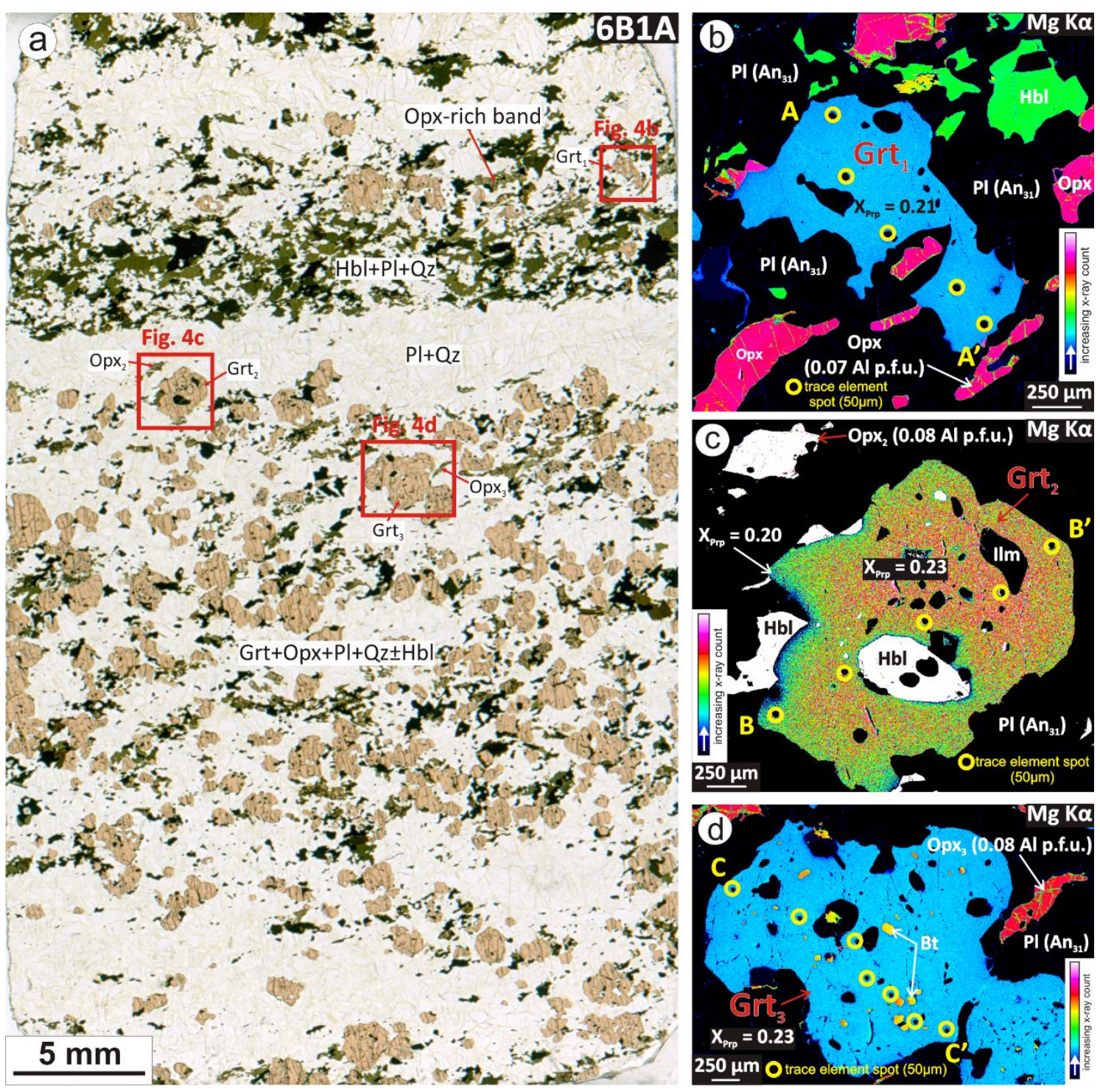

Figure 4: a) Photograph of standard thin-section of garnet granulite (sample 6B1A), illustrating the location of analyzed grains used for thermobarometric calculations. Mg Ka high-resolution X-ray maps of analyzed garnet grains showing the location of major element and REE profiles in (Fig. 5). b) Grt partially replaced by syn- $\mathrm{S}_{2} \mathrm{Opx}+\mathrm{PI}+\mathrm{Qz}$. c) Late to post-kinematic $\mathrm{Grt}_{2}$ displaying hornblende inclusions. Note syn- $S_{2}$ orthopyroxene-fish at the top left. d) $\mathrm{Grt}_{3}$ with abundant biotite and plagioclase inclusions and pressure shadow composed of $\mathrm{Opx}+\mathrm{Pl}+\mathrm{Qz}$ at the top right.

\subsection{Felsic granulite (samples 3B1, 5B1)}

Sample 3B1 is mainly composed of orthopyroxene (15-20\%), plagioclase (45-50\%) and hornblende (5-10\%), quartz (5-10\%), with minor K-feldspar (1-5\%), biotite (1-5\%) and accessory apatite, zircon, chlorite and calcite, similarly to sample 5B1. Euhedral to subhedral orthopyroxene is magnesian $\left(X_{\mathrm{Mg}}=0.55-0.58\right)$ and has Al-rich cores (0.07-0.09 Al p.f.u $)$ with a slight depletion towards the rims (0.06 Al p.f.u). Fewer grains show minor substitution at their rims to hornblende or biotite + quartz intergrowths. Subhedral to anhedral plagioclase is characterized by near homogeneous $\mathrm{Ca}$ 
contents $\left(\mathrm{An}_{30}\right)$ with a slight decrease of orthoclase from core to rim $\left(\mathrm{Or}_{2.8-1.0}\right)$. The amphibole present is classified as magnesiohastingsite and occurs as anhedral grains associated with opaque minerals, which partially replaced orthopyroxene.

\subsection{Garnet granulite (sample 6B1)}

Sample 6B1A is characterized by a compositional banding, with granoblastic bands composed mainly of garnet (35-40\%), plagioclase (25-30\%), quartz (10-15\%) ribbons, with minor orthopyroxene (5-10\%), hornblende (1-5\%) and biotite (1-5\%), alternated with orthopyroxene and hornblende-rich granonematoblastic bands (Fig. 4a). The main foliation is defined by syn-kinematic hornblende, plagioclase, garnet, opaque minerals, orthopyroxene-fish (Opx $;$; Fig 4c) and fine-grained pressure shadows consisting of hornblende + plagioclase and orthopyroxene + plagioclase wrapping garnet porphyroblasts ( $\mathrm{Grt}_{2}$ and $\mathrm{Grt}_{3}$; Figs. 4c-d), implying in deformation concomitant to the development of amphibolite and granulite facies fabrics. Orthopyroxene is magnesian ( $\left.X_{\mathrm{Mg}}=0.55-0.59\right)$ and characterized by Al-rich cores (0.08 Al p.f.u) with a slight decrease at the rims (0.06 Al p.f.u). Amphibole is classified as magnesiohastingsite (Supplementary Fig. A1). Anhedral plagioclase $\left(A n_{30-31}\right)$ has quartz, apatite and zircon inclusions. Biotite inclusions in $\mathrm{Grt}_{3}$ are magnesian $\left(X_{\mathrm{Mg}}=0.60-0.66\right)$ and titaniferous (0.3 Ti p.f.u).

Syn-kinematic garnet ( $\mathrm{Grt}_{1}$; Fig. 4b) has quartz and plagioclase inclusions, and is partially replaced by orthopyroxene + plagioclase (Fig. 4b). Major element zoning is characterized by a minor increase in $X_{\text {Alm }}$ accompanied by a decrease in $X_{\text {Prp }}$ from core $\left(\mathrm{Alm}_{53} \operatorname{Prp}_{22} \mathrm{Grs}_{16} \mathrm{Sps}_{11}\right)$ to rim $\left(\mathrm{Alm}_{55} \operatorname{Prp}_{19} \mathrm{Grs}_{16} \mathrm{Sps}_{11}\right.$ ) (Fig. 5). Grt ${ }_{1}$ is marked by a distinctive chondrite-normalized REE pattern compared to $\mathrm{Grt}_{2}$ and $\mathrm{Grt}_{3}$. Grt $\mathrm{Gr}_{1}$ is HREE-enriched, displays HREE- and MREE-depletion from core $\left(\mathrm{Yb}_{N} / \mathrm{Gd}_{N}=8 ; D \mathrm{Dy}_{N} / \mathrm{Gd}_{N}=3\right)$ to $\operatorname{rim}\left(\mathrm{Yb}_{N} / \mathrm{Gd}_{N}=2 ; D \mathrm{Dy}_{N} / \mathrm{Gd}_{N}=2\right)$ and strong negative Eu anomalies $\left(\mathrm{Eu} / \mathrm{Eu}^{*}=0.17-0.21\right)$. Late to post-kinematic euhedral garnet (Grt ${ }_{2}$; Fig. $\left.4 \mathrm{c}\right)$, with hornblende inclusions, has a similar major element composition ( $\mathrm{Alm}_{52-54} \operatorname{Prp}_{20-23} \mathrm{Grs}_{16} \mathrm{Sps}_{9-10}$ ), with slightly higher almandine and lower pyrope contents at the outermost rims compared to cores. Grt $_{3}$ has abundant biotite inclusions (Fig. 4d) and exhibits a relatively flat compositional profile ( $\operatorname{Alm}_{52-53} \operatorname{Prp}_{22-23} \mathrm{Grs}_{16} \mathrm{Sps}_{8-11}$ ), with a slight increase in $X_{\text {sps }}$ at the outermost rims $\left.\left(S_{p s}\right)_{11}\right)$ related to late retrograde kick-up effect (Kohn \& Spear, 2000). $\mathrm{Grt}_{2}$ and $\mathrm{Grt}_{3}$ are HREE-depleted in one order of magnitude compared to $\mathrm{Grt}_{1}$, and are characterized by cores with flat HREE patterns $\left(\mathrm{Yb}_{N} / \mathrm{Gd}_{\mathrm{N}}=1\right)$, with a slight decrease in HREE contents towards the rims $\left(\mathrm{Yb}_{N} / G_{N}=0.6\right)$, near constant MREE contents $\left(D y_{N} / G d_{N}=1\right)$ and negative Eu anomalies $\left(\mathrm{Eu} / \mathrm{Eu}^{*}=0.12-0.23\right)$. 

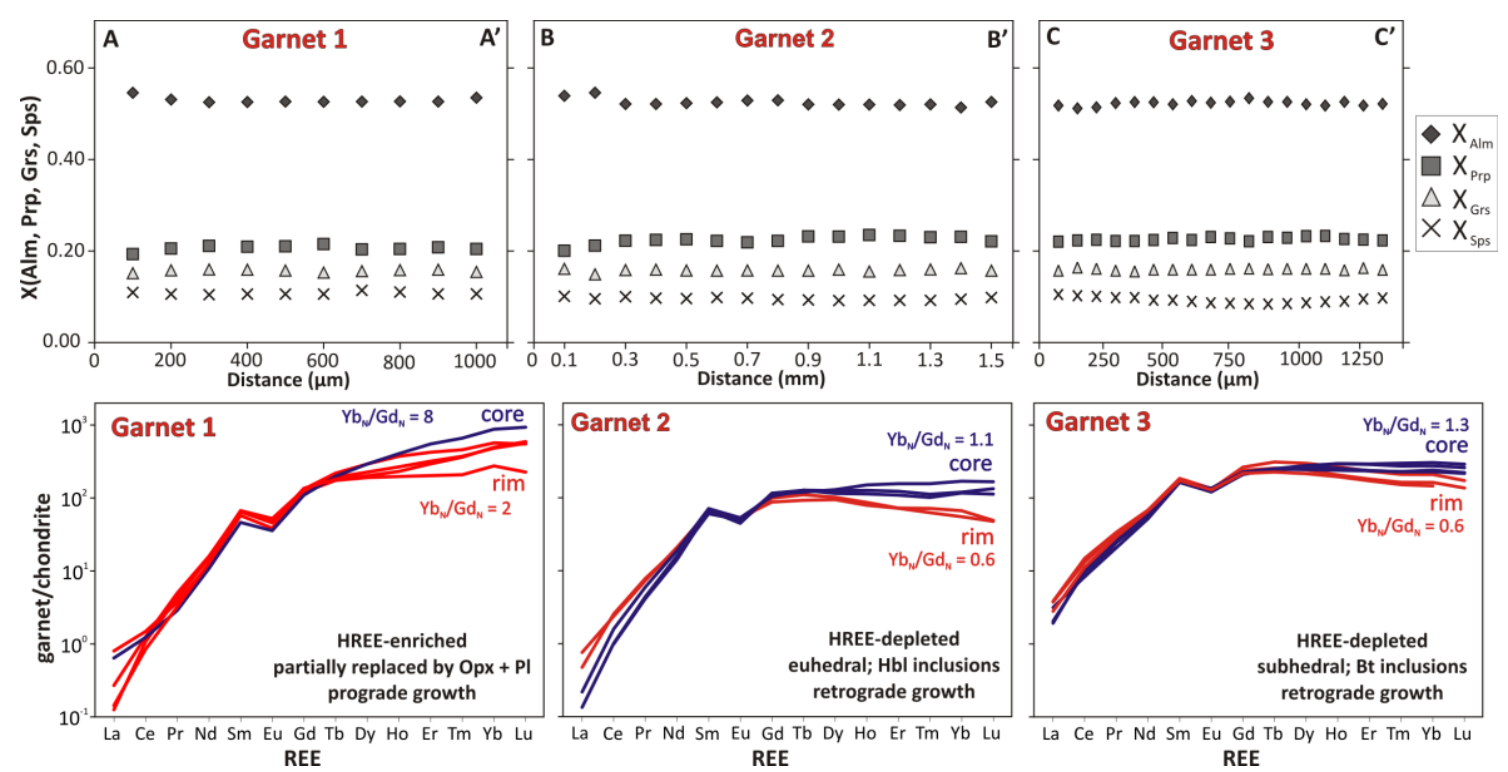

Figure 5: Compositional profiles across $\mathrm{Grt}_{1}, \mathrm{Grt}_{2}$ and $\mathrm{Grt}_{3}$ and corresponding REE patterns normalized to the chondrite values of McDonough \& Sun (1995) in garnet granulite (sample 6B1A).

\section{P-T conditions of partial melting and high-grade metamorphism}

Compositions of coexisting garnet and orthopyroxene in the garnet granulite (samples 6B1A and $6 \mathrm{~B} 1 \mathrm{C}$ ) are used to estimate the pressure-temperature conditions using garnet-orthopyroxene Alsolubility-based thermobarometry, corrected for late Fe-Mg exchange using the RCLC program elaborated by Pattison et al. (2003) and results are reported in ANEXO IV. Peak metamorphic conditions of the M1 stage are calculated using garnet and Al-rich orthopyroxene core compositions (0.08 Al p.f.u) and vary from $881-902{ }^{\circ} \mathrm{C}$ and $11.4-12.1 \mathrm{kbar}$, with average $P-T$ conditions of $894 \pm 9{ }^{\circ} \mathrm{C}$, $11.9 \pm 0.3$ kbar. Orthopyroxene ( $0.06 \mathrm{Al}$ p.f.u) and garnet rim compositions yielded average conditions of $833 \pm 28{ }^{\circ} \mathrm{C}, 11 \pm 0.4 \mathrm{kbar}$. The pressure associated to the metamorphic peak was also estimated using barometers based on garnet-orthopyroxene-plagioclase-quartz equilibrium using several calibrations (Newton \& Perkins, 1982; Perkins \& Chipera, 1985; Eckert et al., 1991). The combination of garnet and orthopyroxene cores with the plagioclase rim compositions gives pressures in the range 11.9-12.7 kbar for garnet granulites at $T=900{ }^{\circ} \mathrm{C}$ using the Newton \& Perkins (1982) and Perkins \& Chipera (1985) methods. Pressure estimates using the Eckert et al. (1991) calibration vary from 12.8$13.3 \pm 1.55 \mathrm{kbar}$ at $T=900^{\circ} \mathrm{C}$. Thermobarometric results indicate that peak metamorphic conditions were achieved at $\mathrm{ca} .900^{\circ} \mathrm{C}$ at $12 \mathrm{kbar}$.

The absence of rutile in the studied rocks prevent the application of Zr-in-rutile thermometry. Ilmenite is the main Ti-bearing phase and minimum temperatures were estimated by Ti-in-zircon thermometry (Watson et al., 2006) to constrain the temperature of melt crystallization assuming $a_{\text {TiO2 }}$ $=0.5$. The titanium contents in bright-CL rims and recrystallized domains vary from 5-12 ppm Ti and yielded minimum temperatures within the ca. $680-755{ }^{\circ} \mathrm{C}$ range in all samples. Slightly higher 
temperatures of $712-788^{\circ} \mathrm{C}$ (7-17 ppm Ti) are recorded in well-developed sector-zoned overgrowths on zircon grains in the hornblende-bearing leucosome (sample A2). Xenocrystic zircon cores record similar temperatures, except grain 16 (Fig.9f) in the garnet granulite (sample 6B1), which has higher $\mathrm{Ti}$ contents (up to $60 \mathrm{ppm}$ ) and yielded the highest temperature of $928 \pm 12{ }^{\circ} \mathrm{C}$.

\section{Whole-rock geochemistry}

Whole-rock major and trace element compositions of studied rocks from the SGN are presented in ANEXO V. Analytical procedures are described in Appendix A. Silica contents in the hornblende-bearing leucosome range from $59-70 \mathrm{wt} \% \mathrm{SiO}_{2}$, similarly to the fine-grained granite (62$74 \mathrm{wt} \% \mathrm{SiO}_{2}$ ) and orthopyroxene-bearing leucosome (58-73 wt\% $\left.\mathrm{SiO}_{2}\right)$. A great deal of major elements $\left(\mathrm{MgO}, \mathrm{FeO}_{\mathrm{t}}, \mathrm{CaO}, \mathrm{TiO}_{2}, \mathrm{P}_{2} \mathrm{O}_{5}\right.$ ) shows negative correlation with increasing $\mathrm{SiO}_{2}$, while $\mathrm{K}_{2} \mathrm{O}$ shows positive correlation (Fig. 6). Most samples are characterized by relatively high $\mathrm{K}_{2} \mathrm{O}$ contents (1-8 wt\%) and plot within the shoshonite field in the $\mathrm{K}_{2} \mathrm{O}$ versus $\mathrm{SiO}_{2}$ classification diagram of Peccerillo \& Taylor (1976) (Fig. 6). Felsic granulite exhibits a limited range of silica contents (53-56 wt\% $\mathrm{SiO}_{2}$, except sample $2 \mathrm{~B} 1$ with 61 wt\% $\mathrm{SiO}_{2}$ ) and $16-20$ wt\% $\mathrm{Al}_{2} \mathrm{O}_{3}$. Garnet granulite has the same silica contents (51-55 wt\% $\mathrm{SiO}_{2}$ ) and mafic granulites are characterized by lower $\mathrm{SiO}_{2}$ contents (46-52 wt\% $\mathrm{SiO}_{2}$ ).

All studied samples are metaluminous according to the $A / N K$ versus $A / C N K$ classification diagram (Frost et al., 2001), except the fine-grained granite and one sample from the hornblendebearing leucosome (sample 6A2), which are weakly peraluminous (Fig. 7a). In the TAS (total alkalis silica) diagram (Middlemost, 1994), hornblende-bearing leucosome plots in the syenite and quartz monzonite fields, the fine-grained granite plots within the syenite and granite fields. Orthopyroxenebearing leucosome samples are classified as monzonite and one sample plots within the granite field (Fig. 7b). Hornblende-bearing and orthopyroxene-bearing leucosomes display similar geochemical features. Both are metaluminous, magnesian, alkalic and plot within the volcanic arc granite and syncollisional granite field in the tectonic discrimination diagram of Pearce et al. (1984), apart from sample $2 \mathrm{~A}$, which plots in the boundary between alkali-calcic and calc-alkalic in the $\mathrm{Na}_{2} \mathrm{O}+\mathrm{K}_{2} \mathrm{O}-\mathrm{CaO}$ (MALI) versus $\mathrm{SiO}_{2}$ diagram (Fig. 7d). Most felsic granulite samples are plotted within the monzonite field in the TAS diagram (Fig. 7b), while mafic granulites are dominantly classified as gabbro. Garnet granulite is ferroan and metaluminous to gently peraluminous in the $A$ /NK versus $A / C N K$ diagram (Frost et al., 2001), which may reflect its high garnet contents. Felsic granulites are ferroan, but plot close to the boundary of magnesian field in the $\mathrm{FeO}_{\mathrm{t}} /\left(\mathrm{FeO}_{\mathrm{t}}+\mathrm{MgO}\right)$ versus $\mathrm{SiO}_{2}$ diagram (Frost et al., 2001). Mafic granulite samples are mostly magnesian (Fig. 7c). 


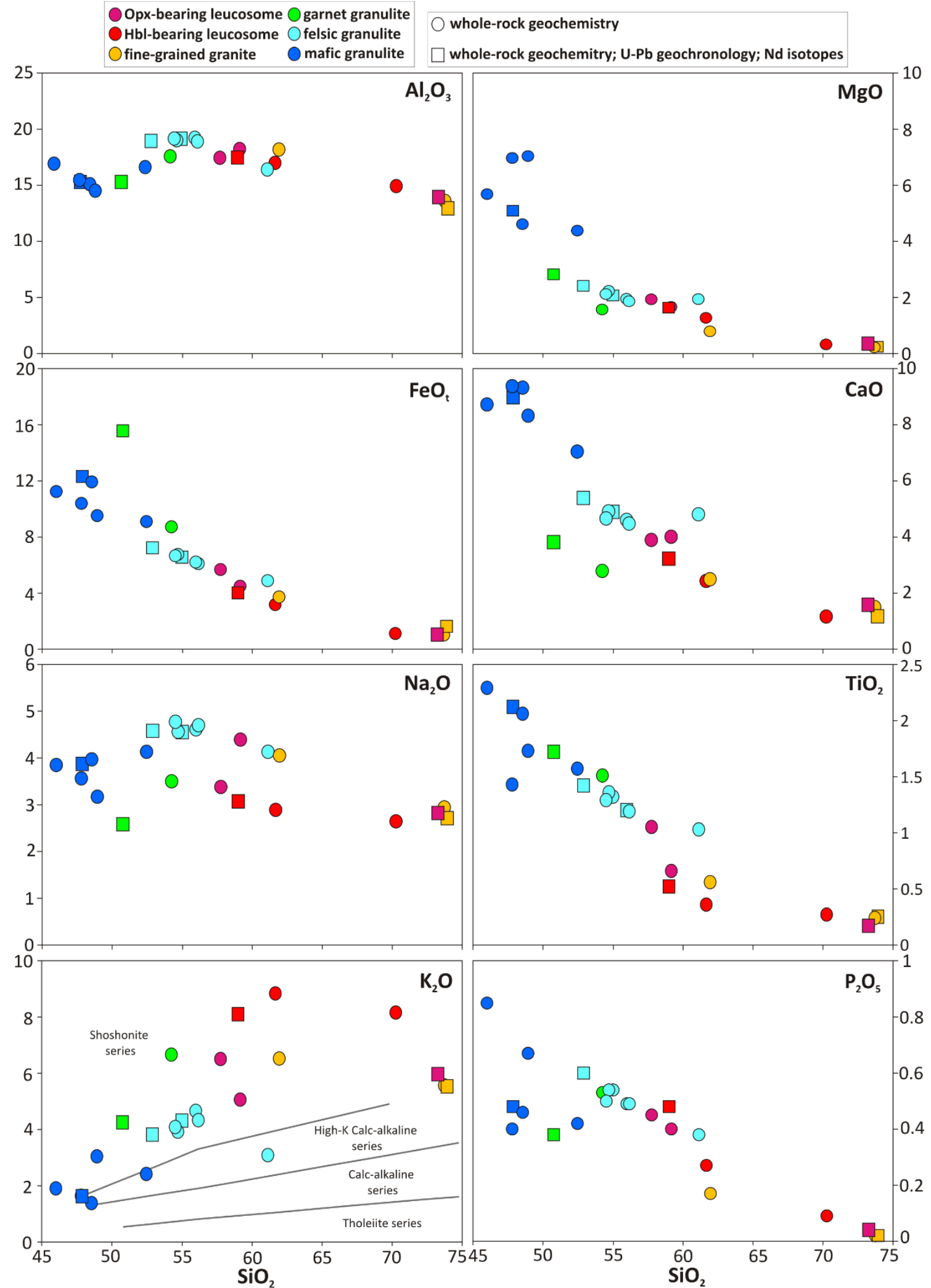

Figure 6: Harker-type diagrams ( $\mathrm{SiO}_{2}$ vs. major elements) for $\mathrm{Hbl}$-bearing leucosomes, Opx-bearing leucosomes, fine-grained granite, felsic and mafic granulites from the $\mathrm{SGN}$. $\mathrm{K}_{2} \mathrm{O}$ vs. $\mathrm{SiO}_{2}$ diagrams shows the magmatic series of Peccerillo \& Taylor (1976). 

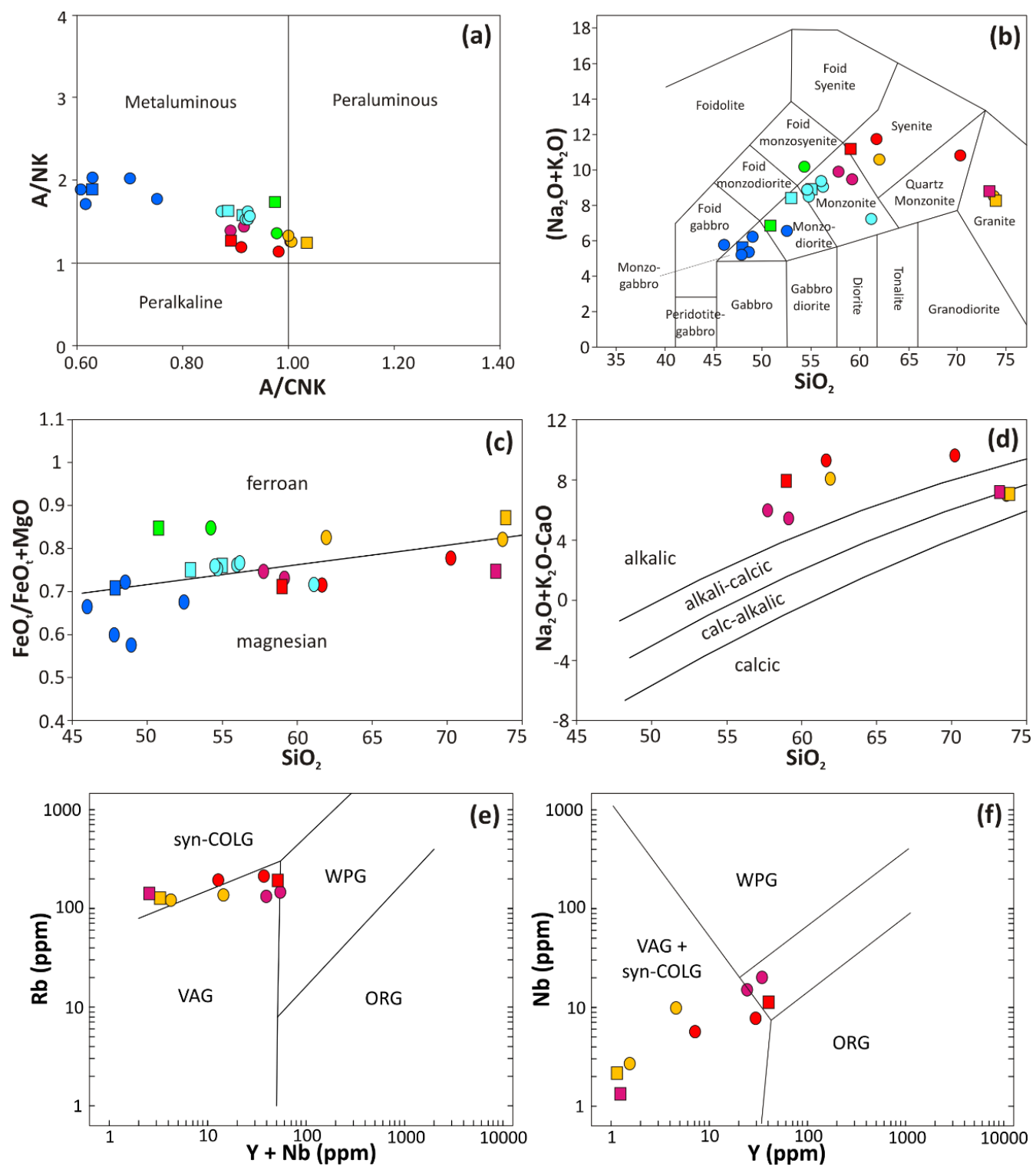

Figure 7: (a) $\mathrm{A} / \mathrm{NK}\left(\mathrm{Al}_{2} \mathrm{O}_{3} / \mathrm{Na}_{2} \mathrm{O}+\mathrm{K}_{2} \mathrm{O}\right)$ vs. $\mathrm{A} / \mathrm{CNK}\left(\mathrm{Al}_{2} \mathrm{O}_{3} / \mathrm{CaO}+\mathrm{Na}_{2} \mathrm{O}+\mathrm{K}_{2} \mathrm{O}\right)$ classification diagram from Frost et al. (2001). (b) TAS (Total alkalis silica) classification diagram (after Middlemost, 1994). (c) $\mathrm{FeO}_{\mathrm{t}} /\left(\mathrm{FeO}_{\mathrm{t}}+\mathrm{MgO}\right)$ vs. $\mathrm{SiO}_{2}$ diagram (modified from Frost et al., 2001). (d) MALI (Modified alkali-lime index) vs. $\mathrm{SiO}_{2}$ (modified from Frost et al., 2001). (e) Rb vs. Y+Nb tectonic discrimination diagram (after Pearce et al., 1984). (f) Nb vs. Y tectonic discrimination diagram (after Pearce et al., 1984). Abbreviations: syn-COLG, syn-collisional granite; VAG, volcanic arc granite; WPG, within-plate granite; ORG, ocean ridge basalt. Color-coding as in Fig. 6.

REE chondrite-normalized patterns and primitive-mantle normalized spidergrams are presented in Fig. 8. Hornblende-bearing leucosome is relatively enriched in $\operatorname{LREE}\left((\mathrm{La} / \mathrm{Yb})_{\mathrm{N}}=16\right)$ and has a weak negative $\mathrm{Eu}$ anomaly $\left(\mathrm{Eu} / \mathrm{Eu}^{*}=0.7-0.9\right)$. One of the samples of this lithotype, $6 \mathrm{~A} 2$, has a more fractionated REE chondrite-normalized pattern $\left((\mathrm{La} / \mathrm{Yb})_{N}=31\right)$ and positive Eu anomaly $(\mathrm{Eu} / \mathrm{Eu} *$ =2.3) (Fig. 8a). Hornblende-bearing leucosome displays an analogous pattern when compared to the 
average continental crust (Rudnick \& Fountain, 1995; Wedepohl, 1995), with enrichment in K, La, Ce, $\mathrm{P}, \mathrm{MREE}$ and HREE, and depletion in Ti, Nb, Th and $\mathrm{U}$ (Fig. 8f).
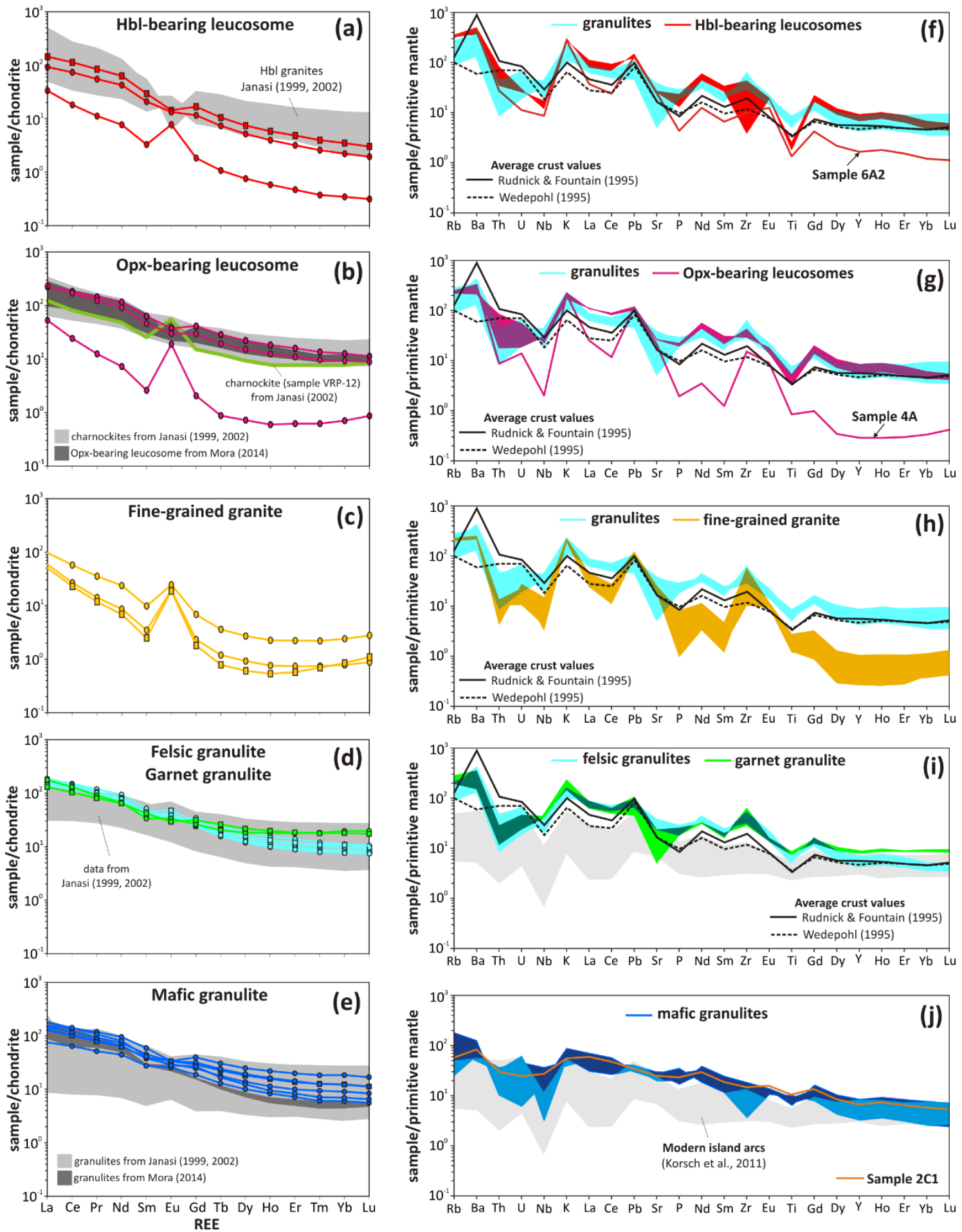

Figure 8: (a-e) Chondrite-normalized REE patterns and (f-j) Primitive-mantle normalized multi-element spidergrams for Hbl-bearing leucosomes, Opx-bearing leucosomes, fine-grained granite, felsic and mafic granulites from the SGN. Chondrite and primitive mantle values are from Boynton (1984) and McDonough \& Sun (1995), respectively. Average crust values from Rudnick \& Fountain (1995), 
Wedepohl (1995) and modern island arcs from Korsch et al. (2011) are shown for comparison. See text for discussion.

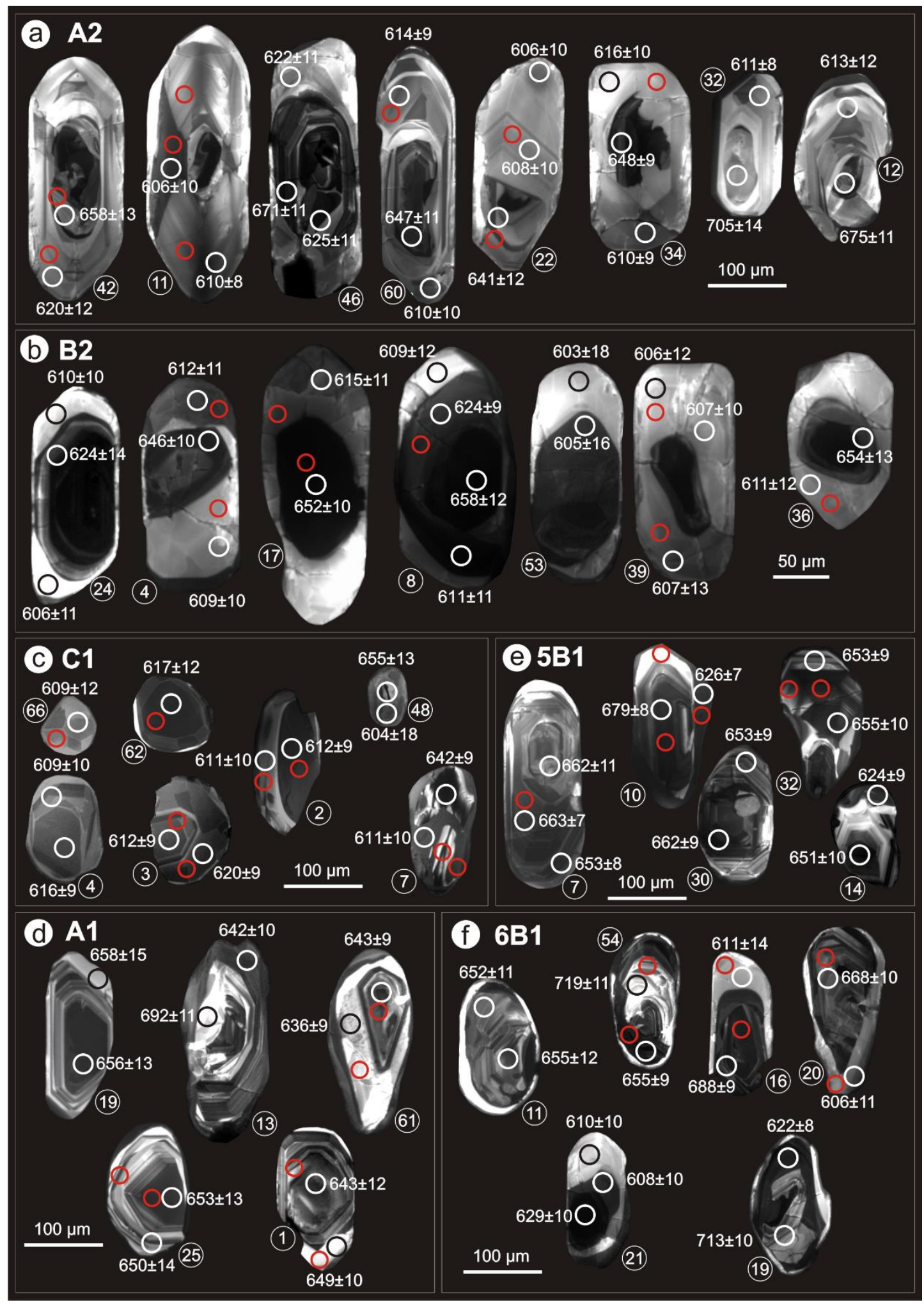

Figure 9: Cathodoluminescence $(C L)$ images of representative zircon grains, with the location of LAICP-MS spot analyses (20 $\mu \mathrm{m}$ diameter) and corresponding ${ }^{206} \mathrm{~Pb} /{ }^{238} \mathrm{U}$ ages in Ma. Red circles indicate the location of trace element analyses (15 $\mu \mathrm{m}$ diameter). (a) zircon from stromatic garnet-biotite 
metatexite, characterized by xenocrystic cores with thick overgrowths typically displaying sector zoning.

REE patterns of orthopyroxene-bearing leucosome are similar to hornblende-bearing leucosome, and are also correlated to mangerites and charnockites patterns from Janasi $(1999,2002)$ and Mora et al., (2014). By contrast, sample 4A is characterized by a strongly fractionated REE chondrite-normalized pattern $\left((\mathrm{La} / \mathrm{Yb})_{N}=75\right)$, a pronounced positive Eu anomaly $\left(\mathrm{Eu} / \mathrm{Eu}^{*}=8\right)(\mathrm{Fig} .8 \mathrm{~b})$, and $\mathrm{Th}, \mathrm{U}, \mathrm{Nb}, \mathrm{Ce}, \mathrm{P}, \mathrm{Sm}$ and HREE depletion relative to average continental crust (Fig. 8g). The finegrained granite has a strongly fractionated REE pattern $\left((\mathrm{La} / \mathrm{Yb})_{N}=40-75\right)$ and a prominent positive Eu anomaly (Eu/Eu* = 1-3) (Fig. 8c). They show a marked Th, U, Nb, P and HREE depletion when compared to average crust values of Rudnick \& Fountain (1995) and Wedepohl (1995) (Fig. 8h).

Felsic granulites are relatively enriched in $\mathrm{K}_{2} \mathrm{O}, \mathrm{TiO}_{2}, \mathrm{P}_{2} \mathrm{O}_{5}, \mathrm{Ba}, \mathrm{Zr}$ and $\operatorname{LREE}\left((\mathrm{La} / \mathrm{Yb})_{\mathrm{N}}=13-23\right)$ and slightly depleted in mobile elements (e.g. Th, $\mathrm{U}, \mathrm{Rb}$ ) when compared to the average continental crust (Fig. 8i). Garnet granulite has a less fractionated REE pattern $\left((\mathrm{La} / \mathrm{Yb})_{N}=7-9\right)$ and shows a marked Sr depletion (Fig. 8i). Mafic granulites exhibit moderately fractionated REE patterns $\left((\mathrm{La} / \mathrm{Yb})_{N}=8-26\right)$, lack of Eu anomaly $\left(\mathrm{Eu} / \mathrm{Eu}^{*}=0.2-0.4\right)$, and geochemical patterns comparable to modern island arcs (Korsch et al., 2011), which are marked by a pronounced Nb negative anomaly in primitive-mantle normalized multi-element diagrams (Fig. 8j).

\section{Zircon U-Pb geochronology and trace element geochemistry}

Analytical procedures for LA-ICP-MS are described in Appendix A. Cathodoluminescence (CL) images of representative zircon grains are shown in Fig. 9. Four distinct zircons domains are identified in all rock types: (1) xenocrystic cores lowly to moderately luminescent, generally with oscillatory zoning, (2) dark mantle moderately luminescent surrounding some of the xenocrystic cores, (3) bright$\mathrm{CL}$ rims exhibiting well-developed oscillatory and/or sector-zoning, (4) lowly luminescent recrystallized domains. Bright- $\mathrm{CL}$ rims and recrystallized domains display a slight depletion in Th, $\mathrm{Y}, \mathrm{U}$ and REE relative to xenocrystic cores. Recrystallized domains are marked by a more pronounced depletion in MREE relative to HREE, given by higher $\mathrm{Yb}_{N} / G d_{N}$ ratios $\left(\mathrm{Yb}_{N} / G d_{N}=21-65\right.$, av. 32). All zircon domains are characterized by variable Th/U ratios between ca. 0.3 and 1 , without any systematic pattern. The main trace element features of zircon domains from distinct lithotypes and U-Pb dates are presented in Table 1. U-Pb results and trace element data are reported in ANEXO VIII and ANEXO VII, respectively and illustrated in Figs.10 and 11. Grey-filled ellipses correspond to rejected data (data >2\% discordant were excluded from concordia age calculations). Errors are reported at $95 \%$ confidence level $(2 \sigma)$.

Zircon populations in the hornblende-bearing leucosome (sample A2) comprises pink to light brown subhedral prismatic grains (150-250 $\mu \mathrm{m} ; 2: 1$ length to width aspect ratio) (Fig. 9a; grains 32, 34) 
and pink to colorless grains (300-350 $\mu \mathrm{m} ; 3: 1$ aspect ratio) with rounded terminations (Fig. 9a; grains $42,11)$. Lowly luminescent xenocrystic cores are surrounded by thick, well-developed oscillatory and/or sector zoning. Xenocrystic cores $(n=21)$ yielded ${ }^{206} \mathrm{~Pb} /{ }^{238} \mathrm{U}$ dates ranging from $641 \pm 12$ to $705 \pm 14$ Ma. Thirty-four analyses of bright-CL oscillatory and sector-zoned overgrowths range between $600 \pm 13$ to $622 \pm 11 \mathrm{Ma}$ and give a concordia age of $612 \pm 2 \mathrm{Ma}$ (MSWD = 0.56) (Fig. 10a).
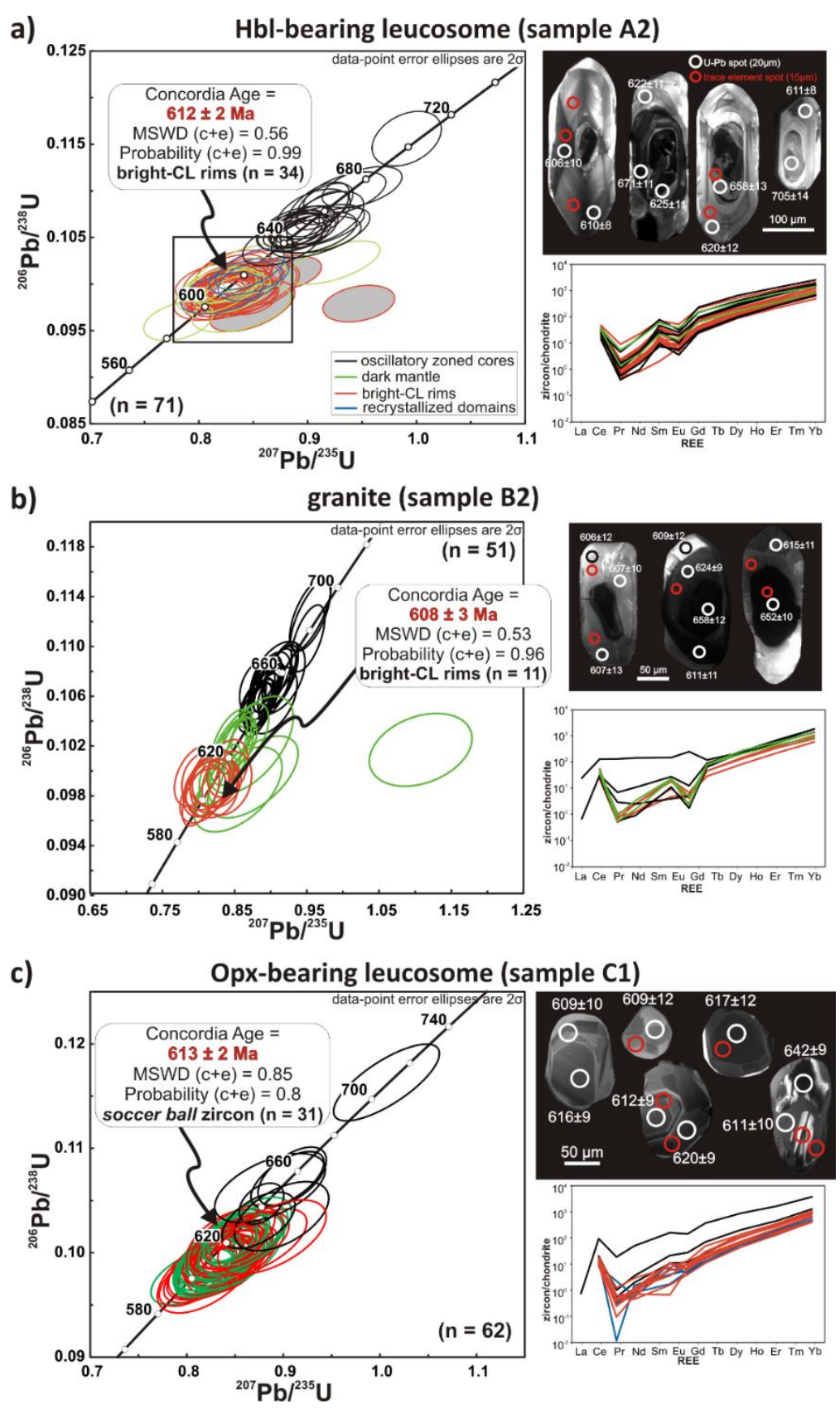

Figure 10: Concordia diagrams showing the results for zircon LA-ICP-MS U-Pb analyses ( $2 \sigma$ error ellipses) from a) hornblende-bearing leucosome (sample A2), b) granite (sample B2) and c) Opx-bearing leucosome (sample C1) of the Socorro-Guaxupé Nappe illustrating the corresponding concordia ages related to the metamorphic event, $\mathrm{CL}$-images of representative zircon grains and chondrite-normalized zircon REE patterns. Dark-grey filled ellipses correspond to rejected data. MSWD (c+e) and probability (c+e): MSWD of concordance and equivalence; probability of concordance and equivalence. 
a) felsic granulite (sample 5B1)

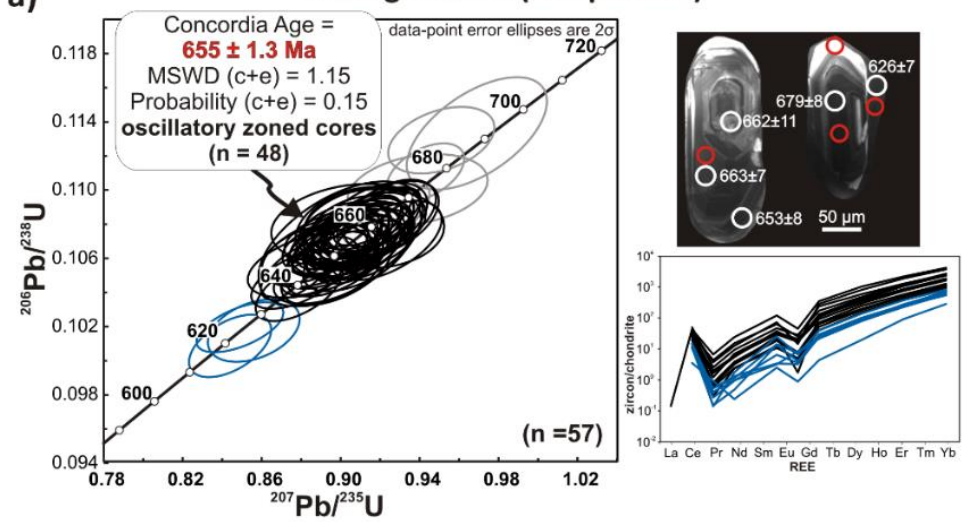

b)

felsic granulite (sample A1)

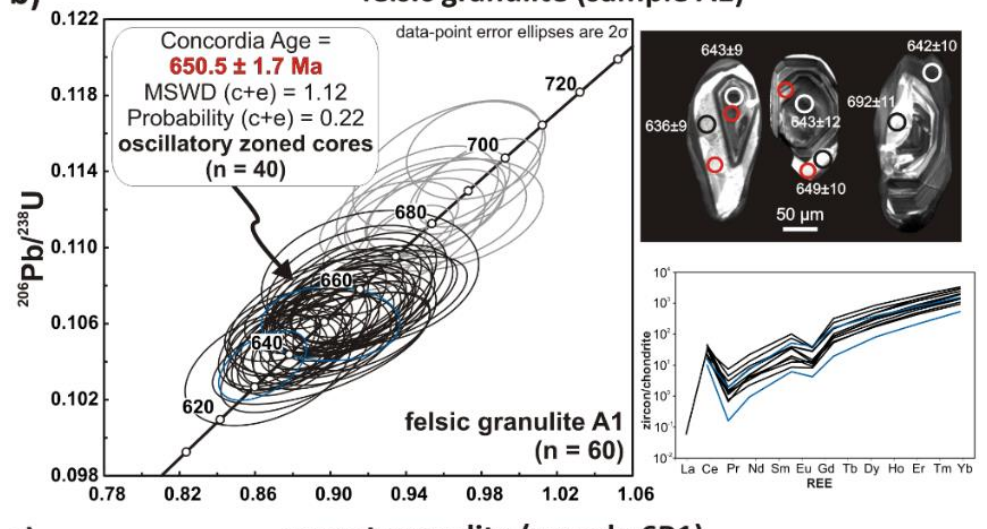

c) garnet granulite (sample 6B1)

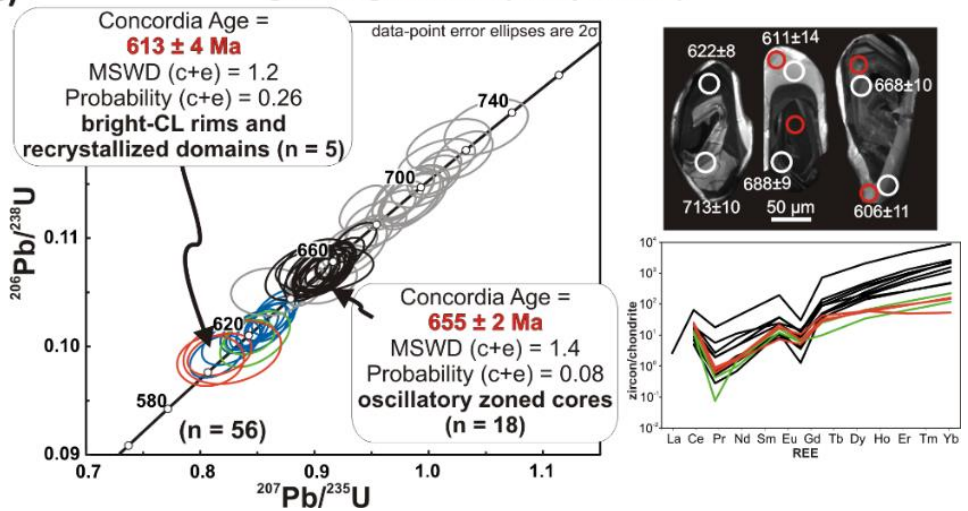

Figure 11: Concordia diagrams showing the results for zircon LA-ICP-MS U-Pb analyses (2 $\sigma$ error ellipses) from a, b) felsic granulite (samples 5B1 and A1), and garnet granulite (sample 6B1) of the Socorro-Guaxupé Nappe illustrating the corresponding concordia ages related to igneous protolith crystallization ages and to the metamorphic event, CL-images of representative zircon grains and chondrite-normalized zircon REE patterns. Light-grey ellipses correspond to rejected data. MSWD (c+e) and probability $(\mathrm{c}+\mathrm{e})$ : MSWD of concordance and equivalence; probability of concordance and equivalence.

Zircon populations in the fine-grained granite (sample B2) is characterized by elongate grains with rounded terminations (150-250 $\mu \mathrm{m} ; 4: 1$ to $3: 1$ aspect ratio) and prismatic grains (150-200 $\mu \mathrm{m} ; 2: 1$ aspect ratio). Lowly luminescent xenocrystic cores are surrounded by a moderately luminescent dark 
mantle, overgrown by thick bright-CL rims (Fig. 9b; grains 24, 8). Xenocrystic cores are dark brown due to effects of metamictization, given the distinctly higher $U$ contents (293-1200, av. 729 ppm) compared to clear, pinkish rims (35-200, av. $69 \mathrm{ppm} \mathrm{U}$ ). Xenocrystic cores $(\mathrm{n}=22)$ yielded ${ }^{206} \mathrm{~Pb} /{ }^{238} \mathrm{U}$ dates ranging from $687 \pm 14$ to $644 \pm 9 \mathrm{Ma}$. Dark mantle distinguishes from bright-CL rims by their higher Hf (1.1 wt\% $\mathrm{HfO}_{2}$ ) and $\mathrm{Y}(458-601$, av. $530 \mathrm{ppm})$ contents, similarly to xenocrystic cores. U-Pb dates obtained for dark mantle range from $632 \pm 11$ to $605 \pm 11 \mathrm{Ma}$, the older dates might represent mixture ages and are thus not reliable. Eleven analyses of bright-CL rims give a concordia age of $608 \pm 3 \mathrm{Ma}$ (MSWD $=0.53$ ) (Fig. 10b).

Orthopyroxene-bearing leucosome (sample C1) comprises mainly colorless to light brown equant, soccer ball zircon (50-150 $\mu \mathrm{m}$; 1:1 aspect ratio) (Fig. 9c; grains 62, 66) and fewer elongate grains (100-150 $\mu \mathrm{m}$; 3:1 aspect ratio) with resorbed oscillatory zoned cores truncated by featureless recrystallized domains (Fig. 9c; grains 7, 48). Oscillatory zoned xenocrystic cores $(n=5)$ yielded ${ }^{206} \mathrm{~Pb} /{ }^{238} \mathrm{U}$ dates ranging from $708 \pm 23$ to $641 \pm 11 \mathrm{Ma}$. Thirty-one analyses in soccer ball zircons give a concordia age of $613 \pm 2 \mathrm{Ma}(\mathrm{MSWD}=0.85$ ) (Fig. 10c).

Felsic granulite (samples 5B1 and $\mathrm{A} 1$ ) is essentially composed of elongate (3:1 aspect ratio) to ovoid (2:1 aspect ratio) zircon grains, pink to light brown in color. Oscillatory zoned zircon $(n=109)$ yielded ${ }^{206} \mathrm{~Pb} /{ }^{238} \mathrm{U}$ dates ranging from $702 \pm 12$ to $648 \pm 8 \mathrm{Ma}$ (Fig. 11a, b). Scarce bright-CL rims are too narrow $(<5 \mu \mathrm{m})$ to be analyzed with the LA-ICP-MS $20 \mu \mathrm{m}$ spot size. Moderately luminescent recrystallized domains range in age from $624 \pm 10$ to $620 \pm 10$ and are characterized by a noticeable MREE depletion relative to $\mathrm{HREE}$, given by higher $\mathrm{Yb}_{N} / \mathrm{Gd}_{N}$ ratios $(21-65$, av. 31) compared to oscillatory zoned cores $\left(\mathrm{Yb}_{\mathrm{N}} / \mathrm{Gd}_{\mathrm{N}}=11-24\right.$, av. 17).

The zircon population in the garnet granulite (sample 6B1) is characterized by brownish, ovoid to elongate grains with rounded terminations (100-200 $\mu \mathrm{m} ; 2: 1$ to $3: 1$ aspect ratios). Lowly to moderately luminescent cores with distinctive higher $Y$ contents (327-4830, av. 1160 ppm) and $\mathrm{Yb}_{N} / \mathrm{Gd}_{\mathrm{N}}$ ratios $\left(10-47\right.$, av. 21) than rims (83-115 $\mathrm{ppm} \mathrm{Y} ; \mathrm{Yb}_{\mathrm{N}} / \mathrm{Gd}_{\mathrm{N}}=1-5$, av. 4), are surrounded by discontinuous dark mantle, overgrown by bright- $\mathrm{CL}$ rims ranging from 5-50 $\mu \mathrm{m}$ in thickness (Fig. 9f; grain 16). Oscillatory zoned zircon $\left(n=41\right.$ ) yielded ${ }^{206} \mathrm{~Pb} /{ }^{238} \mathrm{U}$ dates ranging from $732 \pm 12$ to $647 \pm 8 \mathrm{Ma}$. Bright-CL rims and recrystallized domains range in age from $606 \pm 11$ to $619 \pm 8 \mathrm{Ma}$, and give a combined concordia age of $613 \pm 4 \mathrm{Ma}$ (MSWD = 1.2) (Fig. 11c), similar to hornblende- and orthopyroxene-bearing leucosomes (Fig. 10e). Felsic and garnet granulite record igneous protolith crystallization ages of $c a$. 655-650 Ma.

\section{Sr and Nd isotopes}

The $\mathrm{Sr}$ and $\mathrm{Nd}$ isotopic compositions of six samples are presented in ANEXO $\mathrm{VI}$ and analytical procedures are described in Appendix A. The initial Sr isotopic composition and $\varepsilon N d(t)$ were calculated 
using concordant $\mathrm{U}-\mathrm{Pb}$ zircon ages from this study that represent the time of crystallization, as listed in Table A6. The results are illustrated in a $\varepsilon N d(t)$ versus ${ }^{87} \mathrm{Sr} /{ }^{86} \mathrm{Sr}(\mathrm{t})$ diagram (Fig. 12), and isotopic compositions are consistent with an enriched crustal reservoir. ${ }^{87} \mathrm{Sr} /{ }^{86} \mathrm{Sr}(\mathrm{i})$ ranges from 0.7055 to 0.7080. Depleted mantle model ages (TDM) (De Paolo, 1981) range from 1.6-1.8 Ga and $\varepsilon N d(t)$ values range from -9.9 to -5.1 , except the fine-grained granite (sample 5B2) which yielded a slightly more negative $\varepsilon N d(t)$ value of -11.7 .

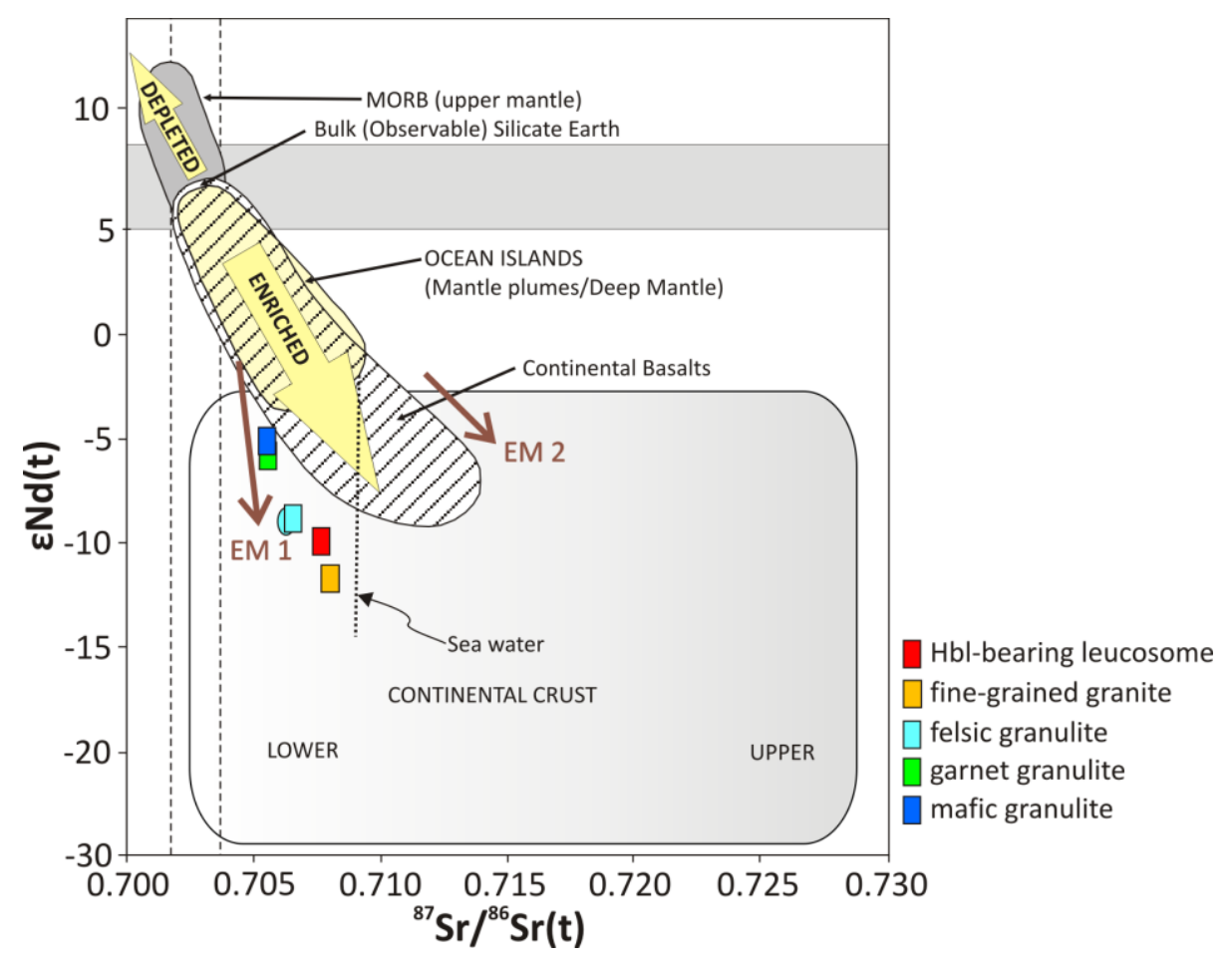

Figure 12: $\varepsilon N d(t)$ vs. ${ }^{87} \mathrm{Sr} /{ }^{86} \mathrm{Sr}(\mathrm{t})$ diagram showing $\mathrm{Sr}$ and $\mathrm{Nd}$ isotope variations of studied rocks in major geochemical reservoirs (adapted from White, 2013). EM1 and EM2 trends are from Weaver (1991).

\section{Discussion}

\subsection{Timing and duration of pre-collisional arc magmatism}

New LA-ICP-MS U-Pb zircon data obtained for six samples from the Basal Granulite Unit allowed a clear distinction between pre-collisional and syn-collisional magmatic events in the SGN. We use integrated zircon U-Pb geochronology and trace element geochemistry to discriminate inherited and non-inherited zircon with more confidence. Lowly to moderately luminescent xenocrystic cores (Corfu et al., 2003) are generally characterized by higher $\mathrm{Y}, \mathrm{U}$ and slightly higher Th contents than bright-CL rims. Th/U ratios are quite variable without any systematic pattern, and do not allow a clear distinction between cores and rims patterns. Xenocrystic cores have positive $\mathrm{Ce}$ and negative Eu anomalies, and steep HREE patterns $\left((\mathrm{Yb} / \mathrm{Gd})_{\mathrm{N}}=10-47\right.$; see Table 1 for details), typical of magmatic zircon (e.g. Rubatto, 2002; Hoskin \& Schaltegger, 2003). The presence of garnet plays an important 
role in the geochemical fingerprint of zircon. A drastic drop in yttrium contents from core to rim in zircon grains is recorded in the garnet granulite (from 4830 to $83 \mathrm{ppm} \mathrm{Y}$; sample 6B1) due to the strong partitioning of $Y$ in the presence of garnet (e.g. Rubatto, 2002; Whitehouse \& Platt, 2003; Kelly \& Harley, 2005; Taylor et al., 2015). The distribution of HREE is also controlled by garnet, manifested by contrasting flat HREE patterns $\left((\mathrm{Yb} / \mathrm{Gd})_{\mathrm{N}}=1-5\right.$, av. 4$)$ in bright- $\mathrm{CL}$ zircon rims in sample 6B1.

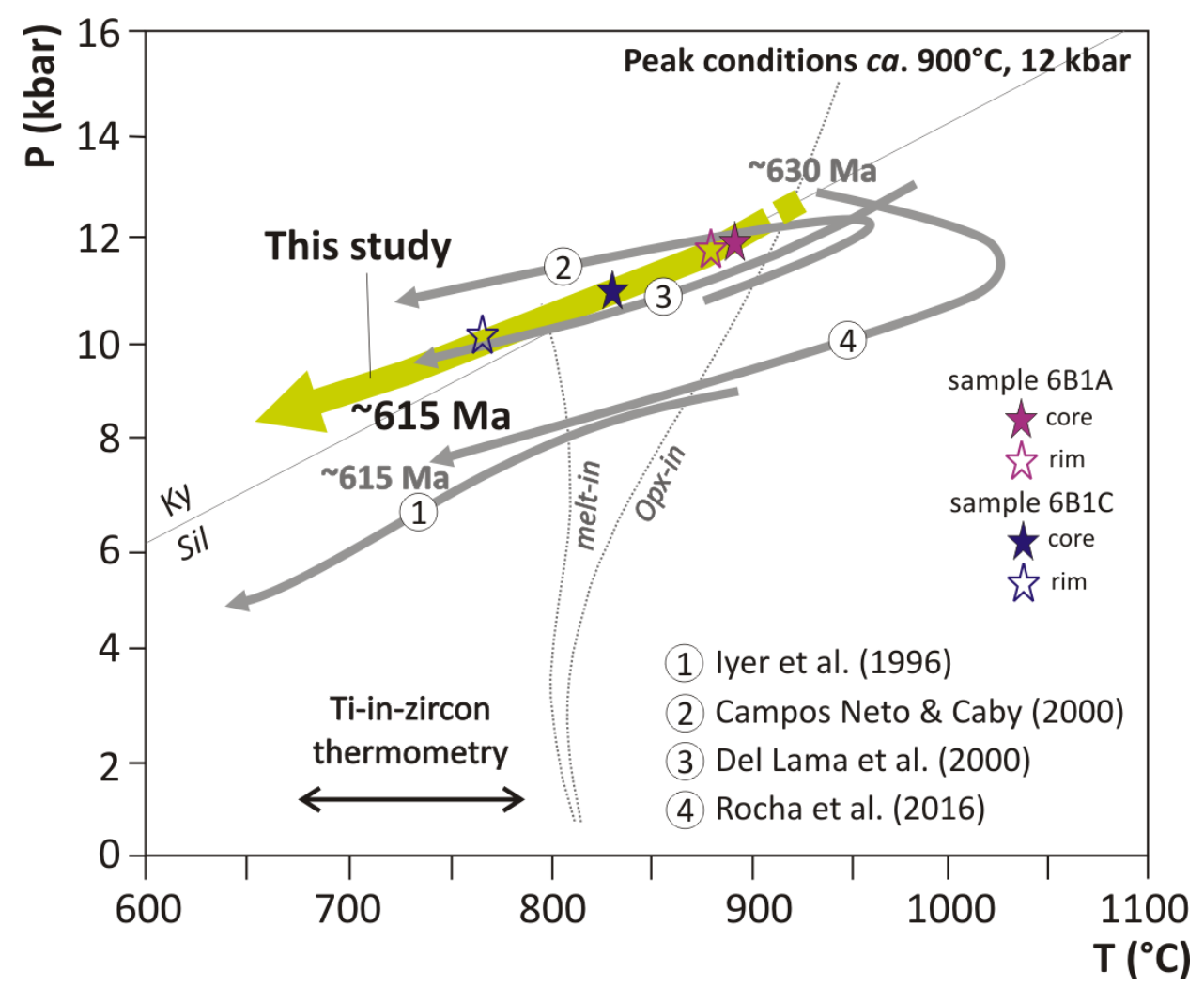

Figure 13: Schematic P-T-t evolution of UHT metamorphism in the SGN constrained by garnet-bearing granulites and compiled data from the literature.

Oscillatory zoned zircon from the felsic granulite (samples A1 and 5B1) and garnet granulite (sample 6B1) yielded dates ranging from $c a$. 730-640 Ma, while bright- $\mathrm{CL}$ rims, sector-zoned overgrowths and recrystallized domains yielded younger dates of $c a .630-600 \mathrm{Ma}$. The concordia ages of ca. 655-650 Ma obtained in oscillatory zoned zircon from felsic and garnet granulite are interpreted to reflect the igneous crystallization ages, characterizing the main period of pre-collisional arc magmatism in ca. 655-650 Ma. Zircon cores from hornblende- and orthopyroxene-bearing leucosomes (samples $A 2$ and $\mathrm{C} 1$, respectively) fall within the same age range of $c a$. 705- $640 \mathrm{Ma}$, even though xenocrystic cores are much more abundant in the hornblende-bearing leucosome. Inherited, xenocrystic zircon cores are particularly common in granitic rocks due to the inability of lowtemperature, Zr-saturated magmas in dissolve completely inherited zircon grains (e.g. Miller et al., 2003). The comparison of ages obtained from leucosomes and their host rocks also provides a means to evaluate inheritance, as host rocks are the likely source of inherited grains (e.g. Crowley et al., 2008). 
Migmatites from the adjacent Metatexite Unit preserve identical inheritance patterns of $c a .800-640$ Ma (Rocha et al., 2016). This age range has also been recognized in other parts of the SGN (Janasi, 2002; Martins et al. 2009; Mora et al., 2014). Field evidence combined with new trace element and U$\mathrm{Pb}$ data of leucosomes and their granulite hosts admit that the pre-collisional arc magmatism occurred within the ca. 730-640 Ma age range, lasting for at least 90 m.y., and that arc magmatism was most abundant during the ca. 655-650 Ma period.

\subsection{P-T-t evolution of UHT metamorphism in the SGN}

Among investigated rocks of the Santa Terezinha Quarry, garnet granulite is the most suitable for constraining the $P-T$ evolution of the Basal Granulite Unit. The mineral assemblage present in the garnet granulite enables the application of garnet-orthopyroxene Al-solubility-based thermobarometry (Pattison et al., 2003), which has been successfully applied in quantifying UHT conditions in rock types without diagnostic UHT mineral assemblages, which are almost restricted to Mg-Al-rich rocks (Kelsey \& Hand, 2015). Garnet granulite (sample 6B1) records peak metamorphic conditions of $c a .900{ }^{\circ} \mathrm{C}$ at $12 \mathrm{kbar}$, followed by cooling with re-equilibration to $c a .770^{\circ} \mathrm{C}$ at $10 \mathrm{kbar}$ (Fig. 13), compatible with previous estimates in the SGN (Campos Neto \& Caby, 1999, 2000; Del Lama et al., 2000, Janasi, 2002; Rocha et al., 2016). It is assumed the calculated values are minimum temperatures and consistent with UHT conditions, based on previous estimates from other garnet granulite within SGN (ca. $1040^{\circ} \mathrm{C}, 14 \mathrm{kbar}$; Del Lama et al., 2000) and (orthopyroxene)-garnet-bearing migmatites from the adjacent Metatexite Unit (ca. $1027 \pm 108^{\circ} \mathrm{C}, 11.7 \pm 1.4 \mathrm{kbar}$; Rocha et al., 2016). The onset of UHT metamorphism in the SGN at ca. 630-625 Ma has been determined by monazite EPMA ages in resorbed $Y$-rich cores preserved as inclusions in garnet and $Y$-rich rims related to apatite (Rocha et al., 2016), and overlaps with age estimates from other studies for the granulite facies metamorphism (e.g. Basei et al., 1995; Janasi, 1999, 2002; Reno et al., 2009; Martins et al., 2009; Mora et al., 2014).

Anhedral garnet partially replaced by orthopyroxene + plagioclase $\left(\mathrm{Grt}_{1}\right)$ is interpreted to document prograde growth based on HREE-enriched cores with slightly steep HREE patterns ((Yb/Gd $)_{\mathrm{N}}$ $=8$ ), indicating minor garnet growth prior to zircon (e.g. Whitehouse \& Platt, 2003; Kelly \& Harley, 2005; Taylor et al., 2015). Euhedral garnet with hornblende inclusions (e.g. Grt 2 ) exhibits a flat HREE pattern marked by HREE depletion from core $\left((\mathrm{Yb} / \mathrm{Gd})_{\mathrm{N}}=1.1\right)$ to $\operatorname{rim}\left((\mathrm{Yb} / \mathrm{Gd})_{\mathrm{N}}=0.6\right)$, with a drastic decrease in total HREE in one order of magnitude compared to $\mathrm{Grt}_{1}$. This suggests that the $c a .613 \pm 4$ Ma zircon bright-CL rims in the garnet granulite (sample 6B1) grew in a reservoir with a limited amount of HREE during or after the appearance of garnet. Substantial zircon growth during melt crystallization is documented in well-developed sector-zoned overgrowths and bright- $\mathrm{CL}$ rims surrounding xenocrystic cores from both hornblende-bearing leucosome (sample A2; $612 \pm 2 \mathrm{Ma}$ ) and fine-grained 
granite (sample B2; $608 \pm 3 \mathrm{Ma}$ ). Appreciable amounts of soccer ball zircon (e.g. Schaltegger et al., 1999 ) in the orthopyroxene-bearing leucosome (sample C1) provides further constraints for the timing of melt crystallization at $c a .613 \pm 2 \mathrm{Ma}(\mathrm{n}=31 ; \mathrm{MSWD}=0.85)$. The $c a .615$ and $608 \mathrm{Ma}$ age peaks are equivalent with the findings of Hackspacher et al. (2004), Martins et al. (2009), Mora et al. (2014) and Rocha et al. (2016), and are interpreted to represent the main episodes of zircon growth during melt crystallization upon cooling within the $c a .680-790{ }^{\circ} \mathrm{C}$ temperature range, based on our new Ti-inzircon results (Fig. 13).

\subsection{Origin of charnockite (orthopyroxene-bearing leucosome) and hornblende-bearing leucosome}

Orthopyroxene- and hornblende-bearing leucosomes are magnesian, metaluminous, alkalic to calc-alkalic and plot in the boundary between volcanic arc granite and syn-collisional granite field in the tectonic discriminant diagram of Pearce et al., (1984). Leucosomes show contrasting REE patterns. Orthopyroxene- and hornblende-bearing leucosomes demonstrate similar geochemical signatures when compared to their regional syn-collisional plutonic equivalents (São Pedro de Caldas and Divinolândia suites; Janasi, 1999, 2002; Mora et al., 2014). They are characterized by high REE contents, LREE enrichment $\left((\mathrm{La} / \mathrm{Yb})_{\mathrm{N}}=16\right)$, weak negative Eu anomalies $\left(\mathrm{Eu} / \mathrm{Eu}^{*}=0.2\right)$ and might represent fractionated melts (Sawyer, 1987). However, two analyzed samples of orthopyroxene- and hornblende-bearing leucosomes (samples $4 \mathrm{~A}$ and $6 \mathrm{~A} 2$, respectively) have contrasting geochemical patterns, including more fractionated patterns, positive Eu anomaly, REE and mobile element depletion relative to average continental crust. This distinct behavior is even more evident in sample 4A (orthopyroxene-bearing leucosome), characterized by a strongly fractionated pattern $\left((\mathrm{La} / \mathrm{Yb})_{\mathrm{N}}=\right.$ 75 ) and prominent positive Eu anomaly $\left(\mathrm{Eu} / \mathrm{Eu}^{*}=8\right)$, and could exemplify cumulates as recognized for the origin of other leucosome veins (Sawyer, 1987). Orthopyroxene- and hornblende-bearing leucosomes display an analogous pattern to the average continental crust (Rudnick \& Fountain, 1995; Wedepohl, 1995) and exhibit geochemical signatures typical of continental arc, characterized by LREE enrichment and marked negative $\mathrm{Nb}$ and $\mathrm{Ti}$ anomalies (e.g. Percival \& Mortensen, 2002). Felsic and garnet granulites have high total alkalis contents, a marked potassium enrichment, less fractionated REE patterns compared to leucosomes, but similar negative $\mathrm{Nb}$ and $\mathrm{Ti}$ anomalies resembling average continental crust patterns (Rudnick \& Fountain, 1995; Wedepohl, 1995). Mafic granulites are characterized by moderately fractionated REE patterns, lack of Eu anomaly and pronounced negative $\mathrm{Nb}$ anomaly, with geochemical patterns comparable to modern island arcs (e.g. Korsch et al., 2011). Geochemical similarities, in addition to field evidence (e.g. transitional contact between both types of leucosome) are consistent with a genetic link between hornblende- and orthopyroxene-bearing leucosomes. It is concluded fractional crystallization was an important process in the formation of the 
observed variety of leucosome compositions, even in a small-scale, e.g. veins and pockets of segregated melt, already within the source. Contrasting REE patterns in leucosomes are suggestive that samples with higher REE contents and negative Eu anomalies are compatible with fractionated melt patterns, and that REE-depleted samples with positive $\mathrm{Eu}$ anomalies are comparable to cumulates, as recognized in other areas (Sawyer, 1987). However, the later display rafts of either garnet granulite or felsic granulite engulfed within the hornblende- and orthopyroxene-bearing leucosomes (samples 6A2 and $4 \mathrm{~A}$ ), suggesting at least a local interaction between leucosomes and granulites through assimilation and/or mixing processes (e.g. Klaver et al., 2015).

\subsection{Implications for the tectonic evolution of the southern Brasilia Orogen}

Several authors (e.g. Campos Neto et al., 2011) have suggested that the SGN could represent the southern extension of the Goiás Magmatic Arc (Pimentel \& Fuck, 1992; Pimentel et al., 2000; Laux et al., 2004). However, juvenile rocks have not been recognized within the SGN yet (Campos Neto et al., 2011). Negative $\varepsilon N d_{(t)}$ values are frequent in many rock types within the SGN (e.g. Janasi, 1999, 2002; Janasi et al., 2009; Mora et al., 2014; Vinagre et al., 2014). One way to explain these less radiogenic $\mathrm{Nd}$ signatures is by contamination and/or assimilation of an older crustal component (e.g. Schoene et al., 2009). Archean and Paleoproterozoic orthogneisses that comprises the basement of the southern Brasília Orogen (Fetter et al., 2001; Cioffi et al., 2016) crops out within a large tectonic window (15-75 km wide) between the two domains of the SGN. The existence of an older crust underlying the SGN could represent a likely contamination source. However, no Archean or Paleoproterozoic zircon inheritance has been recognized as xenocrystic cores in the present study nor in all in-situ geochronological studies currently available in the literature (Mora et al., 2014; Rocha et al., 2016). The presence of abundant inherited zircon xenocrysts within the 730-640 Ma age range rule out the possibility of complete zircon dissolution in the magma. Therefore, contamination-assimilation processes are unlikely to be responsible for the less-radiogenic Nd isotopic signatures identified in this study. Alternatively, less radiogenic $\mathrm{Nd}$ signatures may result from mixtures between enriched lithospheric mantle reservoirs and crustal components (e.g. Hagen-Peter et al., 2015). As proposed by Carvalho et al. (2014), the final emplacement of the SGN most likely post-dates the generation of the magmatic suites, as there is no evidence for participation of the older basement in their genesis. The results obtained in this study, together with data from the literature (Janasi, 1999, 2002; Carvalho et al., 2014; Mora et al., 2014; Vinagre et al., 2014), suggest that the Nd signatures of the SGN are most likely a result of magma generation from enriched-mantle sources or from an unknown or nonidentified crustal source. 


\section{Conclusions}

The present study identified igneous protolith ages of $c a$. 655-650 Ma in felsic and garnet granulites, which characterizes the main period of pre-collisional arc magmatism. The SGN evolved from a subduction-related to a collisional setting, involving the formation of in-situ charnockite melts and hornblende-bearing leucosome at ca. 630-625 Ma during syn-collisional UHT metamorphism. Peak UHT metamorphic conditions were attained at $c a .900{ }^{\circ} \mathrm{C}, 12 \mathrm{kbar}$, by partial melting of felsic granulites. We propose that mafic underplating could be a potential heat source for UHT metamorphism, given the occurrence of syn-metamorphic mafic intrusions in close spatial relation to in-situ hornblende- and orthopyroxene-bearing leucosomes. Contrasting REE patterns in leucosomes provide evidence for the presence of both fractionated melt (higher REE abundance and negative Eu anomaly) and cumulates (lower REE abundance and positive Eu anomaly). Studied samples show isotopic evidence for enriched-mantle sources in their origin, and crustal recycling involving either Archean or Paleoproterozoic older crust have not been recognized yet.

\section{Acknowledgments}

This research was supported by FAPESP grant 13/04007-0. B.C. Rocha acknowledges her FAPESP scholarships (14/05563-6, 12/22380-7) and the staff of Santa Terezinha Quarry for permitting sample collection and offering support during field work. We thank for the assistance of Vasco Loios (CPGeoUSP) and Josh Feldman (IGL-KU) with mineral separation, Marcos Mansueto and Leandro Moraes (NAP Geoanalítica Laboratory-USP) with microprobe major element analysis, Sandra Andrade and Vinícius Martins (NAP Geoanalítica Laboratory-USP) with garnet trace element analysis, Heather Shinogle (MAIKU) with CL imaging, Maggie Sochko (IGL-KU) for LA-ICP-MS technical support and Michael J. Jercinovic (UMASS) for providing full thin-section maps of hornblende- and orthopyroxene-bearing leucosomes.

\section{References}

Andrade, S., Ulbrich, H.H., Gomes, C.B. \& Martins, L., 2014. Methodology for the determination of trace and minor elements in minerals and fused rock glasses with laser ablation associated with quadrupole inductively coupled plasma mass spectrometry (LA-Q-ICPMS). American Journal of Analytical Chemistry 5, 701-721.

Bai, X., Liu, S., Guo, R., Wang, W., 2015. Zircon U-Pb-Hf isotopes and geochemistry of two contrasting Neoarchean charnockitic rock series in Eastern Hebei, North China Craton: implications for petrogenesis and tectonic setting. Precambrian Research 267, 72-93.

Basei, M.A.S., Siga Jr., O., Sato, K., Sproesser, W.M., 1995. A metodologia urânio-chumbo na Universidade de São Paulo: princípios metodológicos, aplicações e resultados obtidos. Anais da 
Academia Brasileira de Ciências 67(2), 221-237.

Boynton, W.V., 1984. Cosmochemistry of the rare Earth elements; meteorite studies. In: Henderson, P. (ed.) Developments in Geochemistry. Amsterdam: Elsevier, pp. 63-114.

Brito Neves, B.B.; Campos Neto, M.C., Fuck, R.A., 1999. From Rodinia to Western Gondwana: An approach to the Brasiliano-Pan African Cycle and orogenic collage. Episodes 22, 155-166.

Campos Neto, M.C., 2000. Orogenic systems from south-western Gondwana: an approach to Brasiliano-Pan African cycle and collage in southeastern Brazil. In: Cordani, U.G., Milani, E.J., Thomaz Filho, A., Campos, D.A. (Eds). Tectonic Evolution of South America, Rio de Janeiro, pp. 335-365.

Campos Neto, M.C., Basei, M.A.S., Janasi, V.A., Moraes, R., 2011. Orogen migration and tectonic setting of the Andrelândia Nappe System: An Ediacaran Western Gondwana collage, south of São Francisco craton. Journal of South American Earth Sciences 32, 393-406.

Campos Neto, M.C., Caby, R., 1999. Neoproterozoic high-pressure metamorphism and tectonic constraint from the nappe system south of the São Francisco Craton, southeast Brazil. Precambrian Research 97, 3-26.

Campos Neto, M.C. \& Caby, R., 2000. Terrane accretion and upward extrusion of high-pressure granulites in the Neoproterozoic nappes of Southeast Brazil: Petrological and structural constraints. Tectonics 14, 669-687.

Campos Neto, M.C., Cioffi, C.R., Moraes, R., Motta, R.G., Siga Jr, O., Basei, M.A.S., 2010. Structural and metamorphic control on the exhumation of high-P granulites: The Carvalhos Klippe example, from the oriental Andrelândia Nappe System, southern portion of the Brasília Orogen, Brazil. Precambrian Research 180, 125-142.

Carvalho, B.B., Janasi, V.A., Henrique-Pinto, R., 2014. Geochemical and Sr-Nd-Pb isotope constraints on the petrogenesis of the K-rich Pedra Branca Syenite: Implications for the Neoproterozoic postcollisional magmatism in SE Brazil. Lithos 205, 39-59.

Cioffi, C.R., Campos Neto, M.C., Möller, A., Rocha, B.C., 2016. Paleoproterozoic continental crust generation events at 2.08 and $2.15 \mathrm{Ga}$ in the basement of the southern Brasília Orogen, SE Brazil. Precambrian Research 275, 176-196.

Clark, C., Fitzsimons, I.C.W., Healy, D., Harley, S.L., 2011. How does the continental crust get really hot? Elements 7, 235-240.

Condie, K.C., 1998. Episodic continental growth and supercontinents: a mantle avalanche connection? Earth and Planetary Science Letters 163, 97-108.

Corfu, F., Hanchar, J.M., Hoskin, P.W.O., Kinny, P., 2003. Atlas of zircon textures. In: Hanchar, J.M., Hoskin, P.W.O. (Eds). Zircon. Mineralogical Society of America. Reviews in Mineralogy and Geochemistry 53, Washington, pp. 469-495.

Crowley, J.L., Brown, R.L., Gervais, F., Gibson, H.D., 2008. Assessing inheritance of zircon and monazite 
in granitic rocks from the Monashee Complex, Canadian Cordillera. Journal of Petrology 49 (11), 1915-1929.

Del Lama, E.A., Zanardo, A., Oliveira, M.A.F., Morales, N., 2000. Exhumation of high-pressure granulites of the Guaxupé Complex, Southeastern Brazil. Geological Journal 35, 231-249.

De Paolo, D.J., 1981. Neodymium isotopes in the Colorado Front Range and crust-mantle evolution in the Proterozoic. Nature 291, 193-196.

Eckert, J.O.Jr., Newton, R.C., Kleppa, O. J., 1991. The $\Delta \mathrm{H}$ of reaction and recalibration of garnetpyroxene-plagioclase-quartz geobarometers in the CMAS system by solution calorimetry. American Mineralogist 76, 148-160.

Fetter, A.H., Hackspacher, P.C., Ebert, H.D., Dantas, E.L., Costa, A.C.D., 2001. New Sm-Nd and U-Pb geochronological constraints on the Archean to Paleoproterozoic evolution of the Amparo basement complex of the central Ribeira belt, southeastern Brazil. $3^{\text {rd }}$ South American Symposium on Isotope Geology (Extended Abstracts, CD-ROM).

Frost, B.R., Arculus, R.J., Barnes, C.G., Collins, W.J., Ellis, D.J., Frost, C.D., 2001. A geochemical classification of granitic rocks. Journal of Petrology 42, 2033-44.

Frost, B.R., Frost, C.D., 2008. On charnockites. Gondwana Research 13, 30-44.

Hackspacher, P.C., Fetter, A.H., Ebert, H.D., Janasi, V.A., Oliveira, M.A.F., Braga, I.F., Negri, F.A., 2003. Magmatismo há ca. 660-640 Ma no Domínio Socorro: Registros de convergência pré-colisional na aglutinação do Gondwana Ocidental. Geologia USP, Série Científica 3, 85-96.

Hackspacher, P.C., Fetter, A.H., Teixeira, W., Dantas, E.L., Ebert, H.D., Trouw, R.A.J., Vasconcelos, P., 2004. Final stages of the Brasiliano Orogenesis in SE Brazil: U-Pb and ${ }^{40} \mathrm{Ar} /{ }^{39} \mathrm{Ar}$ evidence for overprinting of the Brasília Belt by the Ribeira Belt tectonics. In: Weinberg, R., Trouw, R.A.J., Fuck, R.A., Hackspacher, P.C. (eds.), The 750-550 Ma Brasiliano Event of South America, Journal of the Virtual Explorer, Electronic Edition, Vol. 17 (http://virtualexplorer.com.au/article/2004/108/final-stages-of-the-brasiliano-orogeny).

Hagen-Peter, G., Cottle, J.M., Tulloch, A.j., Cox, S.C., 2015. Mixing between enriched lithospheric mantle and crustal components in a short-lived subduction-related magma system, Dry Valley area, Antarctica: Insights from U-Pb geochronology, $\mathrm{Hf}$ isotopes, and whole-rock geochemistry. Lithosphere, doi: 10.1130/L384.1

Harley, S.L., 2008. Refining the P-T records of UHT crustal metamorphism. Journal of metamorphic Geology 26, 125-154.

Hoskin, P.W.O., Schaltegger, U., 2003. The composition of zircon and igneous and metamorphic petrogenesis. In: Hanchar, J.M. and Hoskin, P.W.O. (Eds.). Zircon. Mineralogical Society of America. Reviews in Mineralogy and Geochemistry 53, Washington, pp.27-62.

Iyer, S.S., Choudhuri, A., Pattison, D.R.M., De Paoli, G.R., 1996. Petrology and geochemistry of the Neoproterozoic Guaxupé granulite facies terrain, southeastern Brazil. Precambrian Research 77, 
$23-40$

Jackson, S.E., Pearson, N.J., Griffin, W.L., Belousova, E.A., 2004. The application of laser ablationinductively coupled plasma-mass spectrometry to in-situ U-Pb zircon geochronology. Chemical Geology 211, 47-69.

Janasi, V.A. 1999. Petrogênese de granitos crustais da Nappe de Empurrão Socorro-Guaxupé (SP-MG): uma contribuição da geoquímica elemental e isotópica. Tese (Livre-Docência) - IGc-USP, 304 pp.

Janasi, V.A. 2002. Elemental and Sr-Nd isotope geochemistry of two Neoproterozoic mangerite suites in SE Brazil: implications for the origin of the mangerite-charnockite-granite series. Precambrian Research 119, 301-327.

Janasi, V.A., Vlach, S.R.F., Campos Neto, M.C., Ulbrich, H.H.G.J., 2009. Associated A-type subalkaline and high-K calc-alkaline granites in the Itú Granite Province, southeastern Brazil: petrological and tectonic significance. Canadian Mineralogist 47, 1505-1526.

Kelly, N.M., Harley, S.L., 2005. An integrated microtextural and chemical approach to zircon geochronology: refining the Archaean history of the Napier Complex, east Antarctica. Contributions to Mineralogy and Petrology 149, 57-84.

Kelsey, D.E., 2008. On ultrahigh-temperature crustal metamorphism. Gondwana Research 13, 1-29.

Kelsey, D.E., Hand, M., 2015. On ultrahigh temperature crustal metamorphism: phase equilibria, trace element thermometry, bulk composition, heat sources, timescales and tectonic settings. Geoscience Frontiers 6, 311-356.

Klaver, M., de Roever, E.W.F., Nanne, J.A.M., Mason, P.R.D., Davies, G.R., 2015. Charnockites and UHT metamorphism in the Bakhuis Granulite Belt, western Suriname: Evidence for two separate UHT events. Precambrian Research 262, 1-19.

Korhonen, F.J., Clark, C., Brown, M., Bhattacharya, S., Taylor, R., 2013. How long-lived is ultrahigh temperature (UHT) metamorphism? Constraints from zircon and monazite geochronology in the Eastern Ghats orogenic belt, India. Precambrian Research 234, 322-350.

Korsch, R.J., Kositcin, N., Champion, D.C., 2011. Australian island arcs through time: Geodynamic implications for the Archean and Proterozoic. Gondwana Research 19 (3), 716-734.

Laux, J.H., Pimentel, M.M., Dantas, E.L., Armstrong, R., Armele, A., Nilson, A.A., 2004. Mafic magmatism associated with the Goiás Magmatic arc in the Anicuns region, Goiás, central Brazil: Sm-Nd isotopes and new ID-TIMS U-Pb data. Journal of South American Earth Sciences 16, 599-614.

Ludwig, K.R., 2003. User's Manual for Isoplot 3.00, A Geochronological Toolkit for Microsoft Excel. Berkeley Geochronology Center Special Publication 4.

Martins. L., Vlach, S.R.F., Janasi, V.A., 2009. Reaction microtextures of monazite: correlation between chemical and age domains in the Nazaré Paulista migmatite, SE Brazil. Chemical Geology 261, 271-285.

McDonough, W.F., Sun, S.-S., 1995. The composition of the Earth. Chemical Geology 120, 223-253. 
Middlemost, E.A.K., 1994. Naming materials in the magma/igneous rock system. Earth Science Reviews $37,215-224$.

Miller, C.F., McDowell, S.M., Mapes, R.W., 2003. Hot and cold granites? Implications of zircon saturation temperatures and preservation of inheritance. Geology 31 (6), 529-532.

Mora, C.A.S., Campos Neto, M.C., Basei, M.A.S., 2014. Syn-collisional lower continental crust anataxis in the Neoproterozoic Socorro-Guaxupé Nappe System, southern Brasília Orogen, Brazil: constraints from zircon $\mathrm{U}-\mathrm{Pb}$ dating, $\mathrm{Sr}-\mathrm{Nd}-\mathrm{Hf}$ signatures and whole-rock geochemistry. Precambrian Research 255, 847-864.

Navarro, M.S., Ulbrich, H.H., Andrade, S., Janasi, V.A., 2002. Adaptation of ICP-OES routine determination techniques for the analysis of rare earth elements by chromatographic separation in geological materials: tests with reference materials and granitic rocks. J.f Alloy Compounds $344,40-45$.

Navarro, M.S., Andrade, S., Ulbrich, H., Gomes, C.B., Girardi, V.A.A., 2008. The Direct Determination of Rare Earth Elements in Basaltic and Related Rocks using ICP-MS: Testing the Efficiency of Microwave Oven Sample Decomposition Procedures. Geostandards and Geoanalytical Research $32(2), 167-180$

Newton, R.C., Perkins III, D., 1982. Thermodynamic calibration of geobarometers based on the assemblages garnet-plagioclase-orthopyroxene(clinopyroxene)-quartz. American Mineralogist $67,203-222$.

Pattison, D.R.M., Chacko, T., Farquhar, J., McFarlane, C.R.M., 2003. Temperatures of granulite-facies metamorphism: constraints from experimental phase equilibria and thermobarometry for retrograde exchange. Journal of Petrology 44(5), 867-900.

Paton, C., Hellstrom, J., Paul, B., Woodhead, J., Hergt, J., 2011. lolite: Freeware for the visualization and processing of mass spectrometry data. Journal of Analytical Atomic Spectrometry 26, 25082518. Geostandards and Geoanalytical Research 21 (1), 115-144.

Pearce, J.A., Harris, N.B.W., Tindle, A.G., 1984. Trace element discrimination diagrams for tectonic interpretation of granitic rocks. Journal of Petrology 25, 956-983.

Pearce, N.J.G., Perkins, W.T., Westgate, J.A., Gorton, M.P., Jackson, S.E., Neal, C.R., Chenery, S.P., 1997. A compilation of new and published major and trace element data for NIST SRM 610 and NIST SRM 612 glass reference materials.

Peccerillo, A., Taylor, S.R., 1976. Geochemistry of Eoceno calc-alkaline volcanic rocks from the Kastamonu area, northern Turkey. Contributions to Mineralogy and Petrology 58, 63-81.

Percival, J.A., Mortensen, J.K., 2002. Water-deficient calc-alkaline plutonic rocks of northeastern Superior Province, Canada: Significance of charnockitic magmatism. Journal of Petrology 43(6), 1617-1650.

Perkins III, D., Chipera, S.J., 1985. Garnet-orthopyroxene-plagioclase-quartz barometry: refinement 
and application to the English River subprovince and the Minnesota River valley. Contributions to Mineralogy and Petrology 89(1), 69-80.

Petrus, J.A., Kamber, B.S., 2012. VizualAge: A Novel Approach to Laser Ablation ICP-MS U-Pb Geochronology Data Reduction. Geostandards and Geoanalytical Research 36, 247-270.

Pimentel, M.M., Fuck, R.A., 1992. Neoproterozoic crustal accretion in central Brazil. Geology 20, 375379.

Pimentel, M.M., Fuck, R.A., Gioia, S.M.C.L., 2000. The Neoproterozoic Goiás Magmatic Arc, Central Brazil: a review and new Sm-Nd isotopic data. Brazilian Journal of Geology 30(1): 35-39.

Rajesh, H.M., 2004. The igneous charnockite-high-K alkali-calcic I-type granite-incipient charnockite association in Trivandrum Block, southern India. Contributions to Mineralogy and Petrology 147, 346-362.

Reno, B.L., Brown, M., Kobayashi, K., Nakamura, E., Piccoli, P.M., Trouw, R.A.J., 2009. Eclogite-highpressure granulite metamorphism records early collision in West Gondwana: new data from the Southern Brasília Belt, Brazil. Journal of the Geological Society, London 166, 1013-1032.

Reno, B.L., Piccoli, P.M., Brown, M., Trouw, R.A.J., 2012. In situ monazite (U-Th)-Pb ages from the Southern Brasília Belt, Brazil: constraints on the high-temperature retrograde evolution of HP granulites. Journal of Metamorphic Geology 30, 81-112.

Rocha, B.C., Moraes, R., Möller, A., Cioffi, C.R., Jercinovic, M.J., 2016. Timing of anatexis and melt crystallization in the Socorro-Guaxupé Nappe, SE Brazil: insights from trace element composition of zircon, monazite and garnet coupled to U-Pb geochronology. Lithos, http://dx.doi.org/10.1016/j.lithos.2016.05.020, in press.

Rubatto, D., 2002. Zircon trace element geochemistry: partitioning with garnet and the link between U-Pb ages and metamorphism. Chemical Geology 184, 123-138.

Rudnick, R.L., Fountain, D.M., 1995. Nature and composition of the continental crust: a lower crust perspective. Reviews of Geophysics 33(3), 267-309.

Sato, K., Tassinari, C.C.G., Kawashita, K., Petronilho, L., 1995. O método geocronológico Sm-Nd no IG/USP e suas aplicações. Anais da Academia Brasileira de Ciências 67, 315-336.

Sawyer, E.W., 1987. The role of partial melting and fractional crystallization in determining discordant migmatite leucosome compositions. Journal of Petrology 28(3), 445-473.

Sawyer, E.W., 2001. Melt segregation in the continental crust: distribution and movement of melt in anatectic rocks. Journal of Metamorphic Geology 19, 291-309.

Schoene, B., Dudas, F.O.L., Bowring, S.A., de Wit, M., 2009. Sm-Nd isotopic mapping of lithospheric growth and stabilization in the eastern Kaapvaal craton. Terra Nova 21, 219-228.

Sláma, J., Košler, J., Condon, D.J., Crowley, J.L., Gerdes, A., Hanchar, J.M., Horstwood, S.A., Morris, G.A., Nasdala, L., Norberg, N., Schaltegger, U., Schoene, B., Tubrett, M.N., Whitehouse, M.J., 2008. Plešovice zircon - A new natural reference material for $\mathrm{U}-\mathrm{Pb}$ and $\mathrm{Hf}$ isotopic microanalysis. 
Chemical Geology 249, 1-35.

Tanaka, T., Togashi, S., Kamioka, H., Amakura, H., Kagami, H., Hamamoto, T., Yuhara, M., Orihashi, Y., Yoneda, S., Shimizu, H., Kunimaru, T., Takahashi, K., Yanagi, T., Nakano, T., Fujimaki, H., Shinjo, R., Asahara, Y., Tanimizu, M., Dragasanu, C., 2000. JNdi-1: a neodymium isotopic reference in consistency with La Jolla Neodymium. Chemical Geology 168(3-4), 279-281.

Taylor, R.J.M., Harley, S.L., Hinton, R.W., Elphick, S., Clark, C., Kelly, N.M., 2015. Experimental determination of REE partition coefficients between zircon, garnet and melt: a key to understanding high-T crustal processes. Journal of Metamorphic Geology 33, 231-248.

Trouw, R.A.J., Heilbron, M., Ribeiro, A., Paciullo, F., Valeriano, C.M., Almeida, J.C.H., Tupinambá, M., Andreis, R.R., 2000. The central segment of Ribeira Belt. In: Cordani, U.G., Milani, E.J., ThomazFilho, A., Campos, D.A. (Eds.) Tectonic Evolution of South America. pp. 287-310. $31^{\text {th }}$ International Geological Congress. Rio de Janeiro, Brasil.

Trouw, R.A.J., Peternel, R., Ribeiro, A., Heilbron, M., Vinagre, R., Duffles, P., Trouw, C.C., Fontainha, M., Kussama, H.H., 2013. A new interpretation for the interference zone between Southern Brasília belt and the central Ribeira belt, SE Brazil. Journal of South American Earth Sciences 48, 43-57.

Valeriano, C., Machado, N., Simonetti, A., Valladares, C.S., Seer, H.J., Simões, L.S.A., 2004. U-Pb geochronology of the Southern Brasília belt (SE-Brazil): sedimentar provenance, Neoproterozoic orogeny and assembly of West Gondwana. Precambrian Research 130, 27-55.

Vielzeuf, D., Schmidt, M.W., 2001. Melting relations in hydrous systems revisited: application to metapelites, metagreywackes and metabasalts. Contributions to Mineralogy and Petrology 141, 251-267.

Vinagre, R., Trouw, R.A.J., Mendes, J.C., Duffles, P., Peternel, R., Matos, G., 2014. New evidence of a magmatic arc in the Southern Brasília Belt, Brazil: The Serra da Água Limpa batholith (SocorroGuaxupé Nappe). Journal of South American Earth Sciences 54, 120-139.

Watson, E.B., Wark, D.A., Thomas, J.B., 2006. Crystallization thermometers for zircon and rutile. Contributions to Mineralogy and Petrology 151, 413-433.

Wedepohl, K. H., 1995. The composition of the continental crust. Geochimica et Cosmochimica Acta $59(7), 1217-1232$.

White, W.M., 2013. Geochemistry. Wiley-Blackwell, Oxford, UK, 668 pp.

Whitehouse, M.J., Platt, J.P., 2003. Dating high-grade metamorphism - constraints from rare-earth elements in zircon and garnet. Contributions to Mineralogy and Petrology 145, 61-74.

Whitney, D.L., Evans, B.W., 2010. Abbreviations for names of rock-forming minerals. American Mineralogist 95, 185-187.

Zhao, J.X., Ellis, D.J., Kilpatrick, J.A., McCulloch, M.T., 1997. Geochemical and Sr-Nd study of charnockites and related rocks in the northern Prince Charles Mountains, East Antarctica: implications for charnockite petrogenesis and Proterozoic crustal evolution. Precambrian 
Research 81, 37-66.

Zhao, L., Zhou, X., Zhai, M., Santosh, M., Ma, X., Shan, H., Cui, X., 2014. Paleoproterozoic tectonic transition from collision to extension in the eastern Cathaysia Block, South China: Evidence from geochemistry, zircon $\mathrm{U}-\mathrm{Pb}$ geochronology and $\mathrm{Nd}-\mathrm{Hf}$ isotopes of a granite-charnockite suite in southwestern Zhejiang. Lithos 184-187, 259-280.

\section{APPENDIX A}

\section{Analytical Procedures}

Compositional maps and wavelength-dispersive spectrometry (WDS) analyses were performed using a JEOL JXA-8530F Hyperprobe, Field Emission Electron Probe Microanalyzer (FE-EPMA) at the NAP Geoanalítica Laboratory, Universidade de São Paulo. Quantitative analyses were carried out using a focused beam at $15 \mathrm{kV}$ and 20nA, with a $5 \mu \mathrm{m}$ spot size, except for feldspar analyses (10 $\mu \mathrm{m})$. Compositional maps were collected using an acceleration voltage of $15 \mathrm{kV}$, beam current of $250 \mathrm{nA}$ and a dwell time of 20 ms. Representative analyses of garnet, feldspar, orthopyroxene, amphibole and biotite were recalculated using the A-X software (http://www.esc.cam.ac.uk/research/researchgroups/holland/ax), based on charge balance with double-normalization and are given in ANEXO III. Thermobarometric results are presented in ANEXO IV. Full thin section WDS maps of CeL $\alpha, Y L \alpha, \operatorname{ZrL\alpha }$, $\mathrm{Ca} K \alpha$ and $\mathrm{MgK} \alpha$ were collected on a CAMECA SX-50 electron microprobe at the University of Massachusetts-Amherst Electron Microprobe Facility in two samples (4A, 5B) using an acceleration voltage of $15 \mathrm{kV}$, beam current of $334 \mathrm{nA}$ and $293 \mathrm{nA}$, respectively.

Twenty-four fresh samples were crushed in a steel jaw-crusher and in an agate mill. Wholerock major element composition was obtained by X-ray fluorescence (XRF) spectrometry at ACME Analytical Laboratory (Vancouver, Canada), after fusion with lithium tetraborate. Trace element analyses were performed at the NAP Geoanalítica Laboratory, Universidade de São Paulo by inductively coupled mass spectrometry (ICP-MS) using a Perkin Elmer Plasma Quadrupole MS Elan 6100DRC, after $\left(\mathrm{HF}+\mathrm{HNO}_{3}\right.$ ) acid digestion in Parr bombs for 5 days at $200{ }^{\circ} \mathrm{C}$ (see Navarro et al., 2002, 2008 for further details). The whole-rock geochemical analyses of major and trace elements are reported in ANEXO V.

Zircon was separated using a disk grinder, a Wilfley table, a Frantz ${ }^{\mathrm{TM}}$ isodynamic magnetic separator and standard heavy-liquid techniques at CPGeo (Geochronology Research Center), Universidade de São Paulo. Subsequently, zircon grains were handpicked under a binocular microscope and selected grains were mounted in one-inch epoxy discs and polished to approximately half their thickness to expose the grain cores. Cathodoluminescence $(\mathrm{CL})$ images were acquired using a FEI Versa 3D Dual Beam field emission scanning microscope using low vacuum mode at the Microscopy and Analytical Imaging (MAI) Lab, at The University of Kansas (KU), in order to identify internal compositional zoning. Laser ablation-inductively coupled plasma mass spectrometry (LA-ICP-MS) 
analyses were performed on six different samples (A2, A1, 5B1, 5B2, 6B1, 2C1) at the IGL (Isotope Geochemistry Laboratory) at The University of Kansas, using a Thermo Scientific Element 2 ICP-MS attached to a Photon Machines Analyte.G2 $193 \mathrm{~nm}$ ArF excimer laser ablation. Analytical conditions include a laser fluency of $2.2 \mathrm{~J} / \mathrm{cm}^{-2}$ at a repetition rate of $10 \mathrm{~Hz}$, and spot size of $20 \mu \mathrm{m}$. Elemental fractionation, downhole fractionation and calibration drift were corrected using the GJ1 zircon reference material (Jackson, 2004), and data reduction using the VizualAge data reduction scheme (Petrus and Kamber, 2012) for the IOLITE software package (Paton et al., 2011). The secondary zircon standard Plešovice yielded weighted mean ${ }^{206} \mathrm{~Pb} / 238 \mathrm{U}$ dates of $341 \pm 0.8(2 \sigma)(\mathrm{n}=26 ; \mathrm{MSWD}=1.3)$ and $338.8 \pm 0.9(2 \sigma)(n=26 ; M S W D=1.1)$ during the analytical sessions, within $1 \%$ analytical uncertainty of the $337.13 \pm 0.37 \mathrm{Ma}$ age determined by high precision thermal ionization mass spectrometry (Sláma et al., 2008). U-Pb ages and errors were calculated using the Isoplot software (Ludwig, 2003) and results are given in ANEXO VIII

Zircon trace element analyses were performed on the LA-ICP-MS at the IGL, The University of Kansas. The laser fluency was $2.5 \mathrm{~J} / \mathrm{cm}^{-2}$, at a repetition rate of $10 \mathrm{~Hz}$. External calibration was performed relative to NIST 612 glass using the values from GeoRem database as of Dec09 during zircon analysis. The trace element analyses spots ( $15 \mu \mathrm{m}$ diameter) were placed near the U-Pb dating spots and their location is indicated by red circles in Fig. 8. Internal standards were stoichiometric Si for zircon. Garnet trace elements analyses were performed using a Thermo Scientific iCAP Q ICP-MS coupled to a New Wave UP $213 \mathrm{~nm}$ laser ablation system at the NAP Geoanalítica Laboratory, Universidade de São Paulo. Garnet was analyzed with $55 \mu \mathrm{m}$ spot sizes, a laser fluency of $10.98 \mathrm{~J} / \mathrm{cm}^{2}$, at a repetition rate of $15 \mathrm{~Hz}$. ICP-MS analyses follow the methodology described in Andrade et al. (2014). External calibration was performed relative to NIST 610 glass using the concentrations given by Pearce et al. (1997). The USGS BCR-2G basaltic glass reference material was analyzed as secondary standard during analyses. $\mathrm{Si}$ and $\mathrm{Ca}$ determined by electron microprobe were used as internal standards for each garnet spot analysis. Trace element analyses are reported in ANEXO VII.

Analyses of $\mathrm{Sr}$ and $\mathrm{Nd}$ isotopic ratios were acquired in five samples at CPGeo, Universidade de São Paulo, using a Neptune multi-collector ICP-MS. The same powders used for whole-rock elemental analyses were dissolved in acid, and the elements of interest were separated in ion-exchange columns following the procedures described in Sato et al. (1995). The total procedure blanks were $122 \mathrm{pg}$ for $\mathrm{Sr}$ and $59 \mathrm{pg}$ for $\mathrm{Nd}$. The $\mathrm{Sr}$ and $\mathrm{Nd}$ isotopic ratios were normalized to ${ }^{86} \mathrm{Sr} /{ }^{88} \mathrm{Sr}=0.1194$ and ${ }^{146} \mathrm{Nd} /{ }^{144} \mathrm{Nd}$ $=0.7219$ isotopic ratios for mass fractionation correction. The NBS987 standard yielded a long-term average ${ }^{87} \mathrm{Sr} /{ }^{86} \mathrm{Sr}$ value of $0.710237 \pm 0.0000021$ ( $2 \sigma$ error). The JNdi standard (Geological Survey of Japan; Tanaka et al., 2000; recommended value of ${ }^{143} \mathrm{Nd} /{ }^{144} \mathrm{Nd}=0.512115 \pm 0.000007$ ) yielded a mean ${ }^{143} \mathrm{Nd} /{ }^{144} \mathrm{Nd}$ value of $0.512090 \pm 0.000006$ ( $n=14 ; 2 \sigma$ error), except during the analyses of sample 5B2 ( $0.512068 \pm 0.000006 ; n=6 ; 2 \sigma$ error). The ${ }^{147} \mathrm{Sm} /{ }^{144} \mathrm{Nd}$ ratios were calculated from the concentrations determined by ICP-MS. The results of the Sr and Nd isotopic analyses are reported in ANEXO VI. 


\section{ANEXO III}

Análises de química mineral em granada, feldspatos, piroxênios, anfibólios e micas obtidas através de microssonda eletrônica 


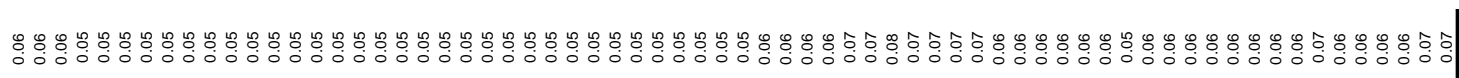

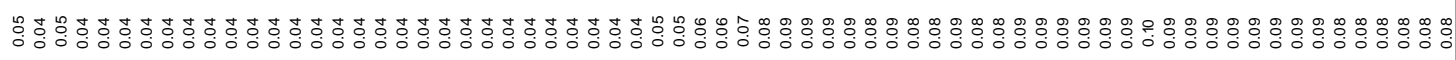

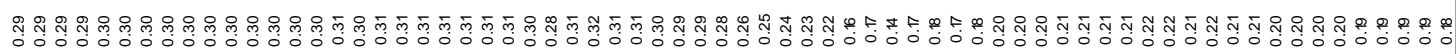

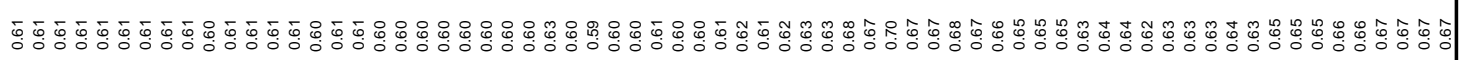

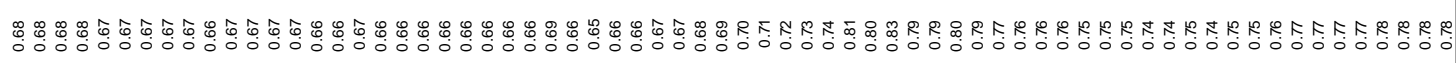

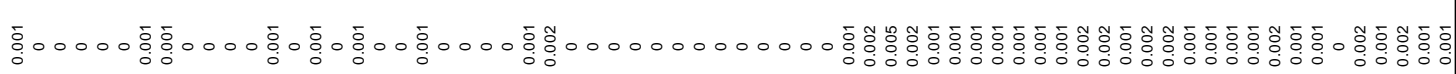

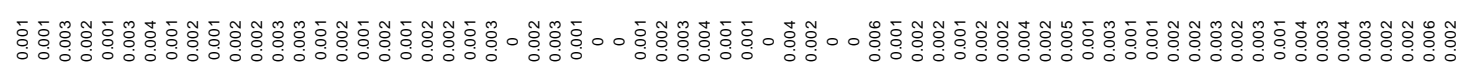

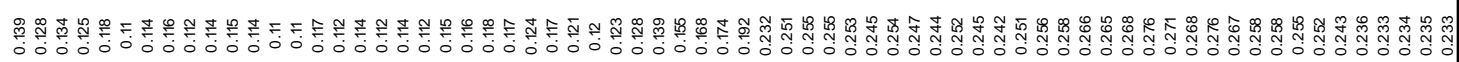

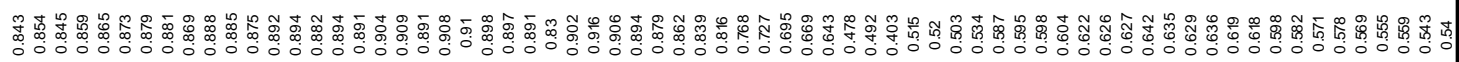
ஜ 0000000 0

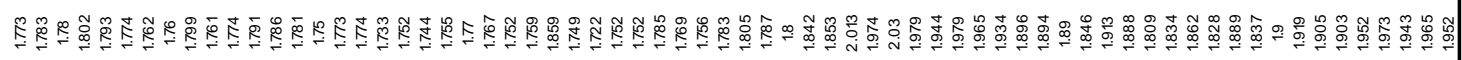

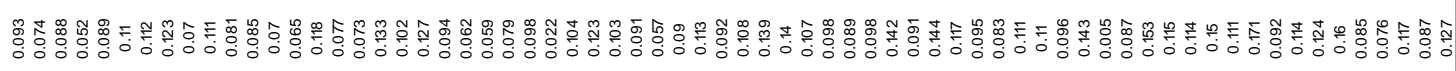

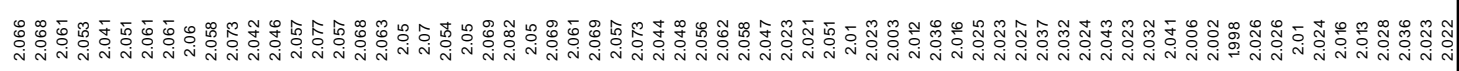

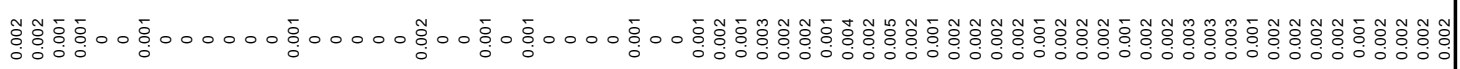

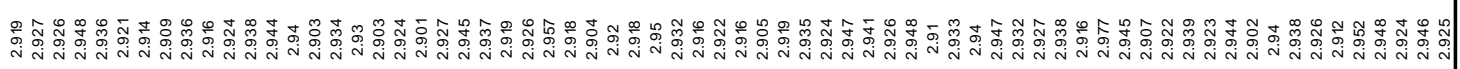

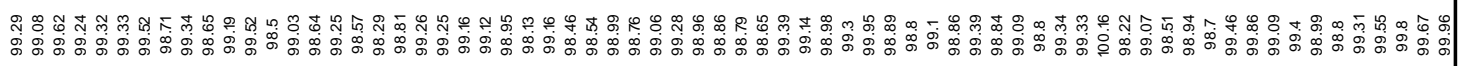
500000

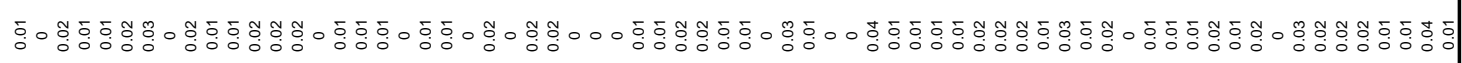

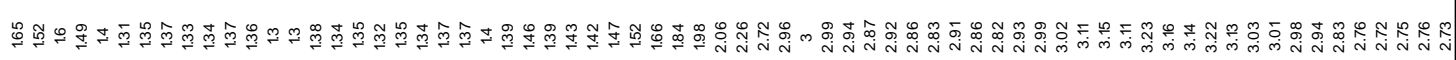

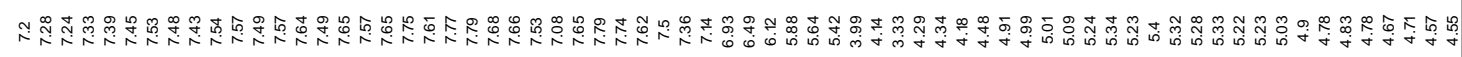

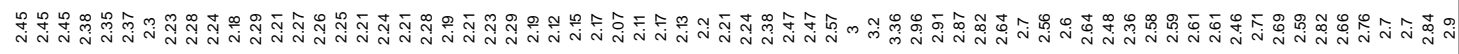

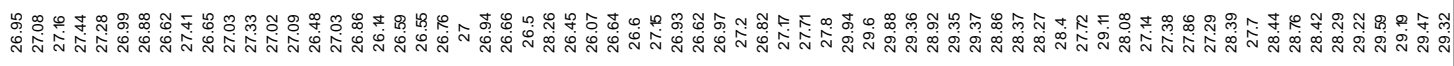

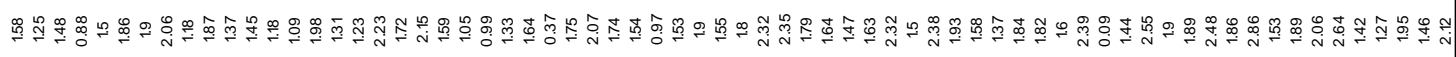

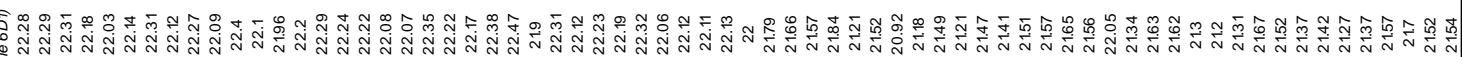

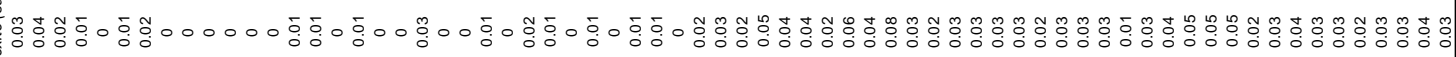

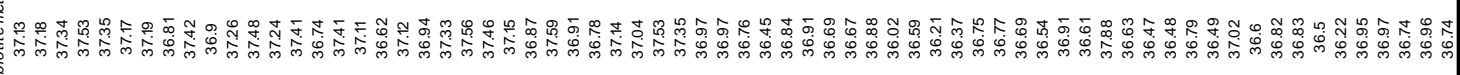

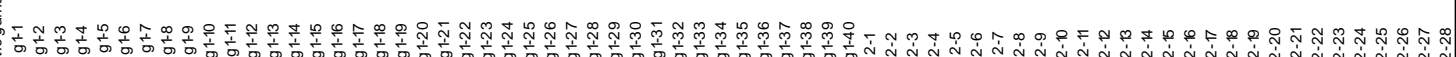

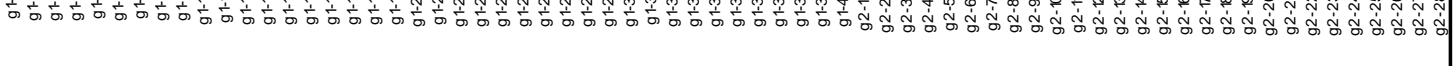




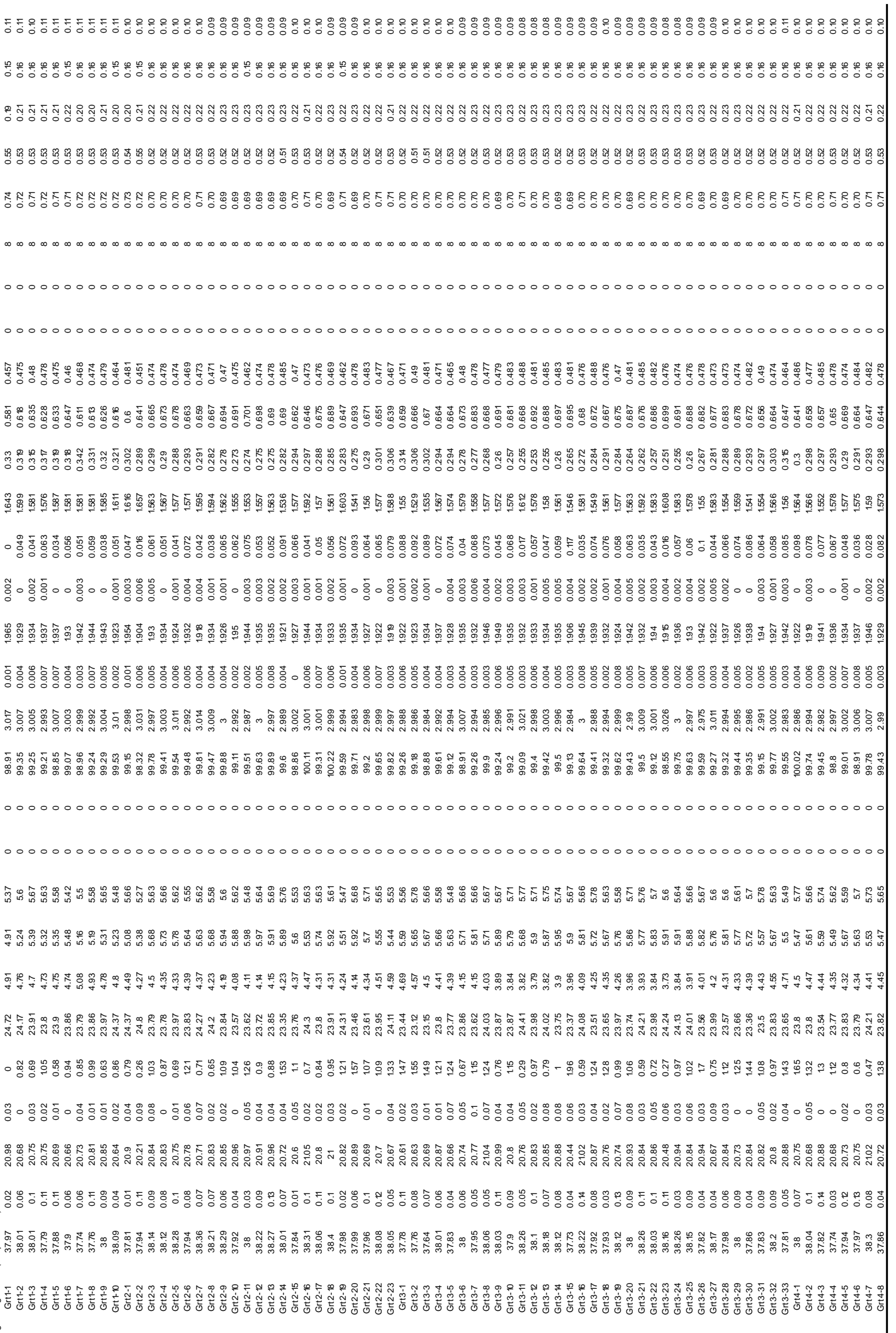




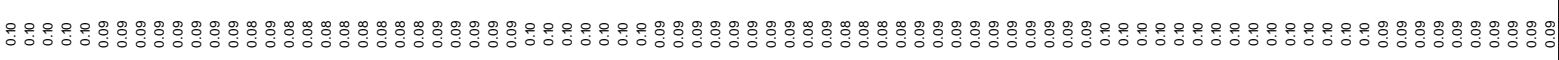

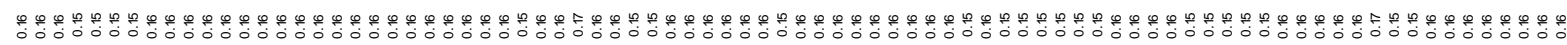

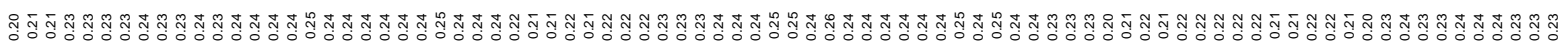

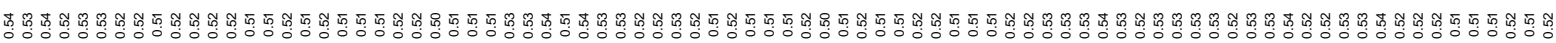

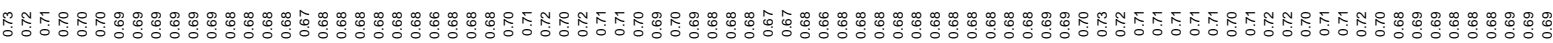

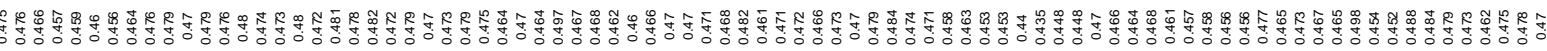

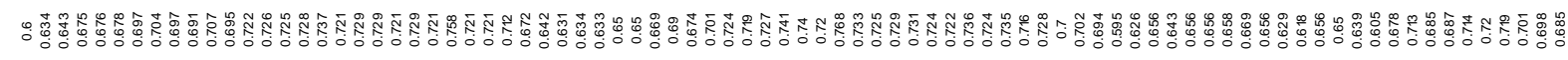

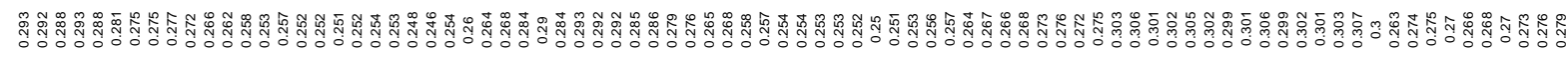

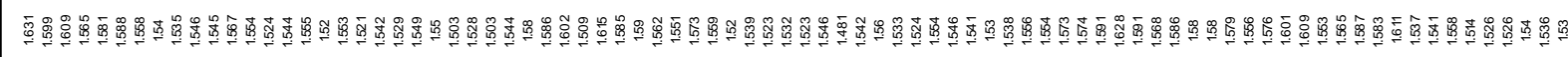

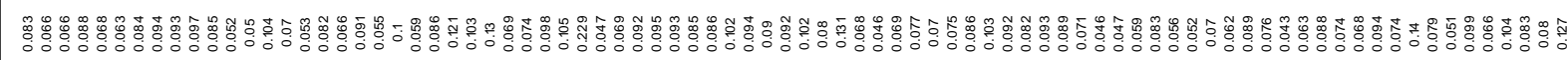

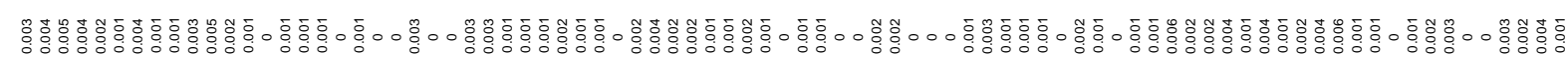

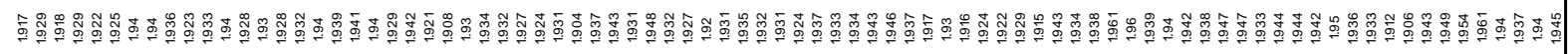

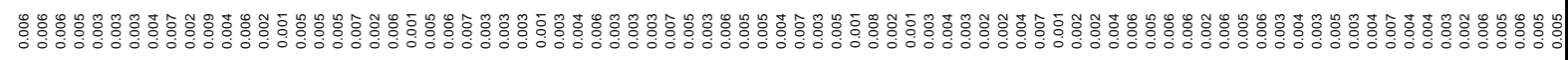

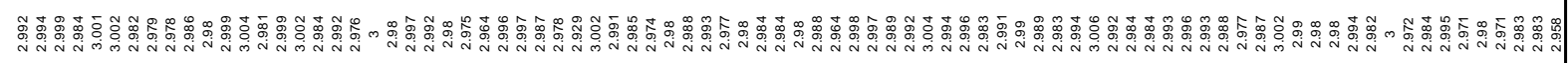

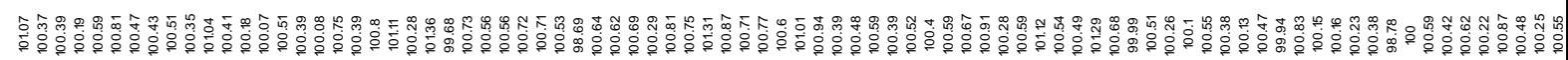
요으. $\frac{2}{2}$

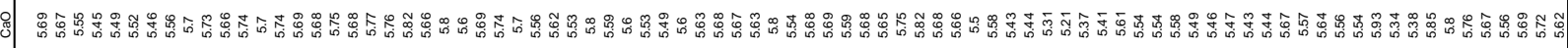

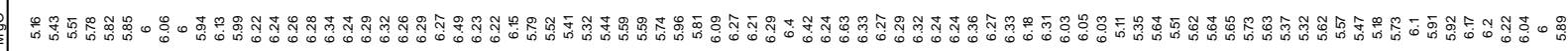

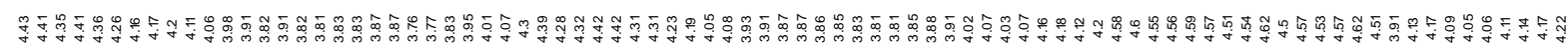

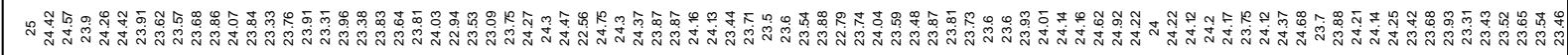

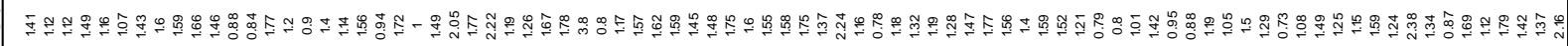

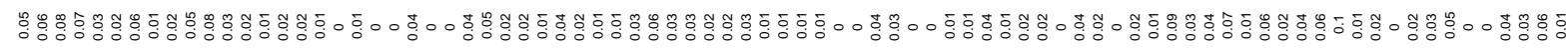

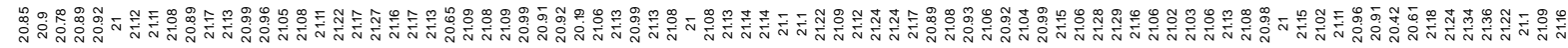

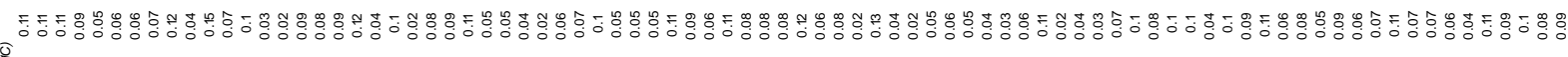

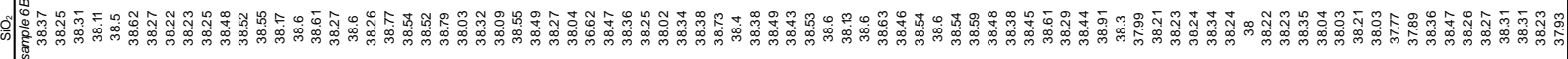

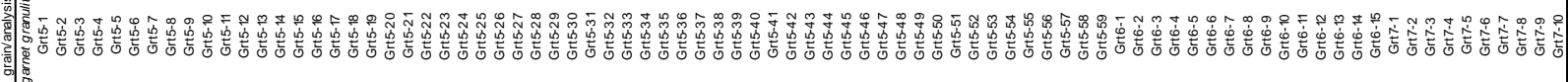




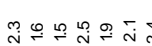

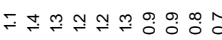

-

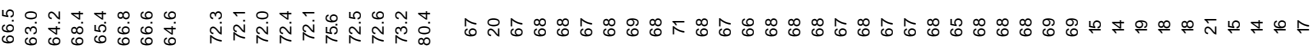

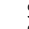

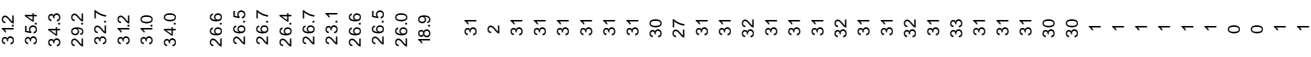

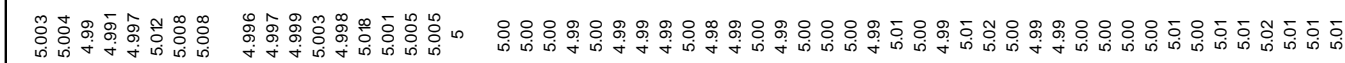

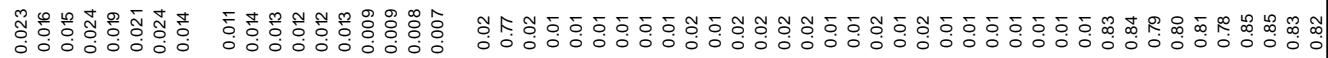

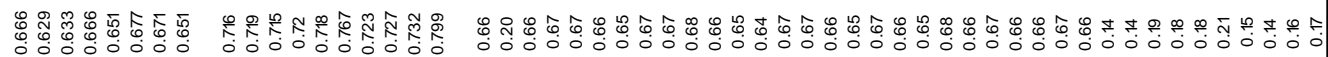

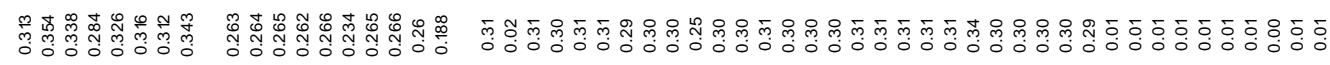

.

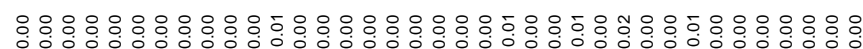

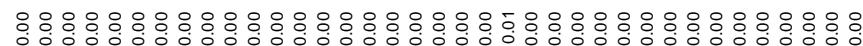

000000000000000000

00000000.00000

0000000000

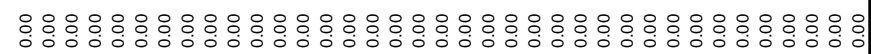

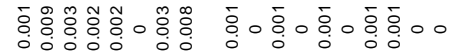

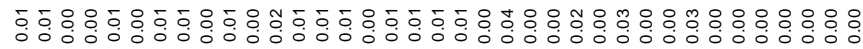

000000000000000000

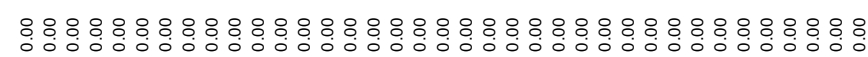

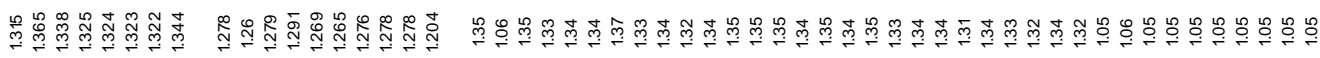

$0000000 \overline{0} 0000000000$

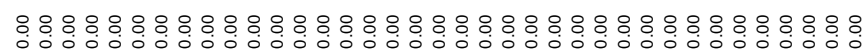

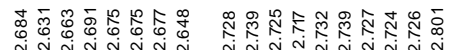

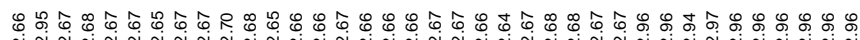

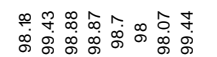

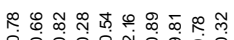

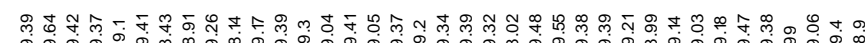

(2)

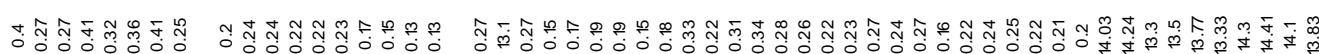

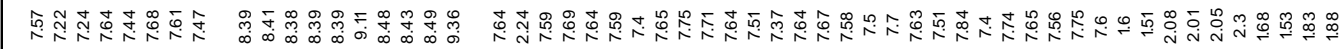

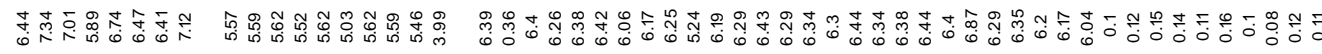

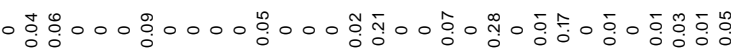

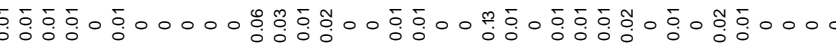

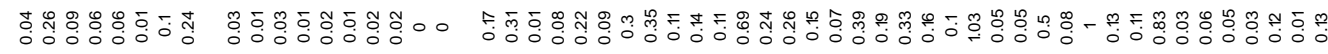

\section{要}

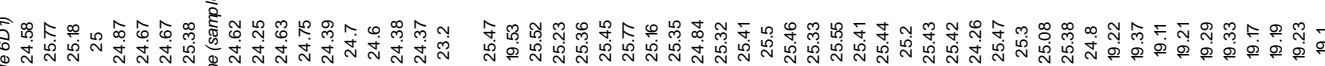

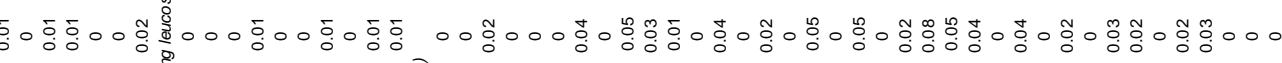

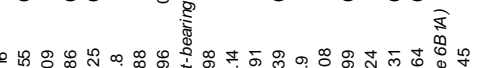

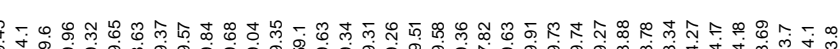

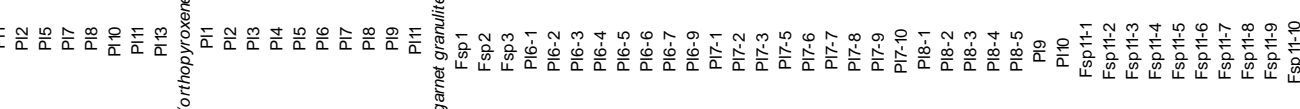




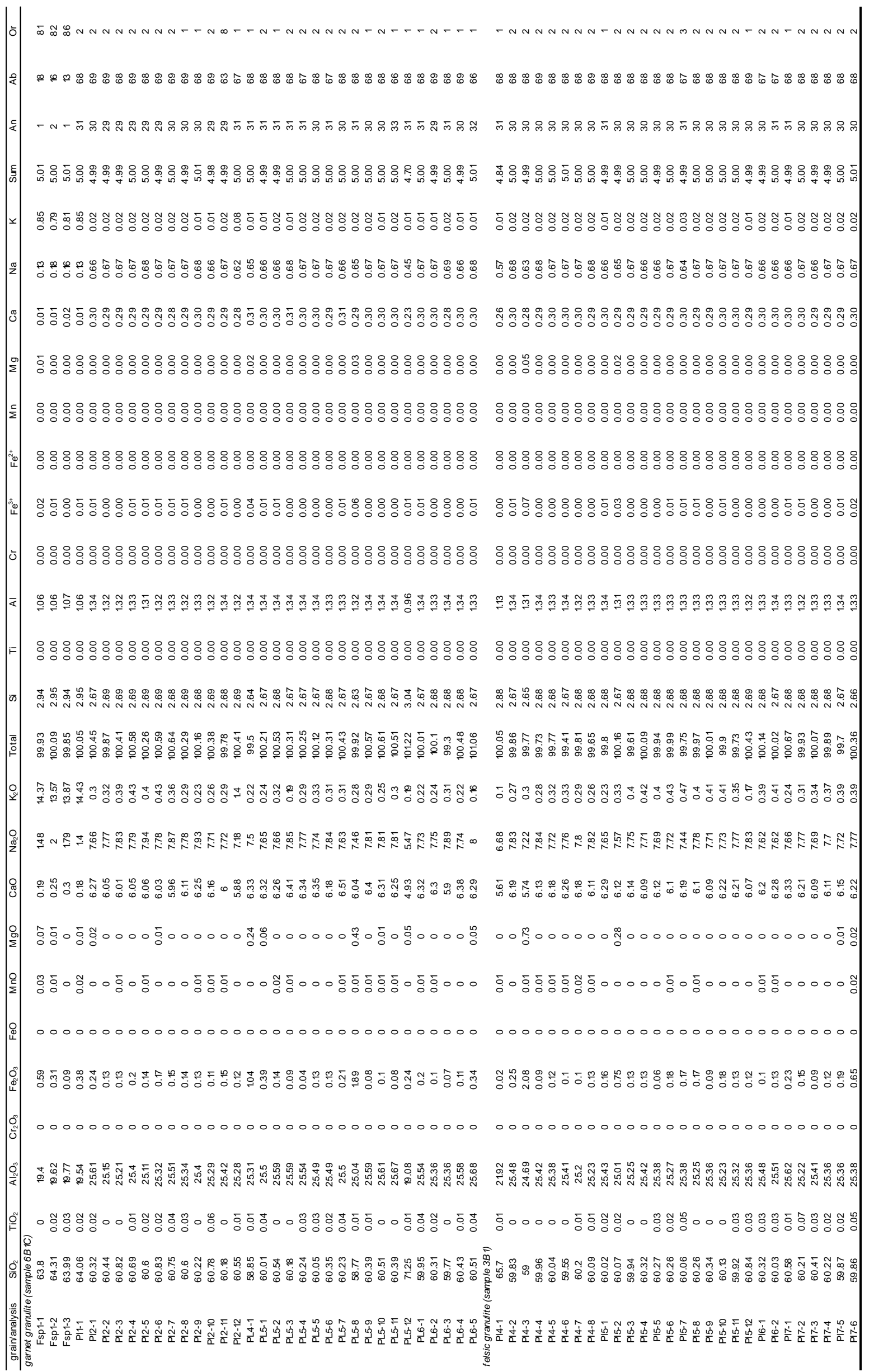




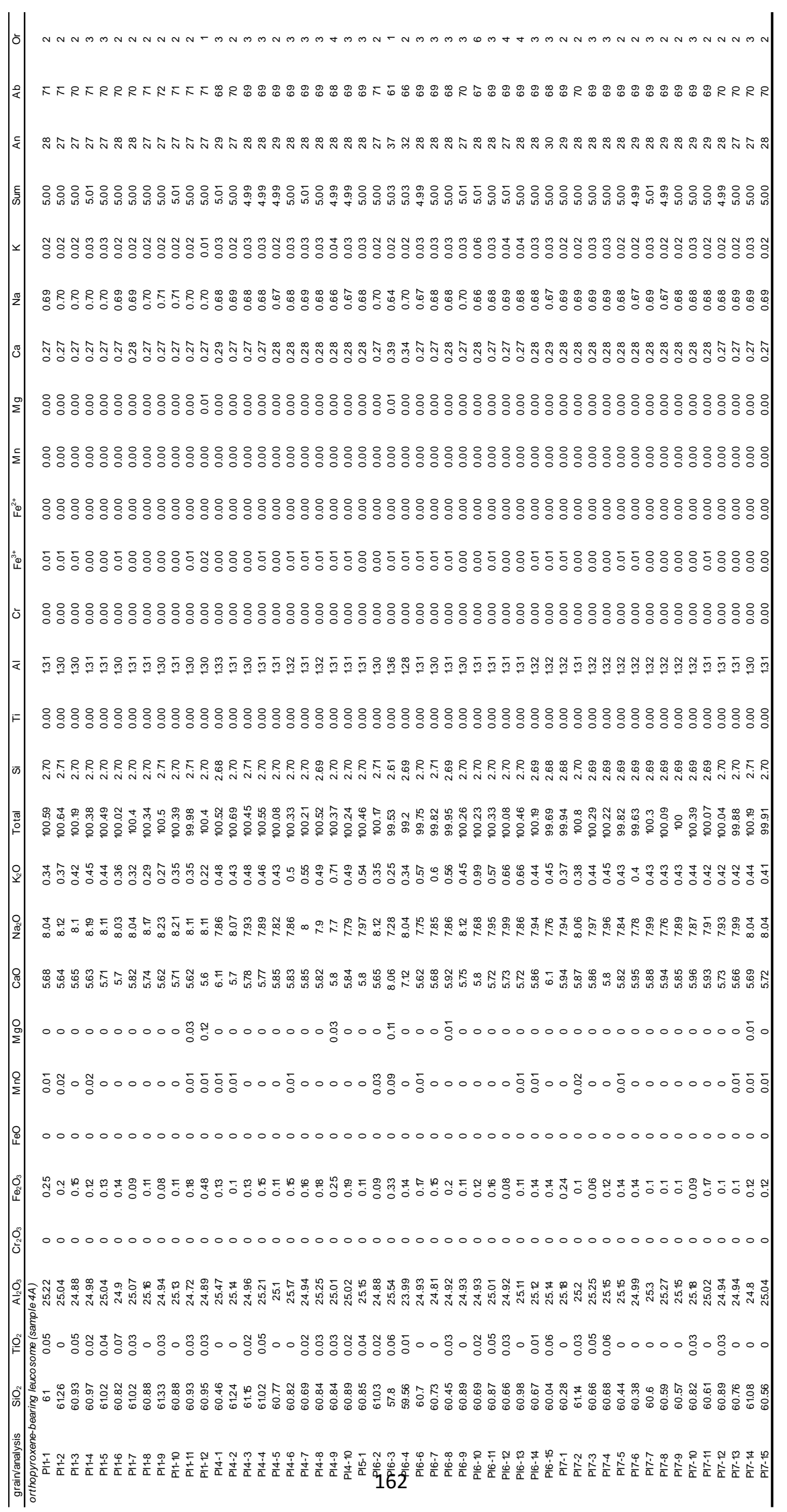




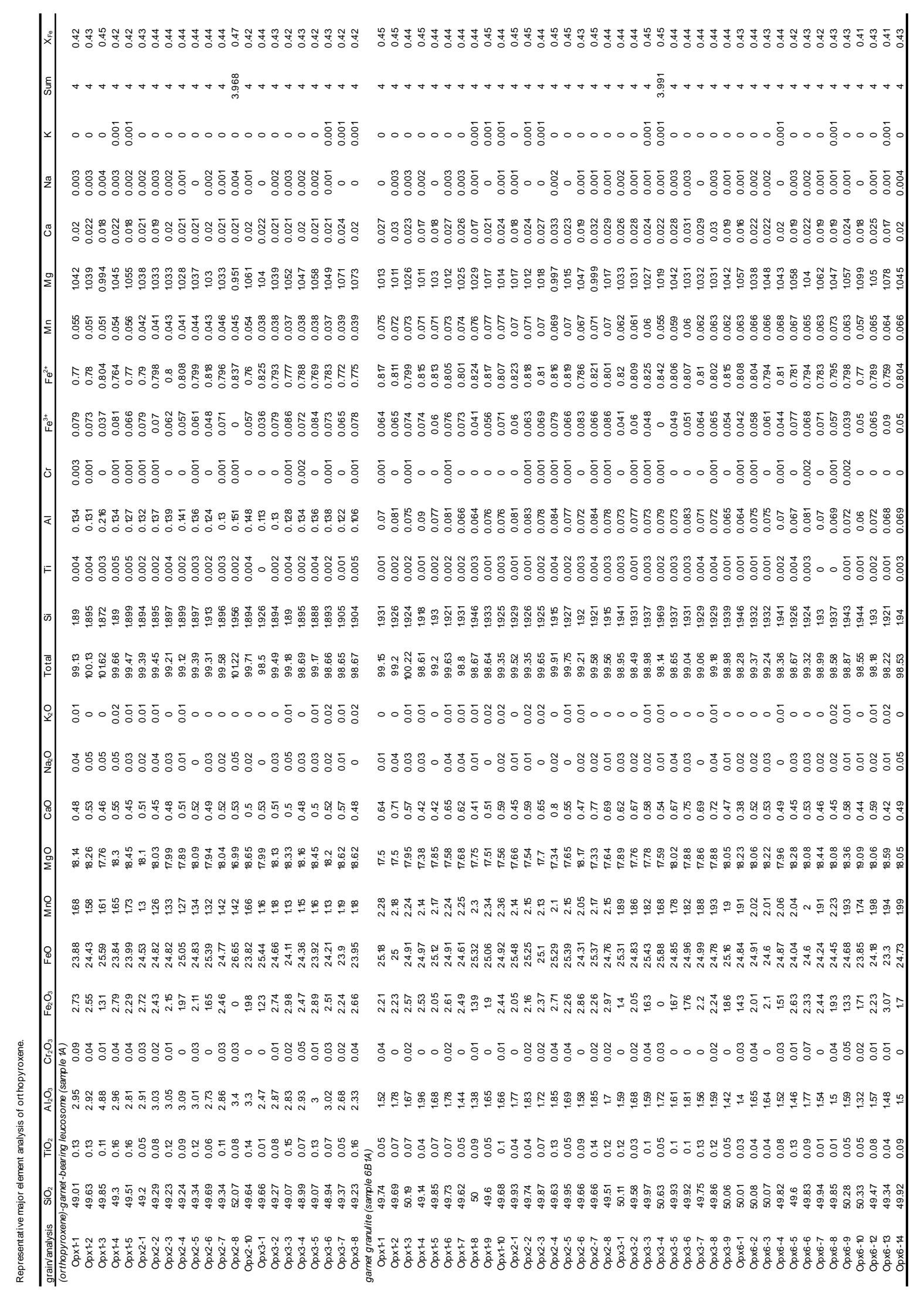




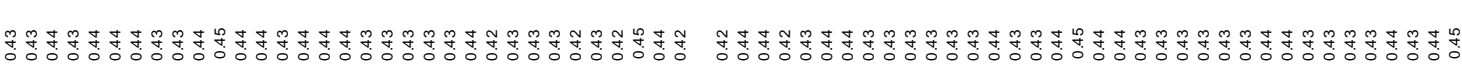

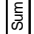

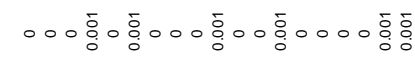

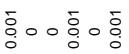

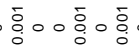

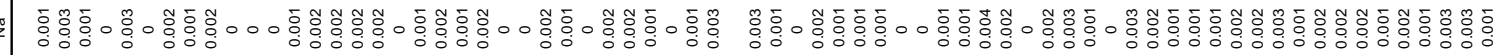

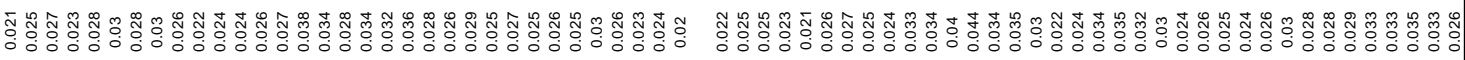

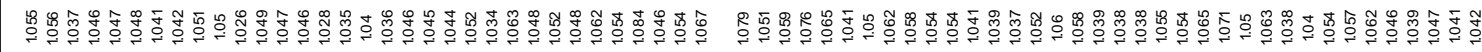

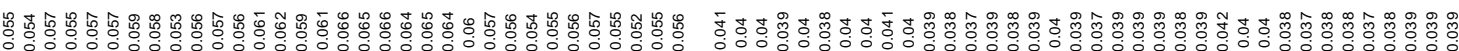

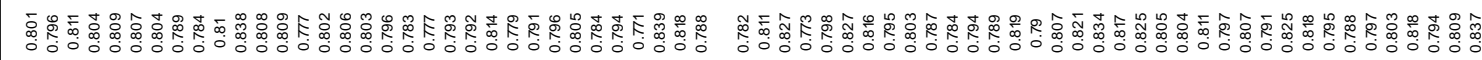

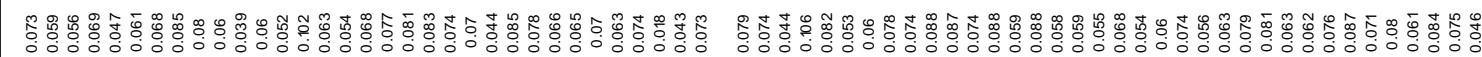

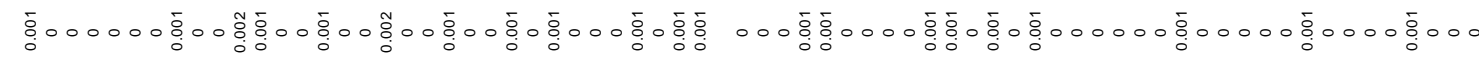

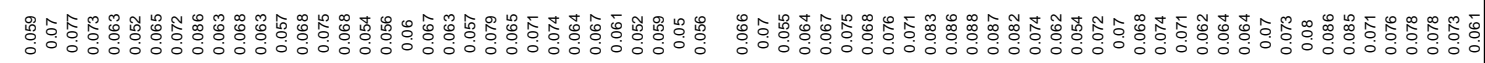

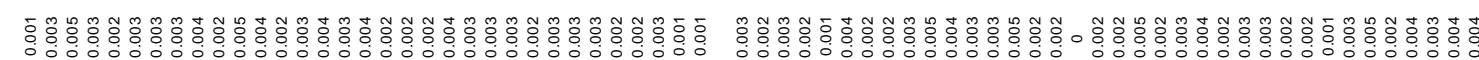

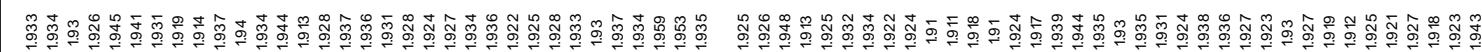

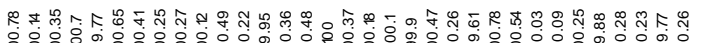

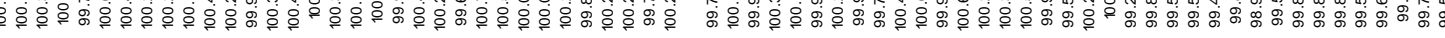

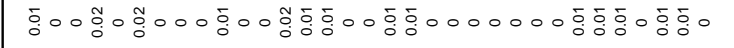

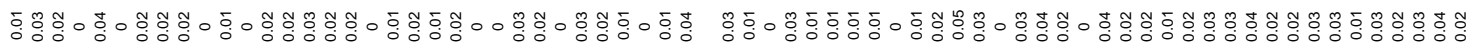

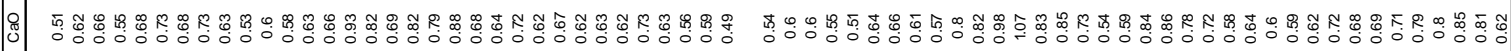

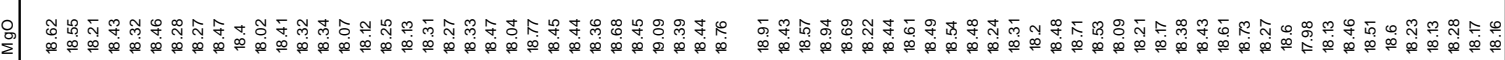

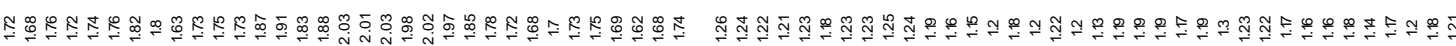

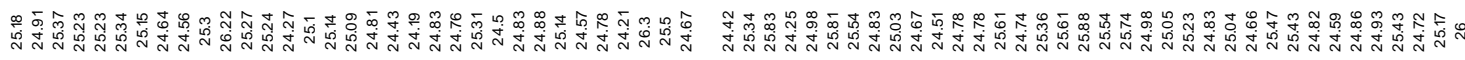

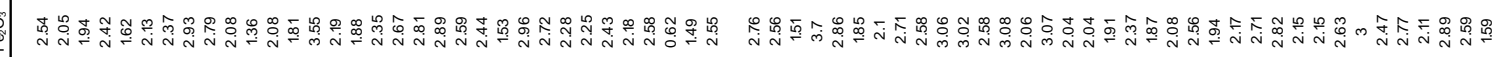

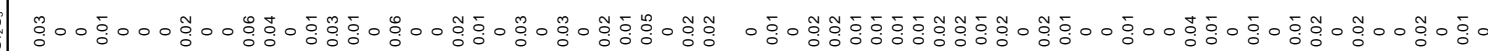

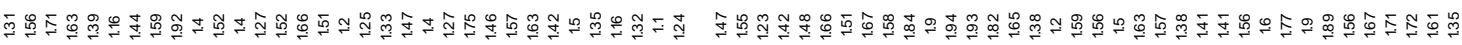

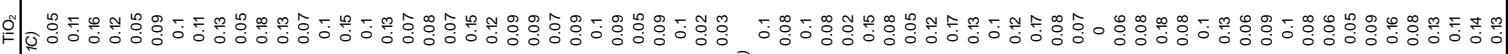
作

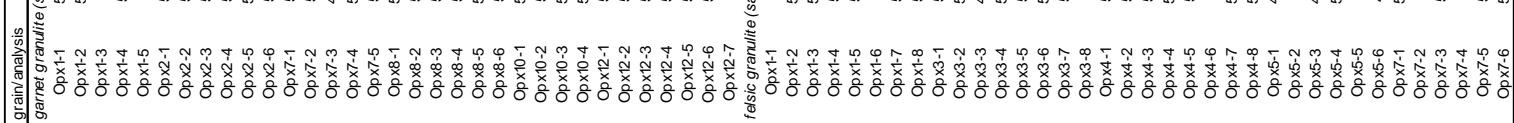




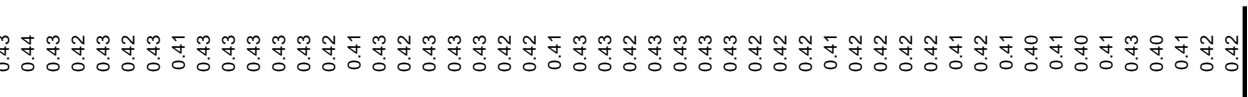

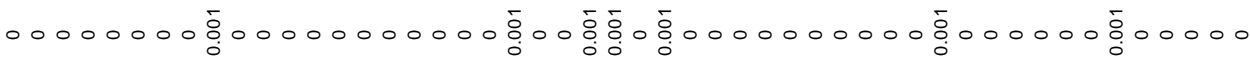

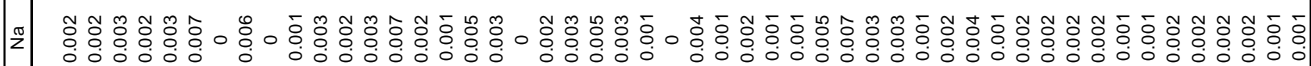

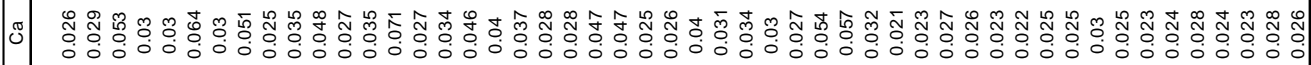

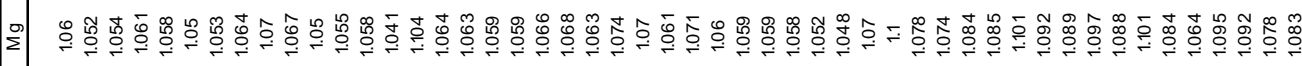

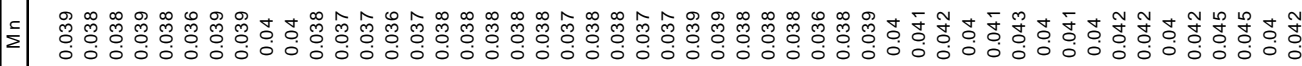

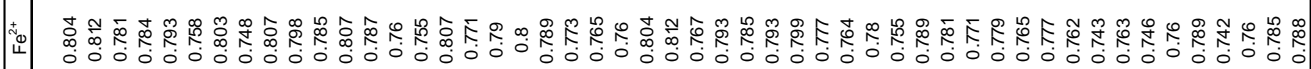

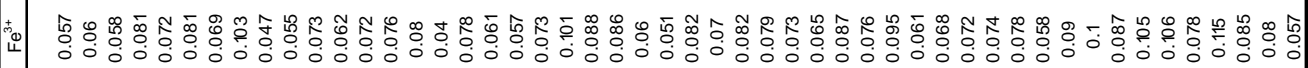

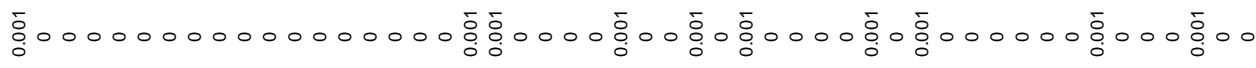

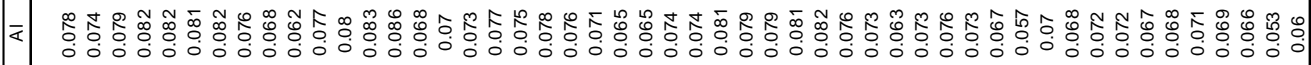

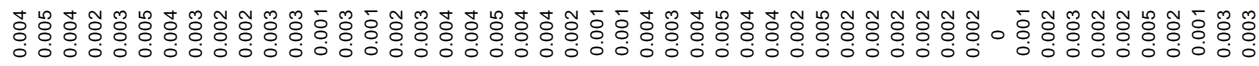

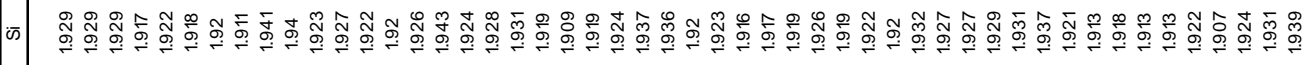

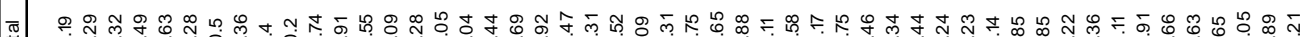

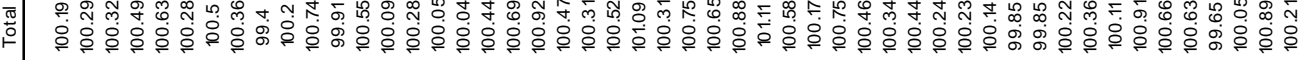

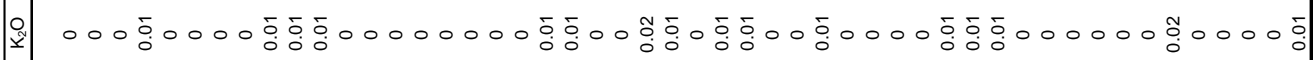

承

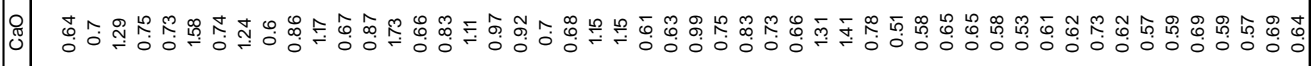

O)

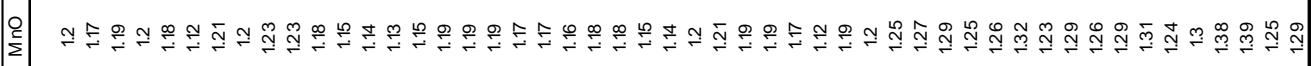

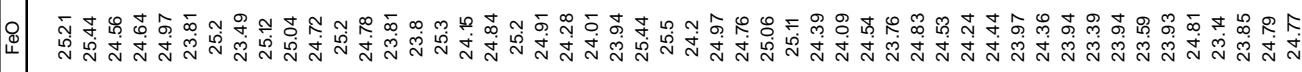

部

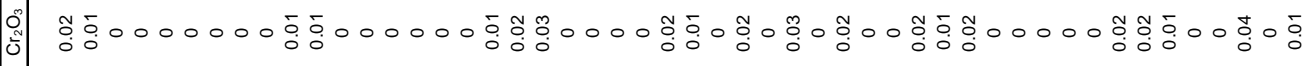

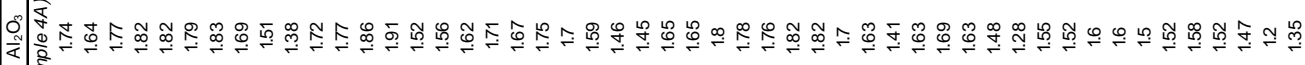

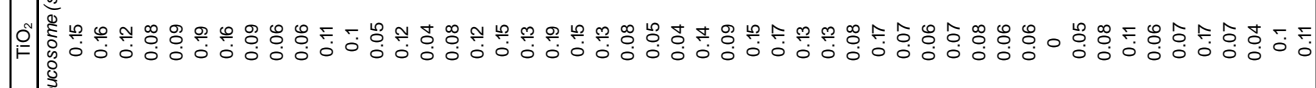

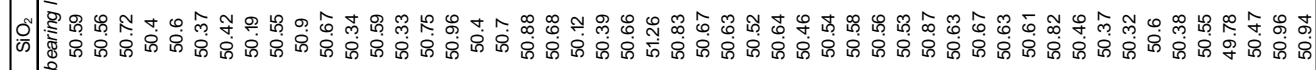

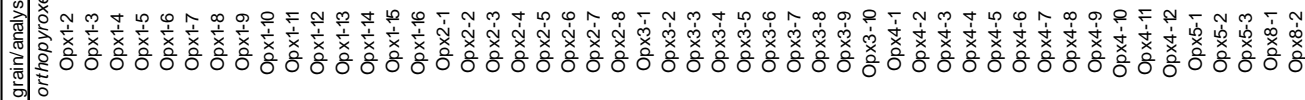




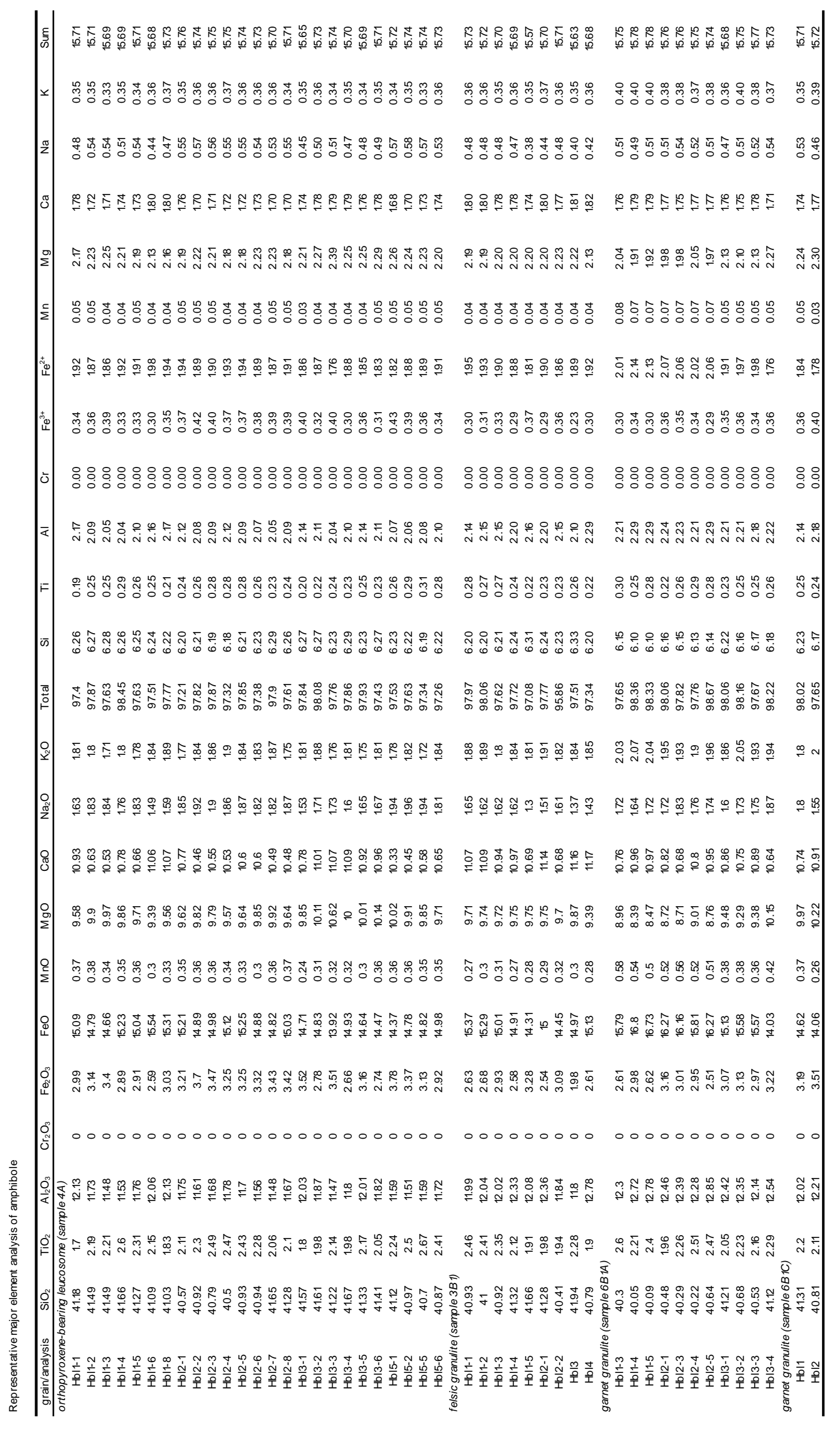




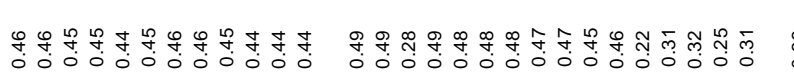

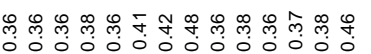

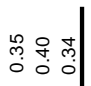

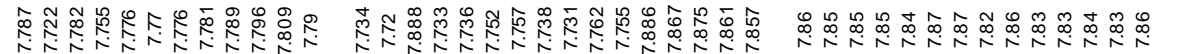

象怘 怘

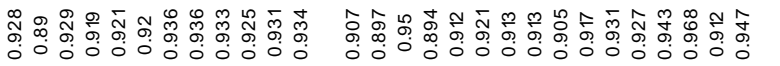

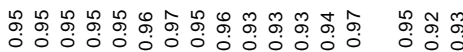

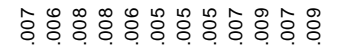

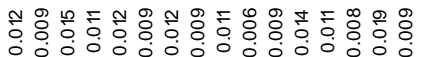

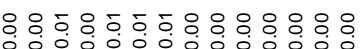

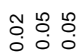

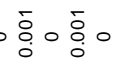

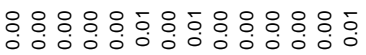

$\because: \because: \circ$

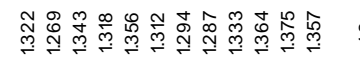

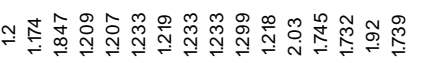

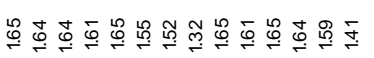

ํํำ 꾿

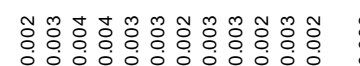

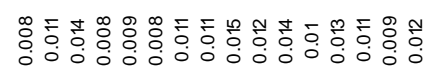

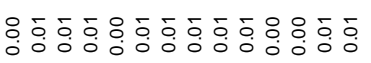

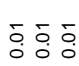

꼴

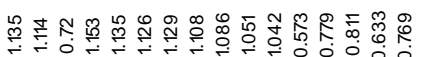

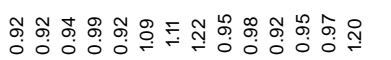

\&্ণ

000000000000

00 กิ่อ

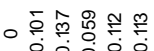

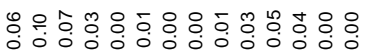

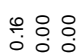

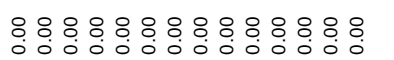

웅:

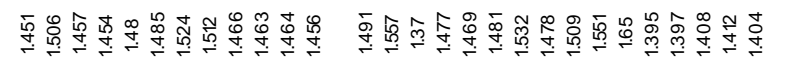

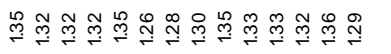

刃ำ

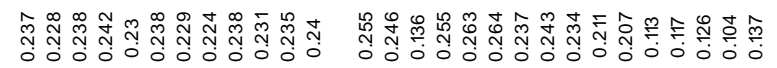

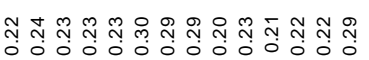

땅잉

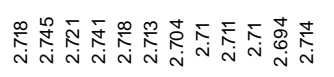

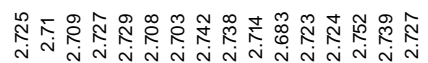

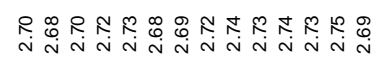

ํํ요요

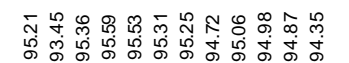

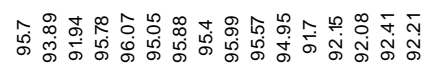

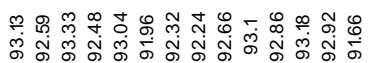

징

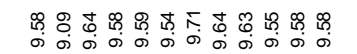

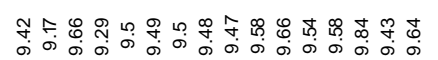

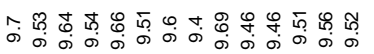

๘承

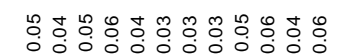

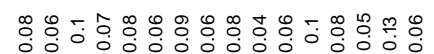

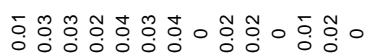

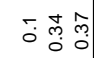

○

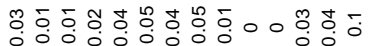

象

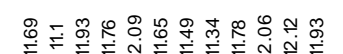

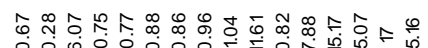

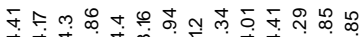

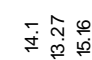

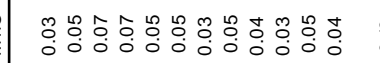

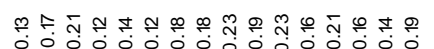

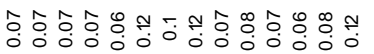

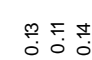

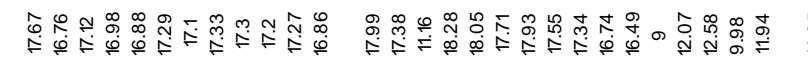

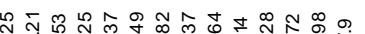

000000000000

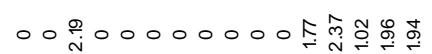

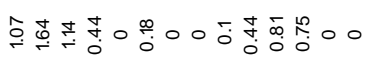

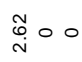

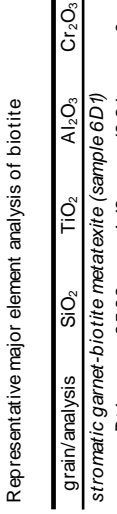

1000000000000

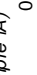

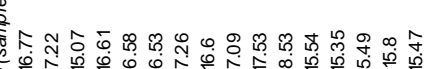

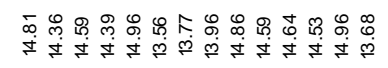

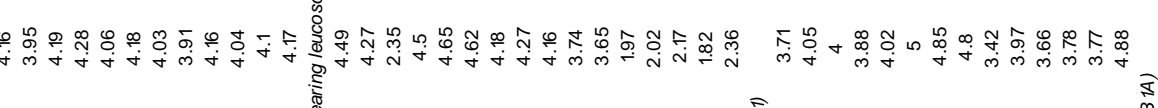

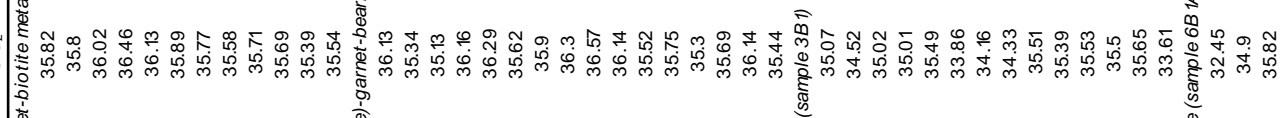




\section{ANEXO IV}

\section{Dados de geotermobarometria obtidas por métodos convencionais}


Geothermobarometry results using the calibration of Pattison et al. (2003)

\begin{tabular}{|c|c|c|c|c|c|c|}
\hline Assemblage & $\mathrm{X}_{\mathrm{Ca}} \mathrm{Grt}$ & M/FM Grt & M/FM Opx & $\mathrm{X}_{\mathrm{Al}}$ Opx & Trclc & P rclc \\
\hline \multicolumn{7}{|c|}{ (orthopyroxene)-garnet-bearing leucosome (sample 1A) } \\
\hline \multicolumn{7}{|c|}{ Grt cores/high-Al Opx cores (M1 stage) } \\
\hline Grt4-25 Opx1-3 Bt14 PI1-4 & 0.074 & 0.431 & 0.55 & 0.054 & 1126 & 13.2 \\
\hline Grt4-25 Opx1-3 Bt1 PI1-5 & 0.074 & 0.398 & 0.514 & 0.054 & 1139 & 13.0 \\
\hline Grt4-66 Opx1-3 Bt14PI1-4 & 0.07 & 0.422 & 0.545 & 0.054 & 1111 & 12.8 \\
\hline Grt4-24 Opx1-2 Bt14 PI1-5 & 0.072 & 0.395 & 0.567 & 0.033 & 918 & 10.3 \\
\hline Grt4-26 Opx2-4 Bt14 PI1-4 & 0.073 & 0.396 & 0.56 & 0.035 & 943 & 10.4 \\
\hline Grt4-25 Opx1-4 Bt14 PI1-4 & 0.074 & 0.402 & 0.571 & 0.034 & 927 & 10.5 \\
\hline Average & & & & & 1027.3 & 11.7 \\
\hline standard deviation & & & & & 108.0 & 1.4 \\
\hline \multicolumn{7}{|l|}{ Grt rims/Opx rims (M2 stage) } \\
\hline Grt4-50 Opx1-5 Bt3 Pl2-6 & 0.061 & 0.372 & 0.552 & 0.032 & 872 & 8.4 \\
\hline Grt4-2 Opx2-1 Bt3 PI1-2 & 0.071 & 0.4 & 0.575 & 0.033 & 904 & 9.8 \\
\hline Grt4-48 Opx3-3 Bt3 PI2-6 & 0.067 & 0.383 & 0.572 & 0.032 & 866 & 9.1 \\
\hline Grt4-2 Opx1-5 Bt3 PI1-4 & 0.071 & 0.397 & 0.579 & 0.032 & 880 & 9.4 \\
\hline Grt4-51 Opx3-8 Bt3 PI2-6 & 0.062 & 0.356 & 0.565 & 0.026 & 801 & 7.8 \\
\hline Average & & & & & 864.6 & 8.9 \\
\hline standard deviation & & & & & 38.4 & 0.8 \\
\hline \multicolumn{7}{|l|}{ garnet granulite (sample 6B1A) } \\
\hline \multicolumn{7}{|c|}{ Grt cores/high-Al Opx cores (M1 stage) } \\
\hline Grt2-9 Opx2-4 Bt2 PI8-3 & 0.156 & 0.337 & 0.557 & 0.021 & 900 & 12.10 \\
\hline Grt2-7 Opx2-7 Bt2 Pl8-4 & 0.157 & 0.334 & 0.552 & 0.021 & 902 & 11.9 \\
\hline Grt3-26 Opx3-6 Bt2 PI6-6 & 0.158 & 0.324 & 0.547 & 0.021 & 897 & 11.99 \\
\hline Grt1-6 Opx6-6 Bt2 PI7-7 & 0.153 & 0.339 & 0.56 & 0.02 & 881 & 11.35 \\
\hline Grt2-20 Opx1-2 Bt2 Pl8-4 & 0.16 & 0.336 & 0.562 & 0.02 & 887 & 11.89 \\
\hline Grt2-20 Opx2-4 Bt2 Pl8-4 & 0.156 & 0.334 & 0.557 & 0.02 & 887 & 11.88 \\
\hline Grt2-8 Opx1-6 Bt2 PI8-4 & 0.16 & 0.338 & 0.558 & 0.021 & 902 & 12.15 \\
\hline Average & & & & & 893.7 & 11.9 \\
\hline standard deviation & & & & & 8.6 & 0.3 \\
\hline \multicolumn{7}{|l|}{ garnet granulite (sample 6B1C) } \\
\hline Grt5-17 Opx10-1 Bt2 PI2-7 & 0.161 & 0.337 & 0.571 & 0.02 & 872 & 11.97 \\
\hline Grt6-7 Opx2-4 Bt2 PI3-3 & 0.153 & 0.345 & 0.563 & 0.022 & 892 & 11.54 \\
\hline Average & & & & & 882.0 & 11.8 \\
\hline standard deviation & & & & & 14.1 & 0.3 \\
\hline \multicolumn{7}{|l|}{ Grt rims/Opx rims (M2 stage) } \\
\hline \multicolumn{7}{|l|}{ garnet granulite (sample 6B1A) } \\
\hline Grt2-25 Opx2-6 Bt3 PI8-5 & 0.156 & 0.34 & 0.578 & 0.018 & 838 & 11.13 \\
\hline Grt2-16 Opx2-5 Bt3 PI8-1 & 0.157 & 0.339 & 0.569 & 0.019 & 866 & 11.57 \\
\hline Grt3-35 Opx3-9 Bt3 PI6-1 & 0.155 & 0.329 & 0.578 & 0.016 & 806 & 10.54 \\
\hline Grt1-10 Opx6-2 Bt3 PI7-1 & 0.154 & 0.339 & 0.57 & 0.019 & 851 & 11.02 \\
\hline Grt2-24 Opx1-8 Bt3 PI8-5 & 0.159 & 0.323 & 0.576 & 0.016 & 803 & 10.53 \\
\hline Average & & & & & 832.8 & 11.0 \\
\hline standard deviation & & & & & 27.7 & 0.4 \\
\hline \multicolumn{7}{|l|}{ garnet granulite (sample 6B1C) } \\
\hline Grt5-30 Opx10-2 Bt3 PI2-1 & 0.156 & 0.329 & 0.583 & 0.016 & 798 & 10.57 \\
\hline Grt6-10 Opx2-1 Bt3 PI3-4 & 0.159 & 0.305 & 0.584 & 0.013 & 738 & 9.6 \\
\hline Average & & & & & 768.0 & 10.1 \\
\hline standard deviation & & & & & 42.4 & 0.7 \\
\hline
\end{tabular}

$\mathrm{M} / \mathrm{FM}=\mathrm{Mg} /(\mathrm{Fe}+\mathrm{Mg}$ ); XAl Opx = Al cations (for a 6-oxygen formula) $/ 4$

Trclc and P rclc: temperature and pressure estimates using RCLC of Pattison et al. (2003) 
Temperature estimates using the Ti-in-zircon thermometer of Watson et al. (2006) in the different rock types

\begin{tabular}{|c|c|c|c|c|c|c|c|}
\hline grain/analysis & position & $\mathrm{Ti}(\mathrm{ppm})$ & $2 \sigma$ & $\mathbf{T}\left({ }^{\circ} \mathbf{C}\right) \mathrm{zrn}$ & error & Age & error \\
\hline \multicolumn{8}{|c|}{ stromatic garnet-biotite metatexite (sample 6D) } \\
\hline$z 6-1$ & c & 5.3 & 1.5 & 685.4 & 22.8 & 662 & 16 \\
\hline$z 10-1$ & c & 5.1 & 2.1 & 679.1 & 33.9 & 679 & 9 \\
\hline z86-1 & c & 7.2 & 1.9 & 710.5 & 22.3 & 661 & 9 \\
\hline$z 79-1$ & c & 8.4 & 1.8 & 724.3 & 18.5 & 650 & 8 \\
\hline$z 75-1$ & c & 8.7 & 3.4 & 723.1 & 35.0 & 651 & 9 \\
\hline$z 67-1$ & c & 18.1 & 4.9 & 793.0 & 27.0 & 703 & 9 \\
\hline z99-1 & sz & 5.8 & 1.2 & 693.9 & 16.8 & 616 & 6 \\
\hline $\mathrm{z} 2-2$ & sz & 7.7 & 1.3 & 717.6 & 14.3 & 606 & 6 \\
\hline$z 9-1$ & $\mathrm{sz}$ & 8 & 1.6 & 720.4 & 17.1 & 611 & 6 \\
\hline$z 10-2$ & sz & 7.1 & 2.7 & 706.5 & 32.8 & 606 & 7 \\
\hline$z 92-2$ & $\mathrm{sz}$ & 7.3 & 1.5 & 712.6 & 17.3 & 610 & 7 \\
\hline z21-1 & sz & 8.3 & 1.8 & 723.2 & 18.7 & 616 & 8 \\
\hline z31-1 & $\mathrm{sz}$ & 7.4 & 1.5 & 713.8 & 17.1 & 612 & 8 \\
\hline z49-1 & sz & 5.8 & 1.9 & 691.5 & 27.0 & 617 & 4 \\
\hline$z 16-1$ & sz & 6.6 & 1.4 & 704.2 & 17.6 & 616 & 11 \\
\hline$z 6-2$ & $r$ & 8.5 & 1.5 & 725.8 & 15.2 & 611 & 8 \\
\hline$z 10-3$ & $r$ & 9.3 & 1.7 & 733.5 & 16.0 & 615 & 9 \\
\hline z91-1 & $r$ & 7.8 & 2.6 & 715.6 & 28.9 & 613 & 7 \\
\hline z86-2 & $r$ & 6.5 & 1.5 & 702.7 & 19.1 & 612 & 9 \\
\hline$z 16-2$ & $r$ & 6.2 & 2.1 & 696.6 & 28.3 & 616 & 11 \\
\hline$z 79-2$ & $r$ & 7.2 & 1.7 & 711.0 & 19.9 & 609 & 11 \\
\hline$z 72-2$ & $r$ & 7.8 & 1.5 & 718.3 & 16.4 & 614 & 10 \\
\hline$z 67-2$ & $r$ & 8.8 & 1.9 & 728.2 & 18.8 & 615 & 5 \\
\hline$z 49-2$ & $r$ & 6.6 & 2.3 & 701.4 & 29.5 & 609 & 6 \\
\hline$z 71-2$ & $r$ & 5.8 & 2 & 691.1 & 28.5 & 642 & 7 \\
\hline \multicolumn{8}{|c|}{ (orthopyroxene)-garnet-bearing leucosome (sample 1A) } \\
\hline$z 105-1$ & $c$ & 5.8 & 1.7 & 692.3 & 24.0 & 692 & 6 \\
\hline$z 9-1$ & c & 8 & 1.8 & 720.0 & 19.3 & 702 & 7 \\
\hline$z 90-1$ & c & 6.5 & 2.3 & 700.0 & 29.9 & 659 & 7 \\
\hline$z 84-1$ & c & 4.8 & 1.7 & 676.1 & 28.5 & 759 & 14 \\
\hline$z 48-1$ & c & 7.6 & 2.2 & 714.4 & 24.8 & 661 & 7 \\
\hline z93-1 & $\mathrm{sz}$ & 8.3 & 1.8 & 723.2 & 18.7 & 609 & 5 \\
\hline z93-2 & $\mathrm{sz}$ & 7.8 & 2.1 & 717.0 & 23.1 & 610 & 8 \\
\hline z83-1 & sz & 6.3 & 1.5 & 700.0 & 19.6 & 621 & 8 \\
\hline z27-1 & sz & 8.3 & 1.2 & 724.2 & 12.4 & 614 & 8 \\
\hline$z 30-1$ & $\mathrm{sz}$ & 4.7 & 1.3 & 676.2 & 21.9 & 610 & 8 \\
\hline$z 34-1$ & $\mathrm{sz}$ & 4.6 & 1.3 & 674.4 & 22.3 & 616 & 7 \\
\hline$z 76-1$ & sz & 4.7 & 1.4 & 675.8 & 23.6 & 614 & 8 \\
\hline$z 40-1$ & sz & 6.9 & 1.7 & 707.3 & 20.7 & 612 & 7 \\
\hline z63-1 & sz & 6.4 & 1.4 & 701.6 & 18.0 & 615 & 5 \\
\hline$z 62-1$ & sz & 6.5 & 1.4 & 702.9 & 17.8 & 609 & 9 \\
\hline$z 61-1$ & $\mathrm{sz}$ & 6.7 & 1.3 & 705.7 & 16.1 & 607 & 8 \\
\hline$z 5-1$ & $r$ & 5.2 & 2 & 681.4 & 31.5 & 616 & 5 \\
\hline$z 7-2$ & $r$ & 8.9 & 1.5 & 729.9 & 14.6 & 619 & 6 \\
\hline$z 12-1$ & $r$ & 4.86 & 0.99 & 680.0 & 16.0 & 607 & 6 \\
\hline$z 28-1$ & $r$ & 5.8 & 1.9 & 691.5 & 27.0 & 616 & 8 \\
\hline$z 37-1$ & $r$ & 8.7 & 2.3 & 726.4 & 23.1 & 620 & 7 \\
\hline \multicolumn{8}{|c|}{ garnet-biotite gneiss (sample 9B) } \\
\hline $\mathrm{z} 15-1$ & c & 5.5 & 2.9 & 680.5 & 45.5 & 655 & 10 \\
\hline$z 25-1$ & c & 6.5 & 2 & 701.2 & 25.8 & 642 & 13 \\
\hline $\mathrm{z} 81-2$ & c & 5 & 1.5 & 680.5 & 24.0 & 642 & 16 \\
\hline$z 73-2$ & c & 7.4 & 3.2 & 708.2 & 38.0 & 652 & 19 \\
\hline$z 69-1$ & c & 5.7 & 3.4 & 679.6 & 53.2 & 644 & 15 \\
\hline$z 62-2$ & c & 7.7 & 2.1 & 715.9 & 23.4 & 643 & 16 \\
\hline$z 11-3$ & re & 6.8 & 2.3 & 704.1 & 28.7 & 653 & 10 \\
\hline$z 11-1$ & re & 8.1 & 1.7 & 721.3 & 18.0 & 603 & 11 \\
\hline$z 25-2$ & r & 7.4 & 1.8 & 713.1 & 20.6 & 610 & 11 \\
\hline $\mathrm{z} 62-1$ & re & 4.9 & 1.1 & 680.3 & 17.7 & 607 & 9 \\
\hline \multicolumn{8}{|c|}{ mafic granulite (sample $7 C$ ) } \\
\hline$z 7-3$ & c & 7.3 & 1.5 & 712.6 & 17.3 & 645 & 9 \\
\hline$z 101-2$ & c & 12.2 & 3.7 & 755.2 & 28.3 & 659 & 12 \\
\hline$z 79-1$ & c & 7.3 & 1.8 & 711.9 & 20.9 & 652 & 9 \\
\hline$z 79-2$ & c & 4.6 & 1.1 & 675.2 & 18.7 & 639 & 14 \\
\hline$z 101-1$ & re & 3.8 & 1.5 & 657.3 & 30.8 & 615 & 7 \\
\hline$z 14-1$ & $\mathrm{sb}$ & 6.3 & 1.8 & 699.1 & 23.7 & 610 & 7 \\
\hline$z 56-1$ & re & 6.9 & 1.7 & 707.3 & 20.7 & 610 & 9 \\
\hline
\end{tabular}

$\mathrm{T}\left({ }^{\circ} \mathrm{C}\right)_{\mathrm{Zrn}=}$ Ti-in-zircon temperature calculated using the calibration of Wat son et al. (2006)

c: core; r: rim; sz: sector-zoned; sb: soccerball; re: recrystallized. 
Temperature estimates using the Ti-in-zircon thermometer of Watson et al. (2006) in the different rock types

\begin{tabular}{|c|c|c|c|c|c|c|c|}
\hline grain/analysis & position & $\mathrm{Ti}(\mathrm{ppm})$ & $2 \sigma$ & $\mathrm{T}\left({ }^{\circ} \mathbf{C}\right) \mathrm{zrn}$ & error & Age & error \\
\hline \multicolumn{8}{|c|}{ Felsic granulite (sample 5B 1) } \\
\hline$z 70-1 c$ & c & 5.9 & 1.9 & 697 & 53.2 & 663 & 9 \\
\hline z69-3re & re & 7.2 & 1.8 & 713 & 42.2 & 639 & 9 \\
\hline$z 69-1 c$ & $c$ & 7.4 & 1.5 & 715 & 34.2 & 662 & 8 \\
\hline z68-2re & re & 9.5 & 2.3 & 737 & 42.8 & 659 & 11 \\
\hline$z 68-1 c$ & $\mathrm{c}$ & 5.4 & 2 & 690 & 60.9 & 657 & 9 \\
\hline$z 7-3 c$ & c & 6 & 1.7 & 698 & 46.7 & 663 & 7 \\
\hline$z 10-2$ re & re & 8.2 & 1.5 & 724 & 31.4 & 626 & 7 \\
\hline$z 10-1 c$ & $\mathrm{c}$ & 8.3 & 1.5 & 725 & 31.0 & 679 & 8 \\
\hline$z 20-1 c$ & c & 8.5 & 1.6 & 727 & 32.5 & 647 & 8 \\
\hline z20-2re & re & 8 & 1.7 & 722 & 36.4 & 646 & 11 \\
\hline z23-1re & re & 7.7 & 1.9 & 719 & 42.2 & 650 & 9 \\
\hline$z 23-2 c$ & c & 9 & 1.9 & 732 & 36.9 & 650 & 9 \\
\hline$z 49-1 c$ & c & 5.5 & 2 & 691 & 59.9 & 658 & 10 \\
\hline z26-2re & re & 6 & 1.8 & 698 & 49.5 & 659 & 12 \\
\hline$z 26-1 c$ & c & 8.3 & 2 & 725 & 41.7 & 655 & 8 \\
\hline z31-2re & re & 8.3 & 1.9 & 725 & 39.5 & 673 & 10 \\
\hline$z 31-1 c$ & $c$ & 6.3 & 1.9 & 702 & 50.2 & 653 & 9 \\
\hline$z 32-2 c$ & c & 6 & 1.8 & 698 & 49.5 & 655 & 10 \\
\hline$z 32-1 c$ & c & 10 & 1.5 & 741 & 26.5 & 653 & 9 \\
\hline$z 39-1 c$ & c & 7.2 & 1.2 & 713 & 27.9 & 652 & 7 \\
\hline \multicolumn{8}{|c|}{ Felsic granulite (sample A 1) } \\
\hline$z 1-2 r$ & $r$ & 8.9 & 1.9 & 730.9 & 37.2 & 649 & 10 \\
\hline$z 1-1 c$ & c & 6.9 & 2 & 709.4 & 48.9 & 643 & 12 \\
\hline $\mathrm{z} 61-1 \mathrm{c}$ & c & 7.9 & 1.9 & 720.7 & 41.2 & 643 & 9 \\
\hline$z 61-2 r$ & $r$ & 6.3 & 1.8 & 702.0 & 47.5 & 636 & 9 \\
\hline$z 58-1 c$ & c & 10.1 & 2.2 & 741.9 & 38.8 & 655 & 8 \\
\hline$z 10-1 c$ & c & 9.5 & 1.3 & 736.6 & 24.0 & 656 & 7 \\
\hline$z 12-1 c$ & c & 9.1 & 1.9 & 732.8 & 36.5 & 692 & 13 \\
\hline$z 17-1 c$ & c & 8.8 & 1.5 & 729.9 & 29.5 & 657 & 13 \\
\hline$z 18-1 c$ & c & 7.7 & 3.3 & 718.6 & 75.8 & 648 & 13 \\
\hline$z 25-1 c$ & c & 10.8 & 2.3 & 747.9 & 38.4 & 653 & 13 \\
\hline$z 25-2 c$ & c & 10.2 & 2.1 & 742.8 & 36.7 & 650 & 14 \\
\hline z34-2c & c & 7.9 & 1.7 & 720.7 & 36.8 & 702 & 12 \\
\hline \multicolumn{8}{|c|}{ Garnet granulite granulite (sample 6B 1) } \\
\hline$z 57-1 c$ & c & 8.5 & 2.8 & 727 & 58.0 & 695 & 12 \\
\hline$z 54-2 c$ & c & 8.8 & 1.8 & 730 & 35.6 & 655 & 9 \\
\hline$z 54-1 c$ & c & 10.1 & 3.7 & 742 & 66.9 & 719 & 11 \\
\hline $\mathrm{z8}-1 \mathrm{dm}$ & $\mathrm{dm}$ & 6.7 & 2.4 & 707 & 60.9 & 627 & 8 \\
\hline$z 8-2 d m$ & $\mathrm{dm}$ & 4.9 & 1.4 & 682 & 45.5 & 624 & 8 \\
\hline$z 16-1 r$ & $r$ & 7.9 & 2.1 & 721 & 45.7 & 611 & 14 \\
\hline$z 17-1 r$ & $r$ & 8.6 & 1.3 & 728 & 26.0 & 656 & 13 \\
\hline$z 17-2 c$ & c & 4.5 & 1.9 & 675 & 68.3 & 622 & 8 \\
\hline$z 18-2 c$ & c & 6.7 & 1.1 & 707 & 27.2 & 652 & 8 \\
\hline$z 18-1 c$ & c & 8.2 & 2.4 & 724 & 50.9 & 692 & 9 \\
\hline$z 20-1 c$ & c & 10.4 & 1.7 & 745 & 29.1 & 668 & 10 \\
\hline$z 20-2 r$ & $r$ & 9.1 & 1.9 & 733 & 36.5 & 606 & 11 \\
\hline z33-2c & c & 8.2 & 2.6 & 724 & 55.3 & 680 & 10 \\
\hline
\end{tabular}




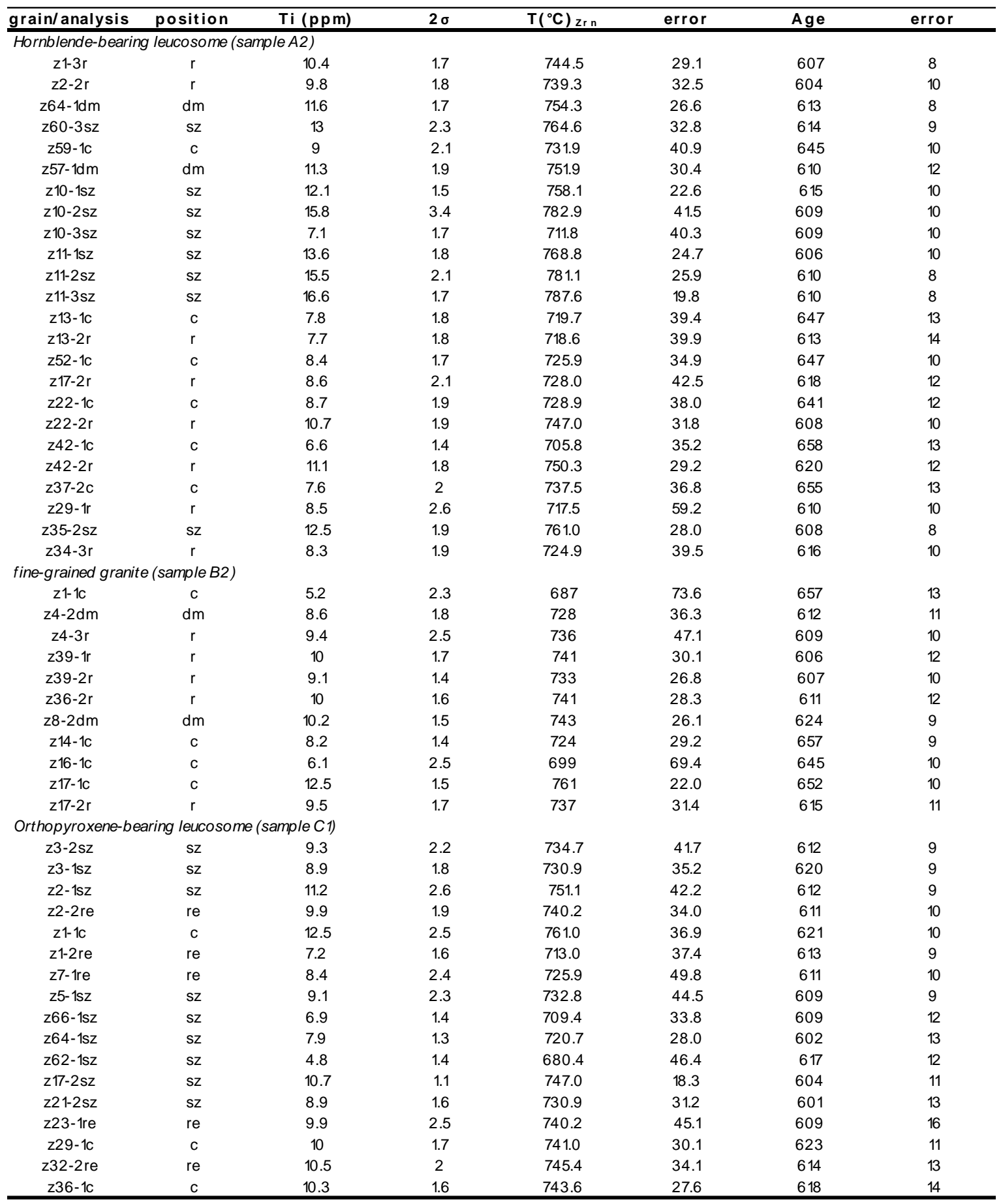




\section{ANEXO V}

Análises de geoquímica de rocha-total de elementos maiores, menores (FRX) e traço (ICP-MS) 


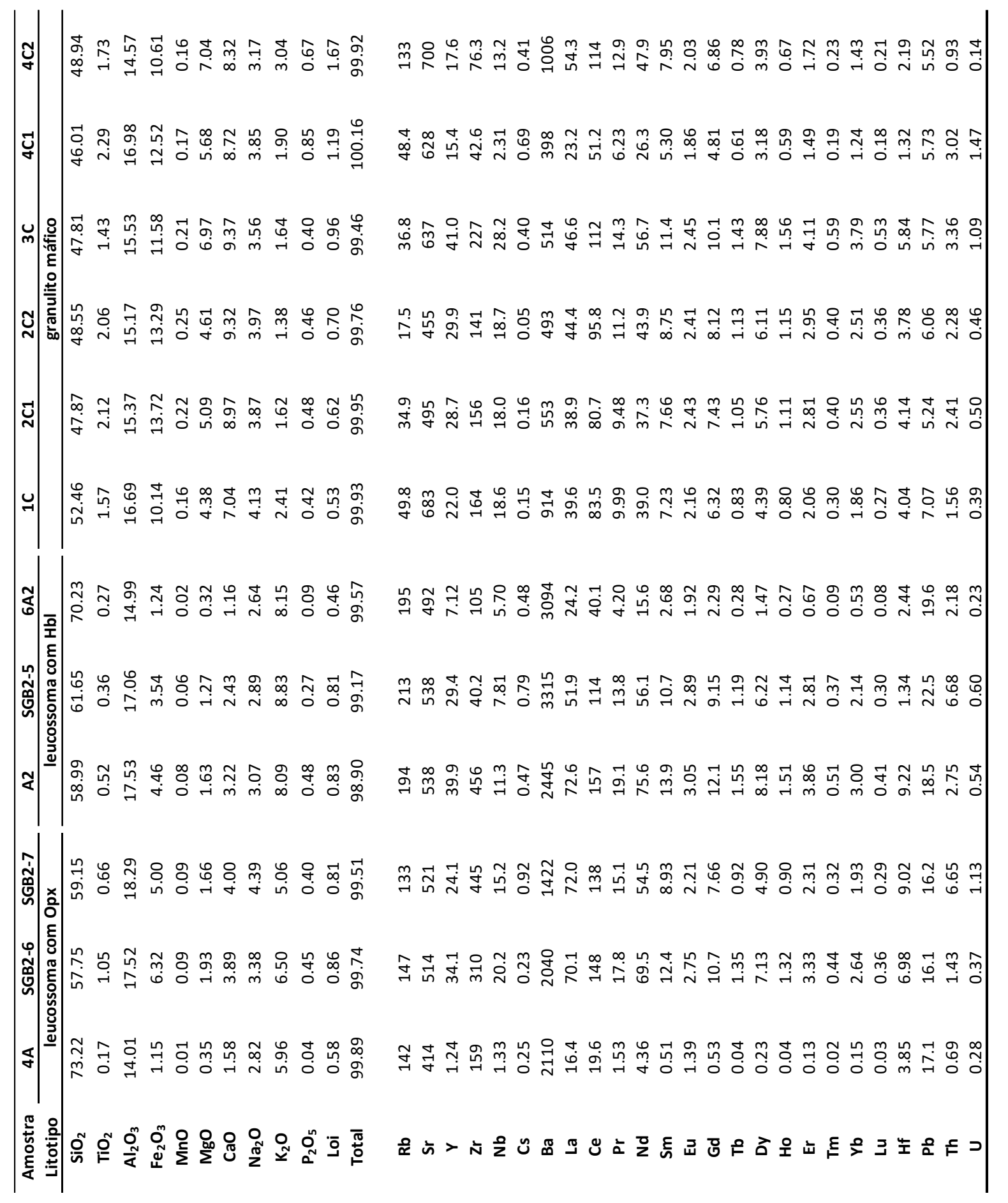




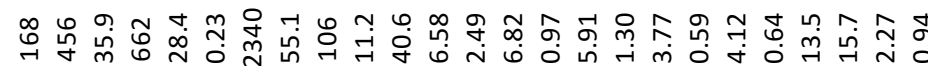

花

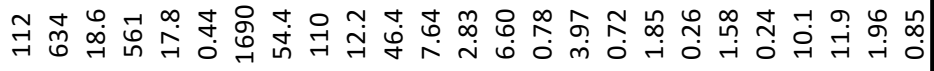

นี

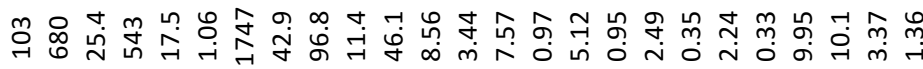

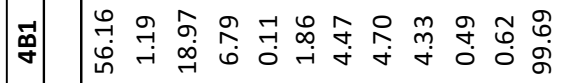

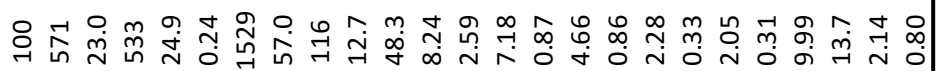

六

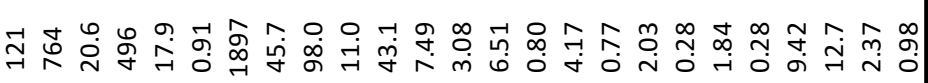

ન્ન

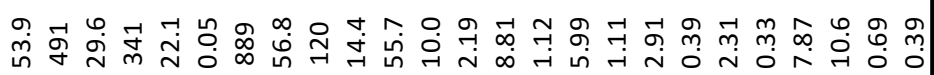

ज्ञ.

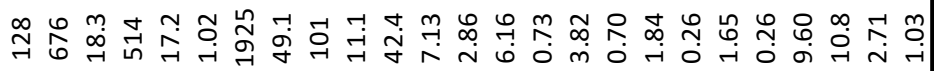

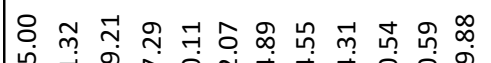

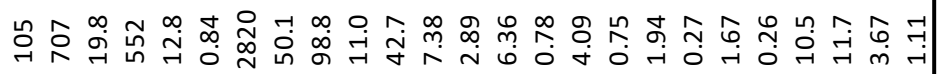

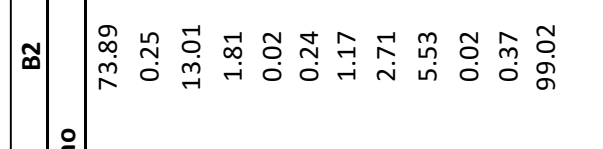

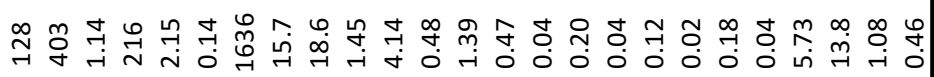

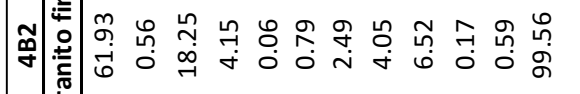

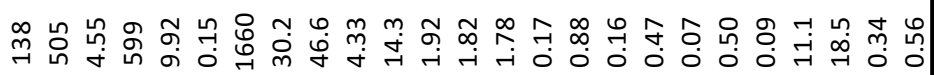

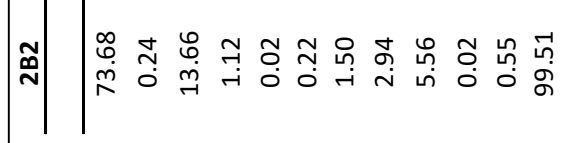

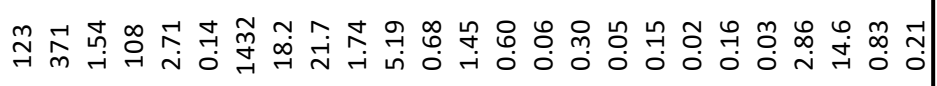

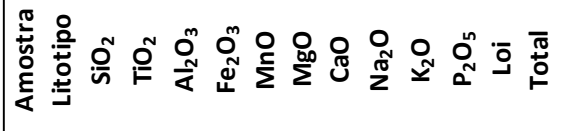

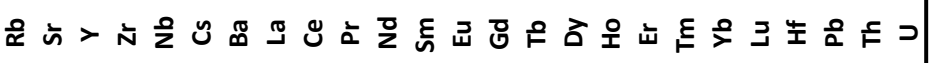




\section{ANEXO VI}

Análises isotópicas de Sr e Nd em rocha-total (ICP-MS) 


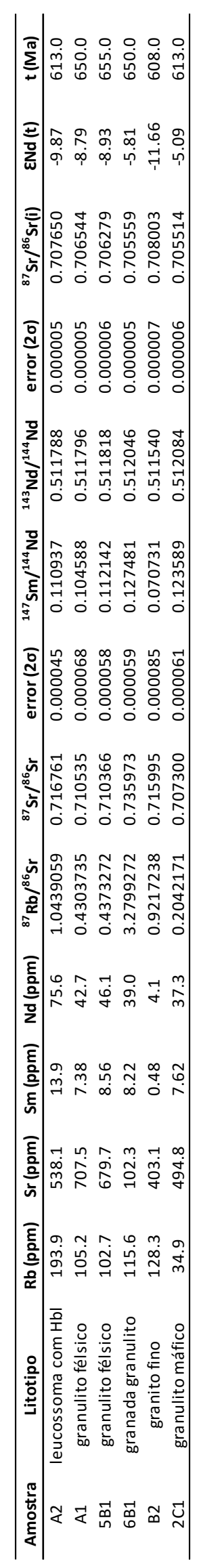




\section{ANEXO VII}

Análises in-situ de elementos-traço em zircão e granada obtidas através de LA-ICP-MS 


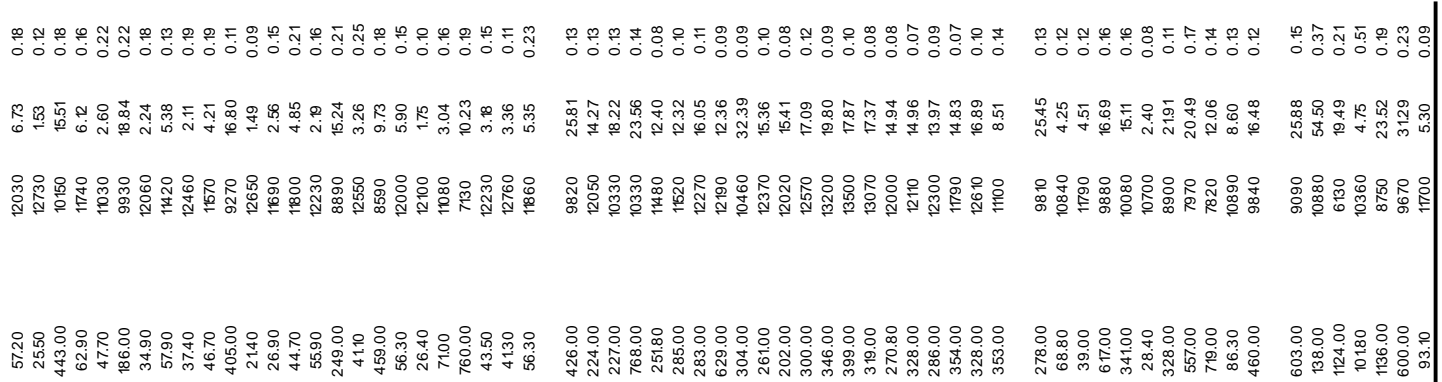

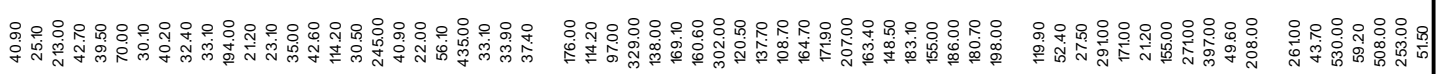

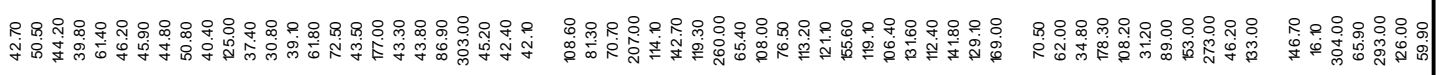

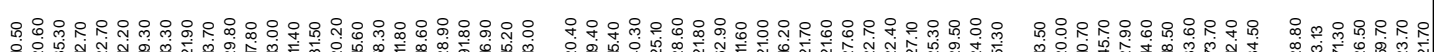

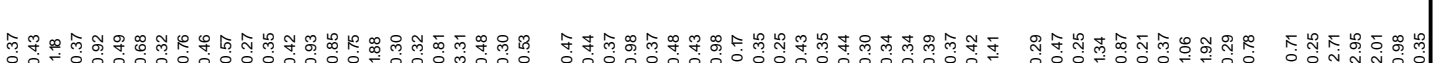

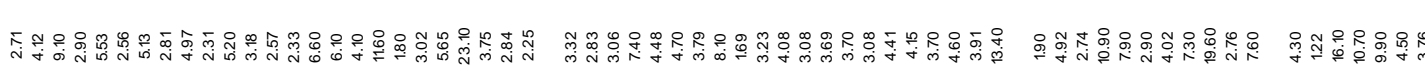

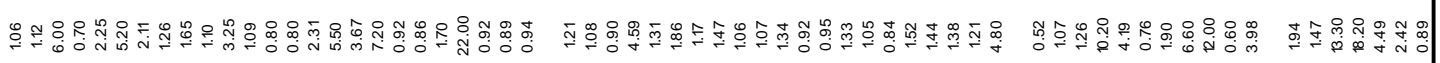

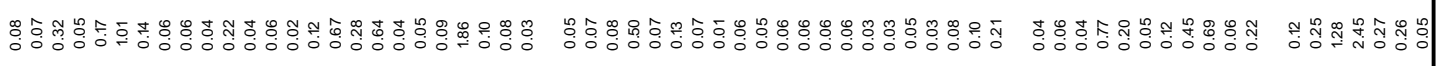

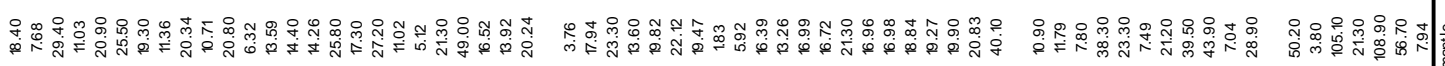

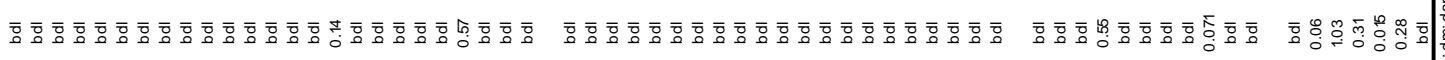

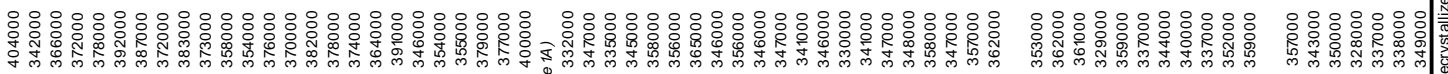

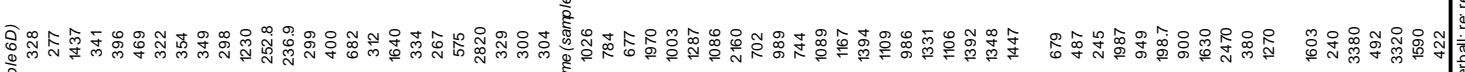
衰

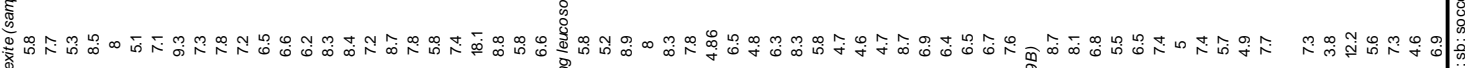
竞 


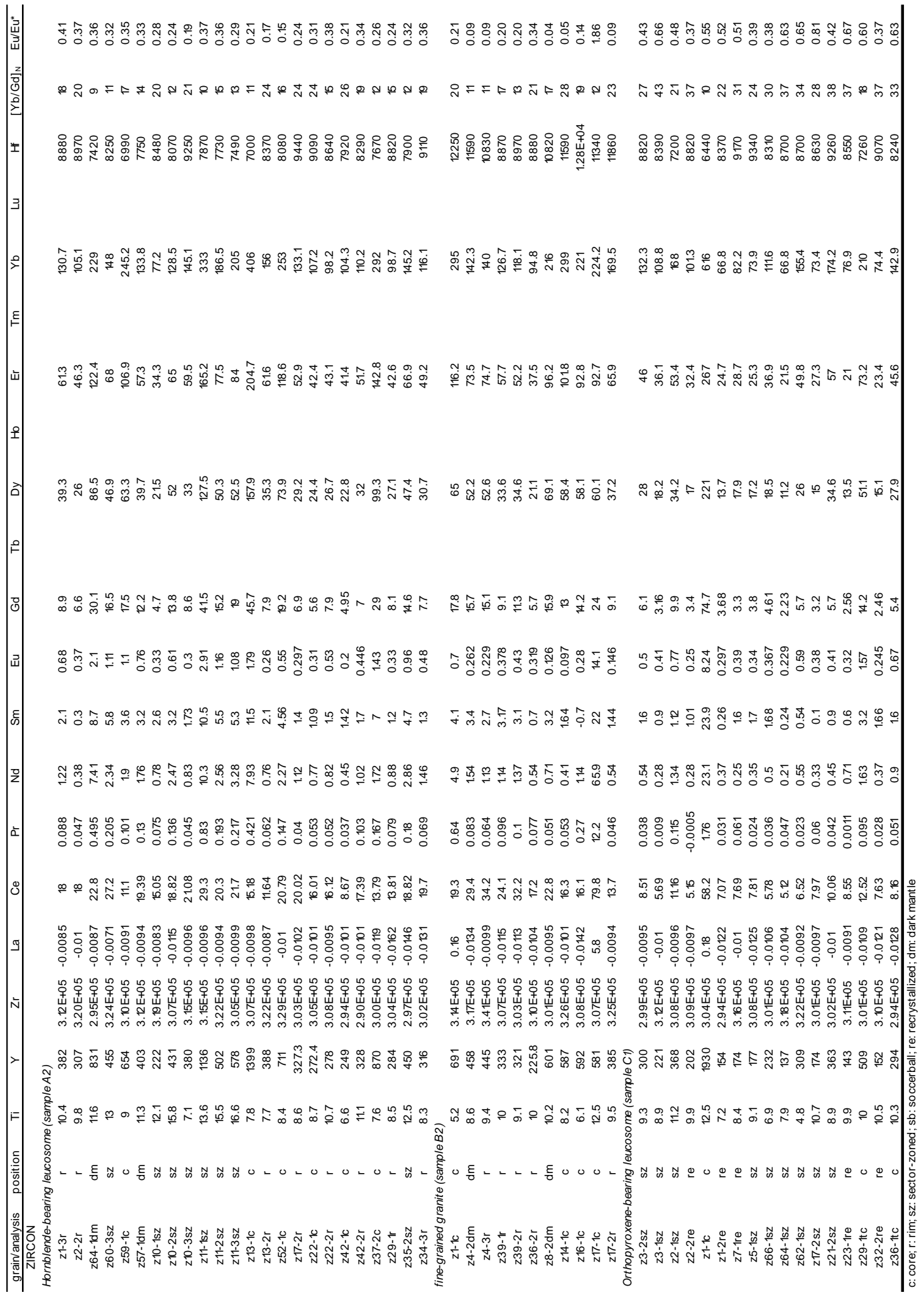




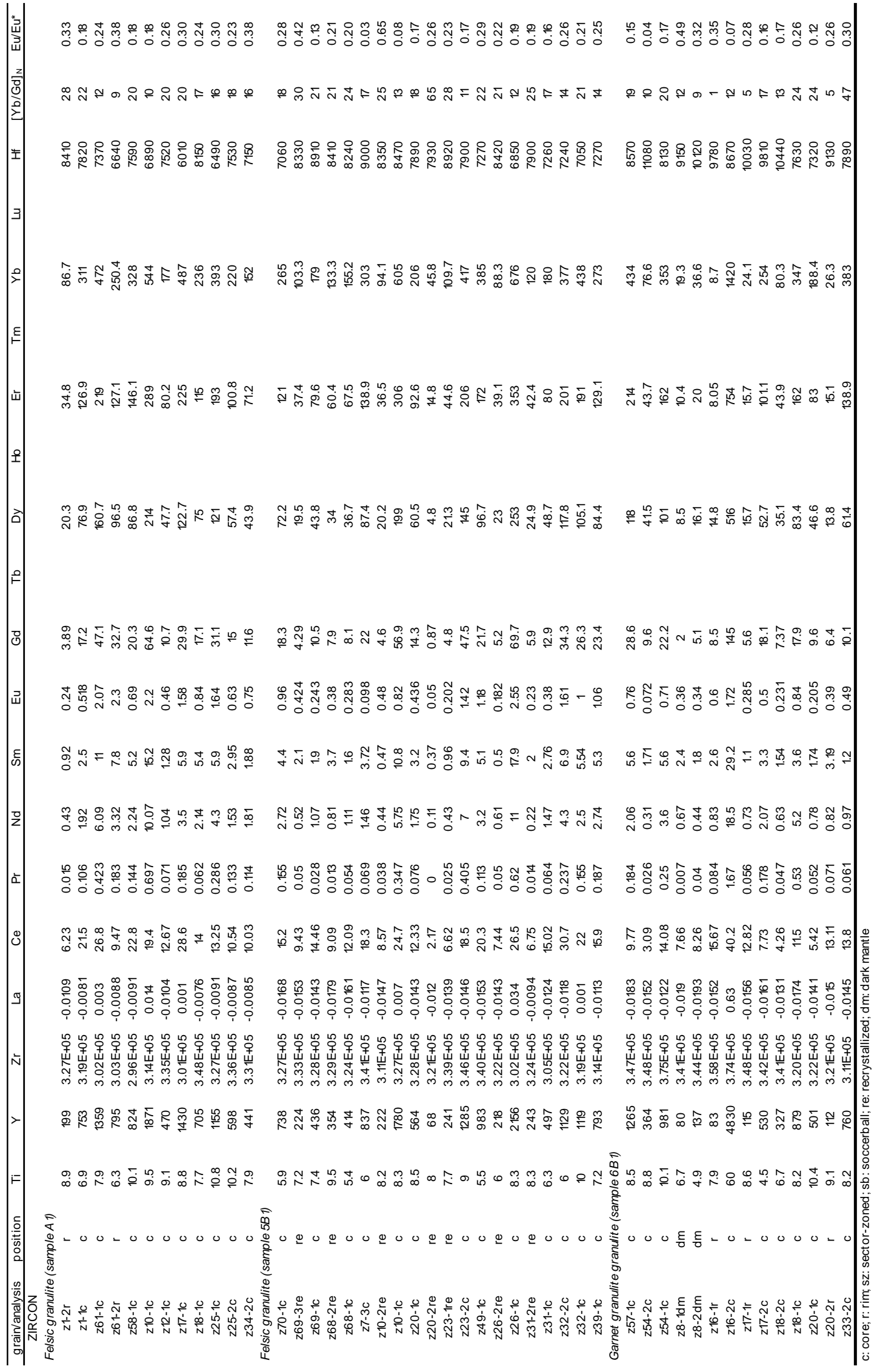




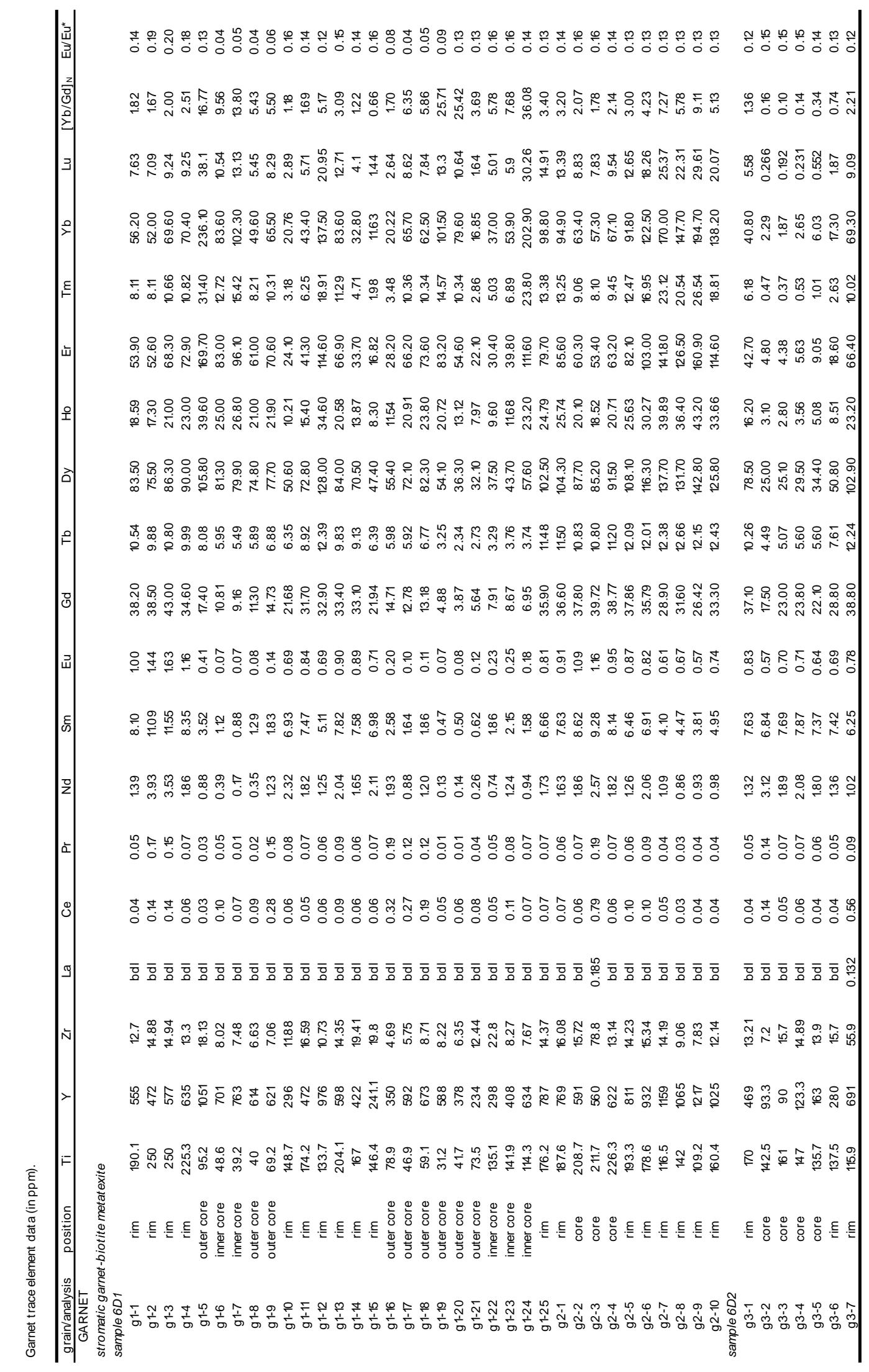




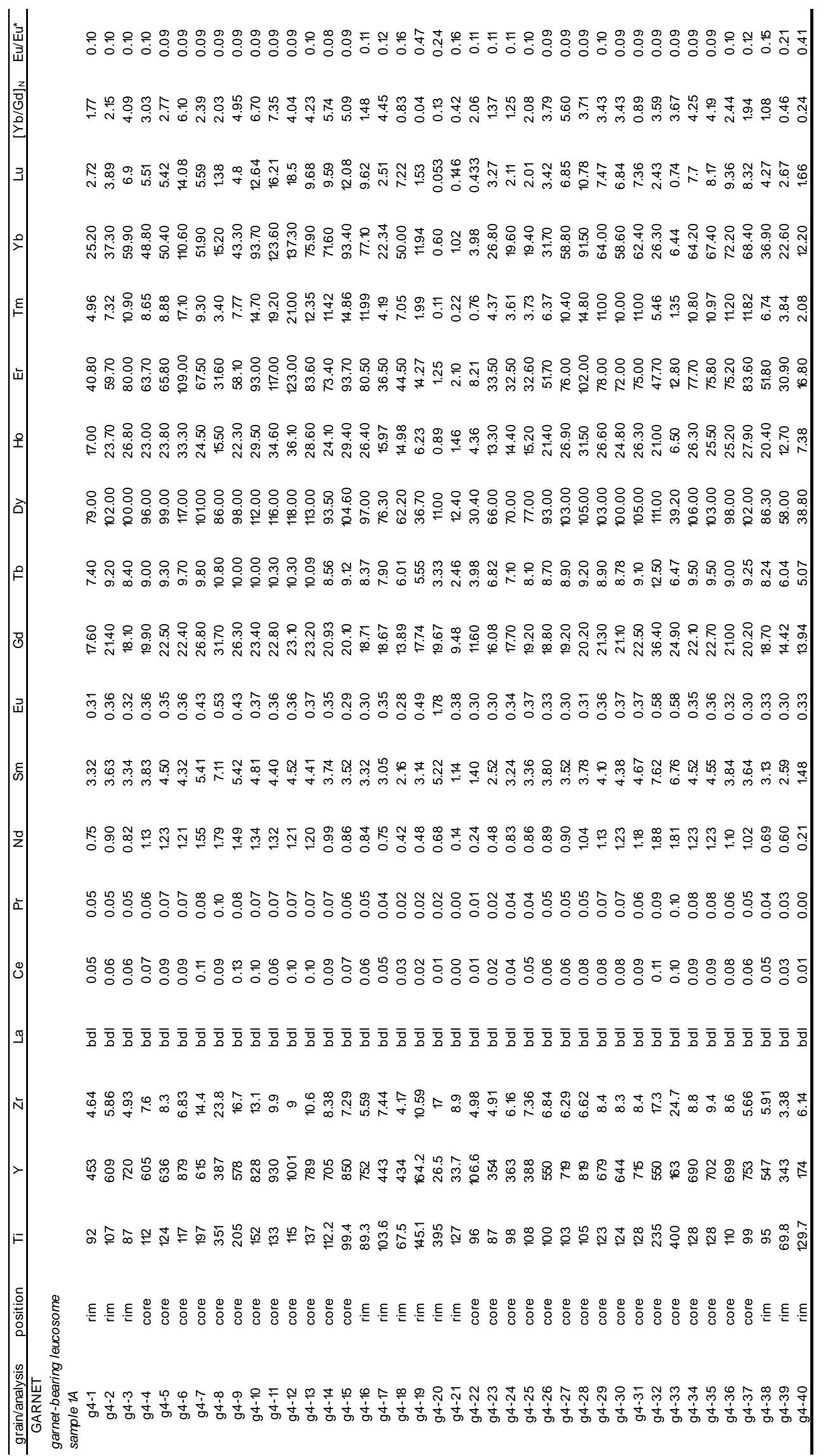




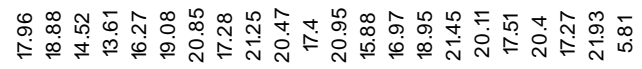

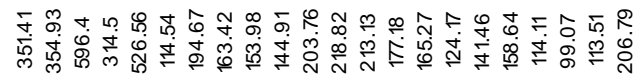
ตดg

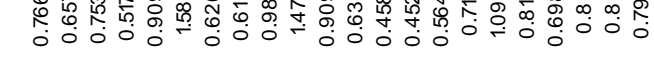

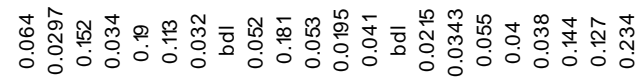

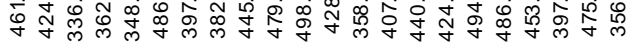

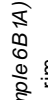

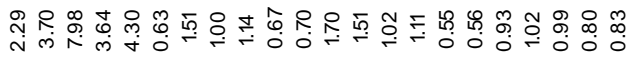

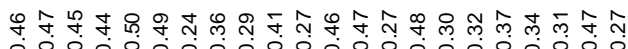

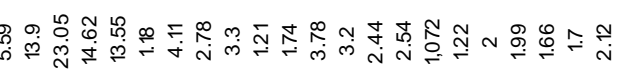

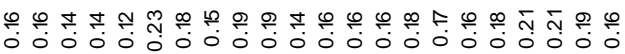

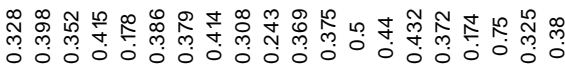

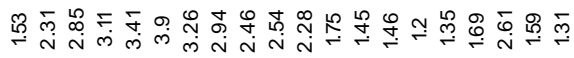

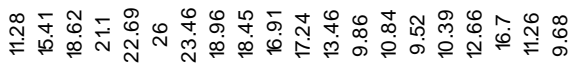
员

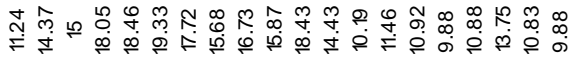

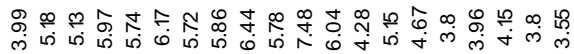

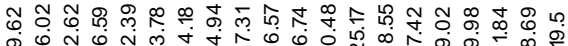

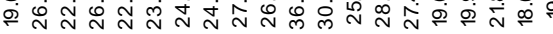

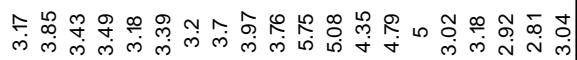

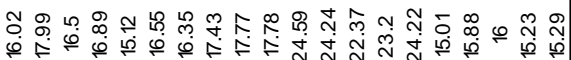

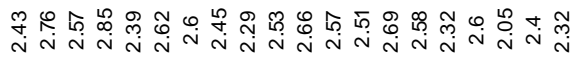

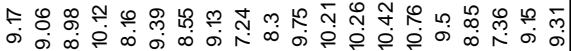

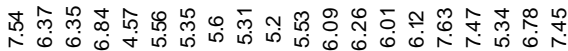

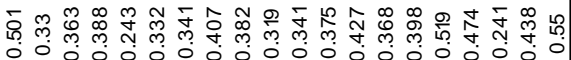

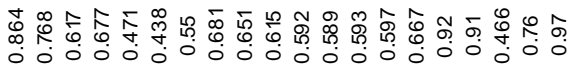

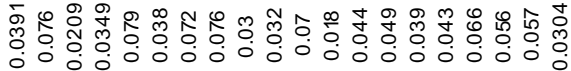

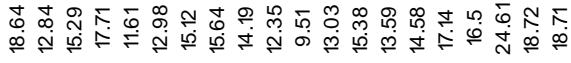

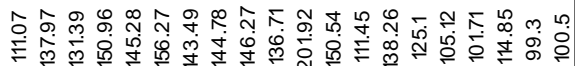

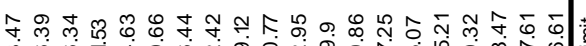

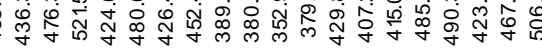
o

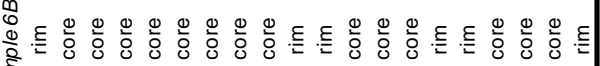

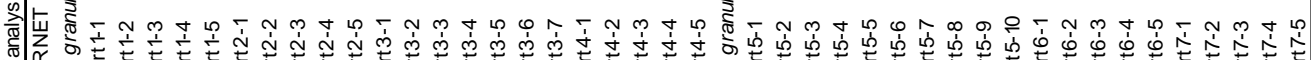

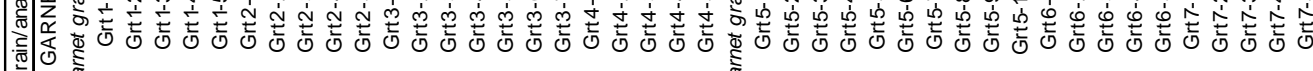
잉 


\section{ANEXO VIII}

Análises de U-Pb em zircão obtidas por LA-ICP-MS 


\begin{tabular}{|c|c|c|c|c|c|c|c|c|c|c|c|c|c|c|}
\hline \multirow{2}{*}{$\begin{array}{l}\text { grain/spot } \\
\text { position }\end{array}$} & \multirow{2}{*}{$\begin{array}{c}\mathrm{U} \\
\mathrm{ppm}\end{array}$} & \multirow{2}{*}{$\begin{array}{c}\text { Th } \\
\mathrm{ppm}\end{array}$} & \multirow[t]{2}{*}{$T h / U$} & \multicolumn{6}{|c|}{ Isotopic ratios } & \multirow[b]{2}{*}{${ }^{206} \mathrm{~Pb} /{ }^{238} \mathrm{U}$} & \multicolumn{3}{|c|}{ Ages (in Ma) $)^{a}$} & \multirow{2}{*}{$\begin{array}{c}\begin{array}{c}\text { Discord } \\
\text { ance }^{\mathrm{b}} \\
\text { (\%) }\end{array}\end{array}$} \\
\hline & & & & ${ }^{206} \mathrm{~Pb} /{ }^{238} \mathrm{U}$ & $2 \sigma$ & ${ }^{207} \mathrm{~Pb} /{ }^{235} \mathrm{U}$ & $2 \sigma$ & ${ }^{207} \mathrm{~Pb} /{ }^{206} \mathrm{~Pb}$ & $2 \sigma$ & & $2 \sigma$ & ${ }^{207} \mathrm{~Pb} /{ }^{206} \mathrm{~Pb}$ & $2 \sigma$ & \\
\hline \multicolumn{15}{|c|}{$\begin{array}{l}\text { stromatic garnet-biotite } \\
\text { metatexite (sample } 6 D \text { ) }\end{array}$} \\
\hline 8-sz2 & 921 & 183.3 & 0.20 & 0.0969 & 0.0010 & 0.8062 & 0.0095 & 0.0599 & 0.0008 & 596 & 6 & 601 & 30 & 0.68 \\
\hline $50-s z 3$ & 334 & 108.6 & 0.33 & 0.0977 & 0.0006 & 0.8114 & 0.0097 & 0.0600 & 0.0008 & 601 & 4 & 606 & 29 & 0.48 \\
\hline $72-s z 2$ & 572 & 184 & 0.32 & 0.0980 & 0.0016 & 0.8140 & 0.0170 & 0.0601 & 0.0014 & 603 & 10 & 626 & 52 & 0.48 \\
\hline $51-\mathrm{sz} 1$ & 449 & 136.1 & 0.30 & 0.0983 & 0.0007 & 0.8131 & 0.0091 & 0.0600 & 0.0008 & 605 & 4 & 600 & 30 & 0.00 \\
\hline $50-s z 2$ & 127.6 & 52.5 & 0.41 & 0.0987 & 0.0012 & 0.8260 & 0.0190 & 0.0604 & 0.0013 & 607 & 7 & 617 & 48 & 0.87 \\
\hline 23-sz2 & 407 & 138.5 & 0.34 & 0.0987 & 0.0014 & 0.8210 & 0.0210 & 0.0602 & 0.0015 & 607 & 8 & 622 & 52 & 0.18 \\
\hline 38-sz2 & 353 & 202.1 & 0.57 & 0.0988 & 0.0009 & 0.8180 & 0.0110 & 0.0600 & 0.0009 & 607 & 5 & 604 & 32 & -0.15 \\
\hline $57-s z 3$ & 285 & 134.8 & 0.47 & 0.0991 & 0.0009 & 0.8250 & 0.0120 & 0.0603 & 0.0010 & 609 & 5 & 612 & 36 & 0.18 \\
\hline 90-r1 & 167.7 & 76 & 0.45 & 0.0993 & 0.0011 & 0.8320 & 0.0170 & 0.0602 & 0.0012 & 610 & 7 & 618 & 44 & 0.60 \\
\hline 9-sz1 & 380 & 217 & 0.57 & 0.0994 & 0.0011 & 0.8220 & 0.0130 & 0.0604 & 0.0008 & 611 & 6 & 618 & 30 & -0.28 \\
\hline 6-r1 & 101.8 & 41.7 & 0.41 & 0.0994 & 0.0014 & 0.8340 & 0.0250 & 0.0602 & 0.0020 & 611 & 8 & 613 & 71 & 0.68 \\
\hline $34-s z 2$ & 200.9 & 84.2 & 0.42 & 0.0995 & 0.0011 & 0.8280 & 0.0170 & 0.0607 & 0.0012 & 612 & 7 & 627 & 45 & 0.03 \\
\hline 51-sz2 & 331 & 163.7 & 0.49 & 0.0996 & 0.0007 & 0.8210 & 0.0110 & 0.0598 & 0.0009 & 612 & 4 & 596 & 31 & -0.58 \\
\hline 90-sz2 & 231.4 & 117.5 & 0.51 & 0.0996 & 0.0012 & 0.8230 & 0.0130 & 0.0603 & 0.0011 & 612 & 7 & 611 & 38 & -0.26 \\
\hline $57-s z 2$ & 432.9 & 104.7 & 0.24 & 0.0998 & 0.0007 & 0.8241 & 0.0092 & 0.0601 & 0.0008 & 613 & 4 & 608 & 28 & -0.51 \\
\hline $56-s z 2$ & 298.4 & 137.9 & 0.46 & 0.0999 & 0.0008 & 0.8242 & 0.0100 & 0.0603 & 0.0008 & 614 & 5 & 611 & 28 & -0.59 \\
\hline 38-sz1 & 552 & 152.3 & 0.28 & 0.0999 & 0.0008 & 0.8300 & 0.0110 & 0.0604 & 0.0009 & 614 & 5 & 624 & 32 & -0.03 \\
\hline 68-sz2 & 374 & 123.6 & 0.33 & 0.0999 & 0.0008 & 0.8290 & 0.0110 & 0.0601 & 0.0009 & 614 & 4 & 601 & 31 & -0.18 \\
\hline 72-r1 & 125 & 57.5 & 0.46 & 0.1000 & 0.0017 & 0.8300 & 0.0250 & 0.0596 & 0.0016 & 614 & 10 & 577 & 58 & -0.33 \\
\hline 84-r1 & 142.3 & 70.8 & 0.50 & 0.1000 & 0.0015 & 0.8400 & 0.0210 & 0.0603 & 0.0016 & 614 & 9 & 608 & 54 & 0.61 \\
\hline 89-r1 & 385 & 89.1 & 0.23 & 0.1000 & 0.0012 & 0.8290 & 0.0150 & 0.0605 & 0.0010 & 615 & 7 & 616 & 36 & -0.29 \\
\hline 67-sz2 & 236.4 & 104.7 & 0.44 & 0.1001 & 0.0008 & 0.8370 & 0.0110 & 0.0608 & 0.0009 & 615 & 5 & 630 & 34 & 0.61 \\
\hline 89-sz2 & 810 & 231 & 0.29 & 0.1002 & 0.0010 & 0.8267 & 0.0100 & 0.0600 & 0.0008 & 615 & 6 & 601 & 29 & -0.62 \\
\hline 8-sz1 & 276 & 95.4 & 0.35 & 0.1002 & 0.0009 & 0.8380 & 0.0110 & 0.0604 & 0.0010 & 616 & 5 & 617 & 33 & 0.39 \\
\hline 21-sz3 & 444 & 158.1 & 0.36 & 0.1002 & 0.0014 & 0.8320 & 0.0180 & 0.0604 & 0.0013 & 616 & 8 & 610 & 47 & -0.23 \\
\hline 99-sz2 & 214.4 & 105.2 & 0.49 & 0.1003 & 0.0010 & 0.8360 & 0.0140 & 0.0603 & 0.0012 & 616 & 6 & 615 & 42 & 0.06 \\
\hline 18-sz2 & 259 & 115.8 & 0.45 & 0.1004 & 0.0015 & 0.8410 & 0.0240 & 0.0607 & 0.0015 & 617 & 9 & 625 & 51 & 0.24 \\
\hline 52-r1 & 118.7 & 47 & 0.40 & 0.1004 & 0.0010 & 0.8330 & 0.0170 & 0.0603 & 0.0013 & 617 & 6 & 610 & 47 & -0.23 \\
\hline 19-sz2 & 358 & 76.2 & 0.21 & 0.1005 & 0.0016 & 0.8340 & 0.0180 & 0.0605 & 0.0012 & 617 & 9 & 616 & 45 & -0.31 \\
\hline 36-r1 & 178.4 & 88 & 0.49 & 0.1005 & 0.0009 & 0.8360 & 0.0140 & 0.0605 & 0.0011 & 617 & 5 & 619 & 40 & 0.08 \\
\hline 49-sz2 & 376 & 214.4 & 0.57 & 0.1005 & 0.0007 & 0.8384 & 0.0100 & 0.0604 & 0.0008 & 617 & 4 & 618 & 30 & 0.18 \\
\hline $18-s z 1$ & 681 & 803 & 1.18 & 0.1006 & 0.0015 & 0.8380 & 0.0200 & 0.0607 & 0.0013 & 618 & 9 & 629 & 48 & -0.10 \\
\hline $40-s z 3$ & 309 & 145.9 & 0.47 & 0.1006 & 0.0007 & 0.8300 & 0.0100 & 0.0603 & 0.0008 & 618 & 4 & 617 & 30 & -0.54 \\
\hline $40-s z 2$ & 228.9 & 108.3 & 0.47 & 0.1007 & 0.0010 & 0.8410 & 0.0160 & 0.0605 & 0.0012 & 619 & 6 & 613 & 42 & 0.10 \\
\hline 25-c1 & 577 & 313 & 0.54 & 0.1046 & 0.0019 & 0.8890 & 0.0260 & 0.0616 & 0.0014 & 641 & 11 & 671 & 50 & 0.62 \\
\hline 71-c1 & 1245 & 44.2 & 0.04 & 0.1047 & 0.0012 & 0.8760 & 0.0150 & 0.0612 & 0.0010 & 642 & 7 & 647 & 36 & -0.55 \\
\hline 79-c1 & 371 & 333 & 0.90 & 0.1060 & 0.0014 & 0.8910 & 0.0200 & 0.0609 & 0.0011 & 650 & 8 & 638 & 41 & -0.40 \\
\hline 56-c1 & 382 & 137 & 0.36 & 0.1061 & 0.0013 & 0.9100 & 0.0200 & 0.0618 & 0.0009 & 650 & 8 & 670 & 34 & 0.91 \\
\hline 91-c1 & 368.4 & 66.5 & 0.18 & 0.1061 & 0.0013 & 0.8930 & 0.0140 & 0.0614 & 0.0010 & 650 & 8 & 653 & 35 & -0.39 \\
\hline $75-c 1$ & 130 & 61.9 & 0.48 & 0.1063 & 0.0016 & 0.9040 & 0.0200 & 0.0616 & 0.0011 & 651 & 9 & 651 & 40 & 0.34 \\
\hline $19-\mathrm{c} 4$ & 203.3 & 108.1 & 0.53 & 0.1067 & 0.0015 & 0.8930 & 0.0210 & 0.0612 & 0.0013 & 654 & 9 & 637 & 45 & -0.85 \\
\hline $86-c 1$ & 268 & 150 & 0.56 & 0.1080 & 0.0015 & 0.9070 & 0.0200 & 0.0608 & 0.0012 & 661 & 9 & 627 & 44 & -0.93 \\
\hline 6-c1 & 272 & 201 & 0.74 & 0.1082 & 0.0027 & 0.9160 & 0.0240 & 0.0613 & 0.0010 & 662 & 16 & 647 & 34 & -0.46 \\
\hline 74-c1 & 383 & 182.9 & 0.48 & 0.1088 & 0.0023 & 0.9270 & 0.0330 & 0.0612 & 0.0016 & 666 & 14 & 643 & 56 & -0.30 \\
\hline 72-c1 & 580 & 72 & 0.12 & 0.1088 & 0.0022 & 0.9270 & 0.0240 & 0.0613 & 0.0011 & 666 & 13 & 654 & 35 & 0.15 \\
\hline $40-c 1$ & 395 & 49 & 0.12 & 0.1109 & 0.0029 & 0.9460 & 0.0240 & 0.0620 & 0.0009 & 678 & 17 & 672 & 32 & -0.44 \\
\hline 30-c1 & 237.7 & 92.6 & 0.39 & 0.1110 & 0.0015 & 0.9580 & 0.0190 & 0.0627 & 0.0011 & 678 & 9 & 705 & 39 & 0.48 \\
\hline $10-c 1$ & 215 & 68.8 & 0.32 & 0.1111 & 0.0015 & 0.9610 & 0.0190 & 0.0620 & 0.0012 & 679 & 9 & 678 & 40 & 0.56 \\
\hline $67-c 1$ & 491 & 345 & 0.70 & 0.1152 & 0.0015 & 1.0000 & 0.0190 & 0.0633 & 0.0012 & 703 & 9 & 715 & 39 & 0.31 \\
\hline 50-c1 & 249 & 167.6 & 0.67 & 0.1318 & 0.0013 & 1.1310 & 0.0180 & 0.0617 & 0.0009 & 798 & 8 & 664 & 32 & -3.92 \\
\hline $87-c 2$ & 142.8 & 66.2 & 0.46 & 0.1081 & 0.0014 & 0.8960 & 0.0170 & 0.0601 & 0.0011 & 662 & 8 & 600 & 40 & -1.89 \\
\hline $84-s z 2$ & 857 & 204.4 & 0.24 & 0.0988 & 0.0011 & 0.8530 & 0.0160 & 0.0626 & 0.0012 & 608 & 6 & 688 & 40 & 2.86 \\
\hline $73-s z 2$ & 455 & 256.3 & 0.56 & 0.0971 & 0.0010 & 0.8340 & 0.0170 & 0.0623 & 0.0012 & 597 & 6 & 681 & 40 & 3.05 \\
\hline 49-r1 & 136 & 64.7 & 0.48 & 0.0990 & 0.0010 & 0.8780 & 0.0190 & 0.0637 & 0.0013 & 609 & 6 & 730 & 44 & 4.89 \\
\hline 92-c1 & 999 & 1440 & 1.44 & 0.1036 & 0.0010 & 0.9420 & 0.0170 & 0.0661 & 0.0013 & 636 & 6 & 810 & 39 & 5.66 \\
\hline 81-c1 & 225 & 91.3 & 0.41 & 0.1050 & 0.0010 & 0.9810 & 0.0200 & 0.0675 & 0.0013 & 644 & 6 & 848 & 41 & 7.22 \\
\hline 68-c1 & 468 & 40.6 & 0.09 & 0.1078 & 0.0018 & 1.0670 & 0.0470 & 0.0702 & 0.0022 & 660 & 10 & 918 & 62 & 10.08 \\
\hline 34-c1 & 323 & 180.1 & 0.56 & 0.1028 & 0.0011 & 1.1210 & 0.0190 & 0.0789 & 0.0013 & 631 & 6 & 1174 & 32 & 17.35 \\
\hline $16-c 1$ & 168.3 & 59.3 & 0.35 & 0.1416 & 0.0022 & 2.0300 & 0.2400 & 0.1030 & 0.0120 & 854 & 12 & 1470 & 210 & 21.07 \\
\hline 23-c1 & 789 & 35.8 & 0.05 & 0.1400 & 0.0120 & 7.5000 & 1.5000 & 0.3380 & 0.0470 & 837 & 70 & 3100 & 260 & 55.24 \\
\hline
\end{tabular}

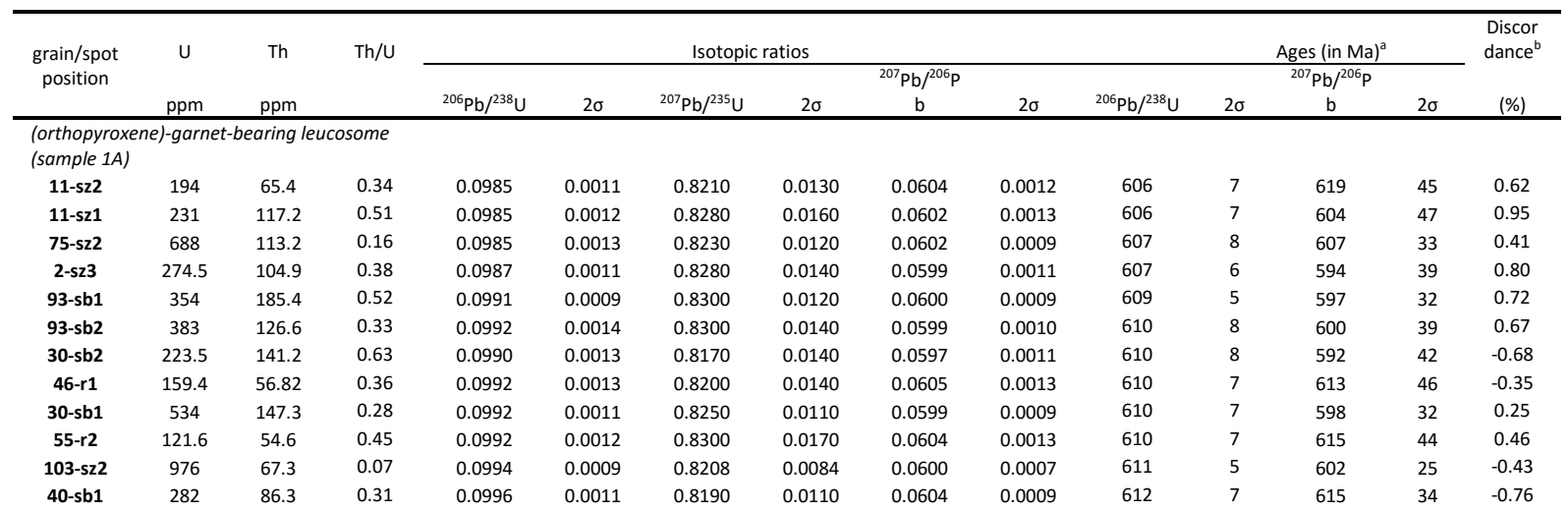




\begin{tabular}{|c|c|c|c|c|c|c|c|c|c|c|c|c|c|c|}
\hline 25-sz1 & 217 & 126.4 & 0.58 & 0.0995 & 0.0013 & 0.8230 & 0.0180 & 0.0599 & 0.0013 & 612 & 7 & 593 & 48 & -0.53 \\
\hline 32-r1 & 152.8 & 66.8 & 0.44 & 0.0997 & 0.0013 & 0.8380 & 0.0160 & 0.0602 & 0.0011 & 612 & 8 & 607 & 40 & 0.76 \\
\hline $35-r 2$ & 743 & 130.5 & 0.18 & 0.0997 & 0.0010 & 0.8300 & 0.0120 & 0.0604 & 0.0008 & 613 & 6 & 617 & 29 & 0.18 \\
\hline 31-r1 & 163.7 & 82.4 & 0.50 & 0.0998 & 0.0012 & 0.8380 & 0.0160 & 0.0606 & 0.0013 & 613 & 7 & 614 & 45 & 0.76 \\
\hline 94-sz2 & 136.8 & 58.2 & 0.43 & 0.0998 & 0.0013 & 0.8380 & 0.0180 & 0.0602 & 0.0015 & 613 & 8 & 611 & 55 & 0.68 \\
\hline 27-sb2 & 299 & 86.8 & 0.29 & 0.0999 & 0.0014 & 0.8320 & 0.0160 & 0.0600 & 0.0011 & 614 & 8 & 603 & 38 & 0.08 \\
\hline 39-sb2 & 327 & 117.2 & 0.36 & 0.0999 & 0.0011 & 0.8270 & 0.0120 & 0.0604 & 0.0010 & 614 & 6 & 617 & 38 & -0.33 \\
\hline 34-sb1 & 316 & 127.9 & 0.40 & 0.0999 & 0.0010 & 0.8420 & 0.0140 & 0.0604 & 0.0010 & 614 & 6 & 620 & 34 & 0.89 \\
\hline 76-sb1 & 319.6 & 128.4 & 0.40 & 0.1000 & 0.0014 & 0.8370 & 0.0160 & 0.0605 & 0.0010 & 614 & 8 & 615 & 38 & 0.65 \\
\hline 63-sb1 & 320 & 82.1 & 0.26 & 0.1000 & 0.0009 & 0.8240 & 0.0100 & 0.0603 & 0.0009 & 615 & 5 & 614 & 31 & -0.64 \\
\hline 34-sb2 & 623 & 124.3 & 0.20 & 0.1003 & 0.0013 & 0.8300 & 0.0140 & 0.0599 & 0.0010 & 616 & 7 & 597 & 35 & -0.31 \\
\hline 5-r1 & 148.3 & 85.2 & 0.57 & 0.1003 & 0.0009 & 0.8410 & 0.0170 & 0.0606 & 0.0013 & 616 & 5 & 619 & 47 & 0.40 \\
\hline 28-sz1 & 181.9 & 98 & 0.54 & 0.1003 & 0.0013 & 0.8290 & 0.0210 & 0.0599 & 0.0013 & 616 & 8 & 591 & 45 & -0.70 \\
\hline 65-r1 & 143.1 & 62.24 & 0.43 & 0.1006 & 0.0018 & 0.8280 & 0.0190 & 0.0605 & 0.0015 & 618 & 10 & 614 & 53 & -0.98 \\
\hline 13-r1 & 157.2 & 68.6 & 0.44 & 0.1006 & 0.0013 & 0.8380 & 0.0170 & 0.0604 & 0.0012 & 618 & 7 & 618 & 43 & 0.00 \\
\hline 7-sz2 & 366 & 121.5 & 0.33 & 0.1008 & 0.0010 & 0.8360 & 0.0130 & 0.0603 & 0.0009 & 619 & 6 & 615 & 34 & -0.32 \\
\hline 75-sz1 & 159.8 & 64.4 & 0.40 & 0.1007 & 0.0018 & 0.8470 & 0.0180 & 0.0601 & 0.0014 & 619 & 11 & 611 & 48 & 0.69 \\
\hline $37-s z 2$ & 404 & 110.8 & 0.27 & 0.1009 & 0.0011 & 0.8360 & 0.0130 & 0.0603 & 0.0010 & 620 & 7 & 612 & 35 & -0.50 \\
\hline 71-r1 & 578 & 17.36 & 0.03 & 0.1009 & 0.0013 & 0.8420 & 0.0160 & 0.0603 & 0.0011 & 620 & 8 & 616 & 40 & -0.03 \\
\hline 39-sb1 & 534 & 111.2 & 0.21 & 0.1010 & 0.0010 & 0.8330 & 0.0110 & 0.0603 & 0.0008 & 620 & 6 & 612 & 29 & -0.85 \\
\hline 83-sb1 & 204.9 & 83.6 & 0.41 & 0.1012 & 0.0014 & 0.8370 & 0.0160 & 0.0598 & 0.0012 & 621 & 8 & 590 & 43 & -0.78 \\
\hline 28-sz2 & 219.9 & 55.8 & 0.25 & 0.1012 & 0.0013 & 0.8400 & 0.0170 & 0.0600 & 0.0011 & 622 & 7 & 595 & 40 & -0.55 \\
\hline 18-r1 & 111.2 & 56.7 & 0.51 & 0.1015 & 0.0014 & 0.8390 & 0.0180 & 0.0596 & 0.0016 & 623 & 8 & 581 & 59 & -0.89 \\
\hline 35-sz1 & 130.2 & 61.4 & 0.47 & 0.1015 & 0.0014 & 0.8390 & 0.0170 & 0.0601 & 0.0012 & 624 & 9 & 606 & 46 & -0.99 \\
\hline $12-c 1$ & 298.7 & 63.2 & 0.21 & 0.1086 & 0.0010 & 0.9290 & 0.0150 & 0.0620 & 0.0010 & 665 & 6 & 674 & 35 & 0.33 \\
\hline $9-c 2$ & 235.3 & 79.5 & 0.34 & 0.1101 & 0.0013 & 0.9480 & 0.0200 & 0.0630 & 0.0013 & 673 & 8 & 708 & 42 & 0.56 \\
\hline $37-c 1$ & 408 & 117.7 & 0.29 & 0.1119 & 0.0014 & 0.9600 & 0.0150 & 0.0620 & 0.0010 & 684 & 8 & 672 & 33 & -0.15 \\
\hline $7-c 1$ & 1437 & 127.7 & 0.09 & 0.1123 & 0.0015 & 0.9570 & 0.0120 & 0.0622 & 0.0007 & 686 & 9 & 679 & 25 & -0.66 \\
\hline $105-c 1$ & 165 & 79 & 0.48 & 0.1134 & 0.0011 & 0.9820 & 0.0150 & 0.0626 & 0.0011 & 692 & 6 & 696 & 36 & 0.33 \\
\hline 9-c1 & 377 & 153.9 & 0.41 & 0.1148 & 0.0012 & 0.9870 & 0.0140 & 0.0624 & 0.0010 & 702 & 7 & 683 & 34 & -0.66 \\
\hline $94-c 1$ & 193.8 & 130 & 0.67 & 0.1152 & 0.0015 & 1.0100 & 0.0270 & 0.0633 & 0.0017 & 703 & 9 & 709 & 57 & 0.73 \\
\hline $105-c 3$ & 758 & 71.1 & 0.09 & 0.1161 & 0.0019 & 1.0120 & 0.0170 & 0.0629 & 0.0009 & 708 & 11 & 703 & 31 & 0.20 \\
\hline $10-c 1$ & 446.9 & 118 & 0.26 & 0.1161 & 0.0013 & 1.0000 & 0.0150 & 0.0628 & 0.0009 & 708 & 8 & 698 & 31 & -0.70 \\
\hline $94-c 3$ & 329 & 76 & 0.23 & 0.1163 & 0.0011 & 1.0240 & 0.0150 & 0.0630 & 0.0009 & 709 & 7 & 715 & 33 & 0.89 \\
\hline $88-c 2$ & 363.2 & 91.7 & 0.25 & 0.1172 & 0.0015 & 1.0330 & 0.0180 & 0.0634 & 0.0011 & 714 & 9 & 713 & 37 & 0.79 \\
\hline $105-c 2$ & 250 & 71.7 & 0.29 & 0.1180 & 0.0008 & 1.0380 & 0.0120 & 0.0633 & 0.0009 & 719 & 5 & 721 & 32 & 0.62 \\
\hline $51-c 3$ & 1976 & 37.6 & 0.02 & 0.1124 & 0.0013 & 0.9210 & 0.0110 & 0.0600 & 0.0007 & 687 & 8 & 605 & 24 & -3.67 \\
\hline 84-c1 & 171 & 45.8 & 0.27 & 0.1243 & 0.0025 & 1.0720 & 0.0350 & 0.0627 & 0.0016 & 759 & 14 & 697 & 51 & -2.71 \\
\hline 48-c1 & 273 & 207 & 0.76 & 0.1080 & 0.0012 & 0.8870 & 0.0140 & 0.0600 & 0.0010 & 661 & 7 & 606 & 36 & -2.37 \\
\hline 88-c1 & 2530 & 43.9 & 0.02 & 0.1111 & 0.0016 & 0.9220 & 0.0160 & 0.0600 & 0.0009 & 679 & 9 & 600 & 32 & -2.23 \\
\hline $62-s b 2$ & 593 & 112.5 & 0.19 & 0.0996 & 0.0010 & 0.8040 & 0.0120 & 0.0598 & 0.0009 & 612 & 6 & 595 & 34 & -1.83 \\
\hline 87-c1 & 563 & 81.8 & 0.15 & 0.1247 & 0.0024 & 1.0800 & 0.0240 & 0.0626 & 0.0010 & 757 & 14 & 692 & 35 & -1.75 \\
\hline 46-c1 & 349 & 55.2 & 0.16 & 0.1050 & 0.0013 & 0.8660 & 0.0140 & 0.0609 & 0.0009 & 644 & 8 & 632 & 31 & -1.72 \\
\hline 63-sb2 & 247 & 100.5 & 0.41 & 0.0997 & 0.0012 & 0.8110 & 0.0130 & 0.0602 & 0.0012 & 613 & 7 & 623 & 45 & -1.69 \\
\hline $40-s b 2$ & 716 & 164.7 & 0.23 & 0.0996 & 0.0018 & 0.8090 & 0.0160 & 0.0595 & 0.0010 & 612 & 11 & 580 & 36 & -1.46 \\
\hline $90-c 1$ & 3160 & 119.1 & 0.04 & 0.1077 & 0.0013 & 0.8960 & 0.0120 & 0.0598 & 0.0007 & 659 & 7 & 595 & 24 & -1.37 \\
\hline 51-c1 & 478 & 73.6 & 0.15 & 0.1150 & 0.0012 & 0.9790 & 0.0140 & 0.0627 & 0.0009 & 702 & 7 & 695 & 31 & -1.30 \\
\hline $65-r 1$ & 674 & 131.5 & 0.20 & 0.0994 & 0.0010 & 0.8090 & 0.0110 & 0.0598 & 0.0008 & 611 & 6 & 595 & 30 & -1.29 \\
\hline 86-c1 & 1406 & 45.2 & 0.03 & 0.1103 & 0.0017 & 0.9230 & 0.0140 & 0.0608 & 0.0011 & 675 & 10 & 629 & 39 & -1.29 \\
\hline $67-s z 2$ & 140.8 & 50.5 & 0.36 & 0.1010 & 0.0013 & 0.8310 & 0.0180 & 0.0604 & 0.0014 & 620 & 8 & 620 & 48 & -1.04 \\
\hline $61-s b 2$ & 346 & 96.2 & 0.28 & 0.0988 & 0.0010 & 0.8080 & 0.0140 & 0.0599 & 0.0010 & 607 & 6 & 594 & 35 & -1.03 \\
\hline 51-c2 & 191.5 & 92.4 & 0.48 & 0.1154 & 0.0013 & 1.0170 & 0.0170 & 0.0648 & 0.0014 & 704 & 7 & 773 & 45 & 1.10 \\
\hline $106-c 1$ & 808 & 165.6 & 0.20 & 0.1059 & 0.0012 & 0.9100 & 0.0210 & 0.0620 & 0.0012 & 649 & 7 & 671 & 43 & 1.10 \\
\hline $86-r 2$ & 210.8 & 101.3 & 0.48 & 0.0989 & 0.0012 & 0.8320 & 0.0150 & 0.0601 & 0.0011 & 608 & 7 & 620 & 39 & 1.11 \\
\hline $83-s b 2$ & 260 & 124.9 & 0.48 & 0.0991 & 0.0013 & 0.8350 & 0.0150 & 0.0601 & 0.0011 & 609 & 8 & 602 & 40 & 1.25 \\
\hline $84-c 2$ & 413 & 145 & 0.35 & 0.1158 & 0.0015 & 1.0250 & 0.0230 & 0.0636 & 0.0012 & 706 & 9 & 723 & 41 & 1.38 \\
\hline 55-r1 & 1193 & 43.9 & 0.04 & 0.0989 & 0.0013 & 0.8360 & 0.0110 & 0.0621 & 0.0008 & 608 & 8 & 675 & 26 & 1.41 \\
\hline $94-s z 4$ & 149.1 & 62.8 & 0.42 & 0.0995 & 0.0012 & 0.8410 & 0.0160 & 0.0600 & 0.0014 & 611 & 7 & 612 & 51 & 1.43 \\
\hline 80-c3 & 515 & 95.8 & 0.19 & 0.1128 & 0.0014 & 0.9940 & 0.0180 & 0.0626 & 0.0009 & 689 & 8 & 693 & 30 & 1.54 \\
\hline 90-r2 & 460 & 17.3 & 0.04 & 0.1023 & 0.0014 & 0.8870 & 0.0150 & 0.0618 & 0.0009 & 628 & 8 & 671 & 35 & 2.76 \\
\hline $12-s z 2$ & 242 & 126.3 & 0.52 & 0.0927 & 0.0009 & 0.7860 & 0.0140 & 0.0612 & 0.0013 & 572 & 5 & 655 & 45 & 2.85 \\
\hline $13-r 2$ & 161.8 & 77 & 0.48 & 0.0946 & 0.0014 & 0.8080 & 0.0170 & 0.0612 & 0.0014 & 583 & 8 & 654 & 47 & 2.96 \\
\hline $76-s b 2$ & 885 & 109.7 & 0.12 & 0.0952 & 0.0012 & 0.8144 & 0.0100 & 0.0617 & 0.0008 & 586 & 7 & 661 & 28 & 3.24 \\
\hline $10-s z 2$ & 369 & 133.1 & 0.36 & 0.0940 & 0.0012 & 0.8240 & 0.0140 & 0.0635 & 0.0011 & 579 & 7 & 724 & 37 & 5.24 \\
\hline $16-r 1$ & 291 & 104.3 & 0.36 & 0.0993 & 0.0012 & 0.9340 & 0.0240 & 0.0676 & 0.0019 & 610 & 7 & 838 & 61 & 8.91 \\
\hline $98-c 3$ & 361.1 & 144.1 & 0.40 & 0.1077 & 0.0012 & 1.0480 & 0.0200 & 0.0704 & 0.0014 & 659 & 7 & 942 & 40 & 9.34 \\
\hline 88-c1 & 717 & 119 & 0.17 & 0.1072 & 0.0017 & 1.1830 & 0.0270 & 0.0791 & 0.0021 & 656 & 10 & 1165 & 50 & 17.03 \\
\hline $103-c 1$ & 462 & 222 & 0.48 & 0.2404 & 0.0026 & 4.2680 & 0.0620 & 0.1289 & 0.0016 & 1389 & 14 & 2082 & 22 & 17.62 \\
\hline
\end{tabular}

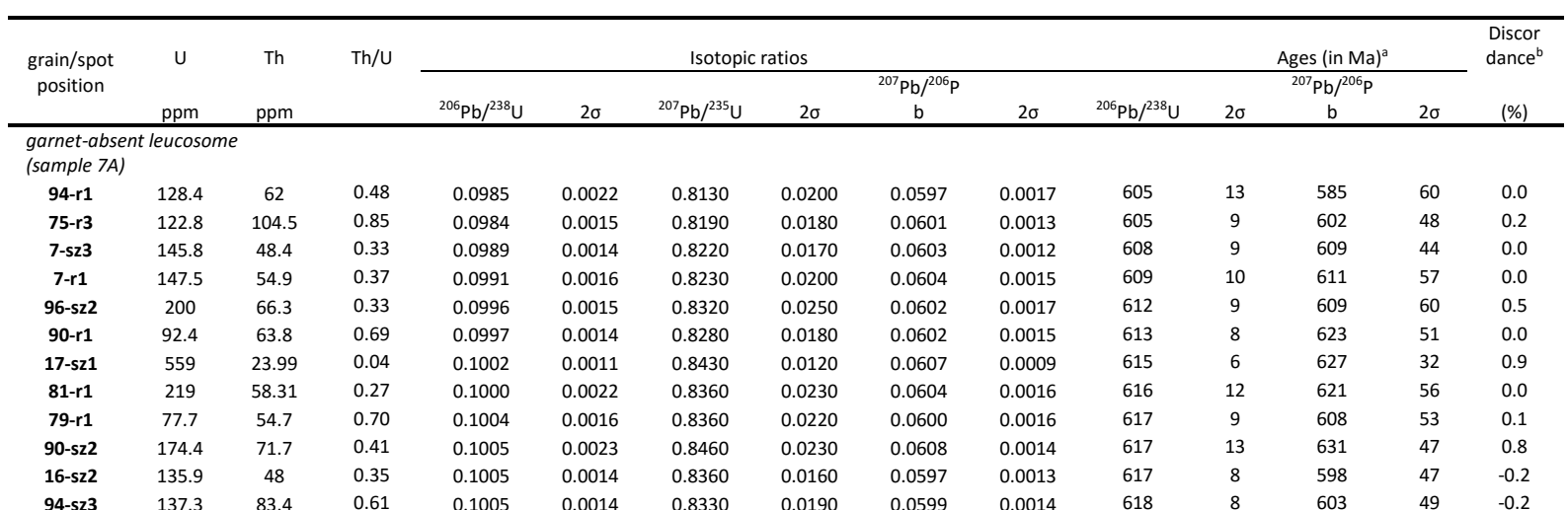




\begin{tabular}{|c|c|c|c|c|c|c|c|c|c|c|c|c|c|c|}
\hline 79-sz2 & 110.4 & 60.5 & 0.55 & 0.1006 & 0.0016 & 0.8400 & 0.0200 & 0.0608 & 0.0014 & 618 & 9 & 616 & 51 & 0.5 \\
\hline $85-s z 2$ & 406 & 16.87 & 0.04 & 0.1007 & 0.0011 & 0.8410 & 0.0120 & 0.0606 & 0.0010 & 619 & 7 & 626 & 35 & 0.1 \\
\hline 94-r2 & 96.6 & 57.9 & 0.60 & 0.1007 & 0.0017 & 0.8450 & 0.0180 & 0.0603 & 0.0014 & 619 & 10 & 616 & 50 & 0.6 \\
\hline $75-s z 2$ & 101.3 & 65.4 & 0.65 & 0.1008 & 0.0016 & 0.8360 & 0.0190 & 0.0601 & 0.0015 & 619 & 9 & 610 & 52 & -0.4 \\
\hline 66-sz1 & 112.2 & 39.89 & 0.36 & 0.1008 & 0.0014 & 0.8400 & 0.0180 & 0.0601 & 0.0014 & 619 & 8 & 610 & 49 & -0.1 \\
\hline 7-sz2 & 86 & 57.4 & 0.67 & 0.1008 & 0.0018 & 0.8350 & 0.0190 & 0.0599 & 0.0014 & 619 & 10 & 593 & 52 & -0.7 \\
\hline $16-r 1$ & 84.7 & 53.73 & 0.63 & 0.1009 & 0.0017 & 0.8440 & 0.0230 & 0.0611 & 0.0019 & 619 & 10 & 662 & 63 & 0.1 \\
\hline 70-r1 & 83.3 & 48.1 & 0.58 & 0.1009 & 0.0017 & 0.8390 & 0.0200 & 0.0600 & 0.0016 & 620 & 10 & 595 & 57 & -0.4 \\
\hline 61-sz1 & 96.7 & 44.06 & 0.46 & 0.1010 & 0.0018 & 0.8460 & 0.0210 & 0.0614 & 0.0013 & 620 & 10 & 653 & 47 & 0.3 \\
\hline 44-sz1 & 103 & 49.2 & 0.48 & 0.1010 & 0.0020 & 0.8480 & 0.0220 & 0.0603 & 0.0013 & 620 & 12 & 605 & 48 & 0.5 \\
\hline $31-c 2$ & 139.8 & 51.85 & 0.37 & 0.1010 & 0.0015 & 0.8430 & 0.0190 & 0.0604 & 0.0016 & 620 & 9 & 620 & 56 & 0.0 \\
\hline 85-r1 & 60.6 & 41.84 & 0.69 & 0.1011 & 0.0018 & 0.8350 & 0.0260 & 0.0593 & 0.0020 & 621 & 10 & 609 & 76 & -0.6 \\
\hline $89-s z 2$ & 164.9 & 61.6 & 0.37 & 0.1011 & 0.0015 & 0.8480 & 0.0220 & 0.0613 & 0.0017 & 621 & 9 & 646 & 58 & 0.3 \\
\hline $42-s z 2$ & 246.6 & 173.2 & 0.70 & 0.1011 & 0.0015 & 0.8490 & 0.0190 & 0.0602 & 0.0011 & 622 & 8 & 607 & 37 & 0.8 \\
\hline 34-sz2 & 384 & 28.8 & 0.08 & 0.1014 & 0.0015 & 0.8480 & 0.0160 & 0.0610 & 0.0011 & 622 & 9 & 641 & 40 & 0.3 \\
\hline 89-r1 & 118.1 & 66.2 & 0.56 & 0.1017 & 0.0020 & 0.8510 & 0.0230 & 0.0592 & 0.0015 & 624 & 12 & 593 & 58 & 0.0 \\
\hline $50-s z 1$ & 92.7 & 41.95 & 0.45 & 0.1023 & 0.0020 & 0.8500 & 0.0230 & 0.0600 & 0.0014 & 627 & 12 & 602 & 50 & -0.6 \\
\hline 21-sz1 & 101 & 57.1 & 0.57 & 0.1023 & 0.0016 & 0.8550 & 0.0210 & 0.0603 & 0.0015 & 628 & 10 & 604 & 55 & 0.2 \\
\hline $81-c 2$ & 136.3 & 69.4 & 0.51 & 0.1045 & 0.0017 & 0.8780 & 0.0220 & 0.0608 & 0.0015 & 641 & 10 & 630 & 53 & -0.2 \\
\hline $90-c 4$ & 256 & 115.8 & 0.45 & 0.1045 & 0.0013 & 0.8770 & 0.0170 & 0.0610 & 0.0012 & 641 & 8 & 631 & 42 & -0.1 \\
\hline $31-c 1$ & 75 & 69.9 & 0.93 & 0.1044 & 0.0023 & 0.8730 & 0.0230 & 0.0597 & 0.0015 & 642 & 13 & 602 & 54 & -0.9 \\
\hline $16-c 3$ & 289 & 90 & 0.31 & 0.1047 & 0.0015 & 0.8780 & 0.0160 & 0.0610 & 0.0011 & 642 & 9 & 632 & 40 & -0.5 \\
\hline $34-c 3$ & 332 & 114.2 & 0.34 & 0.1050 & 0.0014 & 0.8800 & 0.0140 & 0.0599 & 0.0010 & 645 & 8 & 601 & 38 & -0.7 \\
\hline $66-c 2$ & 564 & 52.2 & 0.09 & 0.1054 & 0.0015 & 0.8910 & 0.0160 & 0.0610 & 0.0010 & 646 & 9 & 634 & 36 & 0.1 \\
\hline 96-c1 & 205 & 58.4 & 0.28 & 0.1056 & 0.0014 & 0.8890 & 0.0180 & 0.0607 & 0.0014 & 647 & 8 & 625 & 50 & -0.4 \\
\hline $59-c 3$ & 313 & 205 & 0.65 & 0.1081 & 0.0017 & 0.9270 & 0.0160 & 0.0622 & 0.0011 & 661 & 10 & 678 & 35 & 0.6 \\
\hline $16-c 4$ & 184.5 & 163.8 & 0.89 & 0.1083 & 0.0017 & 0.9230 & 0.0210 & 0.0628 & 0.0013 & 663 & 10 & 695 & 43 & 0.0 \\
\hline $44-c 2$ & 549 & 138.1 & 0.25 & 0.1090 & 0.0018 & 0.9270 & 0.0140 & 0.0609 & 0.0010 & 667 & 10 & 637 & 36 & -0.2 \\
\hline $70-c 2$ & 356 & 254.9 & 0.72 & 0.1054 & 0.0014 & 0.8990 & 0.0140 & 0.0625 & 0.0012 & 646 & 8 & 691 & 41 & 1.0 \\
\hline $50-c 2$ & 468 & 347.3 & 0.74 & 0.1023 & 0.0016 & 0.8720 & 0.0150 & 0.0620 & 0.0011 & 628 & 10 & 667 & 37 & 1.3 \\
\hline $17-c 2$ & 335 & 54.9 & 0.16 & 0.1054 & 0.0015 & 0.9110 & 0.0180 & 0.0638 & 0.0013 & 647 & 9 & 730 & 40 & 1.4 \\
\hline $34-c 1$ & 114.6 & 47.6 & 0.42 & 0.1085 & 0.0020 & 0.8910 & 0.0220 & 0.0595 & 0.0016 & 664 & 12 & 589 & 55 & -2.8 \\
\hline $99-r 1$ & 119.4 & 73.4 & 0.61 & 0.1008 & 0.0018 & 0.8200 & 0.0230 & 0.0595 & 0.0015 & 619 & 11 & 581 & 56 & -1.9 \\
\hline 59-r1 & 90.7 & 49.98 & 0.55 & 0.1042 & 0.0019 & 0.8540 & 0.0240 & 0.0596 & 0.0016 & 640 & 11 & 588 & 57 & -1.9 \\
\hline 75 -sz1 & 840 & 45.88 & 0.05 & 0.0985 & 0.0012 & 0.8380 & 0.0110 & 0.0614 & 0.0009 & 605 & 7 & 648 & 30 & 2.0 \\
\hline $70-r 3$ & 626 & 19.19 & 0.03 & 0.0996 & 0.0013 & 0.8540 & 0.0120 & 0.0618 & 0.0009 & 612 & 8 & 671 & 34 & 2.5 \\
\hline 13-c1 & 402 & 276.8 & 0.69 & 0.1068 & 0.0012 & 0.9550 & 0.0190 & 0.0647 & 0.0012 & 654 & 7 & 769 & 38 & 3.9 \\
\hline $89-c 3$ & 349.1 & 204.9 & 0.59 & 0.1007 & 0.0011 & 0.8900 & 0.0200 & 0.0639 & 0.0014 & 618 & 7 & 739 & 46 & 4.3 \\
\hline $66-c 3$ & 412 & 361.2 & 0.88 & 0.1077 & 0.0015 & 0.9750 & 0.0150 & 0.0653 & 0.0011 & 659 & 9 & 782 & 35 & 4.6 \\
\hline $21-c 2$ & 475 & 172.8 & 0.36 & 0.1077 & 0.0013 & 0.9770 & 0.0170 & 0.0653 & 0.0011 & 659 & 8 & 780 & 36 & 4.6 \\
\hline $44-c 3$ & 388 & 221 & 0.57 & 0.1169 & 0.0019 & 1.0930 & 0.0300 & 0.0679 & 0.0016 & 713 & 11 & 860 & 52 & 4.7 \\
\hline $59-s z 2$ & 823 & 23.32 & 0.03 & 0.1010 & 0.0016 & 0.9130 & 0.0160 & 0.0653 & 0.0015 & 620 & 9 & 784 & 48 & 5.7 \\
\hline $61-c 2$ & 456 & 74 & 0.16 & 0.1071 & 0.0018 & 1.0560 & 0.0220 & 0.0712 & 0.0014 & 656 & 10 & 973 & 39 & 10.4 \\
\hline $90-c 3$ & 249 & 147.8 & 0.59 & 0.1057 & 0.0012 & 1.0580 & 0.0300 & 0.0724 & 0.0021 & 648 & 7 & 990 & 59 & 11.4 \\
\hline $94-c 4$ & 324 & 210.1 & 0.65 & 0.1087 & 0.0017 & 1.1430 & 0.0400 & 0.0759 & 0.0025 & 665 & 10 & 1098 & 69 & 13.6 \\
\hline $61-c 3$ & 448 & 120 & 0.27 & 0.1079 & 0.0020 & 1.1510 & 0.0270 & 0.0778 & 0.0023 & 661 & 11 & 1136 & 60 & 15.0 \\
\hline $95-s z 1$ & 743 & 155.8 & 0.21 & 0.0994 & 0.0013 & 1.0330 & 0.0220 & 0.0757 & 0.0018 & 611 & 8 & 1085 & 48 & 15.1 \\
\hline $95-c 2$ & 130.9 & 158.2 & 1.21 & 0.1089 & 0.0015 & 1.5770 & 0.0440 & 0.1060 & 0.0033 & 666 & 9 & 1715 & 58 & 30.7 \\
\hline $95-c 3$ & 77.2 & 53.6 & 0.69 & 0.1233 & 0.0038 & 2.0070 & 0.0870 & 0.1189 & 0.0045 & 749 & 22 & 1904 & 63 & 32.1 \\
\hline
\end{tabular}

\begin{tabular}{|c|c|c|c|c|c|c|c|c|c|c|c|c|c|c|}
\hline \multirow{3}{*}{$\begin{array}{l}\text { grain/spot } \\
\text { position }\end{array}$} & \multirow{3}{*}{$\begin{array}{c}\mathrm{U} \\
\mathrm{ppm}\end{array}$} & \multirow{3}{*}{$\begin{array}{l}\text { Th } \\
\mathrm{ppm}\end{array}$} & \multirow[t]{3}{*}{ Th/U } & \multicolumn{7}{|c|}{ Isotopic ratios } & \multicolumn{3}{|c|}{ Ages (in $\mathrm{Ma})^{\mathrm{a}}$} & \multirow{3}{*}{$\begin{array}{r}\begin{array}{r}\text { Discor } \\
\text { dance }\end{array} \\
(\%)\end{array}$} \\
\hline & & & & \multirow[b]{2}{*}{${ }^{206} \mathrm{~Pb} /{ }^{238} \mathrm{U}$} & \multirow[b]{2}{*}{$2 \sigma$} & \multirow[b]{2}{*}{${ }^{207} \mathrm{~Pb} /{ }^{235} \mathrm{U}$} & \multicolumn{3}{|c|}{${ }^{207} \mathrm{~Pb} /{ }^{206} \mathrm{P}$} & \multirow[b]{2}{*}{${ }^{206} \mathrm{~Pb} /{ }^{238} \mathrm{U}$} & \multicolumn{3}{|c|}{${ }^{207} \mathrm{~Pb} /{ }^{206} \mathrm{P}$} & \\
\hline & & & & & & & $2 \sigma$ & $\mathrm{b}$ & $2 \sigma$ & & $2 \sigma$ & $\mathrm{b}$ & $2 \sigma$ & \\
\hline \multicolumn{15}{|c|}{$\begin{array}{l}\text { garnet-biotite gneiss } \\
\text { (sample 9B) }\end{array}$} \\
\hline $111-r 1$ & 210.1 & 14.5 & 0.07 & 0.0999 & 0.0013 & 0.8360 & 0.0160 & 0.0609 & 0.0012 & 614 & 8 & 635 & 41 & 0.7 \\
\hline 63-re1 & 510 & 54.6 & 0.11 & 0.0983 & 0.0018 & 0.8130 & 0.0190 & 0.0606 & 0.0011 & 604 & 11 & 617 & 41 & -0.2 \\
\hline 66-re1 & 714 & 53.09 & 0.07 & 0.0983 & 0.0016 & 0.8170 & 0.0150 & 0.0599 & 0.0009 & 604 & 10 & 597 & 33 & 0.2 \\
\hline 62-re1 & 841 & 68.9 & 0.08 & 0.0988 & 0.0016 & 0.8130 & 0.0140 & 0.0600 & 0.0010 & 607 & 9 & 601 & 36 & -0.6 \\
\hline 63-re4 & 506 & 56.6 & 0.11 & 0.0990 & 0.0018 & 0.8170 & 0.0160 & 0.0601 & 0.0010 & 609 & 10 & 599 & 37 & -0.4 \\
\hline 25-r1 & 54.1 & 24.93 & 0.46 & 0.0992 & 0.0018 & 0.8220 & 0.0220 & 0.0605 & 0.0018 & 610 & 11 & 622 & 66 & 0.2 \\
\hline 30-re1 & 356 & 18.14 & 0.05 & 0.0993 & 0.0012 & 0.8250 & 0.0160 & 0.0603 & 0.0010 & 610 & 7 & 610 & 37 & 0.0 \\
\hline 65-r1 & 462 & 49.5 & 0.11 & 0.0992 & 0.0017 & 0.8210 & 0.0140 & 0.0611 & 0.0010 & 611 & 10 & 639 & 35 & -0.3 \\
\hline 23-re1 & 455 & 55.6 & 0.12 & 0.0995 & 0.0012 & 0.8260 & 0.0120 & 0.0599 & 0.0009 & 612 & 7 & 596 & 32 & 0.1 \\
\hline 31-re1 & 614 & 194.6 & 0.32 & 0.0997 & 0.0012 & 0.8260 & 0.0110 & 0.0606 & 0.0009 & 613 & 7 & 626 & 33 & -0.2 \\
\hline 31-re2 & 416 & 52.4 & 0.13 & 0.0999 & 0.0014 & 0.8310 & 0.0140 & 0.0603 & 0.0010 & 615 & 8 & 612 & 36 & -0.2 \\
\hline 15-re1 & 663 & 56.3 & 0.08 & 0.1004 & 0.0013 & 0.8360 & 0.0110 & 0.0602 & 0.0009 & 617 & 7 & 607 & 31 & 0.1 \\
\hline 59-re1 & 485 & 52.2 & 0.11 & 0.1004 & 0.0018 & 0.8330 & 0.0160 & 0.0607 & 0.0012 & 617 & 10 & 626 & 45 & -0.1 \\
\hline 73-re1 & 325 & 27.6 & 0.08 & 0.1008 & 0.0016 & 0.8420 & 0.0140 & 0.0609 & 0.0012 & 619 & 9 & 629 & 41 & 0.1 \\
\hline 59-re2 & 471 & 28 & 0.06 & 0.1008 & 0.0016 & 0.8410 & 0.0140 & 0.0605 & 0.0009 & 619 & 9 & 619 & 32 & 0.2 \\
\hline 28-re1 & 393 & 41.2 & 0.10 & 0.1009 & 0.0014 & 0.8490 & 0.0160 & 0.0614 & 0.0011 & 620 & 8 & 648 & 38 & 0.7 \\
\hline $107-r 1$ & 610 & 50.5 & 0.08 & 0.1034 & 0.0011 & 0.8670 & 0.0110 & 0.0606 & 0.0009 & 634 & 7 & 623 & 30 & 0.0 \\
\hline $44-c 2$ & 411 & 26.05 & 0.06 & 0.1039 & 0.0024 & 0.8790 & 0.0210 & 0.0607 & 0.0013 & 637 & 14 & 633 & 43 & 0.5 \\
\hline $59-c 3$ & 277 & 65.1 & 0.24 & 0.1045 & 0.0018 & 0.8780 & 0.0160 & 0.0611 & 0.0013 & 641 & 10 & 642 & 45 & -0.3 \\
\hline $54-c 2$ & 261.9 & 82 & 0.31 & 0.1046 & 0.0028 & 0.8760 & 0.0220 & 0.0621 & 0.0014 & 641 & 16 & 678 & 49 & -0.5 \\
\hline 78-c1 & 412 & 63 & 0.15 & 0.1046 & 0.0021 & 0.8850 & 0.0160 & 0.0610 & 0.0010 & 641 & 12 & 642 & 38 & 0.6 \\
\hline $58-c 2$ & 322 & 109.2 & 0.34 & 0.1049 & 0.0019 & 0.8780 & 0.0200 & 0.0613 & 0.0013 & 643 & 11 & 651 & 47 & -0.6 \\
\hline 58-c1 & 404 & 190.4 & 0.47 & 0.1049 & 0.0026 & 0.8820 & 0.0200 & 0.0615 & 0.0014 & 643 & 15 & 661 & 45 & -0.3 \\
\hline $69-c 2$ & 436 & 175 & 0.40 & 0.1052 & 0.0027 & 0.8900 & 0.0240 & 0.0616 & 0.0013 & 644 & 15 & 672 & 43 & 0.2 \\
\hline $77-c 2$ & 400.2 & 244 & 0.61 & 0.1052 & 0.0018 & 0.8870 & 0.0150 & 0.0618 & 0.0010 & 645 & 11 & 666 & 34 & 0.0 \\
\hline $36-c 2$ & 329 & 121 & 0.37 & 0.1053 & 0.0019 & 0.8790 & 0.0170 & 0.0609 & 0.0011 & 645 & 11 & 643 & 39 & -0.5 \\
\hline $63-r 3$ & 596 & 27.78 & 0.05 & 0.1054 & 0.0027 & 0.8930 & 0.0190 & 0.0616 & 0.0013 & 646 & 16 & 653 & 45 & 0.5 \\
\hline $65-c 2$ & 201.7 & 72.9 & 0.36 & 0.1055 & 0.0018 & 0.8910 & 0.0180 & 0.0610 & 0.0011 & 648 & 11 & 641 & 40 & -0.1 \\
\hline $29-c 2$ & 341 & 150 & 0.44 & 0.1063 & 0.0024 & 0.8940 & 0.0200 & 0.0605 & 0.0012 & 651 & 14 & 616 & 42 & -0.2 \\
\hline $63-c 2$ & 574 & 121 & 0.21 & 0.1068 & 0.0019 & 0.9020 & 0.0160 & 0.0618 & 0.0009 & 654 & 11 & 664 & 32 & 0.0 \\
\hline $107-c 2$ & 305 & 170 & 0.56 & 0.1069 & 0.0013 & 0.9030 & 0.0130 & 0.0611 & 0.0009 & 655 & 8 & 642 & 32 & -0.1 \\
\hline
\end{tabular}




\begin{tabular}{|c|c|c|c|c|c|c|c|c|c|c|c|c|c|c|}
\hline $15-c 2$ & 275 & 203 & 0.74 & 0.1070 & 0.0017 & 0.9110 & 0.0140 & 0.0612 & 0.0009 & 655 & 10 & 657 & 32 & 0.4 \\
\hline $36-c 1$ & 295 & 111 & 0.38 & 0.1075 & 0.0018 & 0.9190 & 0.0160 & 0.0617 & 0.0012 & 658 & 10 & 671 & 39 & 0.4 \\
\hline $79-c 2$ & 383 & 125 & 0.33 & 0.1078 & 0.0017 & 0.9140 & 0.0170 & 0.0617 & 0.0011 & 660 & 10 & 664 & 37 & -0.2 \\
\hline $78-c 2$ & 164 & 122 & 0.74 & 0.1084 & 0.0020 & 0.9240 & 0.0220 & 0.0617 & 0.0013 & 663 & 11 & 674 & 44 & 0.3 \\
\hline $25-c 2$ & 226 & 152 & 0.67 & 0.1047 & 0.0022 & 0.8960 & 0.0210 & 0.0621 & 0.0012 & 642 & 13 & 672 & 40 & 1.1 \\
\hline $23-c 2$ & 653 & 361 & 0.55 & 0.1049 & 0.0017 & 0.8960 & 0.0150 & 0.0619 & 0.0010 & 643 & 10 & 665 & 34 & 1.2 \\
\hline 81-re1 & 562 & 31 & 0.06 & 0.1005 & 0.0014 & 0.8510 & 0.0130 & 0.0617 & 0.0010 & 617 & 9 & 660 & 35 & 1.4 \\
\hline 54-re3 & 299.5 & 31.8 & 0.11 & 0.1017 & 0.0019 & 0.8700 & 0.0160 & 0.0631 & 0.0012 & 624 & 11 & 717 & 41 & 1.7 \\
\hline 28-re2 & 535 & 29.9 & 0.06 & 0.0993 & 0.0015 & 0.8460 & 0.0170 & 0.0616 & 0.0010 & 610 & 9 & 659 & 33 & 1.9 \\
\hline 77-re1 & 339 & 71.9 & 0.21 & 0.1028 & 0.0017 & 0.9230 & 0.0260 & 0.0653 & 0.0017 & 632 & 10 & 766 & 52 & 4.8 \\
\hline \multirow{3}{*}{$\begin{array}{c}\text { grain/spot } \\
\text { position }\end{array}$} & u & Th & Th/U & & & Isotopi & atios & & & & & (in N & & $\begin{array}{l}\text { Discor } \\
\text { dance }^{b}\end{array}$ \\
\hline & & & & & & & & ${ }^{207} \mathrm{~Pb} /{ }^{206} \mathrm{P}$ & & & & $\mathrm{Pb} /{ }^{20}$ & & \\
\hline & $\mathrm{ppm}$ & $\mathrm{ppm}$ & & ${ }^{206} \mathrm{~Pb} /{ }^{238} \mathrm{U}$ & $2 \sigma$ & ${ }^{207} \mathrm{~Pb} /{ }^{235} \mathrm{U}$ & $2 \sigma$ & b & $2 \sigma$ & ${ }^{206} \mathrm{~Pb} /{ }^{238} \mathrm{U}$ & $2 \sigma$ & b & $2 \sigma$ & (\%) \\
\hline $\begin{array}{l}\text { mafic gran } \\
\text { (sample } 7 c\end{array}$ & & & & & & & & & & & & & & \\
\hline 3-sb1 & 769 & 81.3 & 0.11 & 0.0987 & 0.0011 & 0.8168 & 0.0091 & 0.0603 & 0.0008 & 607 & 6 & 613 & 28 & -0.1 \\
\hline 3-sb2 & 1089 & 162.3 & 0.15 & 0.0987 & 0.0012 & 0.8152 & 0.0096 & 0.0601 & 0.0007 & 607 & 7 & 604 & 27 & -0.2 \\
\hline 14-sb2 & 1055 & 111.7 & 0.11 & 0.0986 & 0.0023 & 0.8150 & 0.0150 & 0.0603 & 0.0011 & 606 & 13 & 608 & 41 & 0.0 \\
\hline 22-r1 & 1081 & 87.2 & 0.08 & 0.0986 & 0.0013 & 0.8180 & 0.0120 & 0.0604 & 0.0008 & 606 & 7 & 616 & 29 & 0.1 \\
\hline 98-re1 & 1090 & 71.9 & 0.07 & 0.0988 & 0.0014 & 0.8140 & 0.0110 & 0.0603 & 0.0009 & 607 & 8 & 613 & 30 & -0.5 \\
\hline $103-r 1$ & 837 & 112 & 0.13 & 0.0992 & 0.0016 & 0.8210 & 0.0140 & 0.0601 & 0.0008 & 610 & 9 & 605 & 29 & -0.2 \\
\hline 56-re1 & 1049 & 119 & 0.11 & 0.0993 & 0.0015 & 0.8230 & 0.0150 & 0.0602 & 0.0010 & 610 & 9 & 613 & 35 & -0.1 \\
\hline 14-sb1 & 522 & 84.1 & 0.16 & 0.0993 & 0.0012 & 0.8260 & 0.0120 & 0.0607 & 0.0008 & 610 & 7 & 623 & 29 & 0.1 \\
\hline 103-re3 & 273 & 44.9 & 0.16 & 0.0996 & 0.0015 & 0.8290 & 0.0180 & 0.0606 & 0.0012 & 612 & 9 & 619 & 43 & 0.1 \\
\hline 28-re1 & 868 & 161.2 & 0.19 & 0.0999 & 0.0021 & 0.8360 & 0.0180 & 0.0610 & 0.0009 & 614 & 13 & 645 & 33 & 0.4 \\
\hline 69-re2 & 738 & 39.84 & 0.05 & 0.1000 & 0.0016 & 0.8340 & 0.0140 & 0.0607 & 0.0010 & 614 & 9 & 626 & 38 & 0.2 \\
\hline 97-re1 & 671 & 57.1 & 0.09 & 0.1000 & 0.0012 & 0.8280 & 0.0110 & 0.0603 & 0.0008 & 615 & 7 & 612 & 30 & -0.3 \\
\hline 101-re1 & 1197 & 68.8 & 0.06 & 0.1001 & 0.0012 & 0.8320 & 0.0110 & 0.0605 & 0.0007 & 615 & 7 & 618 & 26 & 0.0 \\
\hline 103-re2 & 1226 & 207 & 0.17 & 0.1004 & 0.0014 & 0.8350 & 0.0130 & 0.0605 & 0.0008 & 617 & 8 & 620 & 28 & -0.1 \\
\hline 49-re1 & 1579 & 97.1 & 0.06 & 0.1004 & 0.0017 & 0.8370 & 0.0120 & 0.0604 & 0.0008 & 617 & 10 & 617 & 30 & 0.0 \\
\hline 79-r1 & 963 & 53.5 & 0.06 & 0.1005 & 0.0015 & 0.8330 & 0.0110 & 0.0607 & 0.0009 & 617 & 9 & 625 & 31 & -0.3 \\
\hline 99-r1 & 822 & 494 & 0.60 & 0.1005 & 0.0015 & 0.8400 & 0.0130 & 0.0610 & 0.0012 & 618 & 9 & 638 & 40 & 0.2 \\
\hline 7-re2 & 844 & 369 & 0.44 & 0.1006 & 0.0016 & 0.8400 & 0.0130 & 0.0610 & 0.0008 & 618 & 9 & 635 & 28 & 0.1 \\
\hline 60-re1 & 770 & 43.1 & 0.06 & 0.1007 & 0.0015 & 0.8400 & 0.0150 & 0.0606 & 0.0009 & 618 & 9 & 629 & 31 & 0.0 \\
\hline 86-re2 & 855 & 303 & 0.35 & 0.1008 & 0.0015 & 0.8410 & 0.0130 & 0.0611 & 0.0009 & 619 & 9 & 642 & 31 & 0.1 \\
\hline 86-r1 & 1500 & 94.5 & 0.06 & 0.1008 & 0.0025 & 0.8380 & 0.0180 & 0.0602 & 0.0011 & 619 & 15 & 606 & 39 & -0.3 \\
\hline 85-re2 & 811 & 33.9 & 0.04 & 0.1008 & 0.0015 & 0.8380 & 0.0180 & 0.0599 & 0.0010 & 619 & 9 & 596 & 37 & -0.2 \\
\hline 32-r1 & 826 & 56 & 0.07 & 0.1013 & 0.0013 & 0.8420 & 0.0140 & 0.0604 & 0.0009 & 622 & 8 & 613 & 31 & -0.2 \\
\hline 6-re1 & 1014 & 139 & 0.14 & 0.1013 & 0.0014 & 0.8420 & 0.0120 & 0.0601 & 0.0009 & 622 & 8 & 611 & 33 & -0.1 \\
\hline 6-re2 & 981 & 76 & 0.08 & 0.1014 & 0.0011 & 0.8390 & 0.0120 & 0.0603 & 0.0008 & 623 & 7 & 616 & 30 & -0.7 \\
\hline $45-\mathrm{m} 2$ & 765 & 40.8 & 0.05 & 0.1035 & 0.0014 & 0.8680 & 0.0120 & 0.0605 & 0.0009 & 635 & 8 & 621 & 31 & 0.0 \\
\hline $49-\mathrm{m} 2$ & 1325 & 45.54 & 0.03 & 0.1036 & 0.0019 & 0.8720 & 0.0160 & 0.0616 & 0.0012 & 635 & 11 & 661 & 42 & 0.2 \\
\hline $97-c 3$ & 659 & 375.3 & 0.57 & 0.1038 & 0.0014 & 0.8720 & 0.0120 & 0.0610 & 0.0009 & 637 & 8 & 634 & 32 & 0.0 \\
\hline $56-c 2$ & 1141 & 113.8 & 0.10 & 0.1040 & 0.0024 & 0.8670 & 0.0180 & 0.0609 & 0.0013 & 637 & 14 & 638 & 47 & -0.6 \\
\hline 50-c1 & 1222 & 141.2 & 0.12 & 0.1040 & 0.0020 & 0.8720 & 0.0140 & 0.0611 & 0.0010 & 637 & 12 & 646 & 36 & -0.1 \\
\hline 85-c1 & 1245 & 470 & 0.38 & 0.1039 & 0.0019 & 0.8720 & 0.0160 & 0.0606 & 0.0012 & 637 & 11 & 618 & 43 & -0.1 \\
\hline 52-c1 & 1165 & 34.62 & 0.03 & 0.1039 & 0.0016 & 0.8730 & 0.0150 & 0.0607 & 0.0009 & 637 & 10 & 629 & 33 & 0.1 \\
\hline 45-c1 & 729 & 28.14 & 0.04 & 0.1040 & 0.0015 & 0.8760 & 0.0120 & 0.0609 & 0.0009 & 638 & 9 & 641 & 31 & 0.1 \\
\hline $49-c 3$ & 1369 & 56.1 & 0.04 & 0.1040 & 0.0021 & 0.8720 & 0.0180 & 0.0616 & 0.0011 & 638 & 12 & 658 & 39 & -0.3 \\
\hline 98-c2 & 872 & 58.2 & 0.07 & 0.1039 & 0.0014 & 0.8700 & 0.0120 & 0.0608 & 0.0008 & 638 & 8 & 631 & 28 & -0.5 \\
\hline 59-c1 & 1427 & 31.38 & 0.02 & 0.1041 & 0.0016 & 0.8720 & 0.0130 & 0.0606 & 0.0010 & 638 & 9 & 626 & 33 & -0.3 \\
\hline $50-c 2$ & 1027 & 104.3 & 0.10 & 0.1043 & 0.0027 & 0.8710 & 0.0180 & 0.0601 & 0.0013 & 639 & 16 & 600 & 48 & -0.6 \\
\hline 71-c2 & 1160 & 42.42 & 0.04 & 0.1042 & 0.0018 & 0.8750 & 0.0130 & 0.0608 & 0.0009 & 639 & 10 & 630 & 33 & -0.2 \\
\hline 59-с2 & 1423 & 490 & 0.34 & 0.1043 & 0.0023 & 0.8770 & 0.0170 & 0.0606 & 0.0010 & 639 & 13 & 631 & 38 & -0.1 \\
\hline 79-c3 & 644 & 45.4 & 0.07 & 0.1042 & 0.0023 & 0.8790 & 0.0220 & 0.0611 & 0.0012 & 639 & 14 & 650 & 42 & 0.2 \\
\hline $105-c 2$ & 1316 & 109.1 & 0.08 & 0.1042 & 0.0013 & 0.8640 & 0.0130 & 0.0605 & 0.0009 & 639 & 8 & 617 & 31 & -0.9 \\
\hline $99-\mathrm{c} 2$ & 339 & 311 & 0.92 & 0.1044 & 0.0011 & 0.8810 & 0.0140 & 0.0614 & 0.0009 & 640 & 7 & 649 & 30 & 0.5 \\
\hline 71-r1 & 1272 & 44.7 & 0.04 & 0.1046 & 0.0025 & 0.8800 & 0.0220 & 0.0603 & 0.0015 & 641 & 14 & 604 & 53 & -0.2 \\
\hline $104-\mathrm{c} 1$ & 1474 & 38.46 & 0.03 & 0.1047 & 0.0015 & 0.8780 & 0.0130 & 0.0605 & 0.0009 & 642 & 9 & 625 & 31 & -0.4 \\
\hline $32-c 2$ & 389.4 & 469 & 1.20 & 0.1049 & 0.0016 & 0.8850 & 0.0150 & 0.0616 & 0.0010 & 643 & 10 & 657 & 36 & 0.2 \\
\hline $18-c 2$ & 764 & 48.1 & 0.06 & 0.1049 & 0.0020 & 0.8810 & 0.0160 & 0.0610 & 0.0011 & 643 & 11 & 643 & 39 & -0.3 \\
\hline 69-c1 & 601 & 32.46 & 0.05 & 0.1050 & 0.0013 & 0.8820 & 0.0130 & 0.0613 & 0.0010 & 643 & 8 & 646 & 34 & 0.2 \\
\hline $105-c 1$ & 849 & 61.4 & 0.07 & 0.1052 & 0.0018 & 0.8860 & 0.0180 & 0.0609 & 0.0011 & 645 & 11 & 632 & 39 & -0.2 \\
\hline $7-c 3$ & 494 & 243 & 0.49 & 0.1053 & 0.0016 & 0.8860 & 0.0170 & 0.0611 & 0.0010 & 645 & 9 & 642 & 35 & -0.2 \\
\hline $86-c 3$ & 1029 & 194 & 0.19 & 0.1055 & 0.0016 & 0.8800 & 0.0150 & 0.0603 & 0.0009 & 646 & 10 & 614 & 31 & -0.8 \\
\hline 61-c1 & 1269 & 82 & 0.06 & 0.1056 & 0.0015 & 0.8930 & 0.0120 & 0.0613 & 0.0009 & 647 & 9 & 648 & 32 & 0.1 \\
\hline $60-c 2$ & 607 & 667 & 1.10 & 0.1056 & 0.0020 & 0.8910 & 0.0190 & 0.0611 & 0.0009 & 647 & 12 & 640 & 31 & 0.2 \\
\hline $104-c 2$ & 412 & 219.9 & 0.53 & 0.1058 & 0.0017 & 0.8900 & 0.0170 & 0.0610 & 0.0012 & 648 & 10 & 638 & 42 & -0.4 \\
\hline $28-c 2$ & 1225 & 550 & 0.45 & 0.1059 & 0.0017 & 0.8920 & 0.0160 & 0.0605 & 0.0009 & 649 & 10 & 621 & 32 & -0.3 \\
\hline $52-c 2$ & 961 & 39.9 & 0.04 & 0.1058 & 0.0015 & 0.8930 & 0.0150 & 0.0616 & 0.0009 & 650 & 9 & 659 & 31 & -0.2 \\
\hline 7-c1 & 759 & 53.7 & 0.07 & 0.1063 & 0.0011 & 0.8984 & 0.0100 & 0.0613 & 0.0008 & 651 & 6 & 650 & 28 & 0.0 \\
\hline 79-с2 & 963 & 700 & 0.73 & 0.1065 & 0.0016 & 0.8970 & 0.0150 & 0.0612 & 0.0011 & 652 & 9 & 647 & 38 & -0.4 \\
\hline 57-c1 & 2890 & 128.8 & 0.04 & 0.1073 & 0.0028 & 0.9080 & 0.0260 & 0.0606 & 0.0014 & 657 & 16 & 623 & 47 & -0.3 \\
\hline 61-c2 & 846 & 473 & 0.56 & 0.1138 & 0.0032 & 0.9840 & 0.0280 & 0.0634 & 0.0011 & 694 & 18 & 728 & 38 & 0.0 \\
\hline $67-c 2$ & 7450 & 610 & 0.08 & 0.1085 & 0.0018 & 0.8700 & 0.0160 & 0.0581 & 0.0008 & 664 & 11 & 531 & 31 & -4.4 \\
\hline $57-c 2$ & 3210 & 175.6 & 0.05 & 0.1134 & 0.0020 & 0.9280 & 0.0160 & 0.0594 & 0.0010 & 694 & 12 & 578 & 34 & -3.9 \\
\hline $22-c 2$ & 1568 & 112.7 & 0.07 & 0.1076 & 0.0022 & 0.8800 & 0.0220 & 0.0588 & 0.0011 & 659 & 13 & 555 & 40 & -3.0 \\
\hline $97-c 2$ & 727 & 154 & 0.21 & 0.1065 & 0.0017 & 0.8710 & 0.0140 & 0.0599 & 0.0010 & 652 & 10 & 594 & 35 & -2.6 \\
\hline 59-c3 & 1218 & 242 & 0.20 & 0.1083 & 0.0018 & 0.8940 & 0.0150 & 0.0599 & 0.0009 & 663 & 11 & 602 & 32 & -2.3 \\
\hline $29-c 2$ & 1255 & 188.5 & 0.15 & 0.1047 & 0.0015 & 0.8600 & 0.0130 & 0.0601 & 0.0008 & 642 & 9 & 605 & 29 & -1.9 \\
\hline $101-c 2$ & 1585 & 463 & 0.29 & 0.1077 & 0.0020 & 0.8930 & 0.0180 & 0.0603 & 0.0008 & 659 & 12 & 613 & 29 & -1.8 \\
\hline $\begin{array}{c}\text { grain/spot } \\
\text { position }\end{array}$ & U & Th & Th/U & & & Isotopi & atios & & & & & $s$ (in N & & $\begin{array}{l}\text { Discor } \\
\text { dance }^{b}\end{array}$ \\
\hline
\end{tabular}




\begin{tabular}{|c|c|c|c|c|c|c|c|c|c|c|c|c|c|c|}
\hline & \multirow[b]{2}{*}{$\mathrm{ppm}$} & \multirow[b]{2}{*}{$\mathrm{ppm}$} & & \multirow[b]{2}{*}{${ }^{206} \mathrm{~Pb} /{ }^{238} \mathrm{U}$} & \multirow[b]{2}{*}{$2 \sigma$} & \multirow[b]{2}{*}{${ }^{207} \mathrm{~Pb} /{ }^{235} \mathrm{U}$} & \multicolumn{3}{|c|}{${ }^{207} \mathrm{~Pb} /{ }^{206} \mathrm{P}$} & \multicolumn{5}{|c|}{${ }^{207} \mathrm{~Pb} /{ }^{206} \mathrm{p}$} \\
\hline & & & & & & & $2 \sigma$ & $\mathrm{b}$ & $2 \sigma$ & ${ }^{206} \mathrm{~Pb} /{ }^{238} \mathrm{U}$ & $2 \sigma$ & $b$ & $2 \sigma$ & (\%) \\
\hline PL-1 & 586 & 53.6 & 0.09 & 0.0532 & 0.0007 & 0.3931 & 0.0063 & 0.0535 & 0.0009 & 334 & 4 & 348 & 40 & 0.71 \\
\hline PL-2 & 566 & 52.3 & 0.09 & 0.0542 & 0.0005 & 0.3893 & 0.0060 & 0.0524 & 0.0009 & 340 & 3 & 311 & 37 & -1.95 \\
\hline PL-3 & 528 & 44.65 & 0.08 & 0.0544 & 0.0007 & 0.3943 & 0.0065 & 0.0523 & 0.0009 & 342 & 4 & 292 & 41 & -1.30 \\
\hline PL-4 & 522 & 43.49 & 0.08 & 0.0536 & 0.0006 & 0.3954 & 0.0058 & 0.0533 & 0.0009 & 336 & 4 & 349 & 38 & 0.50 \\
\hline PL-5 & 527 & 44.2 & 0.08 & 0.0540 & 0.0007 & 0.3993 & 0.0065 & 0.0535 & 0.0009 & 339 & 4 & 358 & 39 & 0.65 \\
\hline PL-6 & 525 & 42.51 & 0.08 & 0.0540 & 0.0007 & 0.3942 & 0.0076 & 0.0533 & 0.0009 & 339 & 5 & 337 & 41 & -0.53 \\
\hline PL-7 & 542 & 48.9 & 0.09 & 0.0540 & 0.0007 & 0.3980 & 0.0071 & 0.0534 & 0.0009 & 339 & 4 & 343 & 37 & 0.41 \\
\hline PL-8 & 555 & 55.7 & 0.10 & 0.0539 & 0.0008 & 0.3957 & 0.0075 & 0.0532 & 0.0010 & 339 & 5 & 331 & 42 & 0.18 \\
\hline PL-9 & 554 & 60 & 0.11 & 0.0538 & 0.0008 & 0.3991 & 0.0069 & 0.0536 & 0.0010 & 338 & 5 & 354 & 42 & 0.94 \\
\hline PL-10 & 520 & 50.5 & 0.10 & 0.0545 & 0.0008 & 0.3977 & 0.0073 & 0.0528 & 0.0010 & 342 & 5 & 316 & 41 & -0.53 \\
\hline PL-11 & 597 & 69.4 & 0.12 & 0.0541 & 0.0007 & 0.3937 & 0.0074 & 0.0528 & 0.0009 & 340 & 4 & 316 & 39 & -0.89 \\
\hline PL-12 & 550 & 52 & 0.09 & 0.0537 & 0.0007 & 0.3922 & 0.0075 & 0.0532 & 0.0010 & 337 & 4 & 334 & 40 & -0.48 \\
\hline PL-13 & 562 & 53.8 & 0.10 & 0.0536 & 0.0007 & 0.3994 & 0.0073 & 0.0538 & 0.0010 & 337 & 4 & 351 & 43 & 1.58 \\
\hline PL-14 & 545 & 50.4 & 0.09 & 0.0540 & 0.0008 & 0.3932 & 0.0075 & 0.0529 & 0.0009 & 339 & 5 & 322 & 38 & -0.74 \\
\hline PL-15 & 582 & 53 & 0.09 & 0.0530 & 0.0011 & 0.3910 & 0.0100 & 0.0529 & 0.0011 & 333 & 7 & 315 & 48 & 0.48 \\
\hline PL-16 & 565 & 46.67 & 0.08 & 0.0533 & 0.0008 & 0.3887 & 0.0071 & 0.0526 & 0.0010 & 335 & 5 & 307 & 42 & -0.30 \\
\hline PL-17 & 548 & 43.41 & 0.08 & 0.0539 & 0.0008 & 0.3939 & 0.0082 & 0.0533 & 0.0010 & 338 & 5 & 341 & 41 & -0.24 \\
\hline PL-18 & 539 & 42.71 & 0.08 & 0.0534 & 0.0008 & 0.3991 & 0.0064 & 0.0538 & 0.0010 & 335 & 5 & 361 & 38 & 1.64 \\
\hline PL-19 & 545 & 42.58 & 0.08 & 0.0534 & 0.0007 & 0.3947 & 0.0074 & 0.0537 & 0.0009 & 335 & 4 & 353 & 39 & 0.68 \\
\hline PL-20 & 540 & 42.97 & 0.08 & 0.0539 & 0.0008 & 0.3980 & 0.0076 & 0.0537 & 0.0010 & 338 & 5 & 355 & 44 & 0.62 \\
\hline PL-21 & 556 & 45.83 & 0.08 & 0.0530 & 0.0008 & 0.3975 & 0.0077 & 0.0535 & 0.0011 & 333 & 5 & 356 & 48 & 2.21 \\
\hline PL-22 & 555 & 48.3 & 0.09 & 0.0532 & 0.0007 & 0.3938 & 0.0077 & 0.0534 & 0.0009 & 334 & 4 & 346 & 40 & 0.74 \\
\hline PL-23 & 533 & 41.15 & 0.08 & 0.0535 & 0.0008 & 0.3942 & 0.0085 & 0.0537 & 0.0010 & 336 & 5 & 349 & 43 & 0.68 \\
\hline PL-24 & 543 & 41.7 & 0.08 & 0.0531 & 0.0008 & 0.3946 & 0.0074 & 0.0544 & 0.0009 & 334 & 5 & 383 & 38 & 1.13 \\
\hline PL-25 & 571 & 43.4 & 0.08 & 0.0530 & 0.0008 & 0.3922 & 0.0072 & 0.0534 & 0.0011 & 333 & 5 & 340 & 45 & 0.89 \\
\hline PL-26 & 556 & 42.12 & 0.08 & 0.0534 & 0.0009 & 0.3963 & 0.0072 & 0.0539 & 0.0009 & 336 & 6 & 368 & 37 & 1.1 \\
\hline PL-27 & 557 & 40.7 & 0.07 & 0.0528 & 0.0008 & 0.3882 & 0.0072 & 0.0536 & 0.0010 & 332 & 5 & 345 & 43 & 0.4 \\
\hline PL-28 & 535 & 41.16 & 0.08 & 0.0532 & 0.0009 & 0.3868 & 0.0089 & 0.0530 & 0.0009 & 334 & 5 & 328 & 40 & -0.7 \\
\hline PL-29 & 567 & 47.69 & 0.08 & 0.0529 & 0.0008 & 0.3937 & 0.0074 & 0.0539 & 0.0010 & 332 & 5 & 362 & 44 & 1.4 \\
\hline PL-30 & 608 & 44.6 & 0.07 & 0.0534 & 0.0007 & 0.3883 & 0.0062 & 0.0528 & 0.0009 & 336 & 4 & 314 & 38 & -0.8 \\
\hline PL-31 & 598 & 44.1 & 0.07 & 0.0542 & 0.0008 & 0.3972 & 0.0076 & 0.0536 & 0.0011 & 341 & 5 & 352 & 44 & -0.4 \\
\hline PL-32 & 600 & 43.96 & 0.07 & 0.0536 & 0.0008 & 0.3917 & 0.0068 & 0.0532 & 0.0008 & 337 & 5 & 336 & 38 & -0.4 \\
\hline PL-33 & 600 & 43.99 & 0.07 & 0.0533 & 0.0009 & 0.3831 & 0.0069 & 0.0525 & 0.0010 & 335 & 6 & 304 & 45 & -1.8 \\
\hline PL-34 & 605 & 43.85 & 0.07 & 0.0528 & 0.0009 & 0.3894 & 0.0085 & 0.0535 & 0.0010 & 332 & 6 & 343 & 44 & 1.0 \\
\hline PL-35 & 578 & 45.9 & 0.08 & 0.0535 & 0.0009 & 0.3858 & 0.0087 & 0.0530 & 0.0010 & 336 & 6 & 317 & 45 & -1.5 \\
\hline PL-36 & 546 & 42.66 & 0.08 & 0.0525 & 0.0010 & 0.3851 & 0.0075 & 0.0539 & 0.0011 & 330 & 6 & 354 & 47 & 0.2 \\
\hline PL-37 & 534 & 39.5 & 0.07 & 0.0532 & 0.0009 & 0.3894 & 0.0086 & 0.0542 & 0.0011 & 334 & 6 & 368 & 44 & -0.1 \\
\hline PL-38 & 558 & 42.08 & 0.08 & 0.0528 & 0.0009 & 0.3906 & 0.0086 & 0.0541 & 0.0011 & 332 & 5 & 367 & 46 & 0.7 \\
\hline PL-39 & 536 & 40.8 & 0.08 & 0.0542 & 0.0009 & 0.4021 & 0.0076 & 0.0539 & 0.0010 & 340 & 6 & 362 & 41 & 0.8 \\
\hline PL-40 & 554 & 42.9 & 0.08 & 0.0536 & 0.0008 & 0.3943 & 0.0071 & 0.0536 & 0.0010 & 336 & 5 & 351 & 40 & 0.2 \\
\hline PL-41 & 551 & 42.35 & 0.08 & 0.0536 & 0.0009 & 0.3925 & 0.0082 & 0.0532 & 0.0010 & 337 & 5 & 331 & 43 & -0.2 \\
\hline PL-42 & 570 & 43 & 0.08 & 0.0526 & 0.0008 & 0.3957 & 0.0078 & 0.0539 & 0.0010 & 330 & 5 & 362 & 41 & 2.4 \\
\hline PL-43 & 499 & 35.32 & 0.07 & 0.0537 & 0.0009 & 0.3982 & 0.0092 & 0.0540 & 0.0012 & 337 & 5 & 364 & 49 & 0.8 \\
\hline PL-44 & 560 & 43.58 & 0.08 & 0.0534 & 0.0009 & 0.4014 & 0.0088 & 0.0541 & 0.0012 & 335 & 6 & 371 & 51 & 2.2 \\
\hline PL-45 & 559 & 43.69 & 0.08 & 0.0538 & 0.0009 & 0.3987 & 0.0085 & 0.0535 & 0.0010 & 338 & 6 & 348 & 41 & 0.8 \\
\hline PL-46 & 574 & 41 & 0.07 & 0.0534 & 0.0007 & 0.3968 & 0.0074 & 0.0529 & 0.0011 & 335 & 5 & 330 & 46 & 1.3 \\
\hline PL-47 & 566 & 40.29 & 0.07 & 0.0534 & 0.0008 & 0.4013 & 0.0082 & 0.0543 & 0.0011 & 335 & 5 & 375 & 46 & 2.3 \\
\hline PL-48 & 573 & 40.23 & 0.07 & 0.0540 & 0.0009 & 0.4053 & 0.0095 & 0.0540 & 0.0012 & 339 & 5 & 372 & 50 & 1.8 \\
\hline PL-49 & 556 & 43.4 & 0.08 & 0.0529 & 0.0010 & 0.3905 & 0.0077 & 0.0533 & 0.0010 & 332 & 6 & 332 & 42 & 0.6 \\
\hline PL-50 & 551 & 43.19 & 0.08 & 0.0535 & 0.0010 & 0.3902 & 0.0091 & 0.0531 & 0.0011 & 336 & 6 & 328 & 47 & -0.1 \\
\hline PL-51 & 494 & 34.94 & 0.07 & 0.0542 & 0.0010 & 0.4027 & 0.0099 & 0.0530 & 0.0012 & 340 & 6 & 318 & 50 & 1.0 \\
\hline PL-52 & 541 & 42.7 & 0.08 & 0.0534 & 0.0011 & 0.3960 & 0.0110 & 0.0536 & 0.0012 & 336 & 7 & 344 & 52 & 0.7 \\
\hline
\end{tabular}

\begin{tabular}{|c|c|c|c|c|c|c|c|c|c|c|c|c|c|c|}
\hline \multirow{3}{*}{$\begin{array}{l}\text { grain/spot } \\
\text { position }\end{array}$} & \multirow{3}{*}{$\begin{array}{c}\mathrm{U} \\
\mathrm{ppm}\end{array}$} & \multirow{3}{*}{$\begin{array}{l}\text { Th } \\
\text { ppm }\end{array}$} & \multirow[t]{3}{*}{$T h / U$} & \multicolumn{6}{|c|}{ Isotopic ratios } & \multicolumn{4}{|c|}{ Ages (in Ma) ${ }^{\mathrm{a}}$} & \multirow{3}{*}{$\begin{array}{r}\begin{array}{r}\text { Discor } \\
\text { dance }\end{array} \\
(\%)\end{array}$} \\
\hline & & & & \multirow[b]{2}{*}{${ }^{206} \mathrm{~Pb} /{ }^{238} \mathrm{U}$} & \multirow[b]{2}{*}{$2 \sigma$} & \multirow[b]{2}{*}{${ }^{207} \mathrm{~Pb} /{ }^{235} \mathrm{U}$} & \multicolumn{3}{|c|}{${ }^{207} \mathrm{~Pb} /{ }^{206} \mathrm{P}$} & \multirow[b]{2}{*}{${ }^{206} \mathrm{~Pb} /{ }^{238} \mathrm{U}$} & \multicolumn{3}{|c|}{${ }^{207} \mathrm{~Pb} /{ }^{206} \mathrm{P}$} & \\
\hline & & & & & & & $2 \sigma$ & $\mathrm{b}$ & $2 \sigma$ & & $2 \sigma$ & $\mathrm{b}$ & $2 \sigma$ & \\
\hline \multicolumn{15}{|c|}{ Hbl-bearing leucosome (sample } \\
\hline \multicolumn{15}{|l|}{ A2) } \\
\hline $5-1 d m$ & 74.3 & 63.8 & 0.86 & 0.0960 & 0.0017 & 0.7810 & 0.0260 & 0.0590 & 0.0019 & 591 & 10 & 558 & 69 & -1.2 \\
\hline $15-1 \mathrm{dm}$ & 86 & 91 & 1.06 & 0.0974 & 0.0021 & 0.8390 & 0.0370 & 0.0621 & 0.0024 & 599 & 12 & 653 & 86 & 2.8 \\
\hline $15-2 r$ & 56.4 & 50.1 & 0.89 & 0.0976 & 0.0022 & 0.8490 & 0.0320 & 0.0619 & 0.0019 & 600 & 13 & 662 & 68 & 4.2 \\
\hline $36-1 s z$ & 75.4 & 46.89 & 0.62 & 0.0979 & 0.0016 & 0.9470 & 0.0270 & 0.0704 & 0.0021 & 602 & 9 & 925 & 61 & 11.2 \\
\hline $2-2 r$ & 51.2 & 44.9 & 0.88 & 0.0982 & 0.0017 & 0.8100 & 0.0270 & 0.0590 & 0.0018 & 604 & 10 & 565 & 70 & -0.6 \\
\hline $22-3 r$ & 46.5 & 37.8 & 0.81 & 0.0985 & 0.0017 & 0.8330 & 0.0330 & 0.0602 & 0.0020 & 606 & 10 & 597 & 70 & 1.4 \\
\hline $11-1 s z$ & 157.8 & 198 & 1.25 & 0.0986 & 0.0017 & 0.8250 & 0.0260 & 0.0605 & 0.0015 & 606 & 10 & 612 & 55 & 0.9 \\
\hline $1-3 r$ & 60 & 50.1 & 0.84 & 0.0988 & 0.0014 & 0.8150 & 0.0230 & 0.0592 & 0.0015 & 607 & 8 & 566 & 57 & -0.2 \\
\hline $64-2 r$ & 44.3 & 38.5 & 0.87 & 0.0988 & 0.0017 & 0.8410 & 0.0250 & 0.0614 & 0.0019 & 608 & 10 & 640 & 65 & 2.0 \\
\hline $22-2 r$ & 47.1 & 35.91 & 0.76 & 0.0988 & 0.0017 & 0.8310 & 0.0320 & 0.0603 & 0.0024 & 608 & 10 & 605 & 87 & 0.6 \\
\hline $35-2 \mathrm{sz}$ & 88.9 & 66.2 & 0.74 & 0.0989 & 0.0014 & 0.8240 & 0.0190 & 0.0599 & 0.0011 & 608 & 8 & 611 & 41 & 0.4 \\
\hline $7-2$ re & 49.8 & 36 & 0.72 & 0.0990 & 0.0018 & 0.8210 & 0.0310 & 0.0600 & 0.0021 & 608 & 11 & 589 & 77 & 0.0 \\
\hline $63-2 r$ & 47.4 & 35.38 & 0.75 & 0.0990 & 0.0012 & 0.8200 & 0.0260 & 0.0592 & 0.0017 & 608 & 7 & 570 & 66 & 0.0 \\
\hline $45-1 \mathrm{dm}$ & 202.5 & 121 & 0.60 & 0.0990 & 0.0017 & 0.8340 & 0.0260 & 0.0611 & 0.0016 & 608 & 10 & 645 & 53 & 1.1 \\
\hline $55-2 r$ & 61.9 & 49.6 & 0.80 & 0.0991 & 0.0024 & 0.8220 & 0.0310 & 0.0610 & 0.0021 & 609 & 14 & 630 & 77 & -0.3 \\
\hline $10-2 s z$ & 47.1 & 38.8 & 0.82 & 0.0991 & 0.0016 & 0.8190 & 0.0260 & 0.0601 & 0.0017 & 609 & 10 & 580 & 63 & -0.4 \\
\hline $1-2 s z$ & 46.9 & 40.2 & 0.86 & 0.0992 & 0.0011 & 0.8270 & 0.0240 & 0.0609 & 0.0018 & 610 & 7 & 618 & 65 & 0.4 \\
\hline $60-2 s z$ & 62.2 & 51.4 & 0.83 & 0.0992 & 0.0016 & 0.8360 & 0.0270 & 0.0605 & 0.0020 & 610 & 10 & 621 & 70 & 1.0 \\
\hline $11-2 s z$ & 100.8 & 73 & 0.72 & 0.0992 & 0.0014 & 0.8230 & 0.0240 & 0.0601 & 0.0016 & 610 & 8 & 596 & 59 & 0.4 \\
\hline $57-1 d m$ & 66.9 & 59 & 0.88 & 0.0993 & 0.0020 & 0.8160 & 0.0300 & 0.0595 & 0.0018 & 610 & 12 & 572 & 68 & -1.2 \\
\hline $51-1 r$ & 45.2 & 37.6 & 0.83 & 0.0993 & 0.0020 & 0.8210 & 0.0290 & 0.0602 & 0.0018 & 610 & 12 & 605 & 64 & -0.2 \\
\hline $24-2 s z$ & 53.3 & 44.65 & 0.84 & 0.0993 & 0.0018 & 0.8400 & 0.0260 & 0.0611 & 0.0018 & 610 & 10 & 654 & 63 & 1.5 \\
\hline 29-1r & 45.3 & 29.32 & 0.65 & 0.0992 & 0.0018 & 0.8330 & 0.0230 & 0.0607 & 0.0017 & 610 & 10 & 625 & 60 & 1.0 \\
\hline $34-2 s z$ & 51.9 & 38.03 & 0.73 & 0.0993 & 0.0015 & 0.8290 & 0.0220 & 0.0597 & 0.0017 & 610 & 9 & 607 & 58 & 0.4 \\
\hline $45-3 r$ & 51 & 40.4 & 0.79 & 0.0994 & 0.0019 & 0.8230 & 0.0280 & 0.0603 & 0.0019 & 611 & 11 & 593 & 69 & -0.3 \\
\hline $35-1 s z$ & 100.8 & 111 & 1.10 & 0.0995 & 0.0013 & 0.8260 & 0.0210 & 0.0603 & 0.0014 & 611 & 8 & 601 & 51 & -0.2 \\
\hline
\end{tabular}




\begin{tabular}{|c|c|c|c|c|c|c|c|c|c|c|c|c|c|c|}
\hline $32-2 r$ & 78.2 & 66.93 & 0.86 & 0.0995 & 0.0013 & 0.8290 & 0.0190 & 0.0601 & 0.0012 & 611 & 8 & 601 & 44 & 0.1 \\
\hline $59-3 r$ & 52.5 & 41.8 & 0.80 & 0.0996 & 0.0022 & 0.8380 & 0.0330 & 0.0606 & 0.0021 & 612 & 13 & 610 & 77 & 0.5 \\
\hline $5-2 r$ & 58.4 & 60.7 & 1.04 & 0.0996 & 0.0023 & 0.8250 & 0.0300 & 0.0606 & 0.0018 & 612 & 13 & 645 & 63 & -0.7 \\
\hline $29-2 s z$ & 47.4 & 36.5 & 0.77 & 0.0997 & 0.0016 & 0.8310 & 0.0240 & 0.0607 & 0.0019 & 612 & 9 & 628 & 63 & 0.4 \\
\hline $36-2 r$ & 50.4 & 39.3 & 0.78 & 0.0997 & 0.0015 & 0.8390 & 0.0240 & 0.0616 & 0.0016 & 613 & 9 & 674 & 56 & 0.9 \\
\hline $12-2 \mathrm{sz}$ & 82.5 & 75.2 & 0.91 & 0.0997 & 0.0020 & 0.8510 & 0.0320 & 0.0605 & 0.0018 & 613 & 12 & 612 & 65 & 2.2 \\
\hline $13-2 r$ & 125.1 & 19.64 & 0.16 & 0.0997 & 0.0023 & 0.8470 & 0.0370 & 0.0607 & 0.0023 & 613 & 14 & 628 & 84 & 1.1 \\
\hline $64-1 \mathrm{dm}$ & 78.4 & 83.6 & 1.07 & 0.0998 & 0.0014 & 0.8330 & 0.0220 & 0.0606 & 0.0014 & 613 & 8 & 628 & 52 & 0.3 \\
\hline $7-1 \mathrm{dm}$ & 121 & 144.9 & 1.20 & 0.0999 & 0.0016 & 0.8230 & 0.0270 & 0.0599 & 0.0017 & 614 & 10 & 597 & 60 & -0.8 \\
\hline $60-3 \mathrm{sz}$ & 104 & 78.9 & 0.76 & 0.1000 & 0.0016 & 0.8350 & 0.0240 & 0.0603 & 0.0015 & 614 & 9 & 605 & 54 & 0.6 \\
\hline $10-1 \mathrm{sz}$ & 69.2 & 58.2 & 0.84 & 0.1001 & 0.0017 & 0.8420 & 0.0270 & 0.0609 & 0.0018 & 615 & 10 & 621 & 68 & 1.2 \\
\hline $57-2 r$ & 40.5 & 29.45 & 0.73 & 0.1002 & 0.0021 & 0.8330 & 0.0280 & 0.0599 & 0.0018 & 615 & 12 & 617 & 65 & 0.0 \\
\hline $34-3 r$ & 51.6 & 41.16 & 0.80 & 0.1002 & 0.0017 & 0.8140 & 0.0290 & 0.0586 & 0.0018 & 616 & 10 & 529 & 68 & -1.6 \\
\hline $24-3 r$ & 94.3 & 82.4 & 0.87 & 0.1003 & 0.0016 & 0.8380 & 0.0230 & 0.0600 & 0.0015 & 616 & 10 & 592 & 55 & 0.2 \\
\hline $39-2$ re & 160.4 & 104.1 & 0.65 & 0.1003 & 0.0017 & 0.8470 & 0.0240 & 0.0597 & 0.0015 & 616 & 10 & 591 & 55 & 1.6 \\
\hline $17-2 r$ & 50.4 & 41.9 & 0.83 & 0.1006 & 0.0021 & 0.8240 & 0.0320 & 0.0584 & 0.0020 & 618 & 12 & 549 & 78 & -1.8 \\
\hline 51-3re & 105.8 & 69.8 & 0.66 & 0.1008 & 0.0016 & 0.8460 & 0.0300 & 0.0598 & 0.0017 & 619 & 9 & 597 & 67 & 0.3 \\
\hline $2-1 \mathrm{dm}$ & 59.8 & 52.9 & 0.88 & 0.1009 & 0.0016 & 0.8510 & 0.0240 & 0.0609 & 0.0016 & 620 & 10 & 618 & 56 & 0.7 \\
\hline $51-2 \mathrm{dm}$ & 212 & 113.2 & 0.53 & 0.1011 & 0.0026 & 0.8340 & 0.0370 & 0.0605 & 0.0020 & 620 & 15 & 601 & 73 & -0.8 \\
\hline $42-2 r$ & 43.7 & 35.4 & 0.81 & 0.1010 & 0.0021 & 0.8440 & 0.0320 & 0.0607 & 0.0020 & 620 & 12 & 628 & 67 & -0.2 \\
\hline $45-2 r$ & 56.1 & 45.7 & 0.81 & 0.1011 & 0.0016 & 0.8760 & 0.0300 & 0.0627 & 0.0018 & 621 & 10 & 678 & 63 & 3.0 \\
\hline $46-2 r$ & 57.6 & 39.7 & 0.69 & 0.1013 & 0.0019 & 0.8330 & 0.0290 & 0.0601 & 0.0018 & 622 & 11 & 600 & 67 & -1.3 \\
\hline $46-3 \mathrm{re}$ & 207.4 & 44.6 & 0.22 & 0.1016 & 0.0018 & 0.8470 & 0.0260 & 0.0601 & 0.0015 & 625 & 11 & 608 & 53 & -0.3 \\
\hline $55-1 \mathrm{dm}$ & 66.8 & 55.8 & 0.84 & 0.1023 & 0.0019 & 0.9250 & 0.0340 & 0.0660 & 0.0018 & 628 & 11 & 806 & 58 & 5.7 \\
\hline $22-1 c$ & 86.9 & 44.7 & 0.51 & 0.1044 & 0.0020 & 0.8770 & 0.0300 & 0.0606 & 0.0017 & 641 & 12 & 642 & 58 & -0.2 \\
\hline $59-1 \mathrm{c}$ & 110.5 & 106.5 & 0.96 & 0.1053 & 0.0016 & 0.9100 & 0.0320 & 0.0621 & 0.0018 & 645 & 10 & 696 & 61 & 1.3 \\
\hline $52-1 c$ & 94.2 & 51.6 & 0.55 & 0.1056 & 0.0017 & 0.8870 & 0.0280 & 0.0611 & 0.0018 & 647 & 10 & 640 & 67 & -0.7 \\
\hline $60-1 c$ & 192 & 117.6 & 0.61 & 0.1055 & 0.0018 & 0.9070 & 0.0310 & 0.0617 & 0.0018 & 647 & 11 & 656 & 63 & 1.2 \\
\hline $13-1 \mathrm{c}$ & 143.4 & 121.3 & 0.85 & 0.1055 & 0.0022 & 0.9120 & 0.0370 & 0.0617 & 0.0019 & 647 & 13 & 649 & 66 & 2.0 \\
\hline $37-1 c$ & 90.7 & 46.26 & 0.51 & 0.1057 & 0.0015 & 0.8950 & 0.0170 & 0.0607 & 0.0012 & 648 & 9 & 638 & 45 & 0.4 \\
\hline $34-1 c$ & 252.7 & 165.2 & 0.65 & 0.1058 & 0.0015 & 0.8850 & 0.0210 & 0.0616 & 0.0011 & 648 & 9 & 651 & 39 & -0.6 \\
\hline $63-1 c$ & 225 & 132.5 & 0.59 & 0.1058 & 0.0013 & 0.9000 & 0.0210 & 0.0613 & 0.0013 & 648 & 8 & 660 & 46 & 0.4 \\
\hline $39-1 c$ & 218 & 66 & 0.30 & 0.1059 & 0.0017 & 0.8910 & 0.0200 & 0.0607 & 0.0012 & 649 & 10 & 621 & 42 & -0.6 \\
\hline $17-1 \mathrm{c}$ & 180 & 115 & 0.64 & 0.1059 & 0.0020 & 0.8910 & 0.0300 & 0.0610 & 0.0018 & 649 & 12 & 622 & 63 & -0.5 \\
\hline $1-1 c$ & 216 & 202 & 0.94 & 0.1061 & 0.0015 & 0.8920 & 0.0210 & 0.0607 & 0.0014 & 650 & 9 & 629 & 49 & -0.3 \\
\hline $59-2 c$ & 236 & 97.4 & 0.41 & 0.1062 & 0.0019 & 0.9080 & 0.0360 & 0.0624 & 0.0020 & 650 & 11 & 671 & 71 & 0.5 \\
\hline $24-1 c$ & 302 & 114 & 0.38 & 0.1062 & 0.0018 & 0.8950 & 0.0240 & 0.0603 & 0.0014 & 651 & 11 & 618 & 46 & -0.6 \\
\hline $37-2 c$ & 106.3 & 73.1 & 0.69 & 0.1071 & 0.0023 & 0.9160 & 0.0290 & 0.0612 & 0.0015 & 655 & 13 & 649 & 54 & 0.6 \\
\hline $42-1 c$ & 58.4 & 23 & 0.39 & 0.1075 & 0.0022 & 0.9050 & 0.0280 & 0.0614 & 0.0018 & 658 & 13 & 643 & 62 & -0.3 \\
\hline $26-1 c$ & 243 & 137 & 0.56 & 0.1079 & 0.0017 & 0.9130 & 0.0200 & 0.0609 & 0.0011 & 661 & 10 & 634 & 39 & -0.4 \\
\hline $29-3 c$ & 122.8 & 76.3 & 0.62 & 0.1080 & 0.0024 & 0.9090 & 0.0240 & 0.0609 & 0.0014 & 661 & 14 & 641 & 52 & -0.9 \\
\hline $26-2 c$ & 128.8 & 69.1 & 0.54 & 0.1086 & 0.0018 & 0.9160 & 0.0210 & 0.0608 & 0.0012 & 664 & 11 & 626 & 41 & -0.8 \\
\hline $46-1 c$ & 169 & 113 & 0.67 & 0.1097 & 0.0019 & 0.9340 & 0.0310 & 0.0618 & 0.0017 & 671 & 11 & 669 & 59 & -0.3 \\
\hline $12-1 c$ & 92.6 & 41.66 & 0.45 & 0.1104 & 0.0018 & 0.9500 & 0.0300 & 0.0616 & 0.0016 & 675 & 11 & 650 & 57 & 0.1 \\
\hline $32-1 c$ & 174 & 97 & 0.56 & 0.1156 & 0.0024 & 0.9910 & 0.0260 & 0.0616 & 0.0016 & 705 & 14 & 665 & 58 & -1.0 \\
\hline
\end{tabular}

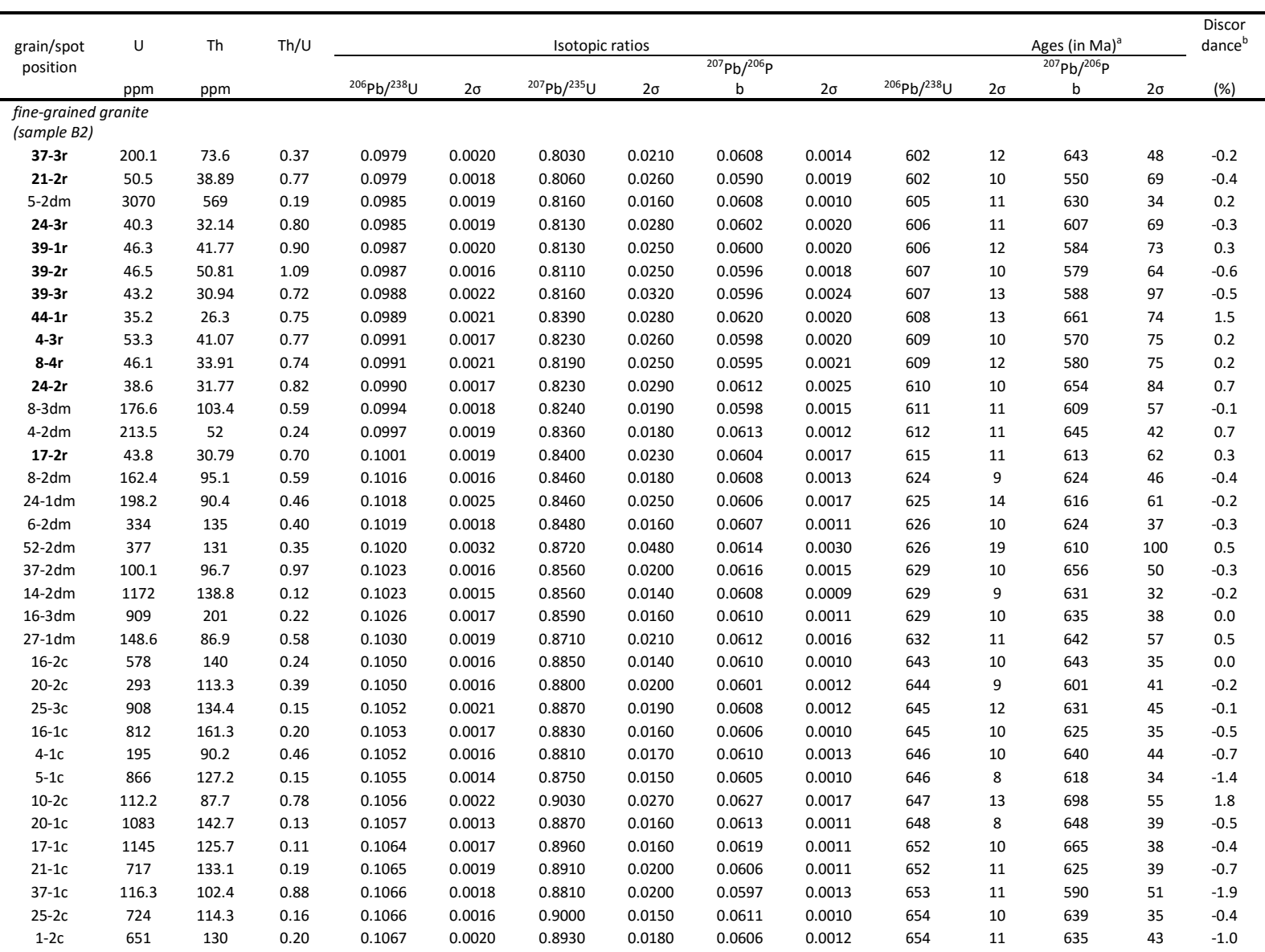




\begin{tabular}{|c|c|c|c|c|c|c|c|c|c|c|c|c|c|c|}
\hline $36-1 c$ & 149.9 & 75.5 & 0.50 & 0.1068 & 0.0022 & 0.8980 & 0.0240 & 0.0613 & 0.0015 & 654 & 13 & 664 & 55 & -0.8 \\
\hline $14-1 c$ & 760 & 121.2 & 0.16 & 0.1072 & 0.0016 & 0.8950 & 0.0160 & 0.0607 & 0.0010 & 657 & 9 & 638 & 36 & -1.2 \\
\hline $1-1 c$ & 1010 & 133.2 & 0.13 & 0.1072 & 0.0021 & 0.9020 & 0.0220 & 0.0608 & 0.0011 & 657 & 13 & 633 & 41 & -0.8 \\
\hline $41-3 c$ & 49.7 & 36.32 & 0.73 & 0.1074 & 0.0024 & 0.9090 & 0.0310 & 0.0608 & 0.0019 & 657 & 14 & 635 & 70 & -0.3 \\
\hline $8-1 c$ & 723 & 139.8 & 0.19 & 0.1075 & 0.0020 & 0.9110 & 0.0190 & 0.0611 & 0.0012 & 658 & 12 & 645 & 39 & -0.2 \\
\hline $6-1 c$ & 1004 & 110.6 & 0.11 & 0.1075 & 0.0021 & 0.9130 & 0.0200 & 0.0611 & 0.0012 & 658 & 12 & 641 & 41 & 0.0 \\
\hline $25-1 \mathrm{c}$ & 701 & 142.2 & 0.20 & 0.1081 & 0.0018 & 0.9140 & 0.0190 & 0.0610 & 0.0011 & 662 & 10 & 640 & 37 & -0.5 \\
\hline $10-1 c$ & 1200 & 606 & 0.51 & 0.1106 & 0.0022 & 0.9510 & 0.0190 & 0.0622 & 0.0012 & 676 & 13 & 685 & 40 & 0.3 \\
\hline $41-1 c$ & 141 & 54 & 0.38 & 0.1125 & 0.0024 & 0.9540 & 0.0230 & 0.0619 & 0.0014 & 687 & 14 & 663 & 47 & -1.2 \\
\hline $41-2 c$ & 792 & 170.6 & 0.22 & 0.1125 & 0.0024 & 0.9550 & 0.0230 & 0.0626 & 0.0012 & 687 & 14 & 695 & 39 & -1.0 \\
\hline $53-1 r$ & 43.4 & 30.5 & 0.70 & 0.0981 & 0.0032 & 0.8470 & 0.0540 & 0.0613 & 0.0035 & 603 & 18 & 560 & 120 & 2.0 \\
\hline $58-1 r$ & 233 & 224.2 & 0.96 & 0.0991 & 0.0024 & 0.8610 & 0.0410 & 0.0618 & 0.0026 & 609 & 14 & 630 & 90 & 2.6 \\
\hline $53-2 \mathrm{dm}$ & 266 & 68.4 & 0.26 & 0.0984 & 0.0028 & 0.8540 & 0.0500 & 0.0611 & 0.0030 & 605 & 16 & 590 & 100 & 2.6 \\
\hline $52-1 \mathrm{dm}$ & 494 & 172.2 & 0.35 & 0.0994 & 0.0027 & 0.8750 & 0.0510 & 0.0625 & 0.0032 & 610 & 16 & 620 & 110 & 3.9 \\
\hline $58-2 \mathrm{dm}$ & 429 & 423 & 0.99 & 0.1016 & 0.0024 & 1.1070 & 0.0580 & 0.0787 & 0.0041 & 624 & 14 & 1160 & 110 & 16.9 \\
\hline $36-2 r$ & 39.3 & 27.32 & 0.70 & 0.0995 & 0.0020 & 0.7970 & 0.0250 & 0.0581 & 0.0017 & 611 & 12 & 527 & 63 & -3.0 \\
\hline \multirow{3}{*}{$\begin{array}{c}\text { grain/spot } \\
\text { position }\end{array}$} & U & Th & $\mathrm{Th} / \mathrm{U}$ & & & Isotopi & atios & & & & & es (in $\mathrm{M}$ & & $\begin{array}{l}\text { Discor } \\
\text { dance }^{\mathrm{b}}\end{array}$ \\
\hline & & & & & & & & ${ }^{207} \mathrm{~Pb} /{ }^{206} \mathrm{P}$ & & & & ${ }^{77} \mathrm{~Pb} / /^{206}$ & & \\
\hline & $\mathrm{ppm}$ & $\mathrm{ppm}$ & & ${ }^{206} \mathrm{~Pb} /{ }^{238} \mathrm{U}$ & $2 \sigma$ & ${ }^{207} \mathrm{~Pb} /{ }^{235} \mathrm{U}$ & $2 \sigma$ & b & $2 \sigma$ & ${ }^{206} \mathrm{~Pb} /{ }^{238} \mathrm{U}$ & $2 \sigma$ & b & $2 \sigma$ & $(\%)$ \\
\hline $\begin{array}{l}\text { Opx-bearin } \\
\text { (1) }\end{array}$ & ucosom & ample & & & & & & & & & & & & \\
\hline $13-2 s z$ & 102.2 & 53.6 & 0.52 & 0.0977 & 0.0022 & 0.8060 & 0.0350 & 0.0594 & 0.0023 & 601 & 13 & 563 & 85 & -0.7 \\
\hline $21-1 s z$ & 271 & 174 & 0.64 & 0.0977 & 0.0023 & 0.8110 & 0.0320 & 0.0601 & 0.0021 & 601 & 13 & 610 & 76 & -0.2 \\
\hline $64-1 s z$ & 145 & 72.9 & 0.50 & 0.0979 & 0.0022 & 0.8180 & 0.0340 & 0.0599 & 0.0021 & 602 & 13 & 593 & 80 & 0.3 \\
\hline 31-1re & 160.5 & 93.2 & 0.58 & 0.0980 & 0.0019 & 0.8200 & 0.0260 & 0.0592 & 0.0017 & 603 & 11 & 582 & 60 & 0.7 \\
\hline $48-2 s z$ & 197.5 & 123.1 & 0.62 & 0.0979 & 0.0030 & 0.8200 & 0.0410 & 0.0609 & 0.0027 & 604 & 18 & 611 & 100 & 0.7 \\
\hline $17-2 s z$ & 112.8 & 69.6 & 0.62 & 0.0983 & 0.0018 & 0.8360 & 0.0300 & 0.0615 & 0.0020 & 604 & 11 & 639 & 70 & 1.7 \\
\hline $57-2 s z$ & 243.8 & 177.5 & 0.73 & 0.0986 & 0.0022 & 0.8260 & 0.0280 & 0.0608 & 0.0018 & 606 & 13 & 612 & 62 & 0.5 \\
\hline $39-1 s z$ & 138.6 & 81.7 & 0.59 & 0.0986 & 0.0022 & 0.8300 & 0.0320 & 0.0610 & 0.0020 & 606 & 13 & 622 & 70 & 1.5 \\
\hline 49-1re & 211.5 & 130.6 & 0.62 & 0.0987 & 0.0019 & 0.8210 & 0.0230 & 0.0604 & 0.0016 & 607 & 11 & 627 & 61 & 0.0 \\
\hline $58-1 s z$ & 186.4 & 97.9 & 0.53 & 0.0988 & 0.0027 & 0.8300 & 0.0410 & 0.0608 & 0.0026 & 607 & 16 & 607 & 91 & 0.7 \\
\hline 11-1re & 107.8 & 59.9 & 0.56 & 0.0987 & 0.0019 & 0.8250 & 0.0310 & 0.0608 & 0.0022 & 607 & 11 & 621 & 78 & 0.8 \\
\hline $5-2 s z$ & 230 & 132.5 & 0.58 & 0.0989 & 0.0014 & 0.8250 & 0.0200 & 0.0605 & 0.0014 & 608 & 8 & 617 & 50 & 0.8 \\
\hline $45-2$ re & 202 & 270 & 1.34 & 0.0989 & 0.0023 & 0.8280 & 0.0310 & 0.0606 & 0.0021 & 608 & 13 & 607 & 74 & 0.3 \\
\hline $4-2 s z$ & 163.7 & 89.8 & 0.55 & 0.0991 & 0.0016 & 0.8240 & 0.0230 & 0.0595 & 0.0016 & 609 & 10 & 609 & 56 & 0.0 \\
\hline 23-1re & 173 & 97 & 0.56 & 0.0992 & 0.0028 & 0.8340 & 0.0390 & 0.0607 & 0.0025 & 609 & 16 & 623 & 90 & 0.5 \\
\hline $25-2 s z$ & 150.6 & 97.1 & 0.64 & 0.0991 & 0.0029 & 0.8340 & 0.0430 & 0.0613 & 0.0029 & 609 & 17 & 620 & 100 & 0.5 \\
\hline $39-2 \mathrm{sz}$ & 203 & 150.5 & 0.74 & 0.0990 & 0.0019 & 0.8330 & 0.0290 & 0.0606 & 0.0019 & 609 & 11 & 606 & 66 & 0.7 \\
\hline $66-1 s z$ & 142.9 & 80 & 0.56 & 0.0991 & 0.0020 & 0.8360 & 0.0310 & 0.0612 & 0.0020 & 609 & 12 & 619 & 71 & 0.8 \\
\hline $05-1 s z$ & 187.7 & 119.1 & 0.63 & 0.0992 & 0.0016 & 0.8420 & 0.0200 & 0.0612 & 0.0015 & 609 & 9 & 630 & 51 & 1.6 \\
\hline $40-2 s z$ & 188.5 & 113.2 & 0.60 & 0.0993 & 0.0020 & 0.8360 & 0.0280 & 0.0601 & 0.0018 & 610 & 12 & 610 & 67 & 0.8 \\
\hline $29-2$ re & 172 & 115 & 0.67 & 0.0990 & 0.0022 & 0.8400 & 0.0280 & 0.0612 & 0.0019 & 610 & 12 & 637 & 66 & 1.3 \\
\hline $2-2 \mathrm{re}$ & 106.6 & 58.5 & 0.55 & 0.0994 & 0.0017 & 0.8250 & 0.0250 & 0.0601 & 0.0017 & 611 & 10 & 605 & 63 & 0.7 \\
\hline 31-1re & 162 & 121.9 & 0.75 & 0.0994 & 0.0021 & 0.8260 & 0.0280 & 0.0609 & 0.0020 & 611 & 13 & 624 & 71 & -0.3 \\
\hline $32-1$ re & 181.9 & 163.1 & 0.90 & 0.0994 & 0.0027 & 0.8310 & 0.0350 & 0.0601 & 0.0022 & 611 & 16 & 585 & 81 & 0.3 \\
\hline $57-1 s z$ & 248 & 238 & 0.96 & 0.0995 & 0.0019 & 0.8370 & 0.0240 & 0.0606 & 0.0017 & 611 & 11 & 620 & 60 & 1.1 \\
\hline 7-1re & 189.2 & 102.8 & 0.54 & 0.0995 & 0.0017 & 0.8330 & 0.0210 & 0.0608 & 0.0015 & 611 & 10 & 627 & 52 & 0.8 \\
\hline $60-1 \mathrm{sz}$ & 131.8 & 70.3 & 0.53 & 0.0995 & 0.0022 & 0.8400 & 0.0360 & 0.0602 & 0.0023 & 612 & 13 & 575 & 84 & 0.6 \\
\hline $25-1 s z$ & 170.4 & 105.6 & 0.62 & 0.0997 & 0.0025 & 0.8470 & 0.0390 & 0.0607 & 0.0024 & 612 & 14 & 592 & 87 & 1.0 \\
\hline $3-2 s z$ & 230.9 & 132.3 & 0.57 & 0.0996 & 0.0015 & 0.8270 & 0.0190 & 0.0596 & 0.0013 & 612 & 9 & 589 & 49 & 0.0 \\
\hline $2-1 s z$ & 113.5 & 61.7 & 0.54 & 0.0996 & 0.0016 & 0.8340 & 0.0190 & 0.0606 & 0.0014 & 612 & 9 & 628 & 50 & 0.5 \\
\hline 1-2re & 174.2 & 103.6 & 0.59 & 0.0995 & 0.0016 & 0.8260 & 0.0200 & 0.0605 & 0.0013 & 613 & 9 & 621 & 49 & -0.4 \\
\hline $36-2$ re & 107.4 & 57.3 & 0.53 & 0.1000 & 0.0027 & 0.8380 & 0.0370 & 0.0612 & 0.0025 & 614 & 16 & 617 & 87 & 0.0 \\
\hline $32-2$ re & 124.8 & 110 & 0.88 & 0.0999 & 0.0021 & 0.8360 & 0.0310 & 0.0604 & 0.0021 & 614 & 13 & 609 & 76 & 0.5 \\
\hline 22-1re & 250.6 & 250.4 & 1.00 & 0.1000 & 0.0023 & 0.8490 & 0.0320 & 0.0610 & 0.0020 & 614 & 13 & 650 & 69 & 1.0 \\
\hline $28-1 s z$ & 189 & 113.7 & 0.60 & 0.1002 & 0.0021 & 0.8420 & 0.0280 & 0.0605 & 0.0019 & 615 & 12 & 606 & 64 & 0.8 \\
\hline $50-1 \mathrm{sz}$ & 162.4 & 100.5 & 0.62 & 0.1004 & 0.0019 & 0.8370 & 0.0260 & 0.0607 & 0.0018 & 616 & 11 & 620 & 63 & 0.3 \\
\hline $40-1 s z$ & 286 & 143.5 & 0.50 & 0.1002 & 0.0021 & 0.8470 & 0.0280 & 0.0610 & 0.0017 & 616 & 12 & 624 & 62 & 0.8 \\
\hline 24-1re & 221 & 133 & 0.60 & 0.1004 & 0.0032 & 0.8520 & 0.0410 & 0.0622 & 0.0028 & 616 & 19 & 631 & 97 & 1.0 \\
\hline $4-1 s z$ & 217.5 & 129 & 0.59 & 0.1003 & 0.0015 & 0.8350 & 0.0200 & 0.0605 & 0.0014 & 616 & 9 & 628 & 49 & -0.1 \\
\hline $62-1 \mathrm{sz}$ & 224 & 130.8 & 0.58 & 0.1005 & 0.0021 & 0.8470 & 0.0350 & 0.0609 & 0.0024 & 617 & 12 & 612 & 82 & 1.0 \\
\hline $36-1 \mathrm{re}$ & 139.6 & 69 & 0.49 & 0.1007 & 0.0024 & 0.8560 & 0.0360 & 0.0615 & 0.0023 & 618 & 14 & 657 & 76 & 1.0 \\
\hline $50-2 s z$ & 209.1 & 110 & 0.53 & 0.1007 & 0.0017 & 0.8450 & 0.0220 & 0.0611 & 0.0016 & 619 & 10 & 623 & 56 & 0.5 \\
\hline $3-1 s z$ & 240 & 145.6 & 0.61 & 0.1009 & 0.0015 & 0.8500 & 0.0240 & 0.0612 & 0.0015 & 620 & 9 & 644 & 52 & 0.6 \\
\hline $53-2 \mathrm{sz}$ & 169.8 & 90.5 & 0.53 & 0.1011 & 0.0025 & 0.8420 & 0.0340 & 0.0599 & 0.0020 & 620 & 14 & 581 & 74 & 0.2 \\
\hline 14-1re & 57.3 & 25.95 & 0.45 & 0.1011 & 0.0026 & 0.8510 & 0.0400 & 0.0602 & 0.0025 & 621 & 15 & 594 & 92 & 0.5 \\
\hline 1-1re & 138 & 105 & 0.76 & 0.1012 & 0.0017 & 0.8440 & 0.0240 & 0.0608 & 0.0016 & 621 & 10 & 624 & 56 & 0.1 \\
\hline $41-1 \mathrm{sz}$ & 149.5 & 82.3 & 0.55 & 0.1010 & 0.0026 & 0.8750 & 0.0410 & 0.0615 & 0.0025 & 622 & 15 & 644 & 87 & 2.0 \\
\hline $13-1 s z$ & 131.7 & 72.4 & 0.55 & 0.1010 & 0.0024 & 0.8590 & 0.0390 & 0.0608 & 0.0026 & 620 & 14 & 634 & 94 & 2.1 \\
\hline $44-1 s z$ & 131.5 & 68.6 & 0.52 & 0.1013 & 0.0027 & 0.8480 & 0.0360 & 0.0613 & 0.0023 & 622 & 16 & 637 & 80 & -0.3 \\
\hline 59-1re & 105.4 & 16.4 & 0.16 & 0.1013 & 0.0027 & 0.8590 & 0.0380 & 0.0614 & 0.0022 & 622 & 16 & 659 & 75 & 0.6 \\
\hline $53-1 \mathrm{sz}$ & 143.4 & 81.2 & 0.57 & 0.1011 & 0.0022 & 0.8580 & 0.0350 & 0.0605 & 0.0020 & 622 & 13 & 597 & 72 & 0.6 \\
\hline $58-2 \mathrm{re}$ & 219 & 116.4 & 0.53 & 0.1014 & 0.0020 & 0.8520 & 0.0280 & 0.0606 & 0.0017 & 623 & 12 & 609 & 61 & 0.2 \\
\hline 29-1re & 194 & 140.3 & 0.72 & 0.1015 & 0.0019 & 0.8530 & 0.0250 & 0.0612 & 0.0018 & 623 & 11 & 634 & 60 & 0.2 \\
\hline $60-2$ re & 181.7 & 111.2 & 0.61 & 0.1020 & 0.0027 & 0.8640 & 0.0370 & 0.0617 & 0.0025 & 626 & 16 & 646 & 84 & 0.6 \\
\hline 38-1re & 261.6 & 242 & 0.93 & 0.1031 & 0.0022 & 0.8750 & 0.0310 & 0.0602 & 0.0018 & 634 & 13 & 614 & 64 & 0.5 \\
\hline $7-2 c$ & 220 & 250 & 1.14 & 0.1047 & 0.0016 & 0.8780 & 0.0190 & 0.0604 & 0.0013 & 642 & 9 & 613 & 47 & -0.2 \\
\hline $51-1 \mathrm{c}$ & 58.1 & 20.76 & 0.36 & 0.1062 & 0.0027 & 0.8870 & 0.0470 & 0.0605 & 0.0027 & 650 & 15 & 593 & 96 & -1.6 \\
\hline $48-1 c$ & 184.7 & 124.7 & 0.68 & 0.1070 & 0.0022 & 0.9050 & 0.0310 & 0.0608 & 0.0018 & 655 & 13 & 635 & 64 & -0.5 \\
\hline $45-1 c$ & 60.5 & 33.6 & 0.56 & 0.1073 & 0.0023 & 0.9100 & 0.0290 & 0.0620 & 0.0017 & 657 & 13 & 673 & 61 & 0.2 \\
\hline $38-2 c$ & 260 & 367 & 1.41 & 0.1163 & 0.0030 & 1.0080 & 0.0450 & 0.0610 & 0.0020 & 709 & 18 & 630 & 72 & -0.1 \\
\hline $44-2 c$ & 132.2 & 70.1 & 0.53 & 0.1035 & 0.0027 & 0.8990 & 0.0400 & 0.0617 & 0.0024 & 634 & 16 & 626 & 85 & 1.9 \\
\hline $41-2 \mathrm{sz}$ & 142.2 & 74.4 & 0.52 & 0.1015 & 0.0029 & 0.8890 & 0.0460 & 0.0614 & 0.0025 & 623 & 17 & 638 & 88 & 3.0 \\
\hline
\end{tabular}




\begin{tabular}{|c|c|c|c|c|c|c|c|c|c|c|c|c|c|c|}
\hline \multirow{3}{*}{$\begin{array}{c}\text { grain/spot } \\
\text { position }\end{array}$} & \multirow{3}{*}{$\begin{array}{c}\mathrm{U} \\
\mathrm{ppm}\end{array}$} & \multirow{3}{*}{$\begin{array}{l}\text { Th } \\
\text { ppm }\end{array}$} & \multirow[t]{3}{*}{ Th/U } & \multicolumn{6}{|c|}{ Isotopic ratios } & \multicolumn{4}{|c|}{ Ages (in Ma) ${ }^{a}$} & \multirow{3}{*}{$\begin{array}{c}\begin{array}{c}\text { Discor } \\
\text { dance }\end{array} \\
(\%)\end{array}$} \\
\hline & & & & \multirow[b]{2}{*}{${ }^{206} \mathrm{~Pb} /{ }^{238} \mathrm{U}$} & \multirow[b]{2}{*}{$2 \sigma$} & \multirow[b]{2}{*}{${ }^{207} \mathrm{~Pb} /{ }^{235} \mathrm{U}$} & & ${ }^{207} \mathrm{~Pb} /{ }^{206} \mathrm{P}$ & & & & ${ }^{77} \mathrm{~Pb} / 206$ & & \\
\hline & & & & & & & $2 \sigma$ & $\mathrm{b}$ & $2 \sigma$ & ${ }^{206} \mathrm{~Pb} /{ }^{238} \mathrm{U}$ & $2 \sigma$ & $\mathrm{b}$ & $2 \sigma$ & \\
\hline $\begin{array}{l}\text { Felsic granu } \\
\text { (sample A1) }\end{array}$ & & & & & & & & & & & & & & \\
\hline $45-1 c$ & 63.2 & 35.8 & 0.57 & 0.1037 & 0.0025 & 0.8670 & 0.0360 & 0.0611 & 0.0024 & 636 & 15 & 607 & 83 & -0.6 \\
\hline $61-2 r$ & 91.5 & 63.9 & 0.70 & 0.1038 & 0.0015 & 0.8640 & 0.0190 & 0.0611 & 0.0013 & 636 & 9 & 635 & 45 & -0.8 \\
\hline $54-1 \mathrm{c}$ & 200.5 & 144.5 & 0.72 & 0.1039 & 0.0021 & 0.8810 & 0.0320 & 0.0608 & 0.0017 & 637 & 12 & 628 & 62 & 0.3 \\
\hline $12-3 c$ & 85.1 & 60 & 0.71 & 0.1043 & 0.0017 & 0.8790 & 0.0230 & 0.0625 & 0.0015 & 639 & 10 & 676 & 53 & 0.2 \\
\hline $8-2 c$ & 95 & 65 & 0.68 & 0.1045 & 0.0016 & 0.8740 & 0.0200 & 0.0611 & 0.0014 & 641 & 10 & 642 & 51 & -0.6 \\
\hline $13-2 c$ & 255 & 94.4 & 0.37 & 0.1047 & 0.0018 & 0.8780 & 0.0270 & 0.0602 & 0.0014 & 642 & 10 & 618 & 52 & -0.6 \\
\hline $28-2 c$ & 70.4 & 37.4 & 0.53 & 0.1047 & 0.0024 & 0.8950 & 0.0470 & 0.0626 & 0.0030 & 642 & 14 & 690 & 100 & 1.1 \\
\hline $61-1 c$ & 237 & 159.7 & 0.67 & 0.1048 & 0.0016 & 0.8730 & 0.0160 & 0.0610 & 0.0010 & 643 & 9 & 636 & 34 & -0.9 \\
\hline $39-2 c$ & 126.9 & 91.7 & 0.72 & 0.1050 & 0.0020 & 0.8970 & 0.0310 & 0.0614 & 0.0018 & 643 & 11 & 646 & 62 & 1.1 \\
\hline $1-1 c$ & 100.5 & 67 & 0.67 & 0.1049 & 0.0021 & 0.8770 & 0.0240 & 0.0605 & 0.0014 & 643 & 12 & 626 & 49 & -0.8 \\
\hline $12-2 c$ & 77.1 & 43.8 & 0.57 & 0.1049 & 0.0013 & 0.8750 & 0.0230 & 0.0613 & 0.0015 & 644 & 8 & 649 & 52 & -0.6 \\
\hline $8-1 c$ & 128.3 & 70.7 & 0.55 & 0.1052 & 0.0016 & 0.8700 & 0.0200 & 0.0605 & 0.0014 & 645 & 9 & 623 & 51 & -1.4 \\
\hline $47-1 c$ & 84.7 & 60.8 & 0.72 & 0.1053 & 0.0023 & 0.8810 & 0.0330 & 0.0603 & 0.0019 & 645 & 13 & 604 & 70 & -1.1 \\
\hline $31-2 c$ & 134.8 & 73.8 & 0.55 & 0.1052 & 0.0020 & 0.9100 & 0.0350 & 0.0618 & 0.0018 & 645 & 12 & 657 & 60 & 1.8 \\
\hline $10-2 c$ & 90.4 & 43.45 & 0.48 & 0.1053 & 0.0014 & 0.8850 & 0.0190 & 0.0613 & 0.0012 & 645 & 8 & 642 & 43 & -0.3 \\
\hline $54-2 r$ & 117.5 & 62.3 & 0.53 & 0.1054 & 0.0021 & 0.8890 & 0.0250 & 0.0599 & 0.0014 & 646 & 12 & 591 & 48 & -0.2 \\
\hline $14-1 c$ & 235.4 & 94.5 & 0.40 & 0.1055 & 0.0018 & 0.8890 & 0.0300 & 0.0610 & 0.0017 & 646 & 10 & 640 & 58 & 0.5 \\
\hline $42-3 c$ & 41 & 15.13 & 0.37 & 0.1055 & 0.0019 & 0.8880 & 0.0360 & 0.0616 & 0.0025 & 647 & 11 & 631 & 87 & 0.2 \\
\hline $18-2 \mathrm{c}$ & 141.7 & 72.9 & 0.51 & 0.1055 & 0.0023 & 0.8850 & 0.0340 & 0.0611 & 0.0019 & 648 & 13 & 637 & 69 & -1.3 \\
\hline $39-1 c$ & 187 & 147.8 & 0.79 & 0.1057 & 0.0020 & 0.9020 & 0.0320 & 0.0612 & 0.0017 & 648 & 12 & 645 & 61 & 0.5 \\
\hline $1-2 r$ & 34.3 & 13.28 & 0.39 & 0.1060 & 0.0016 & 0.9000 & 0.0300 & 0.0613 & 0.0022 & 649 & 10 & 631 & 79 & -0.1 \\
\hline $23-2 c$ & 166 & 92 & 0.55 & 0.1059 & 0.0019 & 0.9090 & 0.0340 & 0.0617 & 0.0018 & 649 & 11 & 666 & 63 & 1.4 \\
\hline $7-1 c$ & 209.2 & 228.3 & 1.09 & 0.1060 & 0.0013 & 0.8870 & 0.0200 & 0.0607 & 0.0011 & 650 & 8 & 624 & 41 & -0.7 \\
\hline $47-2 c$ & 145.5 & 74.6 & 0.51 & 0.1061 & 0.0021 & 0.9180 & 0.0310 & 0.0632 & 0.0019 & 650 & 12 & 697 & 64 & 1.5 \\
\hline $25-2 c$ & 108 & 61 & 0.56 & 0.1061 & 0.0024 & 0.9060 & 0.0310 & 0.0620 & 0.0018 & 650 & 14 & 681 & 64 & 0.6 \\
\hline $7-2 c$ & 60.3 & 27.55 & 0.46 & 0.1061 & 0.0017 & 0.9030 & 0.0250 & 0.0626 & 0.0015 & 650 & 10 & 704 & 49 & 0.6 \\
\hline $39-3 c$ & 96 & 51.2 & 0.53 & 0.1064 & 0.0017 & 0.9030 & 0.0280 & 0.0616 & 0.0017 & 651 & 10 & 654 & 62 & 0.2 \\
\hline $4-2 c$ & 343 & 243 & 0.71 & 0.1067 & 0.0018 & 0.8980 & 0.0180 & 0.0608 & 0.0010 & 653 & 10 & 627 & 35 & -0.3 \\
\hline $25-1 c$ & 145.2 & 131.2 & 0.90 & 0.1067 & 0.0022 & 0.8880 & 0.0340 & 0.0604 & 0.0019 & 653 & 13 & 610 & 66 & -0.8 \\
\hline $28-1 \mathrm{c}$ & 86.7 & 64.9 & 0.75 & 0.1068 & 0.0019 & 0.9050 & 0.0320 & 0.0613 & 0.0019 & 654 & 11 & 630 & 67 & 0.2 \\
\hline $31-1 c$ & 115.2 & 60.4 & 0.52 & 0.1068 & 0.0017 & 0.9090 & 0.0250 & 0.0613 & 0.0016 & 654 & 10 & 642 & 56 & 0.4 \\
\hline $56-1 c$ & 97.6 & 55 & 0.56 & 0.1070 & 0.0017 & 0.9120 & 0.0270 & 0.0610 & 0.0018 & 655 & 10 & 646 & 62 & 0.1 \\
\hline $58-1 \mathrm{c}$ & 158.4 & 97 & 0.61 & 0.1070 & 0.0014 & 0.9120 & 0.0230 & 0.0620 & 0.0013 & 655 & 8 & 682 & 42 & 0.4 \\
\hline $19-1 \mathrm{c}$ & 218.2 & 175.2 & 0.80 & 0.1068 & 0.0021 & 0.9100 & 0.0370 & 0.0612 & 0.0021 & 656 & 13 & 639 & 74 & 0.9 \\
\hline $45-2 c$ & 68.5 & 38.9 & 0.57 & 0.1072 & 0.0022 & 0.9130 & 0.0330 & 0.0604 & 0.0019 & 656 & 13 & 650 & 68 & 0.2 \\
\hline $34-1 c$ & 255.3 & 164.7 & 0.65 & 0.1072 & 0.0019 & 0.9320 & 0.0330 & 0.0621 & 0.0018 & 656 & 11 & 660 & 62 & 1.8 \\
\hline $10-1 \mathrm{c}$ & 204 & 120 & 0.59 & 0.1072 & 0.0012 & 0.8910 & 0.0180 & 0.0617 & 0.0013 & 656 & 7 & 661 & 45 & -1.6 \\
\hline $53-1 c$ & 199 & 150 & 0.75 & 0.1074 & 0.0022 & 0.9090 & 0.0320 & 0.0608 & 0.0016 & 657 & 13 & 626 & 57 & -0.2 \\
\hline $17-1 \mathrm{c}$ & 46.5 & 20.69 & 0.44 & 0.1073 & 0.0023 & 0.9220 & 0.0350 & 0.0635 & 0.0022 & 657 & 13 & 692 & 75 & 1.4 \\
\hline $45-3 c$ & 75.9 & 42.2 & 0.56 & 0.1070 & 0.0021 & 0.9010 & 0.0380 & 0.0607 & 0.0022 & 657 & 13 & 592 & 79 & -0.5 \\
\hline $19-2 c$ & 89 & 48.3 & 0.54 & 0.1074 & 0.0025 & 0.9100 & 0.0360 & 0.0606 & 0.0020 & 658 & 15 & 614 & 74 & -0.6 \\
\hline $46-1 c$ & 121.3 & 71.1 & 0.59 & 0.1074 & 0.0020 & 0.9230 & 0.0360 & 0.0618 & 0.0021 & 658 & 12 & 654 & 72 & 0.3 \\
\hline $23-1 c$ & 161 & 129.7 & 0.81 & 0.1076 & 0.0026 & 0.9120 & 0.0360 & 0.0621 & 0.0022 & 658 & 15 & 668 & 73 & 0.5 \\
\hline $14-2 \mathrm{c}$ & 50.8 & 23.36 & 0.46 & 0.1081 & 0.0025 & 0.9140 & 0.0390 & 0.0611 & 0.0025 & 661 & 14 & 623 & 91 & -0.5 \\
\hline $4-1 c$ & 71.9 & 36.42 & 0.51 & 0.1082 & 0.0014 & 0.9140 & 0.0200 & 0.0619 & 0.0014 & 662 & 8 & 666 & 51 & -0.6 \\
\hline $42-2 c$ & 28.09 & 11.49 & 0.41 & 0.1084 & 0.0029 & 0.9210 & 0.0470 & 0.0612 & 0.0031 & 663 & 17 & 600 & 110 & -0.6 \\
\hline $66-1 c$ & 180 & 133.7 & 0.74 & 0.1097 & 0.0019 & 0.9300 & 0.0170 & 0.0613 & 0.0010 & 671 & 11 & 650 & 34 & -0.6 \\
\hline $58-3 \mathrm{c}$ & 144.4 & 95 & 0.66 & 0.1105 & 0.0014 & 0.9420 & 0.0190 & 0.0610 & 0.0011 & 676 & 8 & 635 & 37 & -0.4 \\
\hline $17-2 c$ & 146.7 & 157 & 1.07 & 0.1107 & 0.0024 & 0.9390 & 0.0350 & 0.0614 & 0.0019 & 676 & 14 & 645 & 66 & -0.9 \\
\hline $42-1 c$ & 155.4 & 69.2 & 0.45 & 0.1113 & 0.0018 & 0.9310 & 0.0300 & 0.0604 & 0.0017 & 680 & 10 & 618 & 62 & -1.6 \\
\hline $46-2 c$ & 58.5 & 27.7 & 0.47 & 0.1117 & 0.0024 & 0.9600 & 0.0430 & 0.0607 & 0.0024 & 682 & 14 & 622 & 84 & -0.4 \\
\hline $66-2 c$ & 58.8 & 23.9 & 0.41 & 0.1119 & 0.0018 & 0.9550 & 0.0300 & 0.0620 & 0.0016 & 684 & 11 & 681 & 51 & -0.3 \\
\hline $31-3 c$ & 82.4 & 36.6 & 0.44 & 0.1119 & 0.0023 & 0.9560 & 0.0390 & 0.0610 & 0.0022 & 684 & 13 & 650 & 77 & -0.9 \\
\hline $53-2 \mathrm{c}$ & 77.2 & 27.68 & 0.36 & 0.1121 & 0.0021 & 0.9560 & 0.0300 & 0.0621 & 0.0016 & 685 & 12 & 683 & 55 & 0.1 \\
\hline $18-1 \mathrm{c}$ & 85 & 44.1 & 0.52 & 0.1124 & 0.0024 & 0.9460 & 0.0350 & 0.0615 & 0.0021 & 686 & 14 & 645 & 70 & -1.9 \\
\hline $56-2 c$ & 435 & 433 & 1.00 & 0.1129 & 0.0018 & 0.9680 & 0.0220 & 0.0618 & 0.0013 & 690 & 10 & 669 & 44 & -0.3 \\
\hline $12-1 \mathrm{c}$ & 46.9 & 21.99 & 0.47 & 0.1134 & 0.0022 & 0.9390 & 0.0290 & 0.0601 & 0.0019 & 692 & 13 & 600 & 68 & -3.1 \\
\hline $13-1 c$ & 110.8 & 32 & 0.29 & 0.1134 & 0.0019 & 0.9780 & 0.0270 & 0.0623 & 0.0014 & 692 & 11 & 681 & 45 & -0.3 \\
\hline $58-2 \mathrm{c}$ & 43.3 & 13.35 & 0.31 & 0.1143 & 0.0028 & 0.9620 & 0.0410 & 0.0612 & 0.0023 & 698 & 16 & 654 & 86 & -2.3 \\
\hline $34-2 c$ & 61.6 & 34.1 & 0.55 & 0.1151 & 0.0021 & 0.9770 & 0.0300 & 0.0604 & 0.0019 & 702 & 12 & 635 & 69 & -1.6 \\
\hline
\end{tabular}

\begin{tabular}{|c|c|c|c|c|c|c|c|c|c|c|c|c|c|c|}
\hline \multirow{3}{*}{$\begin{array}{l}\text { grain/spot } \\
\text { position }\end{array}$} & \multirow{3}{*}{$\begin{array}{c}\mathrm{U} \\
\mathrm{ppm}\end{array}$} & \multirow{3}{*}{$\begin{array}{l}\text { Th } \\
\text { ppm }\end{array}$} & \multirow[t]{3}{*}{ Th/U } & \multicolumn{7}{|c|}{ Isotopic ratios } & \multicolumn{3}{|c|}{ Ages (in Ma) ${ }^{a}$} & \multirow{3}{*}{$\begin{array}{c}\begin{array}{c}\text { Discor } \\
\text { dance }\end{array} \\
\text { (\%) }\end{array}$} \\
\hline & & & & \multirow[b]{2}{*}{${ }^{206} \mathrm{~Pb} /{ }^{238} \mathrm{U}$} & \multirow[b]{2}{*}{$2 \sigma$} & \multirow[b]{2}{*}{${ }^{207} \mathrm{~Pb} /{ }^{235} \mathrm{U}$} & \multicolumn{3}{|c|}{${ }^{207} \mathrm{~Pb} /{ }^{206} \mathrm{P}$} & \multirow[b]{2}{*}{${ }^{206} \mathrm{~Pb} /{ }^{238} \mathrm{U}$} & \multicolumn{3}{|c|}{${ }^{207} \mathrm{~Pb} /{ }^{206} \mathrm{P}$} & \\
\hline & & & & & & & $2 \sigma$ & b & $2 \sigma$ & & $2 \sigma$ & $\mathrm{b}$ & $2 \sigma$ & \\
\hline \multicolumn{15}{|c|}{$\begin{array}{l}\text { Felsic granulite } \\
\text { (sample 5B1) }\end{array}$} \\
\hline $13-2 \mathrm{re}$ & 358 & 95.6 & 0.27 & 0.1008 & 0.0015 & 0.8440 & 0.0170 & 0.0608 & 0.0011 & 619 & 9 & 629 & 37 & 0.3 \\
\hline $14-2$ re & 200.7 & 132.3 & 0.66 & 0.1017 & 0.0015 & 0.8560 & 0.0190 & 0.0610 & 0.0013 & 624 & 9 & 649 & 43 & 0.4 \\
\hline $10-2 \mathrm{re}$ & 284 & 89.4 & 0.31 & 0.1019 & 0.0012 & 0.8490 & 0.0180 & 0.0606 & 0.0010 & 626 & 7 & 615 & 35 & -0.2 \\
\hline $69-3 r e$ & 224 & 92.4 & 0.41 & 0.1041 & 0.0015 & 0.8790 & 0.0180 & 0.0613 & 0.0010 & 639 & 9 & 649 & 33 & 0.2 \\
\hline $18-3 c$ & 156.2 & 93.8 & 0.60 & 0.1047 & 0.0014 & 0.8780 & 0.0190 & 0.0606 & 0.0010 & 642 & 8 & 633 & 37 & -0.4 \\
\hline $70-3 c$ & 98.2 & 86.4 & 0.88 & 0.1050 & 0.0014 & 0.8930 & 0.0220 & 0.0611 & 0.0013 & 643 & 8 & 651 & 45 & 0.7 \\
\hline $62-1 c$ & 305 & 225 & 0.74 & 0.1052 & 0.0014 & 0.8780 & 0.0150 & 0.0604 & 0.0008 & 644 & 8 & 622 & 29 & -0.8 \\
\hline $20-2$ re & 52.8 & 4.96 & 0.09 & 0.1054 & 0.0018 & 0.8980 & 0.0230 & 0.0620 & 0.0012 & 646 & 11 & 676 & 42 & 1.2 \\
\hline $20-1 c$ & 314.4 & 211.9 & 0.67 & 0.1055 & 0.0014 & 0.8890 & 0.0160 & 0.0618 & 0.0010 & 647 & 8 & 659 & 34 & -0.2 \\
\hline $43-1 c$ & 71.5 & 38.8 & 0.54 & 0.1056 & 0.0016 & 0.8860 & 0.0270 & 0.0606 & 0.0015 & 647 & 9 & 622 & 54 & -0.3 \\
\hline $51-1 \mathrm{c}$ & 116.9 & 47 & 0.40 & 0.1058 & 0.0017 & 0.8980 & 0.0210 & 0.0617 & 0.0011 & 648 & 10 & 660 & 38 & 0.1 \\
\hline 23-1re & 51.1 & 20.51 & 0.40 & 0.1061 & 0.0015 & 0.8870 & 0.0220 & 0.0626 & 0.0014 & 650 & 9 & 684 & 47 & -0.6 \\
\hline $14-1 c$ & 105.8 & 85.8 & 0.81 & 0.1061 & 0.0017 & 0.9080 & 0.0220 & 0.0622 & 0.0012 & 651 & 10 & 679 & 40 & 0.7 \\
\hline $47-1 c$ & 108.2 & 63.8 & 0.59 & 0.1063 & 0.0015 & 0.9020 & 0.0160 & 0.0621 & 0.0013 & 651 & 9 & 666 & 45 & 0.2 \\
\hline
\end{tabular}




\begin{tabular}{|c|c|c|c|c|c|c|c|c|c|c|c|c|c|c|}
\hline $37-1 \mathrm{c}$ & 65.2 & 40 & 0.61 & 0.1064 & 0.0013 & 0.8950 & 0.0200 & 0.0609 & 0.0014 & 652 & 8 & 644 & 48 & -0.6 \\
\hline $30-1 c$ & 107.8 & 69.8 & 0.65 & 0.1064 & 0.0016 & 0.8870 & 0.0220 & 0.0607 & 0.0013 & 652 & 9 & 625 & 46 & -1.2 \\
\hline $9-1 c$ & 259 & 290 & 1.12 & 0.1065 & 0.0019 & 0.9010 & 0.0240 & 0.0614 & 0.0012 & 652 & 11 & 653 & 43 & -0.2 \\
\hline $39-1 \mathrm{c}$ & 148.2 & 82.7 & 0.56 & 0.1065 & 0.0012 & 0.8940 & 0.0170 & 0.0611 & 0.0010 & 652 & 7 & 634 & 34 & -0.5 \\
\hline $51-2 c$ & 125.6 & 88.4 & 0.70 & 0.1066 & 0.0014 & 0.9030 & 0.0180 & 0.0616 & 0.0011 & 653 & 8 & 654 & 38 & 0.1 \\
\hline $32-1 c$ & 97.8 & 61.3 & 0.63 & 0.1066 & 0.0015 & 0.9070 & 0.0200 & 0.0626 & 0.0011 & 653 & 9 & 686 & 38 & 0.5 \\
\hline $31-1 \mathrm{c}$ & 214 & 141.3 & 0.66 & 0.1066 & 0.0016 & 0.9060 & 0.0200 & 0.0620 & 0.0014 & 653 & 9 & 667 & 47 & 0.5 \\
\hline $7-1 c$ & 85.4 & 47.3 & 0.55 & 0.1066 & 0.0014 & 0.9000 & 0.0210 & 0.0607 & 0.0013 & 653 & 8 & 631 & 47 & -0.3 \\
\hline $13-1 c$ & 45.3 & 18.34 & 0.40 & 0.1068 & 0.0030 & 0.9000 & 0.0340 & 0.0618 & 0.0021 & 654 & 18 & 662 & 72 & -0.2 \\
\hline $70-2 c$ & 78.2 & 41.9 & 0.54 & 0.1068 & 0.0017 & 0.9130 & 0.0190 & 0.0617 & 0.0012 & 654 & 10 & 652 & 43 & 0.7 \\
\hline $26-1 c$ & 362 & 460 & 1.27 & 0.1070 & 0.0014 & 0.9030 & 0.0150 & 0.0616 & 0.0009 & 655 & 8 & 661 & 30 & -0.4 \\
\hline $65-1 c$ & 128.8 & 71.1 & 0.55 & 0.1070 & 0.0019 & 0.9230 & 0.0230 & 0.0626 & 0.0015 & 655 & 11 & 701 & 49 & 1.2 \\
\hline $36-1 \mathrm{c}$ & 317 & 287 & 0.91 & 0.1069 & 0.0013 & 0.8980 & 0.0170 & 0.0609 & 0.0010 & 655 & 8 & 634 & 34 & -0.8 \\
\hline $32-2 c$ & 291 & 398 & 1.37 & 0.1070 & 0.0017 & 0.9000 & 0.0200 & 0.0611 & 0.0011 & 655 & 10 & 642 & 39 & -0.7 \\
\hline $36-2 c$ & 192.7 & 158.2 & 0.82 & 0.1072 & 0.0013 & 0.8960 & 0.0200 & 0.0612 & 0.0011 & 656 & 8 & 647 & 38 & -1.3 \\
\hline $18-2 \mathrm{c}$ & 189.2 & 70.6 & 0.37 & 0.1072 & 0.0016 & 0.9050 & 0.0160 & 0.0618 & 0.0011 & 657 & 9 & 667 & 40 & -0.4 \\
\hline $69-2 c$ & 81.3 & 43.4 & 0.53 & 0.1072 & 0.0015 & 0.9070 & 0.0210 & 0.0610 & 0.0013 & 657 & 8 & 630 & 48 & -0.4 \\
\hline $37-2 c$ & 90.7 & 97.6 & 1.08 & 0.1073 & 0.0015 & 0.9060 & 0.0200 & 0.0610 & 0.0013 & 657 & 9 & 633 & 45 & -0.4 \\
\hline $68-1 c$ & 153.2 & 84.2 & 0.55 & 0.1073 & 0.0015 & 0.9130 & 0.0190 & 0.0609 & 0.0010 & 657 & 9 & 636 & 35 & 0.3 \\
\hline $39-2 c$ & 105.4 & 57.44 & 0.54 & 0.1074 & 0.0015 & 0.9110 & 0.0210 & 0.0608 & 0.0012 & 658 & 9 & 632 & 44 & -0.1 \\
\hline $43-2 c$ & 318.9 & 125.4 & 0.39 & 0.1074 & 0.0012 & 0.9090 & 0.0140 & 0.0617 & 0.0009 & 658 & 7 & 660 & 32 & -0.3 \\
\hline $49-1 c$ & 147 & 105 & 0.71 & 0.1074 & 0.0017 & 0.9070 & 0.0200 & 0.0615 & 0.0009 & 658 & 10 & 652 & 32 & -0.6 \\
\hline 9-2re & 154.2 & 182.4 & 1.18 & 0.1074 & 0.0015 & 0.9120 & 0.0190 & 0.0616 & 0.0012 & 658 & 9 & 665 & 42 & 0.3 \\
\hline $62-2 c$ & 60 & 32.71 & 0.55 & 0.1075 & 0.0015 & 0.9080 & 0.0240 & 0.0613 & 0.0015 & 658 & 9 & 635 & 53 & 0.1 \\
\hline $26-2 \mathrm{re}$ & 31.66 & 13.83 & 0.44 & 0.1077 & 0.0020 & 0.9090 & 0.0260 & 0.0617 & 0.0019 & 659 & 12 & 653 & 62 & 0.3 \\
\hline $68-2 \mathrm{re}$ & 42.9 & 18.36 & 0.43 & 0.1077 & 0.0019 & 0.9170 & 0.0290 & 0.0613 & 0.0022 & 659 & 11 & 648 & 81 & 0.3 \\
\hline $49-2 c$ & 76 & 42.23 & 0.56 & 0.1078 & 0.0015 & 0.9110 & 0.0210 & 0.0626 & 0.0015 & 660 & 9 & 685 & 52 & -0.4 \\
\hline $47-2 c$ & 349 & 282 & 0.81 & 0.1078 & 0.0015 & 0.9110 & 0.0160 & 0.0616 & 0.0008 & 660 & 9 & 657 & 27 & -0.4 \\
\hline 6-1re & 32.8 & 11.83 & 0.36 & 0.1080 & 0.0019 & 0.9040 & 0.0320 & 0.0604 & 0.0019 & 661 & 11 & 607 & 68 & -1.2 \\
\hline $30-2 c$ & 192 & 101.7 & 0.53 & 0.1081 & 0.0016 & 0.9160 & 0.0200 & 0.0605 & 0.0011 & 662 & 9 & 628 & 39 & -0.2 \\
\hline $69-1 c$ & 103.6 & 41.8 & 0.40 & 0.1081 & 0.0014 & 0.9150 & 0.0180 & 0.0610 & 0.0012 & 662 & 8 & 633 & 41 & -0.5 \\
\hline $7-2 c$ & 220 & 85.4 & 0.39 & 0.1082 & 0.0018 & 0.9170 & 0.0220 & 0.0612 & 0.0013 & 662 & 11 & 643 & 46 & -0.3 \\
\hline $6-2 c$ & 77.7 & 42.5 & 0.55 & 0.1082 & 0.0016 & 0.9090 & 0.0230 & 0.0604 & 0.0013 & 662 & 9 & 622 & 48 & -0.8 \\
\hline $70-1 \mathrm{c}$ & 140.4 & 75.7 & 0.54 & 0.1083 & 0.0015 & 0.9160 & 0.0200 & 0.0613 & 0.0010 & 663 & 9 & 651 & 36 & -0.4 \\
\hline $7-3 c$ & 262.9 & 104.7 & 0.40 & 0.1083 & 0.0013 & 0.9160 & 0.0160 & 0.0606 & 0.0008 & 663 & 7 & 635 & 31 & -0.5 \\
\hline $6-3 c$ & 184.1 & 143.7 & 0.78 & 0.1083 & 0.0018 & 0.9240 & 0.0210 & 0.0622 & 0.0013 & 663 & 10 & 678 & 44 & 0.0 \\
\hline $18-1 \mathrm{c}$ & 128.7 & 48.1 & 0.37 & 0.1085 & 0.0017 & 0.9250 & 0.0190 & 0.0620 & 0.0012 & 664 & 10 & 671 & 43 & 0.3 \\
\hline $65-2 c$ & 157 & 140.6 & 0.90 & 0.1086 & 0.0016 & 0.9230 & 0.0180 & 0.0607 & 0.0010 & 665 & 9 & 622 & 34 & -0.2 \\
\hline $31-2$ re & 36.5 & 13.42 & 0.37 & 0.1100 & 0.0017 & 0.9390 & 0.0290 & 0.0617 & 0.0019 & 673 & 10 & 667 & 65 & -0.4 \\
\hline $10-1 c$ & 358 & 173 & 0.48 & 0.1110 & 0.0014 & 0.9430 & 0.0160 & 0.0612 & 0.0008 & 679 & 8 & 640 & 29 & -0.7 \\
\hline $36-3 c$ & 120.7 & 71 & 0.59 & 0.1118 & 0.0014 & 0.9200 & 0.0200 & 0.0602 & 0.0011 & 683 & 8 & 612 & 40 & -3.3 \\
\hline $47-3 c$ & 81.2 & 42.8 & 0.53 & 0.1129 & 0.0016 & 0.9510 & 0.0220 & 0.0610 & 0.0012 & 690 & 9 & 640 & 43 & -1.7 \\
\hline $43-3 c$ & 134.7 & 56.8 & 0.42 & 0.1133 & 0.0027 & 0.9690 & 0.0290 & 0.0617 & 0.0015 & 692 & 15 & 657 & 56 & -0.6 \\
\hline grain/spot & u & Th & $\mathrm{Th} / \mathrm{U}$ & & & Isotopi & atios & & & & & es (in I & & $\begin{array}{l}\text { Discor } \\
\text { dance }^{\text {b }}\end{array}$ \\
\hline position & & & & & & & & ${ }^{207} \mathrm{~Pb} /{ }^{206} \mathrm{p}$ & & & & ${ }^{77} \mathrm{~Pb} /{ }^{22}$ & & \\
\hline & $\mathrm{ppm}$ & $\mathrm{ppm}$ & & ${ }^{206} \mathrm{~Pb} /{ }^{238} \mathrm{U}$ & $2 \sigma$ & ${ }^{207} \mathrm{~Pb} /{ }^{235} \mathrm{U}$ & $2 \sigma$ & $\mathrm{b}$ & $2 \sigma$ & ${ }^{206} \mathrm{~Pb} /{ }^{238} \mathrm{U}$ & $2 \sigma$ & b & $2 \sigma$ & (\%) \\
\hline $\begin{array}{l}\text { garnet gra } \\
\text { (sample } 6 \mathrm{~B}\end{array}$ & & & & & & & & & & & & & & \\
\hline $20-2 r$ & 41 & 28.9 & 0.70 & 0.0986 & 0.0019 & 0.8080 & 0.0240 & 0.0597 & 0.0018 & 606 & 11 & 584 & 68 & -1.0 \\
\hline $21-2 \mathrm{dm}$ & 187.5 & 45.9 & 0.24 & 0.0990 & 0.0016 & 0.8130 & 0.0190 & 0.0604 & 0.0014 & 608 & 10 & 615 & 50 & -0.6 \\
\hline $21-1 r$ & 43.9 & 34.7 & 0.79 & 0.0992 & 0.0016 & 0.8160 & 0.0230 & 0.0596 & 0.0017 & 610 & 10 & 585 & 62 & -0.7 \\
\hline $16-1 r$ & 34.5 & 25.45 & 0.74 & 0.0994 & 0.0024 & 0.8270 & 0.0350 & 0.0591 & 0.0027 & 611 & 14 & 556 & 94 & -0.2 \\
\hline $34-2 \mathrm{dm}$ & 141.5 & 73.6 & 0.52 & 0.1003 & 0.0017 & 0.8260 & 0.0210 & 0.0603 & 0.0015 & 616 & 10 & 604 & 53 & -0.9 \\
\hline 53-1re & 92.4 & 114.4 & 1.24 & 0.1006 & 0.0021 & 0.8470 & 0.0250 & 0.0604 & 0.0017 & 618 & 12 & 616 & 64 & 0.6 \\
\hline 29-2re & 74.3 & 55 & 0.74 & 0.1008 & 0.0013 & 0.8420 & 0.0180 & 0.0612 & 0.0014 & 619 & 8 & 642 & 48 & 0.1 \\
\hline $7-2 \mathrm{dm}$ & 291 & 130.5 & 0.45 & 0.1009 & 0.0013 & 0.8350 & 0.0150 & 0.0605 & 0.0011 & 620 & 8 & 616 & 41 & -0.6 \\
\hline $19-2 \mathrm{dm}$ & 308 & 31.1 & 0.10 & 0.1013 & 0.0014 & 0.8390 & 0.0140 & 0.0604 & 0.0010 & 622 & 8 & 624 & 36 & -0.6 \\
\hline $17-2 \mathrm{dm}$ & 365.2 & 100.4 & 0.27 & 0.1014 & 0.0014 & 0.8420 & 0.0140 & 0.0602 & 0.0011 & 622 & 8 & 612 & 38 & -0.3 \\
\hline $5-2 \mathrm{dm}$ & 433 & 25.02 & 0.06 & 0.1017 & 0.0018 & 0.8540 & 0.0190 & 0.0613 & 0.0013 & 624 & 10 & 643 & 46 & 0.5 \\
\hline $8-2 \mathrm{dm}$ & 322.8 & 122.8 & 0.38 & 0.1017 & 0.0014 & 0.8490 & 0.0150 & 0.0603 & 0.0010 & 624 & 8 & 614 & 37 & -0.1 \\
\hline $8-1 \mathrm{dm}$ & 428 & 137.6 & 0.32 & 0.1022 & 0.0014 & 0.8570 & 0.0140 & 0.0605 & 0.0010 & 627 & 8 & 620 & 34 & 0.2 \\
\hline $49-1 \mathrm{dm}$ & 295.9 & 76.9 & 0.26 & 0.1022 & 0.0015 & 0.8600 & 0.0180 & 0.0608 & 0.0011 & 627 & 9 & 638 & 40 & 0.5 \\
\hline $21-3 \mathrm{dm}$ & 1259 & 114.6 & 0.09 & 0.1025 & 0.0017 & 0.8600 & 0.0180 & 0.0612 & 0.0011 & 629 & 10 & 647 & 41 & 0.1 \\
\hline $10-2 c$ & 477 & 65.73 & 0.14 & 0.1054 & 0.0014 & 0.8930 & 0.0140 & 0.0612 & 0.0010 & 647 & 8 & 647 & 35 & 0.2 \\
\hline $28-3 c$ & 794 & 17.3 & 0.02 & 0.1057 & 0.0013 & 0.8900 & 0.0130 & 0.0611 & 0.0009 & 648 & 8 & 641 & 30 & -0.3 \\
\hline $6-1 c$ & 45.4 & 20.71 & 0.46 & 0.1060 & 0.0017 & 0.9070 & 0.0240 & 0.0621 & 0.0018 & 649 & 10 & 691 & 61 & 0.9 \\
\hline $11-2 c$ & 250.8 & 83.5 & 0.33 & 0.1065 & 0.0019 & 0.8970 & 0.0200 & 0.0611 & 0.0012 & 652 & 11 & 642 & 44 & -0.4 \\
\hline $18-2 c$ & 493 & 47.9 & 0.10 & 0.1064 & 0.0014 & 0.8970 & 0.0140 & 0.0615 & 0.0009 & 652 & 8 & 660 & 34 & -0.2 \\
\hline $53-2 c$ & 566 & 43.9 & 0.08 & 0.1066 & 0.0015 & 0.8990 & 0.0150 & 0.0612 & 0.0010 & 653 & 9 & 648 & 34 & -0.3 \\
\hline $5-1 c$ & 294 & 110.5 & 0.38 & 0.1068 & 0.0014 & 0.9060 & 0.0160 & 0.0615 & 0.0011 & 654 & 8 & 659 & 37 & 0.1 \\
\hline $6-2 c$ & 193.4 & 76.5 & 0.40 & 0.1069 & 0.0019 & 0.9030 & 0.0190 & 0.0616 & 0.0013 & 654 & 11 & 654 & 44 & 0.0 \\
\hline $25-1 c$ & 84.3 & 43.6 & 0.52 & 0.1068 & 0.0021 & 0.8880 & 0.0260 & 0.0614 & 0.0016 & 654 & 13 & 661 & 58 & -1.2 \\
\hline $54-2 c$ & 520 & 18.53 & 0.04 & 0.1067 & 0.0015 & 0.9080 & 0.0170 & 0.0612 & 0.0010 & 655 & 9 & 647 & 36 & 0.2 \\
\hline $50-2 c$ & 479 & 46.97 & 0.10 & 0.1070 & 0.0020 & 0.9090 & 0.0220 & 0.0621 & 0.0012 & 655 & 12 & 672 & 41 & 0.6 \\
\hline $57-2 c$ & 342 & 25.13 & 0.07 & 0.1070 & 0.0016 & 0.9060 & 0.0190 & 0.0620 & 0.0014 & 655 & 9 & 663 & 48 & -0.1 \\
\hline $25-2 c$ & 848 & 14.21 & 0.02 & 0.1071 & 0.0016 & 0.8940 & 0.0160 & 0.0613 & 0.0010 & 656 & 9 & 647 & 36 & -1.2 \\
\hline $7-1 c$ & 142.3 & 66 & 0.46 & 0.1071 & 0.0018 & 0.9060 & 0.0200 & 0.0613 & 0.0014 & 656 & 10 & 651 & 50 & -0.3 \\
\hline $28-2 c$ & 51.12 & 31.2 & 0.61 & 0.1071 & 0.0017 & 0.9080 & 0.0350 & 0.0620 & 0.0024 & 656 & 10 & 657 & 83 & 0.0 \\
\hline $17-1 r$ & 44.3 & 27 & 0.61 & 0.1072 & 0.0022 & 0.9010 & 0.0270 & 0.0626 & 0.0020 & 656 & 13 & 689 & 67 & -0.5 \\
\hline $50-1 c$ & 203 & 106.9 & 0.53 & 0.1071 & 0.0015 & 0.9090 & 0.0190 & 0.0612 & 0.0012 & 656 & 9 & 637 & 42 & 0.0 \\
\hline $10-1 \mathrm{c}$ & 373.7 & 119.6 & 0.32 & 0.1076 & 0.0017 & 0.9120 & 0.0170 & 0.0613 & 0.0011 & 659 & 10 & 649 & 37 & -0.2 \\
\hline $12-1 c$ & 535 & 40.4 & 0.08 & 0.1079 & 0.0014 & 0.9170 & 0.0140 & 0.0618 & 0.0010 & 661 & 8 & 665 & 33 & 0.2 \\
\hline $55-2 c$ & 262.3 & 170 & 0.65 & 0.1082 & 0.0015 & 0.9220 & 0.0170 & 0.0617 & 0.0011 & 662 & 9 & 658 & 37 & 0.1 \\
\hline $12-2 c$ & 140.9 & 83.9 & 0.60 & 0.1092 & 0.0021 & 0.9370 & 0.0210 & 0.0621 & 0.0014 & 668 & 12 & 672 & 48 & 0.4 \\
\hline $20-1 c$ & 146.2 & 62.9 & 0.43 & 0.1092 & 0.0017 & 0.9300 & 0.0200 & 0.0615 & 0.0012 & 668 & 10 & 662 & 44 & -0.2 \\
\hline
\end{tabular}




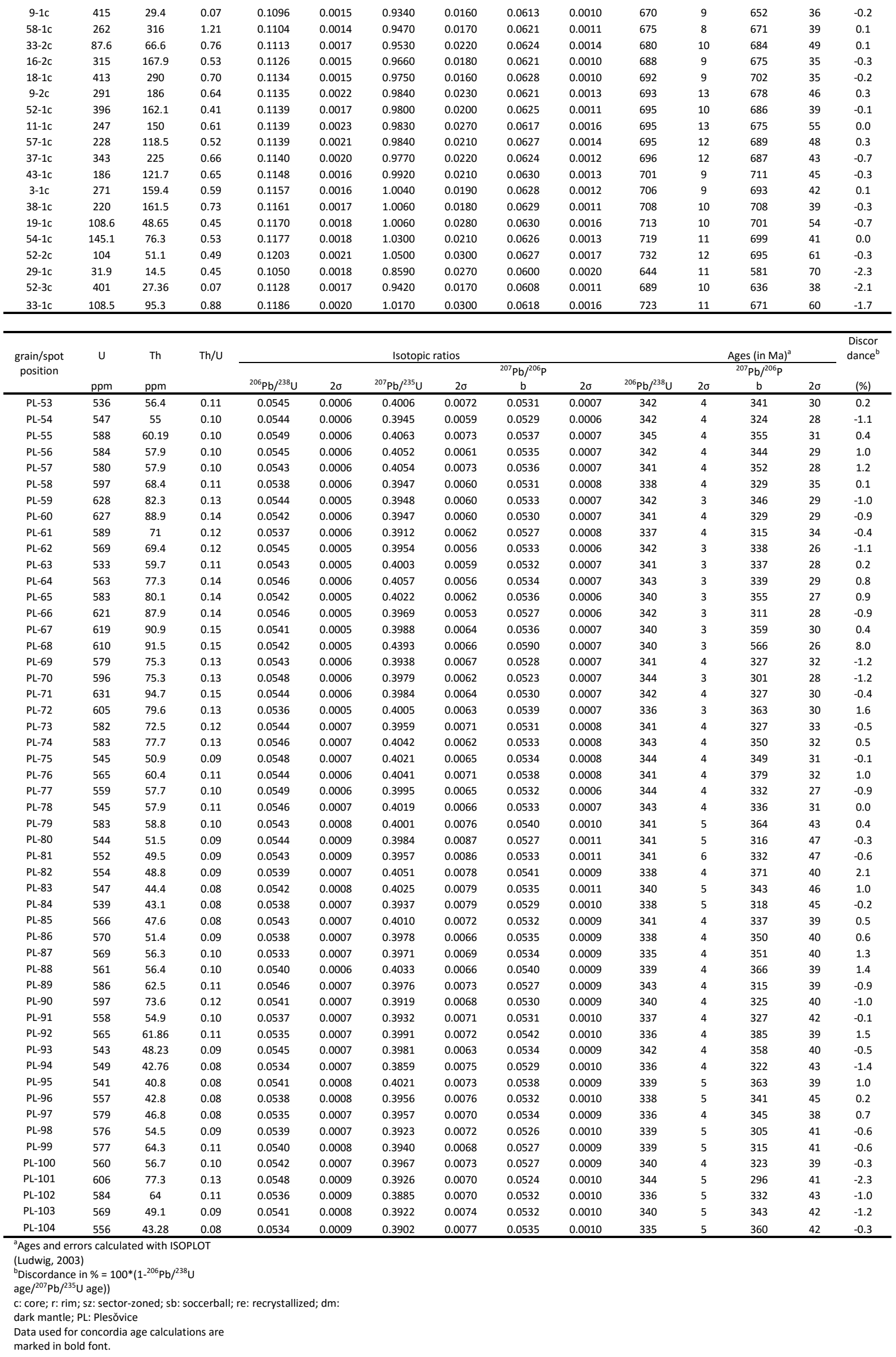




\section{ANEXO IX}

Análises de U-Th-Pb e elementos-traço em monazita obtidas por microssonda eletrônica 


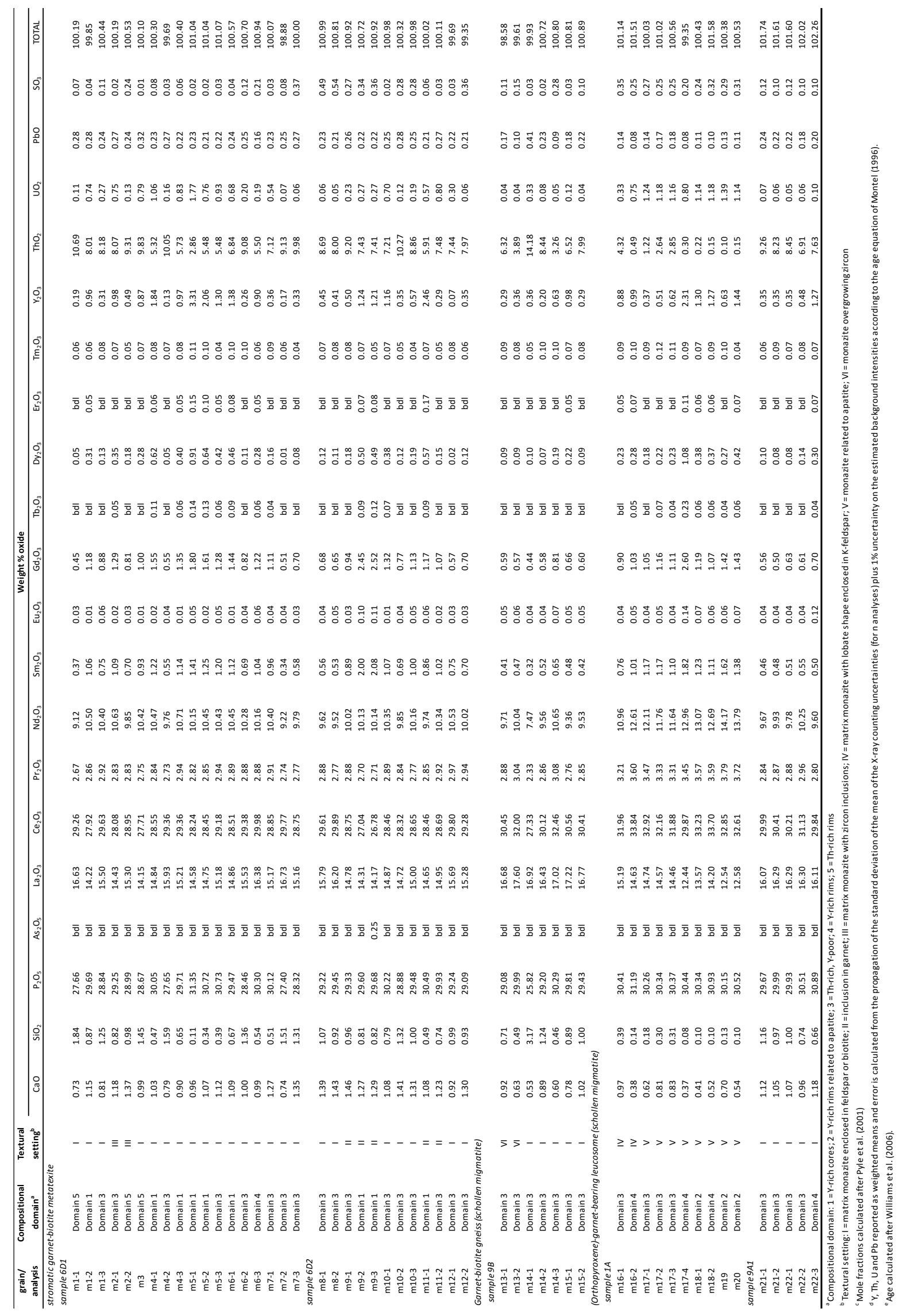




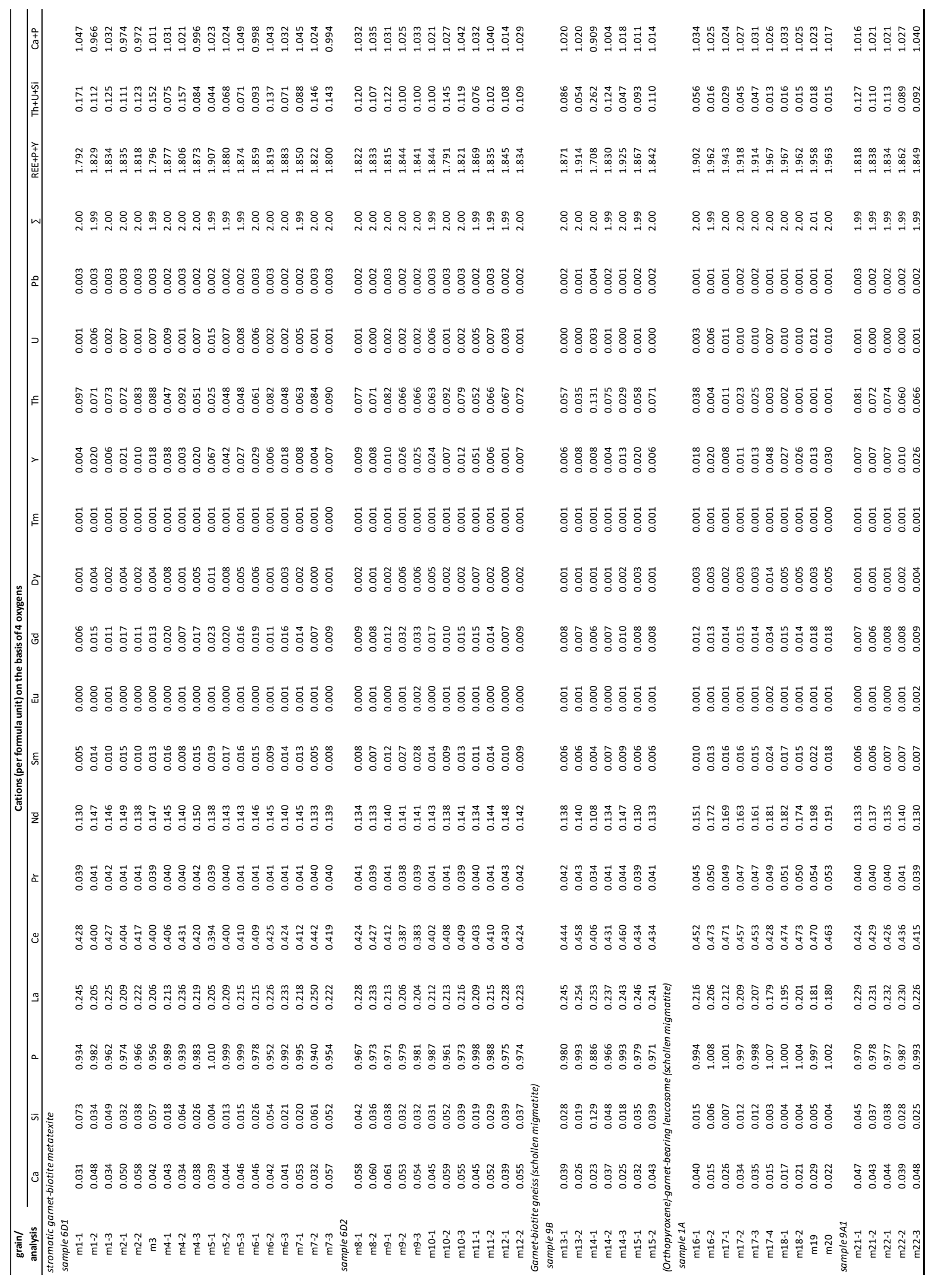




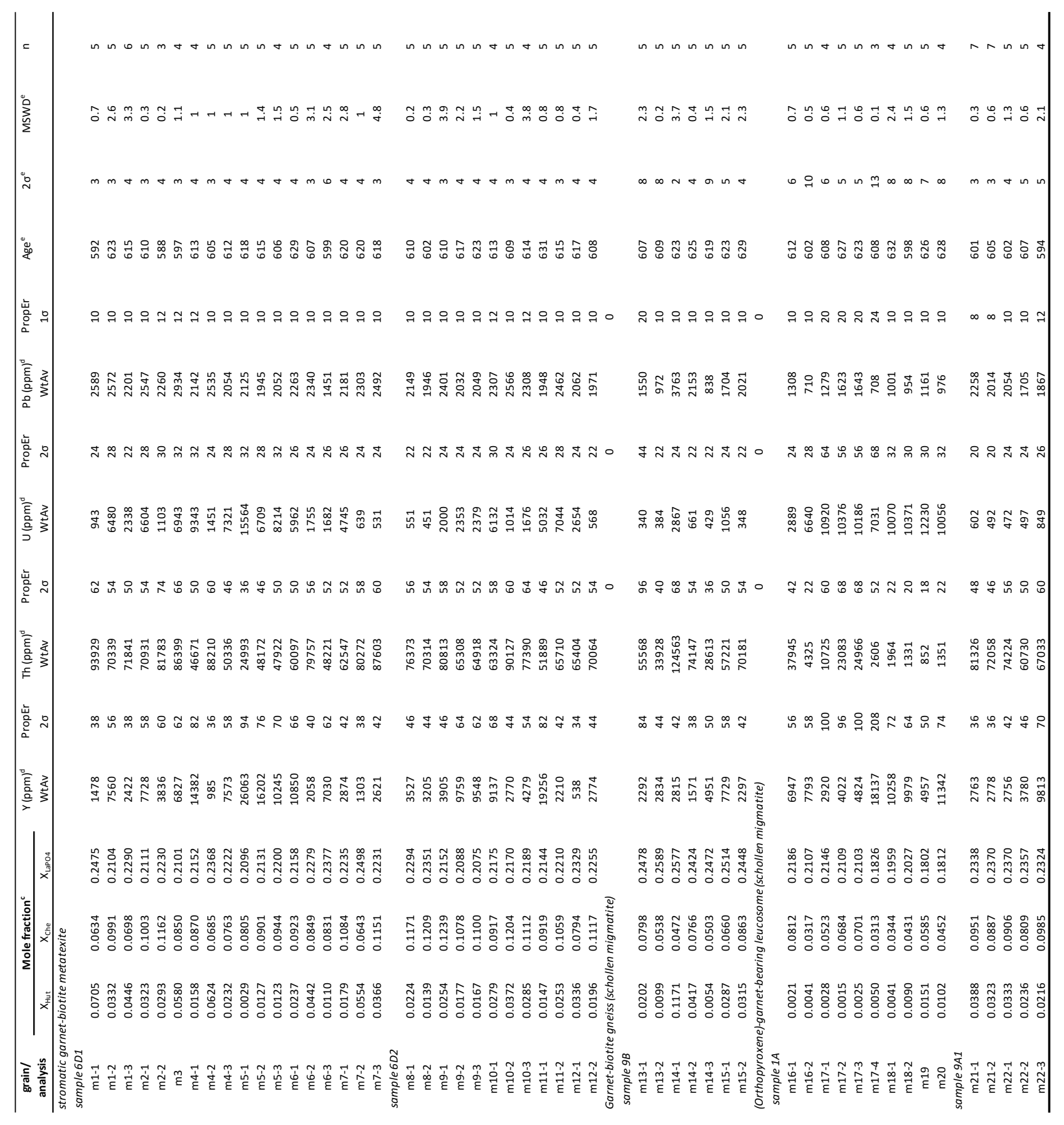




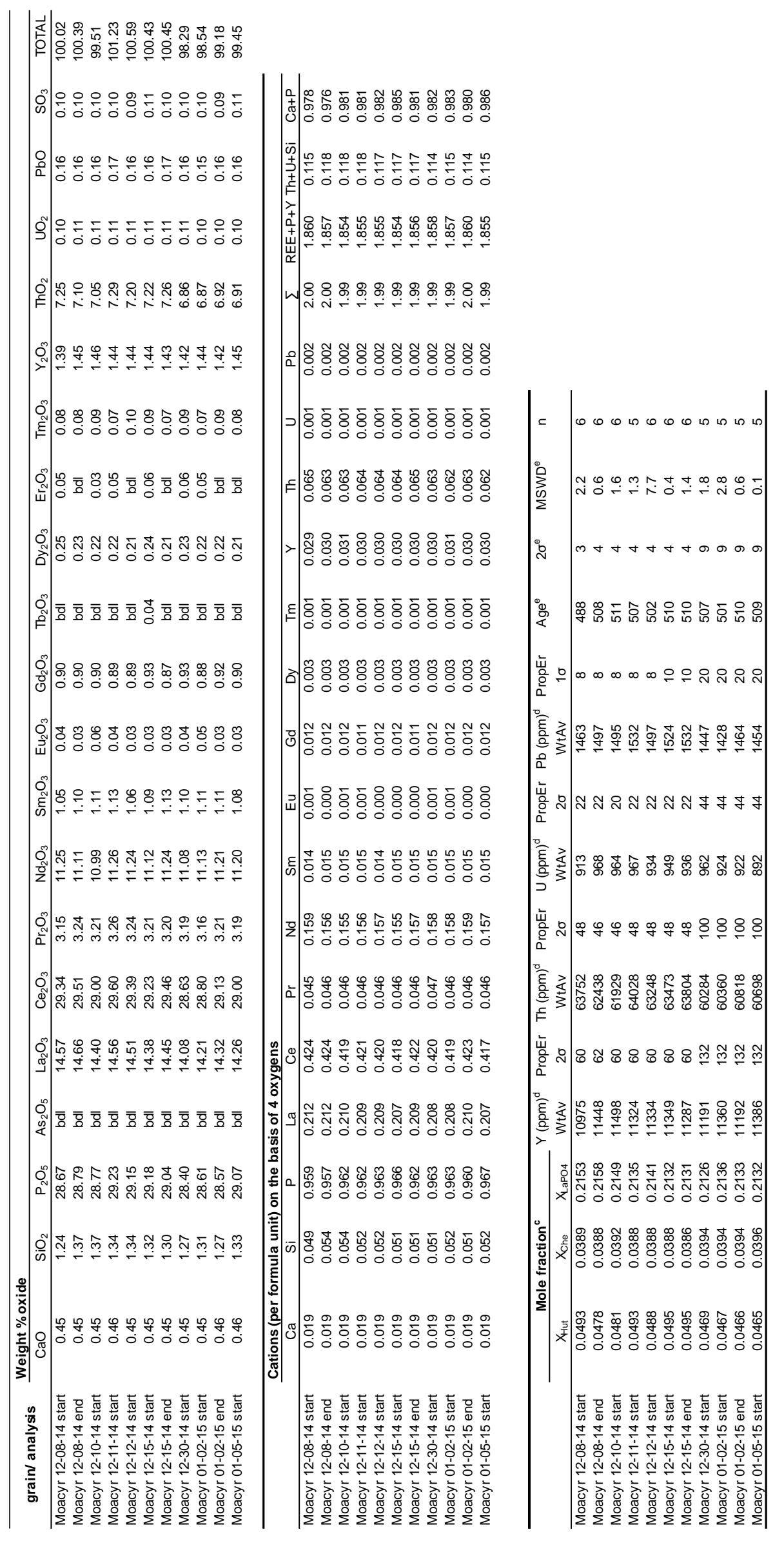




\section{ANEXO X}

Croquis de campo da pedreira Alfenas

(Unidade Metatexítica) 


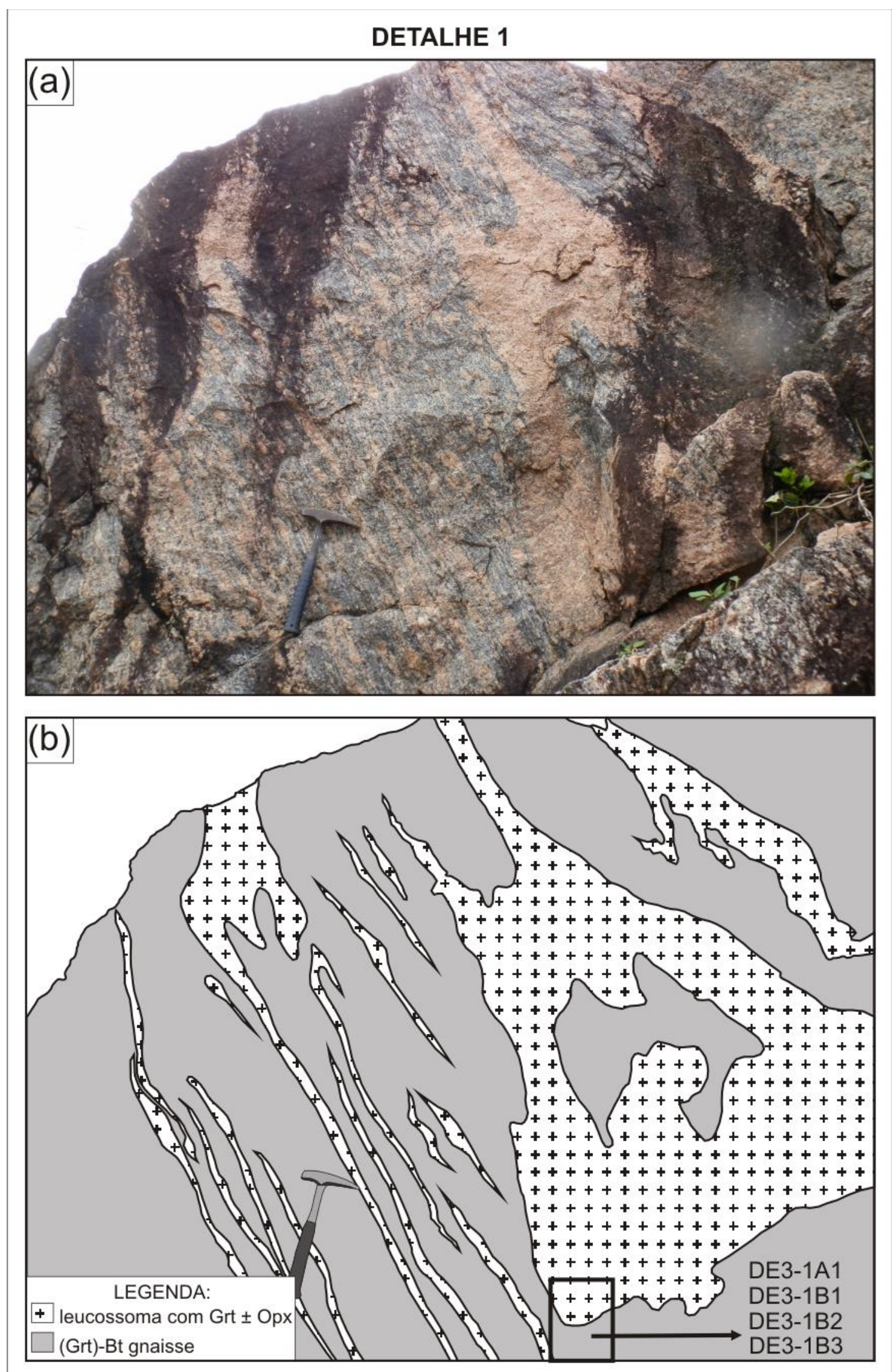




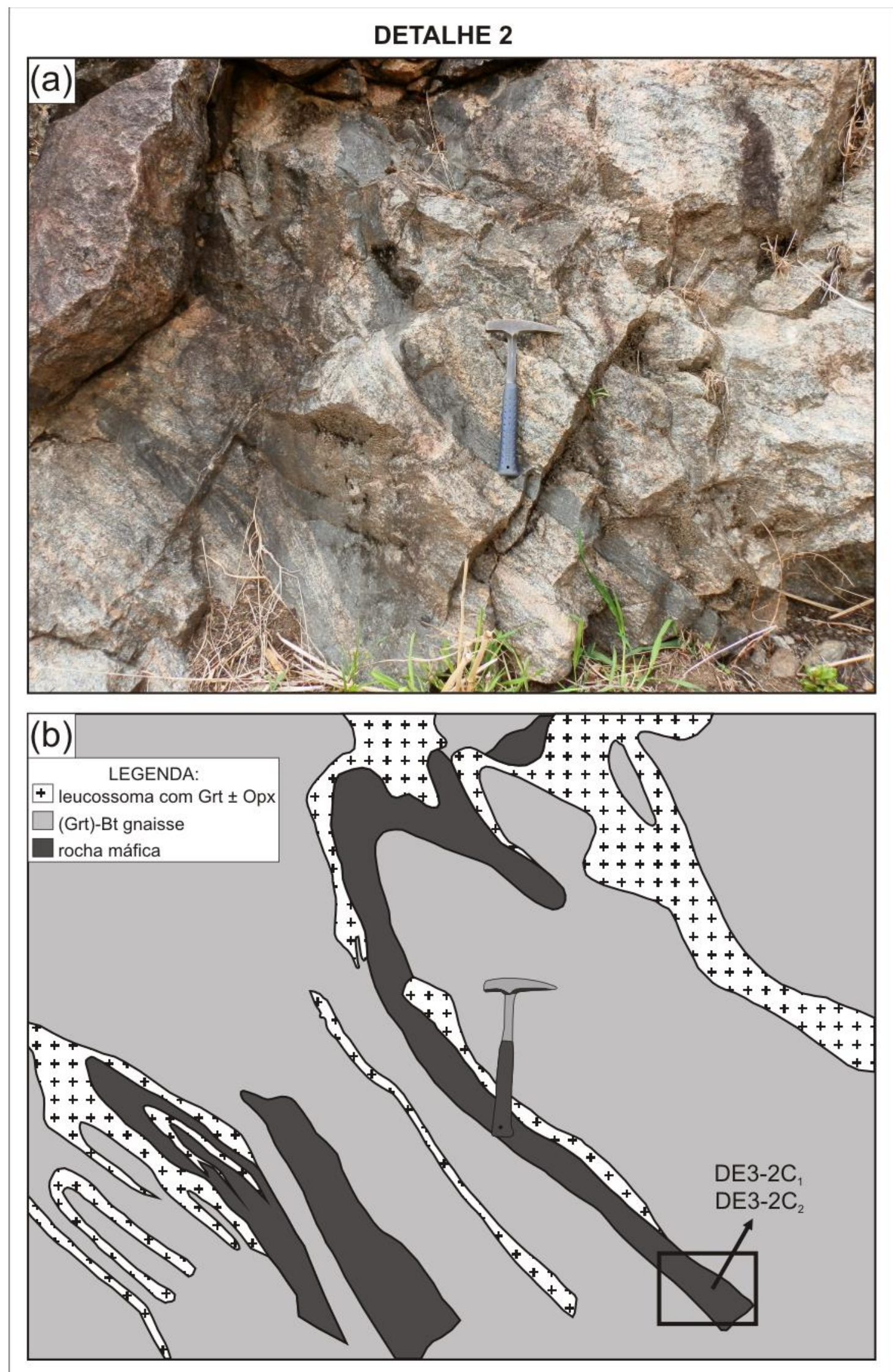




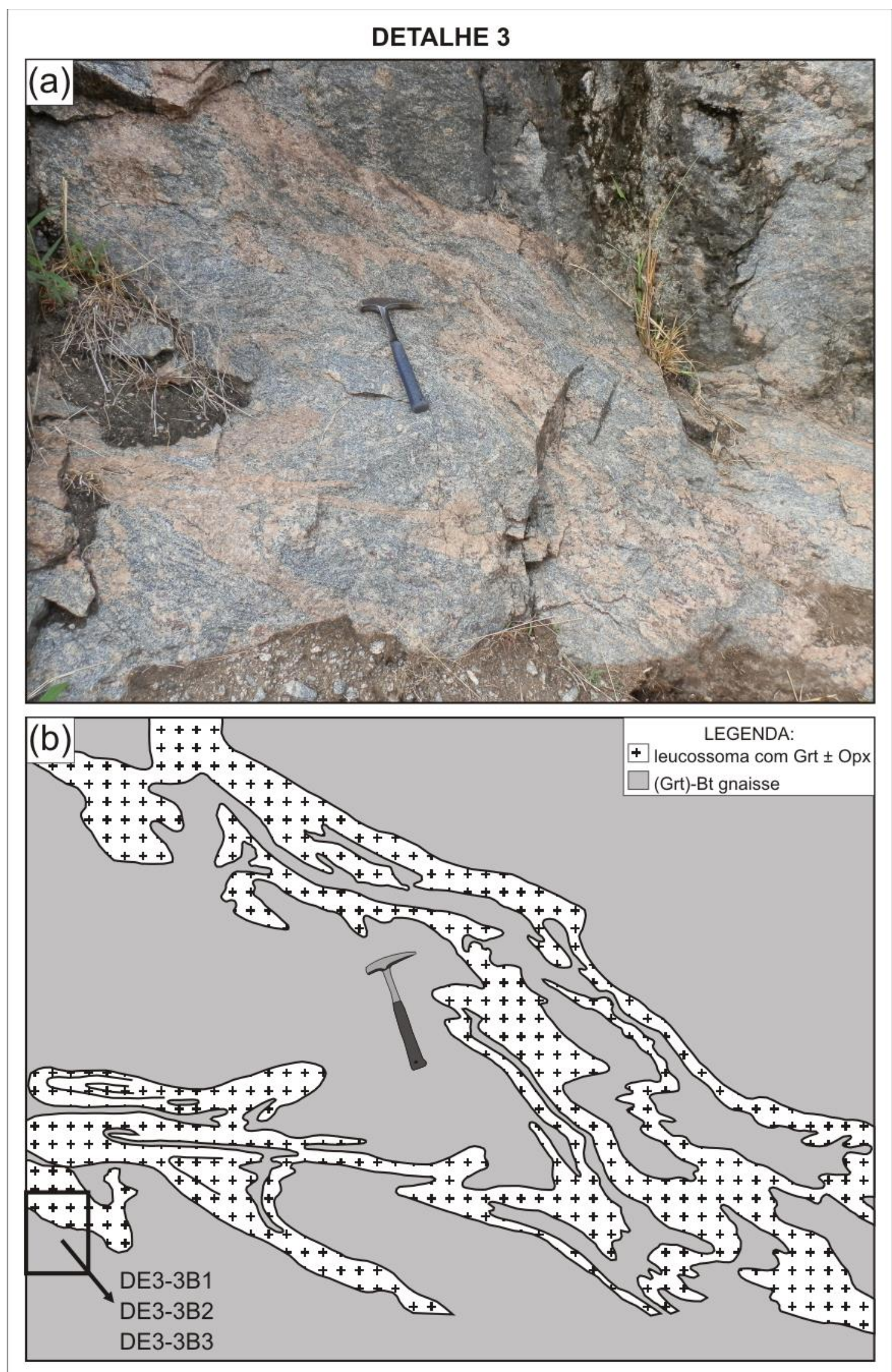


DETALHE 4
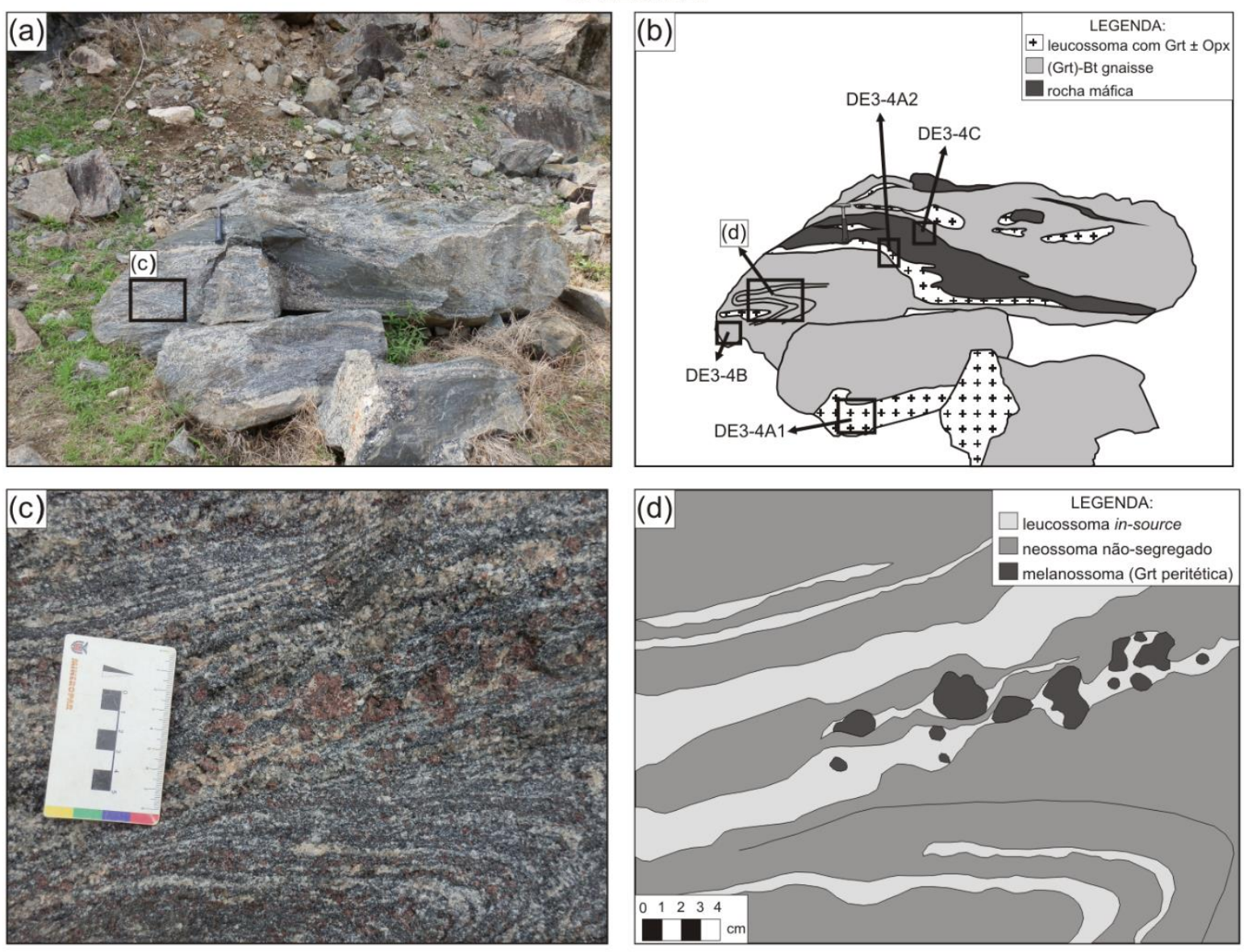

\section{DETALHE 5}
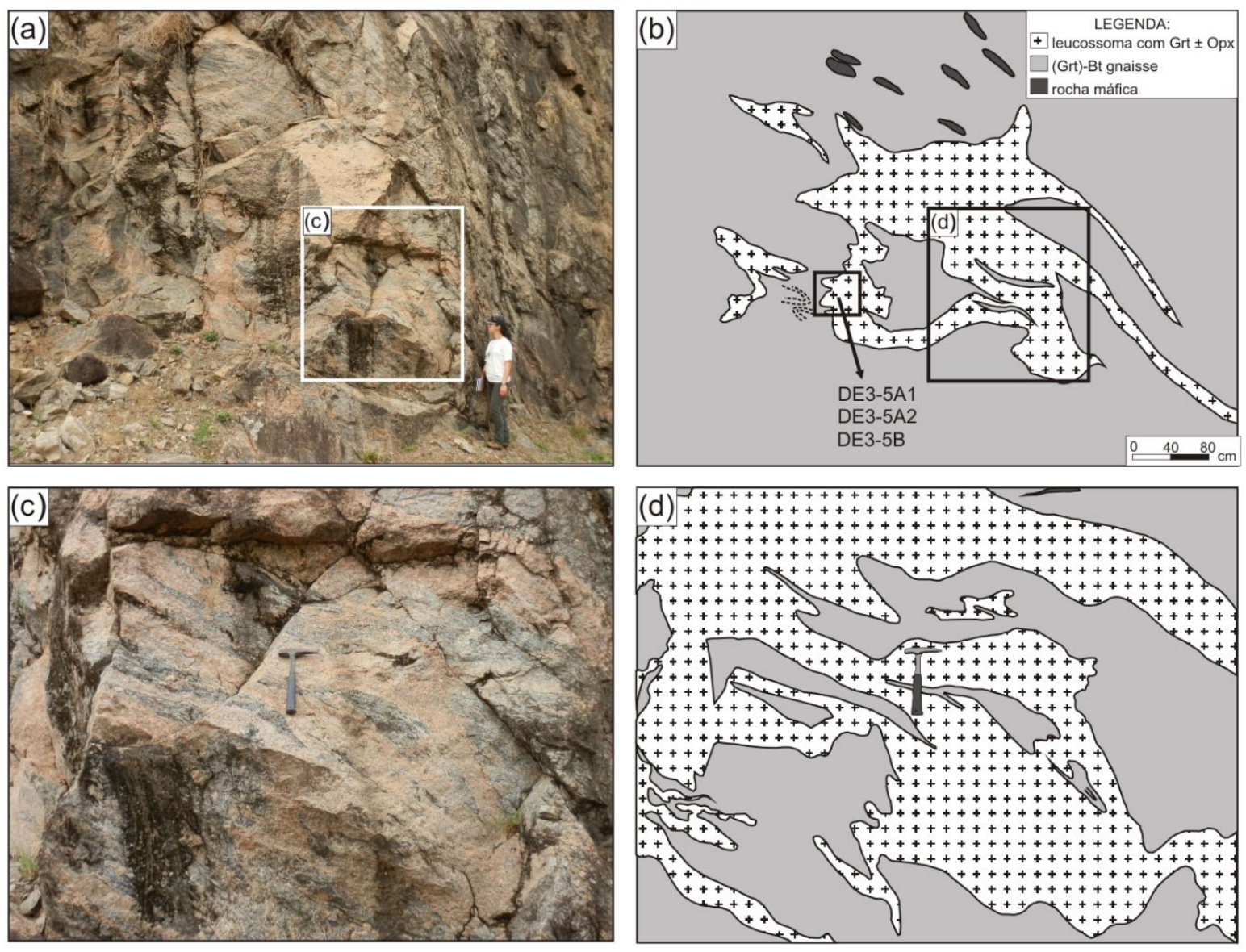


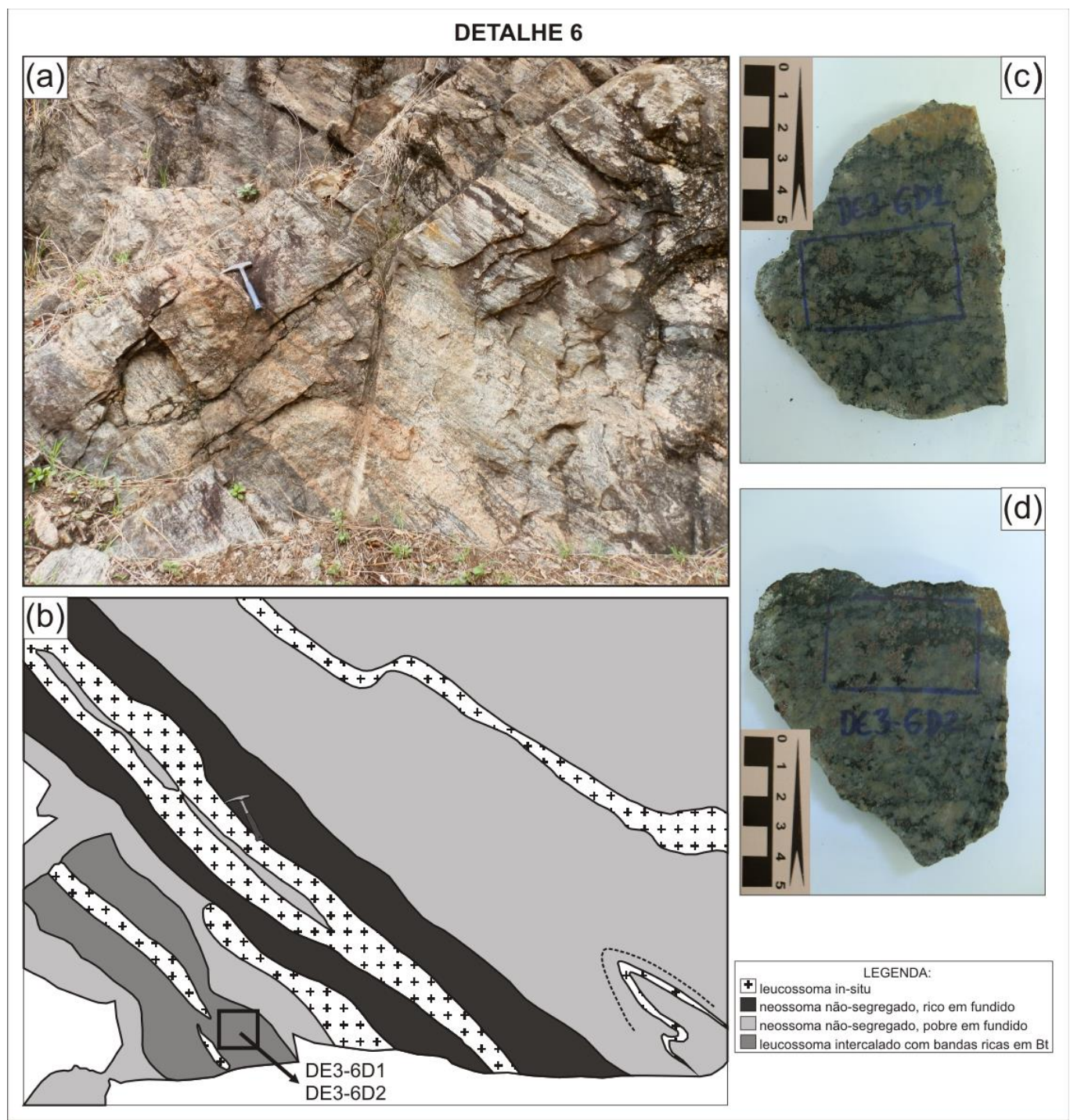

DETALHE 11
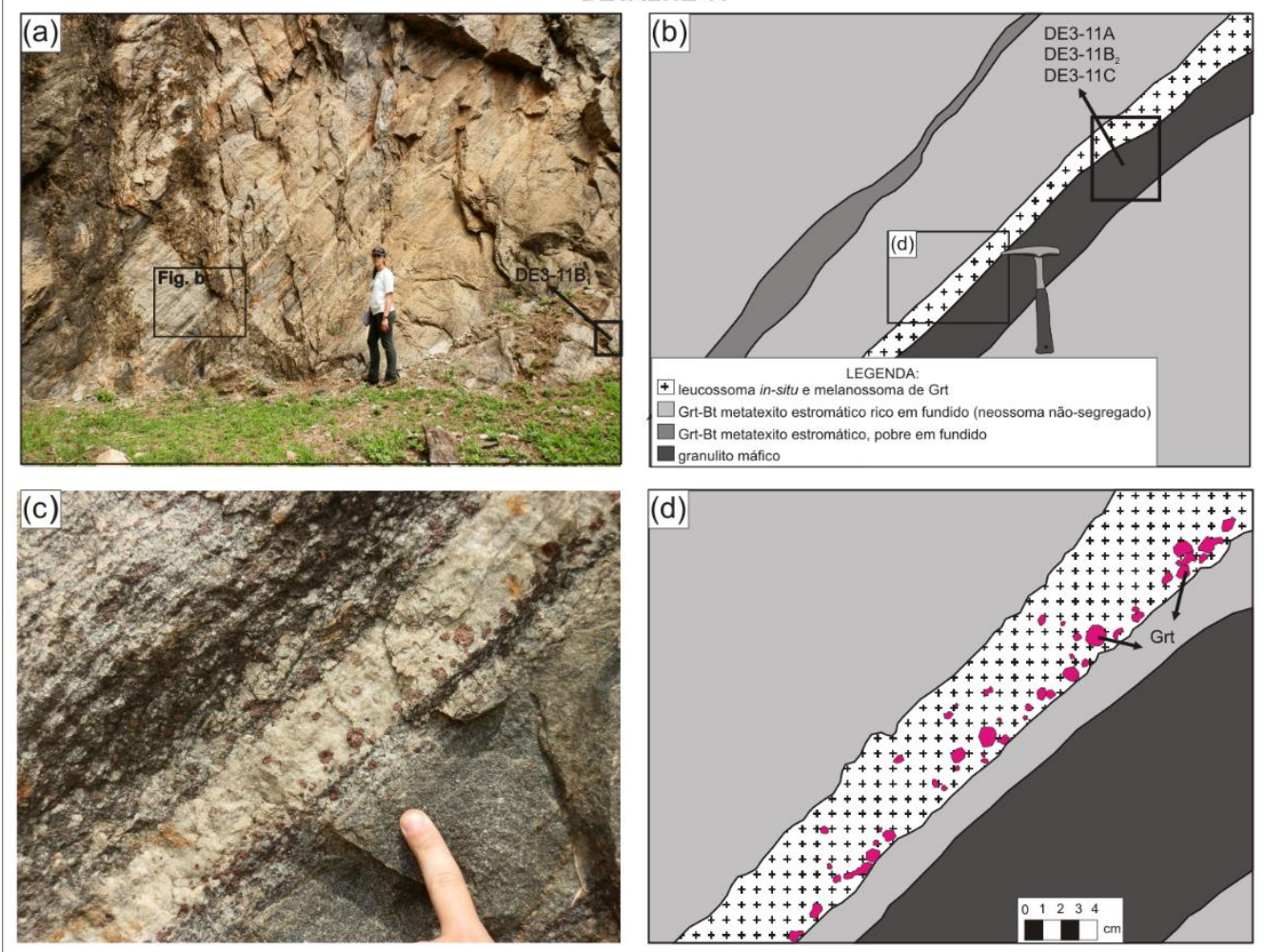


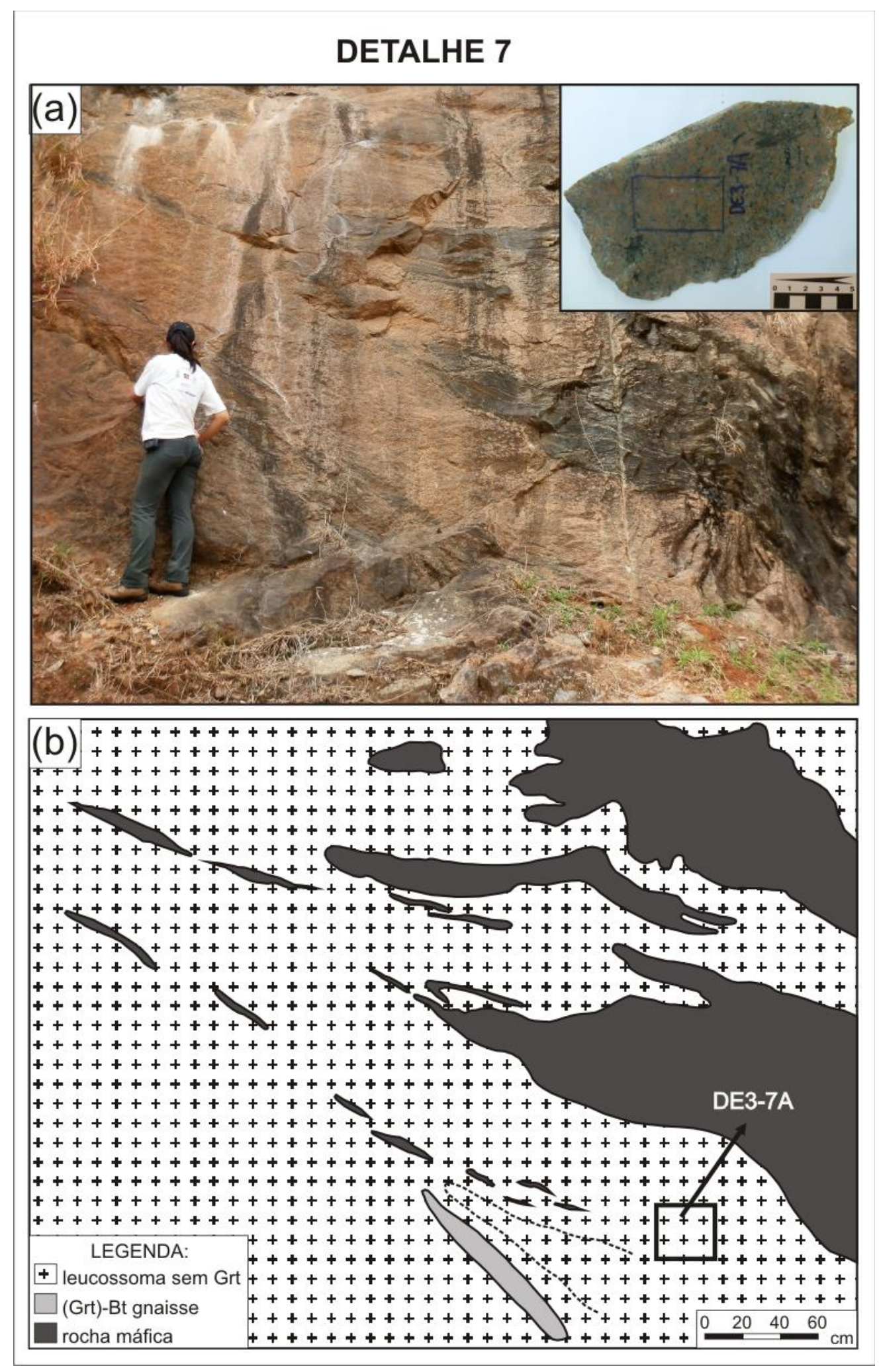


DETALHE 9
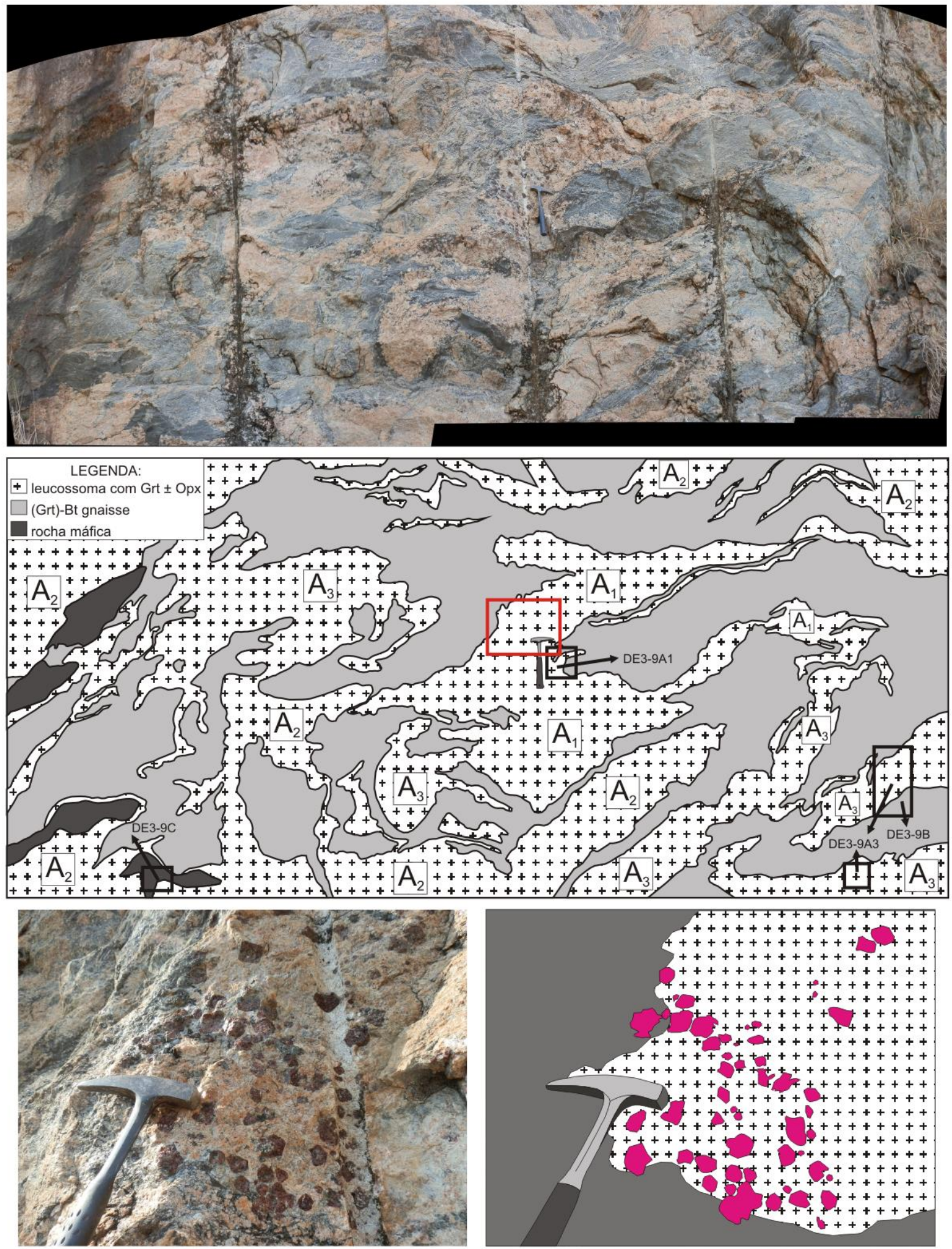


\title{
ANEXO XI
}

\author{
Pranchas de fotomicrografias dos litotipos \\ da pedreira Alfenas (Unidade Metatexítica)
}




\section{PRANCHA I}

\section{Granada-biotita metatexito estromático (amostra 6D1)}
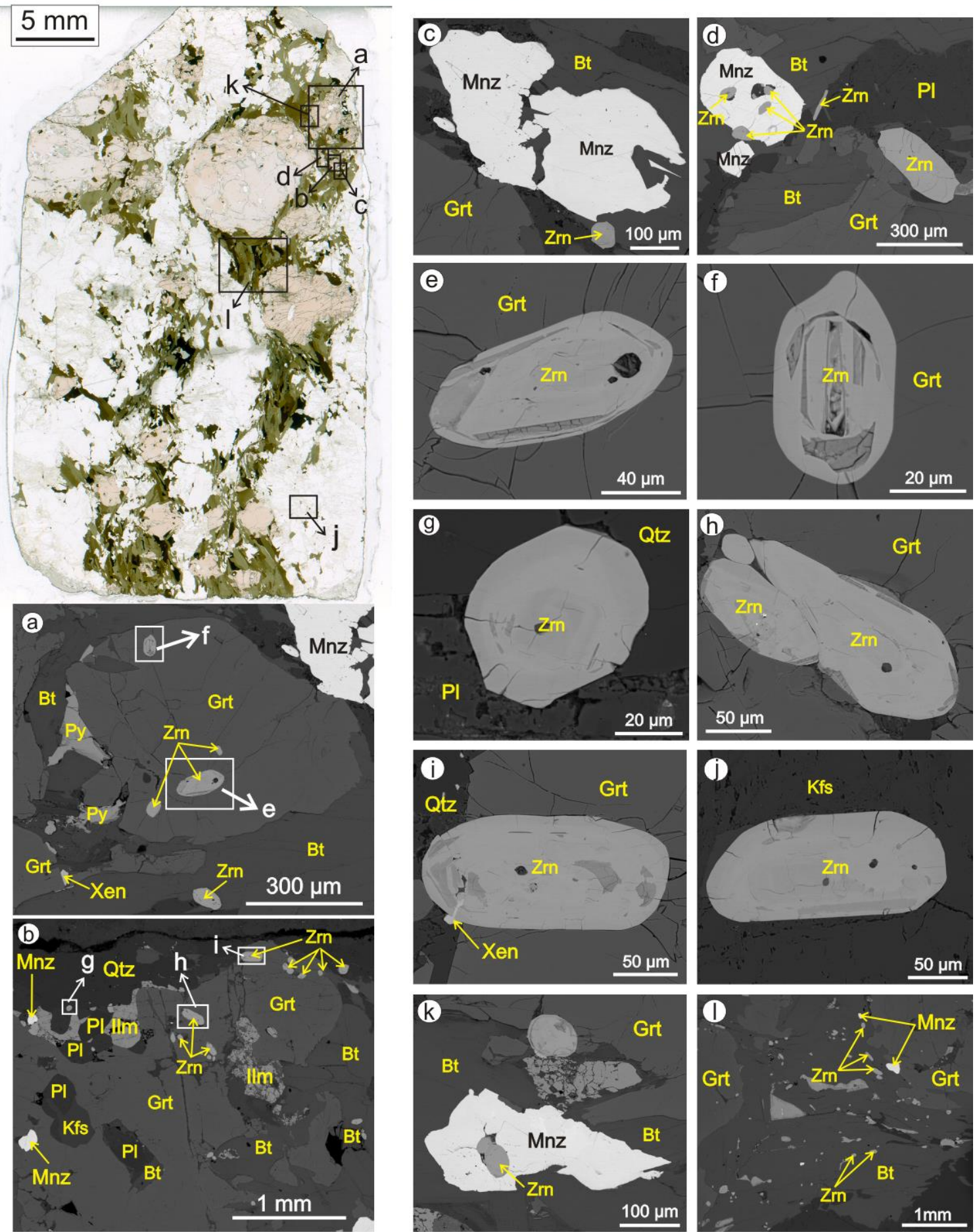

Seção delgada digitalizada do granada-biotita metatexito estromático (amostra 6D1), indicando a localização das imagens BSE. (a) Cristal de granada tardi a póscinemático, rico em inclusões de zircão euédrico a subeuédrico. Notar monazita grossa no canto superior direito (Fig. c); (b) Granada xenoblástica, tardicinemática, rica em inclusões de zircão, monazita, plagioclásio, biotita e feldspato potássico. Notar no canto superior esquerdo, ilmenita na borda da granada rica em inclusões de plagioclásio subeuédrico, que por sua vez apresentam inclusões de zircão; (c) Cristais de monazita xenomórfica, adjacente à granada ilustrada em (a); (d) Duas gerações de zircão, na forma de cristal subeuédrico médio no canto inferior direito, e como inclusões finas em cristal de monazita, no canto superior esquerdo; (e-f) Cristais de zircão inclusos na granada, com padrão de zoneamento complexo e bordas recristalizadas; (g) Zircão zonado parcialmente incluso em plagioclásio; (h) Agregado (cluster) de graõs de zircão zonados inclusos em granada; (i) Zircão parcialmente incluso em granada, com zoneamento complexo e xenotima tardia nas borda; (j) zircão incluso em megacristal de feldspato potássico; (k) Monazita xenomórfica com inclusão de zircão, no selvedge de biotita adjacente à granada; (I) Selvedge de biotita rico em inclusões de zircão e monazita. 


\section{PRANCHA II}

\section{Granada-biotita metatexito estromático (amostra 6D2)}
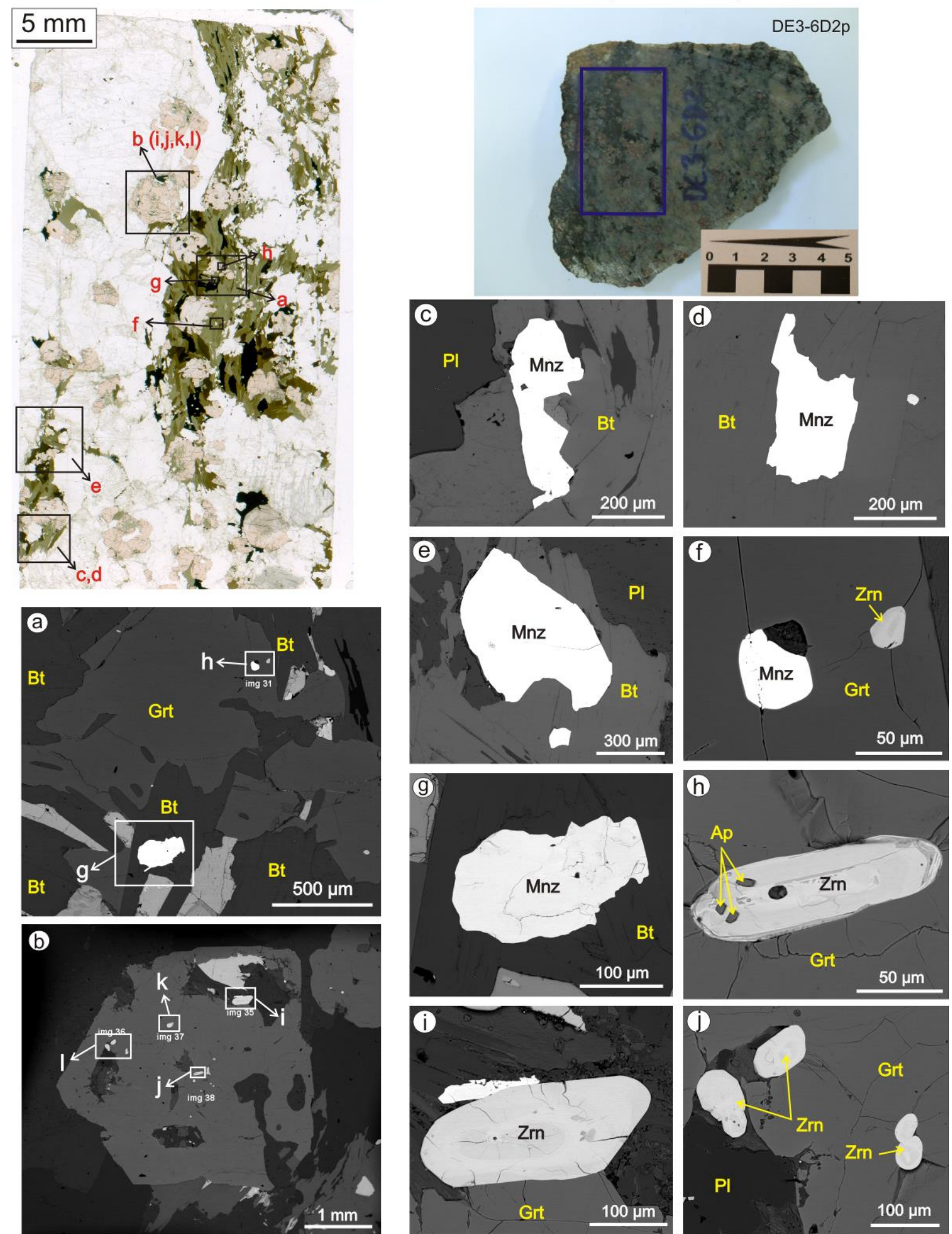

Seção delgada digitalizada do granada-biotita metatexito estromático (amostra 6D2), indicando a localização das imagens BSE e amostra de mão, indicando a localização da seção delgada. (a) Granada parcialmente substituída por biotita e com inclusão de monazita; b) Granada subeuédrica rica em inclusões de zircão. (c-e) Monazita subeuédrica grossa relacionada com biotita da matriz. (f) Monazita do estágio progressivo preservada na forma de inclusão na granada. (g) Monazita euédrica parcialmente substitupida por biotita. (h) Zircão rico em inclusões de apatita incluso em granada. (i) Zircão subeuédrico em contato com a granada. (j) Cristais de zircão inclusos na granada. 


\section{PRANCHA III}

\section{Leucossoma com granada \pm ortopiroxênio (amostra 1A)}
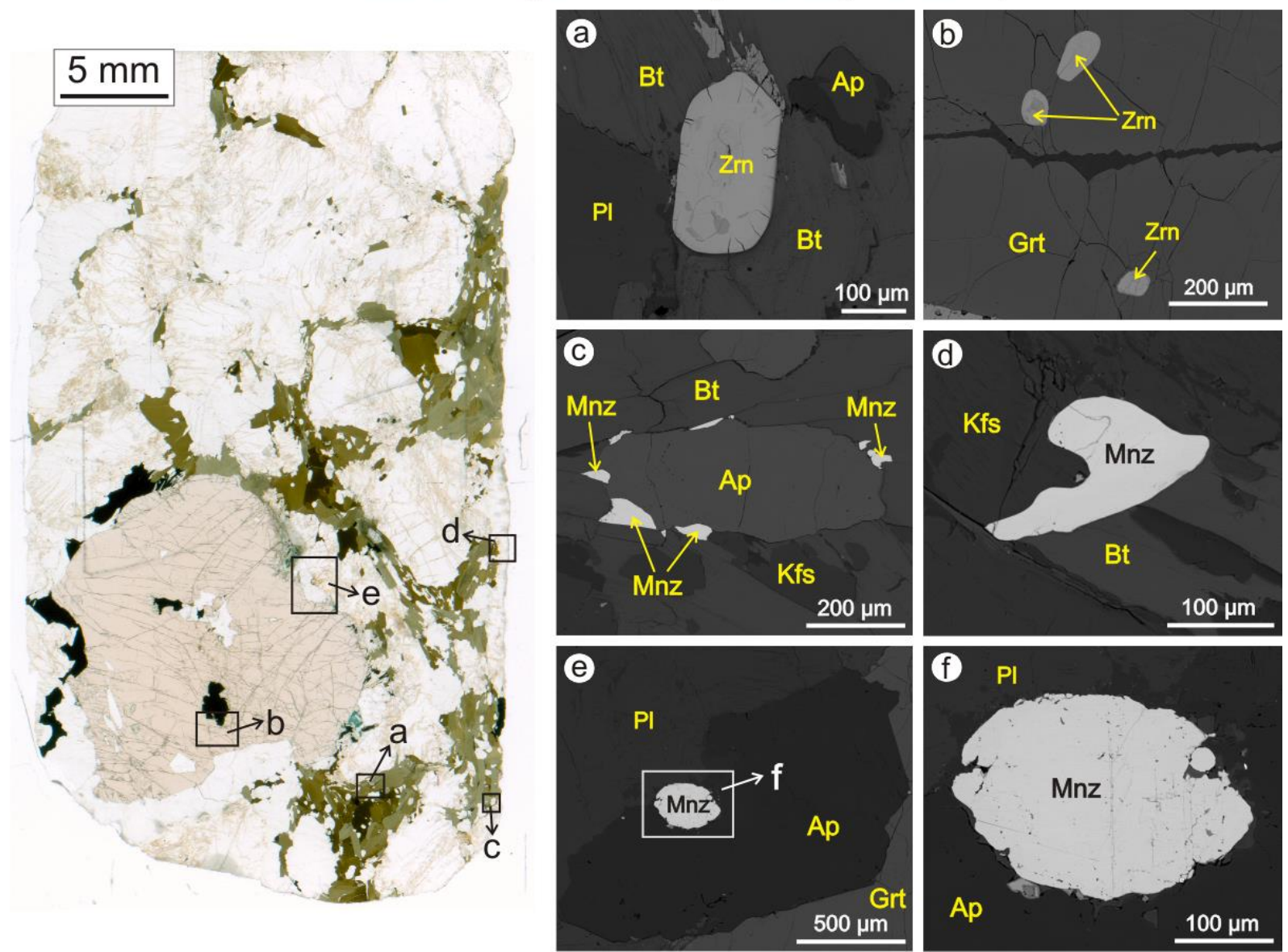

Seção delgada digitalizada do leucossoma com granada \pm ortopiroxênio (amostra 1A), indicando a localização das imagens BSE. (a) Inclusão de zircão subeuédrico em biotita; (b) Inclusões de zircão em granada; (c) Concentração de monazita xenomórfica ao redor de cristal de apatita; (d) Monazita xenomórfica com contatos lobados, parcialmente inclusa em feldspato potássico no contato com a biotita; (e) Monazita inclusa em apatita, que se encontra parcialmente inclusa em granada; (f) Detalhe da imagem anterior. 


\section{PRANCHA IV}

Leucossoma com granada \pm ortopiroxênio (amostra 9A1)
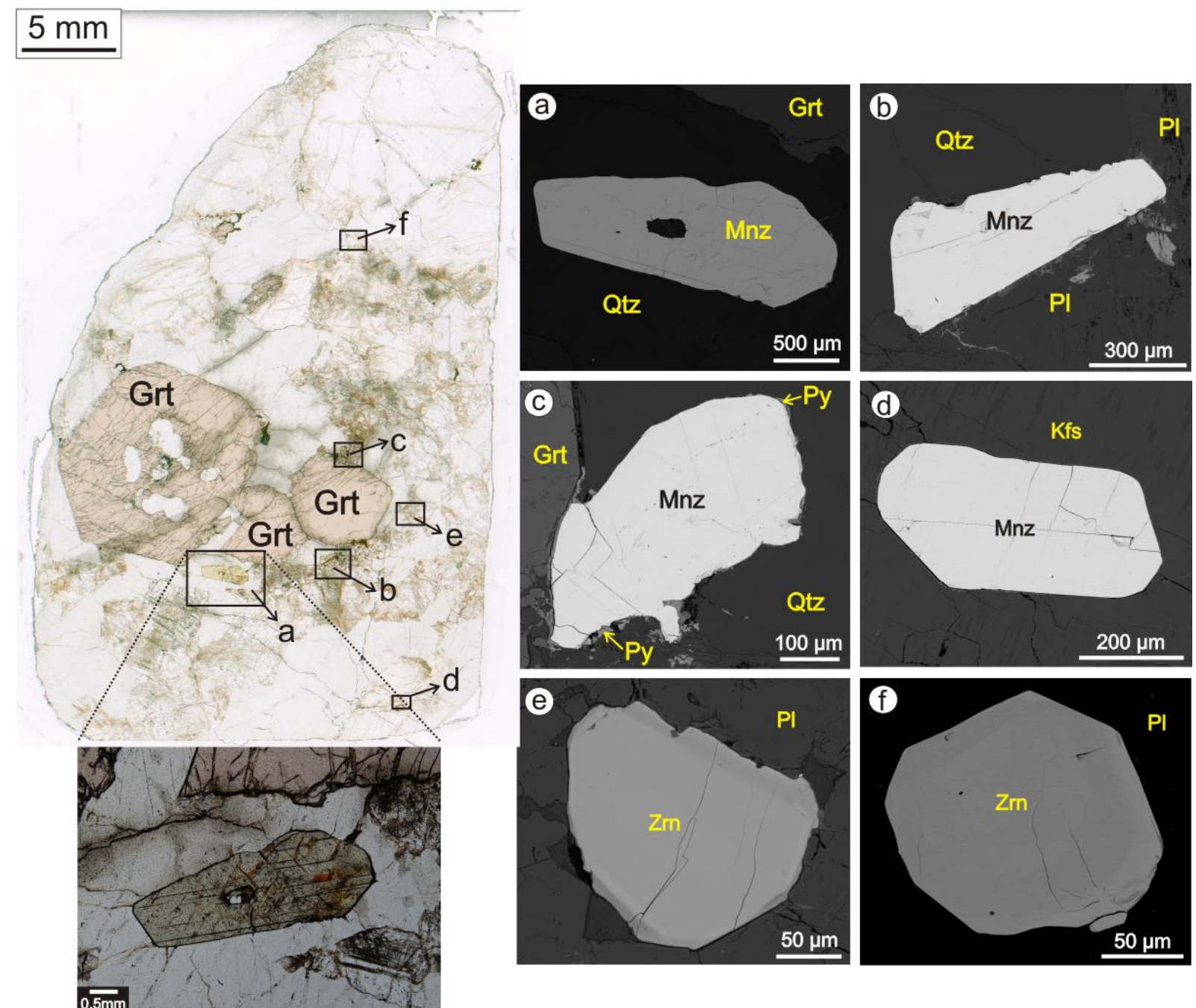

Seção delgada digitalizada do leucossoma com granada \pm ortopiroxênio (amostra 9A1), indicando a localização das imagens BSE. Notar monazita euédrica de dimensão milimétrica, com geminação secundária, no quartzo. (a) Detalhe para o cristal de monazita, que apresenta inclusões de quartzo e biotita; (b) Monazita subeuédrica em contato com quartzo e plagioclásio; (c) Monazita xenomórfica no contato com a gra nada e o quartzo, com diminutos grãos de pirita ao redor; (d) Monazita subeuédrica inclusa em feldspato potássico; (e) (f) zircão incluso em plagioclásio. Notar zoneamento em ambos os cristais. 


\section{PRANCHA V}

Leucossoma com granada \pm ortopiroxênio (amostra 9A1)
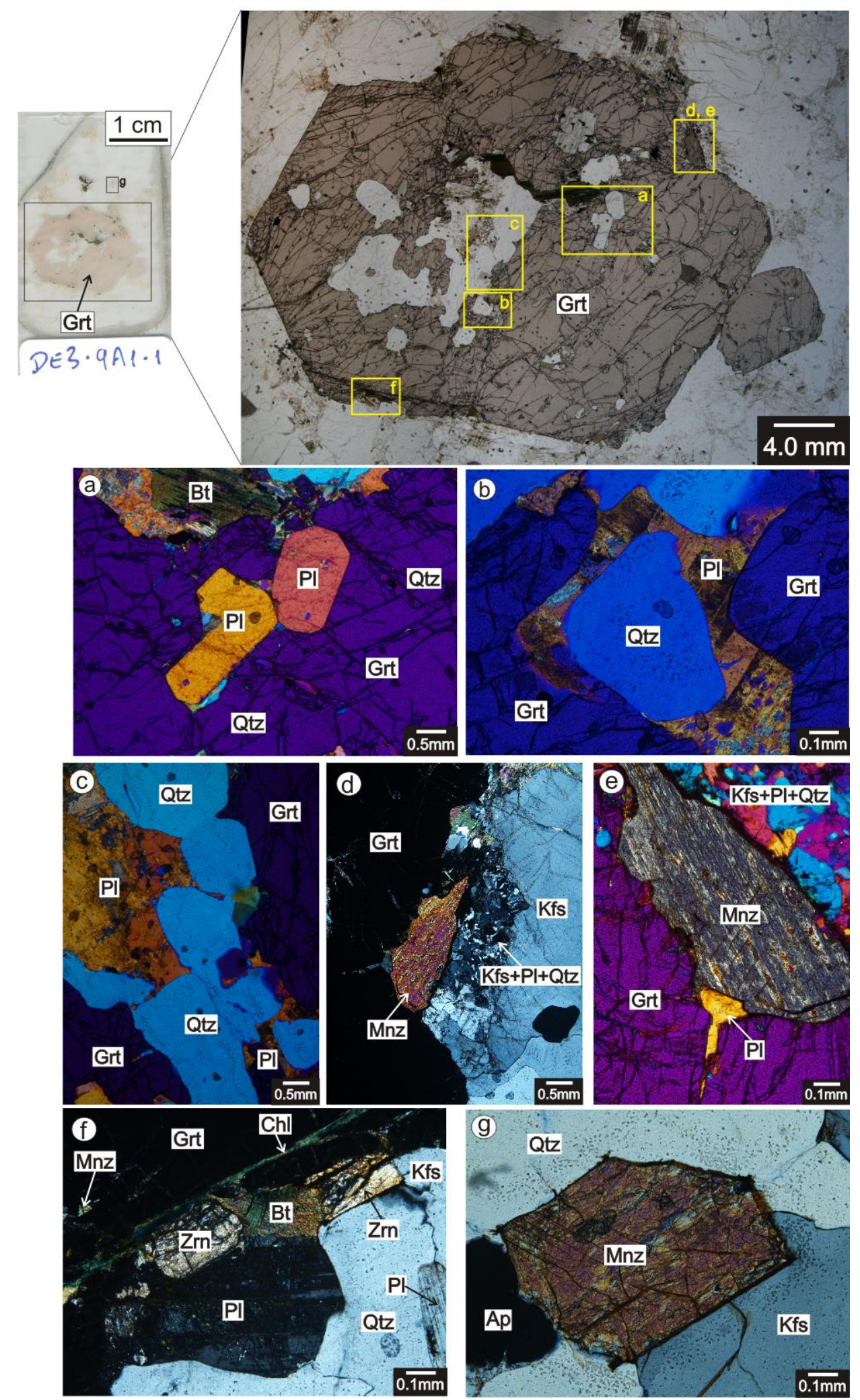

Seção delgada digitalizada do leucossoma com granada \pm ortopiroxênio (amostra 9A1-1), com detalhe de cristal euédrico grosso de granada, indicando a localização das fotomicrografias. (a) Inclusões de plagioclásio euédrico na granada. Polarizadores cruzados, com analisador; (b) Filme intersticial de plagioclásio (amarelo) ao redor de quartzo arredondado (azul claro), mimetizando fundido inclusos em granada. Polarizadores cruzados, com analisador; (c) Fundido de plagioclásio (amarelo), intersticial entre grãos subeuédricos de quartzo, incluso na granada. Polarizadores cruzados, com analisador; (d) Monazita subeuédrica (aprox. $3 \mathrm{~mm}$ ) na borda da granada. Notar agregado poliminerálico constituído por quartzo, feldspato potássico e plagioclásio no contato da monazita com o leucossoma fanerítico grosso. Polarizadores cruzados; (e) Detalhe da monazita anterior. Notar plagioclásio mimetizando fundido (canto inferior, em amarelo), no contato da monazita com a granada. Polarizadores cruzados, com analisador; (f) Cristais de zircão euédricos (aprox. $0.5 \mathrm{~mm}$ ) na borda da granada, com faces retas no contato com o plagioclásio e quartzo, do leucossoma fanerítico grosso. Notar inclusão de monazita na granada (canto superior esquerdo). Biotita com terminação em cúspede no contato do zircão com a granada. Fratura preenchida por clorita tardia na granada. Polarizadores cruzados, com analisador; (g) Monazita subeuédrica no leucossoma, com faces retas no contato com o quartzo. Polarizadores cruzados. 


\section{PRANCHA VI}

Leucossoma com granada \pm ortopiroxênio (amostra 9A3-6)
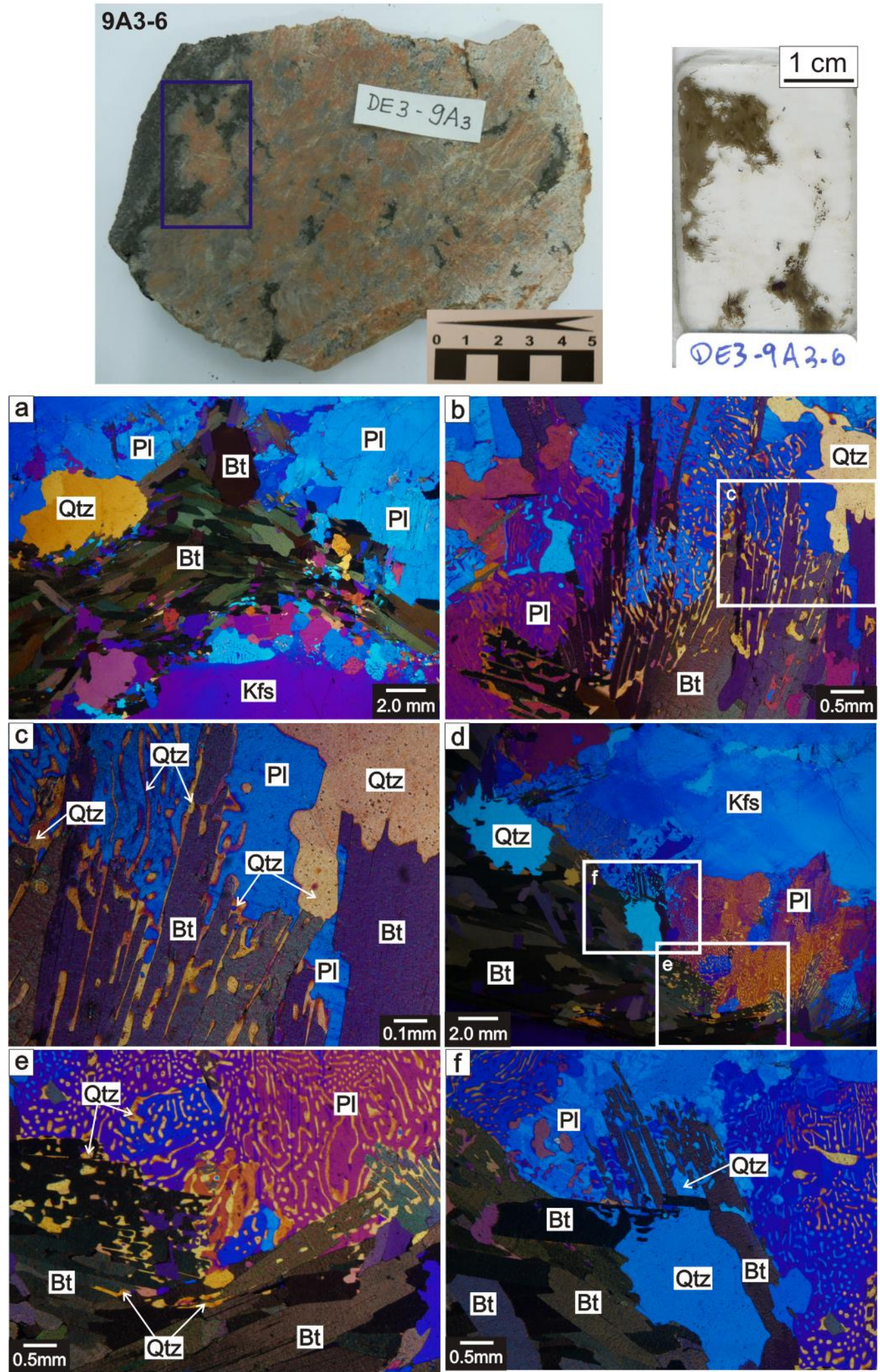

Amostra de mão e seção delgada digitalizada do leucossoma com granada \pm ortopiroxênio (amostra 9A3-6). (a) Selvedge de biotita ao redor de megacristal de feldspato potássico, no contato com (granada)-biotita gnaisse; (b) Biotita esqueletal intercrescida com quartzo no contato da mirmequita com o selvedge; c) Notar que o quartzo intercrescido com a biotita está em continuidade óptica com o quartzo vermicular da mirmequita e com poça de fundido de quartzo, no canto superior direito, onde o quartzo está em contato cúspede-lobado com a biotita; d) Domínio de mirmequitas e poças de fundido de quartzo no contato entre megacristal de feldspato potássico e selvedge de biotita; e) Notar que o quartzo vermicular da mirmequita está em continuidade óptica com o quartzo intercrescido com a biotita e com os filmes e poças de fundido de quartzo no selvedge de biotita; f) Poça de fundido de quartzo em continuidade óptica com quartzo intercrescido com biotita esqueletal e com quartzo vermicular na mirmequita. (a-f) Polarizadores cruzados, com analisador. 


\section{PRANCHA VII}

Leucossoma com granada \pm ortopiroxênio (amostra 9A3-7)
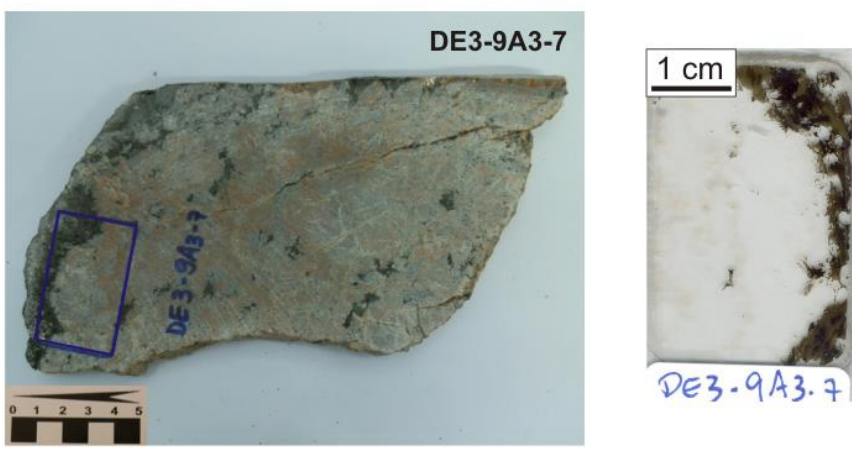

DE3.9A3.7
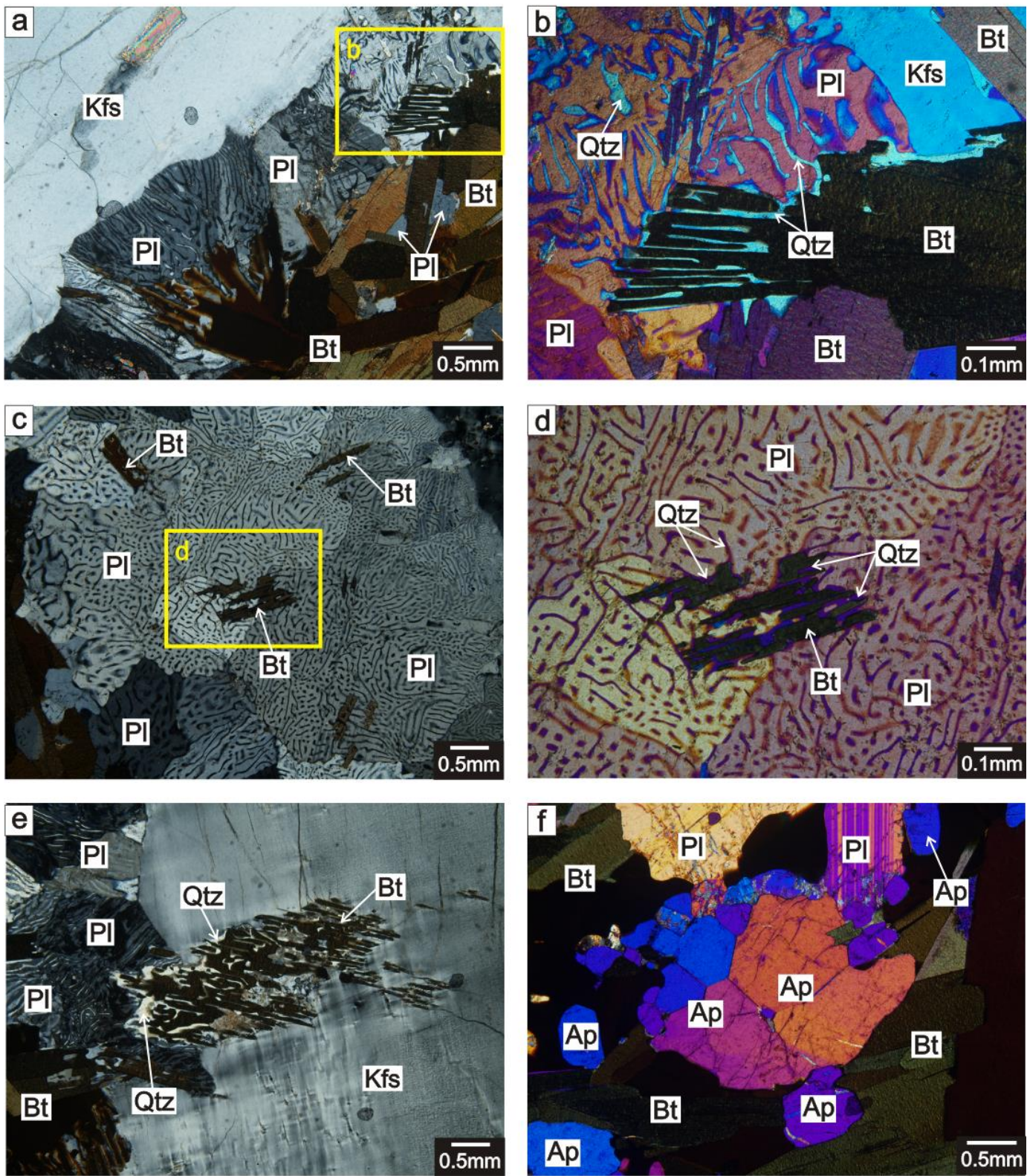

Amostra de mão e secão delgada digitalizada do leucossoma com granada \pm ortopiroxênio (amostra 9A3-7). (a) Plagioclásio na forma de mirmequita no contato do feldspato potássico com o selvedge de biotita. Polarizadores cruzados; (b) Biotita esqueletal intercrescida com quartzo no contato da mirmequita com o selvedge de biotita. Notar quartzo em continuidade óptica. Polarizadores cruzados, com analisador; c) Plagioclásio na forma de mirmequita, com inclusão de biotita esqueletal intercrescida com quartzo. Polarizadores cruzados; d) Notar que o quartzo intercrescido com a biotita está em continuidade óptica com o quartzo vermicular da mirmequita. Polarizadores cruzados, com analisador; e) Inclusão de biotita esqueletal intercrescida com quartzo, parcialmente inclusa em feldspato potássico e parcialmente inclusa em plagioclásio na forma de mirmequita. Polarizadores cruzados; f) Agregado de apatita no selvedge de biotita. Polarizadores cruzados, com analisador. 


\section{PRANCHA VIII}

Leucossoma com granada \pm ortopiroxênio (amostra 9A3-8)
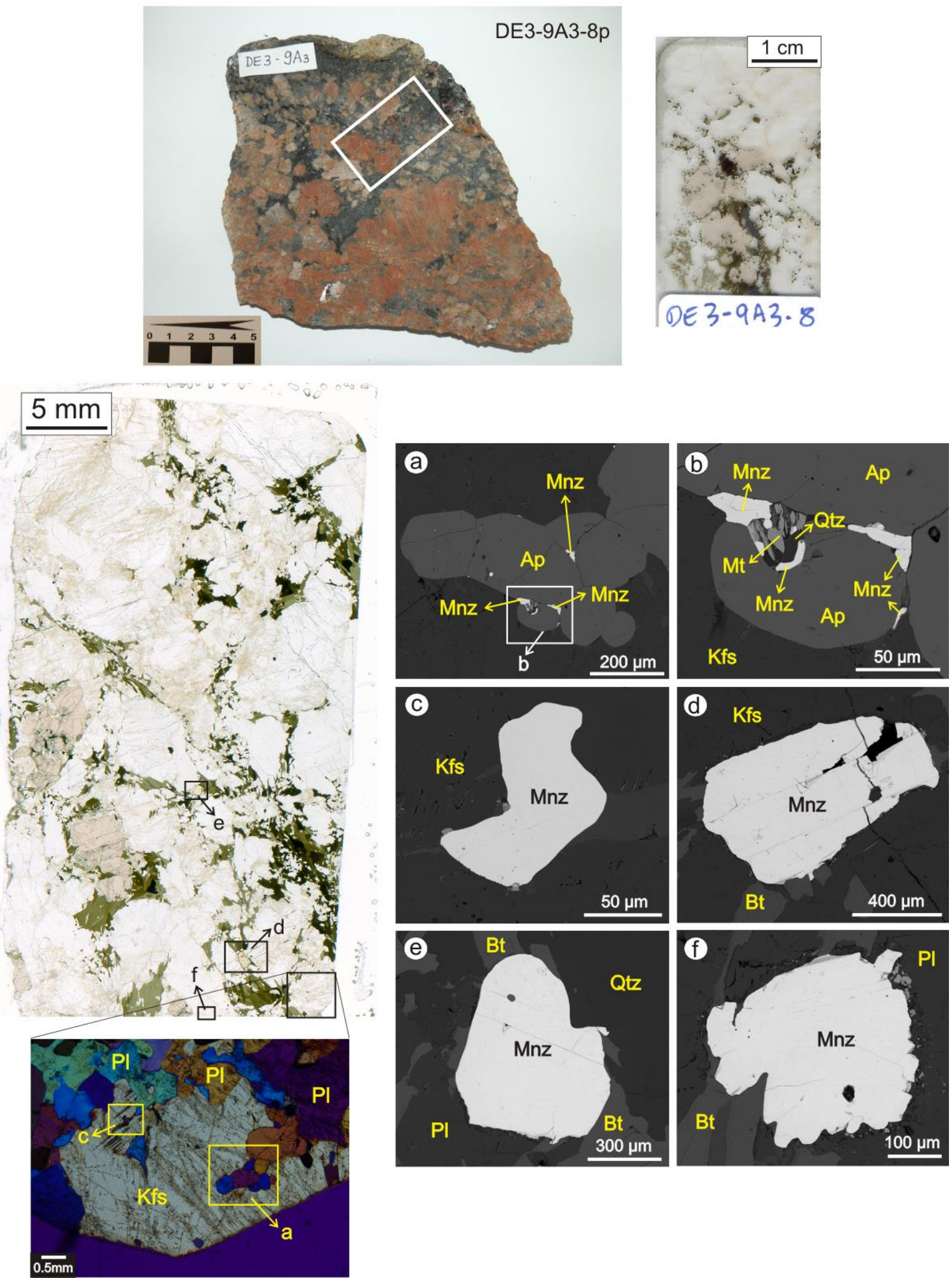

Seção delgada digitalizada do leucossoma com granada \pm ortopiroxênio (amostra 9A3-8), indicando a localização das imagens BSE. Notar feldspato potássico rico em inclusões de fases acessórias, no canto inferior direito. (a) Agregado (cluster) de apatita na forma de inclusão em feldspato potássico; (b) Notar monazita xenomórfica preenchendo interstícios nos contatos entre os grãos de apatita; (c) Monazita xenomórfica, com contatos lobados, inclusa em feldspato potássico; (d) Cristal de monazita euédrico de granulação média no leucossoma; (e) Monazita subeuédrica, com contatos predominantemente retos com o plagioclásio e contatos lobados com o quartzo e a biotita; (f) Monazita xenomórfica com borda de alteração acastanhada, no leucossoma. 


\section{PRANCHA IX}

Leucossoma com granada \pm ortopiroxênio (amostra 9A3-1)

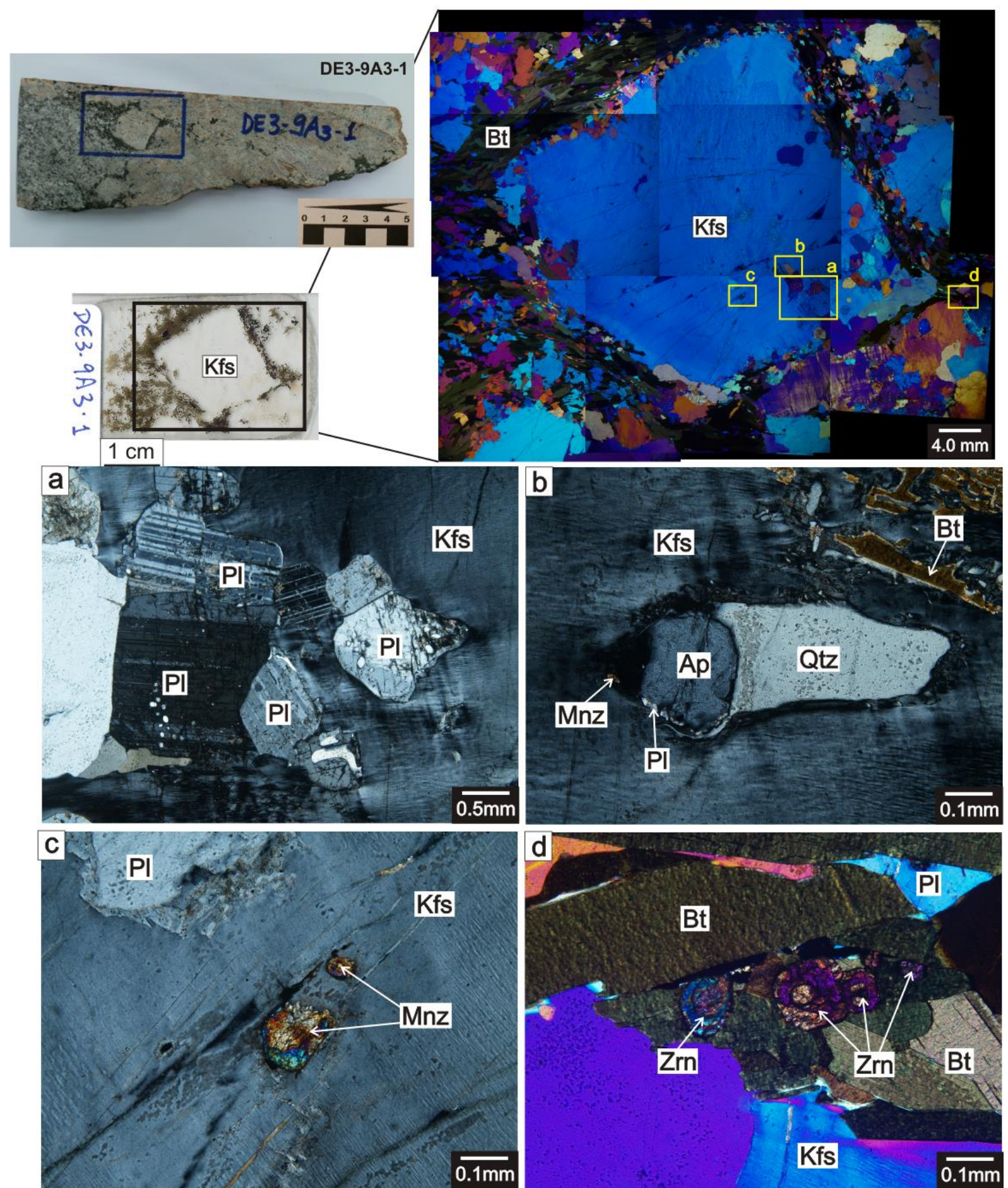

Amostra de mão e seção delgada digitalizada do leucossoma com granada \pm ortopiroxênio (amostra 9A3-1), ilustrando estrutura de deformação de fluxo magmático, com selvedges de biotita envolvendo e isolando megacristais de feldspato potássico. (a) Inclusões de plagioclásio subeuédrico em porfiroclasto de feldspato potássico. Polarizadores cruzados; (b) Inclusão de apatita arredondada e monazita, parcialmente envolvidos por corona fina de plagioclásio em uma poça de fundido de quartzo, sugerindo o aprisionamento de fundido durante a cristalização das fases acessórias. Notar intercrescimento de biotita e quartzo no canto superior direito. Polarizadores cruzados; (c) Inclusões de monazita de até $0.3 \mathrm{~mm}$ no feldspato potássico. Polarizadores cruzados; (d) Cristais subeuédricos a arredondados de zircão no selvedge de biotita. Polarizadores cruzados, com analisador. 


\section{PRANCHA X}

Selvedge de biotita no contato do leucossoma com (granada)-biotita gnaisse (amostra 9A3-3)
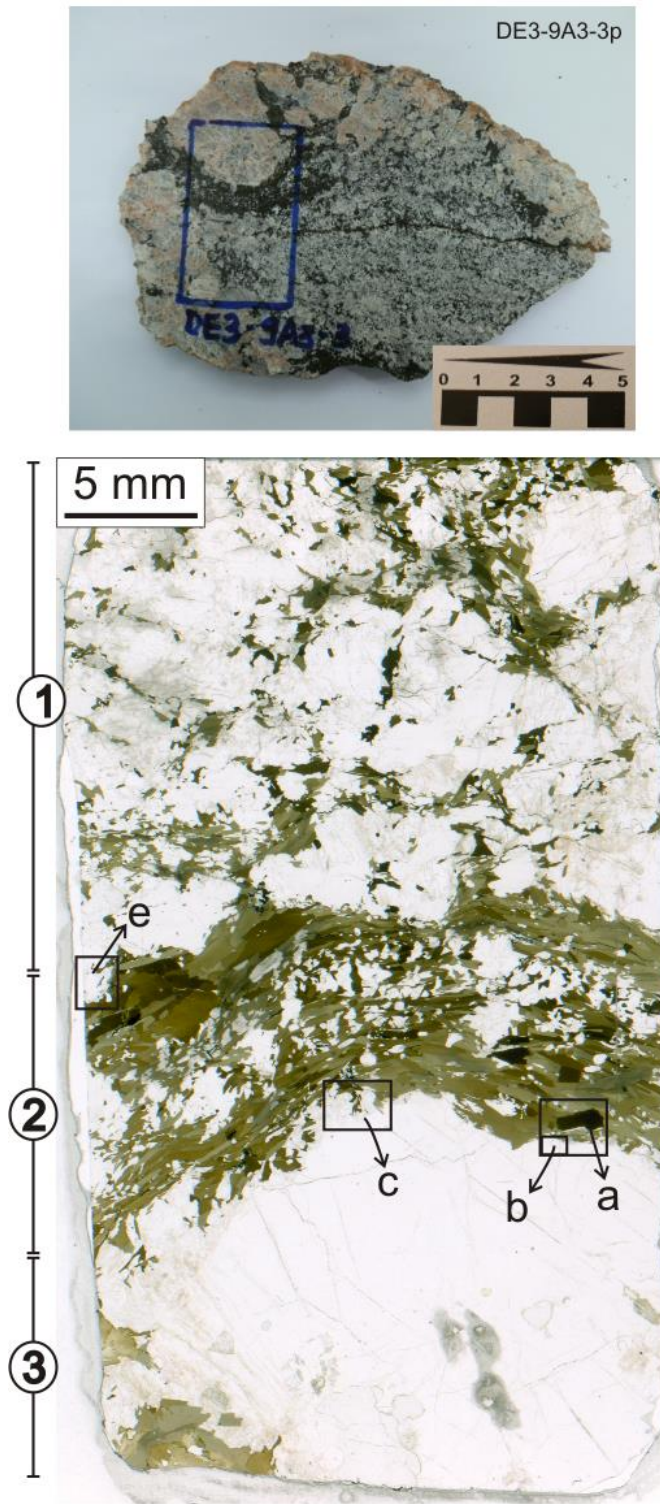

(1) rocha mesocrática cinza

(2) selvedge de biotita

(3) leucossoma fanerítico grosso
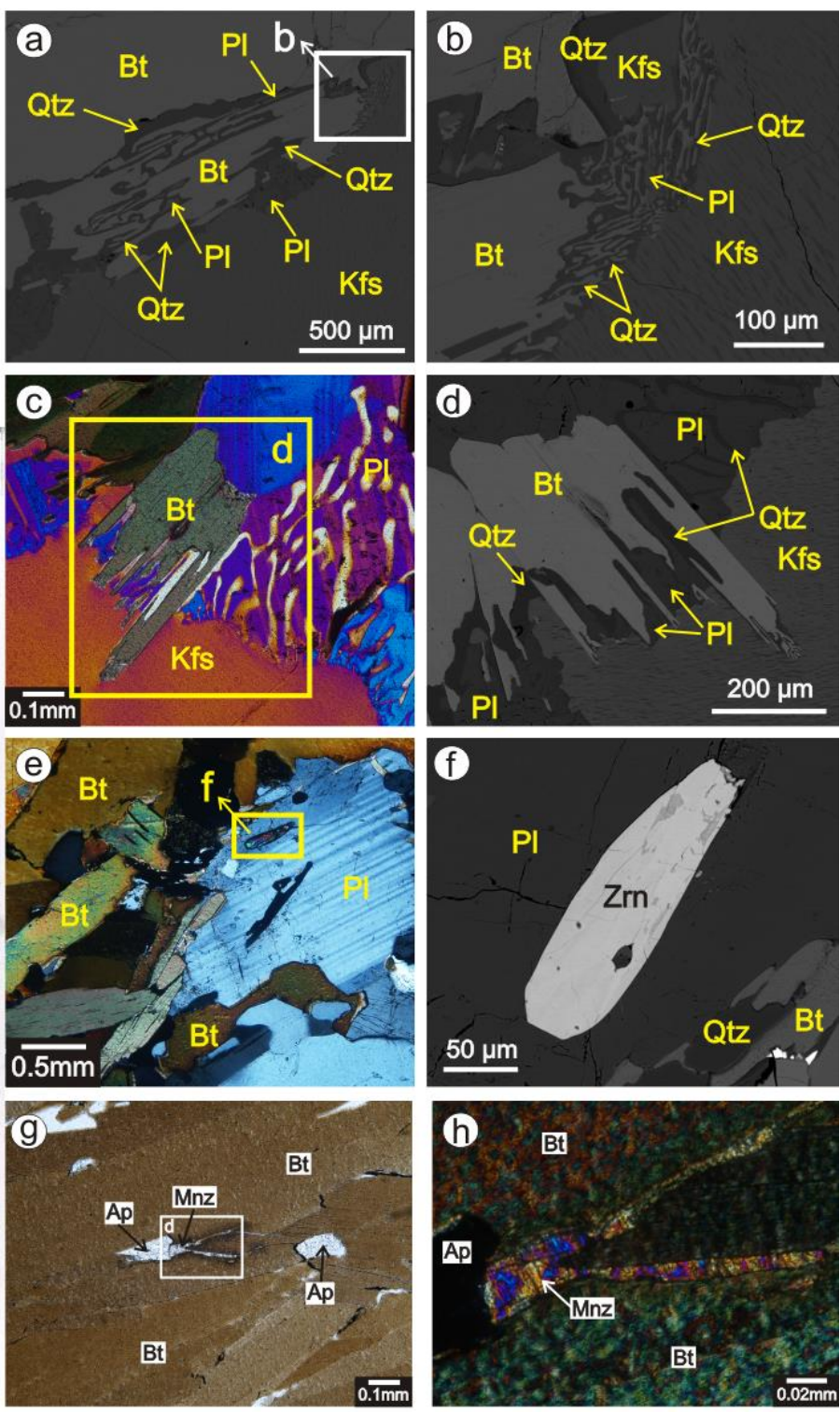

Seção delgada digitalizada da amostra 9A3-3, ilustrando selvdge de biotita no contato do (granada)-biotita gnaisse com leucossoma com granada \pm ortopiroxênio, indicando a localização das imagens BSE e fotomicrografias. (a-b) Biotita esqueletal intercrescida com quartzo no contato do selvedge com o leucossoma. Também ocorrem filmes finos de plagioclásio; (c) Plagioclásio na forma de mirmequita e biotita esqueletal intercrecida com quartzo e plagioclásio no contato com o feldspato potássico. Notar que o quartzo intercrescido com a biotita está em continuidade óptica com o quartzo vermicular da mirmequita; (d) Notar que a biotita esqueletal apresenta filmes de plagioclásio além dos filmes de quartzo; (e) Inclusão de zircão em plagioclásio no (granada)-biotita gnaisse em contato com o selvedge de biotita; (f) Cristal de zircão alongado, incluso em plagioclásio; (g) Monazita e apatita mimetizando fundido nos contatos entre os grãos de biotita, no selvedge de biotita. Polarizadores paralelos; (h) Detalhe da monazita anterior. Polarizadores cruzados, com analisador. 